\title{
Financial lessons from the long history of housing markets
}

Citation for published version (APA):

Korevaar, M. (2021). Financial lessons from the long history of housing markets. [Doctoral Thesis, Maastricht University]. Maastricht University. https://doi.org/10.26481/dis.20210115mk

Document status and date:

Published: 01/01/2021

DOI:

10.26481/dis.20210115mk

Document Version:

Publisher's PDF, also known as Version of record

\section{Please check the document version of this publication:}

- A submitted manuscript is the version of the article upon submission and before peer-review. There can be important differences between the submitted version and the official published version of record.

People interested in the research are advised to contact the author for the final version of the publication, or visit the DOI to the publisher's website.

- The final author version and the galley proof are versions of the publication after peer review.

- The final published version features the final layout of the paper including the volume, issue and page numbers.

Link to publication

\footnotetext{
General rights rights.

- You may freely distribute the URL identifying the publication in the public portal. please follow below link for the End User Agreement:

www.umlib.nl/taverne-license

Take down policy

If you believe that this document breaches copyright please contact us at:

repository@maastrichtuniversity.nl

providing details and we will investigate your claim.
}

Copyright and moral rights for the publications made accessible in the public portal are retained by the authors and/or other copyright owners and it is a condition of accessing publications that users recognise and abide by the legal requirements associated with these

- Users may download and print one copy of any publication from the public portal for the purpose of private study or research.

- You may not further distribute the material or use it for any profit-making activity or commercial gain

If the publication is distributed under the terms of Article $25 \mathrm{fa}$ of the Dutch Copyright Act, indicated by the "Taverne" license above, 


\title{
Financial Lessons from the Long History of Housing Markets
}

\author{
Matthijs Korevaar
}




\section{Copyright $\odot 2021$ Matthijs Korevaar}

All rights reserved. No part of this publication may be reproduced, stored in a retrieval system, or transmitted, in any form, or by any means, electronic, mechanical, photocopying, recording or otherwise, without the prior permission in writing from the author.

This book was typeset using $\mathrm{AT}_{\mathrm{E}} \mathrm{X}$. 


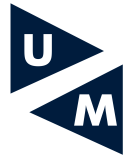

\title{
MAASTRICHT UNIVERSITY
}

\section{Financial Lessons from the Long History of Housing Markets}

\author{
Dissertation \\ to obtain the degree of Doctor at Maastricht University, \\ on the authority of the Rector Magnificus Prof. dr. Rianne M. Letschert \\ in accordance with the decision of the Board of Deans, \\ to be defended in public on 15 January 2021 at 14:00 hours \\ by \\ Matthijs Korevaar
}




\section{Promotor:}

Prof. Dr. Piet Eichholtz

\section{Co-Promotor:}

Dr. Thies Lindenthal (University of Cambridge)

\section{Assessment Committee:}

Prof. Dr. Rachel Pownall, chair

Prof. Dr. Oscar Gelderblom (Utrecht University)

Prof. Dr. Clemens Kool

Dr. Eva Steiner (Pennsylvania State University)

Dr. Stefan Straetmans

This dissertation was funded by the Netherlands Organisation for Scientific Research under the Research Talent scheme (no. 406.16.552). I also thank the Lincoln Institute for Land Policy, the Maastricht Graduate School of Business and Economics and the Economic History Association for additional financial support for data collection. 


\section{Acknowledgements}

This PhD thesis does not only mark the end of my period as a doctoral student, it also marks the end of my time period at Maastricht University. Maastricht has been my home since 2011, and the place where I have been raised as an academic, and I have to thank many people that have helped me on the way. I ended up in Maastricht not only because I very much liked the international economics program at the university, but also because it is pretty much the only city in The Netherlands with some serious hills around. As a skinny cyclist, I preferred climbing over riding in waaiers through the windy polders around my hometown. Unfortunately, my skills as a bike rider were far from sufficient to make it to the Tour de France, so I realized that it would be a safer bet to opt for a route that suited me better: the road to becoming a good economist.

I applied to the bachelor honors program and after an interview with Stefan Straetmans I was admitted and matched to a professor. Stefan, I am very thankful that you matched me to the right person. In September 2012, I had just turned 19, I remember standing in front of office B1.09 feeling both nervous and honored that I was about to meet this unknown but seemingly very important prof. dr. Eichholtz, who would be my mentor. For the first time in my life, I would speak to a full professor.

And then I met Piet. From day one, Piet has been an incredible advisor and mentor. And I literally mean from day one: within 15 minutes of our first meeting, Piet had arranged the opportunity for me to work as a student assistant. Over time, Piet continued to provide me opportunities that I did not see or did not dare to see myself, gradually opening up the world of academia. I would rarely leave Piet's office without a new idea or opportunity in mind. Starting a PhD was a logical next step, and Piet and the entire finance department always supported and encouraged me to engage in research visits, grant applications, and other activities. During these years, Piet always struck the right balance between opening doors for me while also supporting me to develop my own ideas. Without his guidance, this thesis would not be there.

Piet is also exemplary for showing me that one can be a good academic but also make time for other pleasures in life. Most notably, we share a love for cycling, which meant that beyond talking about research Piet could also ask me for online streams of cycling races that were going on or that he encouraged me to go out for a ride on a sunny afternoon. Piet, and I should also thank Margo, even made it possible to still ride a stage in front of the Tour de France peloton. Piet, thank you for everything you have done for me.

While Piet was the 'visionary' of the supervision team, Thies Lindenthal was al- 
ways there for hands-on research advice and help with important issues. When I met Thies for the first time and asked him about one essential skill that would very much help my PhD project, he advised me to learn to code in R. After a few years of learning, I now know how useful this was. Thies, thank you for pointing me in the right direction so many times, and for all the help you provided, either through cracky Whatsapp calls or during my visits to Cambridge. During my first visit, Thies also taught me that academics need proper coffee in the office (and always provided it), so I was quick to buy my own machine and grinder. I still do not make hand-pressed espressos, but I hope I am getting there.

Beyond Piet and Thies, there were many more people that provided me with useful advice during my $\mathrm{PhD}$. I have to highlight two people in particular. First, the name of Marc Francke will appear in two of the six papers that form this dissertation. Marc, I enjoyed working with you and learning from you. You helped to bring some structure in the wild range of ideas and data I came up with, and with a great eye for precision, you also made sure we got the details right. Second, Peter Koudijs gave me the opportunity to experience US academic life for a few months and invited me to come to Stanford University. Peter, thanks for being an excellent host during my visit to Stanford and for the help you provided when navigating the job market. You also helped me to gradually realize what it takes to make financial historical research interesting and relevant for a more general academic audience in finance, and I hope to make use of those skills in the future.

I am also happy to have been able to call the Finance department my academic home. Carina, Francien, and Els were always ready to help me out with all kinds of things necessary to keep me going, from making use of the bike plan to arranging payments for invoices from obscure French data providers. I also benefited a lot from the feedback I received during presentations, lunches, and coffee breaks from Jaap, Jeroen, Paulo, Peiran, Peter, Rachel, Stefan and Stefanie. Within the department Nils, Thomas and Rob were happy to comment on my research and on recent cycling performances.

Since 2016, I was the proud owner of a desk in the little castle on the Tongersestraat 51 , and I have had the pleasure of sharing an office with the best possible office mates. The journey started together with Tobias and Ehsan, and with our $\mathrm{PhD}$ deadlines still far away, this was the time that we could have extensive discussions on issues that went far beyond our research projects. As time passed by, Tobias and Ehsan left for new destinations, and I was happy to be joined in the office by Luuk. I think there are few people as friendly as Luuk, and I am sure that everyone who knows him will agree. Luuk was also the one who managed to make sure that when my brains need a bit of respite, we would go out for a round of table tennis or a cup of coffee. But also Luuk's PhD had an end date, so for the last few months of her PhD I was lucky to be accompanied in the office by Nora. It was also the time that I started worrying about the job market, but since Nora had just survived it, it was good to have her company and advice. During my final year, I was joined by Nagihan, and since we were both on the job market, this was a time to keep each other sharp and motivated while hovering through long job application forms and to jointly celebrate calls for interviews. 
Next to my office mates, I have been lucky to have a great cohort of PhD students around me. Even before I joined officially as a PhD student, I was invited to join the group for a skiing trip to Austria, and two years later we repeated that and headed towards the Georgian Caucasus. Beyond these trips, international conferences, house parties or pizza nights provided a great basis for relaxing evenings and friendship during my time as $\mathrm{PhD}$ student. Thanks for all these great memories Aderajew, Alessandro, Colin, Iman, Inka, Irene, Janek, Katrin, Lidwien, Martijn, Marina, Marten, Michael, Ming, Runliang, Rogier and Pomme.

Also during my visit to Stanford, I was in good company. Amy, Lulu, Joe, and Timur would always be happy to chat about the latest research or go out for coffee and lunch. I also had the pleasure of joining the Stanford Cycling Team, and almost daily rides with team members provided a great basis for friendship. I also have to thank them for giving me the opportunity to ride cycling races for Stanford along the US West Coast: a once-in-a-lifetime experience.

With each of us working on different topics in real estate, sharing Piet as advisor immediately created a special bond with fellow PhD students Mike Langen and Juan Palacios, which was further strengthened by jointly attending many conferences and workshops. Mike, from the first day you were the one that was always up for an adventure and a happy host for many social events. Beyond the adventures in Georgia, Austria, and Spain, I should particularly thank you for the fact that you were willing to drive us through the snow up to Lake Tahoe straight after a long flight from Europe. Surviving the Pontiac in San Francisco also deserves a mention. Thank you for being a great companion on this $\mathrm{PhD}$ journey. Juan, as soon as I was in your eyesight I would hear a loud "Korevaaarrrrrr" or "Dutch Bullet", and good conversations would start. You are always full of energy, and it was a delight to have so many dinners and drinks together, where we could talk both about our own lives as well as the research we were doing. You also always see opportunities everywhere. If you came across an interesting conference or paper or met someone relevant for my own research, you would send me an e-mail or tell me that I should really talk to this person. I am glad you found a good place at MIT, and I am sure you will find an even better place with Esmee when you return to Europe.

Finally, I want to express gratitude to my amazing paranymphs Matteo Bonetti and Paul Smeets. Matteo, you are one of the most modest and kind persons that I know, and it was great to share the PhD journey with you. Writing papers would make our brains work hard, but in the evenings and weekends we would make sure that we would suffer physically on local bike races or hill repeats. And when the hills in Limburg or the were not high enough, you would bring us to your family home in Italy for real races and climbing. Paul, when I started attending finance research seminars, you were this unknown young professor that always made smart remarks in seminars. I am glad that I now know you much better than that. You were always willing to challenge my thinking, and our shared sense of curiosity for many things in the world would always result in good discussions. Most importantly, our friendship also implied that conversations about our academic lives could easily change into a serious personal conversation, and if that wasn't enough you would always bring some humour to the 
table.

As a PhD student in a finance department focusing on real estate topics, venturing into economic history was taking a dive into the unknown. But I have met an amazingly open and helpful community. Early on, I got to know Ronan Tallec, a French historian who introduced me to the astonishing world of Parisian archives and history. Thanks for helping me to find dozens of different data sources that I would have never found myself. I should also thank you and Anne for hosting me in Paris and Blois on multiple occasions.

From my first conference in Alicante, the conferences of the American Real Estate and Urban Economics Association, the Economic History Association and the Cliometric Society have been instrumental for the research I did during my $\mathrm{PhD}$, both by providing extensive funding and support to graduate students, but also by putting me in the position to get to know many scholars and PhD students in real estate and economic history. Jean-Laurent Rosenthal, thanks for hosting me at Caltech, and for your valuable feedback on my work and historical endeavors. Your tremendous knowledge and wisdom, in particular of France's economic history, is inspiring. I am also indebted to the community of Dutch and Flemish scholars working on financial history, to Oscar Gelderblom, Joost Jonker, Christophe Spaenjers and many others. Thanks for always being open to me and providing me with much useful feedback and advice. I think economists have a lot to learn from the way historians approach working with historical data.

Working and collecting archival was one important part of this PhD project. The Amsterdam City Archives have been incredibly helpful throughout this entire process. At the start, they provided me access to the database of real estate transactions on which two of the papers in this dissertation are based, and were always helpful when I needed to consult documents on-site. Later in the process, they were willing to make ten-thousands of scans from archival pieces, so that these could be digitized from distance. Francine Tinnemans, Heleen Thedinga, and Lena Gadzhuk provided excellent research assistance by digitizing much of this historical material. I particularly have to thank Francine for transcribing nearly all of the Amsterdam estate tax records, which were key for my job market paper and will certainly be beneficial for the financial history community in the future.

Beyond academia, I am lucky to have a loving family and a group of friends behind me that have always supported me. When I couldn't stop thinking about my research, they would provide me with much-needed distraction ranging from dinners, holiday trips, bike rides, to great conversations over coffee and beer.

Lieve papa en mama, dank dat jullie mij altijd met warmte en liefde opgevoed hebben, en mij de kans hebben gegeven mijn vleugels uit te slaan. Jullie zullen mij altijd blijven steunen, hoe ver weg of dichtbij ik ook ben. Mama, je bent altijd in gedachten bij me en ik kan je niet genoeg bedanken voor al je goede zorgen. Papa, jij wist misschien wel eerder dan ik dat ik ooit een proefschrift zou gaan schrijven, en dat een studie economie toch beter bij mij zou passen dan de bedrijfskunde. Dank dat je me de goede richting op heb gestuurd.

Last, I want to thank Tabea for sharing the final part of this journey with me, and 
I look forward to all the adventures that are still to come. We ran into each other on a random sunny day in 2019, and since then our paths have merged. When I was about to enter the academic job market, you soon had the courage to tell me that you'd go wherever I'd go, something I didn't even dare to think of myself. You don't need words to find out how I am doing or feeling, and you have always given me the support and love I need, even in stressful times. I can't thank you enough.

Matthijs

Rotterdam, December 2020 


\section{Contents}

1 Introduction 3

1.1 Measurement in Property Markets . . . . . . . . . . . . . 6

1.2 Historical Housing Markets as Experiment $\ldots \ldots \ldots \ldots \ldots$

2500 Years of Housing Rents 13

2.1 Data . . . . . . . . . . . . . . . . . . . . . 17

2.2 Methodology: Estimating Long-Term Indices _ . . . . . . . . . . 20

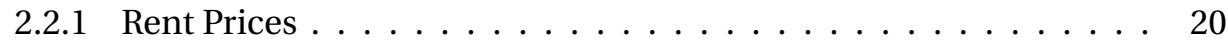

2.2 .2 Robustness Checks . . . . . . . . . . . . . . . . 22

2.3 Housing Rents in the Long Run . . . . . . . . . . . . . . . . . . . . 24

2.3 .1 Trends in Housing Yields $\ldots \ldots \ldots \ldots$

2.4 Urban Growth and Rent Price Growth . . . . . . . . . . . . . . . . 31

2.5 Conclusion . . . . . . . . . . . . . . . . . . . . . 34

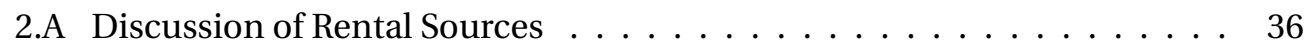

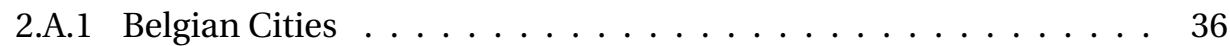

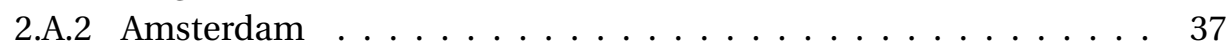

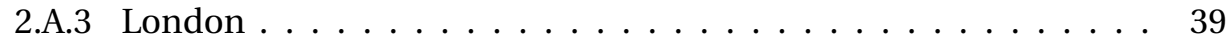

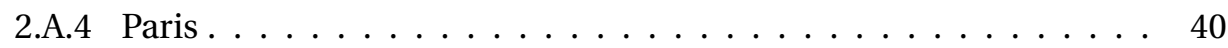

2.B Representativeness of Institutional Sample . . . . . . . . . . . . . . 42

2.C Consumer Prices . . . . . . . . . . . . . . . . . . . 47

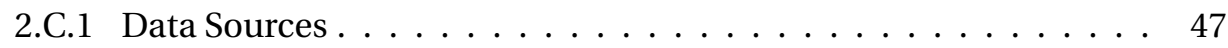

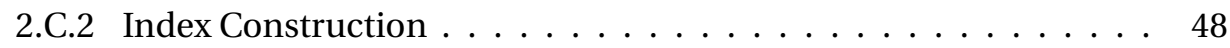

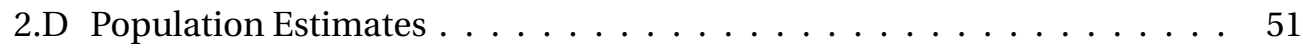

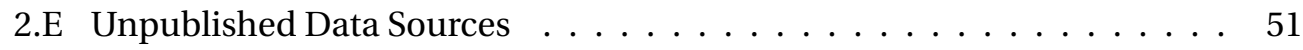

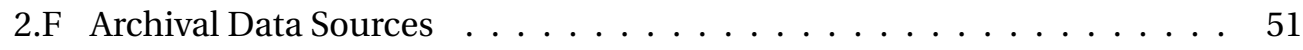

3 Long Run Affordability and (Ine)Quality 53

3.1 Data . . . . . . . . . . . . . . . . . . 56

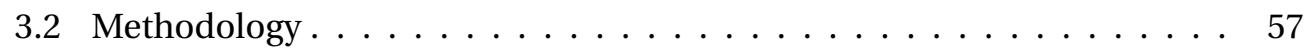

3.2 .1 Housing Affordability $\ldots \ldots \ldots \ldots \ldots \ldots$

3.2 .2 Housing Quality . . . . . . . . . . . . . . . . 58

3.2 .3 Housing Inequality $\ldots \ldots \ldots \ldots$

3.3 Urban Rental Housing in the Long Run . . . . . . . . . . . . . . 59

3.3 .1 Rental Housing Affordability $\ldots \ldots \ldots \ldots \ldots$ 
3.3.2 Housing Quality and Inequality . . . . . . . . . . . . . . . 63

3.3.3 Urban Change in Unregulated Housing Markets . . . . . . . . . . . 66

3.3.4 Regulated Markets . . . . . . . . . . . . . . . . . . 70

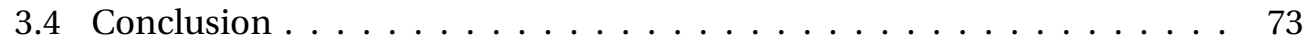

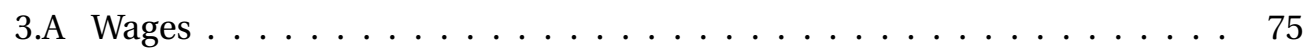

3.A.1 Data Sources . . . . . . . . . . . . . . . . 75

3.A.2 Index Construction . . . . . . . . . . . . . . . . . 76

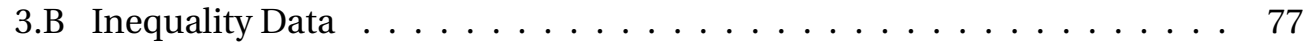

3.C Income Shares on Housing . . . . . . . . . . . . . . 78

3.D Rent Control Index . . . . . . . . . . . . . . . . . . . . 78

3.D.1 Construction Estimates . . . . . . . . . . . 80

4 The Total Return and Risk to Real Estate 83

4.1 Data and Historical Context . . . . . . . . . . . . . . . . . 87

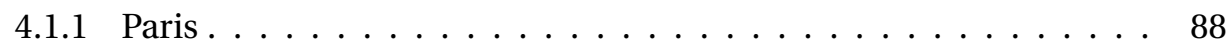

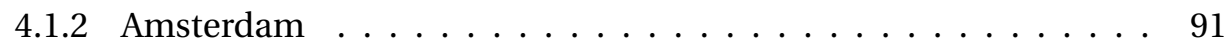

4.2 The Components of Total Housing Returns . . . . . . . . . . . . . . . . . . . . . . . . . . . . . . . . . . . . .

4.2 .1 Capital Appreciation . . . . . . . . . . . . . . . . . . . . . . . . . . . . . . 95

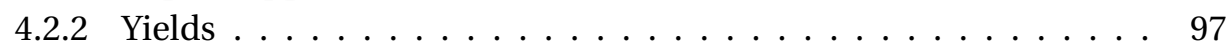

4.3 The Total Return to Residential Real Estate . . . . . . . . . . . . . . 100

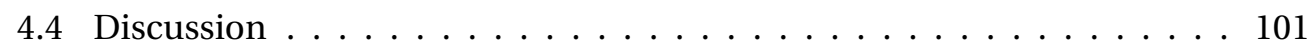

4.4.1 Comparing Our Indices to Previous Work . . . . . . . . . . . . . . 102

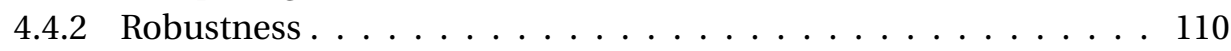

4.4 .3 Representativeness . . . . . . . . . . . . . . . . . . 114

4.5 Idiosyncratic Risks . . . . . . . . . . . . . . . . . . . . . . . . . . . . . . 116

4.5 .1 The Dispersion of Yields . . . . . . . . . . . . . . . 117

4.5.2 The Covariance of Yields and Capital Gains . . . . . . . . . . . 119

4.5.3 Total Return Risk and its Components . . . . . . . . . . . . . . . 121

4.5 .4 Implications . . . . . . . . . . . . . . . . . . . . . . . . . . . . 123

4.6 Conclusion . . . . . . . . . . . . . . . . . . . . . . . 124

4.A Identifying and Adjusting Capitalized Rents . . . . . . . . . . . . . . . . . 125

4.B Tax Data and Analysis for Paris . . . . . . . . . . . . . . . . . 128

4.C Costs for Institutional Property in Amsterdam . . . . . . . . . . . . . 128

4.D Supplementary Figures . . . . . . . . . . . . . . . . 132

5 Reach for Yield and Real Estate 135

5.1 Related Literature . . . . . . . . . . . . . . . . . . . . . . . . . . . . . . . . . . . . . . . . . . . . . . . . . . . . .

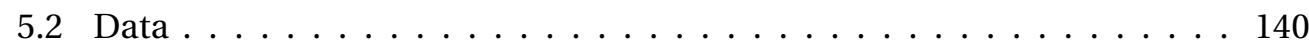

5.2 .1 Real Estate Registrations . . . . . . . . . . . . . . . . . . . . . . . . . . . . . . . 140

5.2 .2 Estate Tax Records . . . . . . . . . . . . . . . . . . . . . . . . . . . . . . . . . . . . . . . . . . . .

5.2 .3 Linking Housing Transactions . . . . . . . . . . . . . . . . . . . . . . . . . . . . . 144

5.3 Motivational Evidence . . . . . . . . . . . . . . . . . . . . . 146

5.3.1 Why Would Investors Reach for Yield? . . . . . . . . . . . . . . . 146

5.3 .2 Investment Porfolios in Amsterdam . . . . . . . . . . . . . . 148 
5.3.3 House Prices in Amsterdam . . . . . . . . . . . . . . . . . . . . 152

5.4 Investor Demand and Housing Cycles . . . . . . . . . . . . . . . . 155

5.4.1 Wars, Bond Supply and House Prices … . . . . . . . . 155

5.4 .2 Empirical Results . . . . . . . . . . . . . . . . . . . 161

5.4.3 Reach for Yield and Housing Market Behavior . . . . . . . . . 163

5.5 Implications . . . . . . . . . . . . . . . . . 167

5.5 .1 Private Credit . . . . . . . . . . . . . . . . . . . 168

5.5 .2 Financial Market Development . . . . . . . . . . . . . . . . . 169

5.5 .3 Housing Wealth Inequality $\ldots \ldots \ldots \ldots$

5.6 Conclusion . . . . . . . . . . . . . . . . . . . . . . . . 172

5.A Additional Context Data . . . . . . . . . . . . . . . . . . . . 173

5.A.1 Real Estate Registrations . . . . . . . . . . . . . . . . . 173

5.A.2 Estate Tax Records . . . . . . . . . . . . . . . . . . 175

5.B Additional Historical Context . . . . . . . . . . . . . . . . . . 178

5.B.1 House Price Developments and Turnover . . . . . . . . . . . . 178

5.B.2 Housing Supply . . . . . . . . . . . . . . . . . . . 181

5.B.3 Real Estate Taxation . . . . . . . . . . . . . . . . . . . . 182

5.B.4 Credit, Mortgages and The Housing Market . . . . . . . . . . . 184

5.C Additional Robustness Checks . . . . . . . . . . . . . . . . . . . 185

5.D Overview Data and Data Sources . . . . . . . . . . . . . . . . . . . 189

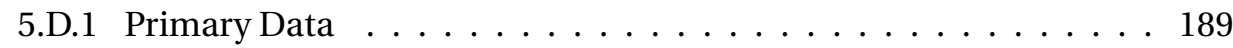

5.D.2 Secondary Data . . . . . . . . . . . . . . . . . . . . 190

5.E Supplementary Tables and Figures . . . . . . . . . . . . . . . . . . 192

5.F List of Archival References . . . . . . . . . . . . . . . . . . . . 193

6 Demography and the Housing Market 195

6.1 Data . . . . . . . . . . . . . . . . . . . . . . . . 199

6.1 .1 Demographic Data . . . . . . . . . . . . . . . . . . 199

6.1 .2 Housing Market Data . . . . . . . . . . . . . . . . . . . . 201

6.2 Analysis: Demographic Structure and Housing Costs . . . . . . . . . . 203

6.2.1 Housing Demand: Rent Prices _. . . . . . . . . . . . . 206

6.2.2 Asset Demand: House Prices and Rent-Price Ratios . . . . . . . . 206

6.2 .3 Robustness Checks . . . . . . . . . . . . . . . . . . . . . 210

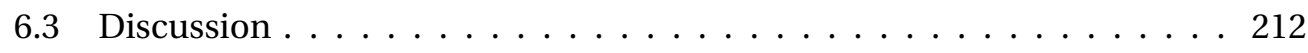

6.3.1 Housing Demand across Age Groups . . . . . . . . . . . . . . . . 214

6.3.2 Housing Investments across Age Groups … . . . . . . . 216

6.3.3 Demographic Demand for Bond Investment . . . . . . . . . . 221

6.4 Conclusion . . . . . . . . . . . . . . . . . . . . . 221

6.A Demographic Demand and Bond Yields . . . . . . . . . . . . . . 224

6.B Supplementary Tables and Figures $\ldots \ldots \ldots \ldots . \ldots 226$ 
7 Housing Markets in a Pandemic 233

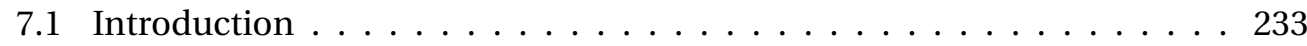

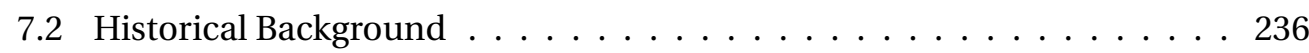

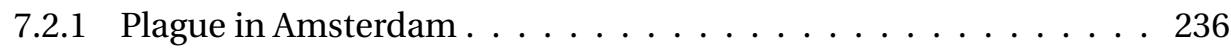

7.2 .2 Cholera in Paris . . . . . . . . . . . . . . . . . . . . . . . . . . . . . . . . . . . . . .

7.2.3 Urban Growth and the Housing Market . . . . . . . . . . . . . . . . 240

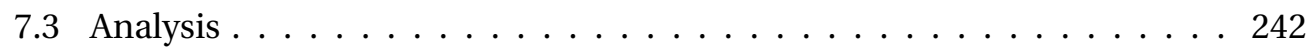

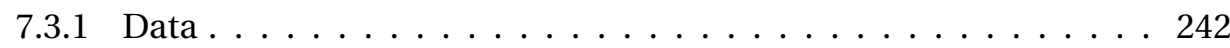

7.3.2 Aggregate Impact on House Prices and Rents . . . . . . . . . . . 243

7.3 .3 Repeat Sales Model . . . . . . . . . . . . . . . . . . . 245

7.3.4 Short-Term Price Responses in Amsterdam . . . . . . . . . . . . . . 246

7.3.5 Neighbourhood Price Responses in Paris . . . . . . . . . . . . . . . 248

7.4 Mechanisms and Implications . . . . . . . . . . . . . . . . . . . . . . . . . . . . . . . . . . . . .

7.4.1 Housing Demand \& Urban Growth . . . . . . . . . . . . . . . . 251

7.4.2 Potential Channels for Short Term Price Drops . . . . . . . . . . . 253

7.4.3 Housing Supply \& Urban Planning . . . . . . . . . . . . . . . . . . . . . . . 254

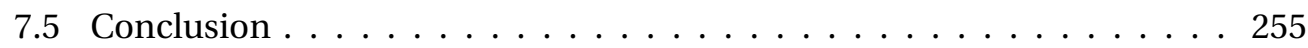

7.A Beyond Prices: Housing Markets in Epidemics . . . . . . . . . . . . 256

7.A.1 Housing Supply and Construction . . . . . . . . . . . . . . 256

7.A.2 Mortgage Originations . . . . . . . . . . . . . . . . . . . . . . . 257

7.A.3 Transaction Volume \& Foreclosures . . . . . . . . . . . . . . . . . . . . . 258

7.A.4 Time-Between-Sales . . . . . . . . . . . . . . . 260

7.B Results Using a Hedonic Price Model . . . . . . . . . . . . . . . . 261

8 Summary of Findings $\quad 263$

9 Research Impact $\quad 265$

9.1 Lessons for Households . . . . . . . . . . . . . . . . . . 265

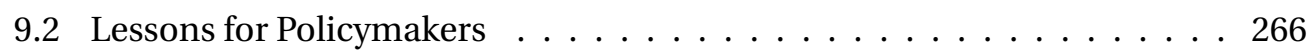

9.3 Lessons for Investors . . . . . . . . . . . . . . . . . . 267 


\section{List of Figures}

1.1 Amsterdam House Prices, $1604-2019 \ldots \ldots \ldots \ldots \ldots$

1.2 Rent Protests, Berlin, $2019 \ldots \ldots \ldots \ldots \ldots$

1.3 Rent Protests, Amsterdam, $1933 \ldots \ldots \ldots \ldots$. . . . . . . . 5

1.4 Average Real Rents and Real Wages, $1500-2018 \ldots \ldots$. . . . . . . . . . 8

2.1 Housing Rents and Land Rents, Paris area . . . . . . . . . . . . . . 24

2.2 Nominal Rent and Consumer Price Indices, 1500-2018 . . . . . . . . . . 26

2.3 Real Rent and Population Indices, 1500-2018 . . . . . . . . . . . . . . . 27

2.4 Yields on Transacted Institutional Properties, 1500-1900 . . . . . . . . . 30

2.5 Population Change and Rents at Varying Time Horizons . . . . . . . . . 32

2.6 Amsterdam Mean Rents . . . . . . . . . . . . . . . . . . . 43

2.7 Antwerp Mean Rents . . . . . . . . . . . . . . . . . . . . . . . . . 44

2.8 Bruges Mean Rents . . . . . . . . . . . . . . . . . . . . . . 44

2.9 Brussels Mean Rents . . . . . . . . . . . . . . . . . . . . . . . 45

2.10 Ghent Mean Rents . . . . . . . . . . . . . . . . . . . . . . . . 45

2.11 London Mean Rents . . . . . . . . . . . . . . . . . . . . . . 46

2.12 Paris Mean Rents . . . . . . . . . . . . . . . . . . . 46

3.1 Real Rent Prices and Real Wages _ . . . . . . . . . . . . . . . 60

3.2 Housing Affordability Indices, $1500-2018 \ldots \ldots$

3.3 Space per Capita in the $19^{\text {th }}-21^{\text {st }}$ Century . . . . . . . . . . . . . . . 65

3.4 Housing Inequality Estimates, $1500-2018 \ldots \ldots \ldots$

4.1 Example of Sommier Foncier Property Information . . . . . . . . . . . 89

4.2 Example of an Amsterdam Auction Card . . . . . . . . . . . . . . 93

4.3 Gross Housing Yields, Paris and Amsterdam . . . . . . . . . . . . . . 98

4.4 Real Total Returns and Capital Gains . . . . . . . . . . . . . . . . . 101

4.5 House Price Indices . . . . . . . . . . . . . . . . . . . . . . . . . . . 103

4.6 Net Yields, Paris and Amsterdam . . . . . . . . . . . . . . . . . . . 106

4.7 Median Excess Gross Yields, per Neighborhood . . . . . . . . . . . . . 118

4.8 Correlation Repeated Yields . . . . . . . . . . . . . . . . . . . . . . 120

4.9 Decomposition of Total Risk . . . . . . . . . . . . . . . . . . . 122

4.10 Example Distribution of Scores, Paris, 1835-1839 . . . . . . . . . . . 126

4.11 Distribution of $\log$ Yields, Paris, 1806-1943 . . . . . . . . . . . . . 127 
4.12 Composition of Costs, Institutional Properties, Amsterdam . . . . . . . . 129

4.13 Tax and Vacancy Rates, Paris and Amsterdam . . . . . . . . . . . . . . 132

4.14 Decomposition of Residual Variance . . . . . . . . . . . . . . . . . 133

5.1 Property Transfer Act, Rembrandt . . . . . . . . . . . . . . . . . 141

5.2 Estate Tax Record, Willem van Collen . . . . . . . . . . . . . . . . . 143

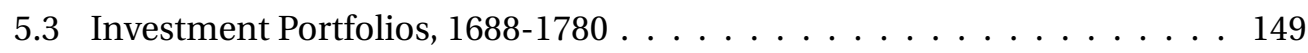

5.4 Bond Yields and Portfolio Composition . . . . . . . . . . . . . . . . 151

5.5 Portfolio Composition and Bond Investment . . . . . . . . . . . . . . . . . . . . . . . 153

5.6 House Prices, Bond Yields and Discounted Rents . . . . . . . . . . . . . . . . . . . . 154

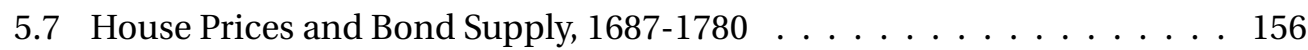

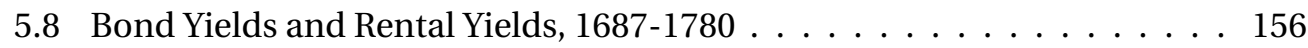

5.9 Difference-in-Difference Estimates, per 5-years . . . . . . . . . . . . . . 167

5.10 House Prices and Private Non-Mortgage Credit . . . . . . . . . . . . 169

5.11 Bond Yields and New Assets . . . . . . . . . . . . . . . . . 170

5.12 Housing Inequality . . . . . . . . . . . . . . . . . . . . . . . . . . . . . . .

5.13 House Prices and Turnover, 1585-1810 . . . . . . . . . . . . . . . . . 179

5.14 Transaction Value Amsterdam Real Estate, 1585-1810 . . . . . . . . . . . . 182

5.15 Population and Construction in Amsterdam . . . . . . . . . . . . . . 183

5.16 Real Estate Transactions and Private Annuities . . . . . . . . . . . . . 185

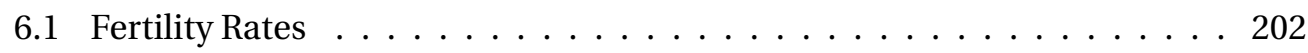

6.2 Lagged Fertility and Rent Prices. . . . . . . . . . . . . . . . . . . 207

6.3 Lagged Fertility and Changes in House Prices and Yields . . . . . . . . . . 209

6.4 Age Structure Population, Amsterdam, 1851 . . . . . . . . . . . . . . . . 213

6.5 Log Housing Demand by Age, Amsterdam, 1851. . . . . . . . . . . . . . . . 215

6.6 Housing Transactions by Age, Amsterdam, 1700-1760. . . . . . . . . . . 218

6.7 The Effect of Lagged Fertility on Bond Yields. . . . . . . . . . . . . . . . . 224

6.8 Log Housing Demand by Age (1851, Amsterdam), with controls . . . . . . 228

6.9 Lagged Fertility and Rent Prices (Non-Overlapping). . . . . . . . . . . . . 229

6.10 Lagged Fertility, Rental Yields and House Prices (Non-Overlapping). . . . 229

6.11 Lagged Fertility and Rent Prices (3-Year Changes). . . . . . . . . . . . . 230

6.12 Lagged Fertility, Rental Yields and House Prices (3-Year Changes). . . . . 230

6.13 Lagged Fertility and Rent Prices (10-Year Changes). . . . . . . . . . . . . . 231

6.14 Lagged Fertility, Rental Yields and House Prices (10-Year Changes). . . . 231

6.15 Lagged Fertility and Rent Prices (Growth Only). . . . . . . . . . . . . . . 232

6.16 Lagged Fertility, Rental Yields and House Prices (Growth Only). . . . . . . 232

7.1 Mortality per 1000 Inhabitants. . . . . . . . . . . . . . . . . . . . . . . . . 238

7.2 Cholera Mortality per 1000 Inhabitants. . . . . . . . . . . . . . . . . 239

7.3 Housing Prices and Rents Around Epidemics. . . . . . . . . . . . . . . 241

7.4 Price-Variation in Neighbourhoods by Cholera Mortality. . . . . . . . . . 250

7.5 Transactions in Paris. . . . . . . . . . . . . . . . . 260 


\section{List of Tables}

2.1 Overview of Rental Data Sources . . . . . . . . . . . . . . . . . 18

2.2 Variance Parameters and Signal-to-Noise Ratios . . . . . . . . . . . . . 22

2.3 Estimates of Log-Difference in House Age Coefficients . . . . . . . . . 23

2.4 Time Trends in Yields . . . . . . . . . . . . . . . . . . . . . . 31

2.5 Regression Estimates: Rents and Population Growth . . . . . . . . . . 33

2.6 Overview Consumer Price Sources . . . . . . . . . . . . . . . . . . . 47

2.7 Expenditure Patterns in an Antwerp Orphanage . . . . . . . . . . . 49

2.8 Base Weights Price Index, Key Years . . . . . . . . . . . . . . . . 50

3.1 Housing Budget Shares in the $20^{\text {th }}$ and $21^{\text {st }}$ Century . . . . . . . . . 62

3.2 Housing Quality Index $(1750-1774=100) \ldots \ldots \ldots$

3.3 Housing Quality, Inequality and Urban Growth, 1500-1913 . . . . . . 69

3.4 Nominal Rent Control and Affordability . . . . . . . . . . . . . . 72

3.5 Overview Wage Sources . . . . . . . . . . . . . . . . . . . 75

3.6 Housing Quality per Capita . . . . . . . . . . . . . . . . 81

4.1 Sources and Sample Sizes Property-Level Data . . . . . . . . . . . . . . 87

4.2 Capital Gains, Rental Yields, and Total Returns . . . . . . . . . . . . 96

4.3 Comparing Return Estimates . . . . . . . . . . . . . . . . . . 102

4.4 Longer Horizons . . . . . . . . . . . . . . . . . . . . . . 107

4.5 Robustness of the Return Estimates … . . . . . . . . . . . 112

4.6 Expense Fraction, Rental Property Institutional Investors $\ldots \ldots \ldots$

5.1 Primary Datasets . . . . . . . . . . . . . . . . . . . . . . . 140

5.2 Descriptive Statistics, War and Non-War Periods, 1688-1780 . . . . . . 159

5.3 The Effect of Bond Supply on House Prices . . . . . . . . . . . . . . 162

5.4 The Impact of Bond Supply on Yields and Risk Premia . . . . . . . . . . 164

5.5 Purchase Frequency, Difference-in-Difference Regressions . . . . . . . 166

5.6 Representativity Collaterale Successie . . . . . . . . . . . . . . . . 176

5.7 Results VAR model, One-Year Changes . . . . . . . . . . . . . . . . 187

5.8 Results VAR model, Two-Year Changes . . . . . . . . . . . . . . . . . 188

5.9 Impact of Bond Supply on Yields and Risk Premia, No Controls . . . . . 192

6.1 Descriptive Statistics, Annual. . . . . . . . . . . . . . . . . . . . . 204 
6.2 Results for Paris and Amsterdam, 5-Year Rent Changes. . . . . . . . . . . 208

6.3 Results for Amsterdam: Rental Yields and House Price Changes. . . . . . 211

6.4 Real Estate Wealth by Age, Amsterdam, 1688-1780. . . . . . . . . . . . . 220

6.5 Bond Investment by Age, Amsterdam, 1688-1780 . . . . . . . . . . . . . . . . . . . . . . . . . . .

6.6 Results for Lagged Fertility and Bond Yields. . . . . . . . . . . . . . . . . . . . . . . . . . . . . . . . . . . . .

6.7 Statistics Rental Value Regressions. . . . . . . . . . . . . . . . . . . . . . . . . . . . . . . . . . . . . . . . . . .

6.8 Transaction Prices by Age. . . . . . . . . . . . . . . . . . 227

7.1 House Prices and Rents in Epidemics. . . . . . . . . . . . . . . . . . . . 244

7.2 Estimation Results Price Responses Amsterdam. . . . . . . . . . . . . . 249

7.3 Estimation Results Price Responses Paris. . . . . . . . . . . . . . . . . . . . . . . . . . . . 252

7.4 Monthly Transaction Volume around Epidemics. . . . . . . . . . . . . . . 259

7.5 Estimation Results for Time-between-Sales. . . . . . . . . . . . . . . . 261

7.6 Estimation Results Price Responses Amsterdam, Hedonic Price Model 262 


\section{Chapter 1}

\section{Introduction}

$21^{\text {st }}$ century housing markets have posited two major challenges to the developed world. In the 2000s, increasing credit supply and housing speculation led to the buildup of a large housing bubble, which eventually resulted in the global financial crisis (Glaeser and Nathanson, 2014; Mian and Sufi, 2015). Following the crisis, central banks injected large sums of money into the economy while also restricting mortgage credit to prevent the next crisis.

Today, many believe we face a housing crisis of a very different kind: an affordability crisis. Many households feel that proper housing is becoming increasingly out of reach, with house prices and rents rapidly rising, in particular in cities. Home-owners increasingly face competition in the housing market from investors (Nijskens et al., 2019; Mills et al., 2019), who might view real estate as an attractive investment opportunity now interest rates are low. According to the United States Human Rights Council, the recent crisis has caused a shift "from housing as a place to build a home, to housing as an investment," highlighting the dual role of housing as a consumption asset and a financial asset.

Societies have started to respond to these issues in different ways. Rent regulation has experienced a revival, with the boldest move taken by the Berlin city council, which recently decided to freeze housing rents entirely for five years. Beyond rent controls, many governments have increased the stamp duty for investment purchases, with Amsterdam even completely prohibiting buy-to-let investments for new construction. In the arena of monetary policy, various central bankers have warned that extended periods of low rates could cause exuberance in housing prices, and called for action. In many places, housing advocates have called for a relaxation of zoning constraints, often considered an important driver of expensive housing (Glaeser and Gyourko, 2018).

At the same time, many of the current problems and their potential solutions are not new. Housing booms and busts have occurred through history (Figure 1.1), and so have tensions between property investors and their tenants. (Figure 1.2).

In $16^{\text {th }}$ century Paris, the central court ruled to reduce rents on all existing contracts to $25 \%$ of their original amounts, after a devastating siege had hit the city (Féli- 
Figure 1.1: Amsterdam House Prices, 1604-2019

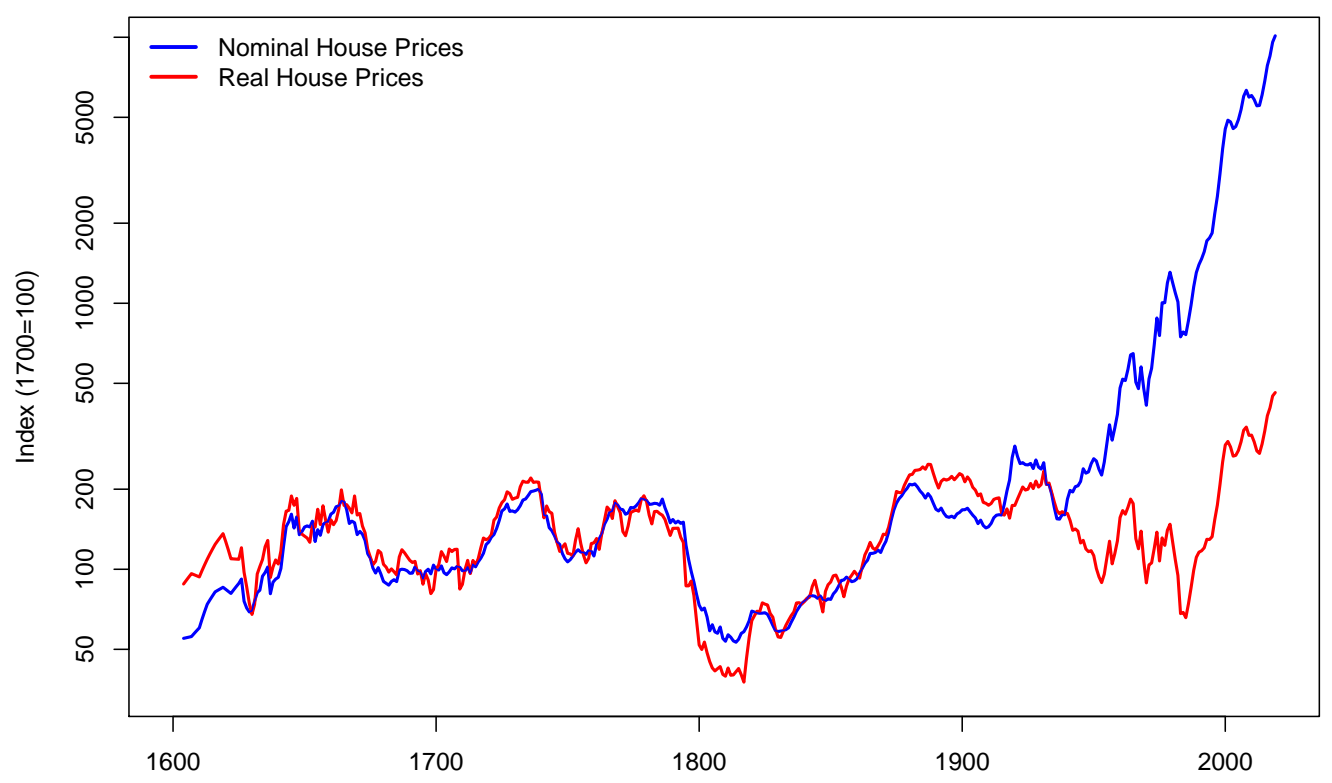

Notes: This plot shows the Amsterdam house price index in both real and nominal terms, using data and methods from Chapters 4 to 6 of this dissertation.

bien, 1725). In $16^{\text {th }}$ and $17^{\text {th }}$ century Amsterdam, a continued influx of migrants forced the municipal government to start a significant expansion of the city, in order to build homes for all these new city dwellers (Abrahamse, 2010). After Amsterdam house prices tumbled in the 1740s, home-owners rebelled to reduce property taxes because "bringing back property prices to their old level will make the bourgeoisie flourish again." In the novel 'Bleak House,' Charles Dickens' character Snagsby talks about London's high $19^{\text {th }}$ century rents: "You find the rent high, do you, sir? Rents are high about here. I don't know how it is exactly, but the law seems to put things up in price."

The plethora of alleged causes of current and past problems on the housing market point out that housing markets are complicated animals. We still lack a complete understanding of the way housing markets function. Nearly all academic literature in finance and economics has used modern settings and data to expand our knowledge of housing markets. This dissertation instead exploits the long course of history to create a better understanding of the dynamics in urban housing markets, both using 'historical experiments' and with newly-collected data and statistics on the long-term evolution of urban housing rents, prices and returns in the past 500 years.

The dual role of housing as a place to live in and as an asset to invest in implies that housing markets can be analyzed from different points of view. In this dissertation, the dominant approach is to analyze housing markets from a financial-economic perspective. The economic and financial literature studying historical housing markets 
Figure 1.2: Rent Protests, Berlin, 2019

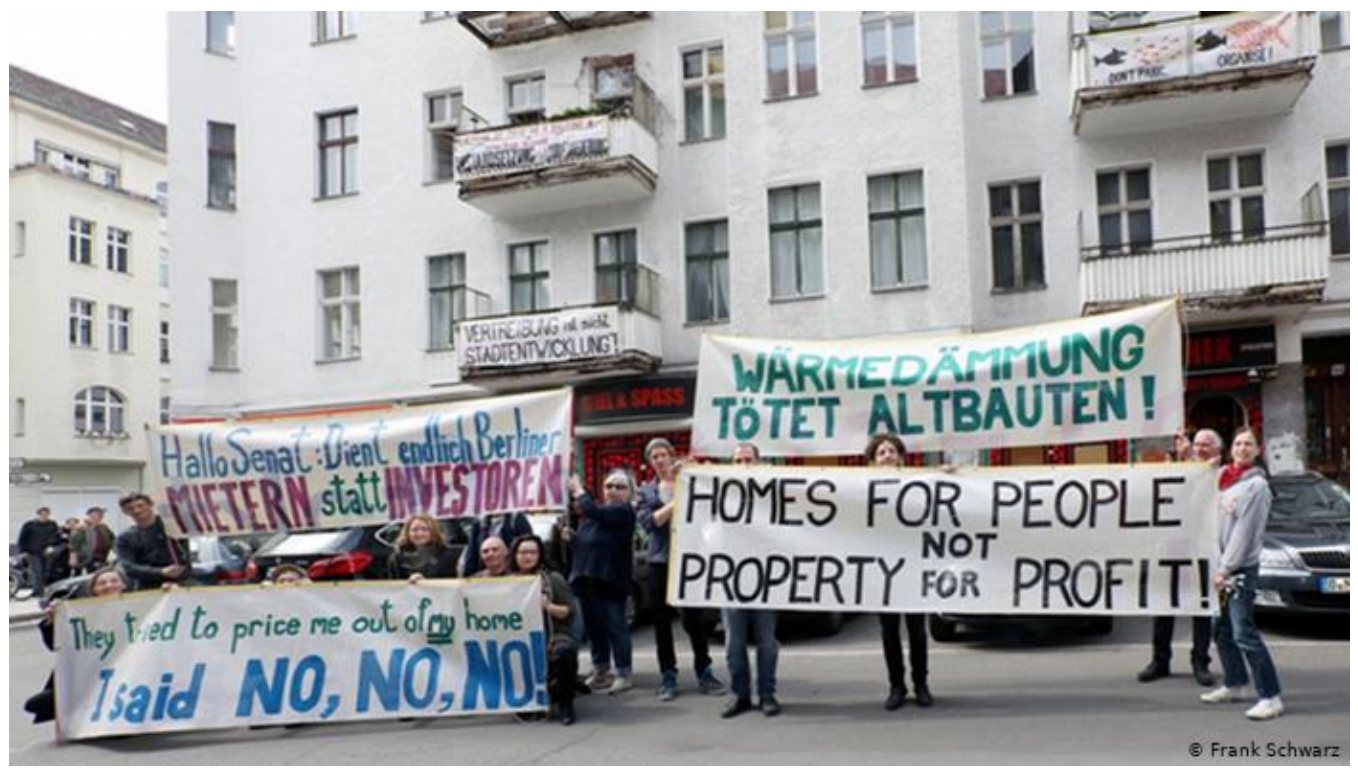

Figure 1.3: Rent Protests, Amsterdam, 1933

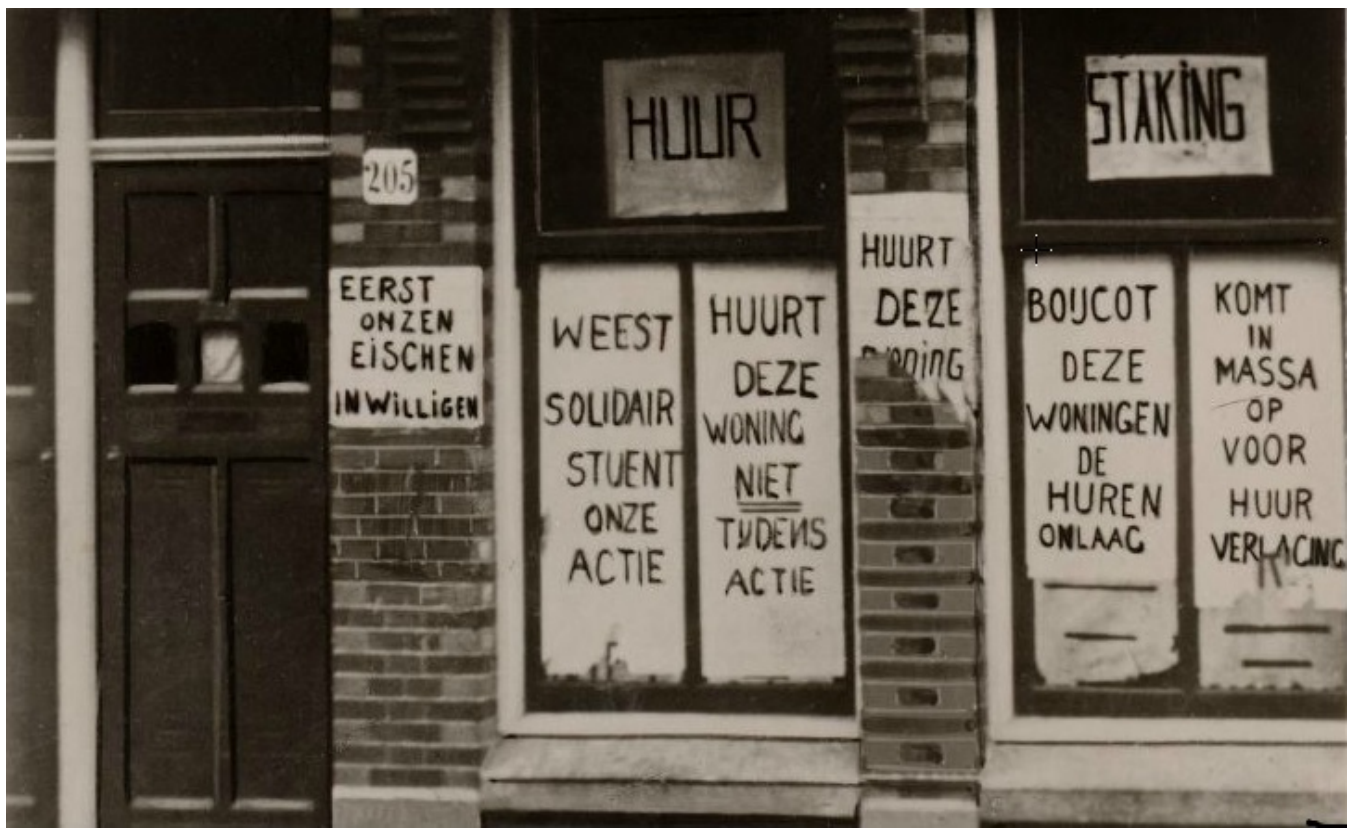

Notes: Rent protests today and in the past. In the 1930s, Amsterdam citizens revolted against high rents and refused to pay them. In 2019, Berlin citizens protested for rent freezes and demanded the expropriation of property from investors. 
is still in its infancy. Beyond a gradually expanding range of studies on the long-term development of house prices and rents (e.g. Eichholtz, 1997; Clark, 2002; Knoll, 2017; Knoll et al., 2017), a handful of studies have used historical settings or long-term data to understand housing market developments (examples include Fishback et al., 2010; Rajan and Ramcharan, 2015; White et al., 2014).

Despite this narrow starting point of view, this thesis aims to address housing market issues that are of general importance. The remainder of this chapter discusses each of these issues in more detail and introduces how the long-term studies in this dissertation can help to better understand housing markets. The next three chapters present three studies that aim to measure and describe the long-term developments in urban housing rents (Chapter 2), housing quality and affordability (Chapter 3), and the return and risk to real estate investments (Chapter 4). Chapters 5 to 7 use the lens of history to provide a better understanding of the drivers of urban rents, house prices, and returns. Chapter 5 studies the role of investor demand in property markets, and Chapter 6 looks at the consequences of demographic structure and population aging on urban house prices and rents. Chapter 7 exploits historical epidemics to study their impact on property prices and rents. This dissertation ends with a summary of the results of these studies and a discussion of their societal implications.

\subsection{Measurement in Property Markets}

A house is an investment for its owner and a place to live for its tenants. For tenants, the cost of living in a property equals its current rental price, and, for longer-term tenants, the risky future levels of rental prices (Sinai and Souleles, 2005). For investors, returns accumulate from these rental payments as well as potential capital gains.

Thus, the evolution of rental prices matters, both for long-term investors and for tenants. However, accurate information on the development of rents is scarce, both historically and contemporaneously. Most studies in economics and finance focus on the evolution of house prices, and not rents. For house prices, Knoll et al. (2017) compile data from 13 developed countries to document a 'hockey-stick' pattern in house prices since 1870, with home prices exploding in the past thirty years. In one of the very few studies on housing rents, Knoll (2017) does not find this pattern, with housing rents climbing $1.4 \%$ per annum in real terms since 1870, relative to an annualized real house price growth of over $2 \%$ per year. The recent explosion in house prices drives nearly all of this diversion. Nevertheless, Jordà et al. (2019a) do find that most of the return to housing investments derives from rental yields, and not from capital gains.

However, a more fundamental problem in interpreting these findings is measurement. To understand why, assume that the log rental price or log property price of any property $i$ in location $j$ at time $t$ can be written as the sum of a quality component $\alpha_{i}$, a market price component $\beta_{j, t}$, and an idiosyncratic price error $\varepsilon_{i, j, t}$ :

$$
p_{i, j, t}=\alpha_{i}+\beta_{j, t}+\varepsilon_{i, j, t}
$$


Equation 1.1 states that the price of an individual property is a function of its quality attributes, such as the amount of floor space and the quality of the bathroom(s) and kitchen(s), and a market price component that varies across locations and over time. Aggregate house prices and rent prices change over time due to changes in housing quality and changes in the value of locations.

This basic insight has three important implications for the way we understand the evolution of prices, returns, and affordability over time. First, indices of rental prices or property prices might be biased if they do not adequately separate changes in quality over time from changes in market prices. This issue is potentially severe: only a few long-term indices of property prices or rents adequately control for quality. This makes it difficult to understand if rent prices and property prices have risen because quality has improved over time, or because housing has become fundamentally less affordable. Making this distinction is crucial in debates about affordability. However, without data on the evolution of housing quality and quality-controlled housing rents over the long run, this has not been possible so far.

Second, house prices and rental prices vary across locations, and the past evolution of prices in a particular area might not necessarily be representative of its future growth. One striking example is Los Angeles. In the 1850 US Census, the population of Los Angeles County was a mere 3,500 people. Today, it is home to over 10 million people, implying a population growth rate of around $5 \%$ per year. At the same time, Los Angeles grew from a rural settlement to one of the most valuable places in the world. It would be difficult to believe that Los Angeles will experience similar growth in the next decades. However, most long-term evidence on the evolution of house prices and rents is based on 'superstar cities' like Los Angeles. So alike evidence from the financial sector (Brown et al., 1992), housing data from the developed world might have a 'survivorship bias:' it focuses too heavily on areas that have been very successful in the past.

Finally, these two issues become jointly even more significant when studying return and risk in property markets. So far, most literature has looked at housing returns either by looking at rent-price ratios from existing indices (Gallin, 2008; Campbell et al., 2009; Ambrose et al., 2013), or by augmenting implied yields from existing rent and price indices with capital gains from a house price index (Brounen et al., 2014; Jordà et al., 2019a). If these rents and sales prices do not cover the same properties in the same locality, or inadequately control for quality, Equation 1.1 suggests these estimates might be significantly off.

These three elements form the motivation for the first three studies in this dissertation. In Chapter 2, which is co-authored with Piet Eichholtz and Thies Lindenthal, we present the first long-term overview of developments in urban rents in Europe, going back more than 500 years. Based on an enormous data collection effort of nearly half a million housing rents, we construct quality-controlled annual rent price indices from 1500 to the present for seven European cities: Amsterdam, Antwerp, Bruges, Brussels, Ghent, London, and Paris. Second, we combine these new nominal rent indices with indices of consumer prices - both existing and newly constructed - to investigate developments in real housing rents. 
Importantly, the seven cities in our sample offer rich data on housing markets against very diverse economic developments. For example, cities as London and Paris started as 'superstar cities' in 1500 and remained so for the entire sample. On the other hand, Bruges was a very successful city in 1500 , but reduced in importance over time and was very poor in the $19^{\text {th }}$ century, only recovering somewhat in the $20^{\text {th }}$ and $21^{\text {st }}$ century.

In real terms, housing rents have grown barely over the long-run, with an average growth of $0.15 \%$ per annum in the cities we study (Figure 1.4). However, there are essential cross-sectional differences that closely relate to the economic trajectories of these cities. For example, while persistent 'superstar cities' such as London and Paris experienced a growth rate of housing rents of $0.3 \%$ per year, 'fallen angels' like Ghent and Bruges experienced no real rental growth at all. These rental growth differences closely correlate to the past population growth rates in these cities. Investors who base their return estimates on past returns in high-growth cities, where most of the currently available long-term data originate from, will thus fundamentally overestimate housing returns when moving forward. Because urban population growth is predicted to slow down, this issue will likely grow in importance over time.

Figure 1.4: Average Real Rents and Real Wages, 1500-2018



Notes: This figure reports the unweighted average of real rent and real wage indices in Amsterdam, Antwerp, Bruges, Brussels, Ghent, London and Paris. These indices will be constructed and motivated in Chapters 2 and 3.

In Chapter 3, which is co-authored with Piet Eichholtz and Thies Lindenthal, we analyze the evolution of urban housing affordability, quality, and inequality since 1500 . Motivated by the recent debates about urban affordability, we aim to identify how 
urban housing affordability has developed over time. To do so, we complement the rental data used in Chapter 2, with information about the development of wages, housing quality and housing inequality.

This long-term perspective sketches a very different picture of the developments in housing affordability. Before 1900, a period of unregulated markets, we find the ratio of wages to quality-controlled prices was relatively stable. In growing cities, we find that increases in rental prices were compensated by increasing wages. Instead, the main negative consequence of long-term urban is an increase in housing inequality. Part of this increase is attributable to differences in rent price increases across cheaper and more expensive segments. In cities that declined in population, we find substantial affordability improvements, because housing supply could not adjust, resulting in large rent price reductions (Glaeser and Gyourko, 2005). After 1900, we find that aggregate housing affordability, in terms of the ratio of quality-controlled rents to wages, improved drastically. For one hour of work, an average worker can now purchase between three to eight times as many units of housing compared to 1900 . Although affordability has recently started worsening in some of the cities we study, rental housing remains far more affordable than before (see Figure 3.2).

If housing affordability improved so much over time, why do urban households spend large fractions of their income on housing? The answer is rising housing consumption. We document that urban rental housing quality and housing consumption per capita have both risen considerably, while housing inequality has reduced substantially. Over time, housing space per capita increased, and homes increasingly contained amenities like electricity, heating, or plumbing. Housing quality already rose considerably from the $16^{\text {th }}$ to the $18^{\text {th }}$ century. Although temporarily halted by the Industrial Revolution, the upward trend in housing quality accelerated in the $20^{\text {th }}$ century, helped by improvements in rental affordability. This time, these benefits accrued more widely than before, as housing inequality reduced substantially.

For investors, the expansion of housing quality and populations implies that residential housing has grown enormously as an asset class. Although buy-to-let investment reduced for most of the $20^{\text {th }}$ century due to rising homeownership rates (Knoll, 2017), residential housing investment has made a comeback recently (Bracke, 2019; Mills et al., 2019). In Chapter 4, which is co-authored with Piet Eichholtz, Thies Lindenthal, and Ronan Tallec, we aim to estimate the actual return and risk to real estate investments for both Paris (1809-1942) and Amsterdam (1900-1979), and at the aggregate and individual property level.

The unique contribution of this chapter is that it builds on actual observations of rents and prices for the same properties over time, rather than implied measures of returns. We hand-collected over 170,000 observations of rents, sales prices, and property-level taxes and costs, covering a representative sample of about 40,000 different properties. The data allow both to construct quality-adjusted total returns indices for rental housing and to estimate the risk and return to rental housing at the individual property level.

In aggregate, we find a total nominal geometric return to rental housing of 6.3 percent for Paris and 8.0 percent for Amsterdam, with index-level standard deviations of 
8.6 percent and 10.3 percent. We find that measuring returns at the house-level matters. Our results indicate lower risk-adjusted returns and low correlations relative to the implied returns in Jordà et al. (2019a), even though these two studies aim to track the same asset base. More importantly, we find that idiosyncratic risk matters. In the short-term, almost all return variance is idiosyncratic and originating from capital gains risk, but the fraction of idiosyncratic risk reduces over time to about $50 \%$ for holding periods of up to 20 years. In the long-term, yield covariance becomes the most important determinant of idiosyncratic risk: properties bought at a higher-thanmarket yield will continue to have high yields in the future.

\subsection{Historical Housing Markets as Experiment}

The red line through the first three studies in this dissertation is that they provide new stylized facts on important parameters in the housing market, based on long-term historical data. The second set of studies exploits historical settings and long-term data to identify important relationships in property markets. There is an expanding trend within economics to use history to provide (close to) causal evidence on relationships that are of general interest (see Cantoni and Yuchtman, 2020). Examples in finance include Koudijs (2016), Koudijs and Voth (2016) and Xu (2018), and in urban economics Nunn and Qian (2011), Bleakley and Lin (2012) and Ambrus et al. (2020). However, the use of specific historical settings and data has been much more limited in housing market research. Booms and busts in house prices or rents have occurred many times in history (Glaeser, 2013), and there is much that can be learned from these historical dynamics.

Chapter 5 exploits the historical setting of $17^{\text {th }}-18^{\text {th }}$ century Amsterdam to examine the impact of investor demand on housing markets. It investigates whether periods of low interest rates cause investors to switch towards buyer higher-yielding assets like real estate, and what the price implications of these shifts are. In the past decade, interest rates have fallen to historically low levels, while investor interest in real estate has surged. Market commentators often describe this shift towards real estate as a 'reach for yield' now interest rates are so low. This reach for yield is nonetheless hard to identify in modern markets because interest rates are endogenous and portfolio data scarce.

I exploit archival data from 164,067 housing transactions and 25,962 investor portfolios to show that Amsterdam experienced large boom-bust cycles in housing prices, but only minor changes in housing rents and bond yields. During these booms and busts, the fraction of wealth invested in real estate rose significantly, in particular for very wealthy rentiers who lived from capital income.

To identify whether these wealthy investors were reaching for yield, I exploit the outbreak of expensive wars abroad. These wars were uncorrelated to the Amsterdam economy, but exogenously increased the supply and yields of Holland government bonds, which wealthy rentiers bought for a stable capital income. When the war ended, and Holland stopped issuing bonds, wealthy rentiers could not reinvest 
their interest payments in new bond issues. Instead of buying bonds in the secondary market, investors increasingly purchased real estate, inflating house prices. Wealthy bondholders were reaching for yield: Facing declining bond yields, they invested increasing shares of their wealth in real estate, and significantly drove up house prices. Because regular home-owners with more limited wealth did not engage in such behavior, the very rich owned an increasing fraction of homes in Amsterdam, resulting in a persistent increase in housing wealth inequality.

Chapter 5 highlights the role of buy-to-let investors in determining the distribution of housing wealth and the level of house prices, particularly in a low interest rate environment. These investors are not the only actors in the housing market. Nowadays, owner-occupiers make most housing purchases. For home-owners, purchasing a property is both a house to live in and a way to accumulate wealth. However, the investment and consumption demand for housing is not stable over the life cycle. The demand for housing consumption is age-dependent, rising fast in early adulthood and flattening gradually for older ages (Mankiw and Weil, 1989). Similarly, life-cycle models predict investment demand for housing to be high for young adults, and to reduce at older ages when individuals consume out of their wealth (e.g. Poterba, 2001; Abel, 2003).

The implication is that investment and consumption demand for housing varies with the demographic structure of the population. These changes might be particularly salient now populations are aging. However, it is unclear how such shifts affect the prices of rental and owner-occupied housing because they are slow and typically endogenous. Chapter 6, which is joint work with Marc Francke, combines Amsterdam and Paris house price and rent data from previous chapters with annual data on fertility and mortality. By looking at centuries of data, we can construct a sufficiently large sample to examine the predictive effects of slow-moving demographic variables on housing costs.

We test whether historical fertility can predict current changes in housing costs. Our primary identifying assumption is that historical fertility predicts current housing demand, but is unrelated to other economic variables that might correlate with current housing demand, after controlling for aggregate changes in population, wages, and consumer prices. We look both at changes in rent prices, which capture consumption demand, and changes in house prices, that capture both investment and consumption demand.

We show that changes in demographic structure have small effects on rent prices. However, we find significant impacts of changes in the demographic structure on house prices and rental yields. A one percentage point increase in fertility about 25 years ago increases current rent prices by $5.4 \%$ and reduces rental yields by about $5 \%$. We find opposite effects for cohorts born around 60 years ago. A fertility increase 60 years ago increases current rental yields and decreases house prices. In short, our results indicate that the age-dependent investment demand for housing is an essential driver of property prices.

Chapter 7, which is joint work with Marc Francke, derives its inspiration from a very recent threat to the housing market: the outbreak of COVID-19. In this chapter, 
we exploit historical outbreaks of cholera in Paris and the plague in Amsterdam to study their impacts on housing markets.

Based on much of the data presented in earlier papers, we document that major epidemics cause significant but short-lived declines in house prices, and have only small effects on rental prices. These effects are most substantial just after the outbreak of an epidemic, and in the worst-affected areas. We argue that epidemics temporarily increase risk aversion, resulting in higher risk premia and lower house prices. However, this price decline is only temporary, and barely visible in rent prices. For both Paris and Amsterdam, the outbreaks did not stop a massive flow of migrants from coming to the city, implying that house prices and rents quickly started growing again. Our findings suggest that urban economies are highly resilient to massive economic shocks, and that it is unlikely that the current pandemic will result in structural reductions in urban housing rents. 


\section{Chapter 2}

\section{Years of Housing Rents*}

Housing is today the world's largest asset class. It has not always been that way. In 1700, only 15 percent of total English and French wealth was invested in housing, with most of the remainder invested in agricultural real estate. Three centuries later, this number had risen to about 60 percent (Piketty and Zucman, 2014), while the capital share of agricultural real estate fell almost to zero. The growth of housing over the past centuries cannot be separated from the fact that population and income growth have enormously expanded the demand for housing consumption. This increased demand has not only resulted in more and larger residential properties, but also in rising real house prices (Knoll et al., 2017). Because of urbanization, this has been particularly the case in cities (Combes et al., 2019).

The rise of housing as an asset class has likely supported the beliefs of both homeowners and investors that residential properties are a good investment for the long term. However, this belief might be misguided. First, most long-run data on housing prices or rents contain a strong bias towards modern "superstar cities": modern capitals or cities that have grown much faster than the general population (Gyourko et al., 2013). ${ }^{2}$ However, the cities that have grown a lot in the past may not be the cities that will grow a lot in the future. History is full of such examples, such as Alexandria, Vijayanagara, and Rome, or the more recent case of Detroit. Similar to a 'survivorship bias' in studies of mutual fund returns (Brown et al., 1992), there might be a 'superstar bias' in studies of housing returns.

Second, urbanization is expected to slow down significantly, in particular in developed countries. In the 1950s, urban populations in developed countries expanded by about 2.5 percent per year. Today, this number is about 0.5 percent, and this growth is predicted to weaken further (United Nations, 2017).

Finally, interest rates have declined towards zero over the past few decades, so that house prices have increased much more than rents. However, over the long term, nearly all asset returns are driven by the cash flows they generate, both in stock mar-

${ }^{*}$ This chapter is co-authored with Piet Eichholtz (Maastricht University) and Thies Lindenthal (University of Cambridge)

${ }^{2}$ Examples include Eichholtz (1997); Eitrheim and Erlandsen (2004); Nicholas and Scherbina (2013); Shiller (2005); Knoll et al. (2017); Knoll (2017). 
kets (Dimson et al., 2009; Le Bris et al., 2019) and housing markets (Jordà et al., 2019a; Chambers et al., 2020; Eichholtz et al., 2020c). This implies that for long-term housing investors it is rental growth that matters.

In this paper, we assess the long-term performance of housing investments by studying urban rents in seven European cities since 1500. Based on about half a million rental cash flows received by institutional investors, we estimate annual rent price indices for Amsterdam, Antwerp, Bruges, Brussels, Ghent, London, and Paris. We show that since 1500 real housing rents have grown by about 0.2 percent per year, but that this growth is skewed towards current-day 'superstar cities. Cities that were 'superstars' in 1500 but did not maintain that status, such as Ghent and Bruges, experienced no long-term rental growth at all.

Our paper makes three important contributions. First, we provide for the very first time a perspective on the long-term evolution of urban rental prices against very diverse economic developments. Studies regarding the long-term performance of urban housing markets often focus on cities that are currently predominant, like New York (Margo, 1996), London (Clark, 2002), Amsterdam (Eichholtz, 1997), Beijing (Raff et al., 2013) or Paris (Duon, 1946). Studies that do include smaller cities, such as the study of Eitrheim and Erlandsen (2004) for Norway, typically cover periods where the studied cities grew much faster than the general population. This focus on high-growth areas could give rise to an urban form of survivorship bias in which price appreciation and rental growth could be systematically overestimated.

On the contrary, the seven European cities that make up our sample started as superstar cities in the $16^{\text {th }}$ century, and then experienced extremely diverse economic, social, and political trajectories. Paris and London remained capital cities, of countries that later became the centers of great empires and that are still among the most important nations on the planet. Amsterdam and Brussels also remained capital cities, but of much smaller countries, and their subsequent urban development was in line with the size of their countries. Antwerp and Ghent kept on prospering initially, but slowed down and then shrunk later, only to regain some of their luster in the $19^{\text {th }}$ and $20^{\text {th }}$ centuries. Bruges was undoubtedly a European superstar city in 1500 , but then ceased to play a role of economic or political influence, getting very poor in the $19^{\text {th }}$, and recovering somewhat in the $20^{\text {th }}$ century, mostly as an interesting tourist destination. We find that these differences are strongly reflected in the level of rents.

Our second contribution lies in the creation of the new rent indices themselves: these are annual-frequency indices, based on primary data, estimated using a state-ofthe-art methodology that accounts for quality differences, consistently applied across cities. These indices - which are the longest in the literature - give important insights into the long-term developments of the housing market rental price.

Our work is closely related to the studies of Knoll et al. (2017) for house prices and Knoll (2017) for housing rents, which diligently splice together pre-existing house price and rent indices to obtain annual indices covering 14 different advanced economies from 1870 to 2015 . However, contrary to this paper, they do not collect primary data and combine indices that widely differ in quality and representativeness, and are mostly not quality-controlled. To our knowledge, the only other attempt to compile rent in- 
dices across countries has been the work of Hoffman et al. (2002), as part of a broader study on real inequality before 1800 . That study does not differentiate between urban and rural rents though, and more importantly, as in Knoll et al. (2017), it combines indices constructed with different methods, some of which do (and many do not) control for housing quality. As the authors acknowledge, and we will show, this can have a dramatic impact on the resulting rent indices and their comparability.

Beyond applying quality controls and covering a more diverse and representative set of cities, our series also span a much longer period of time than existing work. We provide the first consistent overview and comparison of housing rents across cities and centuries, updated to current times. We collected more than 436,000 individual rent observations from archival sources and earlier studies, such as Clark (2002) for London, to estimate indices that go back from today until 1500. There are two important reasons why it is useful to study the evolution of rents before the late $19^{\text {th }}$ century.

First, most urban rental markets in Europe have been under some form of government regulation since the early $20^{\text {th }}$ century (Arnott, 1995), in particular around the World Wars. We find that in these periods, real housing rents fluctuated substantially, and it is unlikely that they are representative of the general long-term evolution in rent prices. Our long-term study gives a perspective on housing rents for the 400-year period before direct rent regulation and other market interventions were introduced, when only demand and supply were setting rent prices.

Second, urban population growth has been exceptionally high over the past 150 years. This enormous increase in demand for urban locations has undoubtedly resulted in increasing prices. However, urban population growth has slowed down significantly, and the European Union projects that about 50 percent of European cities will lose population in the next decades. In line with evidence from Glaeser and Gyourko (2005) for US house prices, we show that urban growth has very different implications for rental price growth than urban decline. In our very long-term dataset, we observe episodes of urban growth followed by extended periods of decline, and this likely provides a more representative picture of future rental growth than studying only the past two centuries that were generally characterized by the triumph of the city.

This brings us to the final contribution of this paper: a better understanding of the long term financial performance of investment assets, and more specifically, housing. Real estate investments have always been the largest asset class, and within the real estate asset class, housing investments have become more important over time relative to land (Piketty and Zucman, 2014). However, unlike the stock market (e.g. Dimson et al., 2009; Siegel, 2014; Annaert et al., 2015; Golez and Koudijs, 2017; Le Bris et al., 2019; Jordà et al., 2019a), there exist relatively few studies that trace the long-term returns of real estate investments.

Recently, Jordà et al. (2019a) compiled total return estimates since 1870 by imputing returns based on the rent indices from Knoll (2017) and the house price indices from Knoll et al. (2017). Chambers et al. (2020) use actual return data to provide estimates for the UK from 1901 to 1970, and Eichholtz et al. (2020c) do so for Paris be- 
tween 1809 and 1942, and for Amsterdam from 1900 to 1979. ${ }^{3}$ The latter two studies find substantially lower risk-adjusted returns than Jordà et al. (2019a), and show that mismeasurement in rent prices plays an important role in understanding these deviations. However, these studies still focus exclusively on estimating long-run returns in an era of significant population growth, particularly in cities. This is not the case in our study.

The total return to any housing investment is the sum of all received rents and the realized capital gain, relative to the initial purchase price. In this paper, we ignore the role of capital gains and focus only on the evolution of housing rents over time. In a standard discounted cash flow model, capital gains can either arise through (expected) real rental growth or through changes in the required return to housing investments. Because we only study rents, our approach does not capture any changes in the latter.

We argue that this is of limited relevance for very long-term investors, such as pension funds, life insurance companies, and sovereign wealth funds. After purchasing or constructing a property, all returns derive from rents, with changes in discount rate playing barely any role. This is in line with existing evidence. Chambers et al. (2020) and Eichholtz et al. (2020c) show that capital gains do not contribute at all to total returns, and in Jordà et al. (2019a) their contribution is minor relative to rental yields. ${ }^{4}$

Fluctuations in discount rates and yields still have very significant implications for the valuations and returns of properties over shorter horizons. In line with this, we provide evidence that the institutional investors in our sample sold their properties at very different yields. However, this paper aims to study the long-term cash flow returns to housing, rather than looking at risk-return characteristics over the short-term.

If the absence of capital gains, which is found in existing studies, is driven by reductions in housing rents, then changes in discount rates could still influence longterm returns. For very long-term returns, however, changes in discount rates do not matter. We find no time trend in the yields and corresponding required returns to housing investments. This suggests that the long-term downward trend in interest rates documented in Schmelzing (2020) does not generalize to housing, or at least not for European economies after 1500. One potential reason for this finding is that the fundamental risk to rental housing investments could be more stationary over time than the risk to government debt. While the latter is currently associated with low default risk, that was not at all the case in previous centuries.

This paper is organized as follows. In Section 2.1, we introduce and discuss the data and data sources, after which Section 2.2 explains the methods to estimate the indices of rent prices. Section 2.3 will present the rent indices in nominal and in real terms. We also discuss the presence of trends in housing yields. Section 2.4 analyzes the evolution of housing rents in periods of urban growth and decline. We end this study with a short summary and some conclusions.

\footnotetext{
${ }^{3}$ The study of Eichholtz et al. (2020c) will be presented in Chapter 4.

${ }^{4}$ Eisfeldt and Demers (2018) find capital gains to be a more important component of total returns. Most likely, this is driven by the enormous decline in interest rates and the resurgence in urban growth since the 1980s, coinciding with their sample period.
} 


\subsection{Data}

Tracking rent prices for seven cities and for more than 500 years at annual frequency implies major data collection challenges. We compile rental cash flow and contract data from dozens of existing historical and contemporary studies, combined with handcollected primary data from archives. This effort resulted in the collection of about 300,000 observations of housing rents, most of which originate from the archives of social institutions, such as churches, monasteries, orphanages, or hospitals. Beyond these sources, we collected additional primary and secondary data on estimated rents from tax registers. These registers provide information on the distribution of housing values in a city, which we use to compute housing inequality and to assess the representativeness of the institutional data. Including these, our database of primary rental data contains over 436,000 observations, about 30 percent of which we hand-collected from archival sources.

Table 2.1 presents an overview of all these different data sources and the number of observations that we used. We provide a very detailed discussion of all these sources, and their representativeness in Appendix 2.A and 2.B. Appendix 2.B also provides plots, for each city, on the number of observations in our dataset in each year. We converted rents for each country into a single local currency (Dutch Guilder, French Franc, Belgian Franc, British Pound), and removed duplicate or non-representative observations from the sample.

Rather surprisingly, it was more difficult to obtain primary data on housing rents for the $20^{\text {th }}$ and $21^{\text {st }}$ century than for preceding centuries. There exist few commercial databases that track housing rents, and due to privacy reasons it is not yet possible to look for rental contract data in archives. Therefore, we had to rely on secondary sources from the mid-20 ${ }^{\text {th }}$ century onward, ensuring to only select sources that (attempt to) control for housing quality. ${ }^{5}$ In most cases, these series are based on the rent component of the CPI, often at the urban level but sometimes using national figures. Although these indices do adjust for quality, there has been some debate about whether they accurately represent market developments. First, the existence of a complicated system of rent controls for a large part of the $20^{\text {th }}$ century makes it by construction difficult to construct a representative index. Second, quality controls might be imperfect. For the United States, Gordon and VanGoethem (2005) argue that the rent component in the CPI from the early $20^{\text {th }}$ century until the $1980 \mathrm{~s}$ is biased downward, given that hedonic improvements in housing quality cannot make up for the increase in mean housing rents relative to the quality-controlled CPI figure. One potential reason for this bias is that renters are less likely to be included in the rental survey when they move, even though rent increases typically occur after signing a new contract. Ambrose et al. (2015) make a comparable point but find bias in a different direction for the 2000s: their repeat-rent index, based only on newly signed contracts, increases much less than the rent component of the CPI. To investigate whether these issues might also affect our findings for the late- $20^{\text {th }}$ and $21^{\text {st }}$ century, we will compare

\footnotetext{
${ }^{5}$ The only exception is Paris, where we rely on a secondary rent index already from 1867.
} 
Table 2.1: Overview of Rental Data Sources

\begin{tabular}{|c|c|c|c|c|c|}
\hline Source & City & Type & $I$ & Years & Obs. \\
\hline \multicolumn{6}{|l|}{ Primary sources, rents: } \\
\hline Henau (1991) & Belgian cities & Rent prices & $\mathrm{Y}$ & $1910-1940$ & 11,711 \\
\hline Segers (1999) & Belgian cities & Rent prices & $\mathrm{Y}$ & $1800-1920$ & 33,088 \\
\hline Verlinden (1972) & Antwerp & Rent prices & $\mathrm{Y}$ & $1500-1876$ & 27,643 \\
\hline Verlinden (1972) & Bruges & Rent prices & $\mathrm{Y}$ & $1500-1800$ & 22,157 \\
\hline Avondts (1971) & Brussels & Rent prices & $\mathrm{Y}$ & $1500-1800$ & 19,150 \\
\hline Van den Eeckhout and Scholliers (1979) & Brussels & Rent prices & $\mathrm{Y}$ & $1800-1940$ & 14,977 \\
\hline Van Ryssel (1967) & Ghent & Rent prices & $\mathrm{Y}$ & $1500-1796$ & 41,492 \\
\hline Avondts and Scholliers (1977) & Ghent & Rent prices & $\mathrm{Y}$ & 1796-1932 & 13,585 \\
\hline Lesger (1986) & Amsterdam & Rent prices & $\mathrm{Y}$ & $1500-1869$ & 48,860 \\
\hline ACA 367.A, no. 141-150 & Amsterdam & Contracts & $\mathrm{Y}$ & 1671-1805 & 7,537 \\
\hline ACA 367.C , no. 100, 1794, 1804-1805 & Amsterdam & Contracts & $\mathrm{Y}$ & 1833-1936 & 11,701 \\
\hline ACA 367.C, no 938, 947, 1498, 1798 & Amsterdam & Rent prices & $\mathrm{Y}$ & 1934-1940 & 348 \\
\hline ACA 201, no. 1973,3596 & Amsterdam & Contracts & $\mathrm{Y}$ & 1849-1928 & 65 \\
\hline ACA 404, no. 156 & Amsterdam & Contracts & $\mathrm{Y}$ & 1843-1942 & 100 \\
\hline ACA 1120, no. $2087-2089,2130$ & Amsterdam & Rent prices & $\mathrm{Y}$ & 1845-1942 & 1,397 \\
\hline ACA 191, no. 979, 987, 991-992 & Amsterdam & Contracts & $\mathrm{Y}$ & 1840-1941 & 295 \\
\hline ACA 612 , no. 432 & Amsterdam & Contracts & $\mathrm{Y}$ & 1853-1884 & 20 \\
\hline Clark (2002) & London / UK & Contracts & $\mathrm{Y}$ & 1225-1914 & 19,246 \\
\hline LMA, CLC/B/216/MS144 & London & Contracts & $\mathrm{N}$ & 1909-1959 & 15,274 \\
\hline Archives Nationales, 66 AJ 2029-2035 & Paris & Contracts & $\mathrm{Y}$ & 1400-1792 & 9,221 \\
\hline Archives de l'APHP, 782 FOSS 1 & Paris & Contracts & $\mathrm{Y}$ & $1733-1820$ & 1,047 \\
\hline Monin and Lazard (1920) & Paris & Contracts & $\mathrm{Y}$ & $1766-1819$ & 2,012 \\
\hline Archives de Paris, DQ18 & Paris & Contracts & $\mathrm{N}$ & $1803-1870$ & 861 \\
\hline \multicolumn{6}{|l|}{ Primary sources, rental values: } \\
\hline ACA 5044, no. 254, 273, 281, 284 & Amsterdam & Rental value & $\mathrm{N}$ & $1647-1650$ & 14,549 \\
\hline ACA 5044, no. $402-405$ & Amsterdam & Rental value & $\mathrm{N}$ & 1733 & 25,328 \\
\hline ACA 5045 , no. $269-323$ & Amsterdam & Rent prices & $\mathrm{N}$ & 1805 & 33,210 \\
\hline ACA 5045 , no. $269-323$ & Amsterdam & Rental value & $\mathrm{N}$ & 1805 & 17,777 \\
\hline ACA 5210, no. 69 & Amsterdam & Rental value & $\mathrm{N}$ & 1815 & 1,619 \\
\hline Fryske Akademy (2018) & Amsterdam & Rental value & $\mathrm{N}$ & 1832 & 30,047 \\
\hline Felixarchief Antwerp, inv. 782 no 1-14 & Antwerp & Rental value & $\mathrm{N}$ & 1584 & 11,852 \\
\hline \multicolumn{6}{|l|}{ Secondary sources, rent indices: } \\
\hline Henau (unpublished) & Belgian cities & Urban & $\mathrm{N}$ & 1941-1961 & \\
\hline Banque Nationale de Belgique (1980) & Belgian cities & National & $\mathrm{N}$ & 1975-1977 & \\
\hline Statistics Belgium (2018b) & Belgian cities & National & $\mathrm{N}$ & $1977-2018$ & \\
\hline Gemeente Amsterdam (2018) & Amsterdam & City & $\mathrm{N}$ & 1940-1994 & \\
\hline Statistics Netherlands (2018) & Amsterdam & National & $\mathrm{N}$ & $1994-2000$ & \\
\hline Dröes et al. (2017) & Amsterdam & City & $\mathrm{N}$ & $2000-2018$ & \\
\hline Samy (2015) & London & City & $\mathrm{N}$ & 1903-1909 & \\
\hline ONS / National Archives RG 77/3 & London & National & $\mathrm{N}$ & $1959-1987$ & \\
\hline Office for National Statistics (2018) & London & National & $\mathrm{N}$ & $1987-2005$ & \\
\hline Office for National Statistics (2018) & London & City & $\mathrm{N}$ & $2005-2018$ & \\
\hline Marnata (1961) & Paris & City & $\mathrm{N}$ & $1867-1957$ & \\
\hline Friggit, by courtesy & Paris & City & $\mathrm{N}$ & $1957-2018$ & \\
\hline
\end{tabular}

Notes: This table shows all different sources of data that we compiled for this paper, for each of the seven cities. Details on each of the individual sources is provide in Appendix 2.A. The table uses the following abbreviations: ACA = Amsterdam City Archives, LMA = London Metropolitan Archives. Column I indicates with Yes / No whether the primary data were based on institutional sources. 
implied and observable improvements in housing quality for this period. Nevertheless, the fact that we have to splice indices constructed with different methods implies that our series are likely less accurate in the $20^{\text {th }}$ and $21^{\text {st }}$ century.

Beyond housing data, we also compiled primary and secondary data on consumer prices in order to assess real rents. For the Belgian cities, we create a new consumer price index (1500-1830), while we rely on existing series for the other cities. The data sources and methodology for our consumer price indices are discussed in Appendix 2.C.

Last, we searched existing sources for population estimates and interpolated population numbers using cubic splines. We employ these population numbers to create population-weighted indices for the Belgian cities and in our later empirical analysis. The population data sources are discussed in Appendix 2.D.

\section{How Representative are Institutional Rents?}

Except for Paris (1809-1860) and London (1909-1959), virtually all of our primary sources originate from the archives of social institutions. Such institutions were very prevalent in most European cities and often had considerable housing portfolios, mostly resulting from bequests or donations over time. They used the rental cash flows of these homes to finance their activities. These institutions were the precursors of the modern-day institutional investors (Gelderblom and Jonker, 2009), and kept extensive archival records of their accounts, of which many have survived the test of time. Although renting from private landlords was more common than renting from such institutions, small-scale landlords did not keep archives. This limitation implies that we have to address two essential issues: did these institutions own a portfolio of housing that was representative of the housing stock of the city, and were these homes leased at market rates?

Compelling evidence shows that these institutions rented their homes at market rates. First, many institutions relied heavily, and some even exclusively, on rental streams to finance their core activities and could not afford to ask below-market rents (Le Roy Ladurie and Couperie, 1970). Correspondingly, they cared significantly about the returns they made on these properties (Gelderblom and Jonker, 2009). For rural properties around Paris, owned by the Cathedral of the Notre-Dame de Paris, Hoffman et al. (2001) provides anecdotal evidence that points towards these charitable organizations aiming to make profits from their property portfolios. Second, these institutions did not use their real estate portfolios to provide below-market rate housing to the poor or other vulnerable groups, and in each city, there was considerable variety in the homes being leased, varying from sober tenements to urban mansions. In a few cases, we found evidence that homes were rented at low or no cost, for example to widows. Such cases were typically clearly indicated and organised separately, and we excluded them from our sample.

To assess the representativeness of the institutional housing portfolio for the housing stock in each city, we compared the mean level of rent in our sample to the mean level of rent obtained from historical fiscal sources or private rents. Plots of these es- 
timates are provided in Appendix 2.B. For the period before World War I, we could obtain such an estimate in 49 cases, spread over various cities and centuries. On average, institutional rents are about 2 percent higher than those obtained from other sources, indicating they are not systematically different from each other. However, in some periods, most notably Amsterdam and Bruges in the $19^{\text {th }}$ and early $20^{\text {th }}$ century, mean rent levels do not seem representative for the entire city. These differences are typically due to small-sample issues since they coincide with periods with lower numbers of observations and institutional owners in the sample. Although observations in these periods can still be used to estimate market rent prices, we should be more careful in using them to infer housing quality. For a more detailed discussion of this comparison and the sources used, we refer to Appendix 2.B. ${ }^{6}$

\subsection{Methodology: Estimating Long-Term Indices}

\subsubsection{Rent Prices}

The literature on the estimation of rent indices has relied on hedonic models and repeated-measures models. We use the latter. The basic repeated measures methodology from Bailey et al. (1963) starts with the observation that the log price on any asset, in this case the log rental price $r_{t}$ on a particular home $i$, can be represented as the sum of three components:

$$
r_{i t}=\alpha_{i}+\beta_{t}+\epsilon_{i t}
$$

The first term, $\alpha_{i}$ reflects the underlying value, and therefore quality, of the home: the key assumption is that this does not change over time, at least at the level of an individual home. The second term, $\beta_{t}$ is the value of the log rental price index, while $\varepsilon_{i t}$ reflects price noise and is assumed to be distributed as $\mathrm{N}\left(0, \sigma^{2}\right)$. Taking differences for any time periods $t=y$ and $t=x$, with $y>x$, the change in log rental price on any home $i$ can be written as follows:

$$
r_{i, t=y}-r_{i, t=x}=\sum_{t=1}^{T} \beta_{t} D_{t, i}+\tilde{\epsilon}_{i t}
$$

$D$ refers to a set of dummy variables that take on the value of 1 if $t=y$ and -1 if $t=x$, and $\tilde{\epsilon}_{i t}$ equals the difference in the two error terms. Equation (2) can be estimated using ordinary least squares (OLS), and subsequently converted to an index by exponentiation. To satisfy the assumption of constant quality between rent reviews, homes in our sample were treated as new observations if there was any indication that the home had been rebuilt, renovated or significantly affected in some other way. Still, it is unlikely that house quality does not change at all. First of all, we cannot account for the

\footnotetext{
${ }^{6}$ We could not formally assess the representativeness of the London sample. For the early $19^{\text {th }}$ century, Clark (2002) used estimates of rents from tax records, and found those to be closely correlated with the average level of rents in his sample for England and Wales. However, our London sample is likely the least representative due to the low number of observations. This is particularly the case before 1770, when our sample contains only 2.5 observations per year.
} 
effect of aging on the properties as we do not know the years in which they were built. Second, minor quality improvements to the property might not have been registered. However, we believe the potential errors are small, as homes were well maintained for, in many cases, hundreds of years. ${ }^{7}$ Since rental contracts were typically signed for several years, we only include a rental observation in the index estimation in the year a new contract had been signed. For the Belgian cities, and most observations from Amsterdam, rent data did not specify new contracts. For these observations, we only include observations where the rent changed, as it implies that a new contract had been signed. The main disadvantage of this approach is that it misses observations where the new contract is signed at the same price. In Paris, this was the case in about 30 percent of contracts. Additionally, as in Clark (2002), we excluded contracts lasting more than 21 years as they likely represent ground leases rather than rents.

The use of repeated contracts implies that in some cities, in particular London and Bruges, the remaining number of observations is low. In such cases, noise in the rent prices can have a large impact on the resulting index. The literature has proposed several adaptations of the original model to improve the signal-to-noise ratio. Probably the most notable of these are the studies by Goetzmann (1992), proposing a Bayesian ridge estimator, and Francke (2010), who develops a generalization of Goetzmann's method that allows for general model specifications that can be compared using likelihood criteria. We follow the model of Francke (2010), and specify the betas in equation (2) not as fixed unknown parameters to be estimated using OLS, but by using a local level model:

$$
\beta_{t+1}=\beta_{t}+\zeta_{t}, \quad \zeta_{t} \sim N\left(0, q_{\zeta} \sigma^{2}\right)
$$

The dependence between the betas is based on the signal-to-noise ratio $q_{\zeta}$. If this ratio is low, the variance of the error terms of the index is low, and the dependence between the betas will be strong, resulting in a smoothening of the index compared to the standard case. Francke (2010) proposes an empirical Bayes procedure to estimate the index. Conditional on the variance parameters $q_{\zeta}$ and $\sigma^{2}$, estimates of the annual coefficients can be obtained using generalized least squares. The variance parameters are subsequently estimated by maximum likelihood. For more detail regarding the estimation method, see Francke (2010).

Table 2.2 contains the output of the estimations of the repeat-rent index based on the methodology of Francke (2010). Note that for Amsterdam, data was not available for the early part of the $16^{\text {th }}$ century, such that our index only starts in 1550 . For Paris, we estimated the index including observations from 1400 onward, since this significantly increased the number of observations available to estimate the growth of the index in the first part of the $16^{\text {th }}$ century. For London, we estimated the indices separately for the periods 1500-1903 and 1909-1959, due to the absence of data between 1903 and 1909, and the difference in data densities between the two samples. To compute a total Belgian city index, we used population-weighted averages. Consistent

\footnotetext{
${ }^{7}$ Some archival records also specify property-related expenses. For example, the Burgerweeshuis, the most prominent institutional owner in Amsterdam, spent about 26 percent of its rental revenue on maintenance between 1682 and 1806 (ACA 367.A, no. 141).
} 
with the observations made earlier in the paper and in Appendix 2.B, the signal-noise ratio for London, and to a lesser extent Bruges, is significantly lower compared to the other cities. This indicates these indices have been smoothed significantly.

Table 2.2: Variance Parameters and Signal-to-Noise Ratios

\begin{tabular}{lrrrrrr}
\hline City & Years & Obs. & Prop. & $\sigma$ & $q_{\zeta}$ & Log likelihood \\
\hline A'dam & $1550-1940$ & 19,299 & 1,228 & 0.06 & 0.72 & $18,475.73$ \\
Antwerp & $1500-1940$ & 6,133 & 473 & 0.15 & 0.54 & 430.16 \\
Bruges & $1500-1920$ & 3,115 & 592 & 0.20 & 0.25 & -449.50 \\
Brussels & $1500-1940$ & 4,304 & 894 & 0.17 & 0.40 & -142.62 \\
Ghent & $1500-1940$ & 6,495 & 1,278 & 0.21 & 0.34 & $-1,167.45$ \\
London & $1500-1903$ & 1,624 & 660 & 0.25 & 0.20 & -400.32 \\
London & $1903-1959$ & 3,165 & 1,141 & 0.08 & 0.56 & $1,469.50$ \\
Paris & $1400-1870$ & 8,712 & 2,364 & 0.15 & 0.53 & 416.00 \\
\hline
\end{tabular}

Notes: This tables provides summary statistics on the estimated rent price indices, following the method of Francke (2010). $q_{\zeta}$ measures the signal-noise ratio, and $\sigma$ measures the standard deviation of the price movements of the index. Signal-noise ratios are lower for cities for which few data is available to estimate the index.

\subsubsection{Robustness Checks}

It is crucial that our rent indices accurately track long-term developments in rental prices. Before proceeding to present and discuss our resulting indices, we therefor perform two more additional checks to assess to what extent our repeat-rent indices might be influenced by potential depreciation or unobserved quality improvements.

First, if we assume that homes are new when they enter our sample, either due to new construction or significant renovation, we can test the assumption of constant quality based on the framework of Harding et al. (2007). To estimate net-ofmaintenance depreciation, they suggest including the log difference in house age in the standard repeat-sales regression introduced in the methodology section. The nonlinearity of the age effect avoids perfect collinearity with the length of the leases and corresponding dummy variables. Using this technique, Harding et al. (2007) estimate that US housing depreciates at an average rate of 2 percent per year.

Of course, the strength of this test is weakened when homes are not new when they enter the sample. Although it is difficult to verify the extent to which this is the case, there is strong evidence from Amsterdam that many of the homes were new or significantly renovated when they enter our sample. First, we found construction or renovation plans for many of these homes in the archives we consulted. Second, analysis of data from Korevaar (2020) on housing transactions in Amsterdam between 1563-1811, reveals that institutions were very inactive in purchasing property. For example, the Burgerweeshuis, the most important real estate owner, was only involved in 41 real estate purchases, while it was involved in 244 sales. However, some homes were cer- 
tainly not new when they were leased for the first time: we could link some of these purchases to homes in our sample.

Taking note of this limitation, Table 2.3 contains the estimate of the ageing coefficient for each city, using the standard repeated-measures model. For both Paris and London, we estimated the regression separately for the institutional sample and the non-institutional sample, given that the upkeep of these properties might have been different. The aging coefficient is highly insignificant in all but one case: London from 1909 to 1959. However, in this case it is positive, implying net appreciation over time rather than depreciation, although the effect is small in magnitude. Hence, if anything, our index might underestimate growth in this period. It is possible that part of this effect is driven by rent controls that correlated with house age, as some rent control measures in this period were directly determined by house age.

Table 2.3: Estimates of Log-Difference in House Age Coefficients

\begin{tabular}{lrrr}
\hline City & Years & Coefficient & P-value \\
\hline Amsterdam & $1550-1940$ & -0.00023 & 0.89 \\
Antwerp & $1500-1940$ & 0.00421 & 0.49 \\
Bruges & $1500-1920$ & -0.00665 & 0.86 \\
Brussels & $1500-1940$ & -0.0014 & 0.86 \\
Ghent & $1500-1940$ & 0.00306 & 0.61 \\
London & $1500-1903$ & 0.0185 & 0.12 \\
London & $1909-1959$ & 0.046 & 0.00 \\
Paris & $1400-1800$ & 0.0011 & 0.77 \\
Paris & $1800-1870$ & 0.0168 & 0.20 \\
\hline
\end{tabular}

Notes: This table reports the results from a standard repeated-measures regression (Bailey et al., 1963) that additional controls for the difference in the log age of the property between repeated rental contracts. The coefficients on the log-difference in house age are reported for each city. A negative and significant coefficient indicates unobserved depreciation, a positive and significant coefficient unobserved quality improvements.

A second way to assess the robustness of the assumption of constant-quality is by comparing local housing rents to local land rents. Depreciation and quality improvements are aspects of the structures built on land, while the land itself does not depreciate. Hence, if quality is adjusted for properly, land rents should evolve similarly to housing rents over the longer run, at least in the period before 1800 when real wages and construction costs did not move much over time. Hoffman (2000) created such a land rent index for the Paris Basin, making use of land leases from the Cathedral of the Notre-Dame in Paris, an institution very similar to the other institutions in our Paris sample. He computed both a mean rent index per hectare, as well as hedonic index that corrected for quality of the land (soil type, land use) and location.

Figure 2.1 compares his decennial indices to a decennial mean rent index based on our data, which does not control for quality, and a decennial repeat-rent index, which does control for quality. As can be seen, the various land rent indices closely track the 
repeat-rent index for Paris, while the mean rent index diverges from each of the indices as housing quality gradually improves. There are some periods where the repeat-rent index also diverges from the land rent index, most notably in the late $18^{\text {th }}$ century, but this does not seem to result in misestimating quality, as the difference between the mean rent and repeat-rent index (the quality index) is not widening systematically in these periods. A second reassuring notion is that quality-improvements seem to matter much less for farm rents. Although leased lands could still contain significant capital, for example in the form of land preparation, buildings or the plants and trees on the land, the hedonic indices suggest these did not affect farmland rents as much as housing rents.

Figure 2.1: Housing Rents and Land Rents, Paris area

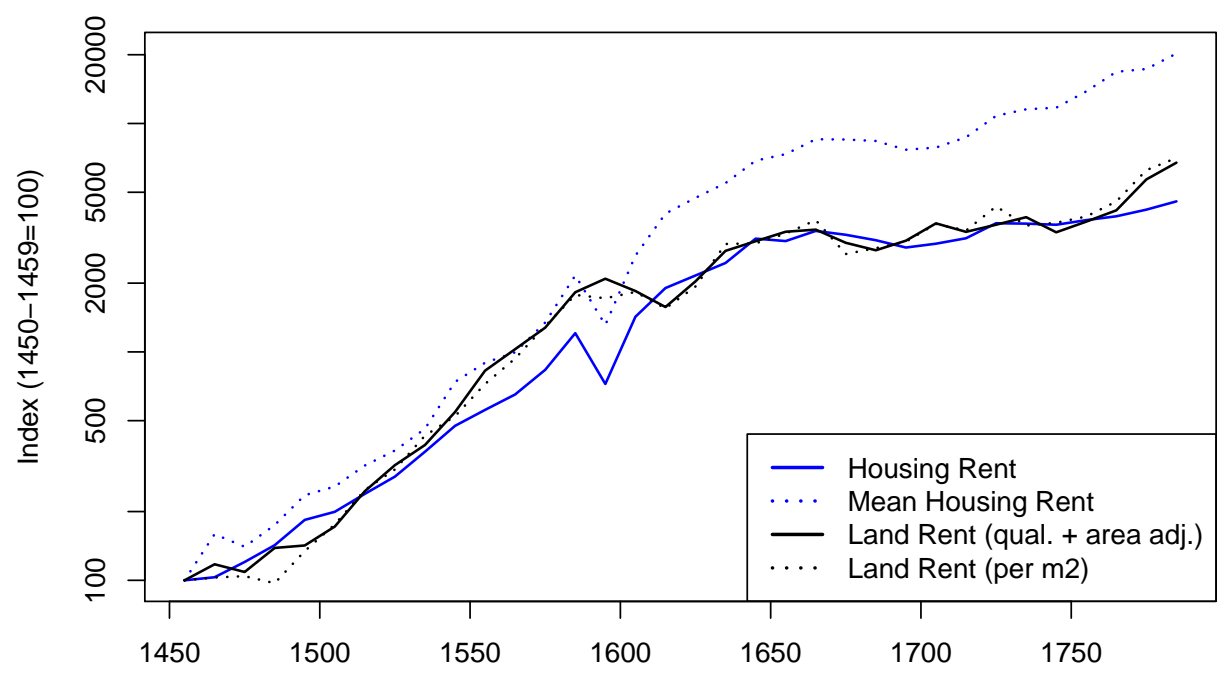

Notes: This figure reports the evolution of our repeat-rent index for Paris and a mean rent index for Paris, relative to the land rent indices reported in Hoffman (2000). All indices are estimated for each decade.

We should note that these farmland rents are not perfectly comparable to housing rents, as urban-rural rent differences might have changed over time, even though most properties were very close to Paris. To complicate matters, land leases also contained the right to levy the tithe, which effectively reduced the rent (Hoffman (2000) adjusted for this). However, imperfections aside, both robustness checks supports our critical assumption that the repeat-rent indices that we estimated indeed adequately control for quality. We therefore now proceed to present and discuss the evolution of rents in our long-term indices.

\subsection{Housing Rents in the Long Run}

Figure $2.2(\mathrm{a}-\mathrm{g})$ reports the rent indices for Amsterdam, Paris, London, and the four Belgian cities, in nominal terms, with CPI plotted for reference. Figure 2.3 presents the same indices in real terms together with population numbers. Population numbers 
are based on municipal boundaries and therefore underestimate the total population due to suburbanization processes in the $20^{\text {th }}$ century. In all cities, population numbers for their respective metropolitan areas continued to grow.

We deflate nominal to real rent based on consumer price indices. Although real rents can be compared in a meaningful way across cities, they exhibit excessive volatility due to the substantial short-term fluctuations in the consumer price indices, in particular before the $20^{\text {th }}$ century. In early modern times, household expenditures have been dominated by the cost of food, especially bread. Prices of grain and other agricultural produce were intrinsically volatile as they depended on the richness of harvests and the conditions for trade.

The first and most striking conclusion from the long-term rent graphs is that rental prices have shown very little growth in the long run. For Paris, the implied annual (geometric) growth rate of real rents is around 0.35 percent over the whole sample period, while in London and Amsterdam, real rents have increased at a rate of 0.2 percent per year. For the Belgian cities, real rent growth has been even less at 0.06 percent per year. This result is in line with existing evidence for urban house prices. Eichholtz (1997) finds little long-term price appreciation for the homes on the Herengracht, Amsterdam's most expensive canal. The same holds for the price index of Shiller (2005) for US homes since 1890. While house prices differ from rental prices in the short to medium run, Ambrose et al. (2013) show, based on data from Amsterdam, that the long-run developments in house prices and rents have been similar.

The second important conclusion is that in the long run, in particular since the $17^{\text {th }}$ century, the seven urban rental markets studied here exhibit strong similarities in terms of rent development. Since 1600, the correlation in 50-year growth rates across cities varies between 0.9 and 0.95 . This finding suggests that these cities have had close economic connections in the last 400 years, and it would imply that benefits from geographic diversification, for example for very long-term rental housing investors like sovereign wealth funds or pension funds, might be smaller than previously thought, at least within Europe (Jordà et al., 2019a).

Beyond the general long-term conclusions, the short- to medium-term developments of the indices also offer interesting perspectives on the economic history of these cities and their housing markets. Discussing 500 years of economic history and rents for seven cities in detail is beyond the scope of this study, but we would like to point out some of the most interesting trends over time and give a few examples of how housing rents often closely reflect a city's fortunes.

Of the more than five centuries that our indices cover, the $16^{\text {th }}$ century was probably one of the most turbulent in terms of rent development. In the first part of the century, real rents were steadily increasing in Paris, but gradually declining in London and the Belgian cities.

In the second part of the $16^{\text {th }}$ century, real rents started falling more quickly in both the Belgian cities and Amsterdam, following the start of the Eighty Year's War in which the provinces of the Low Countries fought against the Spanish. Although the Eighty Years' War was full of twists and turns, it induced an economic shift of the Southern Netherlands, containing Brussels, Antwerp, Ghent, and Bruges, to the North- 
Figure 2.2: Nominal Rent and Consumer Price Indices, 1500-2018
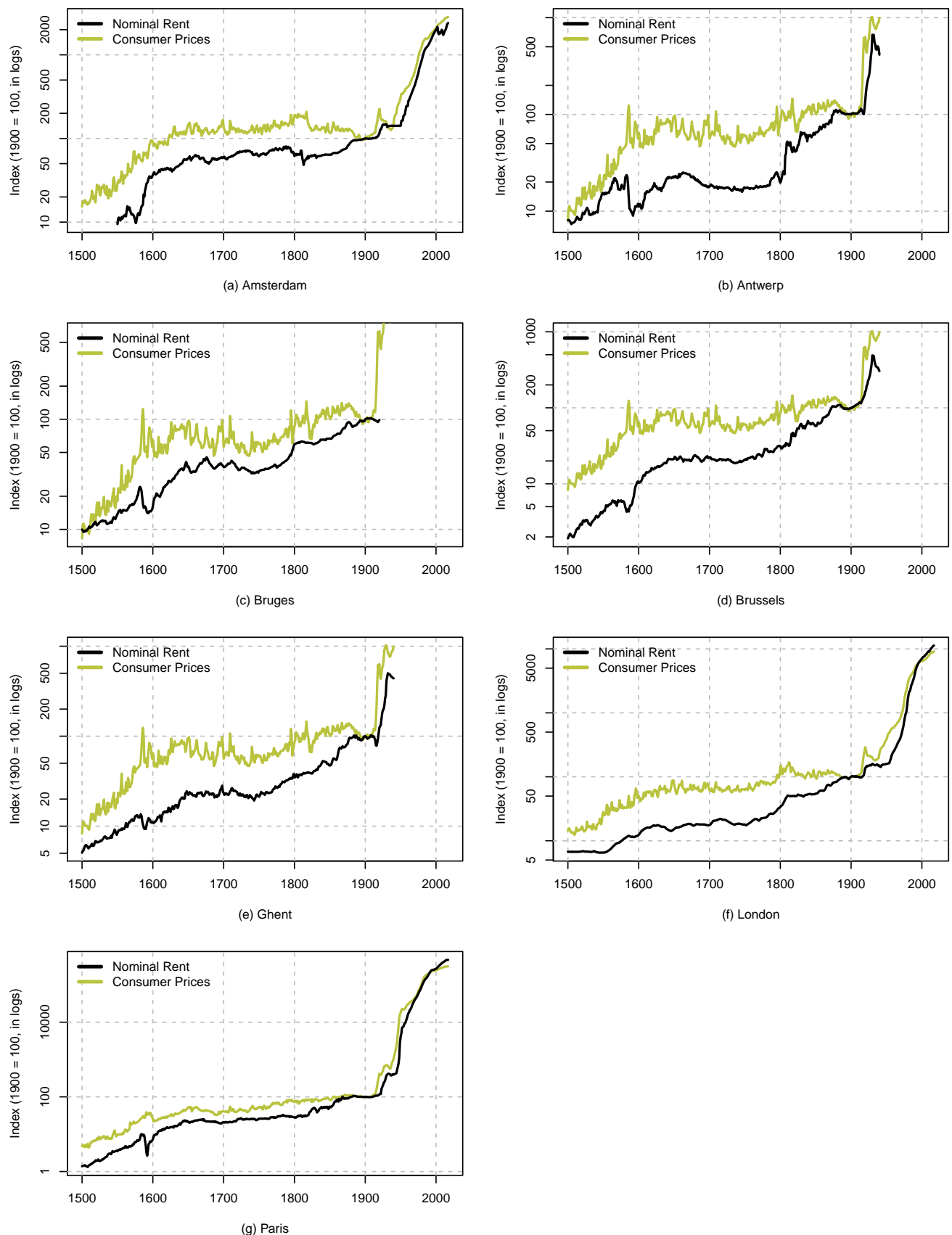

Notes: Scale of Y-axis in logs. The rent price indices estimated for 7 cities are compared to consumer price indices. Year-to-year changes in rents are less volatile than changes in consumer prices. Political and economic shocks, such as the fall of Antwerp to the Spanish in 1585, left a clear mark on the rent indices. 
Figure 2.3: Real Rent and Population Indices, 1500-2018
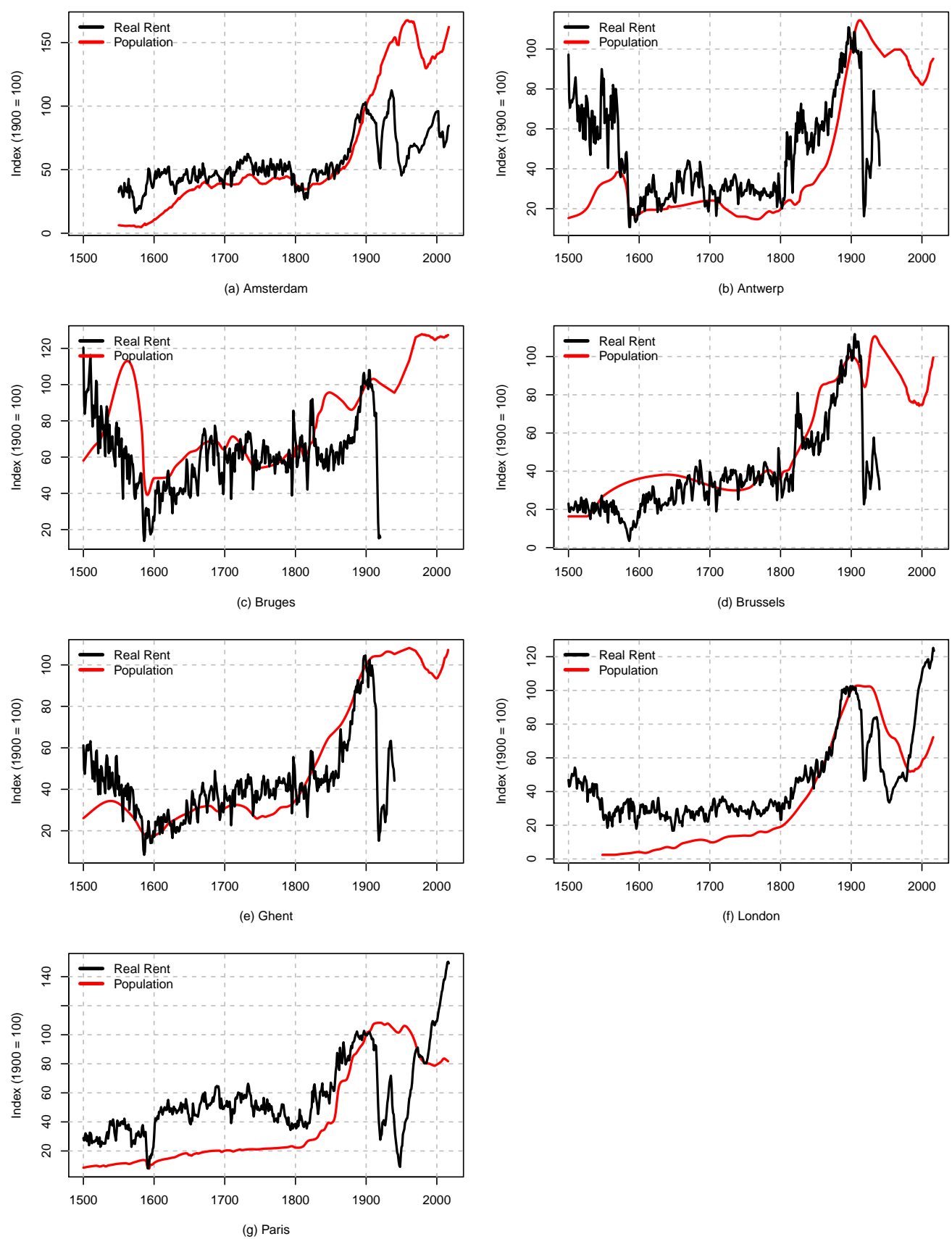

Notes: After correcting for inflation, rent prices (black lines) have been relatively steady for all cities. Population numbers (red lines) are based on municipal boundaries and underestimate total population due to suburbanization processes in the $20^{\text {th }}$ century. In all cities, population numbers for their respective metropolitan areas continued to grow. 
ern Netherlands, most notably Amsterdam. Antwerp, the economic powerhouse in the region for most of the $16^{\text {th }}$ century, was captured by the Spanish in 1585, ensuring Spanish control of the Southern Netherlands as Brussels, Bruges, and Ghent had surrendered already. Many merchants left Antwerp, Bruges, and Ghent and moved to Amsterdam. As is visible in the level of rents, Amsterdam entered its Golden Age, while the Belgian cities experienced an economic depression.

Brussels was the only Belgian city in our sample that came out of the Eighty Year's War wars relatively unscathed. It did not experience population losses as significant as Antwerp's or the two Flemish cities and could sustain its economic status as the capital of the Southern Netherlands. For the other cities, most notably Antwerp, trade opportunities had been severely restricted by the Dutch naval blockade of the river Scheldt, cutting off Antwerp's, Ghent's, and Bruges's access to the sea. For Antwerp, this situation lasted until the end of the $18^{\text {th }}$ century-early $19^{\text {th }}$ century, when the Scheldt was gradually reopened. In that period, Antwerp's housing rents recovered fast, as the city developed once again into one of Europe's leading port cities. The $19^{\text {th }}$ century was much less fortunate for Bruges, and its rental price growth was correspondingly much lower. The city did not industrialize like Ghent, Brussels and Antwerp, and became one of the poorest cities in Belgium.

Paris experienced trouble similar to the Belgian cities at the end of the $16^{\text {th }}$ century. During the Wars of Religion, possession of Paris was important for both the Catholic and the Protestant side of the conflict. These struggles culminated in the Siege of Paris of 1590. Around the Siege, nominal housing rents declined by as much as 75 percent, following the starvation and migration of a large part of the Parisian population, and it took almost 20 years for housing rents to recover fully. The situation was so exceptional that the Parlement de Paris, its most important court, twice ruled that tenants only needed to pay a fraction of their contractual rent amount Félibien (1725). These Parisian laws are among the very first recorded instances of explicit public interference in rental markets.

After the turbulent $16^{\text {th }}$ century, rents were at relatively stable levels throughout the $17^{\text {th }}$ and $18^{\text {th }}$ centuries. However, by the end of the $18^{\text {th }}$ century, real housing rents started to decline substantially in most cities. This decline was most severe in Amsterdam, where it lasted well into the $19^{\text {th }}$ century. Amsterdam had remained one of the most important European cities for most of the $18^{\text {th }}$ century but ended in an intense economic crisis following the start of the French period in the late $18^{\text {th }}$ century. The only city that did not experience a fall in real rents was London. This should not be very surprising. First of all, London's rent levels were at relatively low levels compared to the other cities for most of the $17^{\text {th }}$ and $18^{\text {th }}$ centuries. Second of all, England initiated the Industrial Revolution in the second half of the $18^{\text {th }}$ century, and subsequently dominated the European economy in the $19^{\text {th }}$ century.

The Industrial Revolution did not only lead to the first sustained increases in real wages, but it also led to an urbanization wave, and the first sustained increases in real housing rents across cities. During the $19^{\text {th }}$ century, real rent growth reached unprecedented levels: rents roughly tripled in each of the cities we study.

Although real rent prices also rose enormously throughout the second part of the 
$20^{\text {th }}$ century, particularly in Paris, total growth in this century was close to zero, or even negative for the Belgian cities. Just like the rent swings at the end of the $16^{\text {th }}$ century, $20^{\text {th }}$-century rent developments cannot be seen separately from the wars that ravaged Europe at that time. At the start of the century, urban rent levels were already at high levels and rose even further due to World War I housing shortages. To address affordability concerns, all countries in the sample gradually started to adopt rent controls in the 1910s. It is remarkable how similar the governments in the four countries studied here have acted during this turbulent period. First of all, most rent regulation focused on the nominal level of rents, rather than aiming to stabilize rents in real terms. With nominal rents fixed, hyperinflation and deflation after World War I created unprecedented volatility in real rents. Second, it seems that governments realized approximately at the same time that the combination of frozen rents and high inflation left little incentives for landlords to invest, harming the supply of rental housing. Thus, in each country rents were slowly deregulated from the 1920s onwards (Willis, 1950). Nevertheless, the higher inflation had been, the more difficult it was to restore equilibrium in the rental market. The same process happened during and after World War II: real rents initially declined significantly due to nominal rent controls but could catch up as soon as rent controls were abolished or gradually weakened. After this turbulent period, most countries started to introduce more sophisticated rent control policies (Arnott, 1995), which has likely had a dampening effect on real rent volatility.

Urban rental costs have started rising again in the last part of the $20^{\text {th }}$ century and the $21^{\text {st }}$ century. Although rent growth was particularly limited in the Belgian cities, where real rents are still much below their level from the $19^{\text {th }}$ century, Paris and London are characterized by large increases in housing rents. As we have seen, like in the late $19^{\text {th }}$ and early $20^{\text {th }}$ century, this has led to increasing concerns about housing standards and affordability.

\subsubsection{Trends in Housing Yields}

Changes in rental growth provide a good approximation to the long-term evolution of housing returns when there are no significant trends over time in the required return to housing. For debt assets, Schmelzing (2020) documents a significant downward trend of about 1 basis point per year between 1300 and 2018. If there also would be such a persistent trend in housing yields, estimates of long-term housing returns based on rental growth would be significantly off.

To see why consider a standard asset pricing model for housing that discounts net rental cash flows with the safe interest rate and a risk premium. If safe rates have fallen from approximately 5 percent in 1500 to about 0 today, which is what the numbers in Schmelzing (2020) suggest, house prices must have appreciated substantially. For example, if the housing risk premium is assumed to be constant at 2.5 percent, a fall in rates from 5 percent to 0 percent over the past 500 years suggests an additional annualized appreciation of house prices of about 0.2 percent per year. This appreciation is equivalent to the real appreciation of rental prices that we find, and would result in a doubling of capital gains. 
Figure 2.4: Yields on Transacted Institutional Properties, 1500-1900

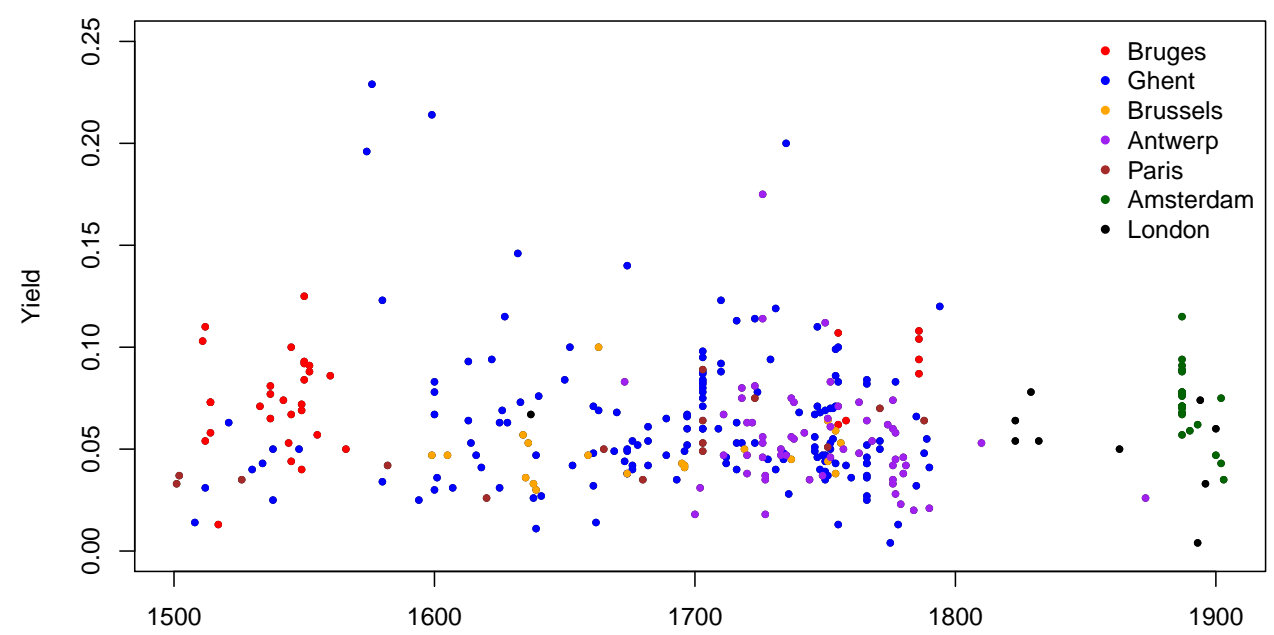

Notes: This plot shows the yields on transacted institutional properties in the various cities that we study. Each dot corresponds to a transaction. A yield of 0.10 corresponds to a yield of $10 \%$.

It is unlikely such a trend exists in the yields to housing, at least in the cities that we study after 1500. Figure 2.4 plots the gross housing yields based on 324 actual transaction prices and rents for properties within our sample that were sold or purchased by the institutions, and for which we have data. In Table 2.4, we report a regression of these yields on a linear time trend. As evident from both Figure 2.4 and Table 2.4, there is no significant downward trend in the yields of these institutional properties.

In both models, the estimated time trend is insignificant and effectively zero. Based on the model without city fixed effects, the $95 \%$ confidence interval ranges between a decline of $0.07 \%$ per year to an increase of $0.04 \%$ per year. Hence, it does not seem that the comparatively small number of observations is driving the absence of any downward time trend in housing yields. Translating this to actual yields, this $95 \%$ confidence interval would imply a change in yields between 1500 and 1900 ranging from -0.4 basis points per year to +0.2 basispoints per year. This is significantly different from the point estimates Schmelzing (2020) provides for interest rates, which he suggests have fallen by 0.6 to 1.6 basispoints per year.

The lack of any decline in housing yields is also backed up by estimates from other studies covering shorter time periods. For a more recent time period, Eichholtz et al. (2020c) find no long-term downward trend in actual housing yields in Paris (18091943) and Amsterdam (1900-1979) using a sample of ten thousands property gross yields. Gross yields average 7\% in Paris (net 4.2\%) and 10\% in Amsterdam (net 5.9\%). This pattern seems to extend to other countries as well: the implied yields in Jordà et al. (2019a) that cover 14 countries in the 1870-2016 display no strong downward trend either. Housing yield data is more scarce for earlier periods. Data from Korevaar (2020) show a gross yield of about $10 \%$ for $17^{\text {th }}-18^{\text {th }}$ century Amsterdam, based on 
Table 2.4: Time Trends in Yields

\begin{tabular}{lcc}
\hline \hline & \multicolumn{2}{c}{ Yield } \\
\hline Year & -0.0001 & 0.0001 \\
& $(0.0003)$ & $(0.0004)$ \\
Constant & $-2.663^{* * *}$ & $-2.816^{* * *}$ \\
& $(0.508)$ & $(0.827)$ \\
\hline City FE & No & Yes \\
\hline Observations & 324 & 324 \\
$\mathrm{R}^{2}$ & 0.001 & 0.068 \\
F Statistic & 0.200 & 3.269 \\
\hline \hline
\end{tabular}

Notes: This table shows the results of a regression of log reported yields in each city on a constant and a time trend. Column 1 does not include city fixed effects, Column 2 includes city fixed effects. ${ }^{*} \mathrm{p}<0.1$; ${ }^{* *} \mathrm{p}<0.05 ;{ }^{* * *} \mathrm{p}<0.01$.

rent-price ratios benchmarked using 789 observations of actual yields. This is similar to the $20^{\text {th }}$ century Amsterdam yield.

In summary, there does not seem to be any long-term downward trend in the yields on housing. This suggests the findings of Schmelzing (2020) do not generalize to housing, and that using rental growth rates is a reasonable proxy to understanding the evolution of long-term housing returns.

\subsection{Urban Growth and Rent Price Growth}

In the previous section, we have provided a descriptive overview of the long-term evolution of housing rents and urban populations in each of the seven cities that we study. The rental trajectories of these cities coincided with changes in their population levels and economic prosperity. Given that there does not seem to be any trend in housing yields over the long-run, and because urban population growth is expected to slow down further, the currently available evidence on high-growth cities might sketch a too optimistic picture of long-term housing rental growth.

In this section, we aim to use our long-term rent and population growth to estimate more formally how housing returns evolve in periods of growth and urban decline. To do so, we restrict our sample to the period from 1500 until 1913, when rental prices were not distorted by government interference, and our sample is entirely based on repeat-rent indices. We also report estimates for the entire sample period.

We separate periods of long-term population growth with periods of decline because these have very different implications on the housing market. When cities grow, expansion of the housing stock can limit rental price growth. When cities decline in population, housing supply does not adjust, and remaining residents will be distributed across existing properties. For this reason, house prices respond stronger to 
urban decline than urban growth (Glaeser and Gyourko, 2005). These existing works have studied recent developments in urban US house prices. Our analysis instead looks at rents over a much longer horizon.

We estimate a set of panel regressions of the following form, for each city $i$ at time $t:$

$$
\Delta_{s} r r_{i t}=\mu_{i}+\beta_{1} \Delta_{25}^{+} \text {pop }_{i t}+\beta_{2} \Delta_{s}^{-} \text {pop }_{i t}+\gamma_{n} r w_{i t}+\varepsilon_{i t}
$$

We let $s$ vary between 1 and 50 to show how the (correlational) real rent price elasticity varies over time horizons. At short-time horizons, supply cannot adjust, but at longer horizons, supply should be able to adjust fully. $\mu_{i}$ is a city fixed effect, and we additional control for changes in real wages $r w_{i t}$ using real wage data presented in Eichholtz et al. (2020a). We estimate the models using overlapping differences. To account for the serial correlation introduced by the overlapping observations, and the potential spatial auto-correlation across cities, we use standard errors based on Driscoll and Kraay (1998).

Table 2.5 reports the entire regression output when using 25 year-changes, both including and excluding a control for wages. In Figure 2.5, we plot the coefficients for the regressions that relate changes in rental prices to urban growth and decline when using varying time horizons, controlling for real wages.

Figure 2.5: Population Change and Rents at Varying Time Horizons

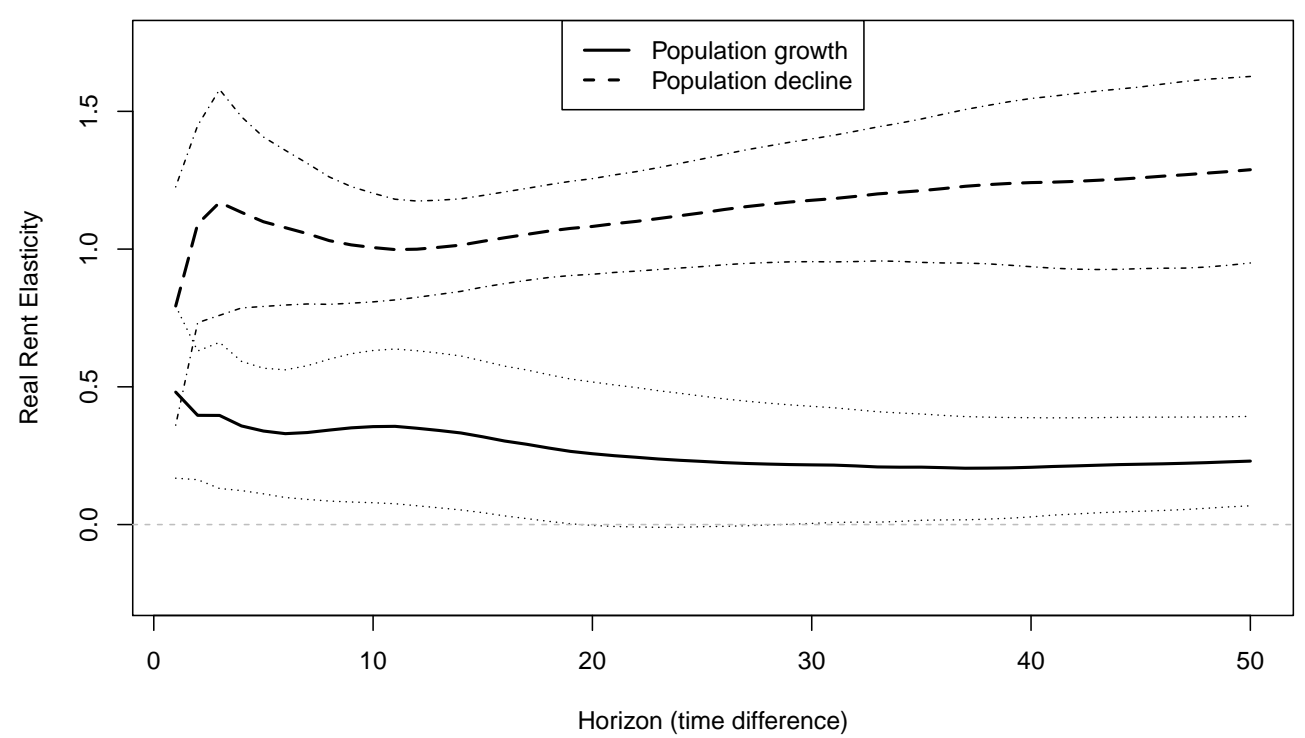

Notes: This figure plots the point estimates for the coefficients on population growth $\left(\beta_{1}\right)$ and population decline $\left(\beta_{2}\right)$ based on regressions of Equation 2.4 using varying time horizons $(\Delta)$, together with $95 \%$ confidence intervals. The coefficients on population growth and population decline are significantly different from each other for all time horizons longer than 3 years, with the elasticity substantially higher for periods of population decline. All regressions control for real wage changes and include city-fixed effects, and are estimated over the entire 1500-2018 time period. 
Table 2.5: Regression Estimates: Rents and Population Growth

\begin{tabular}{lcccc}
\hline \hline & \multicolumn{4}{c}{ Dependent variable: } \\
\cline { 2 - 5 } & \multicolumn{4}{c}{$\Delta_{25} r_{t}^{r}$} \\
& $(1)$ & $(2)$ & $(3)$ & $(4)$ \\
\hline$\Delta_{25}^{+}$pop $_{t}$ & $0.394^{* * *}$ & $0.229^{*}$ & $0.501^{* * *}$ & $0.327^{* *}$ \\
& $(0.149)$ & $(0.121)$ & $(0.166)$ & $(0.131)$ \\
$\Delta_{25}^{-}$pop $_{t}$ & $1.096^{* * *}$ & $1.132^{* * *}$ & $0.984^{* * *}$ & $1.071^{* * *}$ \\
& $(0.162)$ & $(0.100)$ & $(0.201)$ & $(0.125)$ \\
$\Delta_{25} w_{t}^{r}$ & & $0.772^{* * *}$ & & $0.659^{* * *}$ \\
& & $(0.061)$ & & $(0.099)$ \\
\hline Fixed effects & Yes & Yes & Yes & Yes \\
Time Period & Pre-1914 & Pre-1914 & Full & Full \\
\hline Observations & 2,625 & 2,625 & 2,794 & 2,792 \\
$\mathrm{R}^{2}$ & 0.211 & 0.592 & 0.160 & 0.461 \\
Adjusted $\mathrm{R}^{2}$ & 0.209 & 0.591 & 0.157 & 0.459 \\
F Statistic & 350.386 & 1265.1 & 264.844 & 792.74 \\
\hline \hline
\end{tabular}

Notes: This table presents the estimates from a regression of Equation 2.4 using a time-horizon of 25 years. The dependent variable is the 25 -year real change in housing rents. Columns 1 and 3 only include time fixed effects, Columns 2 and 4 include a control for real wages. The first two columns look at the pre1914 period only, when rent controls were nonexistent, the last two columns include the entire sample. Standard errors are based on Driscoll and Kraay (1998). ${ }^{*} \mathrm{p}<0.1 ;{ }^{* *} \mathrm{p}<0.05 ;{ }^{* * *} \mathrm{p}<0.01$. 
For our sample of cities, we observe increasing rents when a city's population grows, and declining rents when cities shrink in population size. In line with the findings of Glaeser and Gyourko (2005), we find housing rents to adjust stronger to population declines than to population growth, at all time horizons. For decline, we find a price elasticity around one, with little variation across time horizons. For growth, we find the elasticity to decline slightly over longer time horizons, consistent with gradual supply adjustment. At a 25-year horizon, a one percent increase in population over a 25 -year period leads to a 0.39 percent increase in real rents (Column 1), and this even reduces to 0.23 percent when controlling for wages (Column 2). In line with the increased importance of supply restrictions in the $20^{\text {th }}$ and $21^{\text {st }}$ centuries, we find somewhat higher elasticities for urban growth when looking at the entire sample period (Column 3 and 4).

Because population growth matters for long-term housing rental growth, it also is a vital component of the total return to housing over time. The past 500 years of urban rental growth in Europe indicate that cities that have grown the most have also experienced the most substantial increases in housing rents. This suggests that investors who form return expectations based on past rental growth in 'superstar cities', which currently comprise the bulk of available data, might be too optimistic about the future. Future urban population growth will likely be much smaller than it has been over the past two centuries, and the return of urban decline in some cities might even result in falling rents. Although our estimates are only correlational, these findings hold irrespective of whether we control for growth in real wages.

\subsection{Conclusion}

In this paper, we have presented a long-term view of urban rental markets in Western Europe, relying on newly constructed indices of rents. For the first time, it is possible to trace the rental trajectories for various European cities from 1500 to the present on a continuous annual basis. Until the $19^{\text {th }}$ century, growth in real urban market rents was close to zero or even negative. Following sustained urban population growth, housing rents rose substantially during the $19^{\text {th }}$ century. Importantly, direct government interference in the rent level did not exist in the first four centuries we study, and the interplay of market forces seems to have done its work in stabilizing long-term real rent levels. In the $20^{\text {th }}$ century, housing rents continued to rise in aggregate, but growth has slowed down significantly.

We show that, absent trends in housing yields, trends in rental prices are the main determinant of housing returns over the long run. Within our sample, we find that rental growth is skewed towards modern 'superstar' cities, which have grown much more in population than the general population. Cities that were economically leading in 1500 but did not maintain that status, such as Ghent and Bruges, experienced no long-term rental growth at all. This implies that investors who base their return estimates from past data of current superstar cities, for which we had most evidence prior to this paper, will likely substantially overestimate future returns. This finding 
is further strengthened by the fact that future urban population growth is expected to slow done significantly in the developed world. Our results show it is crucial to adjust for population growth, and even more so for population decline.

The data collected here provide a valuable source for economists and economic historians. To our knowledge, the dataset presented in this study is the largest historical urban rental real estate dataset constructed to date, and by providing the data and resulting indices to all interested researchers, we hope to have created a solid basis for future research on the long-term history of housing markets. 


\section{A Discussion of Rental Sources}

This section provides an overview of all rental sources, organized per city. A summary of all sources can be found in Table 2.1 in the main text.

\section{A.1 Belgian Cities}

Most Belgian historical rental studies follow a tradition that has been set up in the early 1960s, most notably with the work of Etienne Scholliers on Antwerp rents, also published in Verlinden (1972). The early works, done by Mason for Bruges (Verlinden, 1972), Van Ryssel (1967) for Ghent, Avondts (1971) for Brussels, and Scholliers (Verlinden, 1972) for Antwerp, focused on collecting housing rents for the largest possible number of representative homes. In each of these studies, representativeness was assessed in terms of location, ownership and fluctuations in rents. In each city, rental observations stem from homes spread all over the city. Due to data availability, practically all rents stem from institutional accounts, as explained in the main body of our paper. The main exception to this case is the study of Van Ryssel (1967) for Ghent, where 25 percent of homes stem from private investors and another 12.5 percent from city records. Homes that showed abnormal changes in the level of rents were excluded. In each study homes were only included in the database if rental observations were available for at least 7 years. If observations were available for less than 7 years, but the rent was revised within this period, the home was included as well.

Most rents in these studies were paid annually: monthly, quarterly or half-yearly payments were exceptional and seemed to occur only during very turbulent periods, such as the start of the Spanish occupation. Although the starting dates of the contracts are unknown, annual rents were mostly paid on various religious holidays, such as Christmas, Candlemas or Maria Ascension, which were spread evenly throughout the year. In the index estimation, it is therefore assumed that contracts start mid-year.

Works for the period after the Ancien Regime, from Avondts and Scholliers (1977), Van den Eeckhout and Scholliers (1979), Henau (1991, unpublished) and Segers (1999), vary slightly in methodology but rely on the same set of sources: social institutions. De 'Burelen van Weldadigheid' (offices of kindness) and 'Burgerlijke Godshuizen' (civil alms-houses), were founded after the French revolution and operated like the institutions in place during the Ancien Regime. These institutions were merged in 1925 into a single organization that still exists nowadays in each Belgian municipality in the form of a Public Centre for Social Welfare (OCMW). Their archives formed the source for each of these studies. The work of Henau (1991) covers the period after the start of the World War I until 1940, whereas the others span from 1796 to the first half of the $20^{\text {th }}$ century. Overlapping observations have been removed, as in some cases observations on the same address for the same year appeared in multiple studies. For the study of Henau (1991) and Segers (1999), we also digitized data from the cities of Leuven and Liége, but we did not include indices for these cities in this paper as no data was available before 1800. Chain indices for these cities are presented in the corresponding papers; results for our repeat-rent indices are available upon request. The 
main methodological differences in these later studies are that they are able to exactly estimate rents per calendar year, since the starting dates of the contracts are known. If a contract for example changed mid-year, the annual rent would be based on both the first six months of the old contract and the last six months of the new contract.

It is important to realize that the rental market was severely impacted by rent regulations introduced during World War I. In August 1914, a law was passed that gave the Belgian state the power to adapt contracts during wartime, including rental contracts. In 1919 and 1921 legislation was passed such that large groups of renters did not have to pay rent arrears built up during World War I. In some cases, actual market rents demanded might have therefore been higher than reported in our data, as we only observe the actual rent paid.

Rents were frequently re-capped relative to the rent level on January 1, 1914, with rent ceilings slowly increasing. There was significant variation in the imposition and revision of rent ceilings across municipalities, with the general trend being a relaxation of the regulations throughout the twenties and thirties. Following World War II, rent restrictions were re-imposed until the early fifties to deal with the housing shortages caused by the war.

We unfortunately do not possess underlying data for the unpublished study of Henau, which we have used from 1940 to 1961. Methodologically, this study is similar to Henau (1991), and covers the largest cities in Belgium. Between 1961 and 1975, no rental indices are available at the city level or national level. In order to splice our indices, we have used developments in house prices to proxy for rental prices from Knoll et al. (2017). From 1975, we rely on the rent component of the CPI. The first three years, we use a statistic published in Banque Nationale de Belgique (1980), while from 1977 we rely on the nation-wide CPI published by Statistics Belgium (2018b). The rent component of the Belgian CPI is based on the average rent reported in a monthly survey of 1800 properties in the private sector. Properties remain in the sample for extended periods of time. Changes occur either when tenants do not want to participate in the survey anymore or when old homes are being replaced by newer dwellings to keep the sample representative.

\section{A.2 Amsterdam}

The work of Lesger (1986), our source for Amsterdam from 1550-1854, follows in the tradition of the Belgian rent studies, albeit with one significant difference: the selection of homes based on quality. Whereas the homes in the samples of the Belgian cities were well spread throughout the cities, there might have been a bias towards homes of a particular quality bracket in particular years. Lesger therefore categorized on the quality of the observed home, ensuring that in every year homes from each of the four defined quality categories (from low to high) were in the sample. Each category was defined based on a set of reference homes, for which quality characteristics were available such that a categorization could be made. Homes were subsequently classified based on their rental price relative to the rental prices of the reference homes. 
Homes were only included in the sample if more than five years of rental data was available. If data was missing for less than two years, most likely because the home was not rented, the missing data would be filled with the rent that was paid after the gap. This strategy is somewhat unfortunate for our repeat-sales index, since rent revisions might occur one or two years earlier than they have occurred in reality. It was not possible to trace these observations, but fortunately these gaps were relatively rare.

We complement the data of Lesger with our own archival data collection, using data from various institutional archives kept in the Amsterdam City Archives. Our main source is the archive of the Burgerweeshuis, the Amsterdam orphanage, which has been discussed extensively in the work of McCants (1997). In addition we have collected data from the archive of the Roman-Catholic boys' orphanage, the Brants-Rus Almshouse and various churches: the Walloon Reformed Church, the Remonstrants and Mennonites. For the majority of data, we have attempted to collect data on rental contracts, but for some cases it was only possible to rely on rent payments. For the Burgerweeshuis, we collected but eventually excluded a significant set of contract data prior to the $19^{\text {th }}$ century: the homes in the Noordsche Bosch, an area in Amsterdam. The homes in this neighborhood were initially rented out at below-market rates because they were used to attract textile workers. Correspondingly rent prices of these homes increased much faster than anywhere else in the city.

From 1940 onwards, we do not have sufficient primary sources to allow for the computation of a market rent index. However, this is not problematic since it coincides with a period of strict rent freezes. The first rent controls had been introduced in the Netherlands during World War I (despite Dutch neutrality in the war), following housing shortages and a broader set of government policies to control prices for basic needs during periods of large uncertainty. Initially, rents were fixed by the 'Huurcommisiewet' of 1917, but later rents could increase with the rate of inflation. In the early 1920s governments grip on rents had reduced already, but only in 1927 this was confirmed by law. The rent freeze after the start of World War II remained until 1950, when gradually more sophisticated rent policy was introduced. The idea of the rent policy was to slowly bring the prices of pre-war homes and expensive, but still subsidized, post-war housing back to market level, while keeping rents affordable. While in many municipalities rents were already liberated in the late 1960s, Amsterdam, and most other big cities, remained under rent controls until the late 1970s.

For rent prices in this period until 1994, we rely on a rent price index of the Amsterdam Statistical Office, which we retrieved from its annual yearbook. The methodology used for this statistic followed standards of the Dutch Central Bureau of Statistics. From 1994 until 2000, we rely on the rent component of the Dutch consumer price index. Although the methodology has been updated multiple times, the core of this study is formed by a rental survey currently sent out yearly to about 15,000 Dutch households, whose rent changes are used to estimate the index. To control for unobserved quality changes, the survey does ask whether renovations happened in the past year. If that is the case, only price changes after the renovation are accounted for. A small share of homes is added to and deleted from the sample every year to keep the sample of homes representative. A drawback of this index is that households living 
in private and social housing are surveyed. From 2000 onwards, we make use of an index on average rent per square meter reported in Dröes et al. (2017). Note that this measure only partially controls for quality, as it only takes account of changing space over time, and not of the quality of a given space.

\section{A.3 London}

The main historical study used in our work on the English market is Clark (2002). Clark (2002) assembled a large dataset of rents, consisting of 19,246 observations spanning from 1225 until 1907..$^{8}$ As in the other cases, most rental observations stem from investigations into the activities of charities. Clark's sample consists of data from both Wales and England, but about a quarter of observations originate from London. Not all transactions in the sample of Clark correspond to actual rents. First of all, in about 10 percent of cases tenants had to pay fines or payment for repairs of the building. Since these are generally considered to be part of rental expenses, Clark (2002) annualized these fines and used these to adjust the rental values of the observations. Second, in another 10 percent of cases Clark estimated the rental values of homes from house prices, since no rental payments were mentioned.

Our index is only based on repeated observations on London, both within and outside the City, with rent contracts of 21 years or less. There are 1,624 observations left for the estimation of the index. Before 1770, there are very few observations and a significant number of years have no observations at all. As a result, the signal-to-noise ratio is very low, and hence the model smooths the index significantly.

From 1903 to 1909 we rely on the recent study of Samy (2015), who developed a house and rent price index for London for the period from 1895 until 1939, based on data from the London Auction Mart (1895-1922) and the mortgage registers of the Co-operative Permanent Building Societies (1920-1939). Absent repeat sales, Samy (2015) used the hedonic method to estimate the indices. Unfortunately, no structural characteristics are available for the London Auction Mart data, and only very basic ones (number of rooms, frontage size and property size) for the CPBS data. Hence, his index likely overstates rental price growth. However, since we only use six years of his data (with almost constant prices), this effect does not alter the London index significantly.

From 1909 until 1959, we have collected data on more than 30,000 rent observations from the archives of Trafalgar House Developments Ltd. We have collected data from seal books of two of its subsidiaries: Consolidated London Properties and City \& West End Properties. These companies managed several apartment buildings, shops and offices spread out through London, and their seal books contain data on newly registered leases and renewals on existing ones, listing date, new price and old price. To identify repeat-sales, we first cleaned data on the unit identifiers per building. The unit numbers for each lease were not written down in a consistent way in the seal books, such that it was not always clear which unit exactly was let. After cleaning the

\footnotetext{
${ }^{8}$ Note that the number of observations does not match the number of observations reported in the paper, since Clark added observations to the dataset after publication.
} 
unit numbers, we only matched rents as repeats in case the old rent matched the new rent on the previous observation on that unit. In total fifty percent of data could be matched. For the index, we only used residential rent observations. Devaney (2010) has used the same sources to estimate an office rent index for the City of London.

From 1959 until 1987 we use the nation-wide rent component of the CPI, as produced by the Office of National Statistics. The methodology behind this index has changed multiple times; from the early 1960s onwards the rent component also included the implied cost for owner-occupied housing. After 1987 we rely again on the rent component of the CPI, which is based on a representative sample of homes whose rents are tracked over time. If no rental prices are available for a particular home, it is substituted by a home of comparable quality. As homes in both the private sector and the social sector (local authority rents) are in the sample, the index is not a pure measure of changes in constant-quality market rents. After 2005 we use ONS's experimental index on private housing rents in London, which relies on the same sources as the rent component of the CPI, but only includes homes rented in the private sector.

\section{A.4 Paris}

The landmark study on the history of the Paris rental market is Le Roy Ladurie and Couperie (1970). In their paper, Le Roy Ladurie \& Couperie publish a triennial index from 1400 to 1789 based on about 11,000 leases. Rental data does mostly come from actual lease contracts, stored in the archival records of 26 different social institutions; either religious institutions or hospitals. Only in a minority of cases data originate from accounting books for which the contract date is unknown. Since contracts were most commonly signed for nine years, rent payments from accounting books are not always representative of market rents. We therefore excluded these in the estimation of the index. For the period 1400-1485, which we have not reported in the main body of the paper, insufficient observations on rental contracts were available, such that the index for this period (available on request) is built on both contractual and noncontractual observations.

Le Roy Ladurie and Couperie (1970) made an impressive effort to construct a sample representative for Paris. As mentioned previously, they collected an additional 12,000 leases from private contracts for 23 benchmark years to underline the representativity of the charity rents: no differences in average rental prices were found in the private and charity samples. Additionally, they separated isolated and repeated observations and ensured renovated homes were treated as new observations. Last, properties are well spread around Paris: while each institutions typically only owned real estate close the location of the institution, the large number of institutions covered ensures a sufficient locational spread.

Unfortunately, the authors of the study did not preserve the punch card lists which contained the rents for every home. However, the authors organized transcriptions of the contracts and records, which are stored in the French National Archives. We collected and typed for each of these contracts the identifier and approximate location of the home, the contract date, the date of the accounting year and the rental price. All 
prices were converted to livre tournois.

Following the French Revolution and the dramatic state of the French public finances, all possessions of the institutions were nationalized in 1792, and only privatized again in 1811. Archival data is scarce for this period, and in order to continue our series we have combined several archival and non-archival sources. First, the French government registered the rent on each property and the contract date when all homes were nationalized, and these lists are published in the Sommier des Biens Nationaux de Paris Monin and Lazard (1920). Second, when the properties were returned in 1811, references were made to the underlying notary contracts, which in many cases could still be found in the Archives of the Assistance-Publique des Hopitaux de Paris, the Paris hospital system. It is the latter archive from which we have collected additional archival data in order to combine data from before and after the Revolution.

From 1809 until 1870, we add data from the first register of the Parisian 'sommier foncier'. The sommier foncier is one of the registers that was part of the famous French Enregistrement, and contains data on contracts relating to all Parisian homes, such as inheritances, sales contracts, rental values or auctions. For the taxation of wealth, it was important to keep track of the owners of homes, as well as the value and revenue they generated with their real estate. In the first register, which lasted from 1809 to the 1860s, rent contract data was included as well. We have collected a small sample of this rent data for various streets in central Paris, and since observations are organized per house it allows for the identification of repeat rents. Note these rents are primarily for entire properties, and might thus not account for the presence of subrenting

From 1867 until 1957 we rely on a rent index from Marnata (1961). Marnata collected 11,800 different rents from lease management books from residential neighborhoods in Paris and subsequently used these observations to compute a chained index. Although his index is not a pure repeat sales index but rather a chain index, it controls for quality as it follows the same residential units over long periods of time. The main disadvantage of his study is that most of the residential units in the sample are of relatively high quality, meant for the upper class of society. Since rental developments might have differed in lower class rental units, the index cannot be considered completely representative for the city of Paris.

From 1960 onwards, we make use of various rent indices compiled in data kindly provided by Jacques Friggit. Between 1960 and 1988, this index is based on the rent component of the CPI for the Paris region. From 1989 to 2015, it is based on the median rent per square meter in Paris from the Observatoire des Loyers de l'Agglomeration Parisienne. The latter method likely overstates growth in quality controlled rents, since it only controls for quality improvements due to increased space, but does not take into the account that the quality of a given space has improved as well (e.g. due to better insulation). 


\section{B Representativeness of Institutional Sample}

The quality indices developed in this paper rely strongly on the assumption that the mean rent derived from our sample of institutional rents is representative for the general housing stock in the city. In this appendix, we assess these claims in more detail by comparing the rent estimates from our sample with other estimates of rent prices in the city. We also pair these sources to population data to make estimates of housing quality per capita.

For Amsterdam and the Belgian cities, our main sources for these secondary estimates derive from property tax records. Prior to the $20^{\text {th }}$ century, property taxation was the most common form of taxation and many cities, in particular in the Low Countries, had a developed system of property taxation already from the late medieval period onwards. Taxes were typically levied on the estimated capital or rental value of homes, sketching a fairly representative picture of the value of the housing stock in a city. Correspondingly, historians have already used these registers to make assessments of income inequality (e.g. Soltow and Van Zanden, 1998; Ryckbosch, 2016). From the early $19^{\text {th }}$ century onwards, these systems were replaced by taxes on cadastral income.

These tax records also have several drawbacks. First of all, although the rental or cadastral value is typically aimed to proxy for actual rents, it is difficult to assess how precise these estimates are, particularly since they were rarely updated. If possible, we therefore only collected data in years when such an update took place. If that was not possible, we corrected the rental value for rent price changes that took place since the last correction, often employing the market rent indices estimated in this paper. Second, in various records it was not possible to separate non-residential property (most notably basements and warehouses) from residential property. However, the resulting error is likely small. For example, in 1805 non-residential property only constituted about 11 percent of total rental value in Amsterdam.

In total, we obtained data from 22 tax registers. For most of these, we were able to also collect data on the number of homes in the register, either by collecting all rents in the archival registers or through existing statistics.

Beyond these tax-based rents, data on the level of actual private rents was also available for Paris, Amsterdam and Brussels. For Amsterdam, we computed the average level of rents for seven years between 1909 and 1939 based on census data. For Paris, Le Roy Ladurie and Couperie (1970) collected data on 12,000 (private) rent contracts from the Paris notarial archives, covering 24 years between 1500 and 1788. For Brussels, we computed the average level of private rents in 1865 based on data from the Lokstat-PoppKad database. Overall, we obtained 53 points in time to compare levels of institutional rents to private rents.

In the figures below, we plot for each city these points relative to developments in mean rents in our sample. For reference, we also plotted the number of observations. In each city, the level of mean housing rents is close to the level of housing rents obtained from our sample. Major differences mainly appear in Amsterdam in the early $20^{\text {th }}$ century and Bruges in the $19^{\text {th }}$ century; these parts are not included in our quality 
indices.

In the shorter term, substantial revisions in the sample typically lead to significant volatility in the sample. This is particularly visible in Bruges around 1800, and to lesser extent in Antwerp and Brussels. In each of these cases, the sample changes almost entirely. For London and Paris, developments in annual mean rent levels are substantially more volatile, since these samples are entirely based on rent contracts rather than rent payments. Due to the low number of observations, this issue is particularly severe for London. Correspondingly, no quality index has been constructed for London.

Figure 2.6: Amsterdam Mean Rents

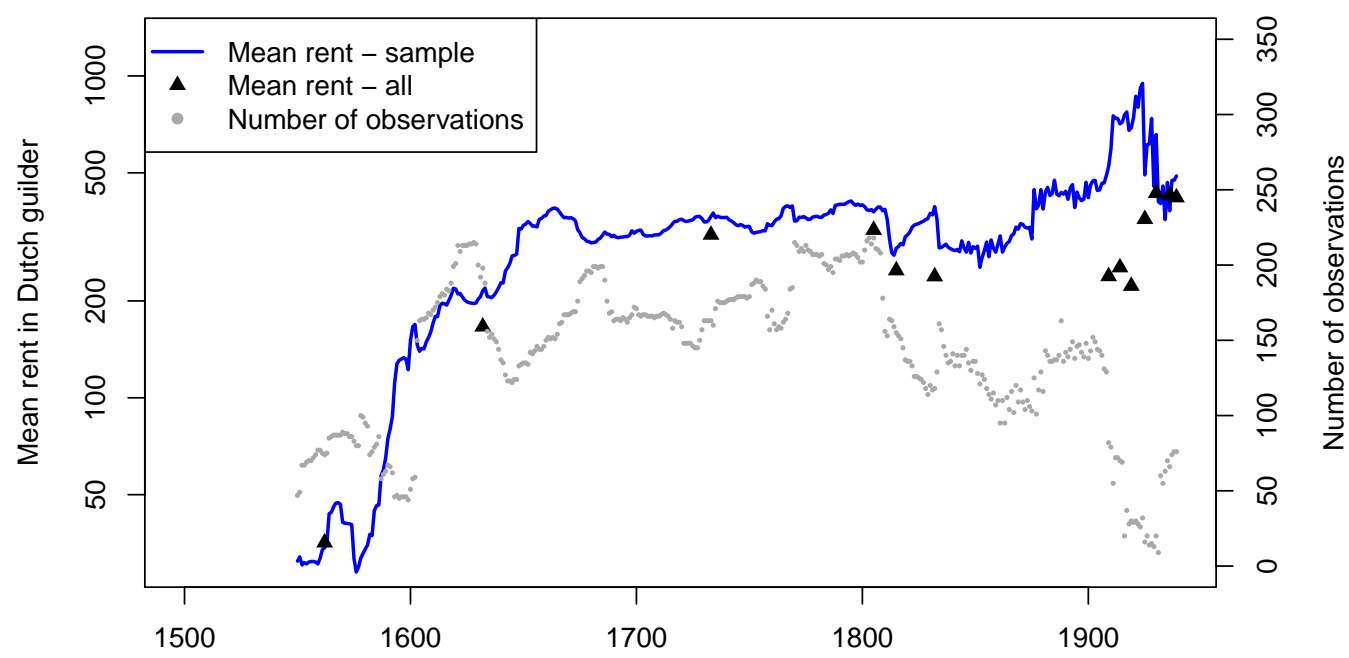

Notes: This figure plots the evolution of the average rent in our Amsterdam sample over time, relative to alternative estimates from sources reporting on rental values or rents in the entire city. The points for the $20^{\text {th }}$ century reflect actual rents rather than rental values. To convert rental values to rents, we used data from the 1805 rent register listing both rental values and actual rents. The light-grey scatter reports the number of observations in the sample. Sources alternative estimates: Soltow and Van Zanden (1998); ACA 5044 no. 254, 273, 281 284, 402-405; ACA 5045 no. 269-323; ACA 5210 no. 69; Fryske Akademy (2018); Laloli (2018). 
Figure 2.7: Antwerp Mean Rents

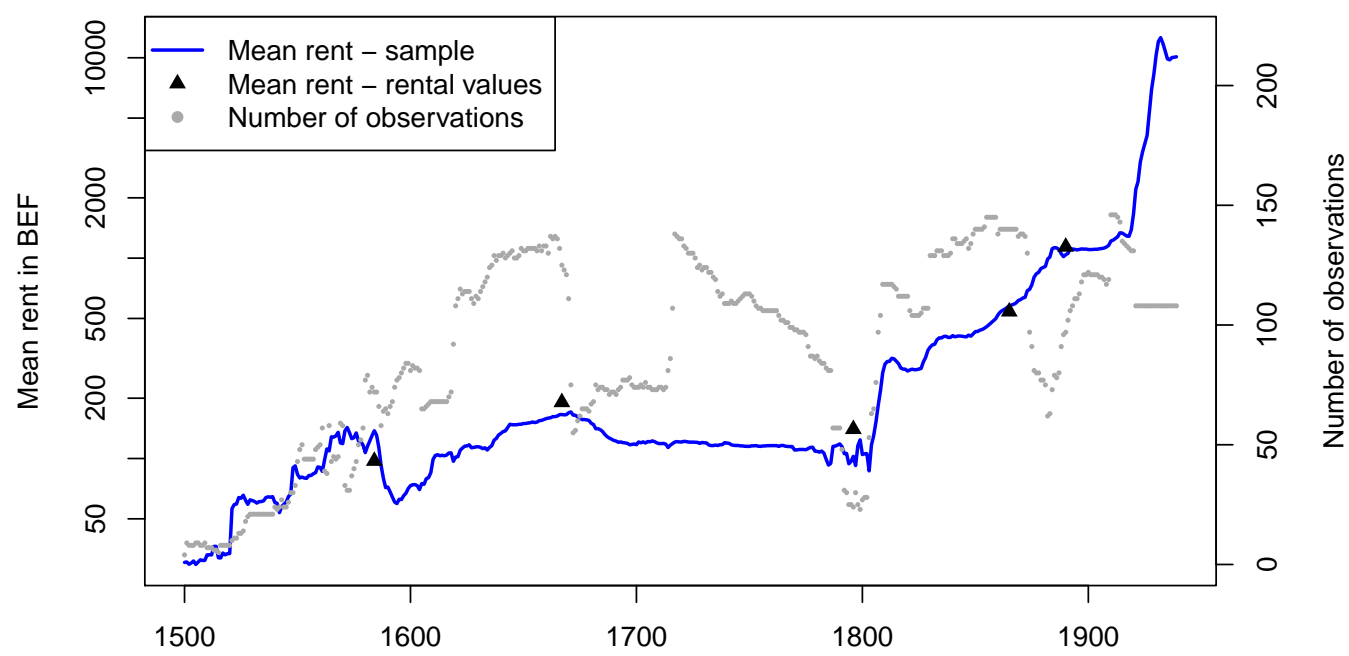

Notes: This figure plots the evolution of the average rent in our Antwerp sample over time, relative to alternative estimates from sources reporting on rental values or rents in the entire city. The light-grey scatter reports the number of rent observations in the sample. Sources alternative estimates: Felixarchief Antwerp 782 no. 1-14, Baetens (1976), De Belder (1977), LOKSTAT-POPPKAD.

Figure 2.8: Bruges Mean Rents

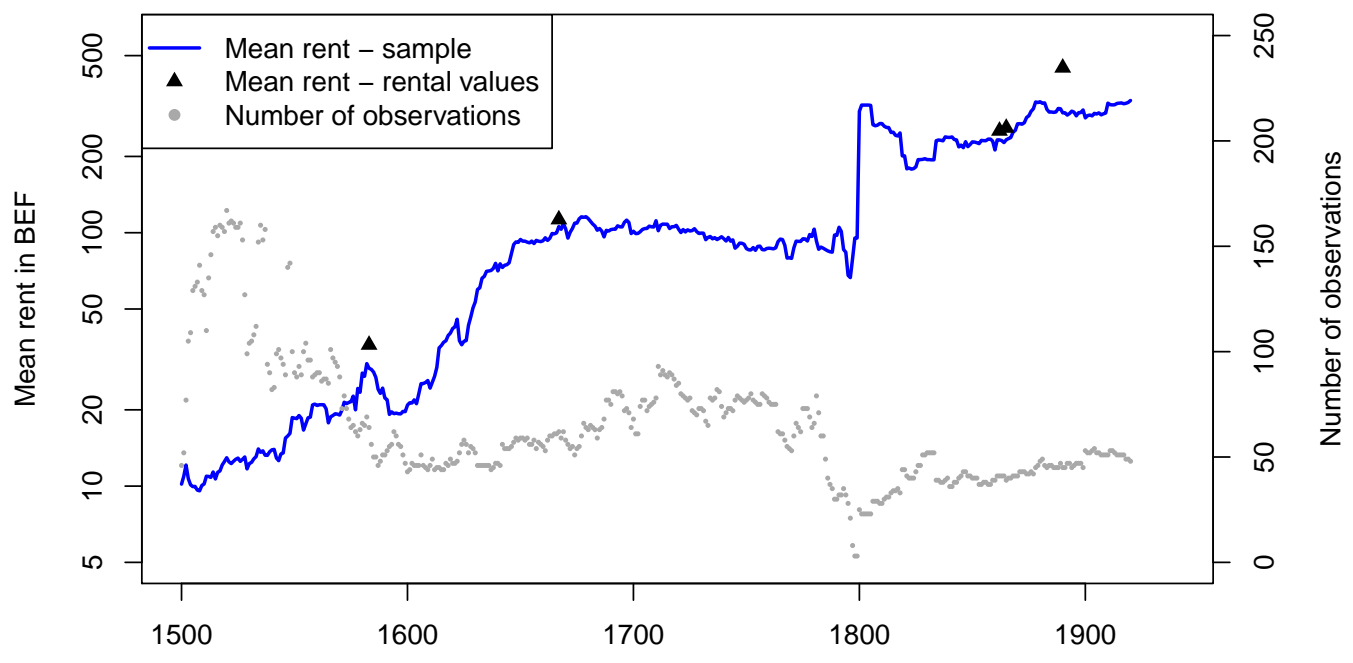

Notes: This figure plots the evolution of the average rent in our Bruges sample, relative to alternative estimates from sources reporting on rental values or rents in the entire city. The light-grey scatter reports the number of rent observations in the sample. Sources alternative estimates: Database Heidi Deneweth, LOKSTAT-POPPKAD, Quetelet Center. 
Figure 2.9: Brussels Mean Rents

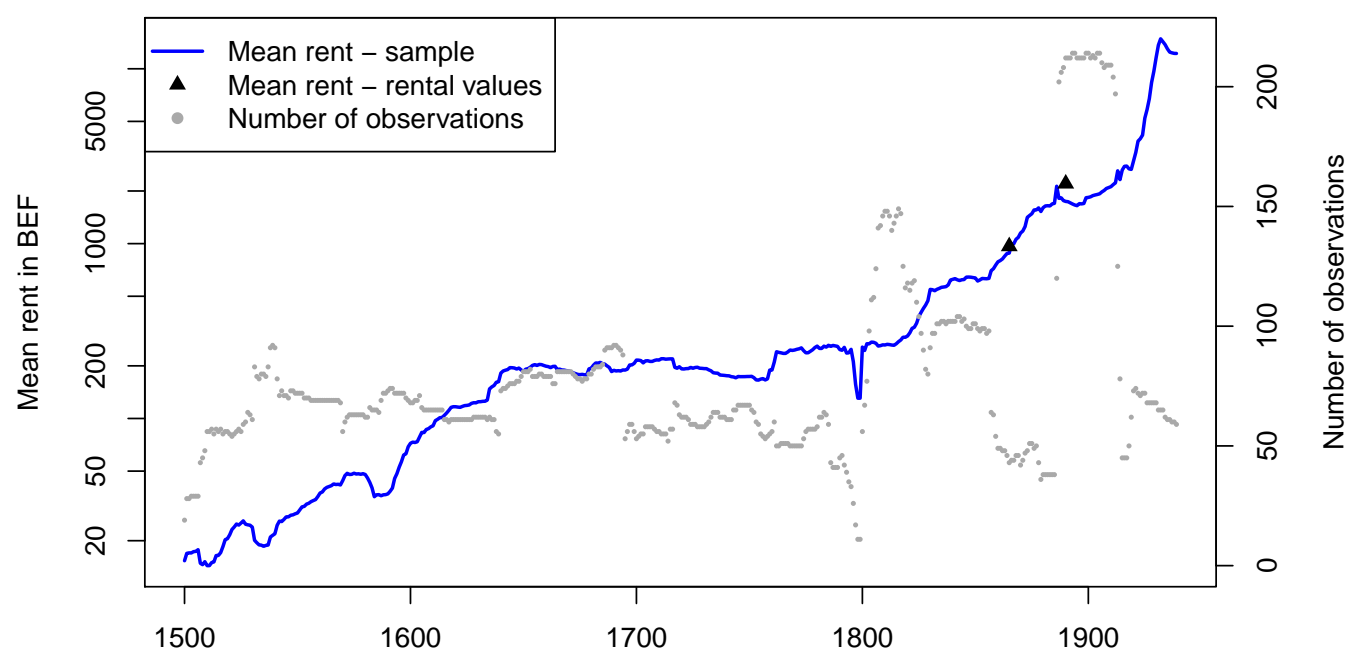

Notes: This figure plots the evolution of the average rent in our Brussels sample, relative to alternative estimates from sources reporting on rental values or rents in the entire city. The light-grey scatter reports the number of rent observations in the sample. Data from Vrielinck indicated the average ratio of cadastral income to average actual rents in 1865 . We used this ratio to transform average cadastral income to actual rents for all other Belgian cities in 1865 and 1890. Sources alternative estimates: Database Sven Vrielinck, LOKSTAT-POPPKAD, Quetelet Center.

Figure 2.10: Ghent Mean Rents

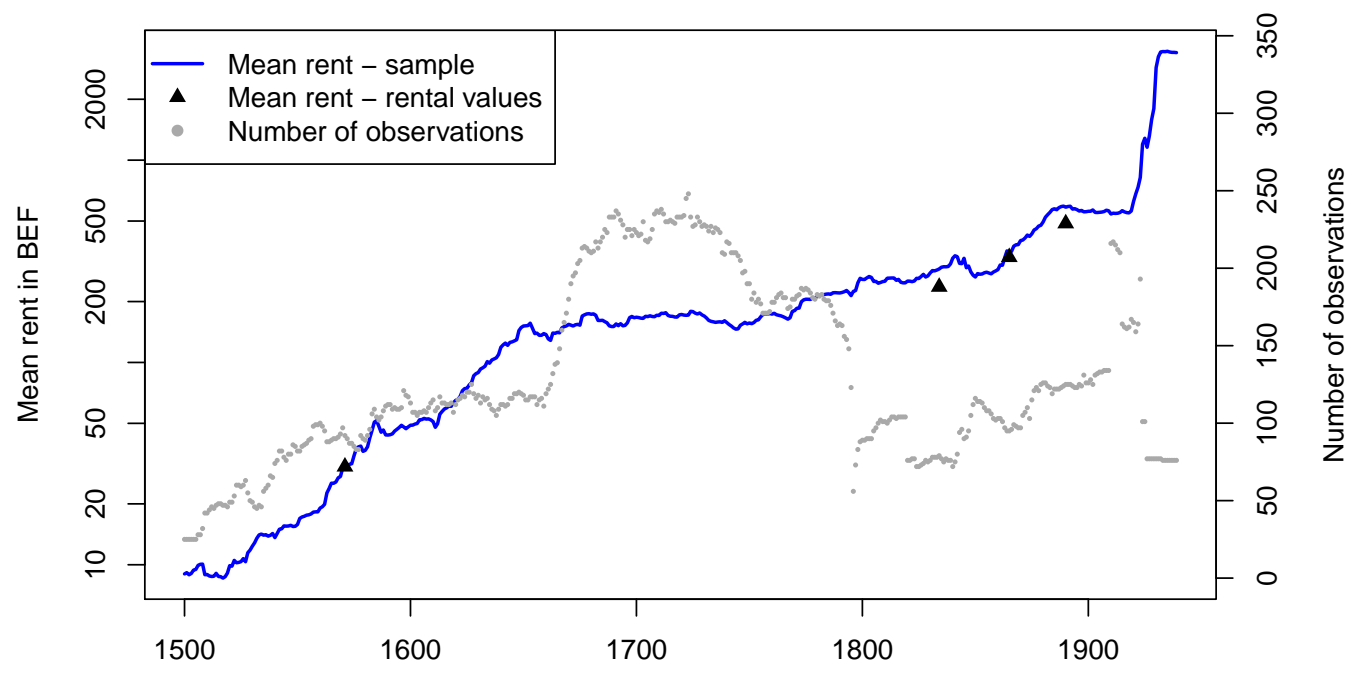

Notes: This figure plots the evolution of the average rent in our Ghent sample, relative to alternative estimates from sources reporting on rental values or rents in the entire city. The light-grey scatter reports the number of rent observations in the sample. The rental value for 1834 is an estimate based on rents from a decade earlier and, most likely, underestimated rents. We therefore correct the value by 25 percent. Sources alternative estimates: Dambruyne (2001), Vanhaute and Hannes (2007), LOKSTATPOPPKAD, Quetelet Center. 
Figure 2.11: London Mean Rents

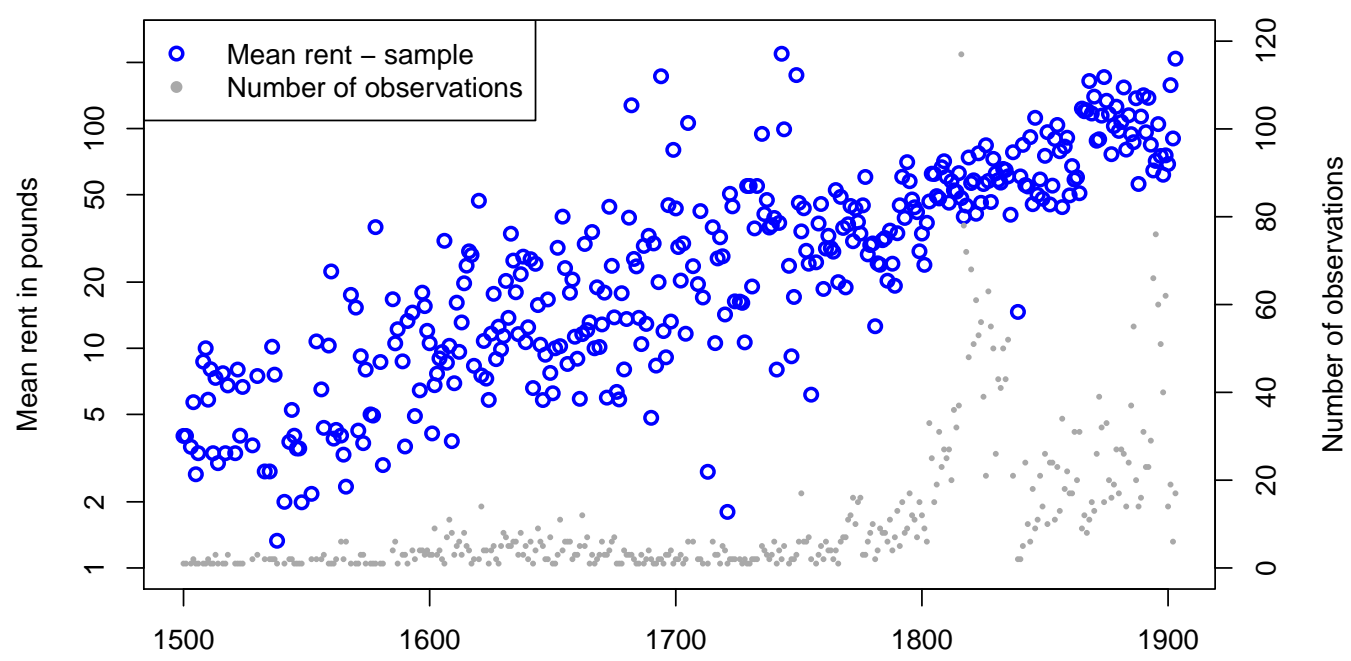

Notes: This figure plots the evolution of the average rent in our London sample. The light-grey scatter reports the number of rent observations in the sample. Note that the number of observations in our London sample is very low, implying average rents are very noisy at annual level. For this reason, the plot provides a scatterplot of mean rents.

Figure 2.12: Paris Mean Rents

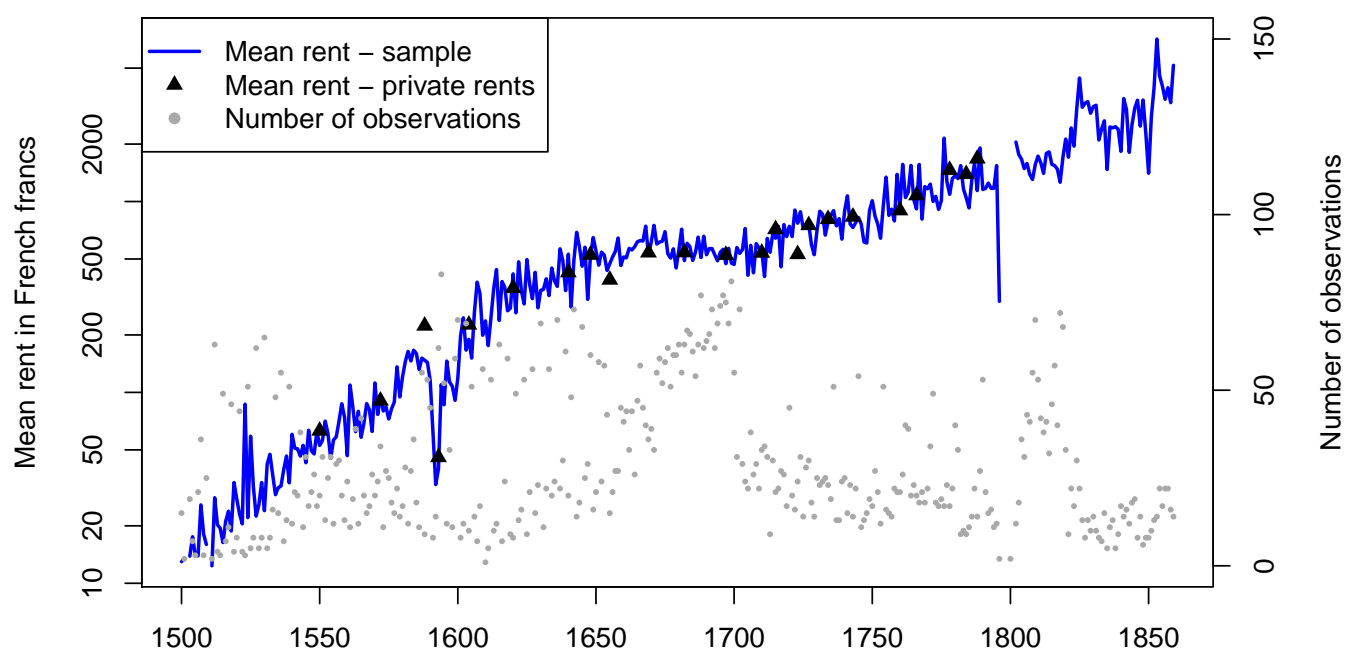

Notes: This figure plots the evolution of the average rent in our Bruges sample, relative to alternative estimates from sources reporting on rental values or rents in the entire city. The light-grey scatter reports the number of rent observations in the sample. Source alternative estimates: Le Roy Ladurie and Couperie (1970). 


\section{C Consumer Prices}

\section{C.1 Data Sources}

Our sources for consumer price data are reported in table 2.6. For most periods, we rely on existing consumer price indices. For Belgium, from 1500-1830, we rely on indices constructed from primary price data; the construction method is discussed in section C2. Primary price data on individual consumption goods are either based on actual purchase prices recorded by these social institutions, or on fixed prices set for tax or exchange purposes. Governments levied small taxes on goods, which were either based on actual market prices paid for the goods or on so-called 'spijker prices', fixed prices set by counties based on prevailing market conditions. Institutions without tax-levying authority used similar practices to set prices for monetary contracts that were settled in kind, providing an additional source of price information. These fixed prices were not always accurate representations of average annual market prices. Prices of goods could fluctuate considerably within a calendar year, as harvests could significantly be affected by bad weather or political instability.

Table 2.6: Overview Consumer Price Sources

\begin{tabular}{llccc}
\hline City/Country & Study & Years & Coverage & Type \\
\hline \multirow{2}{*}{ Belgium } & Michotte (1937) & $1830-1913$ & National & Index \\
& Scholliers (1978) & $1914-1920$ & Urban & Index \\
& Statistics Belgium (2018b) & $1913-2018$ & National & Index \\
Bruges & Verlinden (1972) & $1500-1800$ & Urban & Raw prices \\
Ghent & Verlinden (1972) & $1500-1800$ & Urban & Raw prices \\
Antwerpen & Van der Wee (1963) & $1500-1600$ & Urban & Raw prices \\
& Verlinden (1972) & $1500-1830$ & Urban & Raw prices \\
Brussels & Verlinden (1972) & $1500-1800$ & Urban & Raw prices \\
Amsterdam & Van Zanden (2018) & $1500-1800$ & Regional & Index \\
& Van Riel (2018) & $1800-1900$ & National & Index \\
& Statistics Netherlands (2018) & $1900-2018$ & National & Index \\
Paris & Ridolf (2019) & $1500-1840$ & City & Index \\
& Singer-Kérel (1961) & $1840-1958$ & City & Index \\
& CGEDD (2018) & $1958-1990$ & National & Index \\
& INSEE (2018) & $1990-2018$ & National & Index \\
\multirow{3}{*}{ London } & Allen (2001) & $1500-1913$ & City & Index \\
& Thomas and Dimsdale (2017) & $1913-1988$ & National & Index \\
& Office for National Statistics (2018) & $1988-2018$ & National & Index \\
\hline
\end{tabular}

Notes: The table reports for each city the different sources of consumer price data that we used. Most data covers a strictly urban sample, although data is in some cases at national level. Except for Belgium, we only use secondary time series.

For Antwerp, consumer price data is complemented with data from Van der Wee (1963). Prices are based on the consumer price index constructed by Michotte (1937) from 1830 until the World War I. For the period of World War I, we use an index for 
Brussels from Scholliers (1978). After World War I, a continuous consumer price index (1921-2018) is available from Statistics Belgium (2018b), which uses 1914 as base year and is therefore spliced to the index of Michotte (1937).

Amsterdam consumption prices are from Van Zanden (2018), who computes a price index based on a representative basket of goods for Western Holland between 1500 and 1800. From 1800 to 1910, we use the price index constructed by Van Riel (2018), which we deflate for rental expenses. Consumer prices after 1900 are based on the Dutch national consumer price index from Statistics Netherlands (2018).

For consumer prices in Paris we employ the index developed by Ridolfi (2019) for the period from 1500 to 1840 . Annual figures for this index were kindly provided by Leonardo Rudolfi This index is built on a wide array of primary and secondary sources, improving existing estimates of Allen (2001). For the period from 1840 to 1950, we use the price index for workers from Singer-Kérel (1961). After 1950, we rely on consumer price indices reported in CGEDD (2018) and INSEE (2018). Indices for consumer prices in London covering the 1500-1913 period are from Allen (2001). For the $20^{\text {th }}$ century, we use data from the the Bank of England dataset "a millennium of macroeconomic data" (Thomas and Dimsdale, 2017), from which we used their preferred headline CPI measure. To extend to 2018, we use the standard CPI index of Office for National Statistics (2018).

\section{C.2 Index Construction}

We estimate a new Belgian consumer price index from 1500 to 1830, based on 128 different price series collected from the Verlinden volumes and Van der Wee (1963). ${ }^{9}$ Even though Flanders and Brabant were separate states until 1795, with each having their own currency, we do not estimate a separate index for these regions. We have found no evidence that aggregate consumer prices within Flanders or Brabant were more strongly tied together. This pattern was confirmed when looking at the individual price series.

We have also attempted to construct price indices for each city, as in the short run prices for particular goods could vary across cities, but this turned out to be infeasible. First, the number of series available per city is limited, in particular for Ghent and Brussels, causing their price indices to be unrealistically volatile relative to other cities. Second, the available sources are of varying quality, ranging from monthly averages of market prices to a single price fixed on the day before Christmas. Quality considerations seem more important than differences across cities: high-quality series on the same good across cities tend to be more correlated than high- and low-quality series on the same good within a city.

\footnotetext{
${ }^{9}$ Allen (2001) has already estimated an annual consumer price index for Antwerp / Brabant from 13661913, but his index does not rely on a representative adjustable basket of goods and is likely to understate the true annual volatility in prices due to the strong reliance on interpolated data. As the majority of prices is missing, interpolation results in unrealistically smooth indices, in particular during the $18^{\text {th }}$ century. This will make it much more difficult to identify to what extent nominal rents move with the general price level.
} 
Due to the lack of continuous price series, we have developed a pragmatic method to estimate the consumer price indices, making use of the available data as much as possible. Note that due to the data-driven index estimation strategy, the index developed in this section cannot be classified in standard price index categories; such as the well-known Laspeyres, Paasche or Fischer price indices. The method to construct our indices consists of three steps.

In the first step, the 128 collected price series were stacked into 14 different groups: wheat, rye, barley, peas, butter, egg, cheese, potatoes, buckwheat, beef, chicken, fish, energy, and oils. The first nine groups contain only a single good, whereas the last five groups contain multiple goods representative of the group under consideration. To avoid sensitivity to size discounts or quality differences across cities, as each city had its own measures, we index the individual price series. Base years are chosen to be all years in which individual price series for a group overlap, which avoids strong base-year sensitivity. In case a series has no overlap, it is indexed relative to one or more high-quality series for the same good. Aggregate indices are constructed for each product group by taking averages of the most-representative series. Representativeness is assessed based on the nature of the prices (fixed versus market prices) and the frequency and timing of the observations within a year, with preference given to high-frequency market prices matching the calendar year.

Table 2.7: Expenditure Patterns in an Antwerp Orphanage

\begin{tabular}{|c|c|c|c|c|c|c|c|c|c|}
\hline \multirow[t]{3}{*}{ Year } & \multirow{3}{*}{$\begin{array}{c}\text { Price } \\
\text { Grains }\end{array}$} & \multirow{3}{*}{$\begin{array}{l}\text { Total exp. } \\
\text { Local curr. }\end{array}$} & \multicolumn{7}{|c|}{ Expenditure as \% of total } \\
\hline & & & \multicolumn{4}{|c|}{ Food } & \multicolumn{3}{|c|}{ Nonfood } \\
\hline & & & Grains & Dairy & Meat & Rest & Energy & Clothes & Repairs \\
\hline 1585 & & & $40 \%$ & $9 \%$ & $10 \%$ & $15 \%$ & $3 \%$ & $18 \%$ & $4 \%$ \\
\hline 1586 & 31.1 & 18,737 & $59 \%$ & $13 \%$ & $3 \%$ & $12 \%$ & $3 \%$ & $7 \%$ & $3 \%$ \\
\hline 1587 & 32.7 & 14,184 & $59 \%$ & $6 \%$ & $4 \%$ & $21 \%$ & $2 \%$ & $6 \%$ & $2 \%$ \\
\hline 1588 & 9.78 & 6,627 & $34 \%$ & $16 \%$ & $10 \%$ & $5 \%$ & $7 \%$ & $15 \%$ & $14 \%$ \\
\hline 1589 & 5.87 & 8,852 & & & & & & & \\
\hline 1590 & 10.2 & 10,389 & $25 \%$ & $17 \%$ & & $24 \%$ & $4 \%$ & $21 \%$ & $9 \%$ \\
\hline 1591 & 10.25 & 10,559 & $21 \%$ & $20 \%$ & $7 \%$ & $24 \%$ & $4 \%$ & $22 \%$ & $2 \%$ \\
\hline 1592 & 8.28 & 10,208 & $21 \%$ & $16 \%$ & $7 \%$ & $22 \%$ & $5 \%$ & $18 \%$ & $10 \%$ \\
\hline 1593 & 7.86 & 11,515 & $11 \%$ & $20 \%$ & $7 \%$ & $26 \%$ & $6 \%$ & $23 \%$ & $7 \%$ \\
\hline 1594 & 10.9 & 12,302 & $16 \%$ & $18 \%$ & $9 \%$ & $24 \%$ & $5 \%$ & $21 \%$ & $7 \%$ \\
\hline 1595 & 20.9 & 13,853 & $29 \%$ & $18 \%$ & $7 \%$ & $20 \%$ & $4 \%$ & $17 \%$ & $6 \%$ \\
\hline 1596 & 16.8 & 13,167 & $27 \%$ & $17 \%$ & $6 \%$ & $20 \%$ & $4 \%$ & $16 \%$ & $10 \%$ \\
\hline 1597 & 15.8 & 12,044 & $28 \%$ & $18 \%$ & $7 \%$ & $21 \%$ & $5 \%$ & $13 \%$ & $9 \%$ \\
\hline 1598 & 14.3 & 11,240 & $24 \%$ & $19 \%$ & $7 \%$ & $24 \%$ & $6 \%$ & $13 \%$ & $7 \%$ \\
\hline 1599 & 10.9 & 10,253 & $19 \%$ & $17 \%$ & $6 \%$ & $21 \%$ & $5 \%$ & $19 \%$ & $13 \%$ \\
\hline 1600 & 10.1 & 9,442 & $18 \%$ & $15 \%$ & $9 \%$ & $18 \%$ & $7 \%$ & $24 \%$ & $9 \%$ \\
\hline \multicolumn{3}{|c|}{ Average } & $29 \%$ & $16 \%$ & $7 \%$ & $20 \%$ & $5 \%$ & $17 \%$ & $7 \%$ \\
\hline
\end{tabular}

Notes: The table reports expenses for the Maagdenhuis orphanage in Antwerp, based on data from Scholliers (1960). We use these to estimate budget shares in the CPI. 
In the second step the base weights of each good in the overall price index were determined. Weights are based on scarce information on expenditure patterns of Ghent households and Antwerp orphanages for a handful of years in the late $16^{\text {th }}$ and $19^{\text {th }}$ century, published in Scholliers (1960) and Avondts and Scholliers (1977) (1977) and reported in Table 2.7, for 1600 and 1840. Weights are fixed before 1600, and from 1600 to 1830 interpolated. Potatoes and buckwheat are only included after 1800 due to data availability. It is important to realize that expenditure patterns vary significantly over time and across sources. This becomes evident when looking at the expenditures of the 'Maagdenhuis' in Antwerp relative to the price of grains from 1585 to 1600, reported in Table 2.7. The price of grain, which was the most important component of the household budget until the early $19^{\text {th }}$ century, increased significantly in 1586 due to the uncertainty caused by the Fall of Antwerp to the Spanish in late 1585. Since cereals were, even at very high prices, the cheapest source of calories, inhabitants did not shift their consumption to other goods, but were forced to spend their money on cereals to avoid starvation.

The main problem with the selected base weights is that for some product groups no continuous price observations are available, in particular after 1800. In order to make use of the available data as much as possible, without engaging in excessive smoothing, we vary the weights across years depending on data availability (see Table 2.8) ${ }^{10}$ In case prices for a product group are not available or of insufficient quality, its weight is redistributed to a group (or groups) that is (are) most correlated with the price index of the missing group. In the last step, the prices for each good are converted to index prices and multiplied with the weights to produce the consumer price index.

Table 2.8: Base Weights Price Index, Key Years

\begin{tabular}{cccccccc}
\hline Year & Wheat & Rye & Butter & Cheese & Beef & Chicken & Egg \\
\hline 1600 & $4.0 \%$ & $40.0 \%$ & $16.0 \%$ & $7.0 \%$ & $5.0 \%$ & $5.0 \%$ & $0.5 \%$ \\
1799 & $11.5 \%$ & $23.4 \%$ & $14.3 \%$ & $6.2 \%$ & $9.1 \%$ & $8.3 \%$ & $1.7 \%$ \\
1800 & $13.0 \%$ & $19.0 \%$ & $15.0 \%$ & - & $16.0 \%$ & - & - \\
1835 & $15.1 \%$ & $15.5 \%$ & $15.0 \%$ & - & $16.0 \%$ & - & - \\
\hline Year & Fish & Peas & Barley & Energy & Oils & Potatoes & Buckwheat \\
1600 & $3.0 \%$ & $2.0 \%$ & $6.5 \%$ & $9.0 \%$ & $2.0 \%$ & - & - \\
1799 & $3.0 \%$ & $3.7 \%$ & $5.3 \%$ & $11.5 \%$ & $2.0 \%$ & - & - \\
1800 & - & - & $5.0 \%$ & $14.0 \%$ & $2.0 \%$ & $12.0 \%$ & $4.0 \%$ \\
1835 & - & - & $5.0 \%$ & $14.0 \%$ & $2.0 \%$ & $13.4 \%$ & $4.0 \%$ \\
\hline
\end{tabular}

Notes: The table reports the base weights of each of the different food items in the aggregate CPI. Because data on each food item is not available for each year, weights can shift over time.

\footnotetext{
${ }^{10}$ The weighting schemes for each city are available upon request.
} 


\section{D Population Estimates}

To construct estimates of population for our cities, which we use to make estimates of housing quality per capita, we combined population estimates found in historical studies, and interpolated these using cubic splines. It should be noted that the quality of these estimates varies, in particular for the $16^{\text {th }}$ century. In some cases, estimates could differ significantly. For many early estimates, it was not always clear how they were constructed, such that it was difficult to judge the accuracy of the numbers. From 1820 onwards, we used for all Belgian cities census estimates of population reported in Segers (1999) and Statistics Belgium (2018b). For each city, we used the following sources, which we deemed most accurate:

Antwerp: Quetelet (1846); Verbeemen (1956); Deprez (1957); Marnef (1996). Bruges: Sentrie (2007); Deneweth (2010). Ghent: Dambruyne (2001); Van Werveke (1948); Deprez (1957); Vermeulen (2002). Brussels: Cosemans (1966), Avondts (1971). Amsterdam: Francke and Korevaar (2020). London: Harding (1990), Landers et al. (1993) and Mayor of London (2017). Paris: Francke and Korevaar (2020).

\section{E Unpublished Data Sources}

Deneweth, H. Database Heidi Deneweth based on "Huizen en mensen. Wonen, verbouwen, investeren en lenen in drie Brugse wijken van de late middeleeuwen tot de negentiende eeuw”. Unpublished Ph.D. thesis, 2008. Courtesy of Heidi Deneweth Henau, A. Rent index Belgian cities, 1940-1961. Courtesy of Katharina Knoll.

Historical Databases of Local and Cadastral Statistics (LOKSTAT-POPPKAD), Ghent University, Quetelet Center

Friggit, J. Rent index Paris, various INSEE / OLAP statistics. Courtesy of Jacques Friggit.

Vrielinck. S. Database relation cadastral income and rental value for $19^{\text {th }}$ century Belgium. Courtesy of Sven Vrielinck.

\section{F Archival Data Sources}

Amsterdam City Archives, 191: Archief van het Rooms-Katholiek Jongensweeshuis, no 979, 987, 991, 992

Amsterdam City Archives, 201: Archief van de Waalsch Hervormde Gemeente, no. 1973 and 3596

Amsterdam City Archives, 367.A: Archief van het Burgerweeshuis, oud archief, no 143, 143A, 144, 145, 146

Amsterdam City Archives, 367.C: Archief van het Burgerweeshuis, nieuw-archief, no. 938, 947, 1421, 1794, 1798, 1804-1805 
Amsterdam City Archives, 404: Brants-Rus Hofje en van Christoffel van Brants, no. 156

Amsterdam City Archives, 612: Archief van de Remonstrantse Gemeente, no. 432 Amsterdam City Archives, 1120 : Archief van Verenigde Doopsgezinde Gemeente van Amsterdam en rechtsvoorgangers, no. 2087-2089, 2130

Amsterdam City Archives, 5044: Archief van de Thesaurieren Extraordinaris, no. 254, 273, 281, 284, 402-405

Amsterdam City Archives, 5045: Archief van de Honderdste en Tweehonderdste Penningkamer of Commissarissen tot de Ontvangst van de Honderdste en Andere Penningen: no 269-323

Amsterdam City Archives, 5210: Archief van de Commissaris van de Stedelijke Accijnzen en Belastingen en rechtsvoorgangers, no. 69-75

Amsterdam City Archives, 30525: Collectie Kenniscentrum Amsterdam, no. 2036, 2391 and 3733

Archives de l'Assistance Publique des Hopitaux de Paris, 782 Foss 1 Propriétés urbaines vendues depuis 1807.

Archives de l'Assistance Publique des Hopitaux de Paris, 782 Foss 25, Loyers de maisons 1811

Archives de Paris, DQ18, Sommier Foncier

Archives Nationales, Pierrefitte-sur-Seine, EHESS Archives, cote 66 AJ 2029-2035

London Metropolitan Archives CLC/B/216, Trafalgar House Developments Limited, MS144, 24-25, 28, 59

Felixarchief Antwerpen 781: Gilberte Degueldere, onderzoek over Antwerpse huizen, bewoners en waarden, no 1-14

National Archives RG 77/3. Historic Retail Prices Index, 1947 to 2004 dataset. Retrieved June 18, 2018: http: //discovery . nationalarchives.gov.uk/details/r/ C1152137 


\section{Chapter 3}

\section{Long Run Affordability and (Ine)Quality*}

There is no city in Europe, I believe, in which house-rent is dearer than in London, and yet I know no capital in which a furnished apartment can be hired as cheap. Lodging is not only much cheaper in London than in Paris; it is much cheaper than in Edinburgh of the same degree of goodness. Adam Smith (1776), The Wealth of Nations, Book 1, Chapter 10.

Urban housing is dear for many households and is perceived to have become too expensive in cities all over the world, as a barrage of existing and recently introduced affordability policies attests. For example, London's mayor promised to start building 116,000 'truly affordable' homes by 2022 (Mayor of London, 2018), while Paris and Berlin introduced new strict rent controls in 2019. In New York, over one million housing units are subject to rent regulations, and similar policies are being discussed or have been implemented in various cities across the US, most notably in the San Francisco Bay Area (Diamond et al., 2019).

According to the Cambridge Dictionary (2018), affordable homes are "able to be bought or rented by people who do not earn a lot of money." As appealing as this sympathetically straight-forward definition might sound at first, it turns out to be very unhelpful when analyzing affordability in detail. Housing affordability problems are not merely a matter of rising housing costs meeting insufficient income: they stem from the interplay between house prices, housing rents, income levels, income distributions, and housing quality (Quigley and Raphael, 2005). However, despite the long history of housing market interventions, with many countries already introducing rent control and supply-side measures after World War I (Willis, 1950; Fischel, 2004), we do not know how these variables have evolved, and how they respond to changes in the demand for urban housing.

This paper aims to fill that gap: we present the first truly long-term overview of urban rental housing quality, inequality, and affordability, going back more than 500

${ }^{*}$ This chapter is co-authored with Piet Eichholtz (Maastricht University) and Thies Lindenthal (University of Cambridge). 
years. This is based on the annual rent price indices developed by Eichholtz et al. (2020b), for seven European cities: Amsterdam, Antwerp, Bruges, Brussels, Ghent, London, and Paris. We combine these rent indices with indices of wages to investigate developments in housing affordability, and we test whether rent control played a role in this. We complement this rental information with additional data to construct indices of housing quality that trace trends in housing standards and inequality since 1500 , and we investigate the role of urban growth and decline in each of these developments.

We focus on rents rather than house prices, since renting has been, and still is, the dominant tenancy form in most European cities. The seven cities in our sample offer rich data on housing markets in diverse economic conditions: each city has been an important commerce hub at different periods in time - or still is. Some grew quickly initially and slowed down later, such as Ghent, Bruges, Antwerp, and Amsterdam, while others, notably London and Paris, have continued expanding and retained their leading status in the $21^{\text {st }}$ century. Such shifts possibly had an impact on fundamental equilibria of housing costs, affordability and quality, which are most visible over the long run.

The 500-year perspective taken in this paper offers three contributions that jointly provide a new outlook on the current housing affordability debate. First, the long-term setting allows us to study how rent prices, housing quality and affordability respond to changes in urban populations under a free market regime. With more recent data, unregulated markets are hard to find. Most urban rental markets in Europe have been subject to some form of government regulation since the early $20^{\text {th }}$ century (Arnott, 1995). In both Europe and the United States, zoning regulations often limit the expansion of housing supply (Hilber and Vermeulen, 2016; Glaeser and Gyourko, 2018). However, even in markets without such constraints, housing supply cannot adjust immediately to changes in demand, such that it takes time for the market to reach equilibrium. This implies that long time series are necessary to estimate the effect of urban population changes on housing conditions and rents. ${ }^{2}$

We combine our panel of housing data with data on population changes to study their long-term effects in the unregulated period from 1500 until 1913, expanding the analysis in Eichholtz et al. (2020b). Using 25-year changes, we find that urban population growth leads to an insignificant but modest long-term worsening of housing affordability, with an elasticity of -0.19 . We define housing affordability as the evolution of quality-controlled prices relative to median wages.

These dynamics mask changes in the distribution of rental prices. We show that when cities were growing, and housing supply expanded, average housing quality grew as well. These higher quality homes were likely rented to wealthier citizens that benefited from the growth of the city: wages for ordinary workers did not increase faster than rents. At the same time, we find that rental prices of cheaper properties

\footnotetext{
${ }^{2}$ The recent work of Combes et al. (2019) uses a novel cross-sectional method to estimate the elasticity of urban house prices with respect to population. Their preferred estimate corresponds to an elasticity of 0.2 . However, their estimate is conditional on current French zoning regulations that only allow construction within existing city boundaries.
} 
increased at faster rates than expensive properties. Thus, in free markets, the main long-term consequence of urban growth is not a worsening of aggregate rental affordability, but increasing housing inequality.

Existing historical studies have documented the positive relationship between city size and inequality before the $20^{\text {th }}$ century (Soltow and Van Zanden, 1998; Ryckbosch, 2016), and such a pattern also exists in modern US cities (Baum-Snow and Pavan, 2013; Eeckhout et al., 2014). However, the implications of urban growth on housing inequality have not yet been studied. This is particularly important since housing inequality also captures differences in the value of locations. Although we do not directly study the spatial dynamics of our data, our findings also relate to the literature on segregation. Guerrieri et al. (2013) argue that during housing booms, more affluent residents move into initially poorer neighborhoods, and bid up prices there, leading to gentrification. This mechanism could explain why rental prices of cheaper properties increase more when cities are growing. Such segregation has been directly linked to rising inequality (Fogli and Guerrieri, 2019).

Dynamics in urban housing conditions are very different when cities are declining in population. In line with Glaeser and Gyourko (2005) and Eichholtz et al. (2020b), we find a much larger elasticity of affordability with respect to the population when population declines, around one, since durable housing supply cannot adjust. Correspondingly, after controlling for rent price changes, we find no evidence for changing housing consumption when cities decline. Urban decline also does not seem to fully revert increases in housing inequality that resulted from earlier urban growth: evidence for such reversals is weak.

Our second main contribution is that we present new stylized facts regarding the development of urban housing affordability in the regulated $20^{\text {th }}$ century. In the early $20^{\text {th }}$ century, the ratio of wages to housing rents fluctuated significantly, and we estimate whether rent controls played a role in driving these changes in affordability. A wide range of papers discusses the impact of rent control policies on housing costs. The earliest paper warning that such measures can have negative consequences is Friedman and Stigler (1946), and since then, different authors have pointed at lower maintenance incentives (Downs, 1988), negative neighborhood effects (Sims, 2007; Autor et al., 2014), and the misallocation of housing (Glaeser and Luttmer, 2003). A recent paper of Diamond et al. (2019) exploits quasi-experimental variation in rent control in San Francisco, and finds that housing supply decreases and city-wide rents increase in response to rent control. Our paper exploits variation in inflation rates to show that nominal price controls caused considerable improvements in affordability over the short run. Our setting does not allow us to study their potentially harmful long-term effects. However, we do show that aggregate housing affordability, in terms of the ratio of quality-controlled rents to wages, improved drastically between the early and late $20^{\text {th }}$ century. Although affordability has recently started worsening in some of the cities we study, rental housing remains far more affordable than in the centuries before.

Third, we document that urban rental housing quality and housing consumption per capita have both risen considerably, while housing inequality has reduced sub- 
stantially. The physical attributes and the size of homes in our sample improved over time. In the early centuries covered in our study, the defining attribute of a typical dwelling was space, and little of that. Gradually, housing space per capita increased, and amenities like heating, running water, plumbing, access to sewers or electricity became standard features of urban dwellings. The timing of these updates is remarkable: housing quality already rose considerably from the $16^{\text {th }}$ to the $18^{\text {th }}$ century, suggesting that urban living standards already improved prior to the Industrial Revolution, although primarily for the rich. This is both visible per capita and per home. During the Industrial Revolution, housing quality stagnated, or sometimes even declined, before rising again in the late $19^{\text {th }}$ century. The upward trend continued in the $20^{\text {th }}$ century, helped by improvements in rental affordability. This time, these benefits accrued more widely than before, as housing inequality reduced substantially.

Better affordability seems to be at odds with households' expenditure shares on housing reaching new heights, but this paper shows that most increases in housing expenses stem from improvements in housing quality and quantity rather than rising prices for a given set of housing attributes. This has also been hypothesized by Quigley and Raphael (2004), who apply various measures to trace affordability in the United States from 1960 until the early 2000s, and also include rental housing. They find that the ratio of housing expenses to income has increased over time, in particular for low-income renters, and that this may be due to improvements in housing quality. However, we find that in some cities, housing quality improvements have halted recently, while our data for Amsterdam show that housing inequality is rising again. The latter pattern is also visible in the United States (Aladangady et al., 2017).

This paper proceeds as follows. The next section will present the original data we have recovered for this paper, as well as sample statistics for all the data we employ, both for the rent indices and for the new data. We will then discuss our measurement methods for housing affordability, inequality, and quality. The section after that will show our results, and we will end the paper with a short summary and some conclusions.

\subsection{Data}

We track rent prices, housing quality and affordability for seven cities in four countries: Amsterdam, London, Paris, and the Belgian cities Antwerp, Bruges, Brussels, and Ghent, and we do that for the period from 1500 until 2018.

The data on rent levels we use in this paper are based on the recently developed urban rent indices from Eichholtz et al. (2020b). We also use their population and consumer price estimates. Their rent indices are based on a database of rent observations containing over 436,000 rent prices, covering most cities until the first half of the 20th century. We will use this primary data also to make inferred estimates from housing quality, and to assess housing inequality. For our assessment of housing inequality, we complement the rental data in Eichholtz et al. (2020b) with rental value distributions from other sources and time periods. We discuss these sources in Appendix 3.B. 
Besides rental data, we also compiled primary and secondary data on wages, in order to assess rental housing affordability. An overview an detailed discussion of these sources is presented in Appendix 3.A. For the Belgian cities, we created a new wage index (1500-1830). We rely on existing series for the other cities, and the time period after 1830. As much as possible, we have selected wage data that closely reflect the marginal product of labor. This is important, because our affordability estimate is targeted to measure the number of units of housing that can be purchased per unit of work.

Until the $19^{\text {th }}$ century, most of our wage indices are based upon day wages of workers in the construction sector. An advantage of using these wages is that most of these jobs are still existent nowadays, such that it is possible to make long-run comparisons. A drawback is that wages in the construction sector varied significantly with season, level of skill, the amount of beer money and the riskiness of the job at hand. This is not always identified exactly in the records and, especially if data is scarce, is likely to cause noise in our index compared to the 'true' wage level. For later periods, our indices are based on national or local indices of wages. Most of these indices track hourly wages, some reflect weekly earnings. Note that in the $20^{\text {th }}$ century, the introduction of taxes and employer contributions makes it more difficult to have wage indices that consistently reflect the marginal return to working, since only a very small fraction of such taxes or costs directly benefit the worker proportional to the amount of his labor.

\subsection{Methodology}

\subsubsection{Housing Affordability}

The literature offers no single definition of 'housing affordability' but explores a wide range of approaches. On one side of the spectrum, for example in Glaeser and Gyourko (2003), housing is considered unaffordable if housing costs exceed construction costs. On the other end, housing affordability is viewed as an income issue. For example, in the residual income approach, which is favored in the overview of Stone (2006), affordability issues arise if insufficient income is left after paying housing costs. The main problem with such an approach is that it relies on housing and income standards, which vary over time.

In this paper, our main measure of affordability in city $i$ at time $t$ expresses affordability as the ratio of wages to rent prices.

$$
\text { Affordability }_{i t}=\frac{W_{i t}}{R_{i t}}
$$

The affordability attempts to measure how many units of housing can be bought per unit of labor: the rent price index measures the cost of one unit of housing of constant quality, and the wage index measures the return to one unit of labor. In practice, this measure is primarily based on day wages until the $19^{\text {th }}$ century, and hourly wages afterward. Such an approach is in line with earlier work of Gyourko and Linneman 
(1993) and Gyourko and Tracy (1999), who study developments in US housing affordability but look at owner-occupied housing rather than rental housing, and do not appropriately control for quality.

Because we have not collected construction cost data, we cannot identify exactly how rent prices evolved relative to the costs of new construction, as in Glaeser and Gyourko (2003). ${ }^{3}$ They find that house prices primarily deviate from construction costs due to zoning constraints. Given that we study markets without such constraints over the very long-term, such deviations are most likely absent in our setting, at least before the $20^{\text {th }}$ century. Instead, our interest is to determine how much long-term 'equilibrium' rent prices and affordability change as cities grow and decline.

\subsubsection{Housing Quality}

The basic repeated measures methodology from Bailey et al. (1963) starts with the observation that the log price on any asset, in this case the log rental price $r_{t}$ on a particular home $i$, can be represented as the sum of three components:

$$
r_{i t}=\alpha_{i}+\beta_{t}+\epsilon_{i t}
$$

The first term, $\alpha_{i}$ reflects the underlying value, and therefore quality, of the home: the key assumption is that this does not change over time, at least at the level of an individual home. The second term, $\beta_{t}$ is the value of the log rental price index, while $\varepsilon_{i t}$ reflects price noise and is assumed to be distributed as $\mathrm{N}\left(0, \sigma^{2}\right)$.

Since the repeat-rent index provides an estimate of the market price component, we can simply rewrite equation (2) to obtain an estimate of implied housing quality $\alpha_{i}$. Rewriting (2):

$$
r_{i t}-\beta_{t}=\alpha_{i}+\epsilon_{i t}
$$

Taking averages over all properties $i$ at each time period $t$ :

$$
\bar{\alpha}_{t}=\bar{R}_{t}-\beta_{t}
$$

Exponentiating (3.4), we can use the indexed ratio of the mean rent index to the quality-controlled rent index as a measure of average quality. The quality index reflects the monetary value of quality improvements over time, which have two dimensions: improvements in the quantity of space consumed and changes in the quality of a given space due to construction improvements, such as plumbing, better insulation, higher ceilings or the installation of bathrooms or kitchens. Quality improvements external to the property are not taken into account: these are included in market prices.

As changes in the composition of the sample sometimes lead to significant noise in the developments of average rents in the short term, we only compute housing quality

\footnotetext{
${ }^{3}$ We should note though that until the $19^{\text {th }}$ most wage data is based on day wages for construction workers, so in this period our measure of affordability does at least partially account for changes in construction costs
} 
indices for periods of 25 years between 1500 and 1900. For London, not enough data is available to compute a quality index for any period. Instead, we report data from Clark (2002) who has estimated an implied quality index for England and Wales, based on a method very close to ours. Last, we compute a joint rent and quality index for the Belgian cities, based on a population-weighted average. We do not extend our quality indices to the $20^{\text {th }}$ century, as from the 1910s no new homes are added to our samples. Also, the introduction of social housing and rent control policies in the $20^{\text {th }}$ century implies that the rent paid cannot be used anymore to infer housing quality. For this period, we will use census data to examine whether housing quality improved.

\subsubsection{Housing Inequality}

One issue with our aggregate measures of rental housing affordability and quality is that they do not take into account variation in rental price appreciation and dwelling quality across market segments. Affordability issues are particularly pressing for those with lower incomes, and prices of their properties might appreciate faster than those in other segments. For example, Glaeser et al. (2012) and Guerrieri et al. (2013) document that properties in cheaper neighborhoods appreciated faster during house prices booms than those in more expensive neighborhoods. This could reflect gentrification processes, as in Guerrieri et al. (2013), but also changes in credit availability (Landvoigt et al., 2015). Of course, only the former would apply to long-term rental prices.

To investigate this, we estimate rent price indices for above- and below median properties using the data that was collected by Eichholtz et al. (2020b). For each rental observation, we determine whether it is above or below the median price in the sample in that particular year. Next, we determine whether a pair of repeat-rents is consistently above or below the median. We estimate an above- and below- median rent price index using pairs consistently above or below the median price, based on a standard repeat-sales index, following the methodology outlined in Eichholtz et al. (2020b)

To further study the evolution of housing inequality over time, we compute the Gini coefficient for the distribution of housing quality values at various points in time. These inequalities reflect differences in both structure and location quality.

\subsection{Urban Rental Housing in the Long Run}

\subsubsection{Rental Housing Affordability}

Figure 3.1 reports the rent indices for Amsterdam, Paris, London, and the Belgian cities, both in real terms, together with estimates of the real wage development. Given that most developments in aggregate rent prices have already been discussed in Eichholtz et al. (2020b), we focus our discussion on their development relative to wage levels.

The first and most striking conclusion from the figure is that rental prices have shown little real growth in the long run. Unsurprisingly, wage growth has been particularly significant in the $20^{\text {th }}$ century. Both our real rent and real wage indices adjust 
Figure 3.1: Real Rent Prices and Real Wages

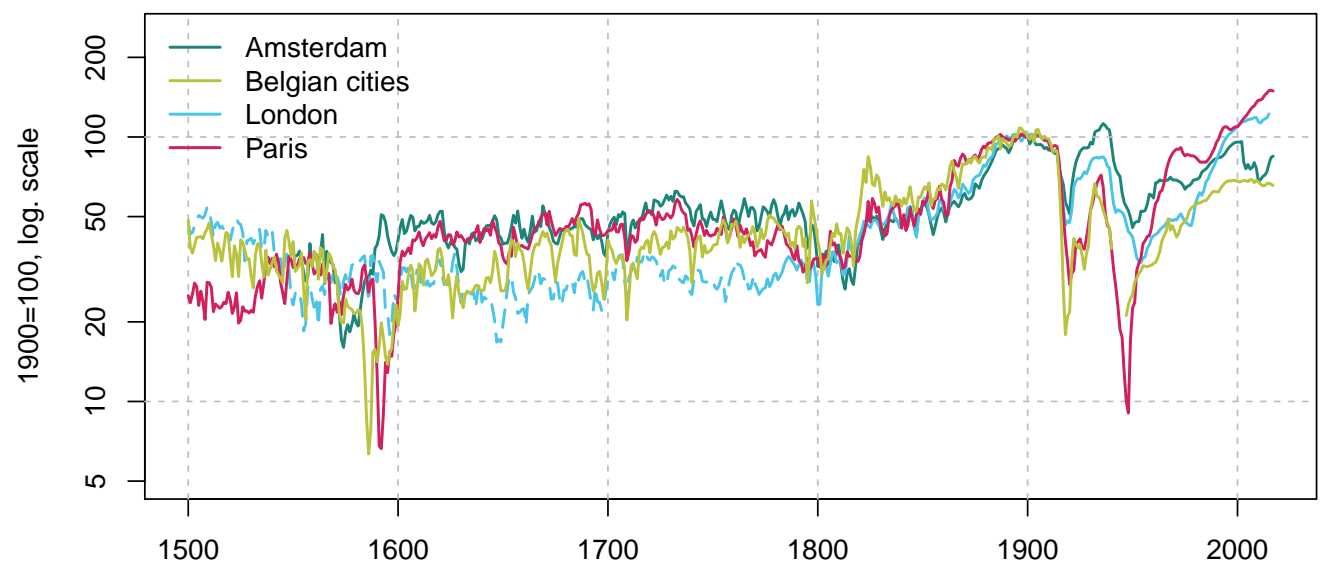

(a) Real Rent Indices, 1500-2018

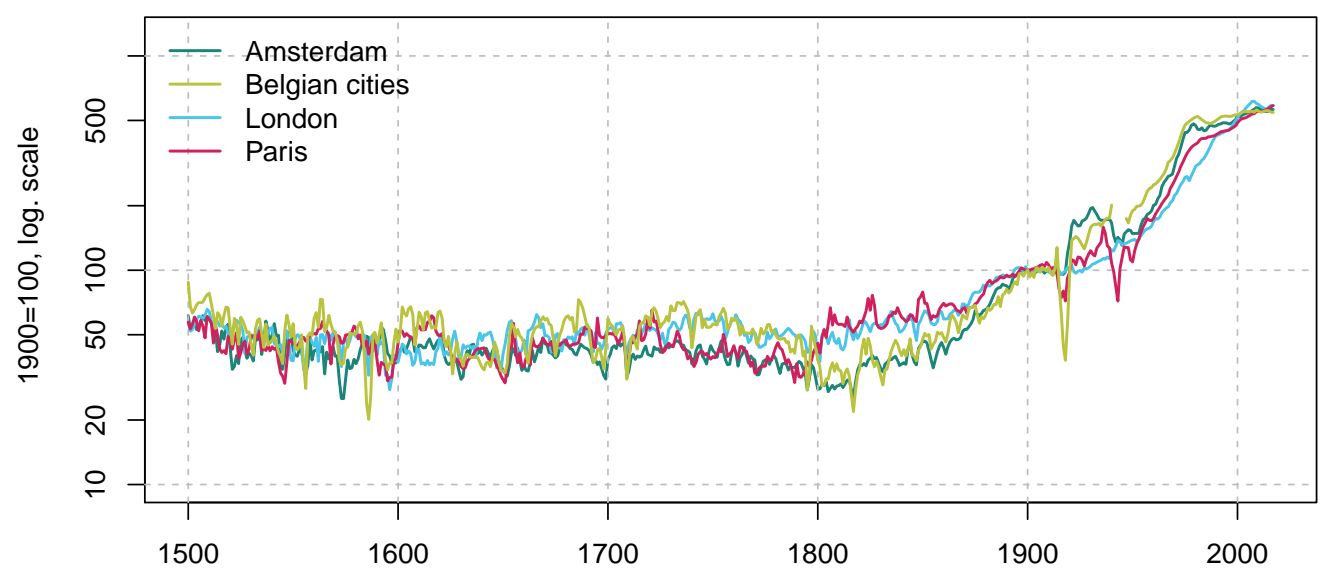

(b) Real Wage Indices, 1500-2018

Notes: The plots compare the developments in real rental prices (Figure 3.1a), using the indices from Eichholtz et al. (2020b), to developments in real wages (Figure 3.1b). Rents and wages are deflated using the CPI. Data is aggregated for the Belgian cities by using a population-weighted average of the individual indices. From 1940, the Belgian index covers all urban areas. 
for consumer prices. However, this is not necessary when we are only interested in their relative prices: our indices of housing affordability. Figure 3.2 plots the indices of housing affordability that we have constructed for each of the studied cities. The pattern emerging from the figure is rather surprising: housing has never been as affordable as it has been over the past few decades and has improved tremendously in the period between World War I and 1980, albeit with stark fluctuations. Housing affordability did not improve at all before the $20^{\text {th }}$ century: between 1500 and 1900, it even worsened significantly in Paris and the Belgian cities, while staying roughly constant in London and Amsterdam.

Figure 3.2: Housing Affordability Indices, 1500-2018

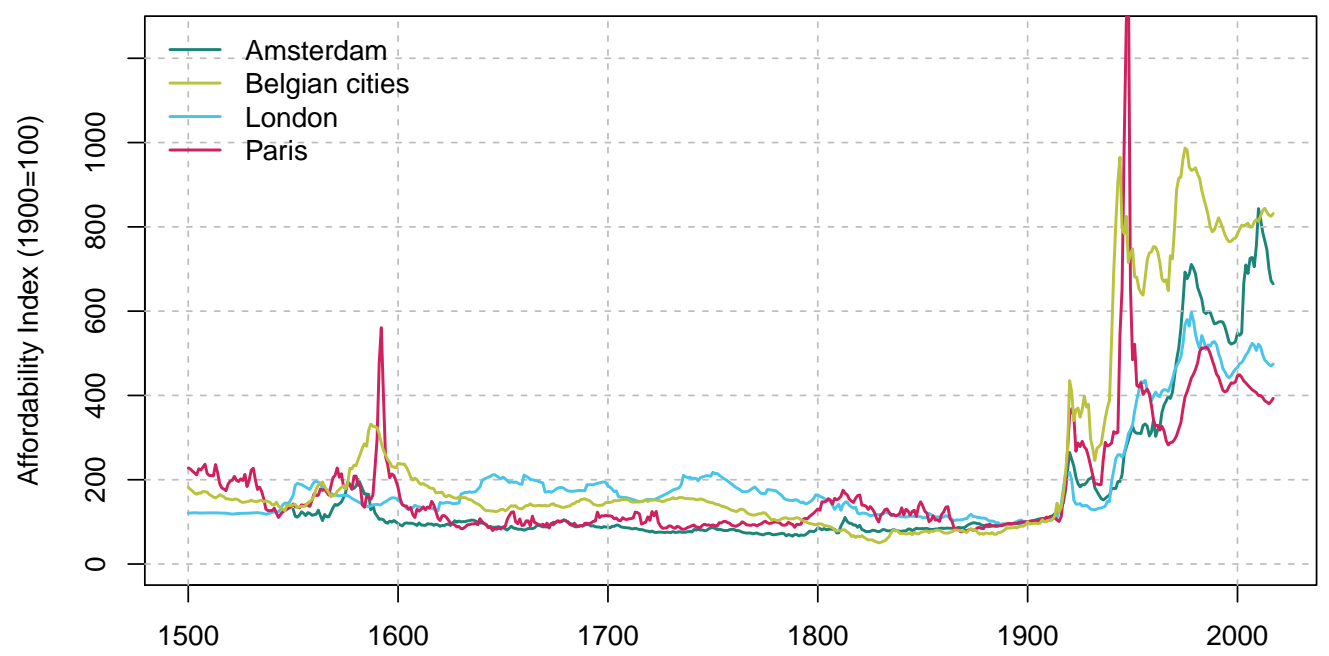

Notes: This plot shows the developments in the housing affordability index, which is defined as the indexed ratio between the wage index and the rental price index. High levels of the affordability index imply affordable housing.

Beyond these long-term developments, there are substantial differences in affordability both across cities and over shorter periods. Before 1800, most of these are due to differences in rents. Correspondingly, the Belgian cities and London were relatively more affordable compared to Amsterdam and Paris during the $17^{\text {th }}$ and $18^{\text {th }}$ century, in line with the remarks of Adam Smith at the start of this paper. At the end of the $18^{\text {th }}$ century, this gradually changed, as rent growth outpaced growth in wages. In the $19^{\text {th }}$ century, part of the increase in rents was compensated by increasing wages, which also had started rising gradually. However, it took until the early $20^{\text {th }}$ century before wage growth outpaced rental price growth. This was not an even process. Due to strict rent controls, housing rents could not rise with inflation in the period around the World Wars. Rent controls were particularly stringent in Paris, which explains the large peak in affordability after World War II, when real rents had dropped dramatically.

The result of these unprecedented improvements in affordability in the $20^{\text {th }}$ century is that one unit of labor today buys approximately four to eight times as many 
units of rental housing as it could in 1900. To illustrate these affordability improvements more clearly, we collected data on the share of rental expenses in the household budget for all of our cities, both in the early $20^{\text {th }}$ century and for very recent years. Subsequently, we use our affordability indices to estimate the budget share needed nowadays to buy the same bundle of housing services as the early- $20^{\text {th }}$ century household consumed while keeping the number of hours worked constant.

Table 3.1: Housing Budget Shares in the $20^{\text {th }}$ and $21^{\text {st }}$ Century

\begin{tabular}{lcccc}
\hline City & Year & Budget Share & Implied Share in 2015 & Coverage \\
\hline Amsterdam & 1911 & $16.25 \%$ & $2.59 \%$ & Renters \\
Amsterdam & 2015 & $38.90 \%$ & & Renters \\
Amsterdam & 2015 & $36.70 \%$ & & All \\
Belg. cities & 1910 & $11.60 \%$ & $1.46 \%$ & Renters \\
Brussels & 2016 & $33.80 \%$ & & All \\
Belgium & 2016 & $30.40 \%$ & & All \\
Paris & 1900 & $18.10 \%$ & $4.60 \%$ & Renters \\
Paris & 2008 & $34.00 \%$ & & Renters \\
Paris & 2011 & $19.10 \%$ & & All \\
London & 1925 & $18.43 \%$ & $5.41 \%$ & Renters \\
London & 2015 & $39.17 \%$ & & Renters \\
London & 2015 & $28.86 \%$ & & All \\
\hline
\end{tabular}

Notes: This table compares expenditure shares on housing at the start of the 20th century to more recent observations. Appendix 3.C reports the sources for these household budget shares. In all cities, expenditure shares have increased over time.

Table 3.1, column 3, shows that the share of rental expenses in the household budget has increased substantially in all cities. This also holds when including the expenses of home-owners, who tend to be wealthier and spend a smaller part of their income on housing. However, when we calculate the budget share that would have been needed today to purchase the average early $20^{\text {th }}$ century housing bundle, we see that it is substantially lower than in the early years of the $20^{\text {th }}$ century. This is most striking in the Belgian cities and in Amsterdam, but it also holds true in London and Paris: only 1.5 to 5.4 percent of the 2015 household budget would have been needed to buy the housing bundle of a century earlier.

Evidently, the discrepancy between these budget shares implies that housing quality must have gone up substantially: households could only increase their budget shares on housing if they consumed more housing. However, we should be careful to use these data to infer by how much housing quality has gone up: working hours and household sizes have changed substantially, our $20^{\text {th }}$ century rent indices are based on less accurate spliced indices, and housing expenses are nowadays strongly influenced by housing policy. However, the magnitude of the changes we find suggests that the real question is not whether housing quality improved, but when and by how much. 


\subsubsection{Housing Quality and Inequality}

Table 3.2 reports the index of housing quality in the studied cities between 1500 and 1900. For reference, we report the quality index of Clark (2002) for England and Wales. Housing quality has improved substantially in each city, although at varying rates: it increased most in Paris, and the least in Amsterdam and England. Part of this might be because no data is available for England and Amsterdam in the $16^{\text {th }}$ century, when we already see marked improvement in the Belgian cities and in Paris. The timing of these quality upgrades is similar across cities: improvements in housing quality took place mostly prior to the Industrial Revolution. During the late $18^{\text {th }}$ and most of the $19^{\text {th }}$ century housing quality stagnated or even declined a bit, while increasing again at the end of the $19^{\text {th }}$ century.

Table 3.2: Housing Quality Index (1750-1774 = 100)

\begin{tabular}{lcccc}
\hline Time period & Belgian cities & Amsterdam & Paris & England (Clark, 2002) \\
\hline $1500-1524$ & 51 & & 33 & \\
$1525-1549$ & 62 & & 35 & \\
$1550-1574$ & 68 & 59 & 40 & \\
$1575-1599$ & 76 & 55 & 43 & 64 \\
$1600-1624$ & 76 & 87 & 50 & 67 \\
$1625-1649$ & 90 & 91 & 56 & 72 \\
$1650-1674$ & 99 & 119 & 64 & 61 \\
$1675-1699$ & 101 & 110 & 67 & 75 \\
$1700-1724$ & 104 & 104 & 69 & 86 \\
$1725-1749$ & 105 & 102 & 79 & 100 \\
$1750-1774$ & 100 & 100 & 100 & 93 \\
$1775-1799$ & 91 & 100 & 109 & 90 \\
$1800-1824$ & 91 & 112 & 126 & 85 \\
$1825-1849$ & 96 & 97 & 149 & 88 \\
$1850-1874$ & 100 & 85 & 150 & 101 \\
$1875-1899$ & 142 & 88 & & \\
\hline
\end{tabular}

Notes: This table shows the developments in the housing quality index for each of the cities we study. The Belgian index is based on a population-weighted average of the quality index for the 4 Belgian cities. Bruges is excluded for the $19^{\text {th }}$ century because its sample is insufficiently representative.

The early cross-city improvement in housing quality may be surprising at first. One explanation may be an increase in the available housing space per capita. For Paris, where we report the largest improvements in housing quality, Hillairet (2004) estimates that the population density of the city reduced from 640 people per hectare in the late $14^{\text {th }}$ century to just 180 people per hectare in 1789 , suggesting that more housing space became available per capita. In a more qualitative account, PardailhéGalabrun (1991) describes how Parisian dwellings became much less crowded during the early-modern period. For Amsterdam, the expansion of the city during its Golden 
Age led to the construction of its famous circular canals and the large mansions along these.

Second, construction quality of homes gradually improved during the $16^{\text {th }}$ and $17^{\text {th }}$ century, as wooden and clay homes were gradually replaced by stone homes, and roofs were constructed using tiles rather than thatch. Van Ryssel (1967) documented that during the $17^{\text {th }}$ century an increasing number of homes had a more fire-resistant stone façade. The change from thatch to tiles already took place in the $15^{\text {th }}$ and $16^{\text {th }}$ century. Baer (2014) also reports significant improvements in the construction quality of homes in $17^{\text {th }}$ century London, and concludes that housing quality improved consistently and for all income groups. ${ }^{4}$ Beyond these changes on the outside of homes, De Vries (2008) describes a shift in the organization of the interior of homes, with functional spaces becoming much clearer defined: separate bed chambers appeared, as well as drawing- and dining rooms, even in middle-class homes. ${ }^{5}$

A potential concern is that the quality indices discussed so far only measure the increases in housing quality per home. In case families became larger, or more people started sharing or sub-letting their homes, our quality indices are not an accurate measure of housing quality per capita, which is most relevant when discussing the evolution of the standard of living. Such concerns are relevant: Adam Smith explains the relative affordability of London housing as the result of mass-scale sub-letting of parts of dwelling homes (Smith, 1776). Smith's observation suggests that the number of people per house may have varied substantially across cities (and potentially over time). To address these concerns, we need to look at housing space per capita.

For a limited set of years, the rental database of Eichholtz et al. (2020b) provides information on the entire cross-section of rental values in Amsterdam and the four Belgian cities. For Paris, statistics from Duon (1946) and Lyon-Caen (2018) provide information on the total rental value of all properties. If we scale the total rental value of all properties in a city by the number of inhabitants, we can estimate the mean rent per inhabitant. Next, we can compute the quality index on the basis of mean rents per capita, rather than mean rents per property. Appendix Table 3.6 reports the resulting quality index per capita, and its findings are in line with the estimates in Table 3.2.

We cannot extend our housing quality index into the $20^{\text {th }}$ century, due to lack of primary data. To shed light on housing quality in the more recent era, however, we have collected census data for all cities in the sample. Given the societal importance

\footnotetext{
${ }^{4}$ Note that the quality index of Clark does not report quality improvements in the $17^{\text {th }}$ century but in the $18^{\text {th }}$ century. This might be because this development was specific to London, or due to the low number of observations in Clark's sample in the $17^{\text {th }}$ century.

${ }^{5}$ Our finding of improved average housing quality in the pre-industrial era might be indicative of an improvement in the general standard of living, supporting the views of De Vries (2008) and Broadberry et al. (2015). Absent increases in affordability and real day wages, one possibility is that citizens increased their consumption by working more. Such an expansion is debated, but there is increasing evidence that changes in day wages may underestimate developments in annual pre-industrial income. Another possibility is that these quality improvements were primarily enjoyed by wealthier citizens that benefited from urban growth, such as successful merchants. We have very limited information on the evolution of their incomes, but existing evidence suggests that pre-industrial urban growth led to larger inequality in housing consumption (Ryckbosch, 2016).
} 
of housing conditions, censuses have included variables on the number of persons per house, as well as the number of rooms per person. Although the definition of what constitutes a room varies across censuses, the number of rooms per capita should give us a reasonable idea of the development of housing space per capita - a key quality attribute. Figure 3.3 reports the level of rooms per capita in each of the studied cities, where we have used a population-weighted average of the Belgian cities. In all cities, the number of rooms per capita has increased. If the size of the average room increased as well, these data sources might even underestimate the change in housing space per capita. The only city for which we have the data to investigate this is Amsterdam, and we find that the growth in the number of square meters of housing space per capita, available since 1982, has been more than twice as high as the increase in in the number of rooms per capita. However, even without controlling for

Figure 3.3: Space per Capita in the $19^{\text {th }}-21^{\text {st }}$ Century

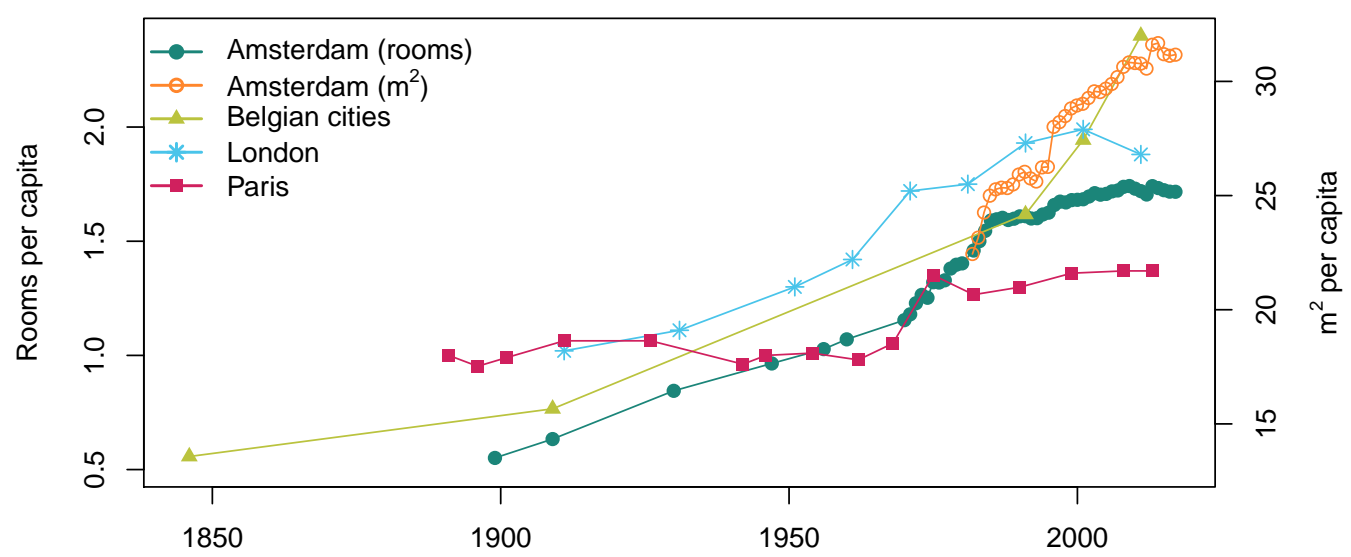

Notes: This figure shows the development in space per capita for each city, again aggregating the Belgian cities. Sources: London: Mayor of London (2017), Paris: INSEE, Amsterdam: Statistics Netherlands (2018); Gemeente Amsterdam (2018), Belgian cities: Census data provided by StatBEL.

room size, the increase in rooms per capita is notable. The growth is particularly large in Belgium. Relative to 1846, the average person has almost five times more rooms available nowadays. In Paris, the increase is smallest, but even there the number of rooms per capita has increased by approximately fifty percent. The relative ranking of the improvements in rooms per capita across cities is consistent with the affordability indices: affordability improved most in Belgium, followed by Amsterdam and London, with Paris reporting the smallest affordability improvements.

Beyond increases in the quantity of housing space, the quality of a given amount of space increased also significantly over the $20^{\text {th }}$ century. The sources of census data used in Figure 3.3 also provide information on such quality improvements, although primarily for the second part of the $20^{\text {th }}$ century. Nevertheless, large quality increases are visible even in this relatively short time period. For example, around fifty years ago proper sanitary facilities were still not the norm. In 1944, only 16 percent of Parisian households had a bathroom in their home, and about 46 percent had a proper toilet 
(at end of the $19^{\text {th }}$ century, this was just 25 percent). By 1999, toilets and bathrooms were present in over 90 percent of homes. In the Netherlands, toilets were already found in 86 percent of homes in 1956, although private bathrooms were only available for a quarter of the population. By 2001, both figures had reached 100 percent. In the Belgian cities, practically all homes contained a toilet and bathroom in 2001, but toilets (60 percent) and bathrooms (50 percent) were not standard even as late as 1970 , the first year in which the census asked about these conditions.

Similar improvements can be reported for the prevalence of central heating. At the end of World War I, central heating was only present in a quarter of Parisian homes, and this increased towards 50 percent around 1970. Similar values were recorded for urban homes in Belgium. The Netherlands lagged very much behind: by 1964, only 9 percent of homes were connected to a central heating system. Nowadays, that is over 90 percent. Beyond central heating, toilets and bathrooms, the $20^{\text {th }}$ century also saw a rise in the number of homes with piped water and electricity, although these facilities had already reached a large number of homes in the $19^{\text {th }}$ century: in 1891 , 85 percent of Parisian households already had private access to water. More recently, better insulation of walls and windows has likely contributed to better housing quality by improving indoor climate and comfort. The improvements in space per capita and in amenities suggest housing quality has indeed continued to expand significantly during the $20^{\text {th }}$ century, in line with improvements in affordability.

Housing has not only become more affordable and of higher quality, but the housing market has also become more equal over the last century. For Amsterdam, Antwerp, Bruges and Ghent, we can estimate Gini coefficients on housing inequality for the years for which the complete distribution of housing rental values is available - either based on actual rents or on rental value estimates of owner-occupied homes. For three Belgian cities, 4-5 full crossections shed light on the period from 1500 to 1890 . The Amsterdam data extends to the present (see the appendix of Eichholtz et al. (2020b) for a discussion of the sources used). Figure 3.4 reports the trend in estimated Gini coefficients.

Until the late $19^{\text {th }}$ century housing provisions were very unequal - and persistently so. Before 1900, we find Gini coefficients between 0.4 and 0.65 , which are in line with the higher levels in income and housing inequality found by Milanovic et al. (2010) and Ryckbosch (2016). Apparently, relatively few households benefited from the improvements in housing quality in this period. However, during the $20^{\text {th }}$ century inequality reduced, at least in Amsterdam, to much lower levels. The great compression in housing inequality we document for post-1900 Amsterdam is in line with the findings of Piketty (2014) for the income distribution and the earlier found city-wide increases in housing quality and affordability. Housing inequality has increased again since the 1980 's, which coincides with the halt in affordability improvements.

\subsubsection{Urban Change in Unregulated Housing Markets}

The tightening of affordability and the increasing inequality gap observed over the most recent decades fuels worries about the future of cities, despite all the gains made 
Figure 3.4: Housing Inequality Estimates, 1500-2018

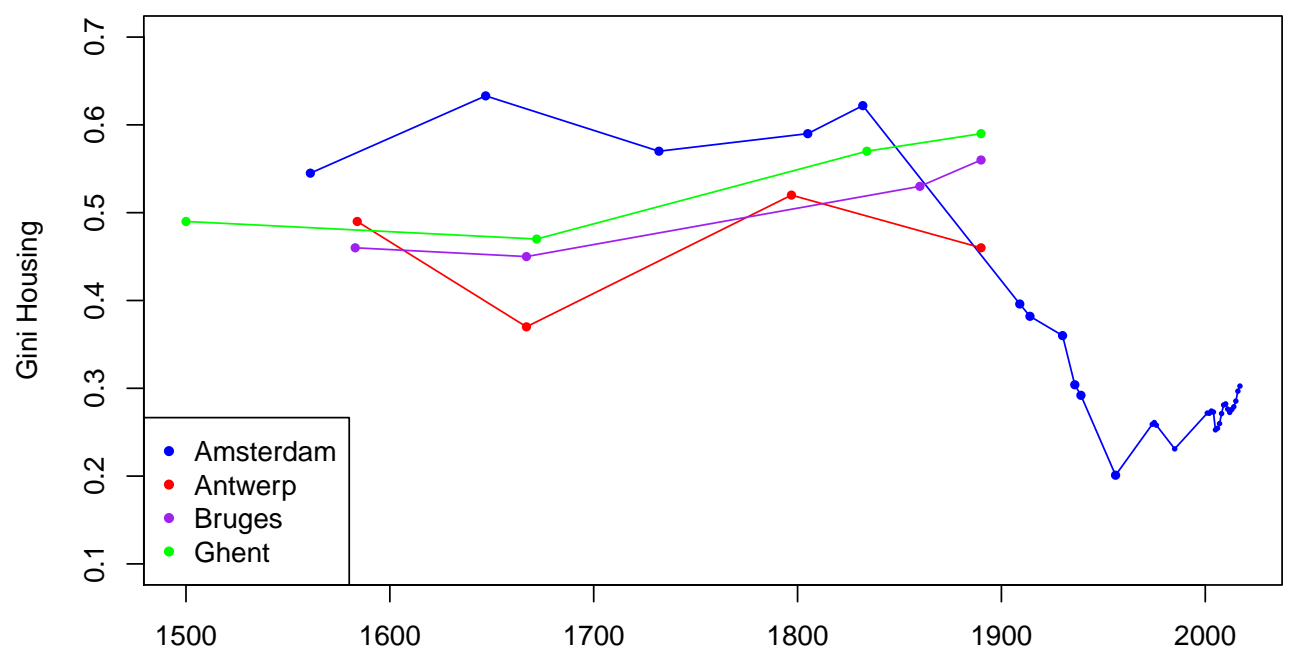

Notes: This figure reports the estimate Gini coefficients on housing inequality for Amsterdam, Antwerp, Bruges and Ghent. Data sources are provided in Appendix 3.B.

on these issues in the preceding century. Florida (2017), for instance, raises the alarm about a "new urban crisis", painting a bleak picture in which a city's success depresses housing affordability, increases inequality and ultimately erodes the economic basis on which it depends. However, the recent worsening of affordability might also be partially attributable to inappropriate housing policy, for example through zoning laws (e.g. Glaeser and Gyourko, 2018).

Our exceptionally long affordability and housing quality time series, in combination with data on long-term population growth, allow us to test whether urban prosperity indeed causes these detrimental side effects over the long-term, in an environment devoid of government interference. To do so, we restrict our sample to the period from 1500 until 1913, when rent control and other forms of government interference in the housing markets took off. Thus, our estimates aim to identify the long-term impact of population dynamics on housing affordability, housing quality and inequality, in free markets. ${ }^{6}$

We separate periods of long-term population growth with periods of decline because these have very different implications on the housing market, as Glaeser and Gyourko (2005) showed for US house prices, and Eichholtz et al. (2020b) also found for rent prices in the cities we study. However, when cities grow, expansion of the housing stock will change more than just prices: it might both change the distribution of rental prices and the distribution of housing quality. For the recent US house price boom, Glaeser et al. (2012) and Guerrieri et al. (2013) document that prices in cheaper neighborhoods appreciated faster than those in more expensive neighbor-

\footnotetext{
${ }^{6}$ This extends the analysis for housing rents in Eichholtz et al. (2020b), presented in the previous chapter
} 
hoods. When cities decline in population, housing supply does not adjust, and remaining residents will be distributed across existing properties. For this reason, house prices respond stronger to urban decline than urban growth (Glaeser and Gyourko, 2005).

The existing studies focus on recent developments in urban US house prices. Our analysis instead looks at rental affordability over a much longer horizon, and also studies changes in the quality and inequality of housing. Analysing inequalities in rents is arguably more relevant than inequalities in house prices, as renting is more common in most (European) cities than owning, especially among the poor. Additionally, the economic history literature has widely employed urbanization as a proxy for economic growth. In line with this, we aim to assess whether urban population growth also translated into growing housing consumption, here defined as increasing quality of the average dwelling.

We estimate a set of panel regressions of the following form, for each city $i$ at time $t$ :

$$
\Delta_{25} y_{i t}=\mu_{i}+\beta_{1} \Delta_{25}^{+} \text {pop }_{i t}+\beta_{2} \Delta_{25}^{-} p o p_{i t}+\gamma_{n} x_{i t}+\varepsilon_{i t}
$$

The 25-year changes in $y_{i t}$ correspond to the various dependent variables of interest for each regression: housing affordability, housing quality, and housing inequality. We study inequality in rental price growth across segments, and inequality in housing consumption. The vector $x_{i t}$ contains controls, and $\mu_{i}$ is a city fixed effect. We use 25year changes for several reasons. First, a low frequency of observations reduces noise and enables us to measure changes in population and housing quality sufficiently precise. Second, 25-year changes leave sufficient time for the housing stock, and corresponding rental price, to adjust to increasing demand. Although we focus on 25-year differences, we do not want to note that we obtain comparable results for all horizons between 10 and 50 years.

We estimate the models using overlapping differences. For the regressions, we use data from all time periods before 1913, given the limited intervention of government in the housing market before 1913. To account for the serial correlation introduced by the overlapping observations, and the potential spatial auto-correlation across cities, we use standard errors based on Driscoll and Kraay (1998). For the regressions that make use of data on inferred housing quality, we exclude periods where our sample is likely not representative for the aggregate housing stock or where we have no data (see Eichholtz et al. (2020b) for more detail). This implies that next to London, we have excluded Amsterdam after 1800, Paris after 1790 and Bruges after 1795.

Table 3.3 reports the outputs of the regressions that relate changes in affordability, quality and inequality to urban growth and decline. First, we find that housing affordability barely worsens when populations grow (Column 1). The estimated coefficient of -0.188 is small and statistically insignificant. Population decline, however, leads to rents falling faster than wages: a one percent decline in population increases the difference between wages and rents by 1.10. This result is in line with the estimates reported in Eichholtz et al. (2020b) for rents only. 
Table 3.3: Housing Quality, Inequality and Urban Growth, 1500-1913

\begin{tabular}{|c|c|c|c|c|c|}
\hline & \multicolumn{5}{|c|}{ Dependent variable: } \\
\hline & \multirow{2}{*}{$\begin{array}{c}\Delta_{25}\left(w_{t}-r_{t}\right) \\
(1)\end{array}$} & \multicolumn{2}{|c|}{$\Delta_{25} q_{t}$} & \multirow{2}{*}{$\begin{array}{c}\Delta_{25}\left(r_{t}^{h}-r_{t}^{l}\right) \\
(4)\end{array}$} & \multirow{2}{*}{$\Delta_{25}\left(q_{t}^{h}-q_{t}^{l}\right)$} \\
\hline & & (2) & (3) & & \\
\hline$\Delta_{25}^{+} p o p_{t}$ & $\begin{array}{l}-0.188 \\
(0.150)\end{array}$ & $\begin{array}{c}0.359^{* * *} \\
(0.059)\end{array}$ & $\begin{array}{c}0.401^{* * *} \\
(0.065)\end{array}$ & $\begin{array}{c}-0.214^{* * *} \\
(0.061)\end{array}$ & $\begin{array}{c}0.247^{* *} \\
(0.101)\end{array}$ \\
\hline$\Delta_{25}^{+} p o p_{t}$ & $\begin{array}{c}-1.108^{* * *} \\
(0.162)\end{array}$ & $\begin{array}{c}-0.214^{* *} \\
(0.092)\end{array}$ & $\begin{array}{l}-0.042 \\
(0.082)\end{array}$ & $\begin{array}{l}0.092^{*} \\
(0.054)\end{array}$ & $\begin{array}{l}-0.092 \\
(0.123)\end{array}$ \\
\hline$\Delta_{25} w_{t}^{r}$ & & & $\begin{array}{c}0.149 * * \\
(0.072)\end{array}$ & $\begin{array}{c}-0.076^{* * *} \\
(0.028)\end{array}$ & $\begin{array}{c}0.031 \\
(0.071)\end{array}$ \\
\hline$\Delta_{25} r_{t}^{r}$ & & & $\begin{array}{c}-0.155^{* * *} \\
(0.058)\end{array}$ & & $\begin{array}{l}-0.037 \\
(0.055)\end{array}$ \\
\hline$\Delta_{25} p_{t}$ & $\begin{array}{c}0.051 \\
(0.096) \\
\end{array}$ & & & & \\
\hline Fixed effects & Yes & Yes & Yes & Yes & Yes \\
\hline Observations & 2,632 & 1,931 & 1,931 & 1,931 & 1,931 \\
\hline $\mathrm{R}^{2}$ & 0.285 & 0.087 & 0.127 & 0.082 & 0.022 \\
\hline Adjusted $\mathrm{R}^{2}$ & 0.283 & 0.084 & 0.123 & 0.079 & 0.017 \\
\hline F Statistic & 348.465 & 91.625 & 69.816 & 57.492 & 10.726 \\
\hline
\end{tabular}

Notes: This table reports regression estimates of Equation 3.5, where we regress different dependent variables on 25-year changes in population, separating growth $\left(\Delta_{25}^{+} p o p_{t}\right)$ and decline periods $\left(\Delta_{25}^{+} p o p_{t}\right)$. In Column 1, we use 25-year changes in affordability as dependent variable. Columns 2 and 3 use quality changes as dependent variable, controlling for real wages and real rents (Column 2) or only for changes in real wages (Column 3). In Column 4, we use the difference in rental price appreciation between abovemedian and below-median housing as dependent variable. Column 5 uses the difference in quality for high-quality and low-quality housing as dependent variable. This is defined as the change in the interquartile range of house rental values in our samples, deflated for market prices. All regressions use city fixed effects, and standard errors are based on Driscoll and Kraay (1998), with maximum lag length of 30 years. ${ }^{*} \mathrm{p}<0.1 ;{ }^{* *} \mathrm{p}<0.05 ;{ }^{* * *} \mathrm{p}<0.01$ 
Column 2 reports the impact of population growth and decline on housing quality. Indeed, when urban populations grow and the housing stock expands, we observe that the quality of the housing stock increases. For a one percent increase in population, the quality of the rental housing stock goes up by 0.36 percent. Conversely, in times of population decline, decreases in population actually correlate with increasing housing consumption. When urban populations fall, rental prices reduce substantially, as the housing stock cannot adjust. This implies that the existing housing stock will be distributed among fewer people, and that there will be more housing space per capita available. In line with this, the positive effect of urban decline on housing consumption disappears after we control for changes in real rent prices and wages, which we do in Column 3. It is important to realize that our sample only covers properties that are leased and maintained: vacant properties might of course gradually depreciate.

Average housing quality statistics do not reveal how quality gains are distributed across neighborhoods and market segments. Columns 4 and 5 of Table 3.3 present estimated coefficients for population dynamics on inequality. In Column 4, we estimate whether rental prices of properties below and above the median appreciate at different rates when cities grow or decline. The coefficient for $\Delta_{25}^{+} p o p_{t}$ is negative $(-0.214)$ and statistically significant. This implies that rents for the less affluent are rising faster than rents for the well-off when cities are growing, suggesting stratified residential markets. One reason for this fact could be the presence of endogenous gentrification when cities are growing (Guerrieri et al., 2013). There is limited evidence for a reversal of this price inequality when cities are declining in population: the gap shrinks slightly when population declines, but this effect is only significant at the 10 percent level. This might be due to limited statistical power, because most cities have grown rather than declined over time.

Our cross-sectional estimates of housing inequality in the previous section did not allow to account for changes in rent prices across segments. In Column 5, we investigate whether differing rates of price appreciation across segments also lead to increases in inequality in housing consumption. To construct our dependent variable, we computed for each city 25-year changes in the log interquartile range of rent prices, and substracted the price difference between above and below median properties (which we used in Column 3). ${ }^{7}$ Thus, our dependent variable measures the change in the difference in housing quality between the $25^{\text {th }}$ and $75^{\text {th }}$ percentile. Indeed, column 5 shows that when cities grow, housing quality above the median grows faster than housing quality below the median. This suggests that in free markets and over the long term, housing inequality grows when cities expand in population.

\subsubsection{Regulated Markets}

Until about 1900, housing markets operated without much intervention from governments. This changed drastically in the $20^{\text {th }}$ century, as governments became increasingly concerned with housing quality, inequality and affordability. One major change was the introduction of rent controls after the World Wars. Given that the two big

\footnotetext{
${ }^{7}$ We used 3-year moving averages for Paris
} 
jumps in affordability we observe in Figure 3.2 exactly coincide with the introduction of rent control in the cities we investigate (during and after World War I and right after World War II), it is tempting to infer the two were related. But establishing any causal effect of these rent controls on affordability remains difficult. First, once introduced, rent control did not change often if at all, providing for very few observations of policy changes. Second, rent control measures tended to be accompanied by complementary policies to subsidize housing construction. Third, at their heyday, rent controls were applied to all properties, providing no useful control group.

To measure their effects on affordability, we exploit that changes in inflation rates across countries provides variation in the tightness of nominal rent controls that is plausibly exogenous to local housing markets. Most early rent controls were stated in nominal terms, either as outright rent freezes or as a fixed limit on the rate of rent price increases (Arnott, 1995). In case of substantial inflation, rent prices would be unable to adjust with inflation, while wages remained unrestricted. Thus, the higher inflation, the tighter the nominal rent control, and the larger its potential benefit on affordability.

The identification of such an effect relies on two crucial assumptions. First, inflation rates should only affect the tightness of the rent control, and have no other effects on housing affordability, either directly or indirectly. This implies that inflation rates should have no correlation with changes in affordability in the absence of rent controls. Second, our measure of rent controls should only capture periods of strict nominal controls, and not anything else. To identify these, we have studied rental regulations in each of the four countries, and constructed a dummy variable for the presence of strict nominal rent controls that applied to all rental contracts on existing housing. Appendix3.D provides more information on the construction of this variable. As a secondary measure, we use the regulation index of Kholodilin (2018), which contains a measure for the presence of nominal rent controls. This measure is broader than ours: it for example also covers periods when only subsets of properties are controlled.

In our baseline model, we estimate the following panel regression, for each city $i$ at time period $t$.

$$
\begin{array}{r}
\Delta\left(w_{i t}-r_{i t}\right)=\mu_{i}+\beta_{1} \text { RentControl }_{i t}+\beta_{2} \operatorname{RentControl}_{i t} \times \Delta p_{i t} \\
+\beta_{3} \Delta p_{i t}+\gamma_{x} x_{i t}+\varepsilon_{i t}
\end{array}
$$

We estimate this regression for Amsterdam, London, Paris and the combined Belgian cities, including city fixed effects. $\Delta p_{i t}$ refers to changes in inflation, and $x_{i t}$ are

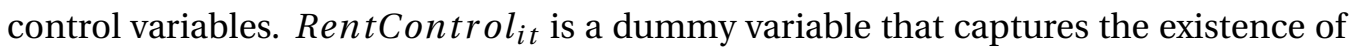
nominal price controls. Standard errors are Driscoll-Kraay errors, with lag length selected by the Bayesian Information Criterion.

The results reported in Table 3.4 show that the existence of nominal rent control itself is unrelated to improvements in affordability. However, the extent to which these controls are binding matters: We expect that higher inflation rates will render the nominal rent controls more binding, resulting in larger affordability gains. This is 
exactly what we find: inflation in the absence of rent control does not affect affordability, but when we look at the interaction term of inflation and the nominal rent control dummy, which measures inflation when nominal rent control is present, a one percent increase in inflation increases rental housing affordability by 0.6 percent. This finding is robust to the use of the measure of rent controls from Kholodilin (2018).

Table 3.4: Nominal Rent Control and Affordability

\begin{tabular}{|c|c|c|c|c|}
\hline & \multicolumn{4}{|c|}{ Dependent variable: } \\
\hline & \multicolumn{4}{|c|}{$\Delta\left(w_{t}-r_{t}\right)$} \\
\hline & (1) & (2) & (3) & (4) \\
\hline \multirow[t]{2}{*}{ RentControl $_{i t}$} & -0.001 & -0.009 & -0.005 & -0.015 \\
\hline & $(0.014)$ & $(0.007)$ & $(0.014)$ & $(0.014)$ \\
\hline \multirow[t]{2}{*}{$\Delta p_{i t} *$ RentControl ${ }_{i t}$} & $0.609^{* * *}$ & $0.455^{* * *}$ & $0.618^{* * *}$ & $0.845^{*}$ \\
\hline & $(0.080)$ & $(0.156)$ & $(0.078)$ & $(0.458)$ \\
\hline \multirow{2}{*}{$\Delta p_{i t}$} & 0.033 & $0.041^{*}$ & 0.023 & -0.050 \\
\hline & $(0.027)$ & $(0.023)$ & $(0.027)$ & $(0.434)$ \\
\hline \multirow[t]{2}{*}{$\Delta p o p_{i t}$} & & & $-0.634^{* * *}$ & -0.416 \\
\hline & & & $(0.143)$ & $(0.550)$ \\
\hline \multirow[t]{2}{*}{ Constr $_{i t}$} & & & & -0.002 \\
\hline & & & & $(0.004)$ \\
\hline Fixed effects & Yes & Yes & Yes & Yes \\
\hline Observations & 2,010 & 2,010 & 1,959 & 382 \\
\hline $\mathrm{R}^{2}$ & 0.105 & 0.072 & 0.137 & 0.193 \\
\hline Adjusted $\mathrm{R}^{2}$ & 0.102 & 0.069 & 0.134 & 0.178 \\
\hline F Statistic & 77.986 & 51.622 & 77.400 & 17.862 \\
\hline
\end{tabular}

Notes: This table reports regression estimates of Equation 3.6, where we regress changes in rental housing affordability, measured by the indexed ratio between wages and rents, on a rent control index interacted by inflation. Columns 1, 3 and 4 use our measure of periods of strict nominal rent controls, Column 2 uses the measure of Kholodilin (2018) that also includes periods with second generation rent controls. Column 3 additionally controls for population changes, Column 4 also controls for housing construction. All regressions use city fixed effects, and standard errors are based on Driscoll and Kraay (1998). ${ }^{*} \mathrm{p}<0.1$; ${ }^{* *} \mathrm{p}<0.05 ;{ }^{* * *} \mathrm{p}<0.01$.

We further control for changes in population. Note that our estimates of population changes contain some measurement error until the $19^{\text {th }}$ century, when most population estimates are interpolated. Nevertheless, the estimate on population has the predicted sign and significance. We do not estimate the coefficient separately for urban growth and decline, because the possibility for supply adjustment is very small at an annual level. For a small subset of data, we have also collected information on construction rates (see Appendix 3.D.1). This variable follows the number of newly built properties relative to total population. We normalized this variable for each city, 
to account for differences in the definition of construction. After controlling for new construction, the interaction term is less significant due to the large reduction in the number of observations, but the economic significance remains roughly the same.

To sum up, nominal rent control seems to have played some role in the rapid improvement in urban rental housing affordability we observe in the $20^{\text {th }}$ century. However, it is important to note that the effect we find is of a short-term nature, as it involves annual changes in inflation and the real economic value in the rent control. The longer-term effect that rent control likely has on new supply is left out of our analysis: we do not have detailed information on construction, and many governments heavily subsidized construction during periods of rent controls.

\subsection{Conclusion}

This paper traces the trajectories of urban rental housing affordability, housing quality, and inequality in seven European cities from 1500 to the present. For the first 300 years, real rents did not grow significantly in most cities. However, the average quality of housing units gradually improved in time. This increase in quality was not uniformly distributed across all housing segments, and housing inequality increased when cities expanded. During the $19^{\text {th }}$ century, real rents started to increase significantly, however not exceeding the growth rates of real wages. Initially, these increases in housing costs seemed to hamper further increases in housing quality, but from the late $19^{\text {th }}$ century onward housing quality started improving again.

Importantly, governments did not interfere in rental markets for the first four centuries studied here. The interplay of market forces stabilized long-term real rent levels relative to wages: real rents increased when cities were growing, but improvements in wages appear to have compensated for these. Instead, the main negative consequence of urban growth over the long term is an increase in housing inequality. Part of this increase is attributable to differences in rent price increases across cheaper and more expensive segments. More research is needed to also investigate the spatial implications of this.

When wages started to outpace growth in rents during the first 75 years of the $20^{\text {th }}$ century, possibly with the support of intervening governments, households could expand their housing consumption (and expenditure shares on housing) even further to the high levels currently observed, while housing inequality fell. Rent control does seem to have played a role in short-run affordability improvements. More empirical work is still needed on the long-run effects, though. More recently, housing affordability seems to have worsened slightly, particularly in London and Paris. Nevertheless, in all cities we study rental housing has been much more affordable during the past few decades than it has been at any time before.

This paper shows that in order to estimate housing affordability it is essential to look at income, quality-controlled market rent indices and measures of housing quality and inequality simultaneously. Excluding any of these components can result in an incomplete picture of housing affordability. However, even in the modern era quality- 
controlled rent indices are barely available (Ambrose et al., 2015), and data on developments in housing quality and inequality are even harder to find. We hope our findings will stimulate researchers or statistical offices to also produce such estimates for the $21^{\text {st }}$ century.

The relevance of this study goes beyond housing affordability. For economic historians, we provide important new evidence on the way the household budget was spent on housing, and our rent indices and estimates of housing quality shine new light on the historical standards of living: housing quality seems to have improved very significantly prior to the $19^{\text {th }}$ century. 


\section{A Wages}

\section{A.1 Data Sources}

An overview of all sources of wages data is presented in table 3.5.

Table 3.5: Overview Wage Sources

\begin{tabular}{lllll}
\hline City/country & Study & Years & Coverage & Type \\
\hline \multirow{2}{*}{ Belgium } & Peeters (1939) & $1831-1913$ & National & Index \\
& Scholliers (1978) & $1914-1919$ & City & Index \\
& Cassiers and Solar (1990) & $1913-1959$ & National & Index \\
& FOD-WASO (2018) & $1959-2018$ & National & Index \\
Bruges & Verlinden (1972) & $1500-1628$ & City & Raw wages \\
Ghent & Verlinden (1972) & $1500-1800$ & City & Raw wages \\
Antwerp & Van der Wee (1963) & $1500-1605$ & City & Raw wages \\
& Verlinden (1972) & $1606-1834$ & City & Raw wages \\
Amsterdam & De Vries and Van der Woude (1997) & $1500-1815$ & Regional & Index \\
& Horlings and Smits (1996) & $1816-1913$ & National & Index \\
& Schrage et al. (1989) & $1913-1939$ & National & Index \\
& Statistics Netherlands (2018) & $1939-2018$ & National & Index \\
Paris & Ridolfi (2019) & $1500-1870$ & City & Index \\
& Singer-Kérel (1961) & $1870-1946$ & City & Index \\
& Bayet (1997) & $1913-1951$ & National & Index \\
& INSEE (2018) & $1951-2018$ & National & Index \\
\multirow{3}{*}{ London } & Allen (2001) & $1500-1913$ & City & Index \\
& Thomas and Dimsdale (2017) & $1914-2016$ & National & Index \\
& Office for National Statistics (2018) & $2016-2018$ & National & Index \\
\hline
\end{tabular}

Observations on daily wages of masons, carpenters, slaters and their helpers are obtained for Bruges (1500-1628), Ghent (1500-1799) and Antwerpen (1500-1840) from the Verlinden (1972) series. These are converted to a total index based on the methodology discussed in section D2. The study of Peeters (1939) provides us with an aggregate index of hourly wages in various Belgian industries from 1831-1913. For later periods we rely on a multitude of publications on industrial wages. Scholliers (1978) provides estimates for Brussels wages during World War I. Cassiers and Solar (1990) produce an index of gross hourly wages for the 1913-1959 period. From 1960 onward, we use the average hourly wage increases for all employees (the Belgian government makes a division between 'laborers' and 'service workers') from the official estimates of FOD-WASO (2018), the Belgian ministry of labor.

For Amsterdam, we use day wages in the construction sector from 1500 to 1815, which we have from De Vries and Van der Woude (1997). Wages from 1815 to 1913 are based on nominal day wages reported in the study of Horlings and Smits (1996). Wage data for the period from 1913-1939 from Schrage et al. (1989), and refer to average day wages across sectors. From 1939 onward, we rely on the average wage increases from collective labour agreements, which cover most of the Dutch labor force. Given that this figure has not yet been updated to 2018, we use the Statistics Netherlands (2018) 
index on hourly cost of labour to extend to the present.

The wage index for Paris for the period 1500-1860 is based upon average day wages of laborers and craftsmen, from the indices reported in Ridolfi (2019). Between 1860 and 1920, we use the weekly wage index for Parisian workers from Singer-Kérel (1961). To correct for changes in the length of the working week, which were particularly prevalent in the early $20^{\text {th }}$ century, we used national figures on nominal hourly wages reported in Bayet (1997) from 1914 to 1951. To fill the gaps in the war years, we still made use of the index of Singer-Kérel (1961). From 1950, we use INSEE (2018) indices on hourly pre-tax wage rates. Since these are not available for 2016-2018, we employ an INSEE index on hourly cost of labor in the construction for the period 2015-2018.

For London between 1500 and 1913, we use the standard day wage index from Allen (2001). From 1913 until 2016, we use a national index of weekly earnings derived from Thomas and Dimsdale (2017) and Office for National Statistics (2018). Since this does not control for changes in the number of hours worked per week, which likely declined, London wages probably slightly underestimate wage growth. This is confirmed by the fact that the London index increases the least of all cities during the $20^{\text {th }}$ century.

\section{A.2 Index Construction}

Wage indices for the Belgian cities are created based on thousands of day wage observations from construction sector workers (1500-1830). No wage index is constructed for Brussels, given the lack of wage data. The wage index for Bruges only spans the period from 1500 to 1628; after 1628 Ghent wages are used for Bruges. An aggregate wage index for Belgium is constructed as well, based on wage data from all cities. Note that for Antwerp, our index is almost entirely the same as Allen (2001), who used the same sources to construct his index.

Wage data come from wage lists published in the Verlinden series; one for every job in every institution, containing the years in which workers were employed, the various salaries that were paid and the number of days a certain salary was paid. In most cases, wages of 'masters' are separated from the wages of 'helpers'. We have excluded observations that make note of special circumstances, such as risky jobs, the provision of beer money or the aggregation of helpers' and masters' salaries. Other large outliers have been removed as well, since these are likely the result of special provisions not identified in the records.

Annual averages of wages are computed based on the remaining observations. Contrary to the consumer price indices, we have interpolated average wages for years where data is missing. This can be justified since the level of wages is extremely stable: contracts show that sometimes workers were paid the same wages for as much as 60 years. Persistent increases in nominal wages occur in every city only in the second half of the $16^{\text {th }}$ century. After interpolating, wages are indexed for each job and subsequently averaged across all jobs to construct the total wage index. 


\section{B Inequality Data}

To estimate the level of housing inequality within a city requires data on the distribution of housing rental values at the household level. The distribution of these values reflects both differences in the value of the actual quality of the house, as well as differences in its location. Such distributions also exist for the early parts of our sample because property taxes were the most common form of taxation. To estimate taxes, cities computed the rental value of properties based on actual rent prices or an estimation of rental value when a home was owner-occupied. Existing studies have used these measures as a proxy for income inequality (e.g Soltow and Van Zanden, 1998; Milanovic et al., 2010; Ryckbosch, 2016).

Until the $19^{\text {th }}$ century, we use the Gini-coefficient of housing inequality for Bruges, Ghent and Antwerp from Ryckbosch (2016). For Amsterdam, we combine Gini-coefficients from Soltow and Van Zanden (1998) with Ginis computed from our own database of rental data. However, for 1647 and 1832 these measures are only available at the home level rather than the household level. Because there often lived multiple households in the same home, we have to transform these measures. To do so, we make the assumption that the ratio of home to household inequality was constant between 1647 and 1732. In that manner, we can use the 1732 ratio, based on Van Zanden (2018) and our archival data, to estimate the level in 1647 . We apply the same procedure to estimate inequality in 1832. In this year, we use the ratio based on data from 1805.

In the $20^{\text {th }}$ and $21^{\text {st }}$ century, we only compute housing inequality data for Amsterdam, since this was the only city for which we are able to find data that would enable us to extend our measure of inequality consistently until the $21^{\text {st }}$ century. For the period between 1909-1940, we use data on the rental prices or values of all properties in Amsterdam, available from Laloli (2018). Contrary to the older tax registers, all these measures are at the household level. One limitation is that owner-occupied housing has not been valued in all periods, which likely was of higher rental value than the average rental property. However, the impact of this on the rent distribution is small, because owner-occupancy rates were only $3-4 \%$ in the first part of the $20^{\text {th }}$ century.

For the second part of the $20^{\text {th }}$ century, we use data on rent prices or rental values from various publications of the Amsterdam Statistical Office, which we retrieved from the Amsterdam City Archives. ${ }^{8}$ Such rental censuses were taken in 1956, 1974-1976 and 1985. One limitation is that the presence of housing policies made rental prices and rental values an imperfect measure of housing quality. Thus, these measures are primarily a measure of housing expense inequality, which might differ slightly from actual housing inequality. We believe this limitation applies particularly to the distribution of rents in 1956. Amsterdam was still under strict rent controls in these periods, that likely had a compressing effect on the distribution of rental prices.

In the $21^{\text {th }}$ century, we use the Gini coefficient on the taxed value of all properties in Amsterdam ( WOZ-waarde), which was directly provided to us by Statistics Amsterdam, due to the confidentiality of the underlying microdata. For tax purposes, every

${ }^{8}$ ACA 30525, Collectie Kenniscentrum Amsterdam, nos. 2036, 2391 and 3733 
residential property in The Netherlands has been valued. The advantage of this measure is that it is computed in exactly the same way for owner-occupied housing, rental housing and social housing, despite the different (implied) rentals for these properties. Although such property taxes existed already in the $20^{\text {th }}$ century, their valuation has changed significantly over time. For this reason, Statistics Amsterdam only provided data between 2000-2018, when there were few changes in the tax valuation of properties. One limitation of these measures is that they do not include rentals or sub-rentals of rooms. However, less than 5\% of households rent a room, and Statistics Amsterdam estimated that they would have only a very small impact on inequality.

\section{C Income Shares on Housing}

To reconstruct expenditure shares on housing we searched both for historical data for the early $20^{\text {th }}$ as well as modern expenditure shares for the $21^{\text {st }}$ century. For Amsterdam, we used a study of Claeys (1921) on 23 households in Amsterdam that were surveyed just after World War I. Contemporary data was retrieved from Statistics Netherlands (2018). Surprisingly, we found the most reliable estimates of expenditure shares in urban Belgium in a publication of the Great Britain Board of Trade (1910), which reported shares for middle-income households in industrial towns. Contemporary data on expenditure shares, both for owner-occupiers and renters, was retrieved from the housing survey of Statistics Belgium (2018b). For Paris, we used historical estimates from Duon (1946), while contemporary data on Parisian rent shares was taken from ADIL (2009) and from INSEE (2018) for both owner-occupiers and renters. For London, the earliest estimates of expenditure shares we could find were published in Jones (1928), for a sample of 50 London families. Today, the Mayor of London (2017) publishes expenditure shares. For all modern data, household budget shares accounted for potential rent benefits.

\section{D Rent Control Index}

We use two different measures of rent controls for our analysis in the main part of the paper. First, we use the measure of nominal rent controls from Kholodilin (2018), which is one of the inputs in his total rent regulation index. This dummy takes the value of 1 if any form of nominal rent control is present in a given year. If rent regulation is only introduced or changed through the year, it uses the share of time the rent control was present. One disadvantage of the index of Kholodilin (2018) is that it does not allow to distinguish between first generation rent controls and more modern ones that are more flexible (e.g Arnott, 1995). A second disadvantage is that it is a national measure. For example, in The Netherlands rents were regulated at the local level rather than at national level. Only recently this system has been nationalized. We therefore also create a secondary rent control index that restricts the index of Kholodilin (2018) to the most stringent nominal rent controls, and also accounts for differences in rent controls across localities or housing classes. We motivate our index here. 
For The Netherlands, we use information from a report of the Dutch Rental Committee (Huurcommissie, 2017). Rent controls were introduced in 1917, and these freezed the level of rents on smaller homes at the level of 1916. In 1918, rents on more expensive properties were frozen as well. At the same time, municipalities could introduce rental committees that would judge whether landlords were allowed to raise the rent if maintenance costs for example increased. Rent controls were gradually relaxed from 1922 until they were fully liberalized on January 19, 1927. To account for this, our rent control index linearly decreases from 1 to 0 in this period.

Rents were frozen again on December 27, 1940 following the outbreak of World War II in 1940. Because rent laws were set at the national level, but differed across municipalities, we use information from rent regulation published in the Dutch Staatsblad, which published all applicable laws. Until January 1951, no changes on rents were allowed. Between 1951 and 1967, rent increases were strictly set by the government, and had to be adhered to. Rent increases were announced on average every two years. In this period, our rent control index takes the value of $2 / 3$. In some municipalities, rents were already liberalized by the 1960s, as rents had caught back up to their market level. Between 1968 and 1981, rent increases in Amsterdam were capped, but could be set freely below that cap. In this period, the rent control index takes the value of $1 / 3$.

In Belgium, interwar rent control laws are discussed in Bettendorf and Buyst (1997). They were introduced in 1919 following the housing shortages that had built up during World War I. Homes were frozen relative to the level of 1914. Rents were gradually decontrolled across housing classes between 1927 and 1929, so we linearly reduce the rent control dummy. After 1929, only properties with very low rentals were controlled by the market. To account for this, we keep the value of the rent control dummy at 0.1 until 1938, when also these properties were de-controlled. Rent control was reinstated in 1940 following the outbreak of World War II. Rent controls were abolished in 1957 except for subsidized housing (which is not in our sample), when we change the rent control index back to zero (Brown, 1970). There was some reimposition of rent controls in the 1960s and 1970s, but we do not incorporate these as rental information is missing from Belgium between 1961-1977.

In France, the rent control regime was most severe (see Bonneval, 2011). Rent controls were initially only applied in 1914 for those drafted for war, but applied to all properties from 1919. Rents were fixed by applying a coefficient relative to the rent level of 1914. The exact regulations varied across properties and rent levels, but the law remained firmly in place until 1948, when a new law was passed that ended this regime. It replaced the old system of rent controls, and only applied to certain dwellings. It deregulated rents on new dwellings, but also gave tenants the right to stay in old dwellings for low regulated rents. The share of dwellings covered by this law gradually declined from the 1948s onwards, although nowadays a very small set of properties is still under the 1948 law. However, because the 1948 ended strict rent controls on new contracts, we set our rent regulation index to zero after 1948.

In the United Kingdom, rent controls were introduced on December 23, 1915 to combat housing shortages caused by World War II. Rents were frozen relative to the 
level of 1914. The law was extended in 1920, and rents remained in full control until 1923. Between 1923 and 1933, the UK government gradually lifted rent controls, and our rent index therefore gradually and linearly declines in this period (Willis, 1950). Rent controls remained in place for cheap properties if the tenant did not change, but since our index only covers new contracts, rarely below this limit, we put the rent control index after 1933 at zero. Rents were frozen again in 1939, and strict nominal controls remained in place until 1957, when more valuable properties were decontrolled. Correspondingly, we set our index at 0.5. From 1965, strict controls were completely removed and replaced by regulated tenancies. The idea of rent regulation rather than rent controls was that rents would be set by the market, but that landlords and tenants could appeal to the government in case of disagreement about the 'fair' rental price (Wilson, 2017).

\section{D.1 Construction Estimates}

To control for the effect of construction, we compiled data on construction levels for our cities for the period of time where such controls played a likely important role. One difficulty in creating such measures is that there exist few consistent measures of construction both over time and across cities. To create a consistent measure across cities and over time, we therefore normalized values per city. If the definition of construction changed within a city, we normalize per construction measure using standard z-scores.

For Amsterdam, statistical yearbooks provide annual estimates on the number of completed residential buildings from 1870-2018 (Gemeente Amsterdam, 2018). To measure the rate of construction, we scale this number by the level of population in the city.

For the Belgian cities, we use data on the number of complete buildings (at the national level) from the annual yearbook of Belgian Statistics (Statistics Belgium, 2018a) from 1940 until 1961. We do not extend this measure after 1961, because our rent index is interpolated between 1961 and 1977. From 1920 to 1940, we use the number of constructed buildings published in Buyst (1992). Again, we normalize both measures after scaling them with the total level of Belgian population.

For Paris, we use data from Duon (1946) on the number of newly constructed housing units between 1870 and 1944. To estimate the number of housing units, we multiplied the number of homes constructed by the number of households per home. Between 1944 and 1967 we use data on completed construction from Mairie de Paris (1967a) for the Seine department, which contains the Greater Paris area. We scale both measures by population, and normalize them.

For London, we use data from Mayor of London (2017) that compiles annual data on completed construction between 1871 and $2017 \mathrm{f}$. We scale this by population, and normalize. 
Table 3.6: Housing Quality per Capita

\begin{tabular}{|c|c|c|c|c|c|c|}
\hline Year & Amsterdam & Bruges & Ghent & Antwerp & Brussels & Paris \\
\hline 1527 & & & & & & 26 \\
\hline 1561 & 66 & & & & & \\
\hline 1571 & & & 45 & & & \\
\hline 1584 & & 33 & & 45 & & \\
\hline 1632 & 50 & & & & & \\
\hline 1667 & & 57 & & 73 & & 45 \\
\hline 1695 & & & & & & 61 \\
\hline 1700 & & & & & & 76 \\
\hline 1713 & & & & & & 56 \\
\hline 1733 & 63 & & & & & \\
\hline 1755 & & & & & & 62 \\
\hline 1796 & & & & 82 & & \\
\hline 1787 & & & & & & 69 \\
\hline 1790 & & & & & & 84 \\
\hline 1805 & 79 & & & & & \\
\hline 1815 & 73 & & & & & \\
\hline 1819 & & & & & & 107 \\
\hline 1832 & 65 & & & & & \\
\hline 1834 & & & 67 & & & \\
\hline 1851 & & & & & & 84 \\
\hline 1865 & & 63 & 84 & 70 & 61 & \\
\hline 1878 & & & & & & 80 \\
\hline 1889 & & & & & & 89 \\
\hline 1890 & & 100 & 100 & 100 & 100 & \\
\hline 1900 & & & & & & 94 \\
\hline 1909 & 100 & & & & & \\
\hline 1911 & & & & & & 100 \\
\hline
\end{tabular}

Notes: This table shows the indexed developments in housing quality per capita, for years for which it can be computed. For the Belgian cities, the index is normalized at $1890=100$, for Amsterdam we use $1909=100$. For all cities, the developments in housing quality per capita are in line with those reported in Table 3.2 in the main paper. The main outlier in the table is Amsterdam in 1561, but it is likely that this number is biased upward, due to a significant underestimate of the total Amsterdam population. This estimate is based on Van Dillen (1929) estimated population by multiplying the number of homes by five, but in all 17th century fiscal records, the estimated number of persons per home is well above 10 , suggesting the 1561 quality per capita figure should be halved. 


\section{Chapter 4}

\section{The Total Return and Risk to Real Estate $^{*}$}

Housing is the world's largest asset class, but with some exceptions, it did not have much institutional investor interest in the decades before the Great Recession. Since then, however, housing markets all over the world have been booming, and so has investor interest. Both private and institutional investors are putting capital into rental housing (Bracke, 2019; Mills et al., 2019). No doubt, their interest has been spurred by the recent performance of housing markets, with high levels of house price growth observed across the globe in the past few decades (Knoll et al., 2017).

In a recent paper, Jordà et al. (2019a) aim to determine the total rate of return to housing and to compare it to the performance of stocks and bonds all over the world. Their results - based on secondary data sources - suggest that housing returns are surprisingly high given their risk. Indeed, in a follow-up paper, Jordà et al. (2019b) point out an unsolved risk premium puzzle for housing investments.

However, the housing returns data on which these papers are based suffers from a number of measurement problems, which has resulted in a debate regarding the question of whether the reported high returns to housing are real, or the result of mismeasurement (Chambers et al., 2020; Eisfeldt and Demers, 2018; Dimson et al., 2018). The main aim of our paper is to shed more light on this issue.

The crucial piece of information that is typically lacking in studies that aim to compute long-term housing returns and risk, both at the aggregate and the individual level, is an accurate assessment of the rental yield. Early papers aiming to assess the total return to housing used an imputed rent (Flavin and Yamashita, 2002) or based it on national accounts data (Piazzesi et al., 2007). More recently, the common approach to deal with this issue is to estimate it on the basis of actual house price and rental series, but these tend to pertain to different housing market segments (e.g. Brounen et al., 2014; Eisfeldt and Demers, 2018; Giglio et al., 2018; Jordà et al., 2019a). This issue goes beyond measuring housing returns themselves. Without data on actual yields,

${ }^{*}$ This chapter is co-authored with Piet Eichholtz (Maastricht University), Thies Lindenthal (University of Cambridge) and Ronan Tallec (University Paris II, Pantheon-Assas) 
the use of implied rent-price ratios or rental returns has been standard in much of the literature on housing markets (e.g. Himmelberg et al., 2005; Sinai and Souleles, 2005; Campbell et al., 2009; Ambrose et al., 2013; Sommer et al., 2013; Favilukis et al., 2017). Our paper overcomes this hiatus, and our first main contribution is to calculate total returns and risks to residential real estate at aggregate and individual property level by studying primary historic data on house prices and rents for the same homes, for two important housing markets: Paris and Amsterdam. We then compare these to existing measures based on implied returns from Jordà et al. (2019a), which cover these two cities for a similar time period.

The second main contribution of our paper lies in a better understanding of the idiosyncratic risk to housing investments. The property-level data in this paper provide a unique picture of the role of idiosyncratic risk - and of the role of the yield component of the return therein - over different holding periods. The risk and market return to housing investments are of limited relevance for investment performance, as many residential property investors hold highly concentrated portfolios, due to the indivisibility of assets, their capital intensity, and high transaction costs. ${ }^{2}$ For markets in which full diversification is unattainable, both theory (see for instance Levy, 1978; Merton, 1987) and empirical work (for example Fu, 2009; Eiling et al., 2019) suggest that idiosyncratic risk and expected returns are linked in the cross-section. Existing work has looked at idiosyncratic capital gains risk in residential properties (e.g. Merton, 1987; Peng and Thibodeau, 2017; Giacoletti, 2019; Eiling et al., 2019). However, this ignores yield risk resulting from changes in the rental values of properties. To the best of our knowledge, our paper is the first to study property-level changes in yields and the contribution of property yield risk to total idiosyncratic risk, and to do that over increasing investment horizons.

Given housing's important role in the economy and investment portfolios, it is important to establish the annual total return and risk to residential real estate in a way that avoids measurement problems as far as possible, using a dataset that is large and representative enough for reliable inference. Our paper aims to measure total returns to residential real estate as accurately as possible, and to assess the risk of that investment, distinguishing between idiosyncratic risk and systematic risk.

It is important to do that in the long run, for two reasons. First, holding periods for rental housing are typically quite long: in our sample, median holding periods are about 10 years, and we aim to study the relative role of idiosyncratic and systematic risk for holding periods up to 20 years. Second, interest rates have been falling from the early 1980s onward, pushing ex-post total returns up. So empirical studies of the total return to rental housing that cover the last 40 years alone would likely be biased upward. A long-term study avoids this problem.

Despite the enormous size of the housing market, data limitations regarding capital appreciation, gross rental yields, and taxes and costs have so far rendered it difficult to make accurate estimates of the total return and risk on long-term residential real es-

\footnotetext{
${ }^{2}$ In the Netherlands, for example, $47 \%$ of the private rental stock is owned by individuals. Of these buy-to-let investors, $80 \%$ own a single property and only $4 \%$ own more than five properties.
} 
tate investments.

Three recent studies have specifically attempted to construct total return and risk estimates to real estate investments. Eisfeldt and Demers (2018) study total returns to rental housing investments between 1986 and 2014 for a panel of cities in the United States. Although they do not observe actual yields in this period, they construct implied yields by extrapolating a city-specific hedonic pricing model for rental properties to owner-occupied properties. Both within and across cities, they find that rental yields decline in price tiers. Cities with lower net yields experience higher price appreciation, but have lower Sharpe ratios because capital gains are more volatile than yields. However, within cities, this logic reverses, as low price tier areas experience higher total returns due to both higher yields and higher capital gains.

Longer observation periods are important to establish the time-series properties of aggregate housing risk and returns over different market conditions and economic cycles. A recent influential paper by Jordà et al. (2019a) constructs total return indices from a great number of existing house price and rent indices, based on construction methods that vary over time and across countries. Given the ambition of their paper, i.e. to assess housing investment returns and risks for a large cross-section of countries between 1870 and today, this is understandable. Their data collection is momentous as it is. However, their series may suffer from measurement error in all dimensions of the total return, i.e. the capital appreciation, the gross rental yield, and in taxes and costs. This might make inferences based on their findings unreliable, and a key motivation for our paper is to investigate the extent to which such long-term implied return series are affected by measurement errors.

Chambers et al. (2020) have made an impressive effort to construct estimates of total real estate returns for England, using the archives of four prominent 'Oxbridge' colleges between 1901 and 1983. The archival ledgers allow to precisely track propertylevel annual rental income and costs over time, and can be matched to transaction prices when properties are purchased or sold. This enables them to measure returns much more precisely, and they find that long-run real estate investment is less profitable than suggested by Jordà et al. (2019a), with a real return to housing of $2.3 \%$, and $5.4 \%$ for agricultural property. Given its aim and sample period, their paper is complementary to our study. Relative to our paper, their study also covers agricultural land and commercial real estate and specifically investigates the role of costs in driving asset-level returns and risk. However, because colleges infrequently transacted property, they cannot directly measure aggregate capital gains and total returns. To derive a total return statistic for the entire period, they use changes in the UK house price index of Knoll et al. (2017) and adjust it to match the yields they do observe.

In this paper, we construct long-term annual total return indices and provide a picture of the return and risk to rental housing investment at the aggregate and the property level, and for different holding periods. To do so, we study two previously unexplored primary datasets of house prices and rents on individual homes for Paris (1809-1943) and Amsterdam (1900-1979). These datasets are large: in total, we handcollected approximately 171,740 observations of rents, sales prices, and property-level taxes and costs, covering a representative sample of about 40,000 different properties. 
We have enough repeated price observations to estimate capital gains using repeatsales regressions to control for changes in housing quality.

The key innovation of our database is that it includes rents and prices for a large representative set of properties. For Paris, we can link property-level sales prices to rent prices retrieved from rental contracts or inheritance records, registered in the years before or after the sale. For Amsterdam, we observe property-level rents and prices concurrently, and in part of the data even repeatedly. In total, we have 63,575 observations of property-level gross yields. Most existing literature uses implied yields from other series, and studies that do measure actual yields rely on small samples from a limited set of investors (Bracke, 2015; Chambers et al., 2020). ${ }^{3}$

We also have property-level information on taxes and costs, but these data only cover a subset of properties, so that we cannot study property-level costs with the same level of detail as Chambers et al. (2020). To construct annual cost series, and convert our gross yields to net yields, we combine our data with city-level data on taxes, costs, and vacancies, similar to Eisfeldt and Demers (2018).

We find total net geometric returns to rental housing of $6.3 \%$ for Paris and $8.0 \%$ for Amsterdam, with index-level standard deviations of $8.6 \%$ and $10.3 \%$, respectively. In real terms, geometric average returns amount to $4.0 \%$ per annum in Paris and $4.8 \%$ in Amsterdam. These returns are significantly lower than reported in Jordà et al. (2019a) and result in approximately 40 percent lower Sharpe ratios, closing most of the gap with equities that Jordà et al. (2019a) document. This gap further reduces after accounting for transaction costs and idiosyncratic risk. The long-term real return to housing can entirely be attributed to the rental yield, with real capital gains around zero. We find that our series of net rental yields are uncorrelated to the implied yield series in Jordà et al. (2019a), showing that it is very difficult to accurately estimate longterm yields from secondary data.

Our property-level return data for Amsterdam allow us to study idiosyncratic risk in residential real estate investment, highlighting the role of yields as a risk component to housing investments. We document significant persistence in property-level yields over time, even up to 20-year holding periods, and even after accounting for differences in yields across neighborhoods. This implies that properties purchased at above-market yields will continue to earn above-market yields many years after the purchase.

In aggregate, we find idiosyncratic risk to be substantial, contributing over half of total return volatility for holding periods of 15 years and above. However, the composition and importance of idiosyncratic risks change over time. In the short term, nearly all total return risk is idiosyncratic and comes from capital gains volatility. Because yields are persistent, yield covariance becomes an increasingly important component of total risk for longer holding periods. Idiosyncratic capital gains risk becomes less important, given the flat structure of idiosyncratic capital gains risk across holding periods (Giacoletti, 2019). Although we cannot account for property-level costs, our

\footnotetext{
${ }^{3}$ Bracke (2015) studies 1,922 yields from London for 2006-2012 and Chambers et al. (2020) use 1,359 distinct transactions to measure yields, of which 549 are for residential real estate.
} 
findings suggest that ignoring yield risk substantially underestimates the role of idiosyncratic risk for housing investments, especially over long holding periods.

In the remainder of the paper, we will first discuss the data and sources. The next section will present measurements of capital returns, gross rental yields, taxes and costs, and net rental yields. Section 4 provides our new residential total return indices, and this is followed by a section discussing our return estimates in comparison to those of other papers, most notably of Jordà et al. (2019a), and relative to equities. That section will also provide a critical evaluation of our own indices, including robustness analyses. Section 6 will provide an analysis of property-level investment risk - both systematic and idiosyncratic - associated with residential real estate investment and the role of the holding period in risk and return. We will end the paper with some conclusions.

\subsection{Data and Historical Context}

We employ two main archival data sources to construct indices of actual rental yields and house prices, for Paris (1809-1943) and Amsterdam (1900-1979), which we complement with data from other sources. Table 4.1 presents a brief overview of the data sources and the number of observations employed in this paper. Importantly, all our data contain observations on the level of rents and sales prices of an entire property. In both Amsterdam and Paris, properties typically contain several housing units.

Table 4.1: Sources and Sample Sizes Property-Level Data

\begin{tabular}{llrl}
\hline Data Type & Period & \# Obs. & Source \\
\hline Paris & & & \\
Sale Prices & $1806-1943$ & 38,168 & Sommier Foncier \\
Rent Prices & $1806-1943$ & 44,379 & Sommier Foncier \\
Matched Yields & $1809-1943$ & 27,722 & Sommier Foncier \\
Taxes & $1809-1926$ & 4,474 & Sommier Foncier, Tax Registers Sainte-Avoye \\
Asking Yields & $1872-1940$ & 10,052 & Le Figaro \\
Realized Yields & $1883-1939$ & 1,060 & Cote des terrains et immeubles, Le Temps \\
\hline Amsterdam & & & \\
Sale Prices & $1840-1979$ & 35,519 & Brouwer \& Zn., Eichholtz (1997), Verwey (1943) \\
Rent Prices & $1900-1979$ & 25,834 & Brouwer \&Zn. \\
Matched Yields & $1900-1979$ & 24,741 & Brouwer \&Zn. \\
Taxes & $1917-1979$ & 9,798 & Brouwer \&Zn. \\
Costs & $1889-1967$ & 2,454 & Burgerweeshuis, Doopsgezinde Gemeente \\
\hline
\end{tabular}

Notes: Paris transaction prices are based on auction prices (34\%) and regular sales (66\%), while Amsterdam data are auction prices $(48 \%)$, regular sales $(8 \%)$ and appraisals $(44 \%)$. Amsterdam rental prices are based on lease contracts $(88 \%)$ and appraised rental values $(12 \%)$. 


\subsubsection{Paris}

We extract the Paris housing data from the Paris land register called the Sommier foncier, which covers the period from 1809 until 1943. This register is part of the wider French administration responsible for collecting taxes on legal acts, the Enregistrement. The Sommier foncier provides information on all property transfers in Paris and served to check the veracity of the declarations of taxes paid on these transfers. The first two series of the Sommier foncier, which cover the period until 1880, also contain information about leases on these properties. For later periods, we obtain data on rents both from donations during lifetime and inheritances after death (successions).

Figure 4.1 presents two pages from the first registers of the Sommier. The left page (top photo) lists all transfers of property, with information about the owners, the transaction price or assessed value, and the date of the transaction and registration. In the first register, the Sommier also lists the paid property tax. The right page (bottom photo) contains the neighborhood name and street address and lists the details of all the leases on the property, including a description of the (part of) the property that was let, the lease price, duration, and the names of the tenants.

The combination of rental prices and house prices for the same properties allows one to compute property-level gross yields, for a period covering more than a century, and for the entire city. To the best of our knowledge, this has hitherto been impossible, even with modern data. Although historians have described this dataset (Daumard, 1958, 1965), the Sommier has not been the subject of extensive use so far, likely because of its enormous size and the complications arising with hand-written data. ${ }^{4}$

We collect data from a random sample of 327 registers, containing properties in the entire city. ${ }^{5}$ In total, we digitize data for approximately 20,000 different residential properties. For each property, we list the street address, the type of legal act, the registered price or value, and the date of registration and transfer. We remove observations that are duplicates, not dated or outside our period, or do not have a price registered. The reduced sample covers 82,547 registrations: regular property sales, auction sales, leases for entire properties, inheritances and donations.

Information on 38,160 property prices originates from data on regular sales and auctions sales, which are representative for all property sales in the city. Auctions sales correspond to about $37 \%$ of the total number of sales, and were a regular way to sell property. 13 percent of the total number of auction sales (5\% of total sales) are earmarked as a judicial sale following a foreclosure or bankruptcy procedure. Notaries directly sent information about transaction prices to the Enregistrement, ensuring the accuracy of the data, and enabling the government to collect a stamp duty. The data

\footnotetext{
${ }^{4}$ A related register of the Enregistrement, containing the declarations of inheritances, has formed the basis for the well-known work of Piketty et al. (2006) on French inequality, as well as subsequent studies.

${ }^{5}$ To draw a random sample of registers, we initially requested registers from the archive that, according to the archival index, contain street names starting with the letter A or B. We stuck to this strategy as much as possible, but due to restrictions in the number of registers we could request per day, we also took pictures of registers that ended up not containing streets with these letters. We collected additional data from the first set of registers to obtain more observations of actual rents.
} 
Figure 4.1: Example of Sommier Foncier Property Information
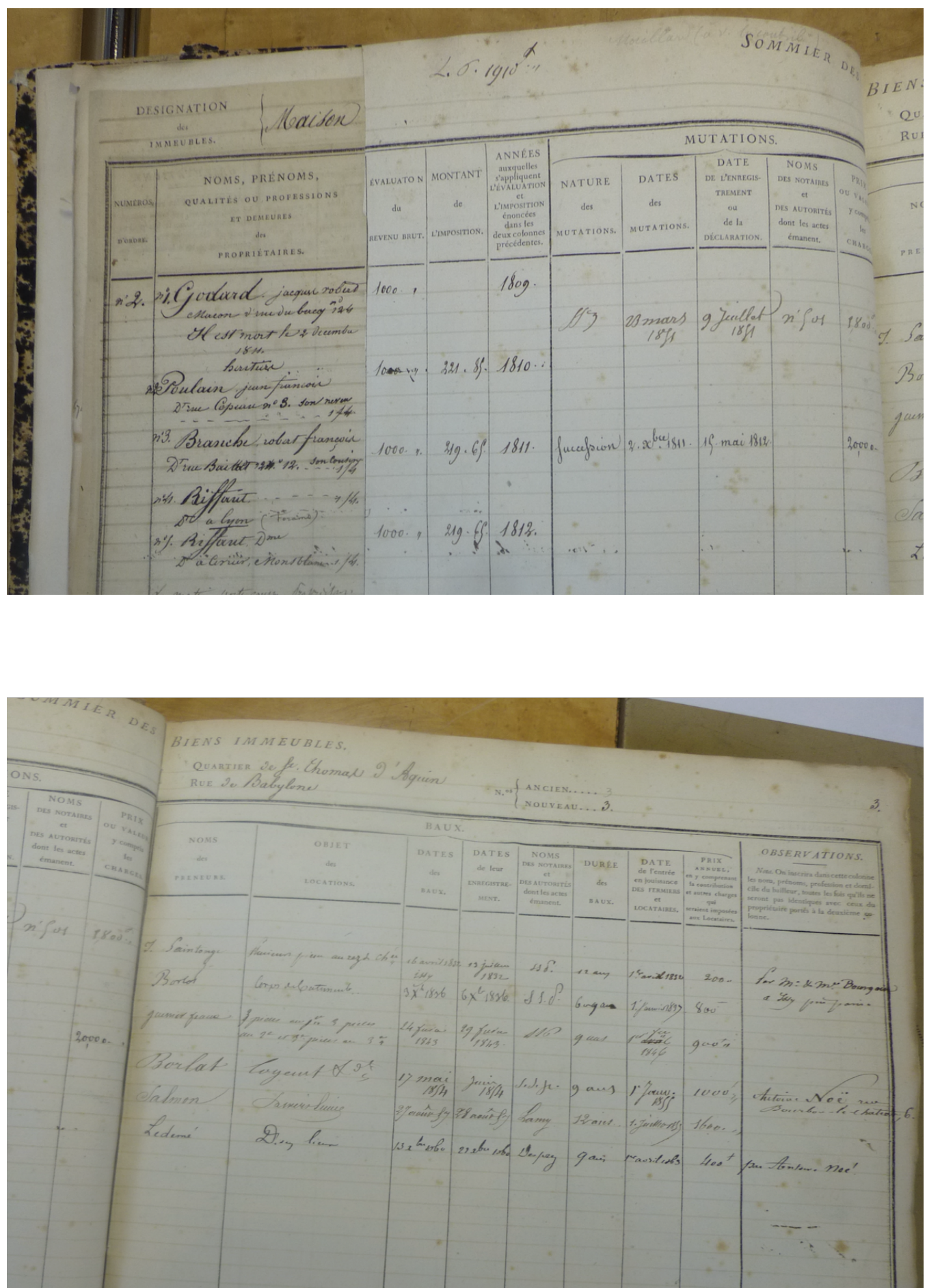

Notes: This is an extract of two pages from the Sommier foncier, in the first register for the house on the Rue de Babylone, number 3. The first picture contains all ownership transfers; the second picture lists the leases on this property. 
we collect cover all property sales for a given property in a given register. In some cases, properties were sold partially, for example when individuals sold an inherited part of a property, or when a property had multiple owners. ${ }^{6}$ These partial sales were not always consistently indicated in the records, which implies there is some noise in the house-level transaction prices.

Data on 44,379 rent prices between 1809-1943 come from rent contracts and from succession and donation values. Before 1870 , about $25 \%$ of rent prices originate from lease prices on newly-signed rental contracts. The relatively low number of rental contracts is driven by the fact that most properties were split into smaller units that were let separately. The rent contracts in the Sommier provide a description of the property that is being let, and we only include observations for which it is clear that the rent corresponds to the entire property. After 1870, almost all rent prices are based on successions and donations, since rent contracts were not registered anymore.

By law, the taxable value of properties in case of successions or donations equaled twenty times the current price of the leases, or the rental value of the property in the rare case the property was owner-occupied. ${ }^{7}$ The heirs declared these amounts and proofs for them to the registration officers, who could verify and control declarations subsequently. Clearly, heirs had a financial incentive to under-report the income from their property. The French government was very well aware of this problem, and to incentivize tax receivers to register the right amounts, they received a fraction of the assessed value (Massaloux, 1989). ${ }^{8}$ We find that verification was very common: in over $20 \%$ of cases the tax receiver imposed extra taxes afterward (insuffisances). We adjust our rent valuations for these insufficiencies.

Because of different registration practices, the succession and donation values in the Sommier foncier were either entered in the books as the rental value or as the capitalized rental value (20 times the rent). The latter was particularly common in the period before 1860. We use data on actual rental contracts and sales prices to infer which rental values are capitalized, and adjusted the data accordingly. In Appendix 4.A we explain this procedure in more detail. In total, we can match 28,287 observations of sales prices to rents on the same property.

After 1918, the legal system to determine succession values changed, and the law stipulated that succession and donation values had to be based on the market value of the properties. ${ }^{9}$ Because the registration officers had extensive experience with assessing succession values based on rental leases, property values continued to be assessed on the basis of rental values. However, the officers applied, depending on the condition of the property, capitalization rates of 10 to 14 , with an average rate of $12 .^{10}$

\footnotetext{
${ }^{6}$ Until World War I, it was not possible to own a designated part of the property, such as a single apartment.

${ }^{7}$ Loi du 22 frimaire an VII, article 27.

${ }^{8}$ The investigative power of the registration officers was enacted formally in law in 1851 (Arrêté $d u 3$ mai 1851, article 2), but price adjustments were already frequent in the decades before that.

${ }^{9}$ Loi du 27 mai 1918, article 1er.

${ }^{10}$ See Le Temps Immobilier, 12 September 1933. Le Temps was a conservative newspaper close to French financial circles. It was published between 1816 and 1942 and from 1932 offered a weekly bulletin devoted to the real estate market.
} 
After 1870, our rent data are almost entirely based on observations of successions and donations, and one might worry that these are not accurately measuring rental prices. This concern might be particularly severe after 1918 when the legal link between the succession values and rental prices disappears. To construct an alternative series of yields, we, therefore, collect 10,052 announcements of property sales from Le Figaro, a major conservative French newspaper, spanning the period from 1872 to 1940. ${ }^{11}$ These ads listed both the rental revenue of a property, the minimum starting bid (mise à prix) in case the property was sold in an auction, or the asking price for a regular sale. Advertisements for regular sales only started appearing after World War I. One limitation of this database is that it is based on asking prices and self-reported rents, which might deviate from actual rental prices and sales prices. Given that the data do not report the actual addresses of the properties, it was not possible to match these asking prices to the subsequent sales prices of the property. To estimate the difference between minimum bids and realized prices, we collect 1,060 observations from data in two real estate news bulletins, the Cote des terrains et immeubles for 1883-1884 and Le Temps Immobilier for 1932-1939, that list both the rental revenue, minimum starting bid, and the realized price.

To obtain estimates of taxes, we collect data on paid property taxes for 2,094 observations in the first register of the Sommier. For each of these observations, we also know the sale or rental price such that we can compute a property tax rate. To obtain tax rates after 1860, we collect 1,704 property-level tax observations for a sample of streets in Sainte-Avoye, a neighborhood in Paris. ${ }^{12}$ We match these to our data from the Sommier. It is not necessary to diversify this tax sample since the law prescribed the equivalence of property tax rates across the city.

\subsubsection{Amsterdam}

The city of Amsterdam had and still has a unique history of selling property for investment purposes in public auctions. Such auctions have been organized since the 1600s and still take place today. The format of these auctions has changed very little over time: before the actual auction, the auction house and organizing realtors use newspapers or other media to promote the properties for sale. During the auction, participants bid on the properties using a unique auction format: the Anglo-Dutch Premium Auction (Boerner et al., 2016). For auctioned properties, the buyer pays the required transaction price and fees and subsequently registers the transfer of property formally. Not every auctioned property would sell; after every non-foreclosure auction the seller still reserved the right to reject a transaction (recht van gunnen).

The market for auctioned property in Amsterdam was large. For the period between 1900 and 1942, we gather statistics on the number of properties put up for sale from the yearbooks of the Amsterdam statistical office (Gemeente Amsterdam, 2018),

\footnotetext{
${ }^{11}$ We collect about 150 observations per year. We excluded 1915-1916 since there were barely any properties advertised for sale due to World War I. The auction market was also at a standstill: 0 sales in 1915 and 1916, 7 in 1917, and 8 in 1918.

${ }^{12}$ Archives de Paris, D13P2/17, 67 à 69.
} 
which indicate that on average about 1000 properties per year were put up for auction. We estimate this was about 2 percent of the housing stock. ${ }^{13}$ Most of these properties were auctioned voluntarily (vrijwillige verkoop), but some properties were sold after foreclosure or bankruptcy (executoriale verkoop). The data do not provide an indication of the number of properties that were sold involuntarily, but the large number of properties put up for auction suggests this was only a minority of cases. Selling investment property in auctions was the norm, and foreclosed properties were sold in the same auctions as regular properties. ${ }^{14}$

Before the advent of modern house price indices, auctions gave market participants important information about market prices and yields. Because most properties were purchased for investment purposes, information on rents and taxes was presented for nearly every property for sale. Properties were typically sold with tenants at current rental prices. If a property was not rented out, the auctions typically listed the assessed rental value of the property. The auctions were public, so individuals could record and register this information. We exploit the archives of the Firma Jan Brouwer \& Zn., who developed a unique card system to store information on sales prices, rents, and taxes of properties sold in these auctions. ${ }^{15}$ One unique aspect of this database is that it appears to have been specifically designed to follow property yields over time for a large sample of investment properties. This system covers the period from 1900 to 1979 and contains information on 19,786 properties. These properties primarily cover residential units, although a significant fraction of properties contains both housing units and office or retail space. In Amsterdam, offices or shops often occupied the front part of the ground floor, with the upper floors or back of the house used for residential rental units.

Beyond registering prices and rents for auctioned properties, the realtor also registered information on the appraisal value of these properties. These appraisals were requested by banks and other mortgage providers. The appraisers assessed both the market value of the property and the rental value because property developers and investors used rental cash flows to pay mortgage interest and amortization (Smid, 2019). If the property was vacant or newly constructed, the appraisers estimated the rental value of the property rather than using actual rent contracts. In a small number of cases, the realtor also listed data on regular sales prices.

Figure 4.2 contains an example of a card for one property. We transcribe all 26,132 cards present in the archives. For each observation, we list the street and house number, as well as the date, the type of value observation (appraisal, auction sale, or regular sale), and the price. In case the property was leased or its rental value was appraised, we also transcribe this information. We only include information on rental prices if the

\footnotetext{
${ }^{13}$ In 1919, there were 45,000 properties in Amsterdam, containing about 140,000 housing units (Gemeente Amsterdam, 2018).

${ }^{14}$ In the 17th-18th century, when properties were already auctioned using exactly the same procedures, but when foreclosures can be identified, Francke and Korevaar (2020) find in a repeat-sales setting that foreclosed properties realized $2 \%$ lower prices than non-foreclosed properties. They argue that this can be caused by unobserved depreciation on foreclosed properties, or by actual discounts.

${ }^{15}$ Source: Amsterdam City Archives, Archive 901.
} 
entire property was rented out. Last, we include information on all mentioned taxes. Next to regular property taxes and municipal taxes, many homes in Amsterdam were subject to mandatory ground leases, which the municipality used for most property developments after 1896 (Nelisse, 2008).

Figure 4.2: Example of an Amsterdam Auction Card

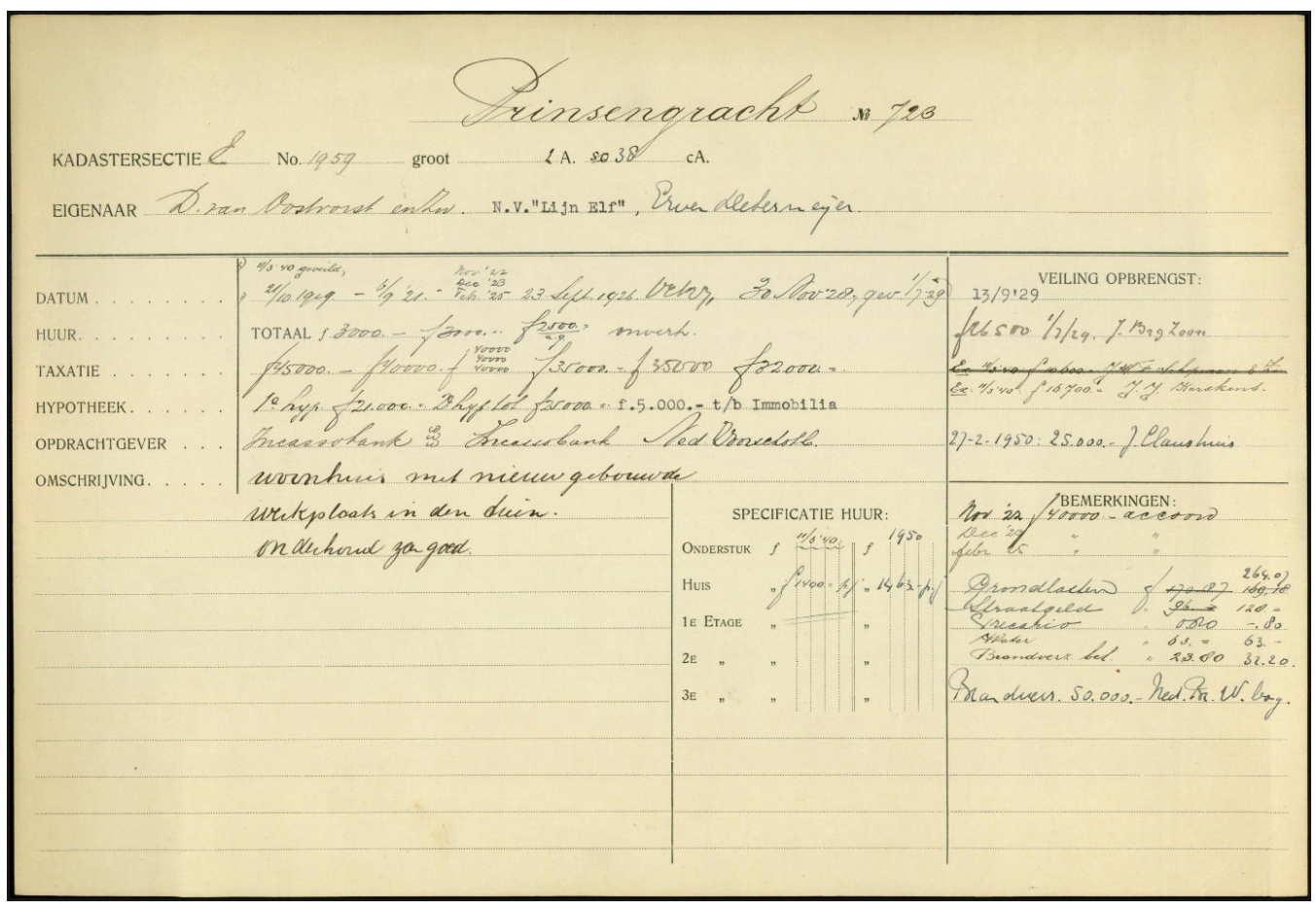

Notes: This figure provides an example of one Amsterdam auction card, for the property on the Prinsengracht 723.

Excluding observations from outside of Amsterdam ( $4 \%$ of the data), this data collection results in 25,834 observations of rents (88\%) or appraised rental values $(12 \%)$, 30,528 transaction prices $(48 \%)$ or appraisals $(52 \%)$, and 9,798 observations of taxes. In 24,741 cases, we have both a rental price and a price observation for the same home in the same year. In 8,579 cases we can also adjust this yield for taxes. To complete our database of prices, we augment it with 2,480 repeated transaction prices from Verwey (1943) for property auctions between 1840 and 1940, and 2,826 transaction prices from the Herengracht index database of Eichholtz (1997), covering the 1840-1972 period. Removing duplicate observations across databases, the total number of prices is 35,519 , and $93 \%$ of these price observations concern the 1900-1979 period.

To provide estimates of non-tax costs, we compile data on actual costs from the archives of two institutional investors: the Amsterdam Orphanage (Het Burgerweeshuis) and the Doopsgezinde Gemeente, an Amsterdam church. Since the 17th century, the Burgerweeshuis has been among the largest institutional investors in the Amsterdam residential real estate market. For social institutions like the Burgerweeshuis and 
the Doopsgezinde Gemeente, property investments provided the largest part of their funding. Eichholtz et al. (2020b) use information on rental contracts from both institutions to construct multiple series of market rent prices, and we refer to their paper for information on the investment activity of these investors. Chambers et al. (2020) use similar data from Oxbridge colleges to obtain estimates of costs.

Although the Burgerweeshuis reduced its property portfolio over time because it deemed investments in bonds and other financial assets more attractive (Gelderblom and Jonker, 2009), the Burgerweeshuis still owned 60 properties until the mid-20th century, containing over 100 rental units. Most of these properties had already been acquired in the 16th and 17th centuries. From its archives, we collect property-level information on rental income and expenses for these units, covering the period from 1937 to 1969. For the Doopsgezinde Gemeente, we obtain data on 30 different properties spanning the period from 1889 to 1924 . Ledgers are incomplete before and after these periods, but these properties likely stayed in their hands for decades or even centuries. The mentioned costs include expenses on maintenance and renovation, taxes, insurance and management costs (only at property level), lost rents due to rentarrears and vacancies, and water use (if not paid by the tenant). In short, this database provides all asset-level costs. In total, this resulted in 2,454 property-level observations of rental prices and corresponding costs.

\subsection{The Components of Total Housing Returns}

In this section, we estimate the components of the total returns of residential real estate in Paris and Amsterdam. The return to rental housing investments for a property (or a portfolio of properties) consists of both capital gains and net rental yields (Equation 4.1).

$$
\operatorname{Return}_{i, t}=\frac{P_{i, t}-P_{i, t-1}}{P_{i, t-1}}+\frac{R_{i, t}\left(1-c_{i, t}-\tau_{i, t}\right)}{P_{i, t-1}}
$$

$P_{i, t}$ and $R_{i, t}$ equal the sale and rent price of the same property $i$ at time $t$. To estimate our total returns as precisely as possible, and to establish how measurement error could contribute to wrongly specified returns, we split this equation into three parts. First, we study the role of capital gains measurement in the assessment of the total rate of return to housing. The main challenge here is to adequately control for housing quality, as well as to have sufficiently large and representative samples of housing sales. Second, we look at gross rental yields: the current or estimated rent divided by the sales price. ${ }^{16}$ We compare how these actual yields differ from implied yields derived from secondary indices. Third, we study the implications of costs and taxes on yields, with a particular focus on property-level taxes $(\tau)$. We proxy for non-tax costs (c) using institutional cost data for Amsterdam and findings from other studies and employ time series of vacancy rates to assess vacancy costs.

\footnotetext{
${ }^{16}$ Note that rental yields formally differ slightly from the rental returns defined in equation 4.1. The latter expresses the rent price relative to the sale price in the previous period. Our rent observations specify the annual rental price at the time of the transaction: we thus assume this is equal to the rental price for the upcoming year.
} 


\subsubsection{Capital Appreciation}

The literature has employed a wide set of methods to estimate house price indices, some aiming to control for changes in quality of the underlying housing stock, and some not. Of the former, the two most commonly used are the repeat-sales method (Bailey et al., 1963) and the hedonic method (Rosen, 1974). In a standard framework, the log price of a transaction $\left(p_{i}\right)$ at time $t$ can be written as the sum of a 'quality' component $(\alpha)$ and a time-varying market value component $(\beta)$ plus a transaction error $(\varepsilon)$.

$$
p_{i, t}=\alpha_{i}+\beta_{t}+\varepsilon_{i, t}
$$

Crucial to both methods is that they attempt to separate improvements in the quality of homes from increases in market prices. Because the quality of the housing stock has increased throughout the 20th century, inadequate quality control will result in indices with an upward bias (Eichholtz et al., 2020b). In the repeat-sales method, which we employ for both cities in this paper, this is accomplished by focusing on repeated transactions of the same properties. Because we do not have observations on actual housing quality for the properties in our sample, using the hedonic alternative is not feasible.

For both Paris and Amsterdam, we estimate a standard repeat-sales index, controlling for the type of sale observed in the data. For the Parisian index, we use data from 1806 to 1943 to estimate the index but only report on its development from 1809 to 1943 when the number of repeat-sales is large. For Amsterdam, we include price observations for the entire period from 1840 to 1979 but only report on the index development from 1900 to 1979, the period for which we have yield data besides transaction prices.

To reduce the sensitivity of our index to extreme outliers, which may signal unobserved changes in quality or cases where only part of a property was sold (but not indicated), we exclude price pairs that have a log price difference exceeding 1.95 or below -1.95 after correcting for log changes in the rent price index from Eichholtz et al. (2020b) ( $>600 \%$ or $<-86 \%$ ). For Paris, this removes 1,456 price pairs, leaving us with 17,770 price pairs to estimate the house price index. For Amsterdam, we use 15,125 transaction pairs to estimate the index, excluding 161 outliers.

Table 4.2 Panel A provides summary statistics of the new house price indices. We find comparable figures for both cities. For Paris, we find a geometric average capital gain of $2.4 \%$ (arithmetic: $2.8 \%$ ), with a standard deviation of $8.7 \%$. Adjusted for inflation, the capital gain is $0.3 \%$ per year. ${ }^{17}$ For Amsterdam, we find a geometric average annual log capital gain of $2.6 \%$ (arithmetic: $3.1 \%$ ) and a standard deviation of $10.4 \%$. Adjusting for inflation, the real log capital gain averages $-0.6 \%$ per year.

\footnotetext{
${ }^{17}$ We use the CPI indices assembled in Eichholtz et al. (2020b) for both Paris and Amsterdam. These are city-specific CPI indices pooled from various sources.
} 
Table 4.2: Capital Gains, Rental Yields, and Total Returns

\begin{tabular}{|c|c|c|c|c|c|c|c|c|}
\hline \multirow[t]{2}{*}{ Index } & \multirow[t]{2}{*}{ Period } & \multicolumn{2}{|c|}{ Geometric } & \multicolumn{2}{|c|}{ Arithmetic } & \multicolumn{2}{|c|}{ Real Geom. } & \multirow[t]{2}{*}{ Sharpe } \\
\hline & & Mean & SD & Mean & SD & Mean & SD & \\
\hline
\end{tabular}

\section{Panel A: Capital Gains}

$\begin{array}{lrrrrrrr}\text { Paris } & 1809-1943 & 2.4 \% & 8.7 \% & 2.8 \% & 8.9 \% & 0.3 \% & 10.3 \% \\ \text { Amsterdam } & 1900-1979 & 2.6 \% & 10.3 \% & 3.1 \% & 10.6 \% & -0.6 \% & 10.3 \%\end{array}$

Panel B: Gross Yields

$\begin{array}{lrrrrr}\text { Paris } & 1809-1943 & 6.9 \% & 1.1 \% & 7.2 \% & 1.2 \% \\ \text { Amsterdam } & 1900-1979 & 9.9 \% & 2.0 \% & 10.5 \% & 2.3 \%\end{array}$

Panel C: Net Yields

$\begin{array}{llllll}\text { Paris } & 1809-1943 & 3.9 \% & 0.7 \% & 4.0 \% & 0.7 \% \\ \text { Amsterdam } & 1900-1979 & 5.4 \% & 1.2 \% & 5.5 \% & 1.2 \%\end{array}$

Panel D: Total Returns

\begin{tabular}{lrrrrrrrr} 
Paris & $1809-1943$ & $6.3 \%$ & $8.6 \%$ & $6.8 \%$ & $8.9 \%$ & $4.0 \%$ & $10.2 \%$ & 0.25 \\
Amsterdam & $1900-1979$ & $8.0 \%$ & $10.3 \%$ & $8.7 \%$ & $10.6 \%$ & $4.8 \%$ & $10.3 \%$ & 0.34 \\
\hline
\end{tabular}

Notes: This table reports the headline estimates for capital gains, gross yields, net yields and total returns for both Paris and Amsterdam in geometric terms, arithmetic terms and in real geometric terms. Sharpe ratios for total returns are computed based on long-term bond rates for both cities. 


\subsubsection{Yields}

\section{Gross Yields}

To estimate the gross annual rental yield for the two cities, we divide the summed rental prices of properties in the sample by their summed sales prices for each year. For Amsterdam, all yields are based on the rental price in the year of the sale. For Paris, we typically do not observe the value of the rent price $(R)$ in the same year as the sales price $(P)$, and we adjust for this using Equation 4.3. On average, we observe two rent price observations and two house price observations for each property. To be able to compute yields, we link each property sale to the nearest rent observation on the property before the sale (at time $t-x$ ) and after the sale (at time $t+z$ ), with $x$ and $z$ limited to 30 years. We adjust these rent observations for changes in market rent prices, which we estimated using a repeat-rent index $(R P I)$ based on observations of rental contracts, successions, and donations, estimated using equation 4.2. To compute the final yield, we apply linear interpolation, so that rent observations closest to the sales price get the most weight, and divide these by the sales price at time $t$ :

$$
\text { Yield }_{i, t}=\frac{z}{x+z} \times \frac{R_{i, t-x}}{P_{i, t}} \times \frac{R P I_{t}}{R P I_{t-x}}+\frac{x}{x+z} \times \frac{R_{i, t+z}}{P_{i, t}} \times \frac{R P I_{t}}{R P I_{t+z}}
$$

At the annual level, the estimates on portfolio yields can be sensitive to extreme observations in the data. Most importantly, very large properties or properties with extreme yields can distort the yields at the annual level. To combat this we remove observations that have log yields deviating more than 1.39 from the median log yield in the sample (more than $300 \%$ larger or $-75 \%$ smaller). Second, we remove observations with extremely high rent levels $(>800 \%$ of the median house rent). For Paris, there remain 24,827 gross yields in the sample, and for Amsterdam 25,058 yields. Again, this procedure removes a larger fraction of observations for Paris (10\% of data, 2,895 yields) relative to Amsterdam (3\% of data, 683 yields), due to the larger amount of noise in the Parisian data.

Table 4.2 Panel B shows a Parisian gross log portfolio yield for rental housing of $6.9 \%$, with a standard deviation of only $1.1 \%$. For Amsterdam, the average gross log portfolio yield equals $9.9 \%$ with a larger standard deviation of $2.0 \%$. We plot the series in Figure 4.3. For Paris, the gross yield moves in a rather limited range, roughly between 5 and 10 percent, with relatively high yields in the Napoleonic Era, after the Siege of Paris in 1870, and during the Great Depression. The picture is more volatile for Amsterdam than for Paris. Amsterdam yields are quite stable until 1965, and then start increasing substantially in the late 1960s, with the gross yield peaking at more than 20 percent in the 1970s. The evolution of yields in the overlapping period appears to be similar, with yields declining at the end of World War I, but increasing in the 1920s and 1930s. The correlation between the gross yields for Paris and Amsterdam in that period is 0.75 . 
Figure 4.3: Gross Housing Yields, Paris and Amsterdam

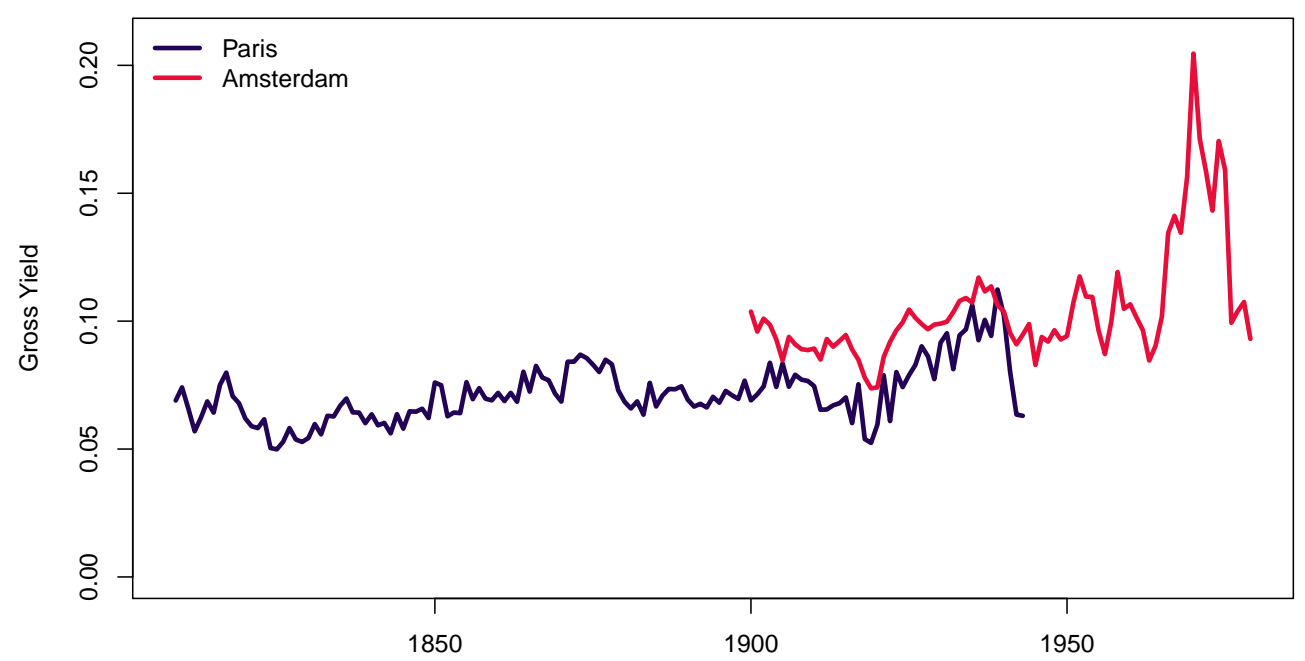

Notes: This graph provides gross yields to rental housing for Paris (1809-1943) and Amsterdam (19001979). For Paris, the gross yield moves in a rather limited range, roughly between $5 \%$ and $10 \%$ For Amsterdam, the average gross yield is $10 \%$, with a peak of $20 \%$ in the 1970 s. In the periods the Paris and Amsterdam series overlap, they correlate closely (corr. $=0.75$ ).

\section{Costs}

For Paris, we compute the average annual tax rate directly for a subset of 2,094 transaction prices or rents between 1809 and 1854 for which we have information on the level of the annual property tax, expressing it as a fraction of total rent. Between 1855 and 1917, we match tax payments on the properties in Sainte-Avoye to the rental prices coming from successions, donations and rental contracts in the Sommier. To match rental prices to tax payments, we use the same procedure that we employ to match rental prices to sales prices, by finding the nearest rent price on the property and adjusting these for changes in the market price. We compute the average tax rate based on these matched observations and interpolate it for years where data is missing. Because tax rates were very stable in this period, this likely does not introduce major errors. After 1917, we use data from Duon (1946) who computed the fraction of property taxes borne by the property owner annually, expressing it as a fraction of gross rent. $^{18}$

For Amsterdam, a third of the rental yield observations include the required propertylevel taxes $(9,798$ observations). The most important of these were direct property taxes, street taxes, and a fee for the use of water. For properties with leaseholds, we also register land lease costs. From 1924 onward, there are sufficient observations available to estimate the level of taxes as a fraction of total rents. ${ }^{19}$ To do so, we compute the average tax rate in each year, controlling for differences in tax rates due to

\footnotetext{
${ }^{18}$ Appendix 4.B provides a more detailed discussion of the tax system and the sources we used.

${ }^{19}$ The rental tax rate can be estimated more precisely than the tax rate as a fraction of property value.
} 
the presence of land leases. To estimate the level of tax yields before 1924, we estimate a repeated-tax index based on 635 annual observations of taxes for properties of the Doopsgezinde Gemeente between 1900 and 1924. We use the 1924 tax rate to splice these to the tax rate series from the yield database. For periods of missing data (1915-1916) we interpolate the tax rate.

In Amsterdam, annual taxes account on average for $14.8 \%$ of property rental value, with a volatility of $5.6 \%$. In Paris, tax rates amount on average to $10.7 \%$ of the rental value with a volatility of $4.3 \%$. A plot and discussion of the series of tax rates and vacancy rates are provided in Appendix Figure 4.13.

To measure vacancy rates, we make use of city-level statistics. For Amsterdam, we compute the annual vacancy rate in Amsterdam by dividing the number of vacant housing units in the market by the total number of housing units in Amsterdam. For most years, this is reported in the statistical yearbooks of the Municipality of Amsterdam (Gemeente Amsterdam, 2018) or in the national housing census. In case data was missing, we linearly interpolate vacancy rates (1900-1908, 1945-1946, 1948-1955, 1957-1965). Vacancy rates in Amsterdam were low, with an average of $2 \%$, a low of $0.3 \%$ right after World War II, and a high of 5.5\% in 1935. For Paris, we use estimated vacancy rates based on the statistical yearbooks of Paris and data on the number of vacant accommodations given by Faure and Lévy-Vroelant (2007) and Duon (1946). Prior to 1869 , there is no vacancy data available, and we use the 1869 number for this period. We linearly interpolate data in periods with missing data, mostly in the 1870s and 1880s. Vacancy rates average $3.1 \%$ of rental value in Paris.

One limitation of our sample is that we do not have asset-level information on costs other than taxes, implying that we have to make estimates of these costs based on other sources of data. The approach we take in this paper is to make a well-informed estimate of the total amount of costs other than taxes and vacancies, using estimates from our Amsterdam cost data and findings from other literature.

First, we estimate the average fraction of non-tax and non-vacancy costs in our institutional cost sample from Amsterdam. Excluding vacancy costs and taxes, but including maintenance costs, management costs, and insurance costs, the cost fraction on residential properties averages $31.8 \%$ in our sample. This value reduces to about $26.5 \%$ when we control for location and the relative value of properties. Appendix 4.C provides a more detailed discussion of our cost data and analysis.

In comparable studies, the fraction of non-tax costs typically amounts to approximately 30-35\% of rental value. For the United States, Eisfeldt and Demers (2018) apply a fixed fraction of about $35 \%$ of the total rental value as costs, and add time-varying local property tax costs and vacancy costs to this estimate, as we do in this paper. ${ }^{20}$ Chambers et al. (2020) have full information about property-level costs and study a comparable time period as we do. They find actual costs for residential real estate of $32.7 \%$ of gross rental income (excluding taxes, but including vacancy costs). The cost fractions they identify fluctuate substantially over time but only apply to a very

\footnotetext{
${ }^{20}$ They assume non-tax and non-vacancy costs are the sum of $2.13 \%$ of property value and $6.63 \%$ of rental value, which equates to about $35 \%$ of the property value based on the gross yields in their sample.
} 
specific group of investors: Oxford and Cambridge colleges. For Paris, the tax authorities assumed a 25\% maintenance cost fraction since the French Revolution, excluding management and insurance costs (Duon, 1946). Jordà et al. (2019a) also discuss the evolution of maintenance costs historically, and find that maintenance, management and insurance costs constitute about $30 \%$ of gross rent without strong time trends.

Based on our findings in Table 4.6 and other estimates in the literature, we apply a fixed cost fraction to our gross yields of $30 \%$ of rental value for both Paris and Amsterdam, excluding costs for vacancies and taxes.

\section{Net Yields}

The next step is to convert the gross rental yields reported in Table 4.2 Panel B to net rental yields, using our estimates of costs, taxes and vacancy rates. These are reported in Panel C of Table 4.2, and we observe a net yield for Paris of 3.9\% for the full 18091943 sample period, and a net yield of $5.4 \%$ for Amsterdam for the 1900-1979 period.

Given that there is some uncertainty surrounding the true level of maintenance and management costs, and its evolution over time, these numbers might be different if cost fractions differed from our estimates. For example, if the true cost fraction excluding taxes and vacancies was $25 \%$ or $35 \%$ of rental value, instead of $30 \%$, net yields would increase respectively decrease by $0.35 \%$ in Paris and $0.5 \%$ in Amsterdam.

\subsection{The Total Return to Residential Real Estate}

This section provides aggregate statistics on total returns for Paris and Amsterdam, both in nominal and in real terms. To deflate nominal returns into real returns, we use the CPI indices assembled in Eichholtz et al. (2020b) for both Paris and Amsterdam. These are city-specific CPI indices pooled from various sources. We combine the housing capital value index reported in Section 3.1 with the net yield development in Section 3.2 by directly applying Equation 4.1 to get the total net return to rental housing in Paris and Amsterdam. Table 4.2 Panel D provides statistics for these series.

First, the geometric average net return to rental housing is $6.3 \%$ for Paris (arithmetic: $6.8 \%$ ) and $8.0 \%$ for Amsterdam (arithmetic: $8.7 \%$ ). In real terms, geometric returns in both cities are more similar: $4.0 \%$ in Paris and $4.8 \%$ in Amsterdam. The lack of any real capital gains on housing for both Paris and Amsterdam also implies that the real total long-term returns on housing over time accumulate from rental cash flows rather than capital gains. The standard deviations of the nominal total return are $8.6 \%$ for Paris and $10.3 \%$ for Amsterdam, almost equalling the standard deviation of the capital return for these cities.

In order to assess risk premiums and Sharpe measures, we use series of long-term bonds returns that we can apply consistently over time, since bill rates are not available for all time periods. For France, we use the bond yield on French 5\% annuities before 1833, and the 3\% annuity between 1833 and 1943. For the Netherlands, we take the long-term Dutch government bond yield from 1900 to 1979 , also reported in Jordà et al. (2019a). Relative to long-term government bonds, housing earned a risk 
premium of about $2.1 \%$ in Paris and $3.5 \%$ in Amsterdam. Combining this with the standard deviations of the geometric total returns gives a Sharpe ratio of 0.25 for Paris and 0.34 for Amsterdam.

Figure 4.4 reports the evolution of real cumulative returns over time for both Paris and Amsterdam. Real total returns dwarf capital gains but the disproportionate influence of capital gains on total return volatility is evident, especially for Paris after 1914. The consequences of World War I scarred the performance of real estate investments in Paris, as France experienced significant inflation and introduced nominal rent controls. This was much less the case in Amsterdam, as the Netherlands was neutral during World War I. In Amsterdam, real total returns accumulated steadily up to the 1930s, then went into a 20-year hiatus following the Great Depression and World War II, before picking up pace again in the 1950s.

Figure 4.4: Real Total Returns and Capital Gains

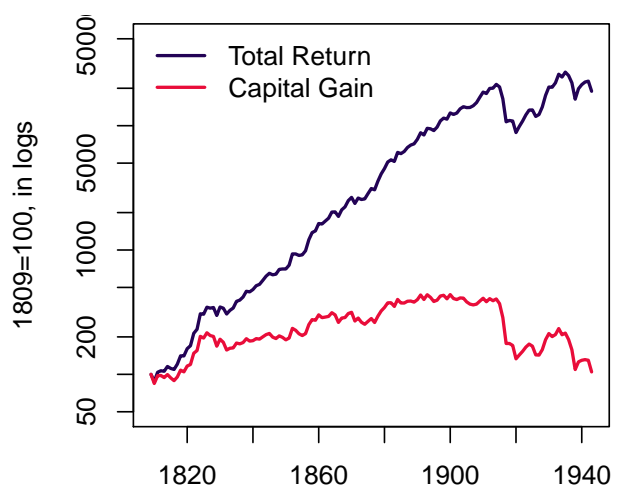

(a) Paris

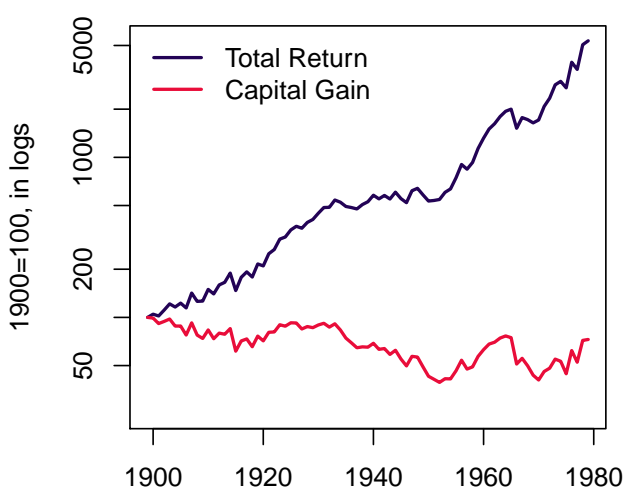

(b) Amsterdam

Notes: These graphs depict inflation-adjusted cumulative total returns and capital gains for Paris and Amsterdam. Real capital gains are dwarfed by total returns but the price volatility is very visible, especially for Paris after 1914. World War I scarred the real estate investment performance in Paris but did not affect Amsterdam much. In Amsterdam, real total returns accumulated steadily up to the 1930s, then went into a 20-year hiatus before picking up pace again in the 1950s.

\subsection{Discussion}

Having established our main estimates for housing returns and yield in both Paris and Amsterdam, this section aims to discuss these estimates in more detail. First, we want to address how our estimates compare to the results reported in Jordà et al. (2019a) and in other related literature, and discuss the likely role of measurement error in the differences between our estimates and previous series. This section also discusses how our improved estimates for Paris and Amsterdam change our view regarding the performance of housing as an asset class, particularly relative to equities. We will end the section with a discussion of potential limitations and issues with our estimates, and perform a series of robustness checks. 


\subsubsection{Comparing Our Indices to Previous Work}

\section{Capital Gains}

We start our comparison of total housing returns by looking at changes in house prices for Paris and Amsterdam. Figure 4.5a and 4.5b depict our newly estimated repeat-sales indices in nominal terms, and compare the nominal indices with other housing series, most specifically those used by Knoll et al. (2017), on which the total return estimates in Jordà et al. (2019a) are based. Table 4.3 provides numerical comparisons.

Table 4.3: Comparing Return Estimates

\begin{tabular}{|c|c|c|c|c|c|c|c|c|}
\hline \multirow[t]{2}{*}{ Index } & \multirow[t]{2}{*}{ Period } & \multicolumn{2}{|c|}{ Geometric } & \multicolumn{2}{|c|}{ Arithmetic } & \multicolumn{2}{|c|}{ Real Geom. } & \multirow[t]{2}{*}{ Corr. } \\
\hline & & Mean & SD & Mean & SD & Mean & SD & \\
\hline \multicolumn{9}{|l|}{ Panel A: Capital Gains } \\
\hline Paris & 1840-1943 & $2.4 \%$ & $8.6 \%$ & $2.8 \%$ & $8.9 \%$ & $-0.6 \%$ & $10.3 \%$ & \\
\hline Paris (Duon, 1946) & 1840-1943 & $2.7 \%$ & $5.8 \%$ & $3.0 \%$ & $6.0 \%$ & $-0.2 \%$ & $8.5 \%$ & 0.39 \\
\hline Paris & 1871-1943 & $2.4 \%$ & $9.3 \%$ & $2.9 \%$ & $9.7 \%$ & $-1.5 \%$ & $11.3 \%$ & \\
\hline Paris (Knoll et al., 2017) & 1871-1943 & $3.2 \%$ & $7.6 \%$ & $3.5 \%$ & $8.6 \%$ & $-0.7 \%$ & $9.2 \%$ & 0.31 \\
\hline Amsterdam & 1900-1979 & $2.6 \%$ & $10.3 \%$ & $3.1 \%$ & $10.6 \%$ & $-0.6 \%$ & $10.3 \%$ & \\
\hline Amsterdam (Ambrose et al., 2013) & 1900-1979 & $3.5 \%$ & $26.0 \%$ & $7.0 \%$ & $27.3 \%$ & $0.4 \%$ & $25.6 \%$ & 0.31 \\
\hline Amsterdam (Knoll et al., 2017) & 1900-1979 & $3.9 \%$ & $10.9 \%$ & $4.6 \%$ & $11.2 \%$ & $0.8 \%$ & $9.5 \%$ & 0.40 \\
\hline \multicolumn{9}{|l|}{ Panel B: Net Yields } \\
\hline Paris & 1871-1943 & $4.3 \%$ & $0.6 \%$ & $4.4 \%$ & $0.6 \%$ & & & \\
\hline Paris (Jordà et al., 2019a) & $1871-1943$ & $4.9 \%$ & $0.7 \%$ & $5.0 \%$ & $0.8 \%$ & & & 0.11 \\
\hline Amsterdam & 1900-1979 & $5.4 \%$ & $1.2 \%$ & $5.5 \%$ & $1.2 \%$ & & & \\
\hline Amsterdam (Jordà et al., 2019a) & 1900-1979 & $6.3 \%$ & $2.1 \%$ & $6.5 \%$ & $2.3 \%$ & & & -0.08 \\
\hline \multicolumn{9}{|l|}{ Panel C: Total Returns } \\
\hline Paris & $1871-1943$ & $6.7 \%$ & $9.3 \%$ & $7.3 \%$ & $9.6 \%$ & $2.8 \%$ & $11.4 \%$ & \\
\hline Paris (Jordà et al., 2019a) & 1871-1943 & $8.1 \%$ & $7.8 \%$ & $8.6 \%$ & $8.8 \%$ & $4.2 \%$ & $9.6 \%$ & 0.30 \\
\hline Amsterdam & 1900-1979 & $8.0 \%$ & $10.3 \%$ & $8.7 \%$ & $10.6 \%$ & $4.8 \%$ & $10.3 \%$ & \\
\hline Amsterdam (Jordà et al., 2019a) & 1900-1979 & $10.2 \%$ & $10.6 \%$ & $11.1 \%$ & $10.8 \%$ & $7.1 \%$ & $9.2 \%$ & 0.39 \\
\hline
\end{tabular}

Notes: This table compares our results on capital gains, net yields and total returns to previous studies. The correlation coefficient is computed as the correlation in capital gains, yields, or log returns with our baseline series. The house price indices from Knoll et al. (2017) are used to compute capital gains and corresponding total returns in Jordà et al. (2019a). The price index of Duon (1946) for Paris was smoothened using a moving average of unknown length. This explains the low volatility and correlation of this series and that of Jordà et al. (2019a), who use Duon's index until 1937. Until 1965, the Ambrose et al. (2013) index for Amsterdam is based on a small number of transactions along the Herengracht, Amsterdam's most affluent canal, resulting in very high volatility and low correlation. Knoll et al. (2017) use a smoothened version of this index.

For Paris, Knoll et al. (2017) used the index of Duon (1946) for the period between 1870 and 1935. This index is likely the world's oldest repeat-sales index, although it is unclear how this index was constructed exactly. Duon traced all previous sales for the 4,389 homes sold in Paris between 1941 and 1944 and used this to estimate a house 
Figure 4.5: House Price Indices

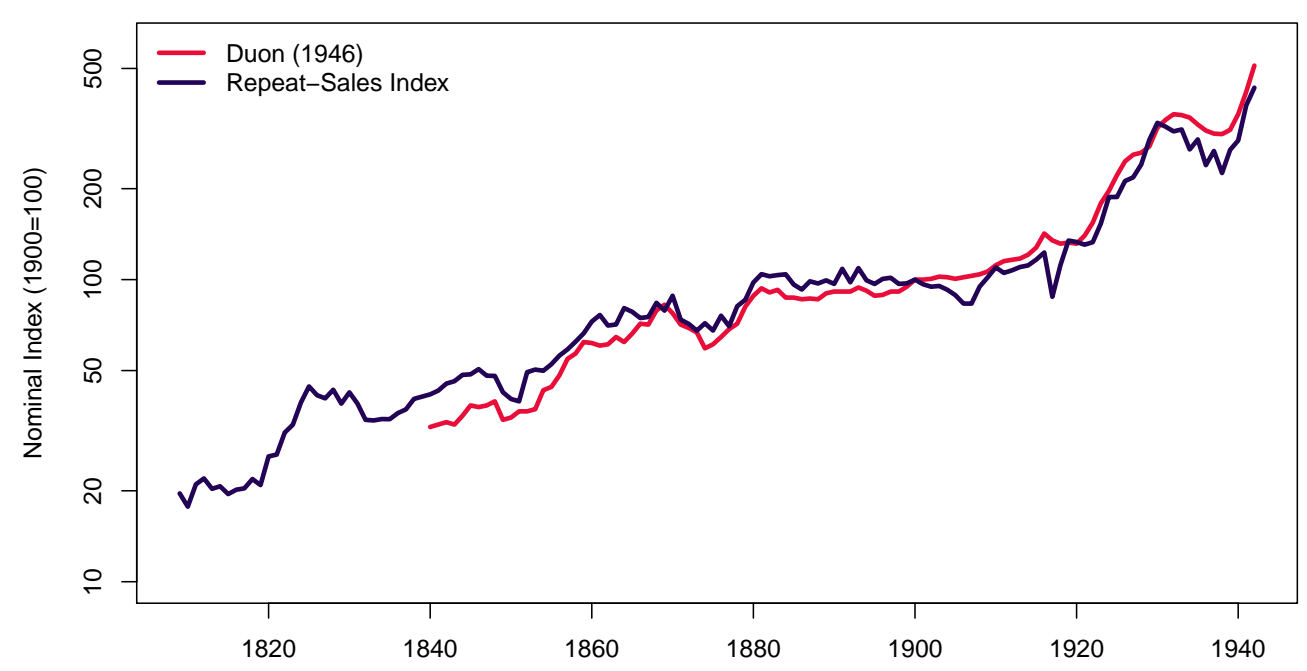

(a) Price Index, Paris, 1809-1943

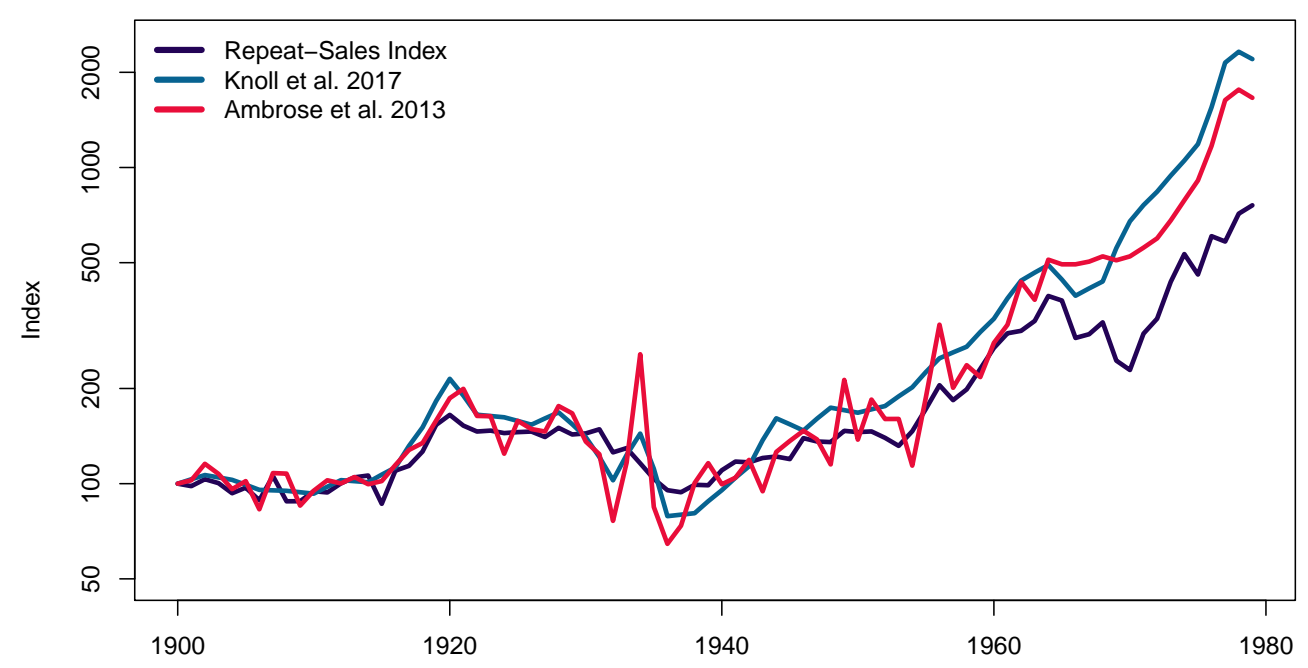

(b) Price Index, Amsterdam, 1900-1979

Notes: The plots compare our new repeat-sales indices for Paris and Amsterdam with earlier repeat-sales indices that rely on smaller samples, and sometimes apply smoothing techniques. The indices from Knoll et al. (2017) switch to national data from 1935 (Paris) and 1970 (Amsterdam) onward. The index of Ambrose et al. (2013) uses national data from 1965. 
price index. Duon then smoothed his index using a moving average of unknown length (Duon, 1943), to cope with the low number of transaction observations.

Given the overlap in methodology, it is not surprising this index displays a very similar long-term development to ours, but due to the smoothing, it is less volatile than our index, which is visible in the graph and in the numbers: the standard deviation of annual capital gains is $5.8 \%$, relative to $8.6 \%$ for our index in the same period, as can be observed in Panel A of Table 4.3. This table also shows a correlation of 0.39 between house price changes according to the Duon index and our Paris house price index.

Knoll et al. (2017) use this index until 1935, and then splice it to a national repeatsales house price index. However, house prices bottomed out in 1935, and because the index of Duon (1946) is smoothed, the splicing takes place at an overly high index level, resulting in an underestimation of the fall in house prices that took place in the 1930s. As a result, Knoll et al. (2017) find much higher average house price growth in this period. So due to the smoothing of the index of Duon (1946), Knoll et al. (2017) substantially underestimate volatility in the 1870-1935 period, and then overestimate price growth afterward due to incorrect splicing. The correlation between the Knoll et al. (2017) index and our Paris index is only 0.31.

For Amsterdam, we compare the capital return part of our index to the indices in Ambrose et al. (2013) and Knoll et al. (2017). Both indices are primarily based on the bi-annual Herengracht index of Eichholtz (1997), which employs repeated sales of 17th-18th century properties along Amsterdam's best-known canal, ensuring constant quality. Ambrose et al. (2013) estimated an annual version of the Herengracht index, while Knoll et al. (2017) annualize the original index by applying the bi-annual observation only for the first of the two years. To interpolate the second year, which is now missing, they take simple averages of the previous and next observation.

These differences in index construction and sample result in substantial differences between our indices and these alternative estimates. Without adjustment, the low number of observations in the annual Herengracht index of Ambrose et al. (2013) results in unrealistically high levels of volatility. The volatility in Knoll et al. (2017) is more realistic and closer to ours, but this seems coincidental given the rather forceful smoothing technique they use. While smoothing can bring volatility down to levels that are seemingly more realistic, it completely changes the process generating annual capital gains, and will result in volatility estimates that are biased and inconsistent. By estimating annual indices - both for Paris and Amsterdam - that are based on much larger sets of repeat sales, our new indices strongly mitigate these estimation problems.

We find that capital gains in Amsterdam are substantially lower in our index relative to Ambrose et al. (2013) and Knoll et al. (2017). The Herengracht database, on which their indices are based, has a very low number of observations from the mid1960s onward, resulting in very high but even more uncertain growth rates of house prices. Knoll et al. (2017) switch to a national house price index from 1970 built on median prices, whereas Ambrose et al. (2013) already do so from 1965. The difference in capital gains is completely caused by this switch to an annual index that does not 
control for quality. Low index quality, as defined by the degree to which the index adjusts for the changing quality of the underlying housing stock, results in apparently higher house price increases, as Gatzlaff and Ling (1994) and Eichholtz et al. (2020a) show.

The issues discussed above result in relatively low correlations between the capital gains in our new house price index for Amsterdam and those in Ambrose et al. (2013) and Knoll et al. (2017): we find levels of 0.31 and 0.40, respectively. Because the volatility of capital gains is much higher than that of yields (Table 4.2), these differences in index quality will also be the main cause of the low correlation in total returns between our series and Jordà et al. (2019a).

We do not think these issues are unique to these series for Paris and Amsterdam but apply to historical series of house prices and rent prices more generally. Given limitations in data availability, long-term series of house prices and rents still frequently build on relatively thin databases, and often splice together indices constructed with different methods, from different localities, and based on different housing quality segments. For example, for rent prices in the United Kingdom, Chambers et al. (2020) suggest the estimates of Jordà et al. (2019a) diverge from those in their paper and in Eichholtz et al. (2020b) due to inappropriate index splicing and insufficient control for quality changes in the underlying housing stock. For house prices in the United States, Fishback and Kollmann (2014) provide an extensive comparison with the well-known index of Shiller (2005) for the years between 1920 and 1940, when the Shiller index relies on self-reported repeat-house values rather than actual transaction prices. They show that the resulting index substantially underestimates the magnitude of the boom and the bust in this period relative to several alternative measures they develop.

\section{Yields}

Figure 4.6 plots the development in net rental yields at the portfolio level for both Paris and Amsterdam relative to the yields in Jordà et al. (2019a). Comparing our net yields to those of Jordà et al. (2019a) for the periods when both samples overlap, we find that our annual net yields are about one percent lower. Correlations between our net yields and those of Jordà et al. (2019a) are only 0.11 for Paris and -0.08 for Amsterdam.

The low correlations with Jordà et al. (2019a) are partly caused by the fact that we adjust for taxes and vacancies, while they do not. However, when we look at correlations between the gross yields (not reported in the table) we observe that they are slightly higher but still low: 0.22 for Paris and 0.21 for Amsterdam. ${ }^{21}$

These low correlations show it is difficult if not impossible to accurately derive the evolution of rental yields over time from series of house prices and rents that relate to different sets of dwellings. The French yield series in Jordà et al. (2019a) are primarily based on quality-controlled series of Parisian prices and rents but originate from different sources and housing market segments, and use different methodologies. For their Dutch yield estimates, Jordà et al. (2019a) combine quality-controlled series of

\footnotetext{
${ }^{21}$ For Paris we also find very low correlations with the Jordà et al. (2019a) yields using alternative measures of yields, with a value of 0.02 when we use the gross yield series based on Le Figaro data.
} 
Figure 4.6: Net Yields, Paris and Amsterdam

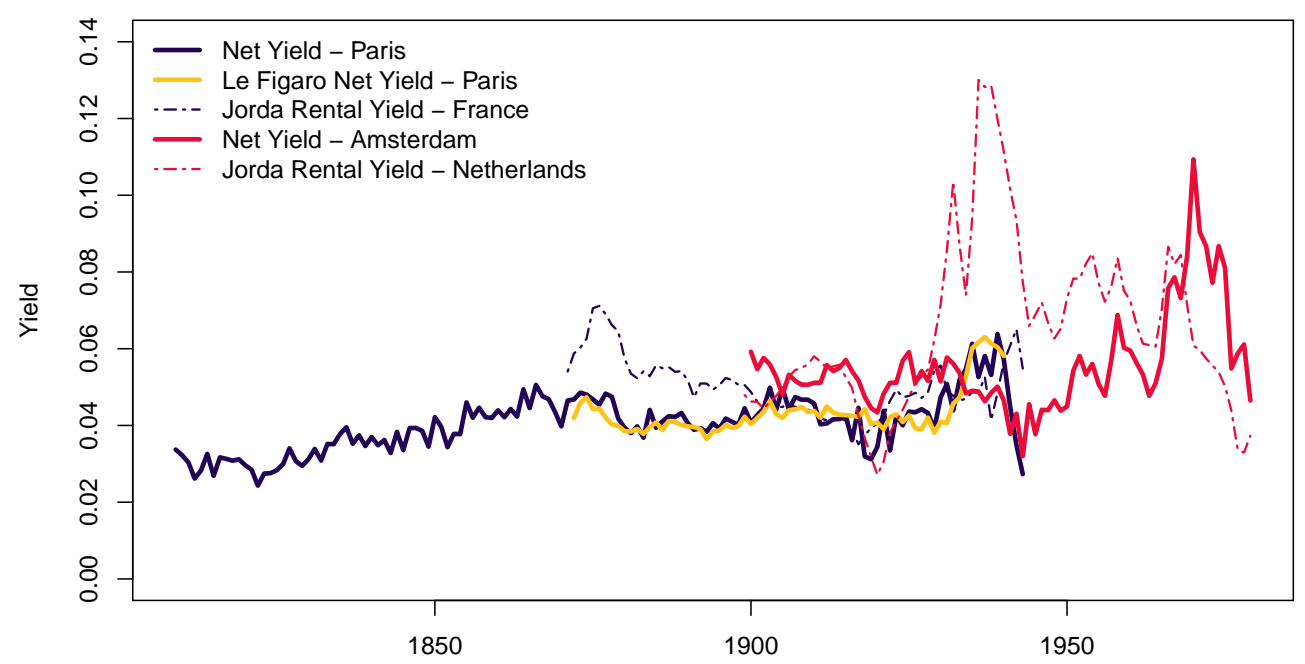

Notes: Net yield estimates for both cities are compared to the implied yield underlying the Jordà et al. (2019a) total return calculation. While the yield series from Le Figaro correlates closely with the estimates from the Sommier, the yield series from Jordà et al. (2019a) show a very different evolution, in particular for Amsterdam.

Amsterdam house prices with national rent price series that do not control for quality. Brounen et al. (2014) use similar data sources and are therefore prone to the same error. These considerations also hold for papers that combine more recent house price and rent data, such as Eisfeldt and Demers (2018) and Giglio et al. (2018).

\section{Total Returns}

Relative to Jordà et al. (2019a), we estimate lower total returns: The difference in annual geometric returns is $1.4 \%$ for Paris, and $2.2 \%$ for Amsterdam. For both cities, about $60 \%$ of the total real return difference between our returns and those of Jordà et al. (2019a) is caused by lower capital gains, and the remaining $40 \%$ can be attributed to lower yields. While the volatility estimates for Amsterdam are comparable to Jordà et al. (2019a), we find higher estimates of volatility for Paris. For the periods where our samples overlap, we find substantially lower Sharpe ratios. For Paris, we find a Sharpe ratio of 0.31 instead of their 0.54 , and 0.34 instead of 0.55 for Amsterdam (Sharpe ratios not reported in the table). ${ }^{22}$

We find low correlation coefficients in annual log returns between our total return series and those of Jordà et al. (2019a), even as both series attempt to track the same asset base. For Paris and Amsterdam, the correlations are 0.30 and 0.39 , respectively.

In the previous subsections, we have already provided a number of reasons why the series used in Jordà et al. (2019a) result in distorted estimates of capital gains and

\footnotetext{
${ }^{22}$ Using bill rates instead of bond yields whenever they are available, our Paris Sharpe ratio is 0.42 against 0.69 in Jordà et al. (2019a), and for Amsterdam, these numbers are 0.44 and 0.64 , respectively
} 
yields over the short term, and we will point at some limitations in our own series in the robustness section. Some of these distortions, such as the use of smoothing in the underlying capital gains series in Jordà et al. (2019a), will reduce correlations in shortterm return estimates, but vanish in importance at longer horizons. We thus might expect higher correlations when computing returns at longer horizons.

To better understand how total returns developed and correlated over mediumterm horizons, Table 4.4 shows the level of average total log yields and returns for different horizons of up to 10 years, both in nominal and in real terms.

Table 4.4: Longer Horizons

\begin{tabular}{|c|c|c|c|c|c|c|}
\hline \multirow[t]{2}{*}{ Index } & \multirow[t]{2}{*}{ Length } & \multicolumn{2}{|c|}{ New Index } & \multicolumn{2}{|c|}{ Jorda et al. } & \multirow[t]{2}{*}{ Corr. } \\
\hline & & Mean & SD & Mean & SD & \\
\hline \multicolumn{7}{|c|}{ Paris, 1871-1943 } \\
\hline Log Yields & 1 & $4.3 \%$ & $0.6 \%$ & $4.9 \%$ & $0.7 \%$ & 0.11 \\
\hline Log Yields & 3 & $12.9 \%$ & $1.6 \%$ & $14.7 \%$ & $2.1 \%$ & 0.17 \\
\hline Log Yields & 5 & $21.5 \%$ & $2.4 \%$ & $24.4 \%$ & $3.3 \%$ & 0.20 \\
\hline Log Yields & 10 & $42.4 \%$ & $4.0 \%$ & $48.1 \%$ & $5.7 \%$ & 0.16 \\
\hline Nominal Log Returns & 1 & $6.7 \%$ & $9.3 \%$ & $7.9 \%$ & $7.5 \%$ & 0.30 \\
\hline Nominal Log Returns & 3 & $20.3 \%$ & $17.4 \%$ & $22.8 \%$ & $14.5 \%$ & 0.59 \\
\hline Nominal Log Returns & 5 & $33.4 \%$ & $22.5 \%$ & $37.5 \%$ & $17.5 \%$ & 0.81 \\
\hline Nominal Log Returns & 10 & $65.4 \%$ & $28.2 \%$ & $74.1 \%$ & $22.5 \%$ & 0.88 \\
\hline Real Log Returns & 1 & $2.8 \%$ & $11.4 \%$ & $4.0 \%$ & $9.4 \%$ & 0.55 \\
\hline Real Log Returns & 3 & $9.2 \%$ & $21.8 \%$ & $11.7 \%$ & $22.2 \%$ & 0.78 \\
\hline Real Log Returns & 5 & $15.6 \%$ & $29.6 \%$ & $19.8 \%$ & $31.9 \%$ & 0.91 \\
\hline Real Log Returns & 10 & $32.2 \%$ & $41.1 \%$ & $41.0 \%$ & $44.7 \%$ & 0.95 \\
\hline \multicolumn{7}{|c|}{ Amsterdam, 1900-1979 } \\
\hline Log Yields & 1 & $5.4 \%$ & $1.2 \%$ & $6.3 \%$ & $2.1 \%$ & -0.08 \\
\hline Log Yields & 3 & $16.2 \%$ & $3.4 \%$ & $19.1 \%$ & $6.1 \%$ & -0.12 \\
\hline Log Yields & 5 & $27.0 \%$ & $5.5 \%$ & $32.2 \%$ & $9.7 \%$ & -0.16 \\
\hline Log Yields & 10 & $53.6 \%$ & $9.7 \%$ & $65.6 \%$ & $17.4 \%$ & -0.22 \\
\hline Nominal Log Returns & 1 & $8.0 \%$ & $10.4 \%$ & $10.2 \%$ & $10.7 \%$ & 0.39 \\
\hline Nominal Log Returns & 3 & $23.4 \%$ & $19.6 \%$ & $31.1 \%$ & $24.3 \%$ & 0.65 \\
\hline Nominal Log Returns & 5 & $38.8 \%$ & $27.1 \%$ & $51.1 \%$ & $33.1 \%$ & 0.75 \\
\hline Nominal Log Returns & 10 & $75.3 \%$ & $37.8 \%$ & $101.8 \%$ & $51.3 \%$ & 0.78 \\
\hline Real Log Returns & 1 & $4.8 \%$ & $10.4 \%$ & $7.1 \%$ & $9.2 \%$ & 0.31 \\
\hline Real Log Returns & 3 & $14.3 \%$ & $17.9 \%$ & $21.8 \%$ & $18.4 \%$ & 0.46 \\
\hline Real Log Returns & 5 & $23.3 \%$ & $23.9 \%$ & $35.8 \%$ & $21.7 \%$ & 0.52 \\
\hline Real Log Returns & 10 & $44.9 \%$ & $33.9 \%$ & $71.4 \%$ & $30.3 \%$ & 0.49 \\
\hline
\end{tabular}

Notes: This table reports average total geometric returns across different horizons, comparing estimates in Jordà et al. (2019a) to our new estimates. We compute these by summing log returns over the respective horizons. Note that the sample periods used to compute annual and longer-term horizons do not fully overlap, because we need more prior return observations to compute returns over longer horizons.

For both Paris and Amsterdam, we find that the low correlations between the yields in our series and those in Jordà et al. (2019a) persist when we compute them based on summed log yields across increasing medium-term horizons. This is concerning for housing return estimates based on implied yields, since in the long run most of the 
real return to housing originates from yields rather than capital gains.

However, over medium-term horizons, the dominant component that is driving total return volatility is still the volatility of capital gains. Comparing the volatility of total yields in Table 4.4 to those of total returns shows that yield volatility remains minor relative to total return volatility at all horizons. This is particularly so for Paris.

We find stronger correlations in nominal and real returns at longer horizons, particularly for Paris. This is consistent with the underlying data. For 93\% of the overlapping sample period, the French capital gains data in Jordà et al. (2019a) is based on a representative but smaller set of Parisian repeat-sales. Given the limited importance of yields in driving total return volatility, the French total return estimates in their paper should correlate highly with our series over longer horizons, when the applied smoothing techniques only have a limited impact on total returns.

For Amsterdam, the increase in correlation for lengthening time horizons is much less pronounced, particularly in real terms. First, yield volatility in Amsterdam is much higher compared to Paris, and therefore also contributes significantly to total return estimates over longer horizons. This should decrease correlations with Jordà et al. (2019a), since implied yield series do not correlate with actual yield series, also over longer horizons. Second, the capital gains series in Jordà et al. (2019a) switch to a national house price index that does not adjust for quality from 1970 onward, which diverges substantially from the capital gains based on our quality-adjusted series for Amsterdam. Finally, most of the increase in correlation in nominal terms appears to be driven by high inflation rates that are reflected in both series, since the increase in correlation between 3- and 10-year horizons is negligible in real terms.

Because small errors in rent or price series can lead to persistent under- or overestimation of yields, we find that implied return and yield series have low correlations with more accurately constructed return series, both in the short and the long term. So only when the underlying series very precisely track the evolution of rents and sale prices and cover the same location and housing market segments, can return estimates from implied returns be informative about the evolution of longer-term returns. Unfortunately, long-term series having such properties are exceedingly rare.

\section{Comparison with Equities}

One important finding in Jordà et al. (2019a) is that rental housing earns substantially higher risk-adjusted returns as compared to equities. Across all countries they study, they find geometric returns to housing to be on average $2 \%$ higher than returns on equities, but with only half the volatility. In a follow-up paper, Jordà et al. (2019b) specifically point to a housing risk premium puzzle.

To make the comparison with equities for Paris rental housing investments, we can employ two high-quality historic series on French equity returns. For the period between 1809 and 1854, we use the index constructed by Arbulu (1998), and for the years from 1854 to 1943 , we use the blue-chip stock market index created by Le Bris and Hautcoeur (2010). Both compute total returns weighted by market capitalization. ${ }^{23}$

\footnotetext{
${ }^{23}$ The index of Le Bris and Hautcoeur (2010) is an improvement over Arbulu (1998), since the Arbulu
} 
Over the full sample period, the log returns on French stock investments equal $6.5 \%$ per year, which is similar to the $6.3 \%$ we find on housing. Given the larger volatility of stock returns of $12.8 \%$, Sharpe ratios on housing $(0.25)$ are still higher than those for equities (0.17). We find similar differences when we restrict our sample to the 18701943 period, when Jordà et al. (2019a) use the index of Le Bris and Hautcoeur (2010), with a Sharpe ratio for housing of 0.31 relative to 0.19 for equities.

For the Netherlands, Jordà et al. (2019a) use the series of Eichholtz et al. (2000) to estimate stock returns, with an average return of $6.3 \%$ and a volatility of $18.8 \%$ between 1900-1979. Using bond yields, this results in a low Sharpe ratio of 0.10 relative to our estimates for Amsterdam rental housing of about 0.34 . We should note that the Dutch equity returns and Sharpe ratios - based on the data of Eichholtz et al. (2000) are low compared to those in other countries in this period (Jordà et al., 2019a). Given data limitations, Eichholtz et al. (2000) estimate dividend yields in the first half of the sample rather than actually measuring them. There is some evidence that this underestimates equity returns. For the 1901-1928 period, Derks (1933) reports total returns to investments in companies with the largest market capitalizations across industries, including all dividends, approximately equally-weighting sampled stocks, and including firms that eventually went bankrupt. The average log total return for these stocks in $1901-1928$ is $6.4 \%$ relative to $4.3 \%$ in the data in Eichholtz et al. (2000). This is similar to the return on housing for this period.

Although our improved estimates close about two-thirds of the gap in Sharpe ratios between housing and equities that Jordà et al. (2019a) report for Paris, and about half of the gap in Amsterdam, our findings still point to higher risk-adjusted returns for housing relative to equities. ${ }^{24}$ Beyond potential limitations in data, we also see more fundamental explanations for this finding.

First, there were substantial transfer taxes on Parisian housing during the period that we study, while such taxes were absent or negligible for stocks. The transfer tax rate in Paris varied between $4 \%$ and $15 \%$ during our sample period, averaging $6.8 \% .^{25}$

If we would compute yields on the basis of property prices plus transfer taxes (so assuming an infinite holding period), property returns would fall by about $0.25 \%$ percent per year, reducing the Sharpe ratio on Paris rental housing to 0.21 . This is a lower bound on the impact of transaction taxes on returns. If we compute taxes based on the median holding period in our repeat-sales sample of 9.57 years, total returns would fall by $0.7 \%$ per year. For our Parisian sample, this would bring the Sharpe ratio on

(1998) index weights returns by the market capitalization of each industry, but averages returns across firms within an industry, which overestimates returns at the end of the sample period. Le Bris and Hautcoeur (2010) instead uses weights at the firm level to compute total returns. Before 1854, the bias in Arbulu (1998) is likely negligible given the low number of stocks per industry. Between 1854 and 1890, returns on both indices are very similar.

${ }^{24}$ Note that Jordà et al. (2019a) use arithmetic returns to compute Sharpe ratios, whereas we report here on geometric average returns. Using arithmetic average returns reduces the relative gap in Sharpe ratios, given the higher volatility of equity returns relative to housing returns.

${ }^{25}$ From the Revolution to 1816 it was $4 \%$, after which it rose to $5.5 \%$, and remained unchanged until 1905 , when it was raised to $7 \%$, then to $10 \%$ in 1920 before rising to $15 \%$ in 1926 . It fell to $12 \%$ in 1929 before rising again to $13.5 \%$ around 1935 . 
housing down to 0.17 , equal to the Sharpe ratio on equities.

For Amsterdam, transaction taxes were lower, amounting to $2.5 \%$ before 1970 and $6 \%$ after that. As a result, computing yields on the basis of sales prices plus transaction taxes reduces yields only by $0.15 \%$. Assuming median holding periods similar to Paris, total returns would fall by $0.3 \%$ per year. This would reduce Sharpe ratios by a small amount to 0.32 .

A second key reason for this gap is that diversification is more costly for real estate than for equities, and for nearly all investors it is impossible to own more than just a few properties. As we noted when estimating capital gains, estimated return volatilities increase once we base them on smaller samples, so reducing Sharpe ratios. We will analyze the role of idiosyncratic risk in the next section, but we will first discuss the limitations of our own index estimations, and do some analyses of their robustness.

\subsubsection{Robustness}

Although our indices offer a substantial improvement over existing ones, both due to the much larger sample and the application of a consistent methodology, some limitations apply to our series of capital gains and yields. We discuss these in this section and perform robustness checks.

\section{Capital Gains}

The repeat-sales methodology alleviates most concerns regarding unobserved quality differences when estimating the capital gains component of our index, but that still leaves a few measurement issues. First, we cannot observe changes in the quality of a given property over time. Since our estimation method tracks the same parcels, most of which still exist today, quality improvements are likely a more significant concern than unobserved depreciation, given the improvements in housing quality in the 19th and 20th centuries. To gauge the magnitude of this, we turn to our Parisian tax sample, which covers a small subset of streets in Paris. The first register of the Sommier (most data from before 1860) reports on the evolution of cadastral values on a property over time. On paper, cadastral values would only change in case of significant quality changes to the property, implying we can use the change in cadastral values between the 1810 s and the 1850 s to estimate the value of unobserved quality improvements and the corresponding bias. We should note that the cadastral values were highly debated, so political elements might have also played a role in their determination (Bourillon, 2008). Additional information comes from the tax register for Sainte-Avoye. For the period between 1855 and 1926 it reports the number of windows on a property over time. Significant renovations or upgrades of properties often resulted in changes in the number of windows, and we use the annual growth rate of the number of windows on a property as an estimate for quality improvement. Adjusting for outliers, as we also did in our own capital gains estimates, both samples point to an unobserved quality improvement of about $0.4 \%$ per year. We should note that between World War I and 1943 this number is likely smaller or even negative: due to 
strict rent controls maintenance expenses fell and older properties started depreciating (Ellickson and Le Bris, 2019; Duon, 1946).

Second, because we do not observe the universe of transactions in a city, but rely on sampling, our series possibly still overestimate the volatility in aggregate capital gains. To estimate the elasticity of volatility with respect to the number of index pairs for our samples, we make 1000 random draws of $99 \%$ of our sample of repeat-sales pairs, and estimate the volatility of the resulting index. For Amsterdam, we find that a $1 \%$ decrease in the number of observations increases index volatility by $0.11 \%$ (or 0.011 percentage point). For Paris, we find a larger elasticity of $0.26 \%$ (or 0.023 percentage point). Increasing the sample size will gradually reduce this elasticity. Combining the first two points, our estimates thus likely slightly overestimate both the level and volatility of capital gains.

A third possible concern relating to the capital component of the total return is that our Amsterdam index not only relies on transaction prices but also on appraisals. If these appraisals deviate from actual transaction prices in systematic ways, our results will be biased. In Figure 4.5b, we also display the house price index based on transaction prices only, and we find a very comparable evolution over time. Table 4.5 Panel B reports summary statistics of both indices. We find a very comparable capital gain $(2.6 \%$ relative to $2.8 \%)$, but larger volatility $(10.4 \%$ relative to $11.9 \%)$. The increase in volatility is primarily driven by the $54 \%$ decrease in the number of observation pairs in the transaction-only index. To illustrate this, we re-estimated the index 1000 times by drawing random $46 \%$ samples from our set of repeat-sales pairs that include appraisals. This results in a $1.4 \%$ average higher estimated volatility, which is very similar to the increase in volatility when moving to observations from transaction prices only.

\section{Yield Estimates}

Several robustness checks assess the degree to which our gross yield series are prone to estimation errors. We report the results of these checks also in Table 4.5.

For both cities, we first compare the average gross yields to annual median yields, which are less sensitive to outliers in the data. We find that these median gross yield levels are similar to the average yields for Paris, where we are most concerned about noise and outliers, and slightly higher for Amsterdam. In Amsterdam, this difference results from the fact that larger and more expensive properties have lower yields, which is not taken into account when looking at median yields.

For Amsterdam, all sales and rent price data are matched in the same year, but some sales observations originate from appraisals. To assess whether our inclusion of appraisal data for Amsterdam results in biased estimates of gross yields we compare gross yields based on auction prices only (11,658 gross yields) to our baseline series that include data from appraisals (24,058 gross yields). We find that the two series result in nearly identical yields and have a correlation very close to one.

For Paris, our gross yields estimates are based on rent observations that are typically not from the same year as the price observation to which we match it. We do adjust the rent observations for changes in the market rent between the year of the 
Table 4.5: Robustness of the Return Estimates

\begin{tabular}{lccccc}
\hline Index & Period & \multicolumn{2}{c}{ Geometric } & Arithmetic & Corr. \\
& & Mean & SD & Mean & SD \\
\hline \hline
\end{tabular}

\section{Paris}

Panel A: Gross Yields

\begin{tabular}{lcccccc} 
All observations & $1809-1943$ & $6.9 \%$ & $1.1 \%$ & $7.1 \%$ & $1.2 \%$ & \\
All observations, rent within 10y & $1809-1943$ & $6.8 \%$ & $1.1 \%$ & $7.0 \%$ & $1.2 \%$ & 0.92 \\
Median Yield & $1809-1943$ & $6.9 \%$ & $0.9 \%$ & $7.1 \%$ & $1.0 \%$ & 0.91 \\
All observations & $1809-1854$ & $6.1 \%$ & $0.7 \%$ & $6.3 \%$ & $0.7 \%$ & \\
Rent contracts only & $1809-1854$ & $6.3 \%$ & $0.9 \%$ & $6.5 \%$ & $0.9 \%$ & 0.77 \\
All observations & $1872-1940$ & $7.4 \%$ & $1.1 \%$ & $7.7 \%$ & $1.2 \%$ & \\
Le Figaro & $1872-1940$ & $7.3 \%$ & $1.0 \%$ & $7.6 \%$ & $1.1 \%$ & 0.81 \\
All observations & $1883-1884 / 1932-1939$ & $8.8 \%$ & $1.3 \%$ & $9.2 \%$ & $1.5 \%$ & \\
Le Figaro & $1883-1884 / 1932-1939$ & $8.9 \%$ & $1.5 \%$ & $9.3 \%$ & $1.7 \%$ & 0.81 \\
Realized Auction Yields & $1883-1884 / 1932-1939$ & $9.3 \%$ & $1.7 \%$ & $9.8 \%$ & $1.8 \%$ & 0.74 \\
\hline
\end{tabular}

Amsterdam

Panel B: Capital Gains

\begin{tabular}{lllllll} 
All observations & $1900-1979$ & $2.6 \%$ & $10.4 \%$ & $3.1 \%$ & $10.7 \%$ & \\
Excluding Appraisals & $1900-1979$ & $2.8 \%$ & $11.9 \%$ & $3.5 \%$ & $12.8 \%$ & 0.86 \\
\hline
\end{tabular}

Panel C: Gross Yields

\begin{tabular}{lrrrrrr} 
All observations & $1900-1979$ & $9.9 \%$ & $2.0 \%$ & $10.5 \%$ & $2.3 \%$ & \\
Excluding Appraisals & $1900-1979$ & $10.1 \%$ & $2.2 \%$ & $10.6 \%$ & $2.5 \%$ & 0.98 \\
Median Yield & $1900-1979$ & $10.5 \%$ & $2.6 \%$ & $11.1 \%$ & $2.9 \%$ & 0.98 \\
\hline
\end{tabular}

Panel D: Net Yields

\begin{tabular}{lllllll} 
All observations & $1900-1979$ & $5.4 \%$ & $1.2 \%$ & $5.6 \%$ & $1.3 \%$ & \\
Excluding Appraisals & $1900-1979$ & $5.5 \%$ & $1.3 \%$ & $5.6 \%$ & $1.3 \%$ & 0.98 \\
\hline
\end{tabular}

Panel E: Total Returns

\begin{tabular}{lllllll} 
All observations & $1900-1979$ & $8.0 \%$ & $10.3 \%$ & $8.7 \%$ & $10.6 \%$ & \\
Excluding Appraisals & $1900-1979$ & $8.2 \%$ & $11.9 \%$ & $9.2 \%$ & $12.7 \%$ & 0.86 \\
\hline
\end{tabular}

Notes: This table compares, for both Amsterdam and Paris, and for various subperiods the baseline estimates on capital gains and portfolio yields in the main body of the paper to alternative specifications and data. We also report correlations with our baseline estimates. For Amsterdam, we compare estimating the index with appraisals (benchmark) or without appraisals. For Paris, we compare benchmark yields to yields from actual rent contracts only, and from asking yields in the newspaper Le Figaro. We also compute a series of yields that only includes rental observations within 10 years of the sale price. Finally, we compute for both cities net yields based on a high- and low-cost scenario. 
rent observation and the price observation, but this may still bias our gross yield estimates. We test whether our yield estimates are sensitive to changing the maximum permissible time difference between a rent observation and a transaction price observation on the same property. If we reduce this difference from 30 years (baseline) to 10 years, estimates do not change significantly.

A potentially more severe concern for the Paris data is that most yields are based on observations of successions or donations, which are based on self-reported values of rental leases, only verified ex-post by registrars. After 1918, legal changes also imply that the link between actual rental prices and succession and donation values becomes much less clear-cut. To assess whether our estimates deviate in fundamental ways from actual rents, we first compare our Parisian yield series to gross yields based on the subset of rent data coming from actual rental contracts, for the period 1809 to 1854. For other periods, there are too few data points on rental contracts to make such a comparison. We find that these approaches result in identical estimates of yields, except that the series based on rental contracts seems more noisier due to the lower number of observations.

To test the validity of the succession and donation data in the final part of the 19th century and during the 20th century, we construct an alternative series of gross yields from the ads in Le Figaro. To construct the series, we separate the advertisements for the 1872-1914 period and the 1917-1940 period, given that ads for regular property sales were not common before World War I. Before World War I, when the data list rental revenues and minimum prices, we estimate gross yields by regressing all individual log yields on year-fixed effects and a set of five-year dummies that take the value of one in case the auction ad did not explicitly specify that the rental revenue was a gross revenue. To arrive at our series of yields, we take the exponentiated coefficients on the year fixed effects, subtracting the median log yield difference $(-0.33)$ between minimum prices and realized prices from the Cote des terrains et immeubles in 1883-1884. From 1917 onward, we combine data from advertisements of auction announcements (with minimum prices and rental revenues) with advertisements for regular sales (with asking prices and gross revenues), and regress log gross yields on year fixed effects. To control for price differences between minimum bid prices and asking prices, we add five-year dummies for advertisements that list minimum bid prices, and again a set of five-year dummies to control for advertisements of minimum bid prices that do not explicitly specify that the rental revenue was a gross revenue. We use the exponentiated coefficients on the year-fixed effects to create the final series.

In Table 4.5 we compare our estimates of succession-based gross yields to the gross yield series from Le Figaro. Figure 4.6 plots the developments in net yields for both series. The resulting estimates are almost identical and correlate strongly. The yield series based on Le Figaro advertisements appears somewhat smoother than our succession-based estimates. This could be caused both by the fact that realized yields move more quickly than asking yields in newspapers, but also by noise in our estimates of succession-based yields. The latter is likely a more important concern after 1918 when we cannot identify the exact capitalization rate used in the succession data, and yields are visibly noisier. 
The gross yields used in this alternative estimate still rely on asking yields rather than realized market yields. To investigate the importance of this, we compare the yields that are based on succession prices with those from realized yields in auctions reported in the Cote des terrains et immeubles (1883-1884, 208 observations) and Le Temps Immobilier (1932-1939, 611 observations). An additional advantage of this data and the Figaro data is that we observe the rents at the same time as the sale price, and that the rents are reported by the seller. If there existed any incentive to under-report rental values in the successions data, then sellers had an incentive to over-report when advertising their properties. We find the realized yields only result in slightly higher average yields compared to the data in Le Figaro and the data from the Sommier. Although the number of observations is low, the realized yields also correlate closely with succession-based yields (correlation $=0.74$ ) and with asking yields from Le Figaro (correlation $=0.92$ ).

In summary, there is no evidence that our baseline estimates of gross yields result in significantly biased estimates of yields. There is some evidence that our yields contain a bit of short-term noise, particularly after 1918, but this does not significantly impact our total return estimates, as the volatility of yields is small relative to the capital gains volatility.

\subsubsection{Representativeness}

We discuss the representativeness of our total return indices here, focusing first on the question of whether the 19th and 20th century period we investigate is representative of present times, and subsequently discussing how our returns compare to those for other regions and cities.

It would seem intuitive that papers investigating housing returns using more recent data than ours would be more representative of current expected returns than the historic study we do, but this is not necessarily the case.

More recent studies (Eisfeldt and Demers, 2018; Favilukis et al., 2017) typically use housing samples starting in the late 1970s or in the 1980s, and interest rates have mostly been on a downward trajectory since then, likely biasing total housing returns upward relative to their long-term average. Given the fact that interest rates do not have room to fall much further, it is unlikely that these favorable conditions for total housing returns will continue. A longer time frame, in which interest rates have been stationary, may yield results that are more representative of the future trajectory of housing returns.

This concern is illustrated by the lack of any real capital gains on housing for both Paris and Amsterdam in our sample. Finding low long-run capital gains is in line with the broader estimates in Jordà et al. (2019a) and Chambers et al. (2020), while Eisfeldt and Demers (2018) find that capital gains and net rental yields contribute evenly to the total return. However, this seems to result from the specific period they study, and the fact they exclusively focus on nominal returns. In nominal terms, capital gains contribute about a third to our total returns.

Another concern regarding the validity of our indices for present times may lie 
in changing housing market institutions. It is important to note that the institutions of the markets we study were not that different from residential housing investment markets in present times. Both Paris and Amsterdam were characterized by a mixture of institutional and private investors, as well as owner-occupiers, much like they are in present times. These markets have also been very similar in terms of property rights and the rule of law regarding housing ownership. The registrations behind the Parisian Sommier foncier continued after World War II, although in a slightly different form. The Amsterdam auctions that we study continue to be held to this day and are still frequently used to buy and sell investment properties.

We now turn to the final, more complicated question as to how the returns we have estimated for Paris and Amsterdam compare to estimates for other regions. If we contrast our estimates to the numbers Jordà et al. (2019a) report for other countries, we find that our real return index for Paris ranks lowest among all countries for which Jordà et al. (2019a) provide return numbers in the $1870-1943$ period. ${ }^{26}$ For all countries that Jordà et al. (2019a) consistently report on in the 1900-1979 period, 8 countries have higher returns and 3 countries have lower returns than Amsterdam, with real returns on average $1.1 \%$ per year higher in other countries.

Without a proper counterfactual, it is difficult to identify whether these differences are driven by measurement error or by actual differences in returns across regions. However, the comparatively low return estimates for Paris and Amsterdam, capital cities that grew substantially over time, do suggest that measurement errors might also impact their return series for other countries. For the United Kingdom, Chambers et al. (2020) also find that the housing returns in Jordà et al. (2019a) are substantially higher than their estimates.

We should note that our return estimates for Paris and Amsterdam are higher than the estimates for residential real estate in Chambers et al. (2020). They report a real total return of $2.3 \%$ for residential real estate and a return of $5.4 \%$ for agricultural real estate. We again want to highlight that it is difficult to establish exactly what is driving these differences. Beyond studying a different country with a slightly different methodology, their data do not consistently come from the same regions, and combine rural and urban data.

In that regard, a more representative comparison might be to look at a consistent urban sample. Although precise return numbers are not available for other cities, implied discount rates of urban housing cash flows could be informative of long-term housing returns. Bracke et al. (2018) use leasehold data to measure housing discount rates in London for different horizons. They find discount rates of housing cash flows in the short-term in the range of 5-6\%. For medium to long horizons of 10 to 75 years, discount rates hover around $4-5 \%$, similar to the real return and net yields we document in this study. For very long horizons of over 100 years Bracke et al. (2018) find lower discount rates of $2-3 \%$. This number is in line with Giglio et al. (2015), who estimate very long-run discount rates based on modern leasehold and freehold data from

\footnotetext{
${ }^{26}$ Their sample only includes four countries in 1870 , increasing to 11 countries by 1900 . Average returns in all these 11 countries are higher in the 1870-1943 period than our estimates for Paris. Nearly all of this data is for urban areas.
} 
London and Singapore.

\subsection{Idiosyncratic Risks}

The indivisibility of assets, high transaction costs, and the capital intensity of real estate investments hamper the construction of well-diversified direct property portfolios. ${ }^{27}$ For markets in which investors cannot fully diversify, theoretical studies (for instance Levy, 1978; Merton, 1987) and empirical evidence (e.g. Fu, 2009; Eiling et al., 2019) suggest a link between idiosyncratic risk and expected returns in the cross-section.

How relevant is idiosyncratic risk at the property level? Giacoletti (2019) shows that idiosyncratic risk accounts for the majority of housing risk in California and that the idiosyncratic variance is constant across holding periods. Sagi (2020) models the price process for US commercial real estate and also finds a dominant role of idiosyncratic risk. Due to data limitations, these and other papers (e.g. Peng and Thibodeau, 2017; Eisfeldt and Demers, 2018) ignore the contribution of income to total return and risk and concentrate on the capital return only. ${ }^{28}$ The novelty of our study is to investigate asset-level systematic and idiosyncratic risk based on total gross returns for different investment horizons of up to 20 years and to highlight the role of yield risk in total return risk. Also, we broaden the geographic and temporal scope of this discourse by using European data and by covering large parts of the 19th and 20th centuries.

Ignoring costs, the total gross log return $r$ for a portfolio of properties of any size $i$ with the holding period $n$ going from year $t=0$ to year $t=n$ is defined as follows, with $y_{i, t}$ denoting $\log ($ Yield +1$)$ at time $t$, and $g_{i, t_{n}}$ the $\log$ capital gain until period $t_{n}:{ }^{29}$

$$
r_{i, t_{n}}=\sum_{j=0}^{n-1} y_{i, t=j}+g_{i, t_{n}}
$$

Correspondingly, the variance of any individual gross property return can be written as follows:

$$
\begin{array}{r}
\operatorname{Var}\left(r_{i, t_{n}}\right)=\sum_{j=0}^{n-1} \operatorname{Var}\left(y_{i, t=j}\right)+2 \times \sum_{0 \leq j<k \leq n-1} \operatorname{Cov}\left(y_{i, t=j}, y_{i, t=k}\right) \\
+2 \times \sum_{j=0}^{n-1} \operatorname{Cov}\left(y_{i, t=j}, g_{i, t_{n}}\right)+\operatorname{Var}\left(g_{i, t_{n}}\right)
\end{array}
$$

Equation 4.5 shows that the variance of a gross housing return is a function of the variance of the yield and the capital gain, as well as the covariance in yields over time,

\footnotetext{
${ }^{27}$ In 1832, half of Amsterdam's property investors owned one building only. About 90 percent of investors owned fewer than five properties (Fryske Akademy, 2018).

${ }^{28}$ For commercial real estate, Peng (2016) combines capital returns and Net Operating Income (NOI) figures to arrive at asset-level total return estimates but does not analyze idiosyncratic risk.

${ }^{29}$ Note that we assume that properties transact at the start of each year, and that annual rents are paid directly afterward, so that yields are earned from $t=0$ until $t=n-1$.
} 
and the covariance of the yield with the capital gain. In the remainder of this section, we aim to assess each of these quantities both at the property level as well as across space, with a focus on the first three terms of equation 4.5. This analysis will mostly focus on Amsterdam, since the Amsterdam sample contains precise repeated data on yields and capital gains at the property level, with yields and capital gains observed at the same time. Because we do not have dwelling-level observations on costs, we only look at gross returns. We both look at the variance of total property-level risk and the variance of property-level idiosyncratic risk. We obtain the latter by deflating yields and capital gains with their average market values.

\subsubsection{The Dispersion of Yields}

Starting with the first term of Equation 4.5, we look at dispersion in yields across different properties. For Paris and Amsterdam, the standard deviations of all log gross property yields are $4.2 \%$ and $4.8 \%$, respectively. Only a minor part of these variations in yields is due to changes in aggregate housing yields: the volatility of residual yields after controlling for changes in market yields is $4.0 \%$ for Paris and $4.1 \%$ for Amsterdam.

Still, city-wide yield estimates might not capture all systematic variation in local yields and total returns. For instance, Giacoletti (2019) studies idiosyncratic capital gains risk at the zip-code level and finds pronounced differences across low- and highincome areas. While the historic cores of Paris and Amsterdam are very compact and at least one order of magnitude smaller than today's cities, yields and returns might differ even at more granular geographic levels.

Figure 4.7 displays the spatial dispersion of gross yields at different periods for neighborhoods in both cities. In both cities, we find higher yields in poor areas, in line with evidence for modern cities from smaller databases (Bracke, 2015; Desmond and Wilmers, 2019).

Investigating the degree of spatial structure in yields more formally, we estimate Moran's I statistics (Moran, 1950) to tests for correlations in yields among nearby houses. For Amsterdam, gross yields in excess of the market without neighborhood controls are found to be strongly correlated. ${ }^{30}$ and the null hypothesis of yields being randomly distributed across Amsterdam can be rejected firmly (p-value: $<0.001$ ). This implies that local factors introduce non-random deviations from the city-wide trends for Amsterdam and that investors cannot expect, on average, the same level of yields across the city.

When calculating excess returns at the neighborhood level, the Moran's I test statistics cease to be significant (p-value: 0.29 ). This implies that the time-invariant neighborhood fixed effects capture most of the spatial heterogeneity in yields and more detailed demarcation of sub-markets or more granular neighborhood-level indices will not improve the empirical fit.

For Paris, the Moran's I statistic is positive but not statistically different from 0 (pvalue: 0.20 ) even before accounting for neighborhood differences. When calculating

\footnotetext{
${ }^{30}$ We find Moran's I, which measures spatial autocorrelation, to be 0.010 , with an expectation of 0.00006 and a variance of 0.0000016 .
} 


\section{Figure 4.7: Median Excess Gross Yields, per Neighborhood}

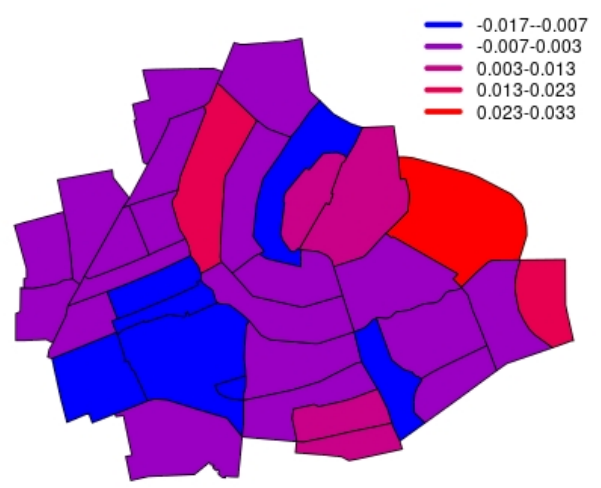

(a) Yields, Amsterdam, 1919-39

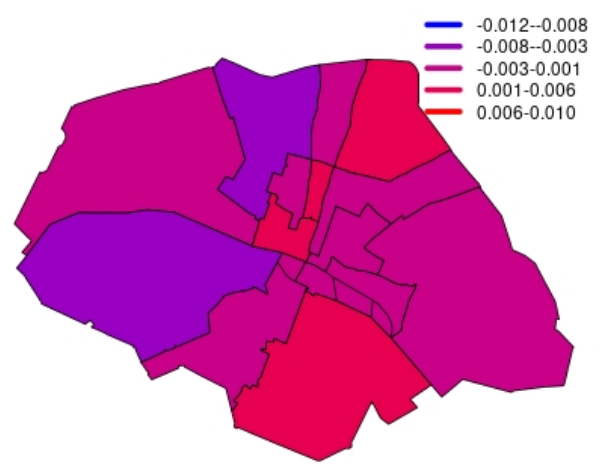

(c) Yields, Paris, $1820-40$

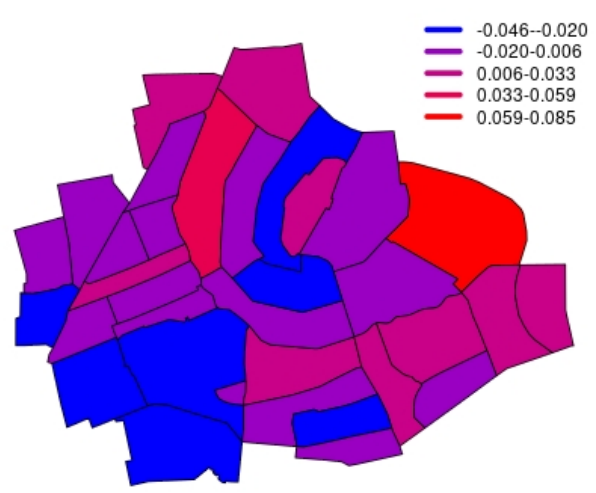

(b) Yields, Amsterdam, 1950-70



(d) Yields, Paris, 1870-1900

Notes:

Excess yields are calculated as the difference of property-level gross yields and city-wide median of yields for a given year. Excess yields are not homogeneously distributed in space as clusters of low yields are found next to high yield areas. For Amsterdam, the deviations from the city-wide averages are large to begin with, getting more pronounced in time but tend to keep the relative ranking: The upmarket canal belt and museum areas, for instance, persistently deliver the lowest yields right next to the high-yield, working class Jordaan. Differences in yields are only partially offset by higher subsequent capital gains. Correlation of asset-level yields at time of purchase and the subsequent capital gains are estimated to be only 0.22 for Amsterdam. In Paris, yields are more densely distributed in space but again mostly persistent in time: Only the northwest experienced a distinct yield shift.

Boundaries are based on Vasserot arrondissements ${ }^{a}$ for Paris and contemporary neighborhoods for Amsterdam.

\footnotetext{
$a_{\text {https://maps.princeton.edu/catalog/stanford-cj936rq6257 }}$
} 


\subsubsection{The Covariance of Yields and Capital Gains}

We now present some stylized facts regarding the second and third terms of Equation 4.5 , the covariance of yields over time, and the covariance of yields with capital gains. To do so, we use a subset of 5,852 transaction pairs from Amsterdam where we observe both the yield at purchase, the yield at the time of sale, and the capital gain.

Aggregating across all holding periods, we find that gross yields at purchase have a low but statistically significant correlation of 0.13 with subsequent capital gains, while gross yields at sale have a negative correlation of -0.21 with realized capital gains. If we compute these correlations on the basis of residual yields, controlling both for yield differences across neighborhoods and market yields, we find stronger correlations of 0.20 and -0.46 respectively. Thus, investors purchasing a high-yield or selling a lowyield property typically realize higher capital gains, irrespective of the holding period.

This result is partially mechanical when transaction prices are distributed around fundamental asset values. However, the positive correlations between initial yields and subsequent capital gains are not strong enough to flatten out spatial differences in yields that persist in time: Figure 4.7 illustrates the persistence of yield differences at the neighborhood level. ${ }^{31}$

The question is to what extent this yield persistence also applies to individual properties, which brings us to the second term in Equation 4.5, the covariance in yields over time. If yields are very persistent over time, the yield at purchase will have a lasting consequence on returns over the entire holding period.

Figure 4.8 plots the correlation in yields across holding periods of up to 20 years, based on the same set of repeated yields. Because we aggregate data by holding period, we only have a limited number of observations for each point in the plots, starting at 587 repeated yields for one-year holding periods and dropping to below 100 repeated yields for holding periods longer than 15 years. This implies that the individual data points are relatively noisy, particularly when considering that data points within a given holding period can come from the entire 1900-1979 period. Second, we also report the residual correlation after controlling for market and neighborhood yields, by subtracting the median yield per year and neighborhood across the sample at the time of each transaction from the property-level yields.

Importantly, the correlation across yields over time is substantial, and only gradually decays over time. Thus, properties with higher or lower gross yields will continue to earn above- or below-market gross yields for decades after purchase. Since the variation in median gross yields over time is small relative to the total variation in yields, we do not find large differences in this pattern when controlling for market prices. However, given persistent differences in yields across neighborhoods, we find a stronger decrease in correlations across holding periods after controlling for neighborhood differences.

\footnotetext{
${ }^{31}$ At the market level, Ambrose et al. (2013) show that while rents and prices are cointegrated, it often takes decades for deviations from long-run rent-price ratios to correct. Price adjustments account for most of the eventual reversion to the mean, which is in line with the positive correlations between yields and capital gains found in this study.
} 
Figure 4.8: Correlation Repeated Yields

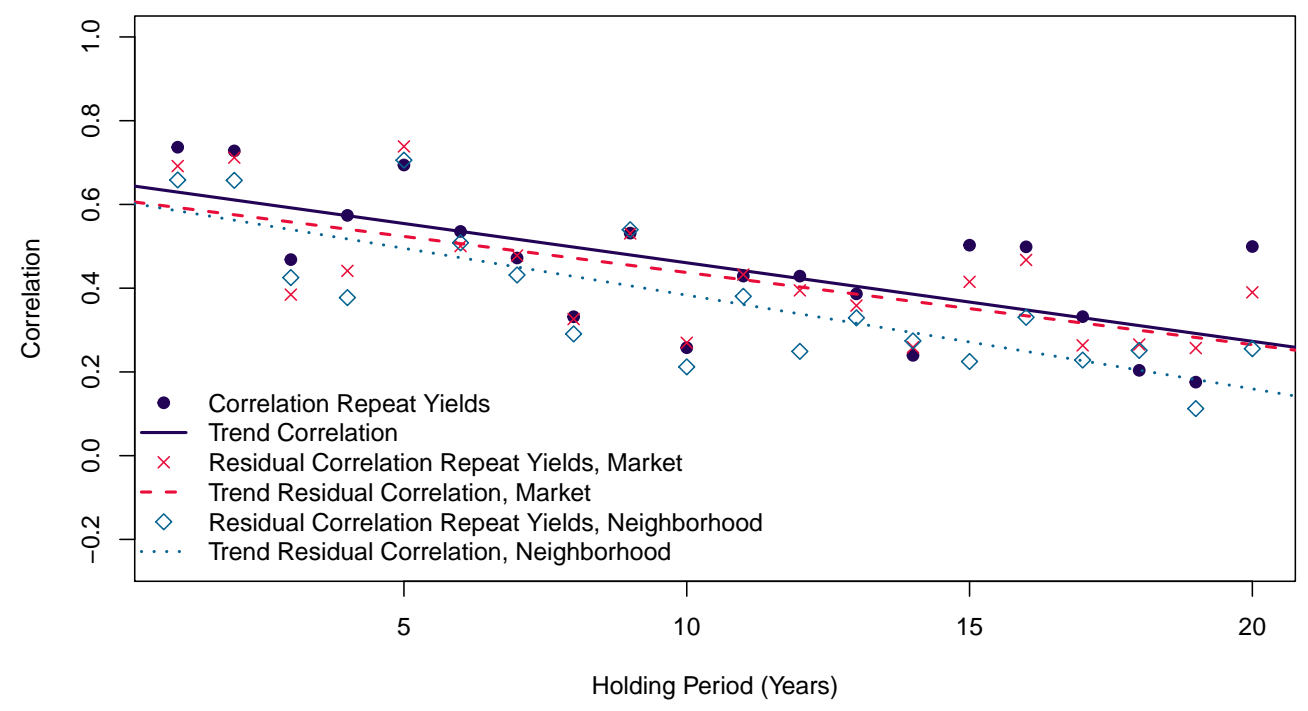

Notes: Based on 4,371 pairs of repeat sales in Amsterdam with holding periods of 20 years or less, the correlation of yields at purchase and sale is estimated for various holding periods (in years). In general, both yields are positively correlated. The effect fades away for longer holding periods. The residual correlations are estimated after subtracting the median yield for the entire market at the time of each transaction from the respective yields. Correlations of neighborhood-level yield residuals fall more quickly in time than correlations for market-wide residuals. 


\subsubsection{Total Return Risk and its Components}

We now proceed to estimate the contribution of each component of Equation 4.5 to the variance of total returns to housing investments for different holding periods. We can compute these numbers both based on total returns and on residuals returns, the latter adjusted for average neighborhood yields and changes in market prices. To estimate these, we pool all 5,582 transaction pairs by holding period and estimate each of the individual variance terms.

We can estimate the variance of yields and capital gains for each holding period directly, but we need to make two assumptions to estimate the covariance terms, since these contain terms that we do not observe in our data. First, we assume that the covariance in yields on a property during a holding period is independent of the length of that holding period, so that we can use the observed covariance between the yield at purchase and the yield at sale to estimate covariances in yields during holding periods. Formally, this implies that for all observations where $k-j=m-l, \operatorname{Cov}\left(y_{i, t=j}, y_{i, t=k}\right)=$ $\operatorname{Cov}\left(y_{i, t=l}, y_{i, t=m}\right)$.

Second, we assume that the covariance between yields during the holding period and the total capital gain is a weighted average of the covariance between the yield at purchase and the capital gain, and the covariance of the yield at sale and the capital gain. This implies that the third term of equation 4.5 can be rewritten as: $2 \times \sum_{j=0}^{n-1} \operatorname{Cov}\left(y_{i, t=j}, g_{i, t_{n}}\right)=n \times \operatorname{Cov}\left(y_{i, t=0}, g_{i, t_{n}}\right)+n \times \operatorname{Cov}\left(y_{i, t=n}, g_{i, t_{n}}\right)$. The main drawback of this assumption is that it magnifies any noise in our estimated covariances between yields and capital gains by a factor $n$. We noted already that we have relatively few repeated-transactions per holding period, implying that we cannot estimate the covariance between yields and capital gains very precisely for each holding period. This noise increases for longer holding periods when the number of observations per holding period drops.

Figure 4.9 plots for each holding period between 1 and 20 years the estimated variance of the total return and its components. Figure 4.9a differentiates between idiosyncratic and systematic risk, Figure $4.9 \mathrm{~b}$ shows the composition of total propertylevel risk.

A clear pattern emerges. For investments with short holding periods, nearly all risk is idiosyncratic and unsystematic risk hardly seems to play a role. But the importance of idiosyncratic risk gradually reduces once we consider longer holding periods.

Importantly, the contribution of each component of total return volatility, depicted in figure $4.9 \mathrm{~b}$, changes over time. Unsurprisingly, most variance in the short term comes from capital gains risk, because the variance of yields is small relative to the variance of capital gains. However, the importance of capital gains variance decays over time, and yield covariance becomes an increasingly important component of total return risk. ${ }^{32}$ Because the correlation between yields and capital gains is positive for the yield at purchase, but negative for the yield at sale, we do not find large aggregate impacts of the covariance between yields and capital gains. Because the negative

\footnotetext{
${ }^{32}$ This pattern also persists when looking at residual yields, adjusting for neighborhood yields and market price changes, which we plot in Appendix D Figure 4.14.
} 
Figure 4.9: Decomposition of Total Risk

(a) Systematic and Idiosyncratic Risk

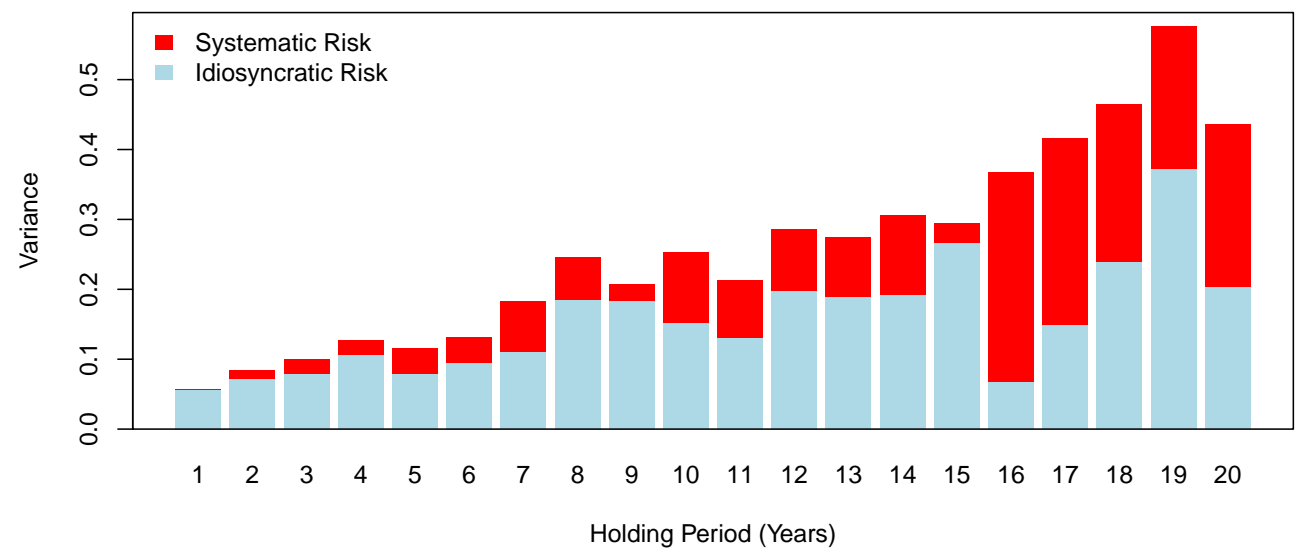

(b) Decomposition of Risk

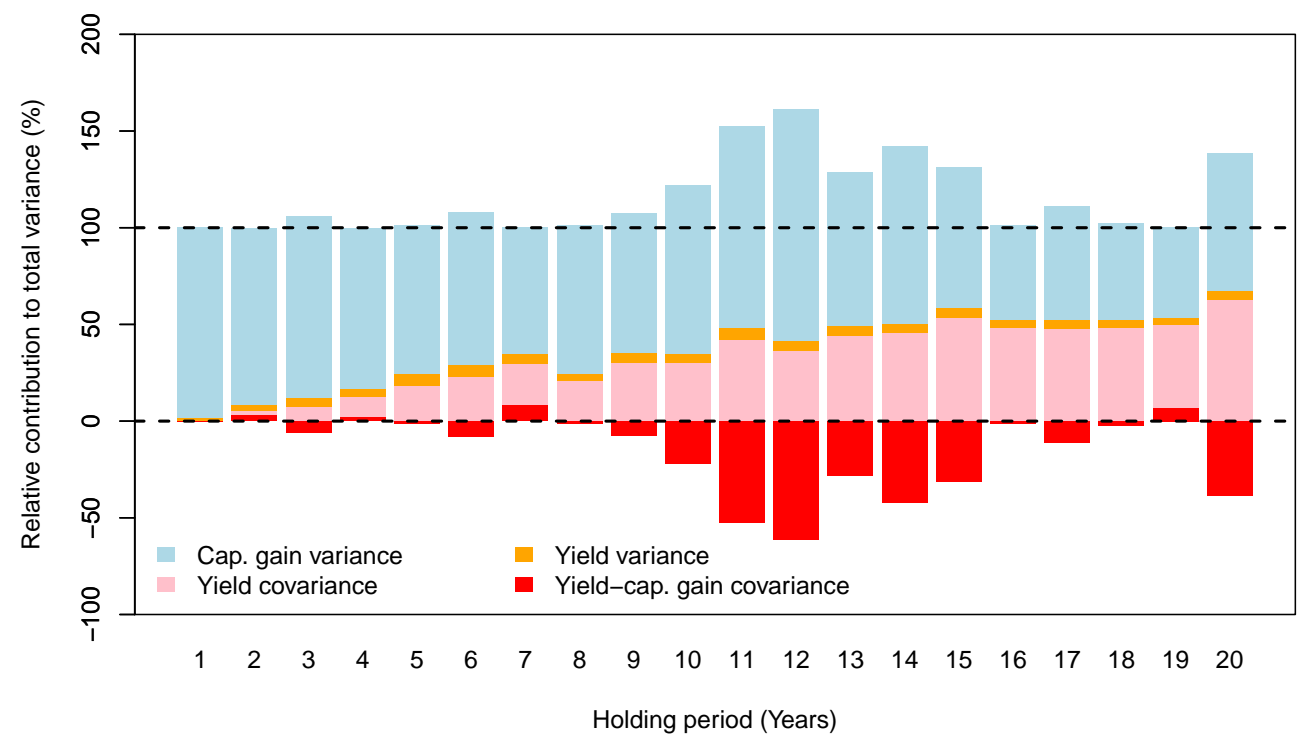

Notes: This plot compares total systematic and idiosyncratic risk based on their variances, and the components of total property-level risk. Residual variance is calculated in excess of city-wide yield and price trends. Most variance in the short term can be attributed to capital gains risk because the variance of yields is small relative to the variance of capital gains. However, the importance of capital gains variance decays over time. 
correlation outweighs the positive correlation, this covariance is negative on average but moves over time due to estimation noise.

\subsubsection{Implications}

Taken together, these results have two important implications for our understanding of the risk and return of individual properties. First, nearly all short-term investment risk at the property level is idiosyncratic, but the fraction of idiosyncratic risk decreases with the holding period, as changes in market-wide trends of capital gains and yields become more important in the long term. For the average holding period of 10 years, we find volatility of market returns of $32 \%$, and volatility of total returns of $50 \%$, which includes idiosyncratic risk. ${ }^{33}$ This implies that for 10 -year holding periods Sharpe ratios would drop by about one third when including idiosyncratic risk.

If idiosyncratic risk followed a random walk - an assumption soundly rejected by Sagi (2020) and Giacoletti (2019) for the idiosyncratic risk of capital gains - the idiosyncratic variance of total returns would scale exactly by the holding period (and volatility by the square root). Our series suggests that the assumption of a random walk should also be rejected for the idiosyncratic risk of total gross returns, although we still document stronger increases in total idiosyncratic risk than Giacoletti (2019), who only looks at capital gains. For example, the five-year idiosyncratic variance is about 0.1 (volatility of around $30 \%$ ), whilst this increases to about 0.25 for twenty-year periods (volatility around 50\%). As a result, the inclusion of idiosyncratic risks has a larger relative impact on total return risk for short holding periods than for long holding periods.

Second, and most importantly, we document that persistence in property-level yields is a crucial risk component for investors, especially in the long run. The increasing importance of yield covariance in total idiosyncratic risk for longer holding periods partially offsets the fact that idiosyncratic capital gains risk barely increases in the holding period (Giacoletti, 2019). This implies that for a long-term investor the initial yield is a much more important source of risk than for a short-term investor, who primarily bets on capital gains. Basically, rents are sticky and will not quickly revert back to their economic fundamentals in case of deviations at purchase. A small part of this persistence can be explained by differences in yields across neighborhoods. Another factor that could be causing these yield differences are structural differences in nontax costs across properties. However, representative long-term data on these costs are difficult to obtain. With short-term data from Milwaukee, Desmond and Wilmers (2019) shows that gross yields are higher in poor areas and that less expensive rental units face higher costs, in line with our evidence for Amsterdam. However, they find that landlords still earn higher net rental returns in poor areas.

Our main results do not change substantially when excluding appraisals from the sample, or when splitting the sample in the pre- and post-World War II period. If many more observations were available, one could estimate capital gains indices at

\footnotetext{
${ }^{33}$ Note that the number of $32 \%$ differs slightly from the $37.8 \%$ reported in Table 4.4 . This is because the figure of $37.8 \%$ is based on all data covering the entire $1900-1979$ period, whereas the $32 \%$ is only based on the small set of repeated observations with a 10-year holding period.
} 
the neighborhood level and fully separate market-wide risk, neighborhood risk, and idiosyncratic risk. Some of the variation in capital gains that we still account for as idiosyncratic risk would then likely be captured by a neighborhood risk factor.

\subsection{Conclusion}

This paper creates new indices describing the net total returns of rental housing for extended periods and compares these to returns reported in recent work (i.e. Jordà et al. (2019a) and Chambers et al. (2020)). We create total return indices for Paris and Amsterdam, for the periods 1809-1943 and 1900-1979, respectively. These indices are based on previously unexplored archival data that we hand-collected and digitized for this study. Our unique contribution lies in the fact that we observe rental yields and values for the same properties, and that we have enough observations to use a repeated measures approach to reliably control for changes in asset quality. In all, we have 44,379 rent and 38,168 price observations for Paris, and 25,834 rent and 35,519 price observations for Amsterdam.

The first main finding is that the geometric average net total return to rental housing is $6.3 \%$ in Paris and $8.0 \%$ in Amsterdam. These returns come with considerable volatility of $8.6 \%$ and $10.3 \%$, respectively. We show that using actual rental yields and capital gains for the same set of properties is essential to obtain reliable estimates of housing return and risk. Relative to Jordà et al. (2019a), who use secondary series, we find substantially lower risk-adjusted returns to housing for both cities and a low correlation with their total return series. This confirms the conclusion by Chambers et al. (2020).

We show that most of the real long-term total return to rental housing stems from the net yield, and that capital returns are small and even negative in real terms for Amsterdam. This is in contrast to Eisfeldt and Demers (2018), who find a more important role for the capital return.

Besides these findings at the index level, our study also makes important contributions regarding property-level investment performance. Our findings regarding the geographic dispersion of rental housing performance and the importance of the holding period show that the yield at purchase is a key determinant of the holding period return at the individual asset level. We find that higher-yielding properties subsequently have higher capital gains, irrespective of the holding period, and that high initial yields are persistent, even over holding periods as long as 20 years.

Regarding the composition of total return risk, we find that the idiosyncratic risk is the dominant part of total risk in the short term, but that the importance of market risk increases over the holding period. Moreover, we show that variation in the capital gain is the dominant factor in total asset risk only in the short term. For holding periods going up to 20 years, yield covariance becomes as important. 


\section{A Identifying and Adjusting Capitalized Rents}

To determine whether a Parisian rent observation from succession and donation values before 1918 is capitalized, we apply a multi-stage procedure. Our intuition is that if we match succession and donation values to transaction prices and actual rent contracts on the same property, we can infer with near certainty whether an observation is capitalized. If a rent is capitalized, dividing the rent by sales prices on the same property should results in yields on average 20 times larger than market yields. Similarly, the capitalized rent price should be on average 20 times larger than the actual rent contracts on the property.

However, because we typically do not observe other sales prices or actual rental contracts in the same time period as the succession or donation, our estimates will be biased if we do not correct for changes in market yields and rent prices.

To estimate a rent price index that we can use to deflate succession values, we use repeated observations of rental contracts, successions, and donations to compute a repeat-rent index, in a similar way as we construct the house price indices. To deal with outliers and capitalized rents, we first deflate all observations with the existing rent index from Eichholtz et al. (2020b), which serves as a prior. We update the index of Eichholtz et al. (2020b) because our aim is not to track rents on new contracts as their index, but current rent payments, which permits us to use a much larger set of observations on successions and donations. To deal with capitalized observations, we exclude pairs that have an absolute index-corrected log rent difference of more than 1. We estimate the index based on all remaining pairs, using their original prices.

Next, we use the scaled rent index divided by the price index to establish a series of prior gross yields. Because both our rent indices and price indices are based on rent prices and sales prices from the same properties, and estimated using exactly the same index technique, this prior yield index should track actual yields relatively closely. To benchmark this index, we set its value so that the period between 1883-1884 has an average yield of $7.1 \%$. For 1883-1884, the data from the Cote des terrains et immeubles provide information on 208 sales prices and rental revenues of properties in Paris.

For each donation or succession $S$ at time $t$, we look up all actual rent contracts $\left(R_{i}\right)$ and sales prices $\left(P_{i}\right)$ on that property that happen within 30 years. For any sales price $j$ on property $i$ taking place at time $s$, with $-30<t-s<30$, we compute the deviation of the estimated yield at time $t$ from the prior yield at time $t$ :

$$
\varepsilon_{i, j, t}=\log \left(\frac{S_{i, t}}{P_{i, j, s}} \times \frac{H P I_{t}}{H P I_{s}}\right)-\log \left(\text { Yield }_{t}^{\text {prior }}\right)
$$

For any rental contract $j$ on property $i$ taking place at time $s$, we compute the deviation of the index-corrected level of rents at time $t$ with the donation or succession value $S$ at time $t$.

$$
u_{i, j, t}=\log \left(S_{i, t}\right)-\log \left(R_{i, j, s} \times \frac{R P I_{t}}{R P I_{s}}\right)
$$

With $n$ denoting the summed number of matched sales prices and $m$ the number 
of matched actual rent contracts, we compute per succession or donation observation $i$ at time $t$ a score:

$$
\text { Score }_{i, t}=\frac{\sum_{j=0}^{n} \varepsilon_{i, j, t}+\sum_{j=0}^{m} u_{i, j, t}}{m+n}
$$

We exclude observations of successions or donations that cannot be matched to a rental price or a sales price. The resulting score measures the average deviation of the succession or donation observation from our prior yield and rent observations. The resulting distribution of scores should peak at zero for observations that are not capitalized, and at three (ln $20 \approx 3$ ) for observations that are capitalized.

To identify the frequency and distribution of capitalized observations, we analyze the resulting distributions of scores at five-year frequencies. Figure 4.10 plots one example for the period of 1834 - 1839. The distribution is clearly bimodal, with peaks around 3 for capitalized observations and peaks at 0 for non-capitalized observations. There is also a limited overlap among the distributions.

Figure 4.10: Example Distribution of Scores, Paris, 1835-1839

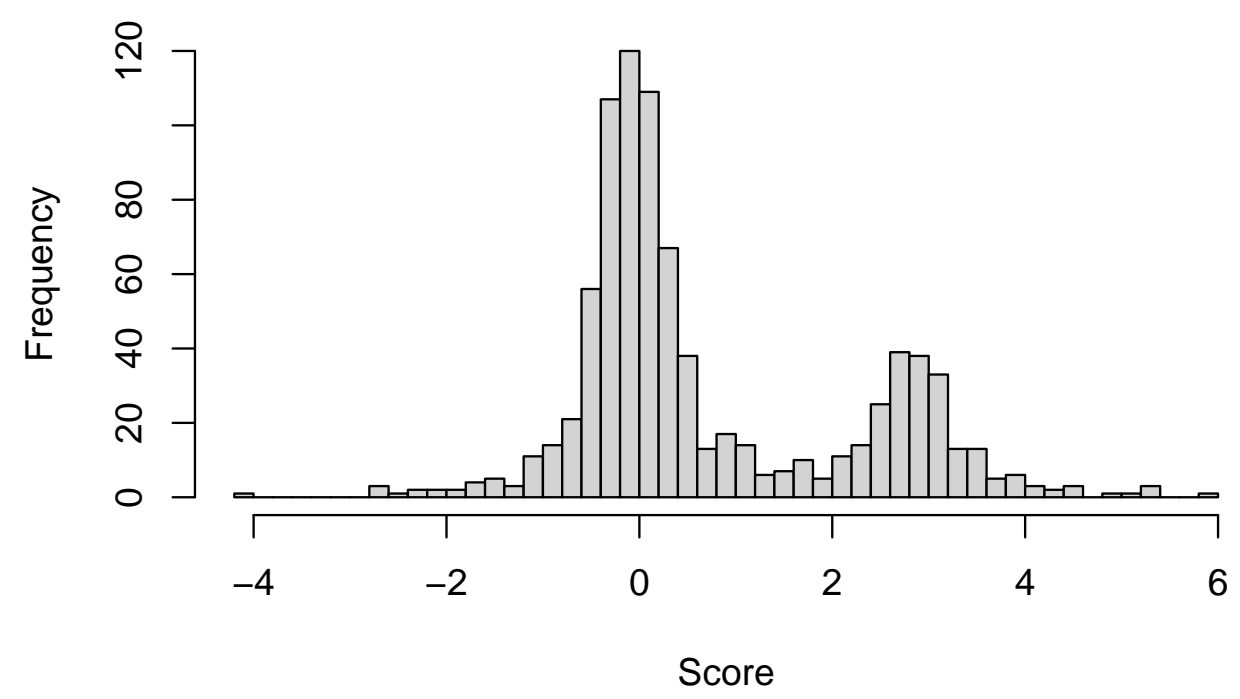

Notes: Distribution of scores for succession and donation observations, by comparing these observations to actual rent contracts on the same properties and on sales prices of the same properties. A score of 0 implies that the succession or donation value matches the actual rent prices and prior yields observed in the data. Capitalized observations center around 3, non-capitalized observations at 0 .

Depending on the fraction of capitalized observations, we adjust the capitalized rent prices. Before 1830, the large majority of succession and donation prices is capitalized. We divide all observations with a score between 1.25 and 4.75 by 20 . Succession and donations with a score between -1 and 1 are not adjusted, observations below 
-1, between 1 and 1.25 and larger than 4.75 are removed. Between 1830 and 1917, most observations are not capitalized. In this period, we do not adjust observations with a score between -1.75 and 1.75 , and we divide succession or donations with a score between 2 and 4 by 20 . We remove observations with a score below -1.75 , larger than 4 or between 1.75 and 2 . The removed rent prices are either extreme outliers, or observations for which there is significant overlap between the distribution of capitalized rents and non-capitalized rents. We remove these observations to reduce uncertainty in our measures, but our results are robust to limiting or extending the number of removed observations. In total, we remove $2 \%$ of the observations on successions and donations (801 observations).

We subsequently use the adjusted data on successions and donations together with the observations on rents to match sales prices to rent prices, following the procedure outlined in the main text. The resulting distribution of log yields (prior to removing outliers), which we plot in Figure 4.11, is smooth without showing evidence of a peak at very high yields, confirming that our analysis has effectively adjusted the capitalized rent observations.

Figure 4.11: Distribution of log Yields, Paris, 1806-1943

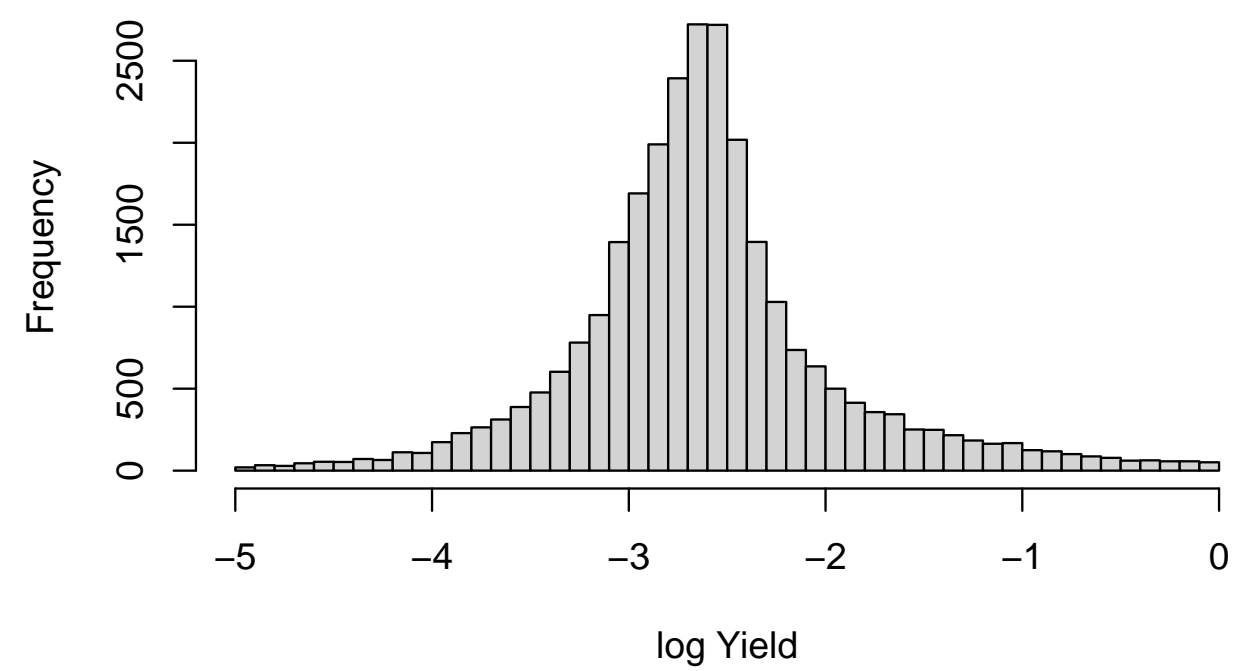

Notes: Distribution of Parisian yields, after accounting for various ways of recording values and rents in the archival records, but before exluding outliers. 


\section{B Tax Data and Analysis for Paris}

Fluctuations in property-level tax rates impact the return to residential real estate. We adjust the gross yield by using a direct tax index levied annually on the inhabitants of Paris. We describe here the nature and the evolution of the taxes that were in effect until 1940.

The French Revolution defined the fundamental principles of taxation that remained in place until World War I. The best description of this tax system is due to legal practitioner Lemercier de Jauvelle (1906). Three main taxes directly affected real estate: a land tax in proportion to a property's cadastral income (contribution foncière), a personal wealth tax based on the rental value of citizens' dwellings (contribution personelle-mobilière), and a tax on doors and windows (contribution des portes et fenetres), a proxy for the luxury of dwellings as manifested by the number of openings to illuminate them. These taxes were annually assessed by the government. ${ }^{34}$

These three taxes were levied according to the presumed value of dwellings. A standard deduction was applied taking into account the owner's costs ( 25 percent tax allowance) to calculate the net cadastral income over which the tax was distributed. The rate for each of these three taxes was set annually and was uniform within a city. All taxes had to be pre-paid by the owners, but the owner could subsequently charge the contribution personelle-mobilière directly to the tenants. The income tax introduced in 1914 radically changed these old taxes. Specifically, its adoption led to the abolition of the tax on doors and windows in 1926. For the post-1914 period, we use data on taxes from Duon (1943), who reports on all taxes that had to be paid by the owner of the property. Until the 1950s, the income tax affected less than a quarter of French tax households (Piketty, 2001).

At the individual asset level, we use the annual amount of taxes imposed on the net cadastral income for almost 4,500 properties between 1807 and 1926 . We then compare these to the income generated by the assets to assess the average tax burden. For the period between 1805 and 1860, we used the tax information noted in the first series of the Sommier foncier which is the most complete available. They give for each house the amount of rental income received, the net cadastral income and the effectively levied taxes. After 1860, we used the statistical data compiled in the land registers of the city of Paris which provide the real rental values of the houses for the years 1862, 1878, 1889, 1901 and 1911 (Département de la Seine, 1890, 1901, 1911). Unpublished tax data relating to the Sainte-Avoye district were used to supplement these statements.

\section{C Costs for Institutional Property in Amsterdam}

We use 2,454 cost observations for the 90 properties of the Amsterdam Burgerweeshuis (an orphanage) and the Doopsgezinde Gemeente (a protestant church) to estimate the fraction of costs over time.

\footnotetext{
${ }^{34}$ We use data on the latter tax to estimate unobserved quality improvements.
} 
Figure 4.12 plots the development in the annual cost fraction, aggregating across all properties in the sample in each year. Between 1925 and 1937, data are interpolated. Annual spending on non-tax costs for these institutional investors varied substantially over time and across properties, since not every property needed maintenance or major renovation at the same time. Because the institutions often pooled major renovations together, and only owned property in a small subset of neighborhoods, we cannot treat our annual measures as representative for the entire city. Instead, we use the average cost figure of both institutions to estimate the expected nontax costs for the average property.

Figure 4.12: Composition of Costs, Institutional Properties, Amsterdam

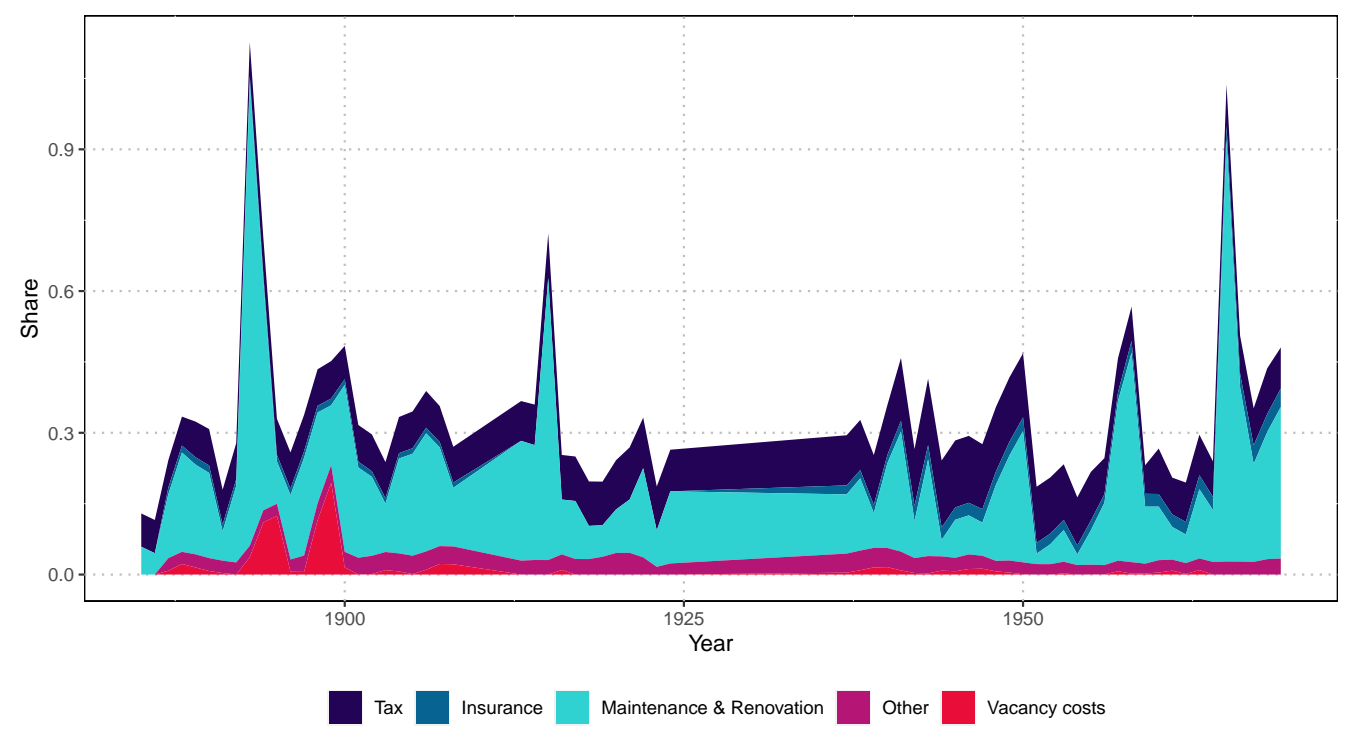

Notes: Figure 4.12 reports the average cost fraction observed among all properties in the sample in each year, compiling data from both the Burgerweeshuis and the Doopsgezinde Gemeente. Data is missing between 1925-1937 and therefore interpolated. The large jumps in the data primarily reflect changes in the maintenance and renovation costs, as properties are typically renovated jointly, causing very high cost fractions in some years.

For each property and in each year, we compute the fraction of rental value that is being spent on costs excluding vacancy costs and taxes. To estimate the average cost fraction in the entire portfolio, we first regress the fraction of costs on the type of property (commercial or residential). This is reported in Columns 1 and 4 of Table 4.6, for non-tax costs and all costs respectively.

Since the cost fraction might change across the distribution of properties and yields, we aim to estimate the fraction of costs for the median property in Amsterdam. To do so, we take the median rental value in the return sample in 1924, when our sample contains over 600 rent observations, and track the market rent price of the 1924 median property using the Amsterdam rent price index of Eichholtz et al. (2020b). We use this median to scale each rental observation $\left(R_{i, t}\right)$ in the database of costs, and 
Table 4.6: Expense Fraction, Rental Property Institutional Investors

\begin{tabular}{|c|c|c|c|c|c|c|}
\hline & \multicolumn{6}{|c|}{ Dependent variable: } \\
\hline & \multicolumn{3}{|c|}{ Non-Tax Costs } & \multicolumn{3}{|c|}{ All Costs } \\
\hline & $(1)$ & $(2)$ & (3) & (4) & (5) & (6) \\
\hline Commercial & $\begin{array}{c}-0.238^{* * *} \\
(0.043)\end{array}$ & $\begin{array}{l}-0.046 \\
(0.053)\end{array}$ & $\begin{array}{c}0.004 \\
(0.061)\end{array}$ & $\begin{array}{c}-0.265^{* * *} \\
(0.044)\end{array}$ & $\begin{array}{l}-0.048 \\
(0.053)\end{array}$ & $\begin{array}{c}0.020 \\
(0.061)\end{array}$ \\
\hline $\log (\mathrm{R})-\log (\mathrm{MedR})$ & & $\begin{array}{c}-0.136^{* * *} \\
(0.021)\end{array}$ & $\begin{array}{c}-0.118^{* * *} \\
(0.023)\end{array}$ & & $\begin{array}{c}-0.154^{* * *} \\
(0.022)\end{array}$ & $\begin{array}{c}-0.130^{* * *} \\
(0.024)\end{array}$ \\
\hline Jordaan & & & $\begin{array}{c}0.214 \\
(0.147)\end{array}$ & & & $\begin{array}{c}0.162 \\
(0.149)\end{array}$ \\
\hline Noordsche Bosch & & & $\begin{array}{c}0.027 \\
(0.039)\end{array}$ & & & $\begin{array}{c}0.039 \\
(0.039)\end{array}$ \\
\hline Old Center & & & $\begin{array}{l}-0.072 \\
(0.054)\end{array}$ & & & $\begin{array}{c}-0.098^{*} \\
(0.054)\end{array}$ \\
\hline Zuid & & & $\begin{array}{c}0.005 \\
(0.189)\end{array}$ & & & $\begin{array}{l}-0.029 \\
(0.192)\end{array}$ \\
\hline Constant & $\begin{array}{c}0.318^{* * *} \\
(0.017)\end{array}$ & $\begin{array}{c}0.265^{* * *} \\
(0.019)\end{array}$ & $\begin{array}{c}0.263^{* * *} \\
(0.030)\end{array}$ & $\begin{array}{c}0.434^{* * *} \\
(0.017)\end{array}$ & $\begin{array}{c}0.374^{* * *} \\
(0.019)\end{array}$ & $\begin{array}{c}0.373^{* * *} \\
(0.030)\end{array}$ \\
\hline Observations & 2,453 & 2,453 & 2,453 & 2,453 & 2,453 & 2,453 \\
\hline $\mathrm{R}^{2}$ & 0.012 & 0.028 & 0.031 & 0.015 & 0.035 & 0.037 \\
\hline Adjusted $\mathrm{R}^{2}$ & 0.012 & 0.027 & 0.028 & 0.015 & 0.034 & 0.035 \\
\hline Residual Std. Error & 0.788 & 0.782 & 0.782 & 0.788 & 0.780 & 0.780 \\
\hline F Statistic & 30.375 & 35.309 & 12.851 & 37.533 & 44.185 & 15.717 \\
\hline
\end{tabular}

Notes: The constant in the regressions in Table 4.6 shows the estimated fraction of rents spent on expenses such as taxes, maintenance costs, and renovations, either excluding taxes (Columns 1-3) or including taxes (Columns 4-6). In Columns 1 and 3, we control for commercial properties, in Column 2 and 5 we also control for the value of the property relative to the median, as more expensive rental properties have a lower cost fraction. In Columns 3 and 6 we control for neighborhood-level differences, with the properties along the canal used as baseline neighborhood.

$$
{ }^{*} p<0.1 ;^{* *} p<0.05 ;^{* * *} p<0.01
$$


estimate the following regression:

$$
c_{i, t}=\alpha+\beta\left[\log \left(R_{i, t}\right)-\log \left(R_{\text {median }, t}\right)\right]+T y p e_{i}+\varepsilon_{i, t}
$$

With $c_{i, t}$ denoting the fraction of non-tax costs and non-vacancy costs spent on a property $i$ at time $t$, and $\alpha$ equalling the cost fraction for the median property. We again control for property type. The results of this regression are reported in Columns 2 and 4 in Table 4.6. To control for differences in location, Columns 3 and 6 add neighborhood fixed effects, with properties in the Canal District (Grachtengordel) used as baseline. The findings in Table 4.6 suggest a non-tax non-vacancy cost fraction of approximately 30 percent, and a total cost fraction of approximately 40 percent.

We find higher but imprecisely estimated costs in the poor Jordaan area, but this is only based on two properties (30 property-year observations). Among the three neighborhoods for which we have most observations, the Noordsche Bosch, the Canal District and the area around the Kalverstraat, we only find an (insignificantly) lower cost fraction in the properties around the Kalverstraat. This is not surprising due to the high location value of the Kalverstraat. Until today, the area around the Kalverstraat is the area with the highest commercial rents per square meter in the Netherlands. 


\section{D Supplementary Figures}

Figure 4.13: Tax and Vacancy Rates, Paris and Amsterdam

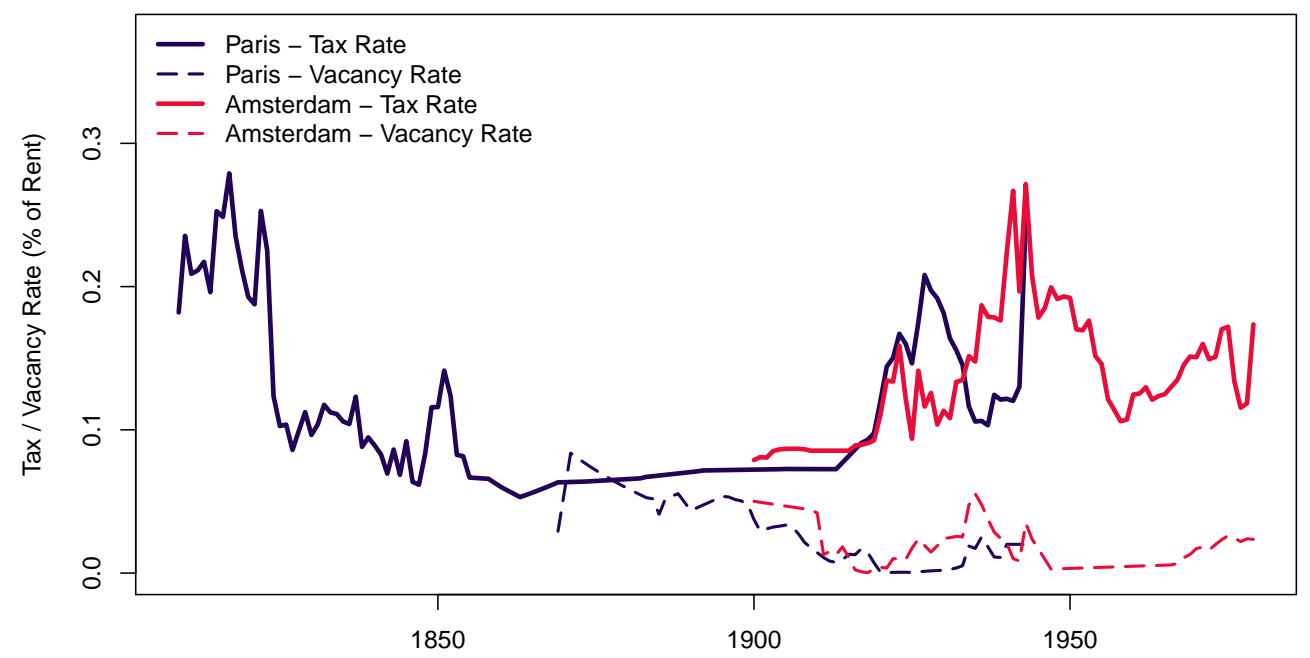

Notes: Figure 4.13 reports the annual tax rate for both Paris and Amsterdam, as a fraction of rents. We also plot the series of vacancy rates for Paris and Amsterdam that we introduced in the data section.

Relative to prices, taxes averaged 15 percent of rental value per year in Amsterdam and 11 percent of rental value in Paris. In both cities, the fraction of rental income lost in taxes varies substantially over time, however. In Paris, large changes in taxes coincided with political and economic instability: taxes were very high after the Napoleonic Wars in the 1810s and after the 1848 revolution. In both Paris and Amsterdam, taxes increased substantially after World War I and during the crisis years in the 1930s.

In terms of vacancies, we find high levels of vacancies in Paris following the crisis and Siege of Paris in 1870, and extremely low levels during the period with strict rent controls after World War I. In Amsterdam, vacancy rates peak during the Great Depression. 
Figure 4.14: Decomposition of Residual Variance

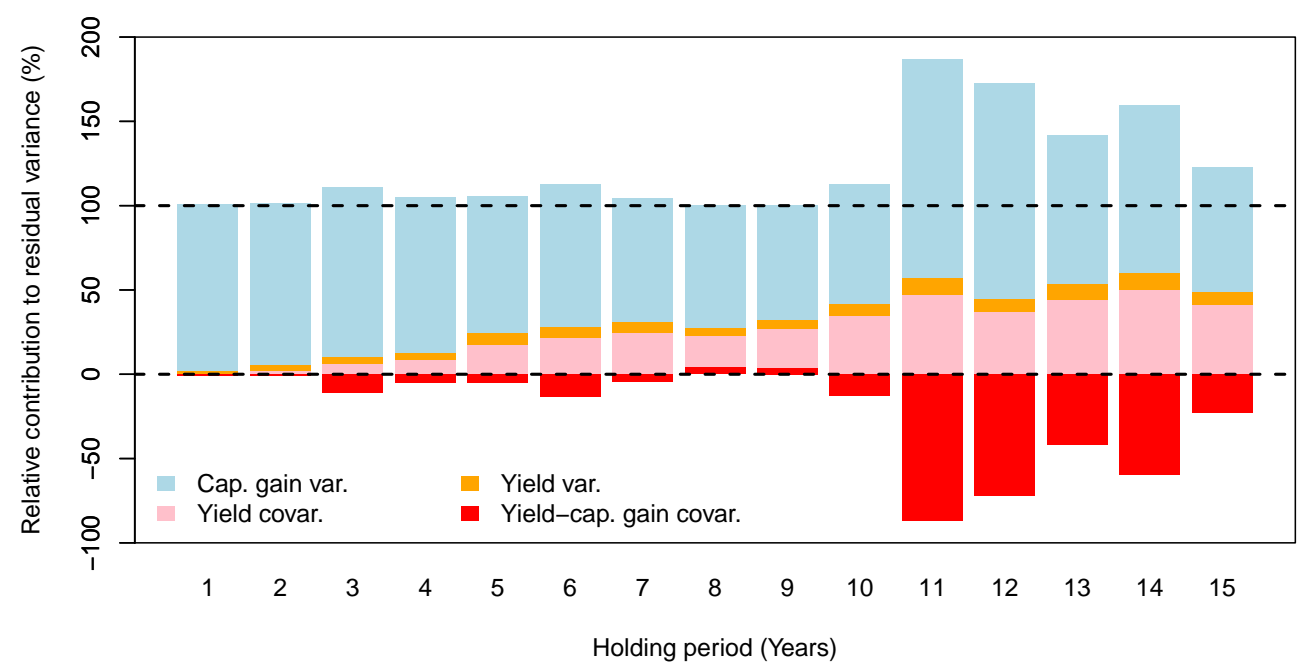

Notes: Most residual variance in the short term stems from capital gains risk as the variance of yields is small relative to the variance of capital gains. However, the dominance of capital gains variance decays as holding periods increase. After period 15, the data become significantly noisier, but the pattern persists. 


\section{Chapter 5}

\section{Reach for Yield and Real Estate}

Over the past decade, interest rates have fallen to historically low levels in many advanced economies. In standard financial theory, such a decline in interest rates should not impact the allocation of wealth among risky and safe assets, because this is only governed by risk preferences and corresponding risk premia (e.g. Campbell, 2017). However, there is increasing concern that investors might be inclined to shift their portfolios towards higher-yielding, riskier assets in order to offset low returns. For example, when the ECB lowered interest rates in September 2019, various central bankers publicly warned this might trigger further asset price increases through reach for yield behavior. ${ }^{1}$ This behavior could be particularly prevalent in housing markets. Investors are increasingly buying real estate (Mills et al., 2019; Bracke, 2019), and policymakers fear this increases house prices and prices out first-time homebuyers. ${ }^{2}$

Although reach for yield behavior has not yet been documented in real estate markets, existing literature has identified reaching for yield in the investment fund industry (Chodorow-Reich, 2014; Hau and Lai, 2016; Andonov et al., 2017; Di Maggio and Kacperczyk, 2017) and in the US corporate bond market (Ammer et al., 2019). However, it is still unclear how this behavior influences asset prices and the mechanisms driving a reach for yield are not yet understood. Most existing work has focused on institutional frictions in the financial sector (Rajan, 2006; Martinez-Miera and Repullo, 2017; La Spada, 2018), but studies have also found evidence for reach for yield behavior in experiments with individuals (Lian et al., 2018) and, theoretically, in models imposing a sustainable spending constraint (Campbell and Sigalov, 2020).

This paper studies whether individual investors reach for yield, and what the implications of this behavior are for aggregate asset prices and the distribution of wealth, with a specific focus on the housing market. Due to the scarcity of portfolio data and the endogenous nature of interest rates makes, it is still difficult to empirically link low interest rates to changes in aggregate asset prices and shifts in investment portfolios. Identification is particularly challenging in housing markets, where low interest rates

\footnotetext{
${ }^{1}$ See "ECB hawks rally against Draghis farewell stimulus," Reuters, September 13, 2019, and "Former central bankers attack ECB's monetary policy," Financial Times, October 4, 2019.

${ }^{2}$ In Amsterdam, where house prices have risen by $60 \%$ in the last five years, the government has recently proposed to ban buy-to-let (The Guardian, March 19, 2019).
} 
directly increase the housing demand of owner-occupiers through changes in mortgage credit conditions.

In the ideal experiment, we would like to observe how investment portfolios, yields, and house prices respond to exogenous shocks in the demand or supply of safe bonds, and corresponding interest rates. These shocks should have no other effects on the economy or housing market. The historical setting in this paper comes close to this ideal experiment. Exploiting the unique characteristics and data of the $17^{\text {th }}-18^{\text {th }}$ century Amsterdam asset markets, this paper shows that individuals reach for yield when interest rates are low, but that this behavior is almost entirely driven by wealthy individuals for whom capital is the main source of income. In Amsterdam, reaching for yield caused large booms and busts in house prices and resulted in growing housing wealth inequality.

The identification in this paper uses periods of war as an instrument for investor demand for real estate. Importantly, wars were uncorrelated to the Amsterdam economy. They were fought outside of Holland and caused by political discontent about the successions of deceased foreign kings. However, wars had enormous implications for investors, as they forced Holland to issue large amounts of bonds. Rentiers bought these bonds as a safe source of income, but saw bond returns and their corresponding capital income exogenously fall in periods of peace. Alternating periods of peace and war caused large booms and busts in house prices, even though bond yields only changed by small amounts. Consistent with the model of Campbell and Sigalov (2020), I show these booms were driven by wealthy rentiers that aimed to offset capital income losses by reaching for yield. During periods of peace, rentiers actively purchased more real estate, and housing risk premia declined substantially. Because individuals with more limited wealth sold their properties or were unable to buy real estate at these inflated prices, reach for yield behavior led to a persistent increase in housing wealth inequality.

Amsterdam has several other aspects that make it an ideal setting to study the impact of investor demand on house prices. The motivation to reach for yield is strongest when interest rates are low, and during the main period of study in this paper, from 1688 to 1780 , yields on perpetual government debt averaged $2.67 \%$. Such persistently low nominal rates are exceptional in history (Homer and Sylla, 1996). These low rates were likely related to a shortage of investment opportunities (De Vries and Van der Woude, 1997). Absent alternatives, $60 \%$ of the total amount of wealth was invested in just two assets: Amsterdam real estate and Holland bonds. Because bond holdings were much more concentrated than real estate holdings, low bond yields primarily reduced the income of wealthy investors. Reaching for yield enabled investors to offset these losses, and real estate was the main asset to do so. This combination of factors makes it possible to identify portfolio shifts and price effects precisely. Later in the $18^{\text {th }}$ century, the combination of low rates and limited asset supply spurred financial development, transforming Amsterdam into the first international capital market. This paper provides, for the first time, a detailed overview of the emergence of these investments.

Despite the enormous amounts of government lending on Amsterdam's capital 
market, its market for private credit was small. Correspondingly, mortgage credit financed only very few property purchases. This rules out that the housing booms and busts were driven by changes in credit conditions, as various papers have suggested for modern housing cycles (e.g. Mian and Sufi, 2009, 2011; Favara and Imbs, 2015; Favilukis et al., 2017). Beyond credit, there were no significant changes in standard housing fundamentals during the main period of study: population, wages, construction, and GDP per capita were stagnant. Expectations about future housing demand thus were unlikely drivers of the observed housing cycles (see Glaeser and Nathanson, 2014), and rent prices changed little over time.

This paper uses archival data on 164,067 real estate transactions in Amsterdam, covering nearly all transactions during the $17^{\text {th }}$ and $18^{\text {th }}$ century. To my knowledge, this is the first dataset that provides full coverage of transactions in a large real estate market for such a long time period. I additionally hand-collected data from 25,962 estate tax records that contain the investment portfolios of $32 \%$ of the Amsterdam population that died with any wealth between 1688 and 1780 . This data makes it possible to link individuals' portfolios to their housing transactions and the level of bond yields. Due to privacy restrictions and data limitations, this has not yet been possible with recent data.

The paper starts by providing new stylized facts of the housing market and aggregate investment in Amsterdam. Matching buyer and seller names to identify repeatsales, I construct a new house price index (1604-1811) that reveals Amsterdam experienced three large booms and busts in house prices. During booms, house prices approximately doubled before reverting to initial values. Two of these boom-bust cycles are well-explained by a standard discounted cash flow model. However, this model fails to account for the large fluctuations in house prices in the first part of the $18^{\text {th }}$ century. In this period, the boom-bust cycle correlated with significant shifts in investor portfolios. During the boom, the share of wealth invested in real estate increased substantially for very wealthy citizens, at the expense of investments in domestic government bonds.

These portfolio shifts correlated with changes in bond yields. For the top $1 \%$ of society, who owned about $57 \%$ of the total wealth, a $1 \%$ decline in yields coincided with a $12 \%$ increase in the share of wealth in real estate, relative to an average investment share of $21 \%$. For investors with limited wealth, these effects were negligible or even opposite. The composition of assets influenced portfolio shifts. Investors with sizeable domestic bond holdings invested a more substantial fraction of wealth in real estate when rates were low.

Of course, these portfolio shifts do not provide any specific information about their underlying causes and the impact of these shifts on house prices. To do so, I exploit outbreaks of war in Europe. During the $17^{\text {th }}$ and $18^{\text {th }}$ century, the Dutch Republic was often drawn into warfare. War engagement was costly and thus forced the Republic to issue large amounts of bonds. Bond issuance coincided with substantial changes in house prices, as house prices were stable or falling during periods of war, but increased during periods of peace. Because rents and interest rates were relatively stable, housing risk premia fluctuated substantially. 
Crucially, periods of war were exogenous to the state of the Amsterdam economy. The Dutch Republic did not initiate these wars, but they resulted from international concerns about the successions of deceased foreign emperors, which could alter the balance of power in Europe. Because the wars were fought abroad with privatized armies (Brandon, 2015), most war spending did not end up in Holland. Accordingly, wars did not correlate significantly with any change in standard economic variables. However, changes in public debt had significant impacts on wealthy investors, who invested most of their wealth in these bonds and saw yields decline when bond issuance halted.

In the empirical analysis, I instrument changes in public debt with a dummy variable for periods the Dutch Republic was at war, and relate these to changes in house prices. A one percent increase in bond supply reduced annual house price growth by about $1.4 \%$, and these effects are robust to the inclusion of a set of relevant economic control variables. Periods of war involving foreign governments that Amsterdam investors were lending to also reduced house prices. These bond supply shocks had a much more significant impact on house prices and corresponding rental yields than on bond yields. Correspondingly, a one percent increase in bond supply increased housing risk premia by $0.7 \%$.

To provide micro-level evidence that these substantial changes in home prices were driven by wealthy investors reaching for yield, I develop a matching method that links unique individuals in the estate tax records to their housing transactions. Using a difference-in-difference approach, I find that wealthy investors became relatively more likely to purchase real estate during periods of peace relative to periods of war. This effect is even more significant for individuals with large bond holdings. Controlling for wealth, large bondholders became twice as likely to purchase real estate during peace compared to periods of war, relative to investors with no or only limited bond investments. For Holland bondholders, this effect disappears later in the sample period, when investors also had the opportunity to invest in higher-yielding foreign government bonds.

The final part of this paper analyzes the broader implications of reach for yield behavior and its potential mechanisms. First, reductions in bond yields correlated strongly with increasing investment in new financial assets across all wealth groups, although the effect is again most significant for the very wealthy. This finding suggests that the development of international capital markets was related to investors' search for higher-yielding investment opportunities, which has long been asserted by financial historians (Riley, 1980; Neal, 1993; De Vries and Van der Woude, 1997), and has also been suggested for modern times (Rajan, 2006). Second, reaching for yield led to a persistent increase in housing wealth inequality, as investors purchased properties from less wealthy home-owners, and price increases kept new home-owners off the market. During the $18^{\text {th }}$ century housing boom, the share of Amsterdam real estate owned by the wealthiest $5 \%$ in the portfolio data increased from $20 \%$ to $34 \%$ and did not reduce afterward. 


\subsection{Related Literature}

This paper relates and contributes to two different kinds of literature. First of all, this paper relates to an emerging set of studies studying whether investors reach for yield, and what the implications of this behavior are. Most of this literature has focused on the behavior of investment funds. In response to lower interest rates, funds increase their exposure to riskier assets (Hau and Lai, 2016; Di Maggio and Kacperczyk, 2017). Such behavior can help to attract investment flows (Choi and Kronlund, 2017), and might also increase asset prices (Hau and Lai, 2016). In the corporate bond market, Becker and Ivashina (2015) find that insurance companies reach for yield by selecting higher-yielding bonds within the same rating class, although they do not study the link with low interest rates. Ammer et al. (2019) use actual foreign investments in US corporate bonds to show that foreign investors increase their exposure to risky corporate bonds when rates are low. In an experimental setting, Lian et al. (2018) show that individual participants also increase their allocations to risky assets when rates are low. However, reaching for yield is often argued to originate from the financial sector, as suggested by Rajan (2006) and theorized by Martinez-Miera and Repullo (2017). La Spada (2018) highlights that reaching for yield can arise due to competitive pressures within the finance industry.

This paper provides evidence that individual investors actively reach for yield when interest rates decline, and that this behavior amplifies asset booms and busts. This behavior is most pronounced among the very wealthy, who use their capital returns to finance consumption expenditures. This empirical finding aligns with the recent theoretical work of Campbell and Sigalov (2020), who highlight that spending constraints can be one mechanism that generates reach for yield behavior. In line with Campbell and Sigalov (2020), the findings in this paper for wealthy individuals might thus also extend to pension funds, sovereign wealth funds and endowments, who also use capital returns to finance a relatively constrained set of expenditure.

In this paper, bond yield reductions originate from exogenous changes to the supply of bonds. Such shocks are also central to the modern debate about reaching for yield. Various papers hypothesize that bond-buying programs by central banks might have increased risk-taking by financial institutions (Goldstein et al., 2018; Albertazzi et al., 2018), but portfolio-level evidence for this is limited (Koijen et al., 2018). Some of these shifts might have gone towards real estate: Frame and Steiner (2018) find effects of the FED's quantitative easing program on the prices of REITs. However, the impact of reaching for yield has not yet been studied for residential real estate markets. Housing differs from other financial assets in essential ways, because it is purchased both for consumption and for investment, with both owner-occupiers and buy-to-let investors active in the market. Because wealthy investors are particularly prone to reach for yield, this paper shows that reaching for yield also has significant implications for the distribution of housing wealth.

Finally, this paper relates to the literature studying the impact of investor demand on house prices. Both institutional investors (Allen et al., 2018; Mills et al., 2019), and private investors (Nijskens et al., 2019; Bracke, 2019) are increasingly purchasing real 
estate. Haughwout et al. (2011), Chinco and Mayer (2015) and Garcia (2019) show that demand from second-home buyers contributed to the dynamics in the US housing bubble in the 2000s. Demand from foreign investors has also been linked to housing price increases (Sá, 2016; Favilukis et al., 2017; Badarinza and Ramadorai, 2018; Cvijanovic and Spaenjers, 2018). This seems particularly prevalent in globally important cities, because real estate in these cities is considered a safe-haven investment (Badarinza and Ramadorai, 2018). These studies support the view that increasing investor demand contributes to house price growth. However, they do not allow us to identify whether investor demand can cause entire housing cycles and whether this is related to reaching for yield.

\subsection{Data}

This paper combines various archival data sources, of which a major part has been newly collected and digitized. Table 5.1 provides an overview of these sources. This section discusses the two most important sources: registrations of estate taxes and real estate transactions. Appendix 5.A provides additional documentation and historical context. Next to these two main sources, I collected additional primary and secondary data to support the empirical analysis. Appendix 5.D presents a complete overview of these sources.

Table 5.1: Primary Datasets

\begin{tabular}{lrc}
\hline \hline Description & Observations & Period \\
\hline Real Estate Transactions & 164,067 & $1563-1811$ \\
Estate Tax Registrations & 25,962 & $1688-1780$ \\
\hline Rental Value New Buildings & 8,780 & $1633-1782$ \\
Non-Mortgage Loans & 37,811 & $1683-1807$ \\
Private Annuities (mortgages) & 8,887 & $1630-1810$ \\
Gross Rental Yields & 782 & $1738-1805$ \\
\hline Burial Records & 890,169 & $1563-1811$ \\
Marriage Records & 255,689 & $1563-1811$ \\
Real Estate Transactions (Den Bosch) & 11,458 & $1662-1838$ \\
\hline
\end{tabular}

Notes: For a detailed overview of the composition of these datasets, see Appendix 5.B and 5.D.

\subsubsection{Real Estate Registrations}

This paper uses data from individual real estate transactions to measure activity in the housing market. From the $16^{\text {th }}$ century until 1810, any individual buying or selling real estate in Amsterdam had to register each transfer at the municipal law court (schepenbank). In Amsterdam, the oldest surviving register of real estate transactions dates 
from 1563, while the last transactions were registered in February 1811 because the French changed the system. Although there were five different legal ways to transfer real estate (see Appendix 5.A), almost all transactions were registered as ordinaris kwijtschelding (regular sale, 85\%), or as a executie kwijtschelding (foreclosure sale, $10 \%$ ). Figure 1 contains an example of a single real estate transfer for the purchase of property by the painter Rembrandt. Appendix 5.A.1 provides a full English transcription of this act.

Figure 5.1: Property Transfer Act, Rembrandt

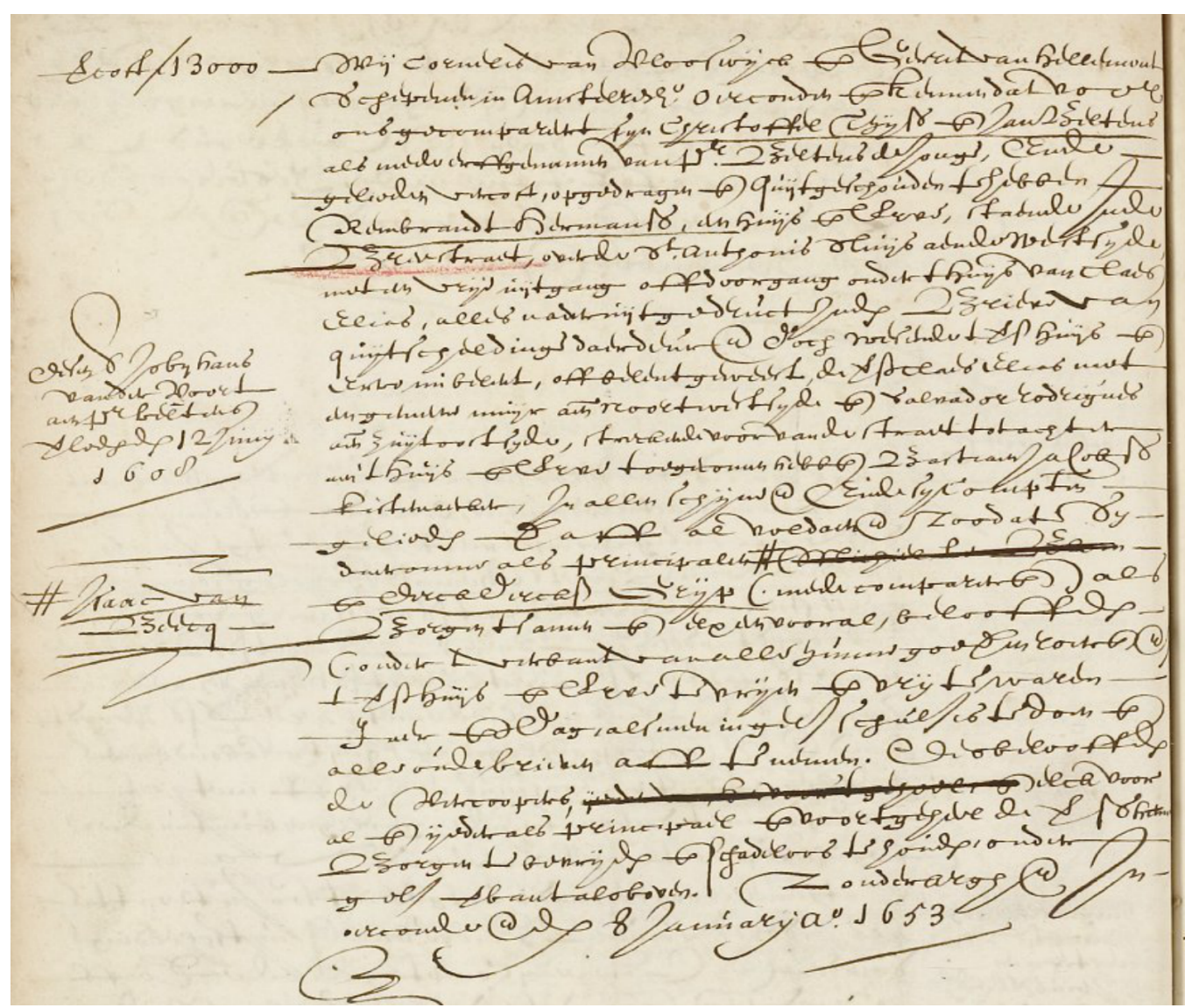

Notes: Figure 5.1 shows a registration of a property transfer. A full transcription of this registration is provided in Appendix 5.A.1. This particular act originates from ACA 5062, Register 45, Page 196, and describes the transfer of property from the heirs of Pieter Beltens to Rembrandt Hermansz, also known as the painter Rembrandt van Rijn. The names of the buyers and sellers are underscored, and written in the top half of the document. The price of 13,000 guilders is mentioned at the top-left, while the registration date (8 January 1653) is written at the bottom of the act. The sold property still exists today and now hosts the Rembrandt Museum.

Nearly all of these registrations have survived in the Amsterdam City Archives. In the past years, the archive and its volunteers have transcribed data on all 164,702 real estate transactions in the registers, involving over 450,000 individuals. This study is 
the first to be able to use this newly-digitized data. ${ }^{3}$ Although a handful of registers did not survive the test of time, the database is fully complete after 1700. Before 1637, there were no prices recorded in the registers for regular sales.

For each transaction, volunteers transcribed information on several variables. First, they recorded the type of transaction, the registration date, and the transaction price. Next, they listed the names of buyer(s) and seller(s), and, whenever available, their job. Most registrations also list whether an individual was widowed or the heir of the original owner. Last, they recorded information on the property. For every transaction, the data contain information on the street name as well as a brief description of the property ('home', 'land', 'warehouse', etcetera). Many records provide a more detailed description of the location of the property. Absent street names and street numbers, this often involved the distance of the house relative to a nearby point of interest. This information could not be coded systematically, because most of these reference points could not be traced back.

\subsubsection{Estate Tax Records}

I use registrations of estate taxes to reconstitute the investment portfolios of citizens of Amsterdam. In the Dutch Republic, estate taxes were levied on inheritances outside of the direct descending line: to heirs that were not children or grandchildren. These taxes were introduced in the $17^{\text {th }}$ century, and although the applicable laws and tax rates modified slightly over time, they were levied consistently until 1810. For each registration, the aldermen made a list of all assets owned by the heiress and their value. Figure 5.2 shows an example of one registration.

Real estate assets were valued by appraisers. If the heiress owned real estate outside of Amsterdam, it would be appraised locally, and the valuation report would be sent to the Amsterdam aldermen. Domestic debt was valued based on its capital sum, except if the debt had been partially repaid or if the debtor had missed debt payments. In the latter case, the debt was valued based on its market value. Equity and assets denominated in foreign currency were valued based on current list prices, and converted to guilders if necessary. Taxes were only levied on the net asset position so that any outstanding loans would be deducted from the total amount.

Together with research assistants, I hand-collected and transcribed data on all registrations between 1688 and 1780, totaling 25,962 observations containing approximately 150,000 different assets. For each registration, I transcribed the name of the deceased individual, the year of registration, and, if available, the death date. For each person, I aggregated the value of its assets both by location (foreign and domestic) and type (government and corporate bonds, equity, real estate, private debt, etc.). A full description of these asset classes is provided in Appendix 5.A.2. Only in a tiny number of cases clerical errors, unclear identification of assets, or bad handwriting made it difficult to transcribe records correctly.

\footnotetext{
${ }^{3}$ I want to acknowledge the support of the Amsterdam City Archives gratefully. Note that the registrations have been indexed and can be found online at https://archief.amsterdam/indexen. Data on house prices, occupations, and various other variables are only available from the full database.
} 
Figure 5.2: Estate Tax Record, Willem van Collen

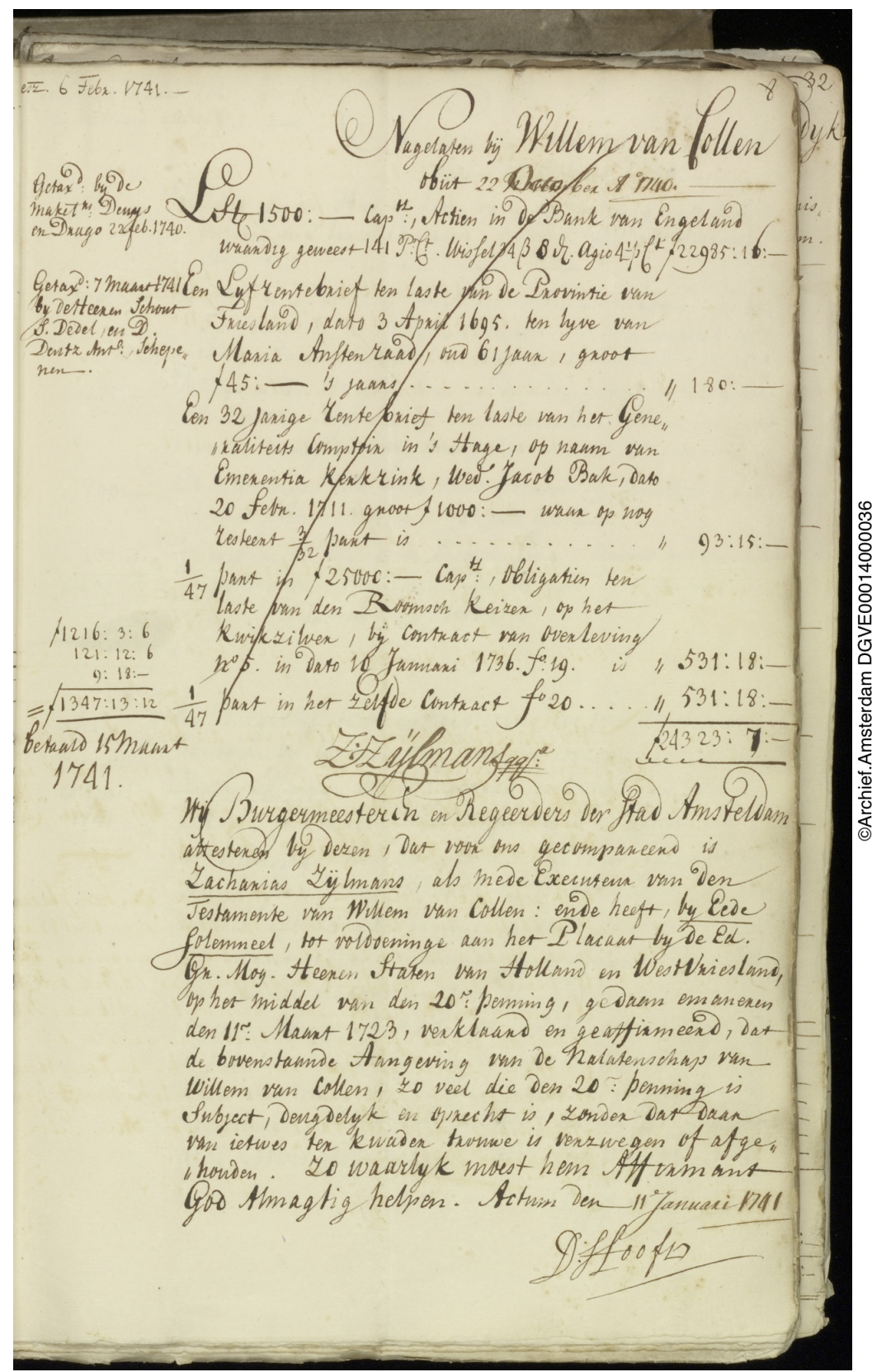

Notes: Figure 5.2 shows one example of an estate tax record, originating from ACA 5046, Register 26, Page 8. Appendix 5.A.2 provides a full transcription of this act. The record starts with the name of the deceased individual (Willem van Collen) and the date of death (October 22, 1740), followed by the list of assets left by the heiress. Every record describes each asset and its value. The value of an asset is reported on the right-hand side of each record. Records were signed by the heir, and followed by a formal statement that confirms the payment of the estate tax. The very bottom of the document mentions the registration date. 
To the best of my knowledge, this paper is the first to provide a systematic overview of investment in $18^{\text {th }}$ century Amsterdam, despite its importance as a global financial market (Neal, 1993). Various historical studies have drawn small samples from these tax records for smaller cities (De Jong, 1985; Kooijmans, 1985; Prak, 1985), arguing they draw a representative picture of investment portfolios. I discuss this assumption in more detail in Appendix 5.A, and use secondary wealth estimates to show the distribution of wealth in the estate tax records is similar to the distribution of wealth for all deceased persons in the city. The main drawback of using estate taxes is that wealth portfolios at death might be slightly different from those of younger cohorts. Historically, this is less of a concern because many people passed away at a young age.

\subsubsection{Linking Housing Transactions}

To provide a link between investment portfolios and real estate transactions, I match individuals in the estate tax records to their housing transactions. Similarly, I match purchases and sales of the same properties to identify aggregate house price movements. Three factors complicate this matching. First, most people did not have unique names. Second, clerks did not always write the names of individuals in the same way, due to the presence of other names and clerical errors. Finally, difficulties in transcription can contribute to errors as well. To properly match transactions and individuals, I combine algorithmic matching with manual data classification. These techniques are comparable to the fully automated matching approach Abramitzky et al. (2019) suggested for US census data.

I start by identifying the gender of each individual by matching the first names of brides and grooms in marriage records to those in the other datasets. I classify the gender of individuals whose first name cannot be matched by hand. Next, I use the 890,000 names present in the Amsterdam burial records to identify a uniqueness score for each individual in the sample of transactions. Young children and individuals that died before 1688 are excluded because these could not have bought or owned property in the sample period. I split the sample of transactions and burial records into $k=$ $1, \ldots, K$ blocks, that are each defined by a unique combination of gender, and the first letter of the first and last name. This assumes that the first letter of first and last names are transcribed correctly. ${ }^{4}$ With each block containing $n_{k}$ individuals, the uniqueness score is defined as the weighted sum of all transformed Jaro-Winkler distances $(j w)$ between individual $i$ in the database of property transactions and all $j$ individuals in the burial records sharing the same gender and first letters:

$$
u_{i}=\sum_{j=1}^{n_{k}} 2 \times \sqrt{\min \left(j w_{i j}^{\text {firstname }}+1.5 \times j w_{i j}^{\text {lastname }}, 0.25\right)}
$$

Jaro-Winkler distances are the most common measure to match names in different databases with potential transcription errors (see Winkler, 1999; Abramitzky et al.,

\footnotetext{
${ }^{4}$ This reduces computation significantly, as it shrinks the number of Jaro-Winkler distances to compute from about 1 trillion to a few billion.
} 
2019). A distance of 0 indicates perfect equality of character strings and a distance 1 of perfect inequality. I compute these distances both for first $(p=0.05)$ and last names $(p=0)$, with $50 \%$ additional weight given to last names. I determined the functional form of Equation 5.1 and the value of the penalty factor $p$ by experimenting with different set-ups, and manually classifying the correctness of the matches. In the end, I used the values that resulted in the largest set of correct matches. Note that Equation 5.1 implies that names with Jaro-Winkler distances equal or larger than 0.25 are never matched.

To match individuals in the transaction records to the estate tax records, I split the sample of estate tax records in the same blocks as the transaction and burial records. Next, each individual in each transaction is matched to the entry in the estate tax records that minimizes the Jaro-Winkler distance defined in the previous paragraph. Of course, the likelihood this is a right match depends both on the uniqueness score $u_{i}$ and the minimum Jaro-Winkler distance, which I discuss later in this paper.

To match housing purchases to sales, I restrict the set of housing purchases to transactions involving homes, adding two additional blocking variables: the street name and the number of sold properties. ${ }^{5}$ This ensures the same properties are being matched. I split the sample into purchases and sales, and compute for each individual $i$ in the sample of purchases the Jaro-Winkler distances with all sellers and all buyers within the same block. A housing purchase is matched to the sale that has the lowest Jaro-Winkler distance if that match satisfies four conditions:

1. The Jaro-Winkler (JW) distance with the nearest seller (minimum) is less than 0.1

2. The JW-distance with the nearest other buyer (minimum) is at least 0.15

3. The second nearest-seller has a JW-distance at least 0.15 higher than the first

4. The purchase happens before the sale

In total, this procedure resulted in 39,123 transaction pairs. Again, these parameters are chosen to strike a good balance between the number of matches and their accuracy. This strategy can only result in mismatches in case of severe misspellings, or if an individual owned multiple properties on the same street, but bought exactly one property and sold exactly on other property during the period covered by the data. Both cases are unlikely. Although there does not exist a 'ground truth' to assess the quality of these matches, high-quality matching should result in precise price indices. Following the standard repeat-sales framework in Bailey et al. (1963), I assume the log price on a property $x$ can be written as $p_{x t}=\alpha_{x}+\beta_{t}+\varepsilon_{x t}$, with $\alpha_{x}$ representing a constant quality component, $\beta_{t}$ the market price component and $\varepsilon_{x t}$ the transaction price error. $^{6}$ Thus, for each matched price pair purchased in year $s$ and sold in year $t$ :

$$
p_{x t}-p_{x s}=\beta_{t}-\beta_{s}+\varepsilon_{x t}-\varepsilon_{x s}, \quad s<t, \varepsilon \sim N\left(0, \sigma^{2}\right)
$$

\footnotetext{
${ }^{5}$ Historically, it was common to own part of a house, either due to inheritance or because full homeownership was not affordable.

${ }^{6}$ Note that the constant-quality is less relevant for the analysis in this paper, because I study changes in prices, and there was limited quality growth in this period. In line with this, median house prices only rise marginally more than the constant-quality price index. See Eichholtz et al. (2020b) for more detail
} 
This equation can be estimated for all transaction pairs using ordinary least-squares, with 1810 used as the baseyear. For the annual index, I only include observations after 1625, because too few price observations are available beforehand. Between 16041625, I estimate an index at a three-year frequency. To control for heteroskedasticity that might arise due to differences in the holding periods, I apply the Case and Shiller (1987) correction. The resulting annual index is precise: the median standard error of each index coefficient is $2.5 \% .^{7}$ I apply the same method to estimate an annual house price index for Den Bosch (1692-1838). Given the lower number of observations, this index is less precise.

\subsection{Motivational Evidence}

To motivate my empirical analysis and identification, this section aims to explain the economic motivation for Amsterdam investors to reach for yield, and subsequently provides novel stylized facts of investment portfolios in Amsterdam and the developments of its housing market. In Appendix 5.B, I provide a more detailed overview of the housing market.

\subsubsection{Why Would Investors Reach for Yield?}

In Amsterdam, only a small fraction of the total population possessed significant wealth. Based on figures from Hart (1973), approximately 15 to $20 \%$ of the Amsterdam population possessed wealth in the 18th century. This group of wealthy individuals roughly consisted of two different groups: Rentiers, who purely lived from their capital income, and working individuals that also possessed wealth. Although the estate tax records do not report on the profession of individuals, data from a one-time income tax in 1742, the Personeele Quotisatie, provides a unique picture into the social structure of this group (Oldewelt, 1945). The 1742 income tax was a one-time tax levied on individuals earning more than 650 guilders per year, consisting of the $25 \%$ highest-income households in Amsterdam.

About $12.5 \%$ of these households, corresponding to about $3 \%$ of the entire Amsterdam population, reported being a rentier. These rentiers had a median income of 1000 guilders per year (mean 2,200 guilders). Although it is not exactly clear how this income was estimated, an average net return of $3.33 \%$ on total assets (in between the net yield on government bonds and the estimated net yield on real estate) would imply the median rentier possessed assets worth about 30,000 guilders. These individuals lived from their capital income and transferred their assets to their heirs upon death. Because these individuals used capital to fund their consumption, fluctuations in interest rates directly reduced their income.

This contrasts with the group of wealthy individuals who also worked and earned regular wages. During the 18th century, wages were extremely stable. The wedde-

\footnotetext{
${ }^{7}$ For reference, this value is $33 \%$ when estimating market prices using average prices. This index is also a substantial improvement over the index of Eichholtz (1997) for the Herengracht, Amsterdam's most famous canal, which relies on average on eight observations per year in this period.
} 
boeken of the government of Amsterdam, which report the salaries of all civil servants, show that wages were constant over time. ${ }^{8}$ Evidence from day wages of masons of carpenters shows a similar pattern for workers in the construction sector (Nusteling, 1985). For these households, fluctuations in interest rates were much less of a concern, because most of their income was earned through labor.

Of course, the distinction between these two groups was not absolute: some rentiers also worked, and some workers also earned substantial capital income. However, it is clear that the propensity to be a rentier increased with wealth. In 1742, the median rentier with 30,000 guilders of financial wealth would rank in the 92nd percentile of the wealth distribution based on the estate tax records. Given that $86 \%$ of individuals in the 1741-1745 period died without any wealth (Hart, 1973), this would be the 98th to 99th percentile of the wealth distribution for the entire population. As $12.5 \%$ of the individuals in the 1742 income tax records reported being a rentier, so about $3 \%$ of the entire population, rentiers likely comprised the large majority of individuals in the upper right tail of the wealth distribution.

The motives of these two different groups to reach for yield are best understood through the recent theoretical work of Campbell and Sigalov (2020). Campbell and Sigalov (2020) develop a model that shows that investors with a sustainable spending constraint increase their allocation to risky assets when interest rates decrease. These investors consume their financial returns, rather than accumulating wealth or running it down. Such a spending constraint is representative for large endowments and sovereign wealth funds, but Campbell and Sigalov (2020) argue it could also be representative for rentiers with a bequest motive, as is the case in this paper. This negative correlation between interest rates and risky asset shares is driven by the fact that rentiers prefer to maintain their consumption levels when interest rates decrease, and thus increase their exposure to riskier and higher-yielding assets at the expense of more risky future consumption. Campbell and Sigalov (2020) show this behavior is particularly significant when interest rates are low, as was the case in historical Amsterdam and again is the case today.

This finding contrasts with the standard Merton (1969) finding that risk-taking is independent of interest rates and only governed by risk-aversion. This standard model is more representative for investors who do not have a significant spending constraint: individuals whose consumption stream is not fully dependent on capital. This implies that reaching for yield is not pervasive across all investors. Although there exists no formal model that computes equilibrium portfolio shares and asset prices in a world where there exist both investors with a sustainable spending constraint (as in Campbell and Sigalov, 2020) and investors without such a constraint (as in the traditional Merton model), we can derive intuitive hypothesis for this case.

First, wealthy investors with a sustainable spending constraint, such as rentiers, will be prone to increase their allocation to risky assets when interest rates decrease, and will thus be willing to accept higher prices and lower expected returns for risky assets. Second, investors that are less reliant on capital income for their consumption

\footnotetext{
${ }^{8}$ Amsterdam City Archives 5039: Archief van de Thesaurieren Ordinaris, no. 768 - 773
} 
and possess more limited financial wealth do not have such a preference, and will find it profitable to sell their assets to these rentiers. As a result, decreasing interest rates will lead to higher equilibrium asset prices than in the standard model with constant risk premia, and rentiers will increase the fraction of risky assets they possess relative to non-rentiers. Finally, housing wealth inequality will increase as reach for yield purchase will increase the fraction of homes owned by wealthy rentiers.

\subsubsection{Investment Porfolios in Amsterdam}

Time-varying portfolio shares of risky assets across different wealth groups are a necessary but not sufficient condition for reach-for-yield behavior to be economically significant. Although the portfolio data collected for this paper do not report on labor income, the fraction of capital income in total income likely correlated very closely with total wealth.

Figure 5.3 reports the evolution of the investment portfolios of Amsterdam citizens from 1688 to 1780 , split into three groups: the bottom $50 \%$ of estates ( $<3100$ guilders), the top 50-95\% (3100-65000 guilders) and the top 5\% (> 65000 guilders), which almost entirely consisted of rentiers. To avoid extremely large estates distorting the wealth distribution, I removed extreme outliers (17 observations, over 1 million guilders) and aggregated data per three years for the first two groups, and per five years for the much smaller top 5\% group. Most wealth concentrated in the top 1\% of society (the top 5\% in the estate tax records), who owned approximately $57 \%$ of total wealth. Piketty et al. (2006) find similar levels of wealth concentration in $19^{\text {th }}$ century Paris.

All three groups invested the majority of their wealth in real estate and domestic government bonds. Nearly all investments in real estate were within Amsterdam (89\%), and most domestic government bonds were Holland bonds (83\%). Similar to today, smaller portfolios primarily consisted of an individual his own house and contained few other assets beyond real estate. The home-ownership rate in Amsterdam was approximately $14 \%$, so buy-to-let investors owned most homes. Investments in equity, corporate bonds, and foreign assets were concentrated among the wealthiest members of society. Importantly, the data show that the market for private credit was small. Absent banks, most loans were peer-to-peer loans (Hoffman, 2000; Gelderblom et al., 2017), but in Amsterdam, these only amounted to a few percents of total assets. Within this group, the share of mortgage loans was relatively constant at approximately $0.5-1 \%$ of total assets. In line with this, I show in Appendix 5.B.4 that the volume of new long-term mortgage loans was negligible relative to the total volume in the real estate market.

While the portfolios of the bottom $50 \%$ of estates were relatively constant over time, there were significant fluctuations in the estates of the top 50\%. From the start of the sample until 1713, the share of wealth invested in government bonds increased drastically at the expense of real estate investments. Because house prices were stable in this period, nearly all new investments must have been in government bonds. After 1713 , this pattern reversed, and the share of wealth invested in real estate increased at the expense of the share invested in government bonds. As we shall see, this change 
Figure 5.3: Investment Portfolios, 1688-1780

Bottom 50\%

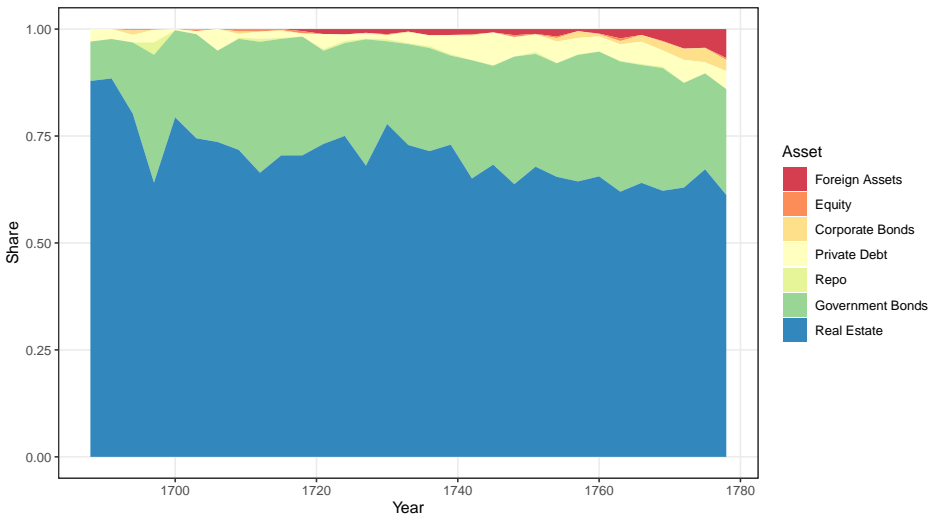

$50-95 \%$

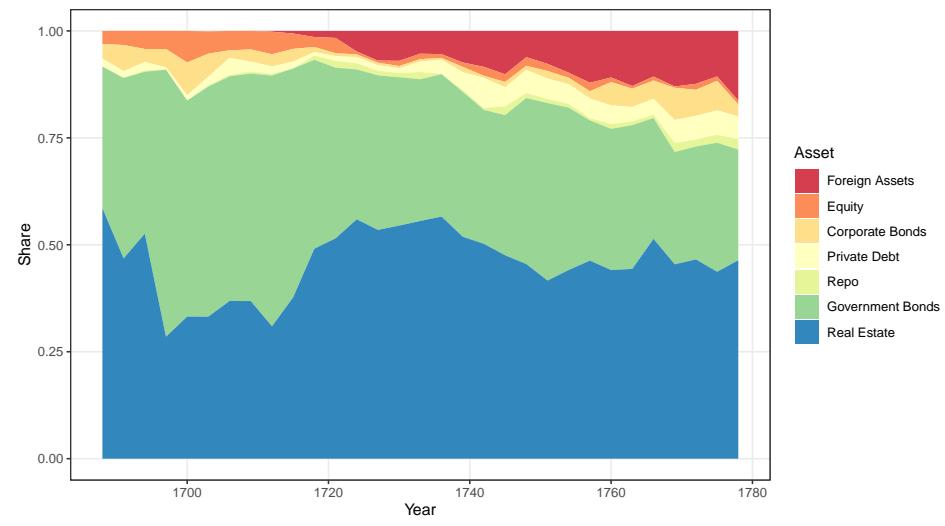

Top 5\%

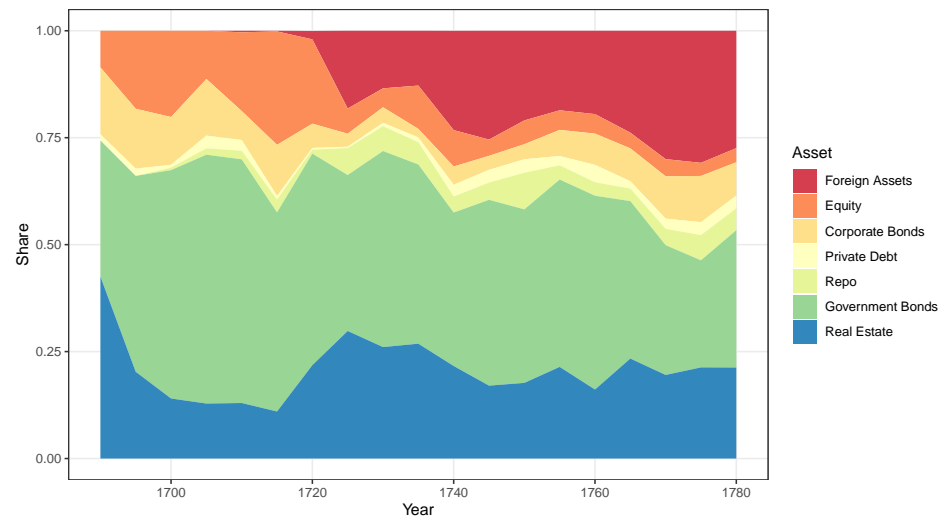

Notes: The plots report on the composition of household portfolios over time for the wealthy population of Amsterdam, separating the bottom 50\%, the top 5\% and the group in between. For a detailed list of assets, see Appendix 5.A.2. 
happened exactly when house prices started booming as well. The share of wealth in real estate gradually stabilized in the late 1720s and started declining from about 1740 until 1760. Due to the gradual development of international financial markets (Neal, 1993), investors increasingly purchased foreign assets from the second quarter of the $18^{\text {th }}$ century onward. These were primarily English securities $(81 \%)$. Following the continued development of financial markets, there were also changes in portfolio composition in the second part of the $18^{\text {th }}$ century, but these occurred primarily in other asset classes than real estate.

To test whether shifts in the share of wealth invested in real estate correlated to the level of the Holland bond yield, I link the share of real estate in each portfolio to the demeaned level of the bond yield $\left(i_{t}-\bar{i}\right)$ for six different wealth groups $(g)$, using the following regression:

$$
\% \text { RealEstate } e_{i, t}=\sum_{g=1}^{6}\left[\alpha_{g}+\beta_{g}\left(i_{t}-\bar{i}\right)_{g}\right]+\varepsilon_{i, t}
$$

The first three wealth groups contain individual portfolios from the first three quartiles of the distribution of portfolio values. Group 4 contains portfolios between the $75^{\text {th }}$ and $90^{\text {th }}$ percentile. The top two groups, which contain the bulk of total wealth, contain the $90^{\text {th }}$ to $95^{\text {th }}$ percentile and the remaining top $5 \%$. All wealth groups are identified by dummies. I estimate this equation with and without weighting for portfolio size, and both using the registered value of domestic bonds (the capital value) and the market value of these bonds. Contrary to other assets, domestic bonds were valued at par as long as the loan had not been in default or partially repaid. I convert their value to market prices based on current bond prices and yields from Gelderblom and Jonker (2011). This bond yield is based on transaction prices of redeemable annuities, bonds similar to British consols. In the 18th century, Holland bond yields were the lowest in the world, and they were the main safe asset for Dutch investors (Gelderblom and Jonker, 2011).

Figure 5.4 plots the results for each model and each wealth group, using White standard errors. In parenthesis, I report for each wealth class the average share of total wealth that was invested in real estate, based on weighted OLS and using the marketvalue of domestic bonds. For the top group, which owned the majority of total wealth, a one percentage point reduction in the bond yield increased the share of investment in real estate by about 12 percentage points, relative to an average share of 21 percentage points. The absolute size of this effect is similar for the other two groups in the top quartile of wealth, but the relative effect size for these groups is smaller, given that they generally invested a higher fraction of their wealth in real estate. The effect changes substantially for the bottom three quartiles, who invested nearly all of their wealth in real estate. For the third quartile, the estimated effect is much smaller, in particular relative to their average real estate holdings. The effect turns insignificant for the second quartile, and reverses for the bottom $25 \%$.

Reductions in bond yields had the most significant impacts on individuals that invested most of their wealth in bonds. These investors might have responded more 
Figure 5.4: Bond Yields and Portfolio Composition

$0-25 \%$ (avg. 66\%)

$25-50 \%$ (avg. $70 \%$ )

$50-75 \%$ (avg. 65\%)

$75-90 \%$ (avg. 50\%)

$90-95 \%$ (avg. 37\%)

$95-100 \%$ (avg. $21 \%$ )

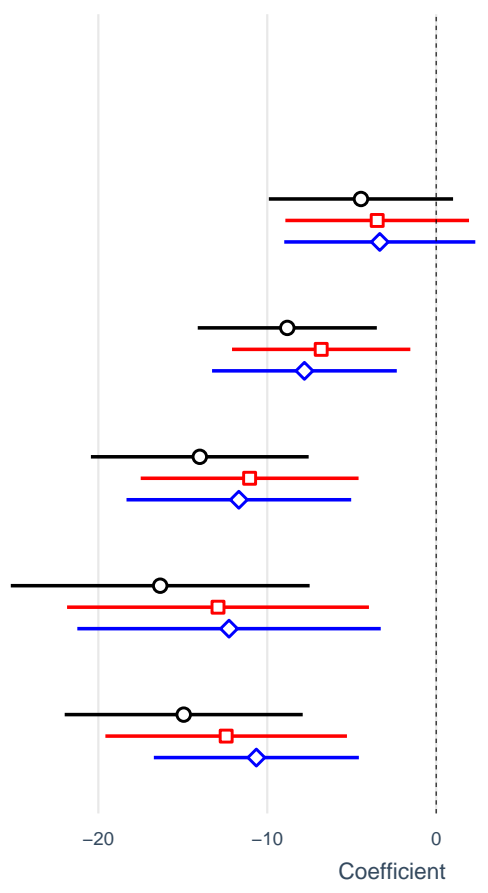

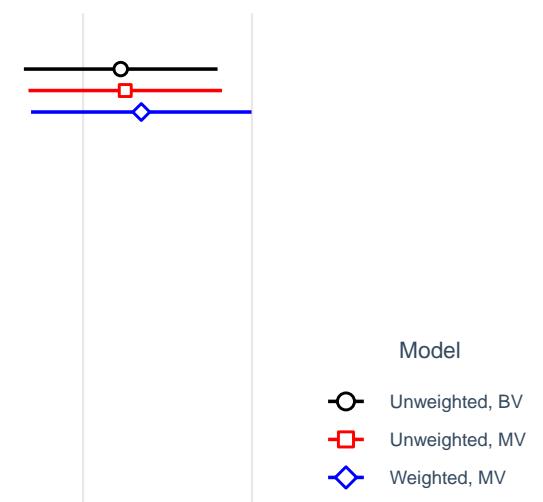

10

Notes: The dots report the coefficients (dots) and 95\% confidence intervals (lines) measuring the impact of a change in the bond yield on the fraction of wealth in real estate. I computed these coefficients for each wealth group, sorting by total wealth, ranging from the bottom $25 \%$ to the top $5 \%$. Average real estate portfolio shares are reported in parenthesis for each wealth group. There are three models estimated. In the top model, I use the unadjusted investment in domestic bonds. In the bottom two models, I adjust the value of domestic bonds using market prices. In the last model, I also weigh each observation by portfolio size. 
strongly to changes in bond yields than other investors, in particular given that rentiers had a preferences for bond investments (De Vries and Van der Woude, 1997). To investigate this, I estimate equation 5.3 for groups that are sorted based on their total holdings of domestic government bonds. Because $55 \%$ of portfolios do not contain any investment in domestic government bonds, I pool these into a single category. Relative to Figure 5.4, I estimate one additional model that also controls for the log of total wealth in each portfolio.

Figure 5.5 plots the estimated coefficients for each wealth group. Investors that owned no or limited amounts of domestic bonds invested relatively more of their wealth in real estate when yields were high. This effect was particularly large relative to their weighted mean exposure to real estate investments, which was only $6 \%$ for the group without domestic bond investments and $15 \%$ for the group with small bond investments. For individuals with larger bond holdings, the effect reduces and turns negative for the top quartile of bondholders. For the top group, a $1 \%$ reduction in bond yields increased the share of wealth invested in real estate by $11 \%$, after controlling for total wealth. This effect does not change significantly in the other models. In short, this suggests that portfolio changes in response to lower interest rates were the largest among investors with very substantial bond holdings.

\subsubsection{House Prices in Amsterdam}

These portfolio shifts did not only coincide with fluctuations in interest rates, they also coincided with fluctuations in house prices. Importantly, house prices in this period fluctuated by more than would be predicted in a conventional standard discounted rent model, with $R_{t}$ the rent index, $\tau_{t}$ the annual tax rate on rental value, $i_{t}$ the net long-term yield on domestic government bonds, and $\pi_{t}$ the risk premium: ${ }^{9}$

$$
P_{t}=\frac{R_{t}\left(1-\tau_{t}\right)}{i_{t}+\pi_{t}}
$$

Figure 5.6 plots the level of house prices relative to the level of discounted rents and the Holland bond yield, which is used to discount the rents. For this benchmark model, I assume risk premia are fixed over time at $2 \%$, which corresponds to the estimated average difference between bond yields and net rental yields in the 18th century. This model is close to some early writings on asset pricing in this period. For example, Zillesen (1800) writes that the 'fundamental law' to value real estate is that "one computes the net revenue of it, and estimates the value of this real estate based on an interest as the course of a more or lesser money provides." In his examples, he capitalizes net-of-tax rents with the presumed required return on housing, and explicitly recognizes that prices increase if "the course of interest declines."

Large booms and busts in Amsterdam were common, both in the $17^{\text {th }}$ century and $18^{\text {th }}$ century. In the early period, most of these changes can be explained by changes in discounted rents, although we should note that bond markets and interest rates were still developing in the 17th century (Gelderblom and Jonker, 2011). Also in the

\footnotetext{
${ }^{9}$ The construction of the long-term yield and rent price series is discussed in Appendix 5.D.
} 
Figure 5.5: Portfolio Composition and Bond Investment

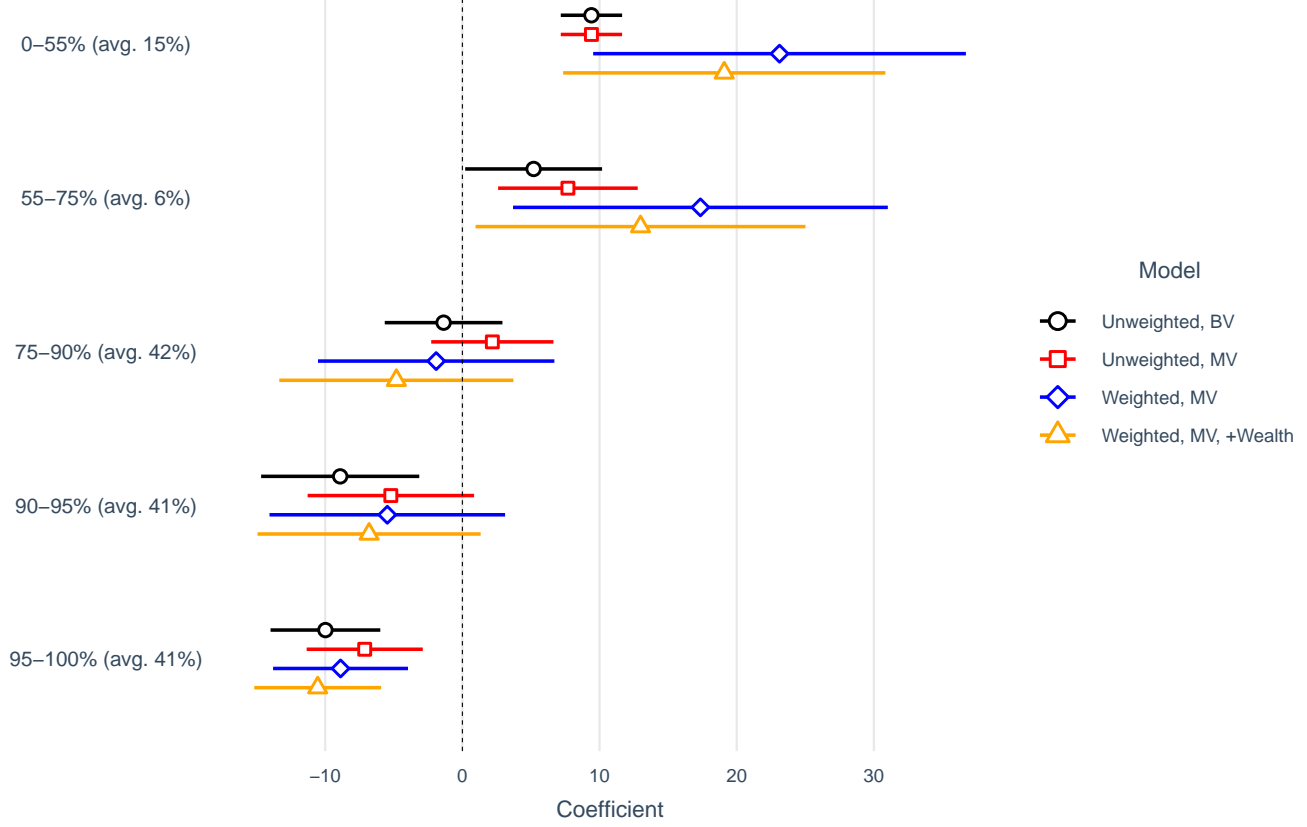

Notes: The dots report the coefficients (dots) and 95\% confidence intervals (lines) measuring the impact of a change in the bond yield on the fraction of wealth in real estate. Contrary to Figure 5.4, the different wealth groups are now sorted by their total bond holdings, ranging from the bottom $55 \%$ (no bond wealth) to the top 5\% (most bond wealth). Average real estate portfolio shares are reported in parenthesis for each bond wealth group. There are four models estimated. In the top model, I use the unadjusted investment in domestic bonds. In the bottom three models, I adjust the value of domestic bonds using market prices. In the last two models, I weigh each observation by portfolio size. In the bottom model, I additionally control for the log of total wealth in each portfolio. 
Figure 5.6: House Prices, Bond Yields and Discounted Rents

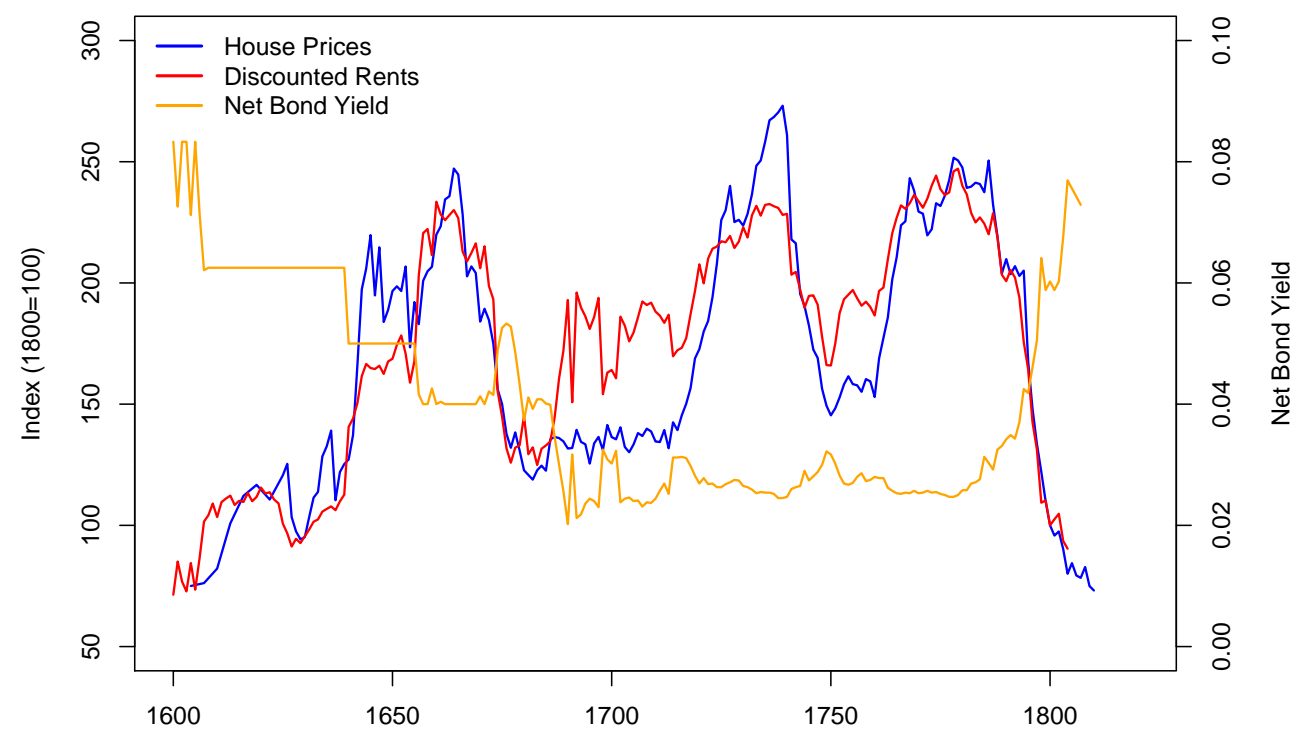

Notes: Figure 5.6 plots the annual index of house prices relative to the level of discounted rents, estimated based on Equation 5.4. The orange line plots the Holland bond yield, which is used to discount the rents.

final part of the sample, the discounted rent model explains most volatility in property prices. However, discounted rents fail to fully capture the large cycle in property prices that is happening between the 1710s and the 1740s. The presence of such excess volatility relative to rent prices and interest rates is a necessary condition if reach for yield behavior impacted house prices.

Bond yields were exceptionally low and stable during this period. Between the end of the $17^{\text {th }}$ century and the $1780 \mathrm{~s}$, Holland issued its perpetual bonds at an interest rate of around $2.5 \%$. To the best of my knowledge, no other economy in the world has ever maintained such low interest rates for a comparable time period (see Homer and Sylla, 1996). This fact becomes even more striking if one realizes Holland sustained this debt with a debt-to-GDP ratio of up to $200 \%$. On the one hand, Holland managed to build a reputation for being a very safe creditor. On the other hand, there was an enormous pool of Dutch savers eagerly looking for a stable source of capital income (Gelderblom and Jonker, 2011). These extended periods of low rates make Amsterdam a useful setting to test for reach for yield behavior.

The remainder of this paper focuses exclusively on the period from 1688 to 1780 , covering the century around the boom-bust cycles between 1713 and 1750. It is during this period that we observe that the housing boom coincides with increasing portfolio shares on housing for the very wealthy.

Several other reasons make this period particularly suitable to study the impact of investor demand - potentially driven by a reach for yield - on house prices. Most importantly, this period is characterized as a period of economic stagnation (De Vries and Van der Woude, 1997), implying that changes in regular economic fundamentals can- 
not explain the booms and busts in asset prices. The data also confirm this. Between the end of the $17^{\text {th }}$ century and the late $18^{\text {th }}$ century, the housing supply and population in Amsterdam did not change much (see Appendix 5.B). Most housing construction that did happen, improved existing homes rather than constructing new ones. Wages and GDP were also stagnant, and the long stagnation of the Amsterdam economy makes future demand growth an unlikely driver of housing dynamics. This was not the case for the other two cycles. During the $17^{\text {th }}$ century, Amsterdam expanded enormously, and the bust in the 1670s correlates closely with the end of this 'Golden Age' of the Amsterdam economy. On the other end, the fall in house prices in the late $18^{\text {th }}$ century coincides with the lost Fourth Anglo-Dutch War and the demise of the Dutch Republic in 1795. Both events are widely considered to have caused significant economic disruption.

\subsection{Investor Demand and Housing Cycles}

The analysis in the previous section shows that wealthy investors, in particular those with significant bond investments, increased their exposure to real estate and other risky assets when interest rates were low, consistent with reach for yield behavior. However, the portfolio data only measure the stock of investments, and thus do not allow to identify why interest rates changed, and how this impacted the behavior of investors on the housing market and the prices they paid. In this section, I exploit exogenous changes in the supply of government bonds to identify the causal impact of investor demand on house prices and housing market activity. To support the identification, I describe the factors driving the supply of bonds, and subsequently estimate their effect on prices and purchase behavior.

\subsubsection{Wars, Bond Supply and House Prices}

Changes in the supply of Holland bonds had important implications for the investment opportunities of large bond investors. If Holland was issuing bonds, investors could (re)invest their capital returns in new issues, and generally did so (Gelderblom and Jonker, 2011). When Holland did not issue bonds, investors had to purchase bonds on the secondary market or had to invest in other assets.

Figure 5.7 plots the level of Holland public debt relative to Amsterdam house prices. Developments in Den Bosch house prices are plotted as well and will be discussed later in this section. The revenues from bond issuance were almost exclusively used to finance warfare, and increases in bond supply therefore correlate almost perfectly with periods of warfare, which are shaded in grey. Figure 5.8 plots the estimated net rental yield relative to the net bond yield, both using average taxes and current taxes, with periods of war again shaded in grey. The level of the net rental yield is based on actual observations of net-of-tax yields, and assumes costs were $30 \%$ of the gross yield. ${ }^{10}$

\footnotetext{
${ }^{10}$ See Appendix 5.D for construction of this series
} 
Figure 5.7: House Prices and Bond Supply, 1687-1780

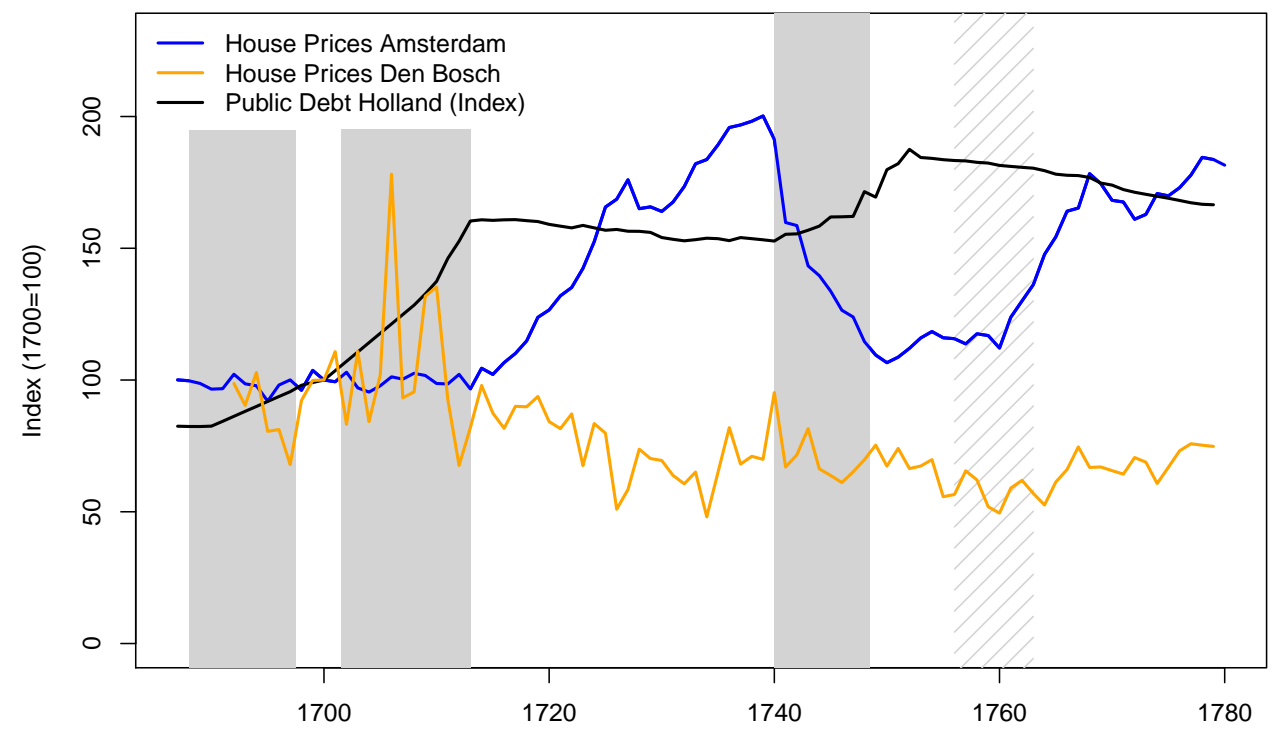

Figure 5.8: Bond Yields and Rental Yields, 1687-1780

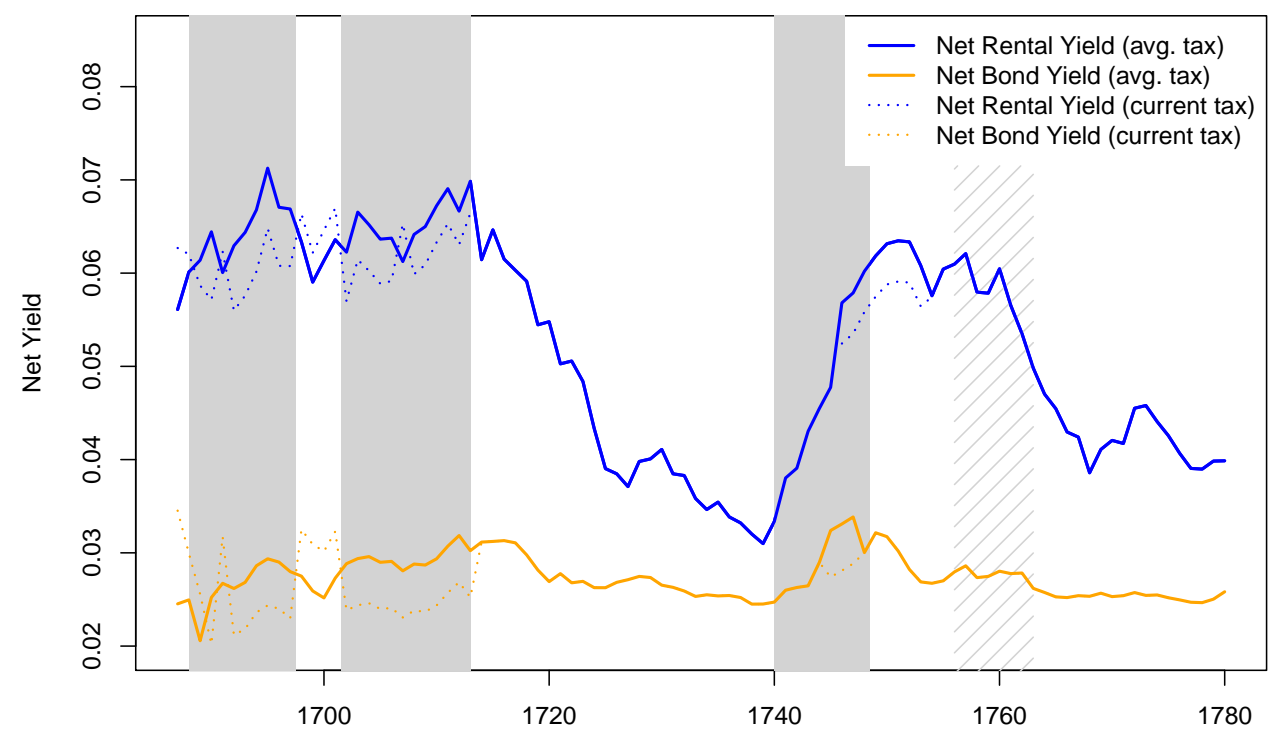

Notes: Figure 5.7 reports the relation between total public debt and house prices in Den Bosch and Amsterdam. Figure 5.8 displays net rental yields and bond yields. The dashed line Figure 5.8 reports the net yield based on current taxes, as taxes varied during periods of war relative to their standard values. Note that the level of net rental yields depends on the assumed maintenance costs $(40 \%)$. If actual maintenance costs were different, the rental yield might be shifted up- or downwards. In both figures, periods of major warfare are shaded in grey; the Seven Years' War (1756-1763) is dashed because it did not involve the Dutch Republic. 
The three main wars in this period that involved the Dutch are the Nine-Years' War (1688-1697), the Spanish Succession War (1702-1713), and the Austrian Succession War (1740-1748). Importantly, these wars were not initiated by the Dutch Republic, but did force the Republic to issue large amounts of bonds. The Nine-Years' War was caused by increasing worry of the Grand Alliance (composed of Britain, the Holy Roman Empire, the Dutch Republic, Savoy, and Spain) about the expansion of France. They worried that France might become too powerful, in particular when the French house would inherit the Spanish throne when its king would die, who had been ill for a long time. It was his actual death that caused the Spanish Succession War. The same issue repeated itself in the Austrian Succession War when the Austrian emperor died.

The Spanish Succession War had the most substantial impact for investors because it forced Holland to issue a record amount of bonds, while bond supply gradually declined in the decades after the war (Figure 5.7). The influence of the Dutch in the outcome of the war was nonetheless small. In 1713, when the Peace of Utrecht was concluded, French diplomat Polignac said "nous traiterons chez vous - de vous - et sans vous" ("We negotiate in your place - about you - and without you," Van Bunge, 2018).

When the Spanish Succession War ended, house prices started booming, while they had been stable during the war and the earlier Nine Year's War. Until the outbreak of another war in 1740, house prices boomed, and rental yields declined substantially, while there were only small declines in bond yields. Prices peaked in 1740 when Holland resumed issuing bonds, and prices and yields started reverting. ${ }^{11}$

The relation is also apparent for the second boom, although to a much smaller extent. In this period, investors had access to a broader set of investment opportunities outside of real estate (see Figure 5.3). Dutch investors purchased significant sums of foreign government debt during the Austrian Succession War and the later SevenYears War (1756-1763), which did not involve the Dutch Republic. Beyond foreign investments, securitized loans to plantation owners in the colonies, invented in 1751, provided new opportunities for investment in the corporate bond market (Van der Voort, 1973).

Following the correlational evidence presented in Figure 5.7 and Figure 5.8, I aim to identify the causal effect of bond supply on house prices. Log-differencing house prices $\left(\Delta p_{t}\right)$ and Holland public debt $\left(\Delta \log (D e b t)_{t}\right)$ to ensure stationarity, I write house prices as a function of changes in bond supply and a set of control variables:

$$
\Delta p_{t}=\alpha+\beta \Delta \log (D e b t)_{t}+\Gamma^{\prime} X_{t}+\varepsilon_{t}
$$

The identification of $\beta$ is challenged for three reasons. First, bonds were supplied to fund warfare, and warfare might have directly impacted the Amsterdam economy. Second, changes in bond supply affected taxation, which could have an impact on house prices. Third, Holland's bond issuing policy might have been influenced by the

\footnotetext{
${ }^{11}$ During the war, bonds purchased in the primary market earned substantially higher returns. In order to attract investors, newly issued bonds were promised to be tax-free for the period of the war, and thus paid a coupon of $4 \%$. This likely explains the large and stable risk premium on housing during the first two wars. Taxation of these bonds started several years after the Spanish Succession War ended.
} 
aggregate demand for financial assets, and thus be correlated to both interest rates and house prices.

\section{Correlation with Economic Outcomes}

If the housing cycle would be the result of changes in economic conditions caused by the war, estimates of equation 5.5 will be biased upwards. However, both contemporaries and economic historians have stressed that the main impact of the war was fiscal. In the memoirs of his travels to Amsterdam, the French philosopher Montesquieu (1729) claims that "the commerce of Amsterdam is more flourishing during war than peace", likely referring back to the fact that the Dutch Golden Age primarily happened in periods of war. He also writes that the "finances of Holland are completely lost" because the Spanish Succession War had been so expensive. Council of State member Cornelis van Slingelandt had proclaimed the same in 1715: "This country is burdened to sinking" (De Vries and Van der Woude, 1997). Existing historical studies also argue that the main impact of the war on the economy was fiscal and that the direct consequences of the war itself were small (e.g Dormans, 1991; Liesker and Fritschy, 2004; Fritschy, 2017). Most of the war was fought outside of the Dutch Republic, and only minimal fighting occurred at the border. Complemented with the fact that warfare in the Republic was highly privatized and a significant part of the troops hired from abroad (Brandon, 2015), this implied that few of the war spending ended up in the Amsterdam economy, nor disturbing it significantly. The war also resulted in minimal territorial changes. ${ }^{12}$

The data also support the hypothesis that these wars had no direct impact on the economy. In the top part of Table 5.2, I present descriptive statistics on various economic variables related to the state of the economy of Holland and Amsterdam, for periods of war and periods of peace. In the last column, I report p-values of standard difference-in-means tests. None of these differences is statistically significant, while there are large and significant changes in Amsterdam house prices and bond supply (middle part of Table 5.2)

To provide further support for this hypothesis, I compare house prices in Amsterdam to those in Den Bosch (1692-1838), a small city in the south of the Dutch Republic, close to the border. Because some of the battles took place near the border, the city hosted military troops during several wars, most notably the Spanish Succession War. As a result, Den Bosch was more directly exposed to the wars than Amsterdam, and subject to similar taxes. However, investors in Den Bosch were not exposed to the market for Holland bonds. Bond markets in the Dutch Republic were local, with each province issuing its bonds in local offices (Feenstra, 2018). Den Bosch was part of the States of Brabant, a "Common Land" under federal rule instead of provincial rule, and therefore did not have a provincial bond office. Investors had to travel to the

\footnotetext{
${ }^{12}$ During the Nine-Years' War and the Spanish Succession War, the main 'gain' of the Dutch was its ability to station troops outside of the Dutch Republic in 'barrier cities' in the Southern Netherlands (current Belgium). These were supposed to provide extra protection against the French, but turned out to be useless in the War of the Austrian Succession.
} 
Table 5.2: Descriptive Statistics, War and Non-War Periods, 1688-1780

\begin{tabular}{lccccccc}
\hline \hline & \multicolumn{9}{c}{ Peace } & \multicolumn{7}{c}{ War } \\
Statistic & $\mathrm{N}$ & Mean & S.D. & $\mathrm{N}$ & Mean & S.D. & P-val. \\
\hline$\Delta \log (\mathrm{CPI})$ & 60 & -0.002 & 0.068 & 33 & 0.009 & 0.087 & 0.515 \\
$\Delta \log (\mathrm{GDP})$ & 60 & -0.007 & 0.080 & 33 & 0.022 & 0.104 & 0.166 \\
$\Delta \log$ (Wages) & 60 & 0.0004 & 0.003 & 33 & -0.0001 & 0.003 & 0.389 \\
$\Delta \log$ (Population) & 60 & -0.0004 & 0.005 & 33 & 0.002 & 0.005 & 0.069 \\
$\Delta \log$ (Rents) & 60 & 0.005 & 0.019 & 33 & 0.0004 & 0.025 & 0.395 \\
$\Delta \log$ (ConstrCPI) & 60 & -0.002 & 0.062 & 33 & 0.006 & 0.101 & 0.689 \\
\hline$\Delta \log$ (HPI, Amsterdam) & 60 & 0.020 & 0.037 & 33 & -0.018 & 0.048 & 0.000 \\
$\Delta \log$ (HPI, Den Bosch) & 60 & 0.005 & 0.140 & 28 & -0.017 & 0.259 & 0.675 \\
\hline$\Delta \log$ (PublicDebt) & 60 & -0.0005 & 0.011 & 33 & 0.022 & 0.017 & 0.000 \\
$\log$ (IntPayments) & 60 & 16.032 & 0.195 & 33 & 15.937 & 0.201 & 0.031 \\
$\Delta \log$ (Yield) & 60 & -0.005 & 0.017 & 33 & 0.011 & 0.023 & 0.008 \\
\hline \% Bond Tax & 60 & 0.015 & 0.001 & 33 & 0.017 & 0.003 & 0.000 \\
$\%$ Property Tax & 60 & 0.164 & 0.025 & 33 & 0.199 & 0.036 & 0.000 \\
$\%$ Wealth Tax & 60 & 0.0002 & 0.001 & 33 & 0.002 & 0.006 & 0.196 \\
$\log$ (ConsumptionTax) & 29 & 15.828 & 0.031 & 31 & 15.850 & 0.070 & 0.110 \\
\hline
\end{tabular}

Notes: Table 5.2 shows descriptive statistics for various annual time series used in the empirical analysis, both for periods of peace (left) and periods of war (right). The column on the far right reports the p-value for a t-test of equality of means. 
office that issued the bond, implying significant travel costs for out-of-town investors (Van Bochove, 2013). Similarly, Amsterdam investors did not invest in Den Bosch's real estate.

Thus, if wars and taxes were causing the housing booms and busts, we should see similar patterns in Den Bosch and Amsterdam. However, both Figure 5.7 and Table 5.2 show this is not the case. There is significant volatility in Den Bosch house prices during the Spanish Succession War, but there are no major trends in prices during and after the war.

\section{Correlation with Taxation}

The bottom part of Table 5.2 supports the view that the main impact of the war was fiscal: war correlates with significant increases in public debt, higher bond yields, and higher wealth taxes. Consumption taxes did not change. Most of these taxes had already been introduced before 1688, and could not be raised anymore (see Fritschy, 2017).

To fund the increasing debt, the government introduced extra annual taxes on real estate and bonds during the Nine Year's War and the Spanish Succession War. Real estate had been taxed already since 1600, although at lower rates. During the war, the total annual tax ranged from $1 \%$ to $2 \%$ of capital value, and this tax was similar for bonds and real estate. In order to attract investors to the primary market, new bond issues were tax-free for the duration of the war, which likely explains the willingness of investors to buy bonds in this period (Gelderblom and Jonker, 2011). The taxes remained in place after the war and were levied for the entire $18^{\text {th }}$ century. Investors viewed them as a permanent reduction in returns. All historical sources quote the $18^{\text {th }}$ century Holland coupon rate as $2.5 \%$ instead of the pre-tax $4 \%$.

Although I will control for these taxes directly, they are an unlikely driver of the housing cycle. Tax rates were comparable for bonds and real estate, and most of the changes in the level of these taxes happened between 1687 and 1713 when house prices were stable. Taxes were unchanged after 1713 until the late 1780s, except for a brief spell in the 1740s, when rates were increased temporarily, and the government started levying hefty one-time wealth taxes. House prices were falling when substantial additional taxes were imposed in 1747-1748, but most of the decrease in house prices had already happened in periods with more limited changes in taxes. ${ }^{13}$

\section{Correlation with Asset Demand}

Discussing the Nine-Years' War, the British mercantilist thinker Davenet wrote that "the act of war is reduced money," as tax capacity and access to investors had become crucial for war engagement (Brandon, 2018). If bond issuance depended on changes in investor demand for assets, which likely correlated with house prices, estimates

\footnotetext{
${ }^{13}$ The additional taxes in 1748 caused a significant rebellion. One of the most prominent movements, the Doelisten, proposed to sell the public Amsterdam post offices in order to reduce taxes on real estate. This would help to "bring real estate back to its old value, and to make the bourgeoisie flourish again."
} 
of Equation 5.5 would be downward biased. To circumvent this issue, I instrument changes in public debt with a dummy for periods the Dutch Republic was engaged in war. The exclusion restriction states that periods of war should be unrelated to investor asset demand. Because the Dutch Republic did not initiate these wars and played no leading role in them, this restriction is most likely satisfied.

The Dutch Republic did not participate in the Seven-Years' War (1756-1763), but this was unrelated to investor demand. Both during the Austrian Succession War and the Seven Years' War, Dutch investors were lending significant amounts to foreign governments, primarily to England. Similar to the domestic case, these wars caused exogenous increases in the investment opportunities of Dutch investors. To estimate their effect on house prices, I will include a dummy variable for these war periods. It is not possible to use actual levels of foreign bond issuance, because there is no detailed data on how new debt issues were transmitted to Dutch investors (Riley, 1980).

\subsubsection{Empirical Results}

In Table 5.3, I report results for both IV and OLS regressions that estimate the effect of changes in bond supply on house prices, both in a model with and without controls. ${ }^{14}$ I only report significant control variables. Insignificant controls include tax variables (changes in bond taxes, real estate taxes, and levels of one-time wealth taxes) and economic variables (log changes in GDP, day wages, consumer prices, population, and construction cost). The two significant control variables are changes in rental prices and the annual log of interest payments to Holland bondholders. The latter was logically a vital determinant of investor demand: the more interest payments bondholders received, the more money they could reinvest.

I find large effects of bond supply on house prices. Based on the two IV-models, a one percent increase in bond supply reduced annual house price growth by about $1.4-1.6 \%$. Periods of increased lending to foreign governments also led to approximately $3 \%$ lower house price growth. In line with the discussion in the previous subsection, the IV-estimates on the effect of changes in bond supply are higher than the OLS-estimates. Comparing estimates across models, effects are not significantly different in the model with all control variables. Both significant control variables have the predicted effects: a $1 \%$ increase in rent prices increased house prices by about $0.7 \%$, whereas a one standard deviation $(20 \%)$ increase in interest payments to bondholders increased annual house price growth by $1.2 \%$. In Appendix 5.C I present an additional robustness check that endogenizes house prices and turnover in a VARmodel, in order to account for the presence of potential (speculative) dynamics among house prices and turnover that cannot be captured in a standard model, as suggested in DeFusco et al. (2017). Although I find weak evidence for such dynamics, this does not alter any of the results presented here.

\footnotetext{
${ }^{14}$ For the IV-estimate, the first-stage F-statistic is 60.16, suggesting the instrument is strong. This can also be derived from Table 5.2 and Figure 5.7. For both models, I use regular standard errors, as standard tests indicated there was no evidence for autocorrelation or heteroskedasticity in the errors.
} 
Table 5.3: The Effect of Bond Supply on House Prices

\begin{tabular}{lcccc}
\hline \hline & \multicolumn{4}{c}{ Dependent variable: } \\
\cline { 2 - 5 } & \multicolumn{4}{c}{$\Delta p_{t}$} \\
& IV & OLS & IV & OLS \\
\hline$\Delta \log (\text { Debt })_{t}$ & $-1.576^{* * *}$ & $-0.826^{* * *}$ & $-1.420^{* * *}$ & $-0.704^{* * *}$ \\
& $(0.404)$ & $(0.253)$ & $(0.389)$ & $(0.250)$ \\
ForeignWarLending $t$ & $-0.038^{* * *}$ & $-0.034^{* * *}$ & $-0.027^{* *}$ & $-0.022^{* *}$ \\
& $(0.011)$ & $(0.010)$ & $(0.011)$ & $(0.010)$ \\
$\Delta r_{t}$ & & & $0.653^{* * *}$ & $0.718^{* * *}$ \\
& & & $(0.214)$ & $(0.202)$ \\
log(IntPayments $)_{t}$ & & & $0.065^{* * *}$ & $0.058^{* * *}$ \\
& & & $(0.022)$ & $(0.021)$ \\
Constant & $0.028^{* * *}$ & $0.021^{* * *}$ & $-1.014^{* * *}$ & $-0.911^{* * *}$ \\
& $(0.006)$ & $(0.005)$ & $(0.355)$ & $(0.335)$ \\
\hline Tax Controls & No & No & Yes & Yes \\
Economics Controls & No & No & Yes & Yes \\
\hline Observations & 93 & 93 & 93 & 93 \\
$\mathrm{R}^{2}$ & 0.096 & 0.177 & 0.316 & 0.379 \\
Adjusted ${ }^{2}$ & 0.076 & 0.159 & 0.213 & 0.286 \\
Residual Std. Error & 0.043 & 0.041 & 0.040 & 0.038 \\
F Statistic & & 9.669 & & 4.076 \\
\hline \hline
\end{tabular}

Notes: Table 5.3 reports regression estimates of Equation 5.5. Column 1 reports estimates without control variables, based on an IV regression where changes in public debt are instrumented with a dummy variable for periods the Dutch Republic was engaged in war. Column 2 reports results for the same regression when estimated using OLS. Column 3-4 reports the results of both regressions when adding control variables. Insignificant controls (log changes in GDP, wages, population, consumer prices and construction, percentage changes in bond and real estate taxes, and levels of one-time wealth taxes) are omitted for brevity. Standard errors are not adjusted as diagnostic tests detected no heteroskedasticity or autocorrelation in the residuals. ${ }^{*} \mathrm{p}<0.1 ;{ }^{* *} \mathrm{p}<0.05 ;{ }^{* *} \mathrm{p}<0.01$. 
To test more specifically whether these bond supply shocks had significant impacts on yields and housing risk premia, I re-estimate equation 5.5 replacing the dependent variable with changes in rental yields $\left(\Delta r_{t}-\Delta p_{t}\right)$ and changes in housing risk premia $\left(\Delta r_{t}-\Delta p_{t}-\Delta i_{t}\right)$. All models control for changes in taxes since these might directly impact the yield. If homes are priced according to Equation 5.4, we should expect no significant impact of changes in bond supply on housing risk premia, which Equation 5.4 assumes to be constant.

Results for these regressions are presented in Table 5.4. ${ }^{15}$ Based on the IV-models, a one percent increase in the supply of bonds increases rental yields by $1.3 \%$ and housing risk premia by $0.73 \% .{ }^{16}$ In the OLS models, the effect is smaller, with $0.7 \%$ and $0.51 \%$ respectively. Most importantly, comparing the IV-estimates and OLS-estimates of changes in rental yields (Column 1 and 2) with those for changes in housing risk premia (Column 3 and 4) suggests the majority of the effect comes from a change in housing risk premia, as the impact of bond supply shocks on risk premia is only about $40 \%$ smaller than the effect on rental yields.

\subsubsection{Reach for Yield and Housing Market Behavior}

To provide more specific evidence on the role of investors in the boom-bust cycle, I use linked portfolio and transaction data to identify which investors became active in the housing market during periods of war and peace. If reach for yield behavior was an important factor driving down housing risk premia, we should expect increased activity of very wealthy investors during periods of peace, in particular for investors with significant bond investments.

I focus on purchases instead of sales because purchases were in almost all cases concluded by the person mentioned as the buyer. Sales were often executed by heirs or widows of the original owner, and could also be foreclosures or unidentified fire sales. To identify all purchases for each individual, I only include transactions of individuals with a uniqueness score $u_{i}$ below 1.5 , which can also be matched to an individual in the estate tax records with a Jaro-Winkler distance less than 0.175. A uniqueness score of less than 1.5 implies that the expected number of individuals having a similar name is less than 0.5 so that in expectation, the individual is unique. In total, the matched sample contains 3257 individuals involved in 5,880 purchases. This is a substantial reduction relative to the 25,967 purchases in the estate tax records. Only about $20 \%$ of individuals had a name that could be classified as unique, and about $60 \%$ of them purchased any real estate during their life. For all matched individuals that ever purchased real estate, I compute the annual number of transactions in each year until the year of death.

To identify the role of wealthy investors in driving housing market activity, I estimate a difference-in-difference model that compares the annual number of purchases of investors (Purchases Pu,t $_{\text {) }}$ with different levels of wealth $(W)$ or bond wealth over time. Treatment periods are periods where the Dutch Republic is at war $\left(W a r_{t}\right)$, with

\footnotetext{
${ }^{15}$ Estimation results without control variables are presented in Table 5.9

${ }^{16}$ Note these are percentage increases, not percentage points.
} 
Table 5.4: The Impact of Bond Supply on Yields and Risk Premia

\begin{tabular}{|c|c|c|c|c|}
\hline & \multicolumn{4}{|c|}{ Dependent variable: } \\
\hline & \multicolumn{2}{|c|}{$\Delta\left(r_{t}-p_{t}\right)$} & \multicolumn{2}{|c|}{$\Delta\left(r_{t}-p_{t}-i_{t}\right)$} \\
\hline & IV & OLS & IV & OLS \\
\hline$\Delta \log (D e b t)_{t}$ & $\begin{array}{c}1.311^{* * *} \\
(0.357)\end{array}$ & $\begin{array}{c}0.700^{* * *} \\
(0.237)\end{array}$ & $\begin{array}{c}0.730^{* *} \\
(0.359)\end{array}$ & $\begin{array}{c}0.506^{* *} \\
(0.247)\end{array}$ \\
\hline ForeignWarLending ${ }_{t}$ & $\begin{array}{c}0.024^{* *} \\
(0.010)\end{array}$ & $\begin{array}{c}0.019^{* *} \\
(0.010)\end{array}$ & $\begin{array}{l}0.017^{*} \\
(0.010)\end{array}$ & $\begin{array}{c}0.015 \\
(0.010)\end{array}$ \\
\hline $\log (\text { IntPayments })_{t}$ & $\begin{array}{c}-0.059^{* * *} \\
(0.021)\end{array}$ & $\begin{array}{c}-0.054^{* * *} \\
(0.020)\end{array}$ & $\begin{array}{c}-0.038^{*} \\
(0.021)\end{array}$ & $\begin{array}{c}-0.037^{*} \\
(0.021)\end{array}$ \\
\hline Constant & $\begin{array}{c}0.921^{* * *} \\
(0.340)\end{array}$ & $\begin{array}{c}0.852^{* *} \\
(0.327)\end{array}$ & $\begin{array}{l}0.601^{*} \\
(0.342)\end{array}$ & $\begin{array}{l}0.576^{*} \\
(0.339)\end{array}$ \\
\hline Tax Controls & Yes & Yes & Yes & Yes \\
\hline Observations & 93 & 93 & 93 & 93 \\
\hline $\mathrm{R}^{2}$ & 0.146 & 0.208 & 0.102 & 0.110 \\
\hline Adjusted $\mathrm{R}^{2}$ & 0.087 & 0.152 & 0.039 & 0.048 \\
\hline Residual Std. Error & 0.039 & 0.037 & 0.039 & 0.039 \\
\hline F Statistic & & 3.754 & & 1.778 \\
\hline
\end{tabular}

Notes: Table 5.3 reports regression results similar to Table 5.3, with the main dependent variable the log change in the rental yield (Column 1 - 2) and the log change in the housing risk premium (Column 3 - 4). Column 1 and Column 3 are based on an IV regression where changes in public debt are instrumented with a dummy variable for periods the Dutch Republic was engaged in war. Column 2 and 4 reports results for the same regression when estimated using OLS. All regressions control for changes in taxes and interest payments to bondholders. Standard errors are OLS errors as standard tests detected no heteroskedasticity or autocorrelation in the residuals. ${ }^{*} \mathrm{p}<0.1{ }^{* *} \mathrm{p}<0.05 ;{ }^{* * *} \mathrm{p}<0.01$. 
the addition of the Seven-Year's War, when Dutch investors were lending significant sums to foreign entities. During these periods, bond supply increased significantly, and bond yields rose. With observations for each investor $i$ alive at time $t$, I estimate the following regression:

$$
\operatorname{Purchases}_{i, t}=\alpha_{0}+\alpha_{1} \text { War }_{t}+\gamma \log (W)_{i}+\beta \log (W)_{i} \times W a r_{t}+\mu_{i, t}+\varepsilon_{i, t}
$$

The main parameter of interest in this regression is $\beta$. I estimate this model with three different measures of wealth. First, I use the log of total wealth, as indicated in equation 5.6. Second, I use a dummy variable that indicates whether the individual has large holdings of Holland bonds while adding a control for total wealth. Large holdings are defined as more than 4000 guilders, which is the level at which the effect of bond yields on real estate investment becomes negative (see Figure 5.5). Third, I estimate a double difference-in-difference model that uses both the log of total wealth and the indicator variable whether the individual has large holdings of Holland bonds. Finally, I included fixed effects for the number of years until death, computed for each investor, but estimated jointly. This fixed effect controls for the fact that I cannot observe the birth year of investors, such that in some cases, the data will contain periods before investors were alive or financially mature.

In the 1720s, foreign investments became much more accessible to Dutch investors, and investors increasingly started purchasing foreign assets (Figure 5.3). This implied that investors also had other investment options next to real estate during periods of peace and declining bond yields. English bonds were the most important of these. The returns on English bonds were in between the returns on Holland bonds and Amsterdam real estate. To account for these new opportunities, I estimate the model both using the full sample period (1688-1780) and the period of limited outside investment opportunities (1688-1725).

Table 5.5 reports the results of these regressions. Across all estimated models, I find that wealthier individuals became more likely to buy real estate during periods of peace. This effect was much more substantial in the early part of the sample when other investment opportunities were limited (Column 4-6). On average, a doubling of wealth led to a 0.004 increase in the number of annual real estate purchases. This is an $18 \%$ increase relative to the base rate of 0.022 purchases per individual per year ( 1 purchase per 45 years). ${ }^{17}$ Of course, the effect captures both 'reach for yield' purchases and the fact that wealthier investors could still afford to purchase real estate when prices were high.

After controlling for wealth, there are no effects of large Holland bond holdings in the aggregate sample. However, when restricting the sample to periods with limited other investment opportunities, I find that large bondholders were substantially more likely to buy real estate during periods of peace. During such periods, the expected number of purchases per year increased by about 0.01 relative to periods of war (Column 5 and 6). This is approximately a $50 \%$ increase relative to the base rate of

\footnotetext{
${ }^{17}$ The base rate underestimates the actual number of purchases per year because I cannot observe when individuals were born, and when they were legally able to buy real estate.
} 
Table 5.5: Purchase Frequency, Difference-in-Difference Regressions

\begin{tabular}{|c|c|c|c|c|c|c|}
\hline & \multicolumn{6}{|c|}{ Dependent variable: } \\
\hline & \multicolumn{3}{|c|}{ Purchase $_{i, t}:$ 1688-1779 } & \multicolumn{3}{|c|}{ Purchase $_{i, t}:$ 1688-1725 } \\
\hline & (1) & $(2)$ & (3) & (4) & (5) & (6) \\
\hline $\operatorname{War}_{t}$ & $\begin{array}{l}0.010^{*} \\
(0.005)\end{array}$ & $\begin{array}{c}-0.005^{* * *} \\
(0.001)\end{array}$ & $\begin{array}{c}0.009 \\
(0.006)\end{array}$ & $\begin{array}{c}-0.002^{*} \\
(0.001)\end{array}$ & $\begin{array}{c}-0.002^{*} \\
(0.001)\end{array}$ & $\begin{array}{c}0.009 \\
(0.007)\end{array}$ \\
\hline $\log (\text { Wealth })_{i}$ & $\begin{array}{c}0.004^{* * *} \\
(0.0004)\end{array}$ & $\begin{array}{c}0.004^{* * *} \\
(0.0004)\end{array}$ & $\begin{array}{c}0.005^{* * *} \\
(0.001)\end{array}$ & $\begin{array}{c}0.003^{* * *} \\
(0.0004)\end{array}$ & $\begin{array}{c}0.003^{* * *} \\
(0.0004)\end{array}$ & $\begin{array}{c}0.003^{* * *} \\
(0.001)\end{array}$ \\
\hline $\log (\text { Wealth })_{i} \times$ War $_{t}$ & $\begin{array}{c}-0.002^{* * *} \\
(0.001)\end{array}$ & & $\begin{array}{c}-0.002^{* *} \\
(0.001)\end{array}$ & $\begin{array}{c}-0.003^{* * *} \\
(0.001)\end{array}$ & & $\begin{array}{c}-0.001^{*} \\
(0.001)\end{array}$ \\
\hline LargeBH $_{i}$ & & $\begin{array}{c}-0.00004 \\
(0.002)\end{array}$ & $\begin{array}{l}-0.002 \\
(0.002)\end{array}$ & $\begin{array}{c}0.009^{* * *} \\
(0.002)\end{array}$ & $\begin{array}{c}0.009^{* * *} \\
(0.002)\end{array}$ & $\begin{array}{c}0.007^{* * *} \\
(0.003)\end{array}$ \\
\hline $\operatorname{LargeBH}_{i} \times$ War $_{t}$ & & $\begin{array}{c}-0.005^{*} \\
(0.003)\end{array}$ & $\begin{array}{c}-0.0004 \\
(0.003)\end{array}$ & & $\begin{array}{c}-0.012^{* * *} \\
(0.003)\end{array}$ & $\begin{array}{c}-0.009^{* *} \\
(0.004)\end{array}$ \\
\hline Constant & $\begin{array}{l}-0.002 \\
(0.005)\end{array}$ & $\begin{array}{c}0.003 \\
(0.005) \\
\end{array}$ & $\begin{array}{l}-0.004 \\
(0.006)\end{array}$ & $\begin{array}{c}0.001 \\
(0.009)\end{array}$ & $\begin{array}{c}0.014 \\
(0.009)\end{array}$ & $\begin{array}{c}0.008 \\
(0.010) \\
\end{array}$ \\
\hline Years-to-Death FE & Yes & Yes & Yes & Yes & Yes & Yes \\
\hline Observations & 217,450 & 217,450 & 217,450 & 125,007 & 125,007 & 125,007 \\
\hline $\mathrm{R}^{2}$ & 0.007 & 0.007 & 0.007 & 0.013 & 0.013 & 0.013 \\
\hline Adjusted $\mathrm{R}^{2}$ & 0.007 & 0.007 & 0.007 & 0.012 & 0.012 & 0.012 \\
\hline Residual Std. Error & 0.235 & 0.235 & 0.235 & 0.190 & 0.190 & 0.190 \\
\hline F Statistic & 21.344 & 21.005 & 20.795 & 21.983 & 21.743 & 21.491 \\
\hline
\end{tabular}

Notes: Table 5.5 reports estimates from the difference-in-difference regression that measures the effect of wealth and / or large bondholdings on the number of purchases. The dependent variable is the number of purchases per individual per year. Column 1 reports estimates of the base-line regression reported in Equation 5.6, which measures the effect of wealth on the annual number of purchases during periods of war and peace. Column 2 compares individuals with large bondholdings (over 4000 guilders) to individuals with no or limited bondholdings, both during periods of war and peace. I control for the log of wealth in this regression. Column 3 reports results for a regression that combines the specifications in Column 1-2, comparing individuals with different wealth levels and different bond investments, both during periods with and without war. Columns 4-6 report the same regression as Columns 1-3, but restrict the sample period to 1688-1725, when international investment was minor. All regressions contains fixed effects for the years until death ${ }^{*} \mathrm{p}<0.1{ }^{* *} \mathrm{p}<0.05 ;{ }^{* *} \mathrm{p}<0.01$. 
purchases for large bondholders. This finding supports the earlier portfolio evidence and shows that investors actively started purchasing higher-yielding real estate assets when Holland stopped issuing bonds, and yields declined.

To provide insight into the dynamic timing of these effects and to check for unobserved time trends, I re-estimate the regression reported in Column 2 of Table 5.5 for 5 -year periods, instead of only distinguishing periods of war and peace. Figure 5.9 plots for each period the estimated coefficient that measures the effect of large bond holdings on the number of purchases per year, controlling for the log of total wealth. As a baseline, I take the period of the Nine-Years' War between 1688-1697. ${ }^{18}$ Bondholders became increasingly more likely to purchase real estate both after the end of the Nine Years' War and after the Spanish Succession War. This effect diminished over time and disappeared by the mid-1730s, consistent with the increase in alternative investment opportunities in this period.

Figure 5.9: Difference-in-Difference Estimates, per 5-years

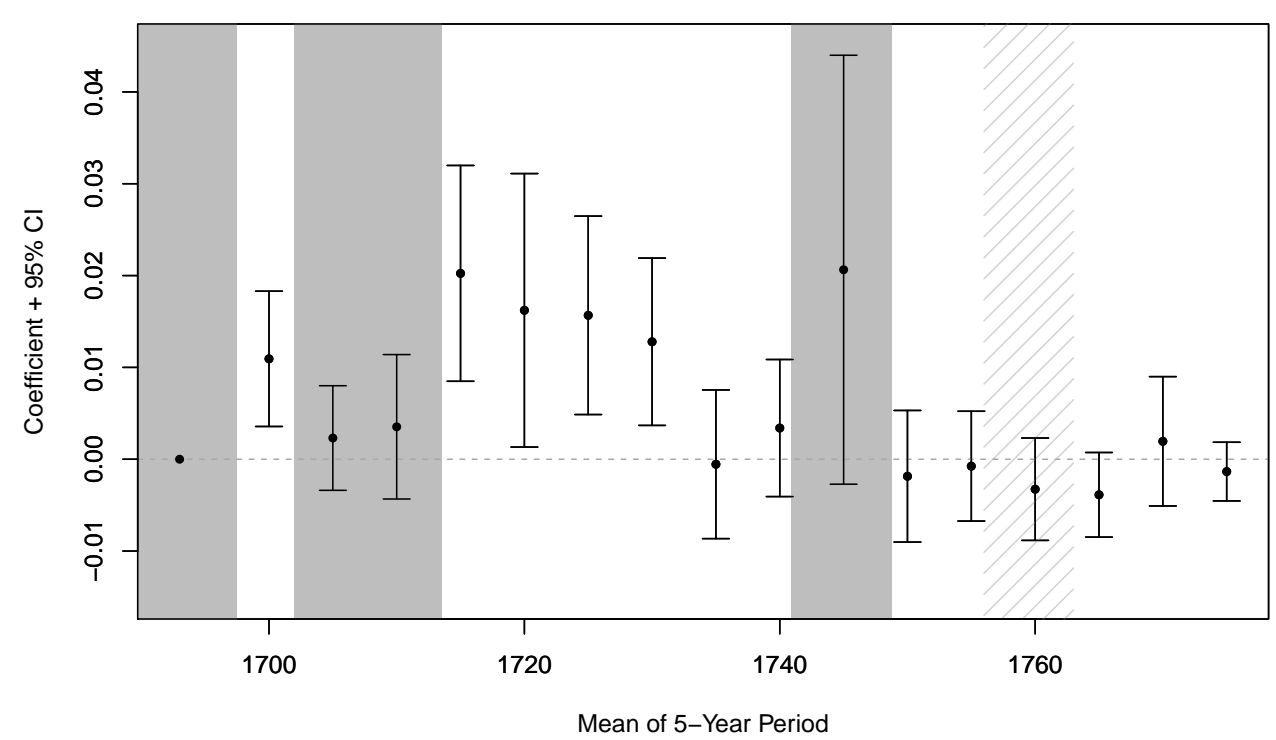

Notes: Figure 5.4 plots the estimated difference-in-difference coefficients that compare for each five-year period the annual number of purchases of large bondholders to those of investors with no or limited bond investments, while controlling for the log of total wealth. For example, in the period from 17181722 large bondholders purchase 0.015 more properties per year than non-bondholders. The average number of purchases in the sample is 0.022 per year.

\subsection{Implications}

In the main body of this paper, I have shown that the cycles in Amsterdam house prices between 1688-1780 were caused by changes in investor demand for real estate and that

\footnotetext{
${ }^{18}$ I aggregate these periods, because the number of matched transactions in this period is small due to missing data.
} 
reach for yield behavior played a crucial role in these demand changes. In this section, I analyze the broader implications of these findings and link them to modern debates. I look at implications for the development of financial markets, the distribution of housing wealth, and the role of credit in housing booms and busts.

\subsubsection{Private Credit}

The booms and busts in Amsterdam were not caused by changes in mortgage credit, as the size of the mortgage market was negligible in this period (see also Appendix 5.B.4). This finding contrasts with the recent US housing boom and bust, which was accompanied by massive changes in mortgage credit. Policymakers have suggested this credit boom was related to increased demand from foreign investors for US assets, who viewed mortgages as a safe alternative for Treasuries (Bernanke et al., 2005, 2011). In Amsterdam, increased investor demand translated directly into real estate investment, rather than increased mortgage supply. However, changes in investor demand for real estate were accompanied by booms and busts in non-mortgage credit.

Figure 5.10 plots the volume of newly registered non-mortgage loans relative to house prices. ${ }^{19}$ The two series are very closely correlated, although the market for non-mortgage credit was much smaller in size, both in terms of flow and stock. Annual registered loan volume was about $30 \%$ of total real estate transaction volume, and the stock of total investment in these loans averaged only $6 \%$ of total real estate investment because most loans had short maturities relative to the average holding periods of real estate.

Why were there similar changes in investment in real estate and non-mortgage loans, even though mortgage loans themselves were small? Most likely, the same factors that drove the increase in real estate investments also increased the supply of non-mortgage loans. When bond supply halted, and bond yields declined, wealthy investors sought alternative higher-yielding investments. Interest rates on nominal private debt were about $4 \%$, and supplying private non-mortgage loans was thus another way for investors to increase their expected returns. ${ }^{20}$

What do these findings imply for modern debates? First, a credit boom is not a necessary condition for a housing boom, as nearly all housing investment was paid directly rather than financed using loans. Second, increased investor demand can cause developments in housing markets and credit markets to be correlated, without inducing a causal relationship between housing and credit. Because investors were looking for alternative investment opportunities next to government bonds, they started purchasing real estate, but also provided more private loans.

\footnotetext{
${ }^{19}$ These series are constructed based on archival registrations of mandatory taxes on registered private debt contracts (see Appendix 5.D). They exclude beleningen, repo-type short-term loans secured on financial assets. No such registrations exist for mortgages, because mortgages were free of taxes, as real estate purchases were already taxed.

${ }^{20}$ The number of investment portfolios with non-mortgage loans is too small to estimate directly whether changes in the share of investment in these loans were related to changes in bond yields.
} 
Figure 5.10: House Prices and Private Non-Mortgage Credit

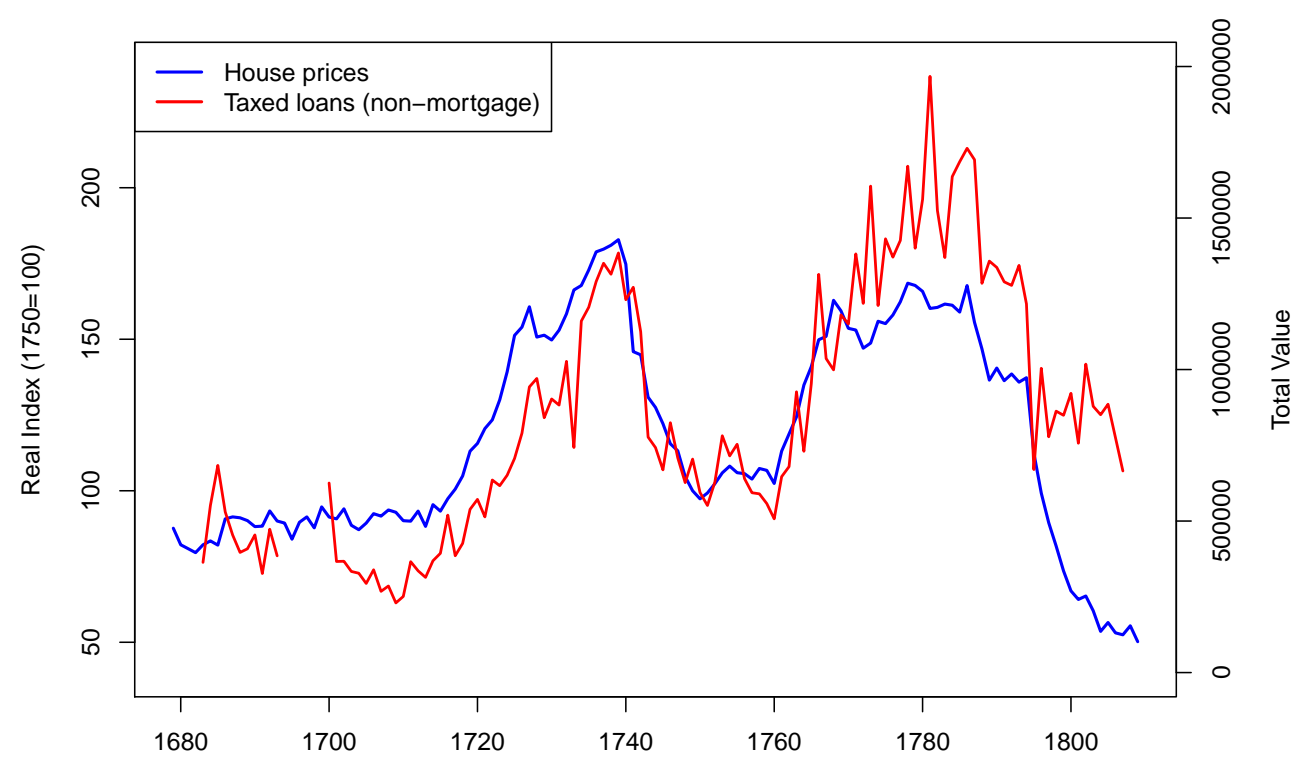

Notes: Figure 5.10 plots the total value of newly issued non-mortgage loans in each year (right axis) and the nominal house prices index (left axis).

\subsubsection{Financial Market Development}

In the early part of the $18^{\text {th }}$ century, investors only had a handful of investment opportunities, and international investment was negligible. However, international investment increased to around $25 \%$ of total wealth by the 1770 s. Although many different explanations have been put forward, economic historians have, among others, attributed the development of international financial markets in this period to the limited availability of attractive investment opportunities within the Dutch Republic (Riley, 1980; De Vries and Van der Woude, 1997). Put differently, low returns in Holland caused investors to search for yield abroad. However, without data on bond yields and investor portfolios, it is difficult to test this proposition.

To identify whether the investment in 'new' financial assets was related to low yields, I re-estimate Equation 5.3 with the share of wealth invested in foreign assets and plantation loans as the dependent variable. Investments in these assets were impossible or difficult at the start of the sample but developed during the $18^{\text {th }}$ century. Although the returns on these assets differed markedly from each other, all had higher yields than Holland bonds. I estimate this model both using value-weighted and unweighted observations. I also estimate a third model that adds a dummy for periods of warfare, which exogenously increased the supply of these new assets.

Figure 5.11 shows the results of these regressions. In brackets, I report the mean weighted exposure per wealth group to investments in foreign assets and plantation loans. Investments in these assets were negligible for the bottom three quartiles but substantial for the wealthiest investors. In line with the findings for real estate, I find 
significant increases in the share of wealth invested in these 'new' assets when rates were low. For the $5 \%$ largest estates, a $1 \%$ reduction in bond yields increased the share of wealth in these assets by more than $20 \%$, relative to a mean exposure of $19 \%$. The enormous effect size suggests that reaching for yield was an important motivation to start investing abroad, and might have fueled the development of international capital markets and new financial instruments.

Figure 5.11: Bond Yields and New Assets

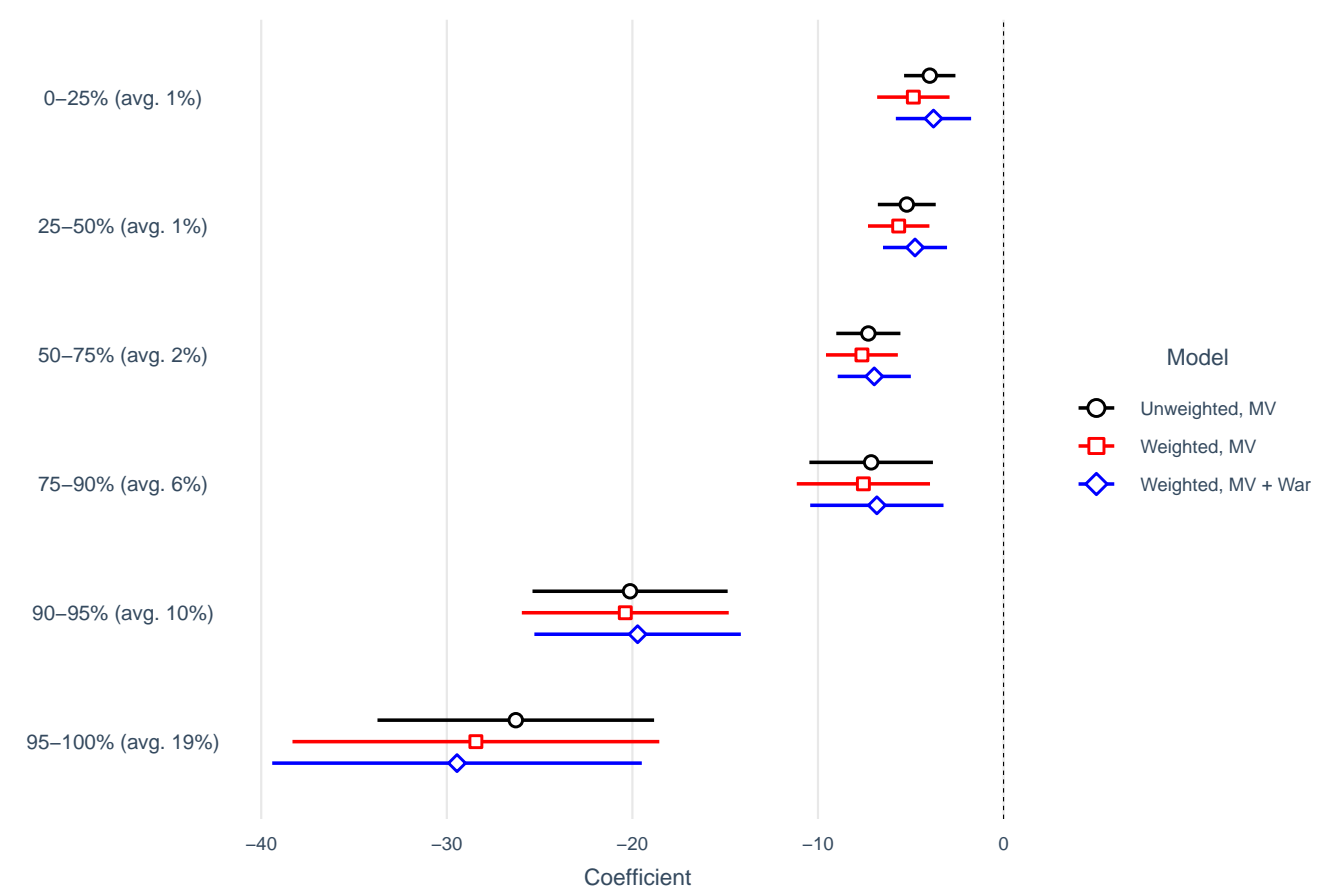

Notes: Figure 5.11 plots the coefficients from a regression that relates the share of wealth in new assets (foreign assets and plantation loans) to the level of the bond yield, for each of the six wealth classes, with $95 \%$ confidence intervals. This coefficient measures the effect of a $1 \%$ change in bond yields on the share of wealth invested in foreign assets and plantation loans. In parenthesis, I report the share of wealth that each group, on average, invested in these assets. All models use the market value of domestic bonds. In the bottom two models, I weigh observations by portfolio size. In the third model, I add a dummy variable for the Austrian Succession War and the Seven-Years' War.

There could be drawbacks to these developments. For example, newly-developed plantation loans, securitized mortgages on plantations in the Caribbean, dramatically went bust following the 1773 financial crisis (Van der Voort, 1973). In the housing market, reaching for yield magnified housing booms and busts. Thus, while reaching for yield might contribute to financial market development, it can also increase asset price volatility. Policymakers have expressed similar concerns in recent discussions about reaching for yield, and the historical case of Amsterdam suggests they might very well have a point. Before the financial crisis, Rajan (2006) raised similar issues. 


\subsubsection{Housing Wealth Inequality}

In the early parts of the $18^{\text {th }}$ century most reaching for yield investments were made in real estate. Because the Amsterdam housing stock was fixed in this period (see Appendix 5.B), investors bought these properties from less wealthy home-owners. Many investors used buy-and-hold strategies (De Vries and Van der Woude, 1997), implying that much of this real estate wealth remained in their hands. Thus, investor demand for real estate might have redistributive effects. This is a major reason why policymakers are currently concerned about buy-to-let investments.

To estimate if investor purchases resulted in shifts in the distribution of housing wealth, I estimate for every ten years the distribution of housing wealth within each wealth group in the estate tax records. Figure 5.12 reports these distributions. Conditional on owning any wealth, the distribution of housing wealth was relatively stable over time, except for one major change. In the ten years between 1715-1724, the heyday of reaching for yield by wealthy investors, the share of Amsterdam real estate wealth owned by the largest $5 \%$ of estates jumped from $20 \%$ to $34 \%$. After 1725 , there were no significant changes in housing wealth inequality anymore.

Figure 5.12: Housing Inequality

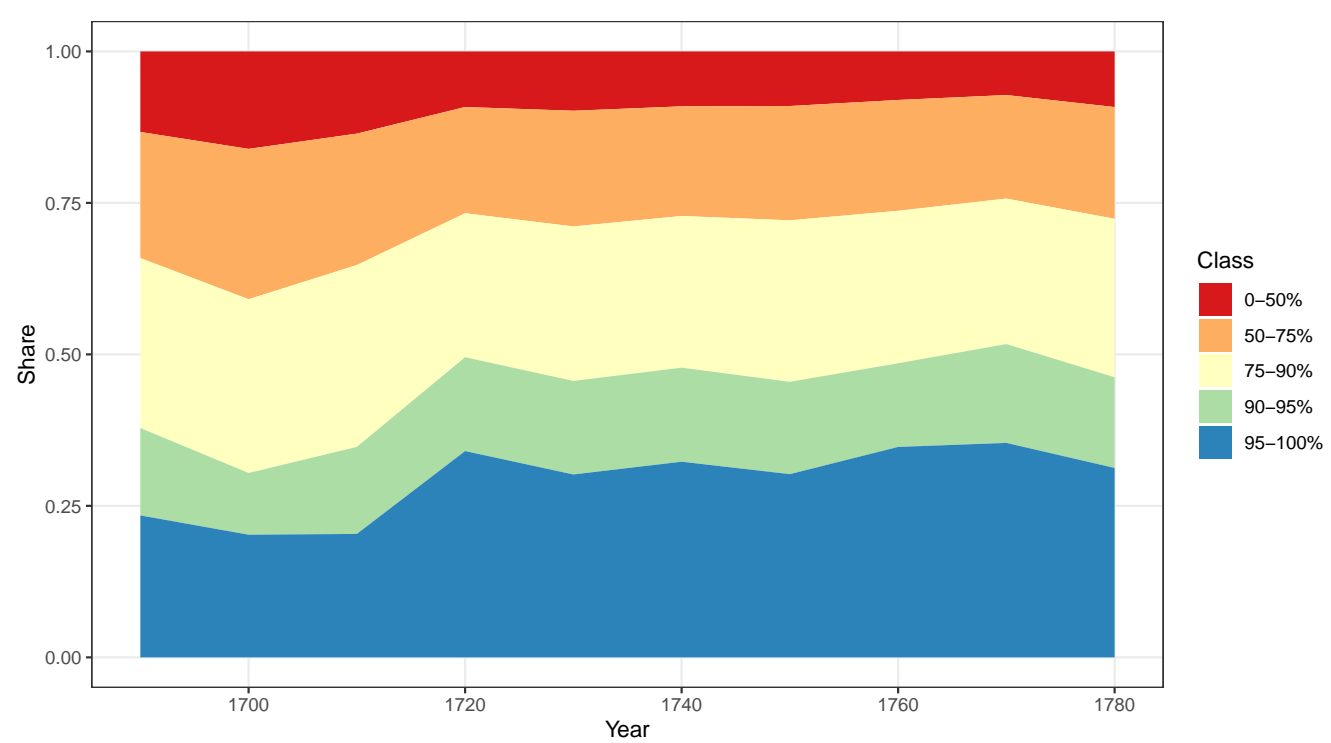

Notes: Figure 5.12 plots for each 10-year period the cumulative distribution of real estate wealth in the sample of estate records, distinguishing five different groups of wealth.

Although Amsterdam society was already highly inegalitarian, the real estate purchases of investors in this period further increased the inequality in housing wealth. Importantly, this increase was persistent. Housing wealth inequality did not reduce when the boom went bust, as investors held on to their properties. This result may still underestimate the actual increase in housing wealth inequality. If wealthy investors purchased the property of people that did not have any other wealth beyond their own 
house, these individuals would not show up in the estate tax records anymore because they had sold all their assets.

\subsection{Conclusion}

This paper shows that investor demand for real estate played a crucial role in generating large booms and busts in house prices in historical Amsterdam. When wars ended, and Holland stopped issuing bonds, wealthy rentiers could not reinvest their interest payments in new bond issues. Instead of buying bonds in the secondary market, investors increasingly purchased real estate, inflating house prices. Wealthy bondholders were reaching for yield: Facing declining bond yields, they invested increasing shares of their wealth in real estate. As a result, housing wealth inequality increased, and house price volatility exacerbated.

The historical case of Amsterdam has valuable lessons for today. Although the modern world does not entirely resemble Amsterdam's rentier society, investors still face similar trade-offs. When rates are low, investors either have to accept lower levels of return and adjust their saving and consumption, or they can switch to assets with higher expected returns and risk. Now interest rates are at historically low levels, there is a lively debate about the existence and implications of reach for yield behavior. The recent surge in current Amsterdam house prices, as well as other cities, has been linked to such increased investor demand (e.g. Nijskens et al., 2019). However, contrary to the $18^{\text {th }}$ century, it is much more challenging to identify the impact of investor demand on prices, and whether these investors are reaching for yield. The historical Amsterdam case shows that individual investors actively decide to reach for yield when interest rates are low and that such episodes can trigger substantial and prolonged increases in asset prices, which might go bust when interest rates increase again. 


\section{A Additional Context Data}

\section{A.1 Real Estate Registrations}

There existed a comprehensive and mandatory system of real estate registrations in Holland since the $16^{\text {th }}$ century (see Van Bochove et al., 2015). This system likely evolved from medieval practices in the Southern Netherlands, where such registrations took place already in the medieval period. The central authority in the registrations of real estate were local law courts (schepenbanken), where aldermen (schepenen) ratified and registered each real estate transaction. Although central laws were governing the registration of mortgages and real estate in the Dutch republic, exact customs and practices varied slightly from place to place. ${ }^{21}$ For Amsterdam, much of the practicalities and customs regarding the real estate and mortgage markets can be found in the books of Rooseboom (1656) and Van Wassenaer (1737). These two documents formed a vital source for the remainder of this section.

In Amsterdam, the oldest surviving register of real estate sales dates from 1563, while the last transactions were registered in February 1811. In total, there were five different legal ways to transfer real estate. The first, and by far the most common, were regular property sales. To ratify these sales, buyers and sellers had to appear in front of aldermen, who created an act of ordinaris kwijtschelding (ordinary remission). Buyers had to bring two guarantors for the transfer. Buyers and sellers that were legally not allowed to transact property, such as women or children, had to be represented by guardians. The acts followed a standard format, and a full English transcription of one such act is given below, for the purchase of property by the painter Rembrandt. The acts contained the most relevant information regarding sales. First, they contained the date and the names of the buyer(s) and the seller(s) of the property, and sometimes also their profession. Representatives were often listed as well. Importantly, the acts always mentioned the names of the original and future owners of the property. For example, if the owner was deceased, the seller(s) would be referred to as the 'heir(s) of' the original owner. The same applied for buyers and sellers not legally allowed to transact property, such as women and children. Properties could have multiple sellers, while multiple buyers occurred less frequently. Second, the act contained a short description of the property and its location. Most transactions are classified as 'house and land', but sometimes the acts provide more detail. It was also possible to own a property partially, and a few percents of the acts mention that parts of properties were sold.

Homes had no house numbers in this period. Acts identified the location of properties based on street names, a near point of interest, or the names of owners of surrounding properties. Unfortunately, the latter has not been collected in the database used for this study. Last, and most importantly, the aldermen included the transaction price for each transfer. Unfortunately, this practice only started in 1637 for regular sales.

\footnotetext{
${ }^{21}$ Many of the applicable rules can be found in the placaatboeken, published in Cau et al. (1658), which contained ordonnances of the Dutch Republic
} 
In case a homeowner defaulted on a loan or fell behind tax payments, his property could be transferred per executie kwijtschelding. In this case, the property would be sold in a foreclosure auction organized by the City of Amsterdam, and the transfer registered with the aldermen. Before such an auction, creditors had to seize the debtors' assets via the bailiff of Amsterdam. This would give the debtor the possibility to repay. If he did not, the aldermen provided creditors a letter that would allow them to auction the property. Creditors were not allowed to participate in the auction but had the right to buy the asset from the winner of the auction in case the proceedings of the auction were not sufficient to repay the debt fully. The earliest registrations of these executie kwijtscheldingen date from 1604 and already include transaction prices.

Because there was a (limited) market for private credit, and real estate the most important collateral for credit, it was possible that creditors still possessed claims on properties that the debtor had already sold. Usually, creditors retained this claim until one year after the purchase. However, to shorten this period, buyer and seller could agree to sell via a procedure of willig decreet at the Court of Holland (see Van Iterson, 1939). The sale would be announced publicly three times with intervals of 14 days, which would give creditors the time to announce themselves, and settle the debt. Afterward, the sale would be registered and creditors would lose their claim on the asset, and could only be paid directly by the debtor. Such a procedure also existed for foreclosures sales, when the sale would be registered as onwillig decreet. Although not a foreclosure sale in itself, willige decreten were used frequently when there was significant concern that debt would not be repaid: the number of decreten correlates closely with the number of foreclosure sales.

The last way to transfer property was via the weeskamer (orphan chamber), a local authority in charge of the asset management of orphans' possessions. They had the legal authority to registers property transactions involving the property of orphans and recorded those in their books of weesmeesterverkopingen. They were not registered with the aldermen.

\section{Transcription Figure 5.1}

This subsection contains the transcription of the real estate transaction in Figure 5.1. In bold are the elements that have been transcribed.

In margin: sold for fl. 13000

We, Cornelis van Vlooswijck and Gerrit van Hellemont, alderman in Amsterdam, write and acknowledge that for us have appeared Christoffel Thys and Jan Beltens as heirs of Pieter Beltens de Jonge, and have sold and remitted to Rembrandt Hermansz a house and yard standing on the Breestraat, over the Sint Anthonis sluice, on the west-side, with a free exit or pass-through to the house of Claes Elias, as has been explained in the acts of remittance about those, and this being the house and yard that is or was next to that of Claes Elias, with the entire wall on the north west side and that of Salvador Rodrigues on the south east side, and reaches from the street until the house and yard 
that belongs to Bastiaen Jacobsz Kistemaecker. And those that have appeared have already committed to the terms, and the principal has brought Isaac van Beecq and Dirck Dircks Grijp (jointly appeared) as joint guarantors, and each has promised with all their movable property that this house and yard has and will be remitted year and day, as one has promised to do, and to remove older acts. This is what the sellers have each promised, and the principal has also promised to keep the guarantors free from losses under the agreements written above. Entered January 8, 1653.

\section{A.2 Estate Tax Records}

To reconstitute the investment portfolios of Amsterdam citizens, I use data from archival records of estate taxes, the so-called collaterale successie. Inheritances from parents towards children were free of taxes, but inheritances in collateral lines were taxed with a $5 \%$ inheritance tax. In 1745 , these taxes were increased to be either $5 \%, 6.66 \%$, or $10 \%$, depending on the distance between the heir and heiress. Registrations of these inheritances have survived in the archives from 1663, although registrations in the early $17^{\text {th }}$ century do not always seem complete.

Every record contains a full list of assets owned by the deceased individual. Most assets were valued based on their market price on the day of registration. However, domestic government bonds were valued at par as long as there had been no formal write-offs on the debt. To value properties, the city of Amsterdam employed several assessors that would appraise the properties owned by the deceased individual. Section 5.A.2 provides a transcription of one of these records.

I have collected and transcribed 25,672 of these registrations, covering all registrations between 1688 and 1780. I classify each asset in each registration in six different aggregate asset classes, which are reported below in section 5.A.2. If a deceased individual had borrowed money, these loans would be subtracted from the total value of its assets. I exclude these liabilities from my analysis: these loans already appear on the asset side (since every borrower has a lender).

There are three potential problems with these sources. First, they only give information on wealth at death, and only for those that do not inherit in the direct line. Wealth at death might not be entirely representative of aggregate wealth in society. This might be particularly pronounced for individuals without children, who make up the majority of registrations. Second, tax evasion might lead to a bias in the estimated portfolios and valuations. The incentive to evade taxes is most significant for the wealthiest, who generally have different investment portfolios compared to individuals with less wealth. Carter (1953), who used these records to estimate foreign Dutch investment between 1740 and 1790, also discusses this issue. ${ }^{22}$ She concludes that this concern is not of major importance. Similarly, the dissertations of Prak (1985); Kooijmans (1985); De Jong (1985), conclude these sources sketch a representative picture of total investment.

\footnotetext{
${ }^{22}$ Unfortunately, she only separated domestic and foreign investments, such that her data could not be used for this study
} 
To test in more detail whether these sources are representative of the total distribution of wealth, I use summary statistics on taxes on burials and marriages from Hart (1973). Amsterdam introduced these taxes during the Seven Years' War to finance the growing debt service. These taxes were progressive, and based on total wealth level. There was no tax (pro deo) for individuals without any wealth, and the taxed increased based on total wealth.

Table 5.6 shows the percentage of the population in each tax bracket conditional on owning any wealth for both burial records, marriage records, and the estate tax records. In general, the two distributions overlap each other very well. The main difference between the estate tax records and the burial tax records originates from the under-registration of small estates. However, Hart (1973) reports that his figures might significantly overstate the share of the population in the fourth investment class because many individuals without any wealth might have decided still to pay the small tax in the first wealth class (3 guilders). Hart (1973) argues some did so in order to avoid being classified as 'unwealthy'. If a few percent of the population without any wealth did so, the measures from the estate tax records would match up with those from Hart (1973).

Table 5.6: Representativity Collaterale Successie

\begin{tabular}{lccc}
\hline \hline & \multicolumn{2}{c}{ \% of Population with } & Wealth \\
\cline { 2 - 3 } & Marriage tax & Burial tax & Estate tax \\
\hline First class $(>12000)$ & 0.197 & 0.225 & 0.218 \\
Second class $(6000-12000)$ & 0.093 & 0.096 & 0.127 \\
Third class $(2000-6000)$ & 0.201 & 0.209 & 0.259 \\
Fourth class $(<2000)$ & 0.509 & 0.47 & 0.396 \\
\hline \% Pro Deo & 0.852 & 0.797 & \\
\hline
\end{tabular}

Notes: Table 5.6 shows the fraction of wealthy citizens within each wealth class based on three different sources: estate taxes, marriage taxes and burial taxes. For the latter two categories, I also report the share of individuals without any wealth. The records from the burial taxes and marriage taxes might slightly overstate the number of people in the fourth class, as people sometimes reported to possess wealth in order not to be classfied as poor.

The data in Hart (1973) also allow us to estimate what fraction of individuals is covered by the estate tax records. Any individual that died with real wealth paid burial tax, but only those without inheritance in the direct descending line paid estate tax. Excluding estates under 2000 guilders, the number of estate tax records with an asset value larger than 2000 guilders is $32 \%$ of the total number of burials with wealth above 2000 guilders. The estate tax records thus cover about a third of individuals in Amsterdam that owned any wealth. 


\section{List of Assets and Examples}

For each estate tax record, I distinguish sixteen asset classes, which I aggregate in seven major asset classes:

1. Real Estate

- Amsterdam real estate (any real estate within Amsterdam)

- Non-Amsterdam real estate: (real estate outside of Amsterdam, mostly land)

- Other real estate (leaseholds, usufruct, life rentals etc.)

2. Domestic Government Bonds

- Holland bonds (various types: bills, life annuities, perpetuals, lottery bonds)

- Other government bonds: municipal bonds, other provincial bonds, Generality debt (federal debt), admiralities)

3. Corporate Bonds

- Corporate bonds (Dutch East India Company, Dutch West East India Company and other colonial enterprises)

- Plantation loans (securitized mortgages to plantations in the Caribbean)

4. Equity

- Stock (Dutch East India Company, Dutch West East India Company and other colonial enterprises)

- Investment funds (mutual funds, tontines)

5. Repo

- Belening: (short-term) loans with financial assets as collateral

6. Private debt

- Non-mortgage debt (schepenkennissen, losrenten, notarial obligations)

- Mortgage-debt (kustingsbrieven)

7. Foreign investments

- English debt (annuities, obligations in Bank of England, South Sea Company, East and West India Company, Million Bank, Exchequer debt etc.)

- English stock (stocks in traded companies)

- Other foreign debt (primarily government bonds in German cities and Austria, later also in France, USA, Russia, Sweden, Denmark and Norway)

- Other foreign equities 


\section{Transcription Figure 5.2}

This subsection contains the transcription of the estate tax record in Figure 5.2. In bold are the elements that I transcribed. Iadded the asset class in parenthesis. The number of assets varies highly across records: wealthy individuals could own hundreds of different assets.

Transcription:

Left with Willem van Collen, deceased 22 October 1740.

1500 British pounds capital stock in the Royal Bank of England, valued at 141 percent with a 34 percent exchange rate and $4.25 \%$ bank agio. 22985 guilders and 15 stuivers (English stock: foreign investments)

A life annuity from the Province of Friesland, dated the 3rd of April 1695, to the body of Maria Amstenraad, 61 years old, at 45 guilders per year. 180 guilders (Holland bonds: domestic government bonds)

A 32-year interest letter from the Generality Office in The Hague, on the name of Emerentia Kerkrink, widow of Jacob Bak, dated 20 February 1711, capital sum 100 guilders where 3/32 part remains. 93 guilders and 15 stuivers (Other government bonds: domestic government bonds)

1/47 part in 25000 guilders capital obligations from the Roman Emperor on the Quicksilver, by contract of survival (tontine) number 5, dated 10th January 1736, folio 19. 531 guilders and 18 stuivers (Investment fund: equity)

$1 / 47$ part in the same contract, folio 20. 531 guilders and 18 stuivers (Investment fund: equity)

We, Mayors and Rulers of the City of Amsterdam, declare that for us has appeared Zacharias Zijlmans, as executor of the will of Willem van Collen, and has by this means, adhered to the Law Passed by the Highly Esteemed Lords of the States of Holland and West Friesland, on the means of the $20^{\text {th }}$ penny, enacted the $11^{\text {th }}$ of March 1623 , and testified and confirmed that the registration of the estate of Willem van Collen, as far as it is due the $20^{\text {th }}$ penny, is true and right, without any evasion or withholding. May God Almighty Help Him. Dated $11^{\text {th }}$ of January 1741.

\section{B Additional Historical Context}

\section{B.1 House Price Developments and Turnover}

Figure 5.13 plots developments in nominal prices, where the CPI (from Van Zanden, 2018) is used as deflator, together with estimates of turnover. I discuss the estimation of turnover in the subsection below.

In the long-run, house prices have not changed much, while (unreported) real prices declined slightly. ${ }^{23}$ The average level of turnover is about $3 \%$, which makes mar-

\footnotetext{
${ }^{23}$ The long-term developments in prices are similar to the Herengracht index from Eichholtz (1997). However, the Herengracht index from does not reveal the very strong boom-bust cycles of the index in figure 5.13. The correlation of the log growth rates between the updated annual Herengracht index (Am-
} 
Figure 5.13: House Prices and Turnover, 1585-1810

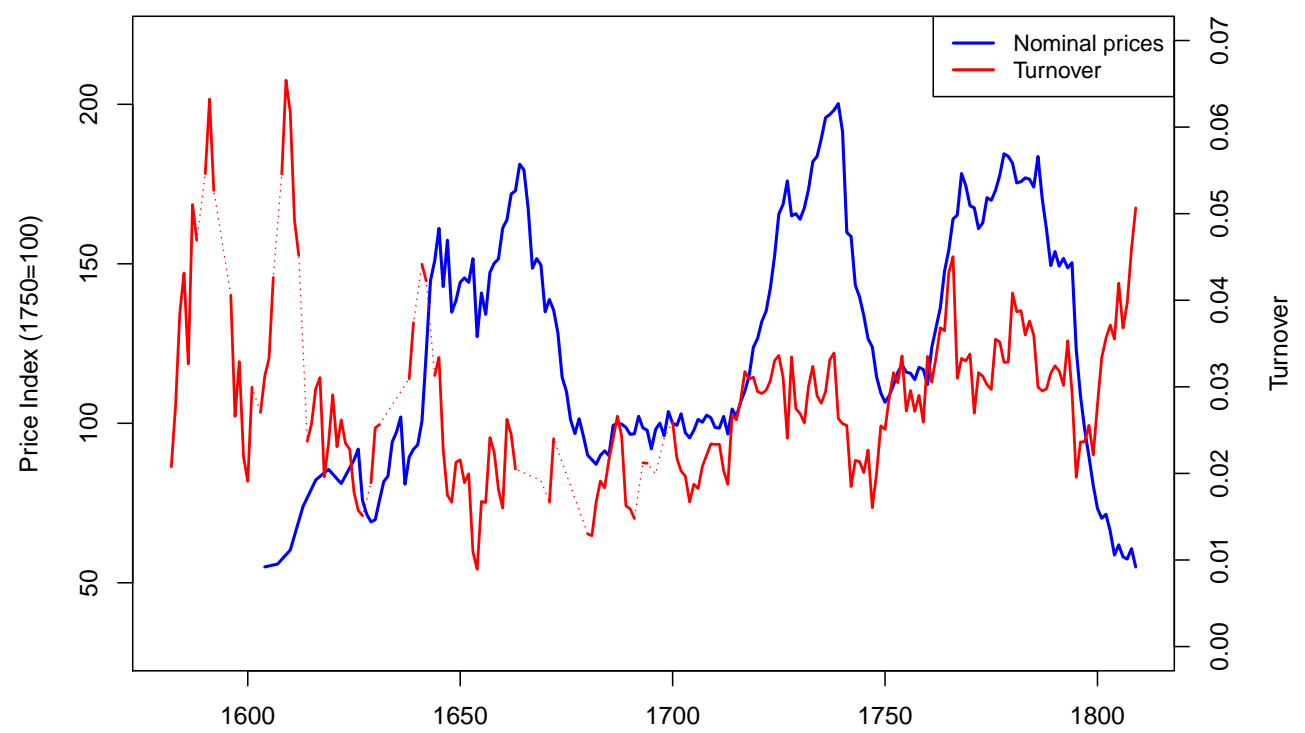

Notes: Figure 5.13 reports the developments in nominal house prices and turnover. The level of turnover is interpolated and dashed in some years in the $17^{\text {th }}$ century, when transaction data is missing.

ket activity similar to what is reported for various European countries today (Dröes and Francke, 2017). The general decline in house prices does not seem very surprising in the historical context: the index starts during the Dutch Golden Age, while ending in the French period, which is widely considered as a period of major crisis in the Dutch economy (De Vries and Van der Woude, 1997).

Of course, the most interesting developments in house prices and turnover are over the shorter-term: there are very strong cycles in both house prices and turnover. During the Golden Age, the population of Amsterdam expanded rapidly, increasing from about 30,000 in 1580 to over 200,000 in the 1660s. To accommodate these increasing population numbers, the City of Amsterdam was expanded based on large planned extension, that, among others, led to the construction of its famous canal ring (see Abrahamse, 2010). From the late $17^{\text {th }}$ century, population numbers and housing supply did not change anymore.

The first and second extensions of the city happened in the 1580s and 1590s, and these extensions led to considerable activity in the real estate market: there are two large cycles in turnover in this period. Plans for the third extension of the city were made in 1609 when the 12-year truce in the Eighty Years' War with the Spanish started. At the same time, activity in the real estate market spiked again, most notably for properties outside of the city walls, which were the subject of the planned extensions.

brose et al., 2013) and my index is also very low: 0.068. As indicated previously, this seems the result of the low number observations in the Herengracht index, rather than differences in house prices at the street level: an unreported index of all three major Amsterdam canals (Herengracht, Keizersgracht, Prinsengracht) almost entirely mimics Figure 5.13 . 
Prices increased during the 12-year truce but started falling substantially between 1625 and 1629 when nominal prices declined by $25 \%$ and real prices even by $45 \%$. The subsequent recovery was strong, and likely constituted one of the most massive booms in Amsterdam housing history: between 1629 and 1645 nominal and real house prices increased respectively by $133 \%$ and $180 \%$, while turnover increased significantly as well. Although there was a downward trajectory in prices during the late 1640s and early 1650s, house prices remained at high levels, and increased towards the peak of the boom in 1664, coinciding with the height of the Dutch Golden Age (De Vries and Van der Woude, 1997). Until 1682, following significant political turbulence in the Republic, both nominal and real house prices declined by more than $50 \%$. The decline was particularly sharp following the Dutch 'year of disaster' 1672: between 1672-1674 house prices decline by $8 \%$ per year in nominal terms and even $11 \%$ in real terms.

After more than 30 years of stable house prices, a second major boom-bust cycle started in 1714. Prices reached their peak in 1739 and reverted to their initial values by 1750. Although less significant, turnover appears to have experienced a similar cycle. The last major boom-bust cycle started in 1760, with the bust being particularly significant. After the Batavian Revolution in 1795, which made the Republic almost entirely dependent on France, prices declined in the following five years on average by $11 \%$ per year in nominal terms and $13 \%$ in real terms. By 1810 , nominal house prices had declined by more than $70 \%$ relative to 1786 , and real prices even by $75 \%$. Interestingly, this was also the only period where turnover moved opposite to house prices. Relatively cheaper properties mostly drove these increases in turnover. It is thus very well possible that these were distress sales, where low-income households sold their assets to obtain liquidity for basic needs. However, over the entire sample, the contemporaneous correlation between house prices and turnover is positive and significant $(\mathrm{r}=0.114)$.

\section{Estimating Turnover}

The construction of a turnover index requires estimating the number of homes transacted annually and the total number of homes in the city. To start with the first, I identify for each transaction the number of homes that are involved. Most transactions are for one home, but partial sales or multiple sales frequently occur as well. For transactions that combine residential and non-residential sales, only the residential part is counted. Subsequently, I adjust for periods with missing data. Since the registers were chronological, data is either complete or entirely missing. If a missing register does not cover an entire year, and more than three months of data is still available for that year, I estimate annual turnover by dividing the total number of transactions in these months by the share of transactions that, on average, occur in these months. I made no estimates of turnover for the ordinaris kwijtscheldingen prior to 1582 due to a lack of data. Data from orphan sales are excluded, as it does not represent the buying and selling behavior from property owners, but rather the management of the orphan chamber.

In the last step, I scale each of the series by the size of the market. Such a step 
is necessary, as the city of Amsterdam expanded significantly in size during the $16^{\text {th }}$ and $17^{\text {th }}$ century. Tax registers reveal that from the 1680s, the size of the city and the number of homes stayed constant. In this period, there are in total around 25,000 properties in the city, of which about $90 \%$ was residential real estate. ${ }^{24}$ It is more difficult to obtain estimates on the number of homes before 1680 when Amsterdam expanded significantly in size and had vast suburbs, which were rarely included in the tax records. Therefore, I rely on existing estimates of the Amsterdam population from Nusteling (1985) and Van Leeuwen and Oeppen (1993), and scale these based on estimates of the number of people per home. For 1680, I assume the number of people per home was equal to the number obtained from the tax records of 1733 (9.4 people per home). Before 1632, I assume 8.42 people per home based on the number of homes reported in Lourens and Lucassen (1997). Between 1632 and 1680, the number of people per home is interpolated linearly.

\section{B.2 Housing Supply}

Any discussion of the historical housing market in Amsterdam cannot bypass the drastic evolution of the city and its economy during the $16^{\text {th }}$ and $17^{\text {th }}$ century. In the 1570 s, Amsterdam was a small city with an estimated population of only 25,000 people (Nusteling, 1985). After joining the Dutch Revolt against the Spanish in 1578, and aided by a large inflow of refugees from the Spanish Southern Netherlands, the city started growing substantially both economically and demographically. It was in this period that Amsterdam developed into the mercantile capital of the world: the Golden Age. From the 1580s until the 1660s, Amsterdam's population increased to over 200,000, approximately a quarter of the total population of Holland. The city its government started a coordinated expansion of the city, which has been described extensively in Abrahamse (2010). This four-stage expansion took place between 1585 and the late $17^{\text {th }}$ century, and expanded the size and housing supply of the city substantially.

The extensions of the city left a crucial mark on the developments in Amsterdam's real estate market. In the first place, the growth of the city significantly increased housing demand and supply, leading to increased activity in the real estate market. Second, during the extensions, real estate investment boomed. Figure 5.14 presents statistics on the annual transaction value in the Amsterdam housing market, in total and per capita terms. ${ }^{25}$

Per capita housing investments peaked in the late 1580s and early 1590s, when the first and second extension of the city took place, and during the 1610s when the third major extension took place. Developments in total transaction value and transaction value per capita were virtually the same since the 1660s, as the population of Amsterdam did not change much after 1660 . As a result of the stagnation, the city was unable to sell all plots of land made available during the fourth extension of the city, which took place in the second half of the $17^{\text {th }}$ century. The city took its loss and converted

\footnotetext{
${ }^{24}$ Source: ACA 5044, inv. nrs. 402-405

${ }^{25}$ Population estimates are from Nusteling (1985) before 1680, and from Van Leeuwen and Oeppen (1993) for 1680-1810
} 
Figure 5.14: Transaction Value Amsterdam Real Estate, 1585-1810

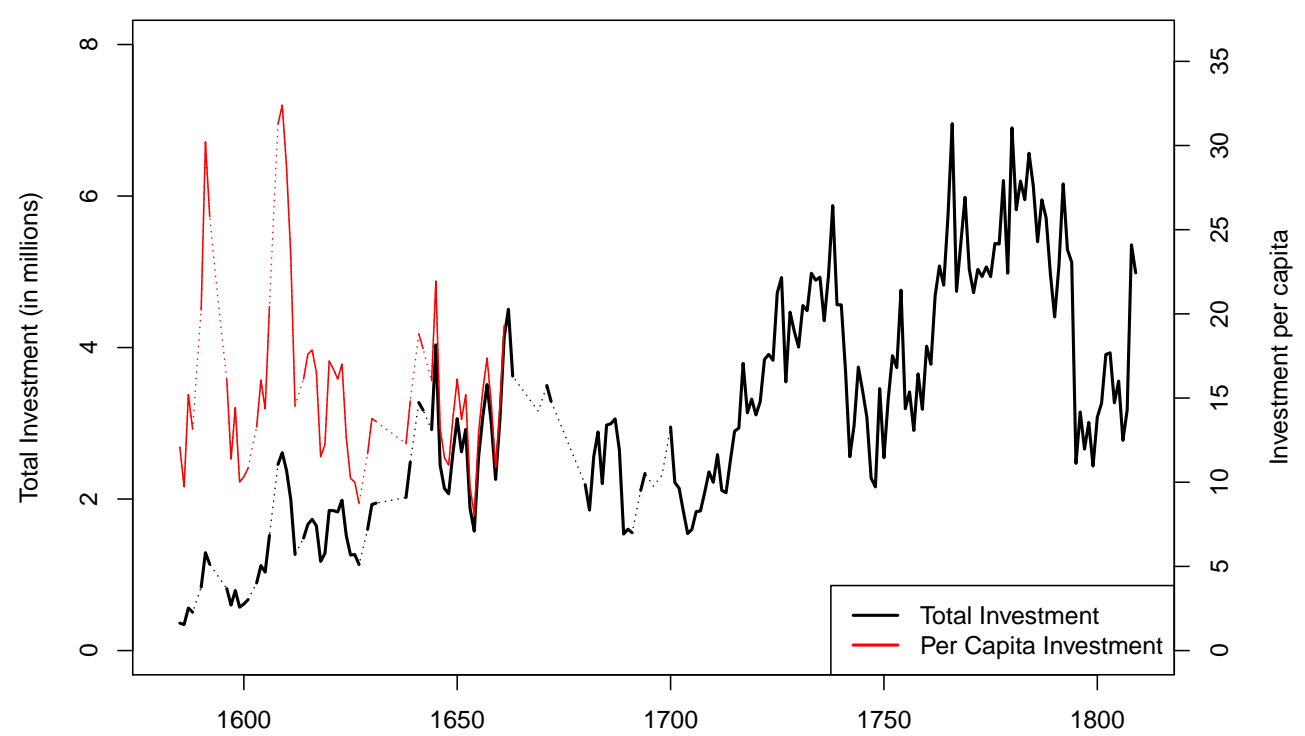

Notes: Figure 5.14 reports the annual total value of all real estate transactions. Prior to 1665, when the city grew substantially, I also report per capita investment. The series only include years in which data is complete or available for at least 6 months (with transactions adjusted for missing months). When data is missing, I used interpolation (dashed).

part of these plots into gardens. These were only converted into residential areas when the population started expanding again in the late $19^{\text {th }}$ century (Abrahamse, 2010).

These patterns are also visible when looking at actual construction and population data. Figure 5.15 plots the level of population in Amsterdam, and the rental value of annually completed construction. Due to the existence of property taxes, new construction was valued when it was completed, and records of these taxations have survived in the Amsterdam City Archives for most years after 1650. I have aggregated all of these to measure the total rental value of new construction relative to the total rental value of the housing stock. After the 1670s, new construction in Amsterdam was negligible.

\section{B.3 Real Estate Taxation}

The system of real estate registration helped both to identify and define property ownership, and allowed for the taxation of real estate, which was among the most important forms of taxation in the Dutch Republic. There were various taxes on real estate, which existed until the French changed the system of real estate registration and taxation at the beginning of the $19^{\text {th }}$ century. ${ }^{26}$ The first tax was the ordinaris verponding, which was a tax on the rental revenue that could be generated from a property, inde-

\footnotetext{
${ }^{26}$ Note that beyond specific real estate taxes, the Dutch government also frequently levied wealth taxes, which included real estate (see e.g. Liesker and Fritschy, 2004)
} 
Figure 5.15: Population and Construction in Amsterdam

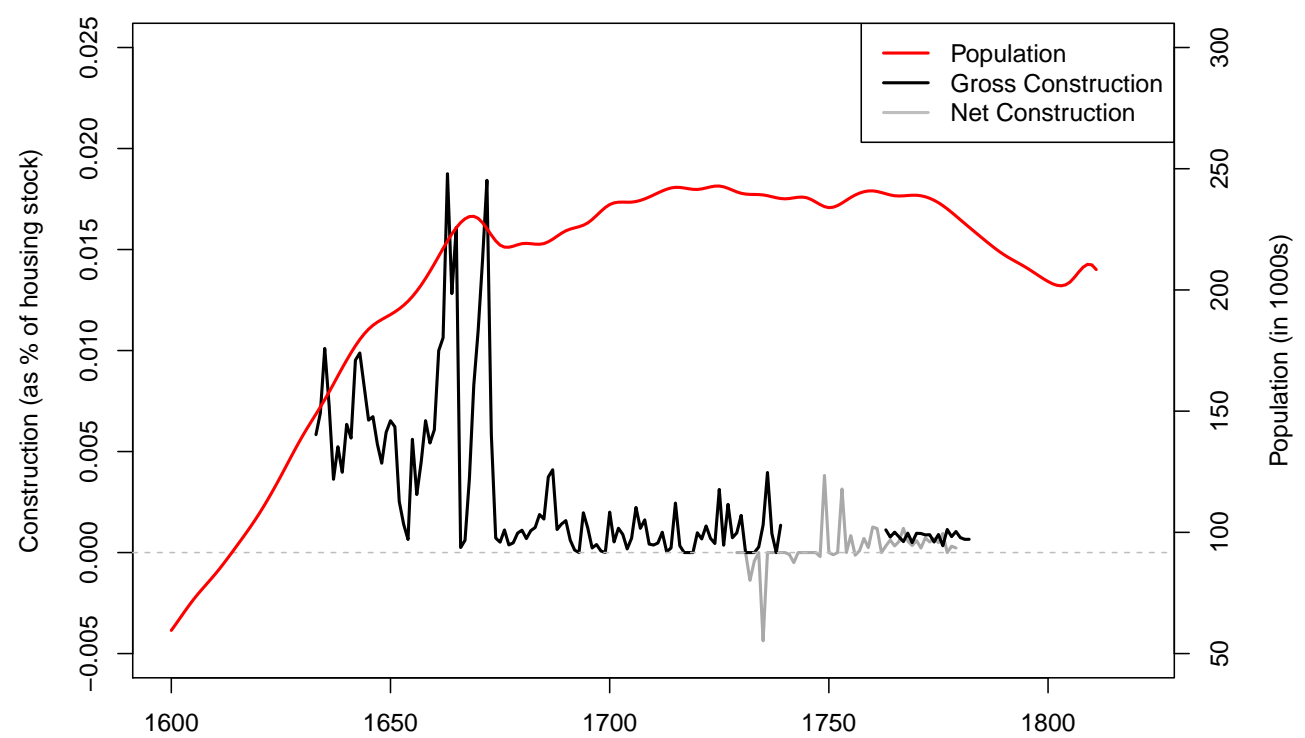

Notes: These series report developments in construction and population for Amsterdam. Gross construction corresponds to the total rental value of newly completed or renovated buildings relative to the total rental value of all buildings in the city. For the $18^{\text {th }}$ century, I also report net construction, which measures the net total change in rental value in Amsterdam.

pendent of tenure status or actual rental prices. Before 1733 , this tax was $12.5 \%$ on the calculated annual rental value. From 1734 until 1805, the tax was reduced to $8.33 \%{ }^{27}$ The aldermen organized the registration of these taxes, and most of these registers have survived in the archives. ${ }^{28}$ The second tax was the extraordinaris verponding. This was a tax on the total value of the property and was in most cases $1 \%$ or $0.5 \%$ of the total value. This tax was levied about once a year on all homes in the city, but its frequency varied depending on the financing needs of Holland. The tax became permanent at end of the $17^{\text {th }}$ century, and continued to be levied until the early $19^{\text {th }}$ century. ${ }^{29}$ The valuations of each property were written down in the tax registers, but rarely updated: in the period of study only in 1632 and 1732 completely new valuations occurred. In other years, only homes that were newly constructed had to be revalued, as well as properties that were split.

The taxation of property in Amsterdam differed from the practices in most modern economies. In most countries, the tax system favors homeownership, because imputed rents are not taxed or because mortgage interest can be deducted from taxable income. Although fiscal frictions between housing and rental markets were absent in Amsterdam, there was one aspect of taxation similar to some modern markets: the

\footnotetext{
${ }^{27}$ Effectively, this did not reduce taxes, since rent prices had increased substantially since 1632 when the last assessment of rental values was made

${ }^{28}$ Source: ACA 5044, inv. nrs. 228-454

${ }^{29}$ Source: ACA 5045, inv. nr. 1-323
} 
presence of transaction taxes. In Holland, such transaction taxes existed at least since the late $16^{\text {th }}$ century. Regular sales were taxed with a $2.5 \%$ transaction tax on total value, and notary records reveal that this transaction tax was typically shared by buyers and sellers. ${ }^{30}$ For execution sales, the transaction tax was $1.25 \%$ because the seller could not contribute to the tax for logical reasons. In 1645, Amsterdam added a city transaction tax, amounting to $1.25 \%$ on regular sales and $0.625 \%$ for execution sales. This tax was only levied on homes sold within the walls of Amsterdam. In 1687, all transaction taxes were increased by $10 \%$, so that the total transaction tax on regular sales was $4.125 \%$ and execution sales $2.0625 \%$.

\section{B.4 Credit, Mortgages and The Housing Market}

In Amsterdam, as in many other pre-modern economies, private credit was supplied via peer-to-peer loans (Hoffman, 2000; Gelderblom et al., 2017). These loans could be registered with the aldermen, with notaries or arranged without the interference of aldermen or notaries. Registration of loans with the aldermen established a senior claim on the borrower's collateral and was in Amsterdam the most common form of private loans. ${ }^{31}$ Importantly, it was mandatory to register mortgages (kustingsbrieven) with the aldermen (see Cau et al., 1658; Rooseboom, 1656; Van Wassenaer, 1737) By law, mortgages were the most senior form of debt and exempt from transaction taxes because the property purchase itself was already taxed.

There were two ways to obtain a mortgage: using a private annuity (losrente) or a private obligation (schepenkennis). Losrenten were private annuities similar to consols: the debtor paid a fixed annual interest rate to the creditor, and always had the option to redeem the debt by repaying the principal. Nearly all losrenten registered with the aldermen were used to purchase real estate and had loan-to-value ratios of up to $100 \%$ (average of $69 \%$ ). Most schepenkennissen were provided as non-mortgage loans, but in a small number of cases, they were also used for mortgage provision. Schepenkennissen had a fixed maturity, often of a few years. In the case of mortgages, they were most often used to set a payment schedule so that the buyer could pay the purchase price in different installments (usually three installments six months apart). In that case, they often did not specify an interest rate.

To estimate the size of the market for long-term mortgages (losrenten) relative to the housing market, Figure 5.16 plots the annual number of newly issued private annuities relative to the number of transactions in the housing market. The vast majority of these annuities were used as mortgages to finance real estate purchases. During the boom in the $17^{\text {th }}$ century, almost $20 \%$ of real estate purchases were financed using such a long-term mortgage. However, the market for these long-term mortgages disappeared towards the end of the $17^{\text {th }}$ century. This implies that the long-term mortgage market cannot be a causal driver of the booms and busts in the housing market in the $18^{\text {th }}$ century.

\footnotetext{
${ }^{30}$ Source: ACA 30452 , inv. no. 504

${ }^{31}$ This excludes the market for beleningen, which were particular repo-type loans collateralized on financial securities.
} 
Figure 5.16: Real Estate Transactions and Private Annuities

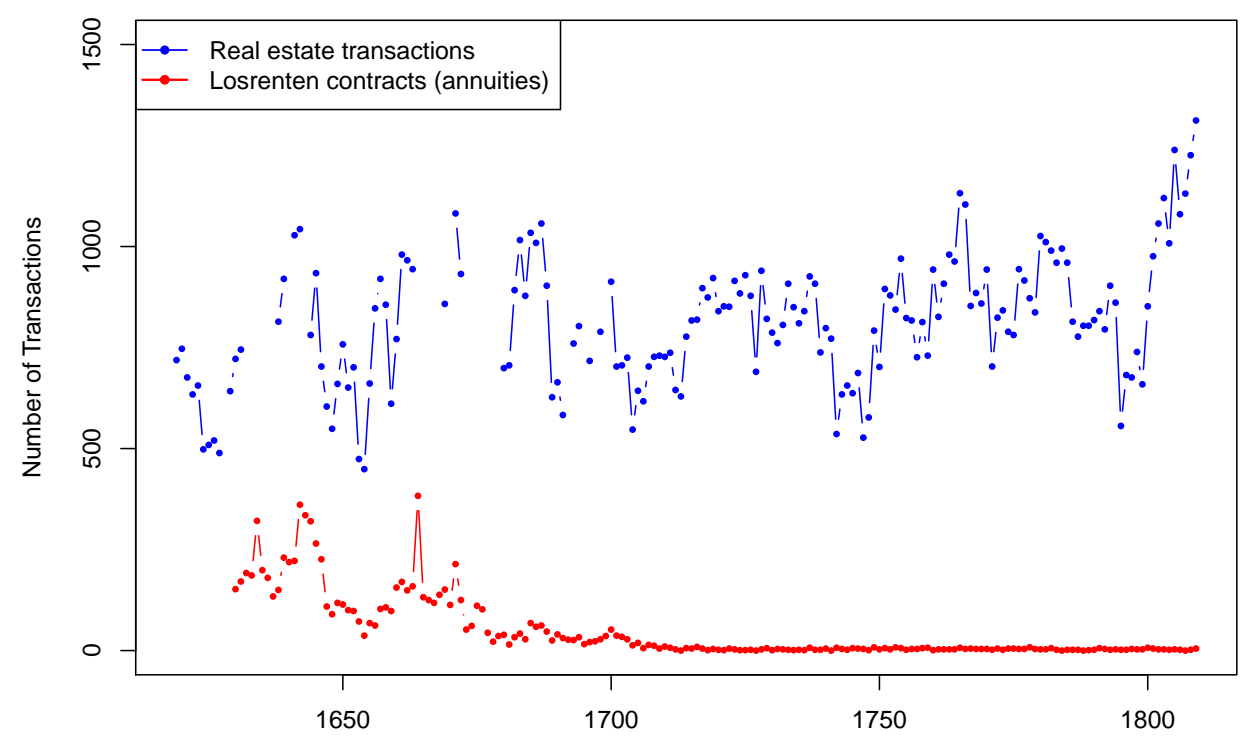

Notes: These series report developments in the number of new long-term mortgages relative to the total number of real estate transactions To avoid underestimation of the number of real estate transactions, the series only contains years in which all transactions have survived. Mortgage counts are based on mandatory annual registrations of private annuities (ACA 5044).

It is possible that schepenkennissen were relatively more frequently used as mortgages in the $18^{\text {th }}$ century compared to the $17^{\text {th }}$ century, as their average maturity increased over time (Gelderblom et al., 2017). However, it is unlikely that the disappearance of the market for long-term mortgages was fully compensated by an increase in the number of mortgages issued schepenkennissen. Data from Gelderblom et al. (2017) show that much fewer loans were registered with the aldermen in Amsterdam during the $18^{\text {th }}$ century. Although these data do not cover mortgage loans registered as schepenkennis, it seems reasonable to assume that the trend in the number of longterm mortgages and the number of non-mortgage loans also extended to short-term mortgages.

\section{C Additional Robustness Checks}

The empirical analysis in section 5.4.2 assumes that shocks to the supply of bonds directly increased house prices, as these shocks influenced the demand for real estate of investors. These shocks thus increased both prices and the number of transactions of wealthy bondholders exposed to the shock (see Table 5.5).

This approach neglects potentially richer dynamics among changes in housing sales and house prices. Recently, various papers have modeled the dynamic relationships between prices and volume to understand the build-up of speculative booms and busts (e.g Piazzesi and Schneider, 2009; Glaeser and Nathanson, 2017; DeFusco 
et al., 2017). One important implication of these studies is that a positive shock to house prices (or optimism about house prices) might endogenously attract more buyers to the housing market. Such speculative behavior could manifest itself in a positive feedback loop between prices and turnover, which is often observed empirically in the form of momentum effects and predictability of prices with turnover. These speculative mechanisms might have also been present in historical Amsterdam, and could be another potential reason why house prices changed more than would be predicted on the basis of standard housing fundamentals (Figure 5.4). In line with this, Figure 5.13 displays a positive correlation between prices and turnover in this period.

Empirically, such mechanisms could manifest itself through lead-lag relationships between house prices and turnover (Ling et al., 2015; Dröes et al., 2017; DeFusco et al., 2017). In line with existing empirical studies, I therefore estimate a more flexible version of Equation 5.5 that endogenizes log changes in house prices and turnover (TO) in a VAR model, with periods of war directly used as an exogenous variable. I also estimate a second model with a more extensive set of control variables $\mathbf{x}_{t}$.

$$
\left[\begin{array}{c}
\Delta \log (H P I)_{t} \\
\Delta \log (T O)_{t}
\end{array}\right]=\left[\begin{array}{c}
\beta_{1}^{\prime} \\
\beta_{2}^{\prime}
\end{array}\right]\left[\begin{array}{c}
\Delta \log (H P I)_{t-1} \\
\Delta \log (T O)_{t-1}
\end{array}\right]+\left[\begin{array}{c}
\gamma_{1}^{\prime} \\
\gamma_{2}^{\prime}
\end{array}\right]\left[\mathbf{x}_{t}\right]+\left[\begin{array}{c}
\varepsilon_{1, t} \\
\varepsilon_{2, t}
\end{array}\right]
$$

I estimate Equation 5.7 both using one-year changes and two-year changes between 1688 and 1780, as empirical literature finds that dynamic relationships among these variables are stronger at the two-year level (DeFusco et al., 2017). Table 5.7 reports the results using one-year changes in prices and turnover, and Table 5.8 using two-year changes.

In line with current literature, changes in house prices are better predicted by lagged changes in turnover and prices at the two-year level than at the one-year level. While there is significant evidence for a momentum effect at the two-year level, there is only feeble evidence that turnover predicts prices. Taken together, this suggests that the exuberant changes in house prices during the boom and bust were not purely the result of speculation. More importantly, endogenizing prices and turnover does not change the main finding of the paper: outbreaks of war, through their effect on investor demand, had substantial impacts on house prices. This effect is significant in all models, and also holds after including control variables. While periods of war also correlated negatively with changes in the level of turnover, this effect is barely significant.

It is important to note that the small number of observations at the two-year level makes it hard to identify the precise economic and statistical significance of momentum and price-turnover effects. ${ }^{32}$ However, the long length of the boom makes it unlike that the boom was purely speculative. House prices increased from 1713 until 1740 , which is much longer than what is typically assumed in a speculative boom. Such a long boom would be more consistent with heightened investor demand for housing, because interest rates were persistently low in this period, and declined only gradually.

\footnotetext{
${ }^{32}$ These effects are larger and more significant when studying the entire sample period
} 
Table 5.7: Results VAR model, One-Year Changes

\begin{tabular}{|c|c|c|c|c|}
\hline & \multicolumn{4}{|c|}{ Dependent variable: } \\
\hline & \multicolumn{2}{|c|}{ No controls } & \multicolumn{2}{|c|}{ With controls } \\
\hline & $\Delta p_{t}$ & $\Delta t o_{t}$ & $\Delta p_{t}$ & $\Delta t o_{t}$ \\
\hline$\Delta p_{t-1}$ & $\begin{array}{c}0.020 \\
(0.103)\end{array}$ & $\begin{array}{c}0.349 \\
(0.355)\end{array}$ & $\begin{array}{l}-0.055 \\
(0.099)\end{array}$ & $\begin{array}{c}0.368 \\
(0.371)\end{array}$ \\
\hline$\Delta t o_{t-1}$ & $\begin{array}{c}0.026 \\
(0.031)\end{array}$ & $\begin{array}{c}-0.240^{* *} \\
(0.108)\end{array}$ & $\begin{array}{c}0.004 \\
(0.030)\end{array}$ & $\begin{array}{c}-0.233^{* *} \\
(0.114)\end{array}$ \\
\hline$W a r_{t}$ & $\begin{array}{c}-0.035^{* * *} \\
(0.010)\end{array}$ & $\begin{array}{l}-0.035 \\
(0.033)\end{array}$ & $\begin{array}{c}-0.037^{* * *} \\
(0.010)\end{array}$ & $\begin{array}{l}-0.013 \\
(0.037)\end{array}$ \\
\hline ForeignWarLending $t$ & $\begin{array}{c}-0.024^{* *} \\
(0.010)\end{array}$ & $\begin{array}{c}0.001 \\
(0.034)\end{array}$ & $\begin{array}{c}-0.018^{*} \\
(0.010)\end{array}$ & $\begin{array}{l}-0.005 \\
(0.036)\end{array}$ \\
\hline$\Delta r_{t}$ & & & $\begin{array}{c}0.742^{* * *} \\
(0.199)\end{array}$ & $\begin{array}{c}0.373 \\
(0.748)\end{array}$ \\
\hline $\log \left(\right.$ IntPayments $\left.s_{t}\right)$ & & & $\begin{array}{l}0.040^{*} \\
(0.021)\end{array}$ & $\begin{array}{c}0.070 \\
(0.080)\end{array}$ \\
\hline Constant & $\begin{array}{c}0.025^{* * *} \\
(0.006)\end{array}$ & $\begin{array}{c}0.016 \\
(0.021) \\
\end{array}$ & $\begin{array}{c}-0.611^{*} \\
(0.340)\end{array}$ & $\begin{array}{l}-1.119 \\
(1.277) \\
\end{array}$ \\
\hline Economic Controls & No & No & Yes & Yes \\
\hline Tax Controls & No & No & Yes & Yes \\
\hline Observations & 92 & 92 & 92 & 92 \\
\hline $\mathrm{R}^{2}$ & 0.238 & 0.081 & 0.434 & 0.183 \\
\hline Adjusted $\mathrm{R}^{2}$ & 0.203 & 0.038 & 0.332 & 0.034 \\
\hline Residual Std. Error & 0.040 & 0.138 & 0.037 & 0.138 \\
\hline F Statistic & 6.788 & 1.908 & 4.224 & 1.231 \\
\hline
\end{tabular}

Notes: Table 5.7 presents empirical estimates for Equation 5.7, with dummies for periods of war and foreign war lending included as exogenous variables in the first VAR (Columns 1-2), and the full set of controls used in the second VAR (Columns 3-4). All changes are one-year changes. Changes in the log level of turnover are based only on regular sales; the construction of this measure is discussed in Appendix 5.B. ${ }^{*} \mathrm{p}<0.1 ;{ }^{* *} \mathrm{p}<0.05 ;{ }^{* *} \mathrm{p}<0.01$. 
Table 5.8: Results VAR model, Two-Year Changes

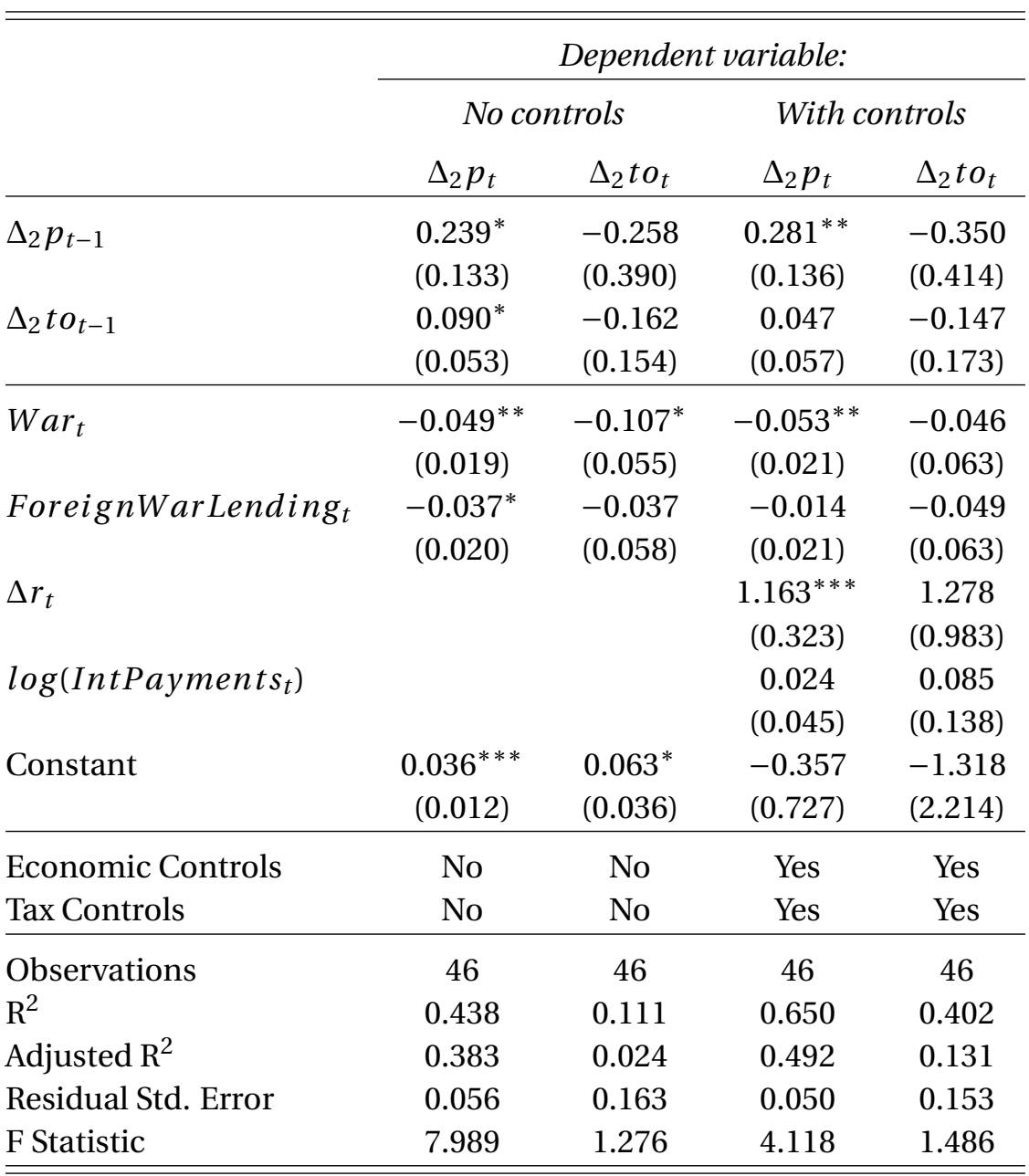

Notes: Table 5.7 presents empirical estimates for Equation 5.7, with dummies for periods of war and foreign war lending included as exogenous variables in the first VAR (Columns 1-2), and the full set of controls used in the second VAR (Columns 3-4). All changes are two-year changes. Changes in the log level of turnover are based only on regular sales; the construction of this measure is discussed in Appendix 5.B. ${ }^{*} \mathrm{p}<0.1 ;{ }^{* *} \mathrm{p}<0.05 ;{ }^{* *} \mathrm{p}<0.01$. 


\section{D Overview Data and Data Sources}

This appendix provides a list of all used data sources in this paper. Note that sources from the Amsterdam City Archives are abbreviated as 'ACA'.

\section{D.1 Primary Data}

Real estate transactions, Amsterdam: ACA 5061, inv. nrs. 2163-2182; ACA 5062 inv. nrs., 1-200; ACA 5066, inv. nrs. 1-58; ACA 5067, inv. nrs. 1-47; ACA 5073, inv. nrs. 910931. See main text and Appendix 5.A for further detail.

Onwillige decreten: Dutch National Archives, Archief van het Hof van Holland (entry no. 3.03.01.01). Data on foreclosure sales in Amsterdam executed via the Court of Holland. Only 59 of such transactions happened in Amsterdam, and I therefore do not use them for further analysis.

Real estate transactions, Den Bosch: Wetzer (2018). Transcribed registrations of real estate transactions from the "Bossche Protocol". Transaction data is available from the period from 1660-1665 and from 1692-1838. The structure of the data is similar to the database from Amsterdam.

Estate tax records: ACA 5046, inv. nrs. 1-71. See main text and Appendix 5.A for further detail.

Marriage and burial records: ACA 5005, inv. nrs. 401-1276. Registrations of marriages and burials for the city of Amsterdam between the early 1550s and 1810. Digitized data kindly provided by the Amsterdam City Archives.

Construction: ACA 5046, inv. nrs. 226, 228, 223, 235-239, 246-253. ACA 5045, 171. These registers contain the appraised rental value of all new or ameliorated buildings in Amsterdam. I collected data on each of these between 1632-1739 and 1763-1782. To convert this into a construction measure, I expressed the total level of construction as a percentage of the total rental value of the housing stock. I obtained data on the latter from property tax registers (ACA 5046, no 229 and ACA 5044, 246-294).

Long-term mortgage loans: ACA 5065, 24-34. To compute the annual number of longterm mortgage contracts, I used mandatory registrations of long-term private mortgages (losrenten, with kusting). I counted each contract in these registers between 1634-1800. These mortgages were annuities that required the debtor to pay an annual interest until he redeemed the loan and repaid the capital sum. Because these loans had no maturity, some lasted for centuries. Although most of these loans were directly used to purchase real estate, a small number of them were used for other purposes.

Short-term non-mortgage loans: ACA 5047, 1-105. I use data on transaction taxes 
for new non-mortgage loans registered with the aldermen, listed in books registering each tax payment. For each of the 105 books, I counted per page the number of new loans and their total value. Although registration of these loans was not mandatory, it was often required by the lender, as it established a senior claim on the posted collateral. See Gelderblom et al. (2017) for more detail on these loans.

Net rental yields: ACA 5048, 86-88, 154-156 and 214-230. To compute net rental yields, I obtained data on 785 actual gross yields from auctions of properties that listed both the rental price and the sales price (between 1737-1739, 1778-1779, and 1799-1803). To transform these into net rental yields, I subtracted the level of annual taxes and assumed maintenance costs to be $30 \%$ of the gross rent. To construct an annual index of yields, I used the existing index of rent prices and house prices, which I benchmarked using the net rental yield in 1799-1803 (similar to Jordà et al. (2019a)). To verify the accuracy of this procedure, I compared the yields in 1737-1739 and 1779-1780 that were implied by the benchmarked indices to those based on actual data. The absolute difference in the average actual yield and the yield implied by the index was less than $0.5 \%$ in both cases.

\section{D.2 Secondary Data}

Property taxes: I compute the level of property taxes as a percentage of the rent or rental value of each property. I started from the 1733 revaluation of property taxes (ACA 5045, 203-268), which lists for each property in Amsterdam the standard annual property tax paid after the revaluation ( $8.33 \%$ of rental value) and before the revaluation $(7.6 \%$ of rental value). This tax had to be paid between once and three times per year. To compute the level of annual property taxes, I use data from Fritschy (2017) that details how often property taxes were levied each year.

Fiscal data: Fritschy (2017). I use the following series from her database, which covers the period from 1600-1794: the annual level of public debt, the annual level and annual percentage of bond tax, the annual level of consumption tax, annual extraordinary wealth taxes, and annual interest payments to holders of Holland bonds. All these series are for Holland only.

Bond yields: Gelderblom and Jonker (2011). These are transaction prices of Holland annuities (losrenten) from the secondary market in Gouda, a city nearby Amsterdam. Before 1670, bond yields are assumed to equal the annual interest rate, due to the absence of prices from the secondary market. This series ranges from 1600 to 1794 . Between 1795 and 1804, I use data on the yields of Holland bills from the June price list of the Maandelykse Nederlandsche Mercurius, correcting for the yield difference between annuity yields and yields on Holland bills. This difference averaged $0.3 \%$ and was fairly stable. To compute the difference, I used a small sample of transactions prices from Holland bills sold in Amsterdam during the $18^{\text {th }}$ century (from ACA 5068, 1-266). 
GDP: Van Zanden and Van Leeuwen (2012). The annual value of the Gross Domestic Product of Holland between 1500 and 1807.

Wages: Van Zanden (2018). Day wages of construction workers in Amsterdam.

CPI and Construction Cost: Van Zanden (2018). Standard consumer price index, with a separate construction cost component.

Population: Van Leeuwen and Oeppen (1993). Population estimate for Amsterdam at 5-year intervals, between 1680-1993. Before 1680, I used data from Nusteling (1985). I interpolated data linearly.

Rent prices: Eichholtz et al. (2020b). Residential repeat-rent index for Amsterdam. 


\section{E Supplementary Tables and Figures}

Table 5.9: Impact of Bond Supply on Yields and Risk Premia, No Controls

\begin{tabular}{lcccc}
\hline \hline & \multicolumn{4}{c}{ Dependent variable: } \\
\cline { 2 - 5 } & \multicolumn{2}{c}{$\Delta\left(r_{t}-p_{t}\right)$} & \multicolumn{2}{c}{$\Delta\left(r_{t}-p_{t}-i_{t}\right)$} \\
& IV & OLS & IV & OLS \\
\hline${\text { log }\left(\text { Debt }_{t}\right)}^{1.413^{* * *}}$ & $0.670^{* * *}$ & $0.738^{* *}$ & $0.444^{*}$ \\
& $(0.377)$ & $(0.234)$ & $(0.368)$ & $(0.239)$ \\
ForeignWarLending $t$ & $0.030^{* * *}$ & $0.026^{* * *}$ & $0.020^{* *}$ & $0.018^{*}$ \\
& $(0.010)$ & $(0.009)$ & $(0.010)$ & $(0.009)$ \\
Constant & $0.022^{* * *}$ & $-0.015^{* * *}$ & $-0.014^{* *}$ & $-0.012^{* *}$ \\
& $(0.006)$ & $(0.005)$ & $(0.006)$ & $(0.005)$ \\
\hline Observations & 93 & 93 & 93 & 93 \\
$\mathrm{R}^{2}$ & 0.037 & 0.134 & 0.048 & 0.064 \\
Adjusted $\mathrm{R}^{2}$ & 0.016 & 0.114 & 0.027 & 0.043 \\
Residual Std. Error & 0.040 & 0.038 & 0.039 & 0.039 \\
F Statistic & & 6.948 & & 3.060 \\
\hline \hline
\end{tabular}

Notes: Table 5.3 reports regression results similar to Table 5.4, excluding control variables. The dependent variable in Columns 1 and 2 is the log change in the rental yield. In Columns 2 and 3 it is the log change in the housing risk premium. Column 1 and Column 3 are based on an IV regression where changes in public debt are instrumented with a dummy variable for periods the Dutch Republic was engaged in war. Column 2 and 4 reports results for the same regression when estimated using OLS. Standard errors are OLS errors as standard tests detected no heteroskedasticity or autocorrelation in the residuals. ${ }^{*} \mathrm{p}<0.1$; ${ }^{* *} \mathrm{p}<0.05 ;{ }^{* * *} \mathrm{p}<0.01$. 


\section{F List of Archival References}

Amsterdam City Archives, Archief van de Thesaurieren Extraordinaris (entry no. 5044).

Amsterdam City Archives, Archief van de Honderdste en Tweehonderdste Penningkamer of Commissarissen tot de Ontvangst van de Honderdste en Andere Penningen (entry no. 5045).

Amsterdam City Archives, Archief van de Secretaris: stukken betreffende de ontvangst van de twintigste penning op de Collaterale Successie (entry no. 5046).

Amsterdam City Archives, Archief van de Secretaris: stukken betreffende het toezicht op de ontvangst van de veertigste, tachtigste, twintigste penning en de hele en halve veertigste penning (entry no. 5047).

Amsterdam City Archives, Archieven van de Schout en Schepenen, van de Schepenen en van de Subalterne Rechtbanken (entry no. 5061).

Amsterdam City Archives, Archief van de Schepenen: kwijtscheldingsregisters (entry no. 5062).

Amsterdam City Archives, Archief van de Schepenen: register van rentebrieven en van transporten van los- en lijfrenten (entry no. 5065).

Amsterdam City Archives, Archief van de Schepenen: register van willige decreten van het Hof van Holland (entry no. 5066).

Amsterdam City Archives, Archief van de Schepenen: register van afschrijvingen bij de willige decreten (entry no. 5067).

Amsterdam City Archives, Archief van de Burgemeesters: willige verkopingen (veilingen van huizen, erven en obligaties) (entry no. 5068).

Amsterdam City Archives, Archief van de Weeskamer en Commissie van Liquidatie der Zaken van de Voormalige Weeksamer (entry no. 5073).

Dutch National Archives, Archief van het Hof van Holland (entry no. 3.03.01.01). 


\section{Chapter 6}

\section{Demography and the Housing Market $^{*}$}

Population aging is one of the most important trends that is currently affecting global society. The share of the global population above age 65 rose from about $5 \%$ to $8 \%$ between 1950 and 2015 and is projected to double to $16 \%$ by 2050 (United Nations, 2017). These trends do not affect all countries equally. In most western economies the large baby boom generation has started to retire, while in developing countries the number of young adults is still increasing. These changes in demographic structure could have profound implications for housing markets, and the main aim of this paper is to empirically estimate how changes in demographic structure affect the housing market and real estate investment.

A large number of financial studies has investigated how changes in demographic structure affect asset prices and portfolio choice (e.g Abel, 2001, 2003; Geanakoplos et al., 2004; DellaVigna and Pollet, 2007; Collin-Dufresne et al., 2017; Leombroni et al., 2020). The main finding in this literature is that the demand for risky assets decreases over the life-cycle so that comparatively large cohorts of young (old) people will increase (decrease) asset prices. However, it remains extremely difficult to estimate and predict the impact of these changes empirically. Demographic changes tend to be very gradual, and due to changes in the economy, birth cohorts do not only differ by age, but also by the economic trajectories they have experienced.

Most financial literature has not studied the role of housing, and focused on the impact of demographic changes on bond and equity investment, even though housing is typically the largest asset in household portfolios. Estimating the effect of demographic changes on house prices is even more complicated, because housing serves a dual role as a consumption asset and an investment asset. Existing housing market literature studying the impact of demographic changes on house prices, typically assumes that consumption demand for housing differs over the life-cycle (e.g Mankiw and Weil, 1989; Takáts, 2012; Eichholtz and Lindenthal, 2014; Hiller and Lerbs, 2016; Green and Lee, 2016), and does not distinguish between age-dependent changes in

\footnotetext{
${ }^{*}$ This chapter is co-authored with Marc Francke (University of Amsterdam).
} 
investment and consumption demand.

In this paper, we make two key contributions. First, we exploit long-term demographic and housing data spanning four centuries, to show that large birth cohorts consistently predict increasing house prices 25 to 30 years later, when entering the housing market, and declining prices about 60 to 65 years later, when approaching the end of their lifetime. By linking individual demographic data to investment portfolios and housing transactions, we show that these aggregate patterns in house prices match micro-level evidence on housing transactions and investment portfolios: The fraction of wealth in real estate and the number of real estate purchases increase strongly at early ages, but declines and reverses at older ages. For bond investment, we document the opposite. Second, we separate pure housing demand effects from investment demand effects by considering the impacts on rents prices, house prices, and rent-price ratios. We show that the predictability of housing costs with demographic data appears both in house prices and rental prices, but that the effect is much stronger when looking at house prices. This suggests demographic housing consumption demand effects are modest relative to age-dependent investment demand effects.

The long-term approach we take in this paper has three main advantages over the existing literature. First, the time span of our data is sufficiently long to study the actual predictability of demographic rates for housing costs over very long horizons. We study the period from the 16th century to 1913, covering many different generations over centuries with relatively limited economic growth. This long sample period makes it possible to separate cohort effects from economic effects. This is difficult using modern data with a more limited time span, because 20th-century birth cohorts differ both by age and by the economic trajectories they experienced. Second, changes in demographic rates were much more frequent in the high-birth and high-death rate periods that we study, implying our data cover multiple baby booms and busts. Recent literature has focused on the post-war baby boom only, because birth rates dropped gradually for the remainder of the 20th and 21st centuries. Third, government intervention in the housing market was limited in the time period that we study (16th - 19th century). Our analysis focuses on Amsterdam, both due to excellent data availability, and the fact that its housing and capital markets developed early on, and functioned similarly to modern markets. We also study rental markets in Paris. In the 20th century, large swings in demographic rates around the World Wars happened at the same time that governments in most western economies started introducing strict rent controls, which significantly impacted house and rent prices. It is therefore difficult, if not impossible, to identify demographic demand effects using more recent data.

The effect of population aging has been studied in urban economics, real estate, and in the broader literature on asset pricing. The general asset price literature hypothesizes that the aging of the 'baby boom' generation led to rising asset prices in the 1990s as 'baby boomers' began to save for retirement and that asset prices would fall when this generation retires, and when they would sell part of their assets.

Various theoretical studies using overlapping generation models (among others Abel, 2001, 2003; Geanakoplos et al., 2004; Leombroni et al., 2020) show that the demographic structure might exert a strong influence on aggregate asset prices. Geanakop- 
los et al. (2004) predict from a theoretical model - calibrated on stylized facts in the US during the postwar period - that (1) the price-dividend ratio is proportional to the ratio of middle-aged to young adults (MY), (2) real rates of return on equity and bonds are increasing in the change of the MY ratio, and (3) the equity premium covaries with the reciprocal of the MY ratio. Collin-Dufresne et al. (2017) take into account that younger people update beliefs in response to aggregate shocks more than older people. ${ }^{2}$

Poterba $(2001,2004)$ documents that there is limited robust evidence for the 'asset market meltdown view': the view that asset prices would fall substantially when the baby boom generation retires. Poterba (2004) concludes that 'the correlation between asset returns on stocks, bonds, or bills, and the age structure of the US population over the last seventy years, is weak.' The positive correlation between the share of the population in the prime working years and the price-dividend ratio is the most robust finding. ${ }^{3}$

The housing market literature on demographic demand effects starts with the seminal work of Mankiw and Weil (1989), who examine the impact of demographic changes on house prices in the United States, primarily using contemporaneous correlations between demographic demand and house prices. Based on cross-sectional census data, they show that housing demand is negligible in childhood, increases sharply from age twenty to thirty, and flattens out afterward. They attributed much of the house price rises in the 1970s and 1980s to the 'baby boom' generation entering the housing market and predicted that prices would fall in the 1990s due to the much lower housing demand from the 'baby bust' generation. Unsurprisingly, their findings generated significant attention in media outlets and were followed by a significant academic debate. While their critics generally accept the notion that housing demand is age-dependent, they generally disagree that this would lead to price predictability (see Woodward, 1991; Hamilton, 1991; Holland, 1991; Engelhardt and Poterba, 1991). In later studies, Pitkin and Myers (1994) and Green and Hendershott (1996) also show that the cross-sectional Mankiw and Weil demand estimates crucially depend on how age effects are separated from cohort effects. After properly accounting for cohort effects, the effects of the age-structure on the population are much smaller. ${ }^{4}$

\footnotetext{
${ }^{2}$ They incorporate generational learning bias in an 'overlapping dynasties model.' The model generates persistent periods of significant over- and underpricing, related to small, persistent mistakes in cash flow expectations on the part of the agents in the economy. Moreover, the price-dividend ratio is empirically more sensitive to macroeconomic shocks when the fraction of young in the population is higher.

${ }^{3}$ Goyal (2004) finds that demographic structure in stock market regressions adds explanatory power. DellaVigna and Pollet (2007) find that for age-sensitive industries, demographic demand growth forecasts significantly predict future stock returns in these sectors while finding no effects for other industries.

${ }^{4}$ With debates about population aging gaining prominence again, recent studies have re-examined the impact of the demographic structure on prices. Eichholtz and Lindenthal (2014) and Green and Lee (2016) make further refinements to estimate the housing demand function by measuring willingness to pay for various housing characteristics across various age groups and cohorts. Takáts (2012) documents that the old-age dependency ratio correlates negatively with house price growth in developed countries. Hiller and Lerbs (2016) find a similar result for German cities, but also note significant heterogeneity across market segments, with population aging even positively associated with real rent growth.
} 
As housing is both a consumption and investment good, we analyze the impact of demographics on rents, prices, and rent-price ratios. Rents move only due to changes in demand for housing services, while rent-price ratios move to changes in investment demand. Housing prices contain both components. Specifically, we test for a positive (negative) relation between current rents and lagged fertility for cohorts corresponding to young adults (seniors). Likewise, we test for a negative (positive) relation between current rent-price ratios and lagged fertility for cohorts corresponding to young adults (seniors). Our central identifying assumption is that historical fertility predicts current housing and asset demand, but is unrelated to other economic variables that could be correlated with current housing and asset demand, after adjusting for basic economic fundamentals such as consumer prices and wages. One implication of the age-dependency of housing demand is that contemporaneous fertility should have a negligible impact on housing costs. ${ }^{5}$

We find that changes in the demographic structure have small effects on rents. For Amsterdam, a one percentage point increase in fertility about 25 years ago increases current rents by $1-1.5 \%$. We find slightly larger effects for Paris of about $2 \%$. These effects disappear for younger and older cohorts, and turn negative for fertility lags corresponding to cohorts in their late fifties or sixties, although these effects are small (around $-1 \%$ ) and only weakly statistically significant. However, we find statistically significant impacts of changes in the demographic structure on house prices and rentprice ratios in Amsterdam. A one percentage point increase in fertility about 25 years ago increases current house prices by $5.4 \%$ and reduces rent-price ratios by about $5 \%$. We find opposite effects for cohorts born around 60 years ago: increases in fertility 60 years ago increase current rent-price ratios and decrease house prices by about $4 \%$. There are no statistically significant effects for other cohorts.

To interpret these results, and identify how they can inform us about the impact of changes in demographic structures on modern markets, we extensively discuss our findings and the differences between the modern context and the historical context we study in this paper. First, we study the role of changing demographic structures over time. To compare our estimates to modern times, we should account for the fact that levels of fertility and mortality have changed drastically since the mid-19th century. In the 1850s, only $48 \%$ of Amsterdam babies would survive until age 25, and this percentage was likely similar before 1850 (Van Leeuwen and Oeppen, 1993), as well as in other cities (e.g. for London: Clark and Cummins, 2009). Correspondingly, we should roughly double our estimates if we extrapolate them to a fertility regime with negligible child mortality, as in most modern developed countries.

To show that our results are driven both by changes in consumption and investment demand for housing, and likely still extend to today, we exploit several micro-

\footnotetext{
${ }^{5}$ This theoretical prediction does not imply that housing costs are unrelated to fertility. Building on the notion that children are a normal good (Becker, 1960), Lovenheim and Mumford (2013) show that house price booms increase fertility among home-owners, while they document no effect for renters. For firsttime homebuyers or young households, Dettling and Kearney (2014) and Laeven and Popov (2017) find that the effect of a housing boom is negative, as it makes purchasing a house more expensive and thus reduces housing consumption and fertility.
} 
level datasets on housing consumption and investment in Amsterdam.

First, we link property rental values in the 1832 housing census to their inhabitants based on the 1851 personal census. We show that housing demand increased rapidly in early adulthood, and decreased at older ages. This shows that the age structure of housing demand in the historical demographic regime did not vary substantially from the structure documented today (Mankiw and Weil, 1989; Green and Lee, 2016), although declines in housing demand at older ages appear smaller today.

Second, in order to estimate the age composition of buyers and sellers in the housing market, we link data from marriage certificates to housing transactions. We show that the years after marriage, which happened on average at age 28, were the most common years to purchase real estate. On the other hand, housing sales peak at about 35 years after marriage, around the age of 65 .

Finally, we link marriage certificates to asset portfolios at death for individuals that died in Amsterdam between 1688 and 1780. Given the limited knowledge about health and disease, death typically came suddenly during the time period we study. Comparing individuals that died at different ages, approximated by the number of years since marriage, we show that individuals that died shortly after marriage possessed a relatively larger fraction of their wealth in real estate compared to individuals that were old. In line with models that compare investments in equity and bonds, we document the opposite relationship for bonds, with older individuals possessing a larger fraction of their wealth in bonds.

In summary, our long-term historical evidence shows that demographic structure is a crucial component of the demand for housing and other assets. Changes in demographic structure exert large and predictive impacts on house prices, and smaller impacts on rental prices. The remainder of the paper proceeds as follows. Section 6.1 briefly introduces the various data sources and the compilation of the aggregate series, and their limitations. It also gives a descriptive overview of the demographic history of Amsterdam and Paris. Section 6.2 presents the estimation results from the effect of lagged fertility on current rent prices, house prices, and rent-price ratios. In Section 6.3 we discuss these results and provide empirical results from housing market activity and portfolios in line with our major findings, and analyze how our historical results relate to the modern context. Section 6.4 concludes.

\subsection{Data}

\subsubsection{Demographic Data}

To construct annual time-series of demographic rates for Amsterdam and Paris we combine archival sources and published studies. Beyond constructing series of historical fertility, the key variable of interest in this paper, we also make use of data on mortality and marriages. We will use annual time series of death rates, migration rates and marriage rates as controls in our main analysis. For Amsterdam, we also use the marriage data to link the age of individuals, approximated by the number of years since marriage, to their portfolio composition and housing market activity. 
For Amsterdam, we use archival civil registers on all individual births, marriages, and deaths in Amsterdam before 1810. These have been digitized by the Amsterdam City Archives (ACA), and are available from 1554 (deaths) and 1565 (births, marriages). ${ }^{6}$ After 1810 we make use of aggregated numbers of births, deaths, and marriages from the Gemeente Amsterdam (1923) and the yearbooks of the Amsterdam Statistical Office (Gemeente Amsterdam, 2019). These same sources also supply population and migration estimates after 1850. For the period before 1850, we use population numbers from Nusteling (1985) and Van Leeuwen and Oeppen (1993) that are available at five-year intervals. To transform these to annual numbers, we use actual fertility and mortality data, while interpolating the implied migration estimates from the population series.

The archival civil registers are not complete: In a small number of cases, records from a church or cemetery are missing for some years. More importantly, there might be an under-registration of births in the early period: After the Reformation of Amsterdam in 1578, Catholic baptisms were likely under-registered for extended periods. Additionally, registration of Jewish births, which we retrieved from Hart (1976), only survived from the late 18th century onwards. ${ }^{7}$

To compute crude Amsterdam birth and death rates in this period, we use an annual weighted-average of the normalized number of births and deaths per church or cemetery. In any year, we only include churches or cemeteries for which records are complete, and normalize these based on the 25-year moving average of the number of births or deaths in that particular church or cemetery. For births, we normalize for the period 1565-1780, while for deaths we do so for the period 1554-1685. To transform this to a crude birth and death rate, we assume that average fertility between 1565 and 1780 was the same as between 1780 and 1810 . For mortality, we use the average rate in the period 1685-1810. For other periods, records are sufficiently complete such that we can use annual counts scaled by population numbers.

For the normalized series, there is no need to scale using population estimates. As long as there are no significant non-linear population changes, the normalization is an accurate estimate of actual birth and death rates. Amsterdam population grew significantly in the late 16th and early 17th century, but there is significant uncertainty regarding the level of population in this period, as also acknowledged in Nusteling (1985). For this reason, we also normalize marriage rates between 1565 and 1585: scaling by the contemporaneous population estimates leads to extreme values.

To approximate actual migration numbers at an annual level before 1850, which we will use as a control variable, we construct estimates on the migration of wealthier citizens by looking at citizenship purchases (poorterschap) between 1564 and 1733 , which were not necessary to live in Amsterdam, but provided certain privileges. ${ }^{8}$ For

\footnotetext{
${ }^{6}$ Source: ACA inv. nr. 5001 and inv. nr. 5009.

${ }^{7}$ For a more detailed discussion of these issues, see Nusteling (1985).

${ }^{8}$ Source: ACA 5014, Archief van Burgemeesters: stadsrekeningen. Privileges included access to the municipal orphanage, membership of guilds, and the possibility to be considered for a position in the Amsterdam government. It was either acquired at birth, through marriage with a 'poorter', or could be purchased for 50 guilders. Based on population estimates, around $10 \%$ of migrants bought 'poorter-
} 
the period 1733-1830, we use estimates of attestations from the Dutch Reformed Church, the largest congregation in Amsterdam, that are published in Hart (1976). Such an attestation was requested when a member of the church moved from or to Amsterdam. The Dutch Reformed Church was the largest congregation in Amsterdam, covering about half of the population. From 1850, actual estimates of migration are available from the yearbooks of the Amsterdam Statistical Office. Since the various migration estimates have different scales, we normalize each component of the entire series using $z$-scores.

For Parisian demographic data, we rely on a multitude of publications on the annual number of births, deaths and marriages Biraben and Blanchet (1999) and Charlot and Dupâquier (1967) together with the Annuaire Statistique de la Ville de Paris, available from 1880 to 1967 (Mairie de Paris, 1967b). For the remainder, we use data published by INSEE, the French Statistical Office. We transform these to crude birth, marriage and death rates, based on population numbers of Biraben and Blanchet (1999) for the pre-revolution period, and data from INSEE and the Parisian Annuaires from the Revolution onwards. For Paris, we have no information on migration.

Figure 6.1 plots the resulting series of fertility for both cities, both at an annual level (Figure 6.1a) and for five-year periods (Figure 6.1b). Most large shocks in fertility and mortality can be related to major historical events. For example, in Paris fertility dropped and mortality increased during and after the Siege of Paris (1590). In Amsterdam, most mortality shocks before 1700 are related to outbreaks of the plague (Noordegraaf and Valk, 1996). The post-World War II baby boom is clearly visible as well.

Beyond these short-term events, the long-term evolution of the series is in line with most of the existing literature. Until the mid-19th century, both fertility and mortality were at high levels and varied significantly from year to year. Relative to today, populations were relatively young with most of the urban population under age 30 and the fraction of older populations declining by age, given the much lower life expectancy. In the 19th century, both fertility and mortality started declining substantially. The decline in fertility occurred much earlier in Paris, where fertility started to decline around 1825, while in Amsterdam, this happened only 60 years later. Fertility increased again during the baby boom after World War II. In Paris, both also soar after World War I, which had much less of an impact on The Netherlands. The historical evidence suggests that such baby booms are not unique historically, and particularly when looking at five-year intervals it becomes clear that periods of relatively high and low birth rates frequently followed each other.

\subsubsection{Housing Market Data}

For house prices, we combine several datasets of individual Amsterdam transaction prices. For the period between the 1600s and 1810, we make use the of database of Korevaar (2020), which covers all housing transactions in Amsterdam between 1700 and 1810 , and the majority of housing transactions in the 17th century. Korevaar (2020)

schap', which probably belonged to the upper class of society (Kuijpers et al., 2002). 
Figure 6.1: Fertility Rates

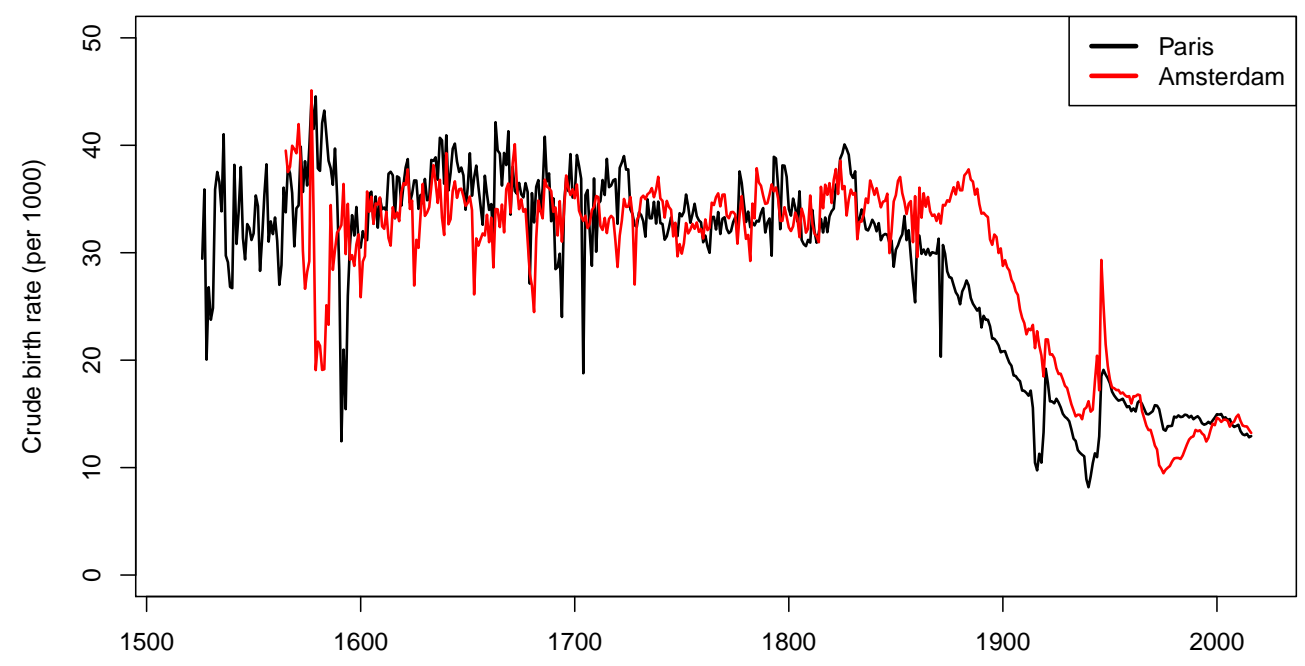

(a) Annual Birth Rates

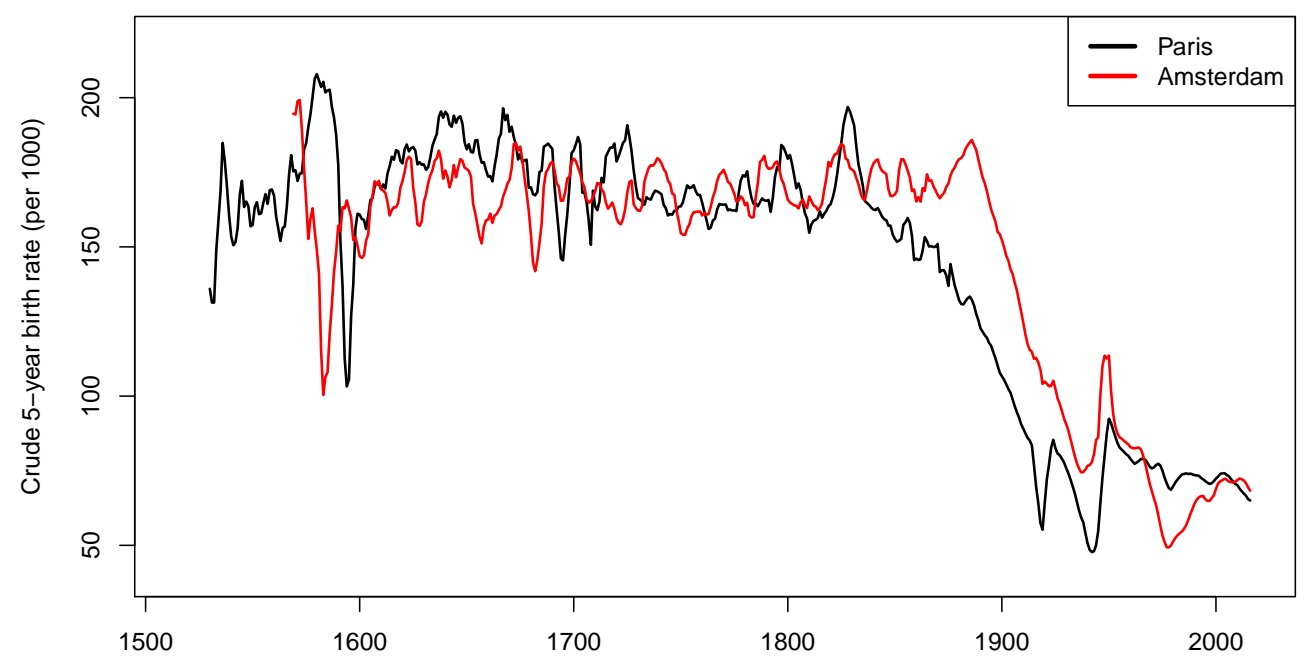

(b) 5-Year Birth Rates

Notes: These figures report the estimate birth rates per 1000 inhabitants for both Paris and Amsterdam. Birth rates are high and volatile until the late 19th century, when they gradually start declining. Birth rates increase again after World War I (in Paris) and after World War II (both cities). 
estimates a repeat-sales index for Amsterdam in the period 1625-1810, with 57,113 repeat-sales identified from a dataset containing all transactions in Amsterdam in this period. We combine the repeat-sales pairs in his paper with 5,269 repeat-sales prices of properties along the Herengracht, Amsterdam's most expensive canal, from Eichholtz (1997). This dataset extends from the 17th century until 1976. For the period 1840-1979, we have additional transaction data from property auctions from Eichholtz et al. (2020c). Note that rates of home-ownership in Amsterdam were low and varied over time, ranging from $30 \%$ in the 16th century to just a few percent for most of the 20th century. As a result, most properties were likely purchased to rent out either entirely or partially.

We combine the observations from all data sources to estimate a repeat-sales index using the methodology of Francke (2010), spanning the period 1625-1979. This method avoids excessive noise in periods with a low number of observations (between 1810 and 1840, and between 1625 and 1737), and is consistent with the rent indices that are based on the same method. ${ }^{9}$

For our indices of rent prices, wages, and consumer prices, we make use of existing indices reported in Eichholtz et al. (2020b), which cover the period from 1500-present for Paris and from 1550-present for Amsterdam. Last, we combine various series of bond yields to construct a series of interest rates for Amsterdam spanning from 1586 to the present. Until 1795 we use data from Gelderblom and Jonker (2011) on the yields on Holland bonds, the most important public debt instrument in the Dutch Republic. Between 1795-1807, we use data on bond prices (and the implied yields) from the Maandelykse Nederlandsche Mercurius, which published price lists of bonds from the 1790s onwards. After 1814 we use the long-term (10-year) Dutch bond-yield. To interpolate between 1807-1814, we use observations from Wilson (1941).

Descriptive statistics on each of the variables that we presented in this section and that will be used in the analysis in the next section, are reported in Table 6.1. The statistics on rent prices, house prices, wages, and consumer prices all refer to annual log-differences. Note that inflation was very limited before 1913, in particular from the early 17 th century onward. Mortality, nuptiality, fertility, and implied migration reflect percentage shares of the total population. For reference, we have also included statistics on annual population changes in the table, but we should note that these are based on interpolated estimates from various studies, such that their annual standard deviation likely underestimates the true standard deviation of population growth.

\subsection{Analysis: Demographic Structure and Housing Costs}

In this section, we estimate the effect of the demographic structure on rent and house prices. Estimating this effect is challenging for two reasons. First, the demographic structure is endogenous. Migration is an essential determinant of urban populations, in particular historically, and most of these migrants are young adults. These migration flows are dependent on the economic opportunities within a city, which them-

\footnotetext{
${ }^{9}$ For more information on the data and the index construction, we refer to the individual papers.
} 
Table 6.1: Descriptive Statistics, Annual.

\begin{tabular}{|c|c|c|c|c|c|c|}
\hline Statistic & Symbol & $\mathrm{N}$ & Mean & St. Dev. & Min & Max \\
\hline \multicolumn{7}{|c|}{ Amsterdam, 1550-1913 } \\
\hline Rents & $\Delta r$ & 363 & 0.007 & 0.040 & -0.191 & 0.278 \\
\hline House Prices & $\Delta h$ & 288 & 0.002 & 0.055 & -0.231 & 0.191 \\
\hline Wages & $\Delta w$ & 363 & 0.006 & 0.014 & -0.063 & 0.072 \\
\hline Prices & $\Delta p$ & 363 & 0.004 & 0.076 & -0.258 & 0.337 \\
\hline Mortality & $M$ & 360 & 0.035 & 0.012 & 0.011 & 0.123 \\
\hline Nuptiality & $N$ & 349 & 0.010 & 0.002 & 0.006 & 0.020 \\
\hline Fertility & $F$ & 349 & 0.033 & 0.004 & 0.019 & 0.045 \\
\hline Migration (Impl.) & $M i$ & 364 & 0.009 & 0.017 & -0.016 & 0.110 \\
\hline Migration (Norm.) & $M i N$ & 350 & -0.024 & 0.962 & -2.540 & 4.829 \\
\hline Population (Estim.) & Pop & 363 & 0.008 & 0.021 & -0.168 & 0.105 \\
\hline$\underline{\text { Bond Yield }}$ & $\Delta i$ & 317 & -0.003 & 0.084 & -0.405 & 0.463 \\
\hline \multicolumn{7}{|c|}{ Paris, 1500-1913 } \\
\hline Rents & $\Delta r$ & 413 & 0.010 & 0.062 & -0.475 & 0.434 \\
\hline Wages & $\Delta w$ & 413 & 0.009 & 0.054 & -0.223 & 0.223 \\
\hline Prices & $\Delta p$ & 413 & 0.008 & 0.068 & -0.264 & 0.411 \\
\hline Mortality & $M$ & 369 & 0.033 & 0.011 & 0.012 & 0.153 \\
\hline Nuptiality & $N$ & 394 & 0.008 & 0.002 & 0.001 & 0.017 \\
\hline Fertility & $F$ & 388 & 0.033 & 0.005 & 0.012 & 0.045 \\
\hline Population (Estim.) & Pop & 413 & 0.006 & 0.025 & -0.260 & 0.174 \\
\hline
\end{tabular}

Notes: This table reports descriptive statistics our series of demographic rates, house prices, rental prices and control variables for both Amsterdam and Paris. All series are continuous and end in 1913, but differ by starting year given differences in data availability. Note that the difference in mean rent price growth and house price growth is primarily driven by significant increases in rental prices between 1550 and 1625 , which are not covered by the house price series. 
selves also might impact housing costs. Second, changes in demographic structure are slow, implying that annual changes are unlikely to pick up sufficient variation in house prices, in particular when using aggregated series.

We deal with these issues in two ways. First, our main regressions estimate the effect of lagged fertility on prices and rents. This has two important benefits: using lagged fertility circumvents the endogeneity of the urban population structure and allows us to examine predictability of housing rents and prices. Existing literature has examined the contemporaneous relation between demographic structure and changes in asset prices and risk premia, assuming the demographic structure is predictable. However, this predictability has not yet been tested. Second, we study developments in five-year fertility in our main specifications to filter out noise. This draws a good balance between picking up actual changes in demographic structure and statistical power. ${ }^{10}$

To estimate the impact of the demographic structure on prices and rents, we estimate the following model:

$$
\Delta_{5} y_{t}=\alpha+x_{t}^{\prime} \beta+\varepsilon_{t}
$$

where $y$ is a vector of (i) rent prices, (ii) house prices, or (iii) rent-price ratios. The vector $x_{t}$ contains the variables of interest: (i) The total five-year lagged fertility $\left(\sum_{j=t-4}^{t} F_{j-l a g}\right)$, and (ii) the total five-year contemporaneous fertility $\left(\sum_{j=t-4}^{t} F_{j}\right)$. We will use various lag lengths, ranging from 10 to 70 . We do not include shorter-lags, because we already control for contemporaneous fertility, and do not extend beyond 70 given that very few people reached such a high age. We include demographic and economic control variables in $x_{t}$ : Five-year total nuptiality $(N)$, mortality $(M)$, migration $(M i)$, and fiveyear changes in wages $(w)$ and consumer prices $(p)$. For house prices, we add five-year changes in bond yields $(i)$. Correspondingly:

$$
x_{t}^{\prime}=\left(\sum_{j=t-4}^{t} F_{j-\text { lag }}, \sum_{j=t-4}^{t} F_{j}, \sum_{j=t-4}^{t} N_{j}, \sum_{j=t-4}^{t} M_{j}, \sum_{j=t-4}^{t} M i_{j}, \Delta_{5} w_{t}, \Delta_{5} p_{t}, \Delta_{5} i_{t},\right) .
$$

Note that we use changes rater than levels for all non-demographic variables, because we could not consequently reject the presence of a unit root. ${ }^{11}$ This also avoids sensitivity of our rent-price ratio to any measurement error, which might accumulate over time when using levels (Eichholtz et al., 2020c).

To account for serial correlation introduced by overlapping observations, we compute Newey-West standard errors using a lag length of five (as we take five-year differences). We will use these in all other estimation results we present in this section. ${ }^{12}$

\footnotetext{
${ }^{10}$ We will consider alternative period lengths in robustness checks.

${ }^{11}$ We tested for the null of a unit root using ADF-tests, KPSS-tests and DF-GLS tests. In most cases all tests give the same results; we differenced variables in case one of the tests indicates the presence of a unit root. All variables are stationary in first differences.

${ }^{12}$ As a robustness check, Figures 6.9 and 6.10 in Section 6.B report coefficients and 95\% confidence intervals based on the average coefficient and standard error from five non-overlapping regressions, where we shifted the start year by one year for each regression. This gives similar results.
} 


\subsubsection{Housing Demand: Rent Prices}

Figure 6.2 presents estimated lagged fertility coefficients and corresponding $95 \%$ confidence intervals for different lag lengths, both for Amsterdam and Parisian rents. Note that by definition, the lags on the $x$-axis correspond to the youngest age group in that particular cohort, so the $23^{\text {th }}$ lag corresponds to the birth cohort that is currently 2327 years old. Table 6.2 presents full estimation results for this particular fertility lag: a one percentage point increase in fertility 23-27 years ago increases rent prices by about $1.25 \%$ in Amsterdam and $2.2 \%$ in Paris.

Figure 6.2 shows that both Paris and Amsterdam display similar trends for older birth cohorts, although we measure the effects for Paris less precisely. The economic and statistical significance is zero for fertility lags corresponding to children or younger teenagers, but gradually increases and starts becoming significant as fertility lags start to include cohorts currently in their twenties. A one percentage point increase in the size of birth cohorts 20-30 years ago increases rent prices by about 1-2.5 percent. The effect disappears again for birth cohorts in their thirties. Although the economic effect turns negative for older cohorts, that are closer to retirement or their end of life, this effect is insignificant for most lags.

The pattern in Figure 6.2 is closely in line with existing estimates of demographic housing demand (e.g. Mankiw and Weil, 1989; Green and Lee, 2016). We only document significant increases in rental prices for cohorts whose housing demand rises rapidly: cohorts currently in their late teens or twenties. This finding suggests that the housing supply does not fully anticipate the growth in demographic housing demand. Nevertheless, the increase in rental prices is relatively mild: a one standard deviation increase in five-year fertility would increase rental prices by $2-5 \%$. This effect would be about twice as large if we could account for child mortality.

Although they are not of primary interest, the results in Table 6.2 suggest that other demographic variables correlate significantly with housing costs as well. In general, all coefficients have their expected signs, but their significance varies across cities. Mortality and fertility seem particularly significant in Paris, while nuptiality and migration are important in Amsterdam. Note again that we cannot interpret these coefficients causally, given that demographic rates and rental prices might both be related to cityspecific conditions for which we cannot entirely control.

\subsubsection{Asset Demand: House Prices and Rent-Price Ratios}

Figure 6.3 reports the effect of lagged fertility on changes in current house prices and rent-price ratios. In Table 6.3, we report the full estimation output for one of these regressions, corresponding to the birth cohort 23-27 years ago: A one percentage point increase in fertility $23-27$ years ago increases house prices by $5 \%$ and reduces rentprice ratios by nearly the same amount.

The effects of lagged fertility on changes in house prices and rent-price ratios are the exact opposite of each other, which confirms that demographic structure has a sig- 
Figure 6.2: Lagged Fertility and Rent Prices.

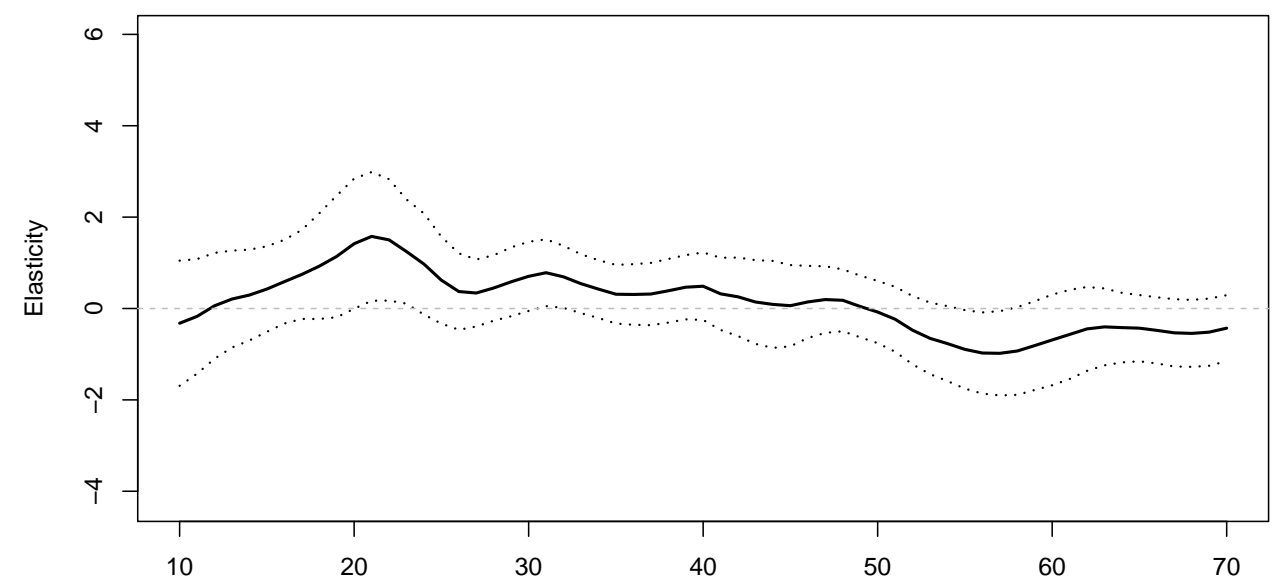

(a) Rent prices, Amsterdam

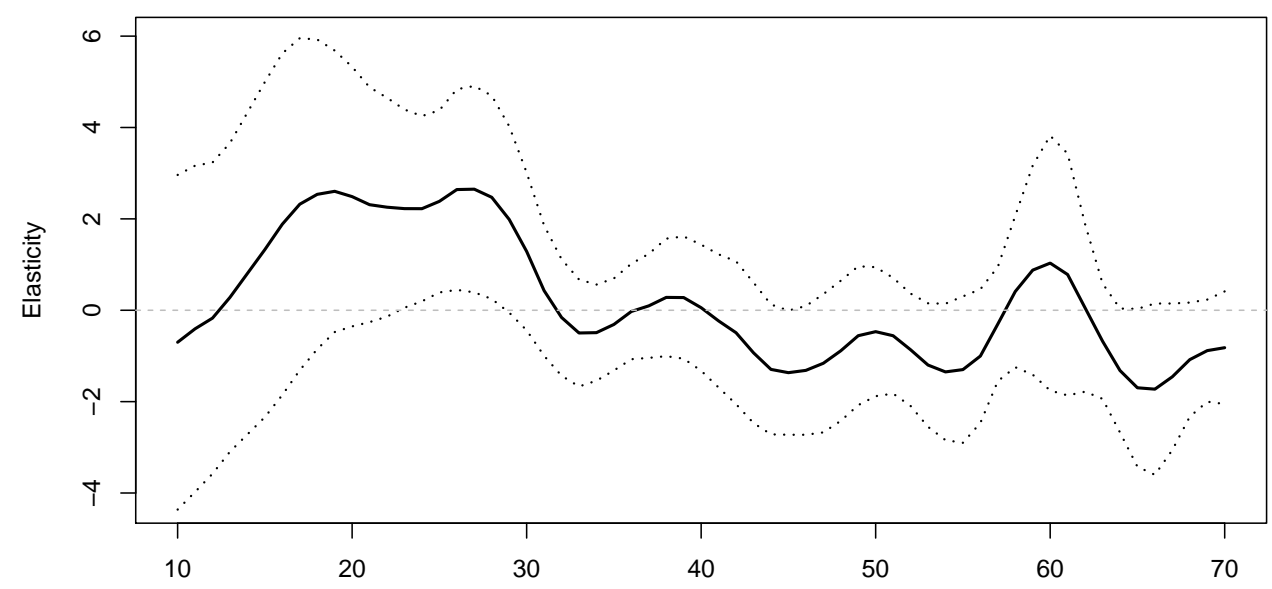

(b) Rent prices, Paris

Notes: These figures report the effect of lagged five-year fertility on 5-year changes in nominal rents in the pre-1914 period. Each point corresponds to a different regression, with the fertility lag and starting year changing over regressions. The fertility lag is reported on the $\mathrm{x}$-axis. For example, a fertility lag of 20 corresponds to the birth cohort currently aged 20-24. Fertility data for Paris start in 1526 and for Amsterdam in 1565. All regressions control for contemporaneous demographic rates, wages and consumer prices (see Table 6.2). Dashed lines reflect 95\% confidence intervals, based on Newey-West standard errors using a lag-length of five years. 
Table 6.2: Results for Paris and Amsterdam, 5-Year Rent Changes.

\begin{tabular}{|c|c|c|}
\hline & \multicolumn{2}{|c|}{ Dependent variable: } \\
\hline & \multicolumn{2}{|c|}{$\Delta_{5} r_{t}$} \\
\hline & Amsterdam & Paris \\
\hline Fertility: $F_{t-23}$ & $\begin{array}{c}1.246^{* *} \\
(0.582)\end{array}$ & $\begin{array}{c}2.225^{* *} \\
(1.106)\end{array}$ \\
\hline Fertility: $F_{t}$ & $\begin{array}{c}0.373 \\
(0.503)\end{array}$ & $\begin{array}{c}2.578^{* *} \\
(1.075)\end{array}$ \\
\hline Nuptiality: $N_{t}$ & $\begin{array}{l}2.743^{*} \\
(1.397)\end{array}$ & $\begin{array}{c}4.226 \\
(3.228)\end{array}$ \\
\hline Mortality: $M_{t}$ & $\begin{array}{c}-0.441^{*} \\
(0.245)\end{array}$ & $\begin{array}{c}-2.305^{* *} \\
(0.983)\end{array}$ \\
\hline Migration (Impl.): $M i_{t}$ & $\begin{array}{l}0.234^{*} \\
(0.141)\end{array}$ & \\
\hline Migration (Norm.): $M i N_{t}$ & $\begin{array}{c}0.003^{* *} \\
(0.002)\end{array}$ & \\
\hline Wages: $\Delta_{5} w_{t}$ & $\begin{array}{c}0.288 \\
(0.192)\end{array}$ & $\begin{array}{c}0.277^{* *} \\
(0.109)\end{array}$ \\
\hline $\mathrm{CPI}: \Delta_{5} p_{t}$ & $\begin{array}{l}-0.017 \\
(0.044)\end{array}$ & $\begin{array}{l}-0.053 \\
(0.095)\end{array}$ \\
\hline Constant & $\begin{array}{c}-0.328^{* *} \\
(0.164)\end{array}$ & $\begin{array}{c}-0.550^{* *} \\
(0.226)\end{array}$ \\
\hline Observations & 322 & 359 \\
\hline $\mathrm{R}^{2}$ & 0.305 & 0.292 \\
\hline Adjusted $\mathrm{R}^{2}$ & 0.287 & 0.280 \\
\hline Residual Std. Error & 0.062 & 0.146 \\
\hline F Statistic & 17.191 & 24.195 \\
\hline
\end{tabular}

Notes: ${ }^{*} \mathrm{p}<0.1 ;{ }^{* *} \mathrm{p}<0.05 ;{ }^{* * *} \mathrm{p}<0.01$. These regressions estimated the impact of demographic factors on five-year changes in rent prices. They cover the time period from 1592-1913 (Amsterdam) and from 1555-1913 (Paris). Fertility observations start and end 23 years earlier. Standard errors are Newey-West errors with a lag length of five years. 
Figure 6.3: Lagged Fertility and Changes in House Prices and Yields

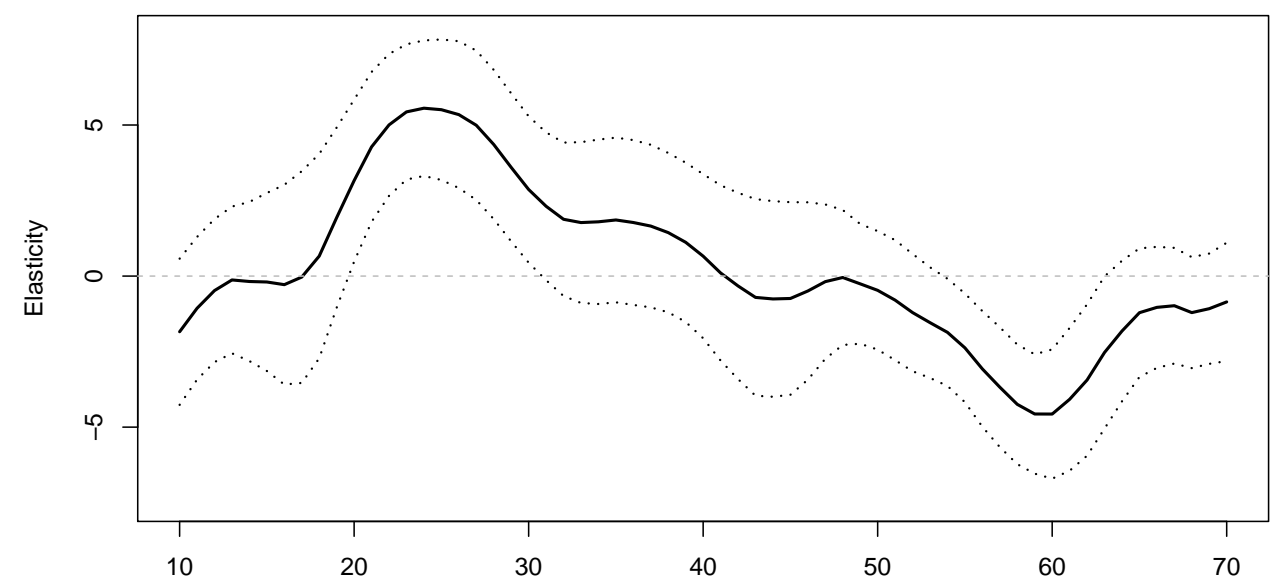

(a) House Prices, Amsterdam

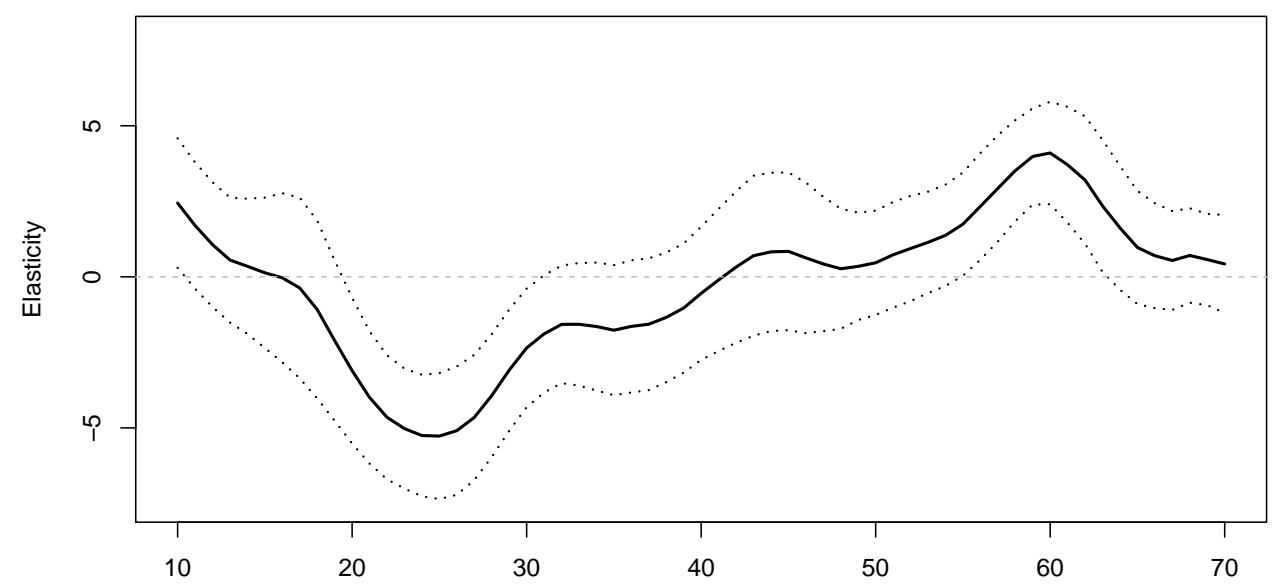

(b) Rent-Price Ratios, Amsterdam

Notes: These figures report the effect of lagged five-year fertility on 5-year changes in log house prices and rent-price ratios in the pre-1914 period. Each point corresponds to a different regression, with the fertility lag and starting year changing across regressions. The fertility lag is reported on the x-axis. For example, a fertility lag of 20 corresponds to the birth cohort currently aged 20-24. Fertility data for Paris start in 1526 and for Amsterdam in 1565. All regressions control for current demographic rates, wages and consumer prices (see Table 6.2). Dashed lines reflect 95\% confidence intervals based on Newey-West standard errors with a lag-length of five years. 
nificant impact on house prices, while the effect on housing rents is mild. ${ }^{13}$ The effect is significant for cohorts between age 20 and 35, and appears to peak for birth cohorts in their late twenties, when effects exceed five percent. The effect becomes insignificant in the thirties and changes sign in the late forties. For fertility lags corresponding to cohorts near or in their sixties, we find both statistically and economically significant reductions in prices of about five percent per percentage point increase in lagged fertility. Rent-price ratios show the exact opposite effect.

These effects are very substantial. An increase in five-year fertility of one standard deviation (1.6\%) would increase house prices 25 years later by over $8 \%$. This effect would be significantly higher after accounting for child mortality. For reference, the US share of the population in their twenties increased from $12 \%$ to $18 \%$ between 1960 and 1980. This share declined again to $13.5 \%$ in 2000. France and The Netherlands experienced similar trends (United Nations, 2017).

Except for normalized migration, and to a lesser extent nuptiality, we find little correlation between house prices and other demographic variables, in line with the findings for rental prices. The fact that normalized migration correlates with changes in house prices, while implied migration correlates with changes in rental prices, is not surprising: normalized migration likely measures migration of wealthier inhabitants of Amsterdam, who are more likely to be able to buy houses. As expected, bond yields are negatively related to house prices and positively to rental-price ratios.

\subsubsection{Robustness Checks}

We consider various other specifications to assess the robustness of our findings. First, we estimate Eq. (6.1) using both three-year and ten-year changes, to assess the extent to which our findings are robust to using different time horizons. Second, we investigate whether our findings also hold when only considering growth periods, estimating Eq. (6.1) on the subset of periods where the population was growing. The effects of demographic housing demand on prices might be different when cities grow compared to when they decline because housing supply can expand when cities are growing (see Glaeser and Gyourko, 2005). When cities are growing, it is also more likely that birth cohorts remain in the city compared to when it declines: when cities decline, newborn children are more likely to die or migrate in the future.

For space considerations, we only report the full coefficient plots in Figures 6.116.14 in Appendix 6.B, and briefly summarize the main results here. For changes in rental prices, we find for all our specifications that the economic effects are in line with the estimates reported in Figure 6.2. In some specifications, we find that the effects become more or less significant. For example, fertility lags corresponding to birth cohorts in their twenties do not significantly predict Parisian rent prices conditional on urban growth, and nor do Amsterdam rent prices when using ten-year

\footnotetext{
${ }^{13}$ Note that the difference between the coefficients on lagged fertility for changes rent-price ratios and house prices suggests the effect is even milder than in Table 6.2. This is because the estimation in Table 6.2 uses a more extended sample, that includes the period with the most considerable demographic fluctuations (16th - early 17 th century).
} 
Table 6.3: Results for Amsterdam: Rental Yields and House Price Changes.

\begin{tabular}{|c|c|c|}
\hline & \multicolumn{2}{|c|}{ Dependent variable: } \\
\hline & $\begin{array}{c}\Delta_{5} h p i_{t} \\
(1)\end{array}$ & $\begin{array}{c}\Delta_{5}\left(r_{t}-h p i_{t}\right) \\
(2)\end{array}$ \\
\hline Fertility: $F_{t-23}$ & $\begin{array}{c}5.434^{* * *} \\
(1.142)\end{array}$ & $\begin{array}{c}-5.024^{* * *} \\
(1.013)\end{array}$ \\
\hline Fertility: $F_{t}$ & $\begin{array}{c}1.378 \\
(0.933)\end{array}$ & $\begin{array}{c}-1.340^{*} \\
(0.789)\end{array}$ \\
\hline Nuptiality: $N_{t}$ & $\begin{array}{c}6.510^{* *} \\
(2.698)\end{array}$ & $\begin{array}{c}-4.333^{*} \\
(2.485)\end{array}$ \\
\hline Mortality: $M_{t}$ & $\begin{array}{l}-0.463 \\
(0.428)\end{array}$ & $\begin{array}{c}0.063 \\
(0.407)\end{array}$ \\
\hline Migration (Impl.): $M i_{t}$ & $\begin{array}{l}-0.262 \\
(0.483)\end{array}$ & $\begin{array}{c}0.463 \\
(0.386)\end{array}$ \\
\hline Migration (Norm.): $M i N_{t}$ & $\begin{array}{c}0.013^{* * *} \\
(0.003)\end{array}$ & $\begin{array}{c}-0.009 * * * \\
(0.003)\end{array}$ \\
\hline Wages: $\Delta_{5} w_{t}$ & $\begin{array}{l}0.829^{*} \\
(0.466)\end{array}$ & $\begin{array}{c}-0.791^{*} \\
(0.377)\end{array}$ \\
\hline $\mathrm{CPI}: \Delta_{5} p_{t}$ & $\begin{array}{l}-0.143 \\
(0.112)\end{array}$ & $\begin{array}{c}0.175^{* *} \\
(0.083)\end{array}$ \\
\hline Interest rate: $\Delta_{5} i_{t}$ & $\begin{array}{c}-0.387^{* * *} \\
(0.089)\end{array}$ & $\begin{array}{c}0.289 * * * \\
(0.071)\end{array}$ \\
\hline Constant & $\begin{array}{c}-1.395^{* * *} \\
(0.320)\end{array}$ & $\begin{array}{c}1.292^{* * *} \\
(0.202)\end{array}$ \\
\hline Observations & 285 & 285 \\
\hline $\mathrm{R}^{2}$ & 0.428 & 0.363 \\
\hline Adjusted $\mathrm{R}^{2}$ & 0.409 & 0.342 \\
\hline Residual Std. Error & 0.132 & 0.116 \\
\hline F Statistic & 22.818 & 17.375 \\
\hline
\end{tabular}

Notes: ${ }^{*} \mathrm{p}<0.1 ;{ }^{* *} \mathrm{p}<0.05 ;{ }^{* * *} \mathrm{p}<0.01$. These regressions estimated the impact of demographic factors on five-year changes in house prices (Column 1) and rental yields (Column 2), estimated for the time period from 1629-1913. Fertility observations start and end 23 years earlier. Standard errors are Newey-West errors with a lag length of five years. 
changes. On the other hand, we find in some specifications that fertility significantly negatively predicts future rent prices for fertility lags corresponding to older birth cohorts. This effect is particularly pronounced when we look at periods of urban growth (Figures 6.15-6.16), and it also appears slightly earlier for Paris than for Amsterdam. As a result, the effect of lagged fertility on changes in rent-price ratios is also somewhat smaller for these older cohorts. For changes in house prices, as well as rent-price ratios, results are consistent across all other specifications: We find that lagged fertility significantly increases house prices and decreases rent-price ratios for birth cohorts in their twenties, and does precisely the opposite for birth cohorts currently in their sixties.

Summarizing, these findings suggest that current fertility has a mild positive effect on rental prices 20-30 years from now, and a weaker and generally insignificant effect on rent prices about 60 years from now. We also find such effects on house prices, but they are much larger and more significant. Correspondingly, effects on changes in rent-price ratios go precisely in the opposite direction. Thus, most of the effect of demographics on house prices is due to increased demographic demand for housing as an investment asset, with much smaller effects coming from changes in demographic demand for housing consumption.

\subsection{Discussion}

Our analysis in the previous section indicates that changes in demographic structure have large and predictable impacts on house prices, but smaller impacts on rental prices. Large cohorts of young adults will increase house prices significantly, while large cohorts of older people will reduce house prices and demand for housing investment. In this section, we aim to discuss these findings and their implications in more detail and examine how our historical numbers translate to the current context.

In our analysis, we have examined the predictability of future rent and house prices with current levels of fertility. To interpret our coefficients for this historical period compared to today, it is crucial to examine differences in life expectancy across time periods. With $s_{t}(j)$ denoting the survival probability of newborn babies at time $t$ until age $j$, our estimates underestimate the effect of the remaining cohort alive at age $j$ by a factor $\left(1-s_{t}(j)\right)$. Because survival probabilities have changed fundamentally over time, a child born today is much more likely to reach older ages than in our sample period.

Figure 6.4 plots the age structure, based on data from the 1851 Amsterdam household census provided by Fryske Akademy (2018). Because fertility and mortality rates did not start to decline until the end of the 19th century, this plot likely presents a fairly representative picture of the average age structure of the population: Most of the population was very young, and it was rare for people to reach old ages. Of course, due to fluctuations in birth rates, death rates and migration the demographic structure was subject to changes over time. Except for high levels of child mortality, the demographic structure in historical cities looked much more similar to those in developing 
countries today, who are still experiencing their demographic transition.

Figure 6.4: Age Structure Population, Amsterdam, 1851.

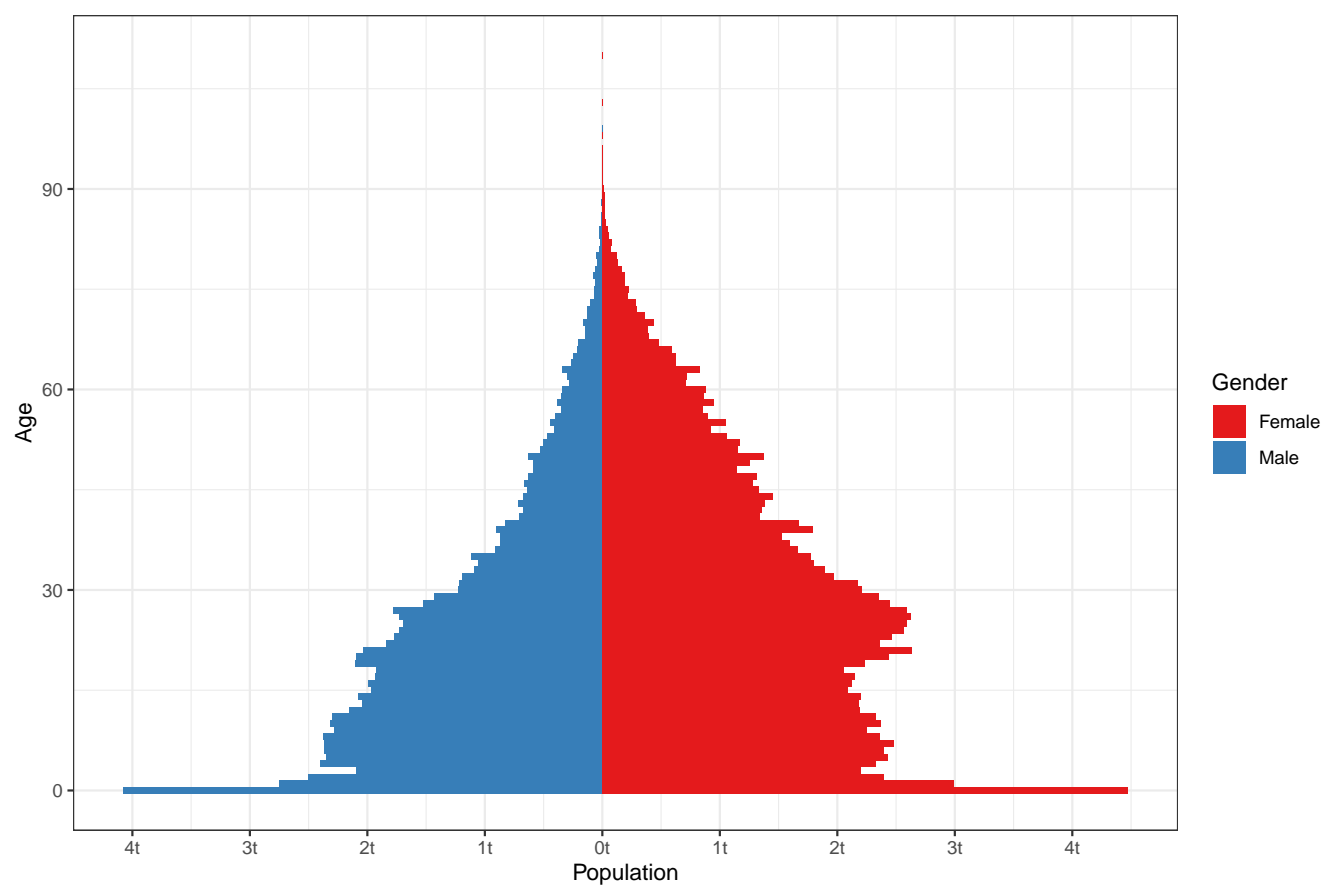

Notes: This figure plots the distribution of the Amsterdam population across genders and age groups in 1851. Because infant mortality was significant, there is a large drop-off between age 0 and age 1 . About $50 \%$ of newborn children would reach age 15 .

Van Leeuwen and Oeppen (1993) use this data in demographic models and estimate that approximately half of the population reached age 18. This number is in line with other estimates for London in the 17th century (Clark and Cummins, 2009). The second feature of Figure 6.4 is that very few people reached old ages. Van Leeuwen and Oeppen (1993) estimate that only $20 \%$ of the population would reach age 60 , while nowadays about $95 \%$ of the newborn is expected to reach that age.

Because individuals can only rent or buy real estate when they are old enough to leave their parental house, it is evident that we should double our estimates for all birth cohorts currently above age 15-19. If we use mortality figures for older individuals, to translate our estimates to the modern context, we should multiply our estimates on the impact of current fertility on prices 20-30 years later by a factor of 2 to 2.5 , and the impact on prices 60 years later by a factor almost five. However, we should also take into consideration the age-structure of housing consumption and investment demand today and in the past. Only when they are similar, these theoretical factors would be correct. We study the dependence of housing demand on the age structure of the population in more detail in the next subsection. 


\subsubsection{Housing Demand across Age Groups}

To study differences in housing demand across age groups today and in the past, we start from a very simple model, where aggregated housing demand for a household simply equates the summed housing demand of each of its members, with housing demand entirely dependent on age:

$$
D=\sum_{n=1}^{N} D\left(\mathrm{age}_{n}\right)
$$

As the rent paid by a household is the result of its total demand for housing services, one can directly estimate Eq. (6.2) by regressing the paid rental prices on dummy variables reflecting the age composition of each household. This is the approach applied by Mankiw and Weil (1989), who use US census data to estimate Eq. (6.2), and identify that housing demand increases substantially between age 20 and 30 , and reduces at older ages.

To grasp how housing demand correlated with age in the time period that we study, we link the 1832 cadastral rent census of Amsterdam to the household census of 1851, using data from Fryske Akademy (2018). This provides information on all tenants of each property in Amsterdam, including information on their age, and the rent or rental value of these properties in 1832. To the best of our knowledge, this is the only source available to estimate urban housing demand so far back in history. Because the population and economy of Amsterdam changed little between 1832 and 1851, the cross-section of rental prices in 1832 provides a fairly representative picture of the cross-section of rental prices in 1851, the year for which we know the characteristics of all tenants in these properties. To reduce measurement error, we exclude parcels that were split between 1832 and 1860 and properties with no assessed value in 1832. In total, our data cover 17,339 properties containing a total of 167,003 inhabitants, about $75 \%$ of the total number of inhabitants in 1851 . Note that most properties housed multiple families.

Next, we regress $\log$ house rental value in 1832 on inhabitant age dummy variables, in line with the analysis from Mankiw and Weil (1989). The basic idea behind this analysis is that differences in rental values of properties proxy for differences in the bundle of housing services provided by these properties. Based on this assumption, we expect that age groups with higher levels of housing demand on average live in more expensive housing. Figure 6.5 plots the coefficients of a regression of the log rental value of each house on inhabitant age dummy variables, in line with the analysis in Mankiw and Weil (1989). For reference, we have plotted a loess curve through the estimated population coefficients. Standard errors around the coefficients are around $5 \%$ until age 30 and gradually increase to over $10 \%$ at age 70 .

Figure 6.5 shows that housing demand is negligible in childhood, and starts increasing in the late teens, with a particularly large jump at age 18 . Note that it was common for teens to move out of their parental houses at young ages and start working, which explains that housing demand already starts increasing at approximately age 15. Housing demand keeps increasing until the thirties, and then gradually starts 
Figure 6.5: Log Housing Demand by Age, Amsterdam, 1851.

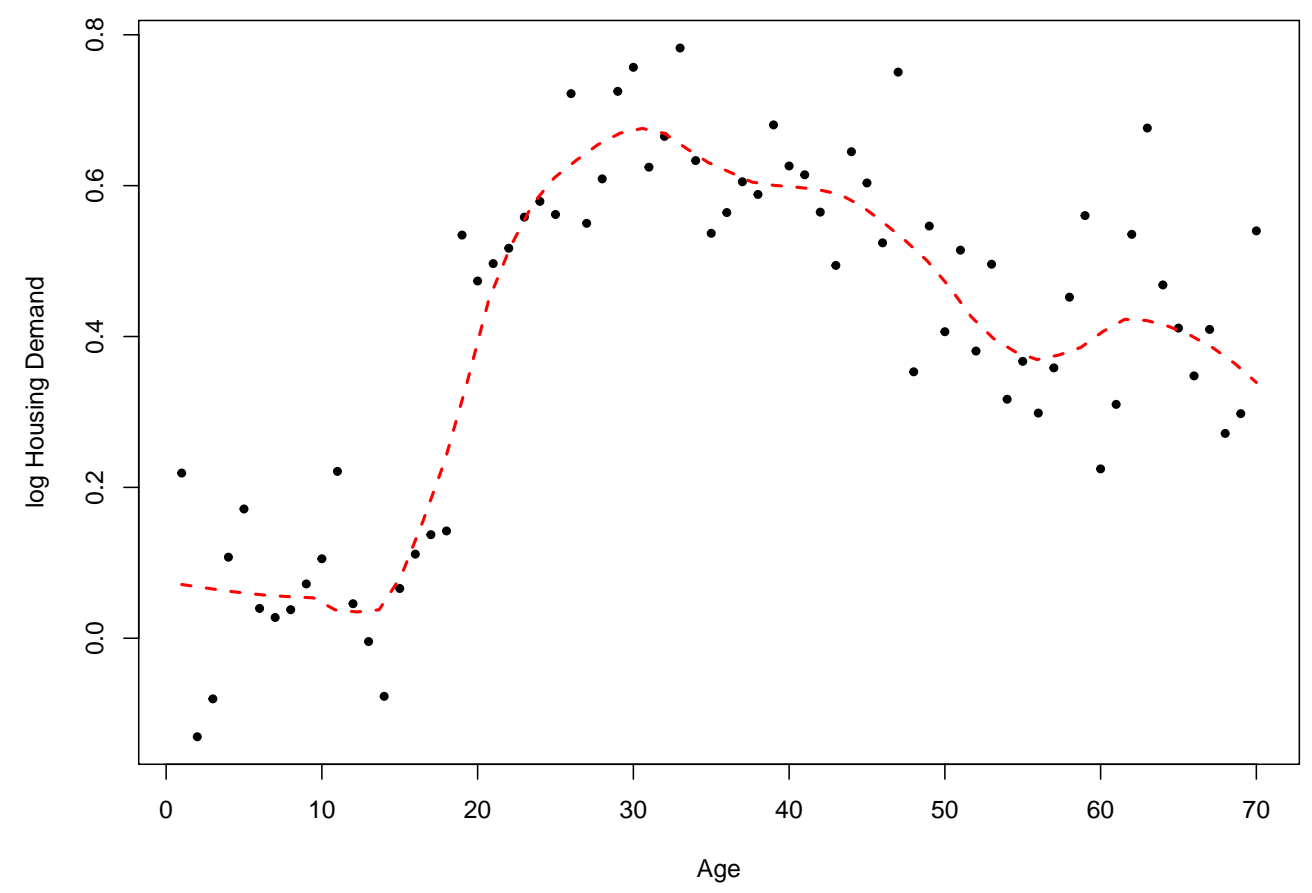

Notes: This figure plots the annual coefficients of a regression of property log rental value (in guilders) on age-dummy variables for each inhabitant, which decomposes property rent by the age of its inhabitants. Summary statistics are provided in Table 6.7. Standard errors are around $5 \%$ up to age 30 , and gradually increase to over $10 \%$ at age 70 . We exclude ages after age 70 due to a low number of observations. For reference, we plot a loess curve through the points (quadratic, span $=0.3$ ). 
leveling off at older ages. Note that the trend in Figure 6.5 is very much in line with the results in Figure 6.2a. Exactly for the ages at which housing demand is supposed to increase (decrease), we report positive (negative) predictability of rent prices with current fertility.

The pattern in Figure 6.5 is also comparable to the one documented in Mankiw and Weil (1989). Recent studies have pointed out that housing demand drops only marginally after accounting for differences in the economic opportunities across cohorts (Green and Hendershott, 1996; Eichholtz and Lindenthal, 2014; Green and Lee, 2016). Green and Lee (2016) show that demand for housing services only declines by about $10 \%$ between age 65 and 90 . In our estimates, the drop in housing demand towards older ages is much larger, with total housing demand dropping by approximately 40 percent between age 40 and 70 . The fact that this drop in total housing demand is about four times larger as in modern context, largely compensates for the fact that only one fifth of the number of newborn babies would reach age 60 compared to today.

One advantage of our historical setting is that for most periods economic growth was limited, implying cohort variation in incomes was likely less substantial than in the 20th century. This is not to say that incomes did not differ across cohorts historically. For example, Amsterdam experienced a very deep and long economic crisis in the late 18th century and early 19th century, which might have still hurt the 1851 incomes of the older population that experienced the crisis. Although the census does not report on income, it does report on the profession of each individual. Supplementary Figure 6.8 reports the estimation output of a model, where we include profession and marital status fixed effects for the main tenant, often the household head. This likely correlates closely to household income. This results in a similar pattern as in Figure 6.5, except that the decline in housing demand between age 40 and 50 becomes steeper.

In summary, to translate our historical estimates on the impact of current fertility on rental prices twenty to thirty years later to modern contexts, we should roughly double our estimates. This implies that a one percentage point increase in five-year birth rates increase rental prices about 25-years later by approximately 2.5 to 4.5 percent, following our estimates in Figure 6.2 and Table 6.2. For older ages, the large decrease in housing demand at older ages relative to modern times offsets the comparatively low fraction of newborns that reach old ages in our historical sample. Translating the evidence in Figure 6.2 to today thus suggests that the aggregate impact of a large cohort of senior people on total housing demand and rent prices is limited.

\subsubsection{Housing Investments across Age Groups}

The census measures demand for housing consumption. Because wealthier households can decide whether to rent or buy property, and have the option to allocate their wealth to other investments such as bonds or equities, the age structure of housing demand is not necessarily the same as the age structure of demand for housing investments. The fact that house prices and rent-price ratios move much more in response 
to lagged fertility than rental prices, suggests the latter channel is comparatively more important.

Again, there are many potential reasons why the age structure of housing investment today might differ from the past. Most notably, the increasing availability of mortgages has made property ownership available to a much larger group of people than before. Second, the much lower levels of income and wealth implied that most people historically died without any property, both in Paris and Amsterdam (Hart, 1976; Piketty et al., 2006). However, about two-thirds of people in 17th-18th century Amsterdam that died with any wealth owned real property, with government bonds the second most popular investment, present in about a quarter of estates (Korevaar, 2020).

The key metric to assess whether demographic demand is shifting housing investment and house prices, is the age of buyers and sellers in the market. Understandably, it is hard to reconstitute these numbers going back hundreds of years. However, using data and matching procedures described in Korevaar (2020), we can link data on buyers and sellers to their marriage records for all housing transactions in Amsterdam in the period 1700-1760. Due to limitations in the registration of names in the birth records, it was not possible to link housing transactions to birth records and link housing transactions to the actual ages of buyers and sellers.

We only match individuals that have a unique name. This implies that their name, or a very close approximation of it, only occurs once in the marriage registers of Amsterdam (1650-1810). ${ }^{14}$ In total, our matched database contains information on 5,694 individuals transacting property.

Although the marriage records do not provide information on age, most individuals in Amsterdam married in their mid- to late-twenties, following the European Marriage Pattern (van Zanden et al., 2019). ${ }^{15}$ For the subset of buyers and sellers with unique names, Figure 6.6 provides the estimated distribution of housing purchases and sales grouped by years since marriage.

Figure 6.6 shows that very few individuals transacted property long before they married or more than sixty years after they married, suggesting the matching procedure resulted in very few mismatches. The distribution for property sales is wider, given that a large fraction of sales happened after death by the heirs of the original owners. More importantly, there are clear differences between the ages at which individuals buy real estate, and at which they sell real estate. After marriage net demand for additional housing investments rises quickly. In the first few years after marriage, the number of purchases rises more rapidly than the number of sales. Between 10 and 20 years after marriage, the number of property purchases stays relatively constant, while the number of sales increases. Over 20 years after marriage the number of

\footnotetext{
${ }^{14}$ Matches are computed for each individual in the transaction or estate tax records by computing the minimum Jaro-Winkler distance to the closest person in the marriage register. This Jaro-Winkler distance should be less than 0.1, and the name should (in expectation) be unique. See (Korevaar, 2020) for the exact computation of uniqueness scores.

${ }^{15}$ The archival marriage records do provide information about ages, but this information has not been digitized.
} 
Figure 6.6: Housing Transactions by Age, Amsterdam, 1700-1760.

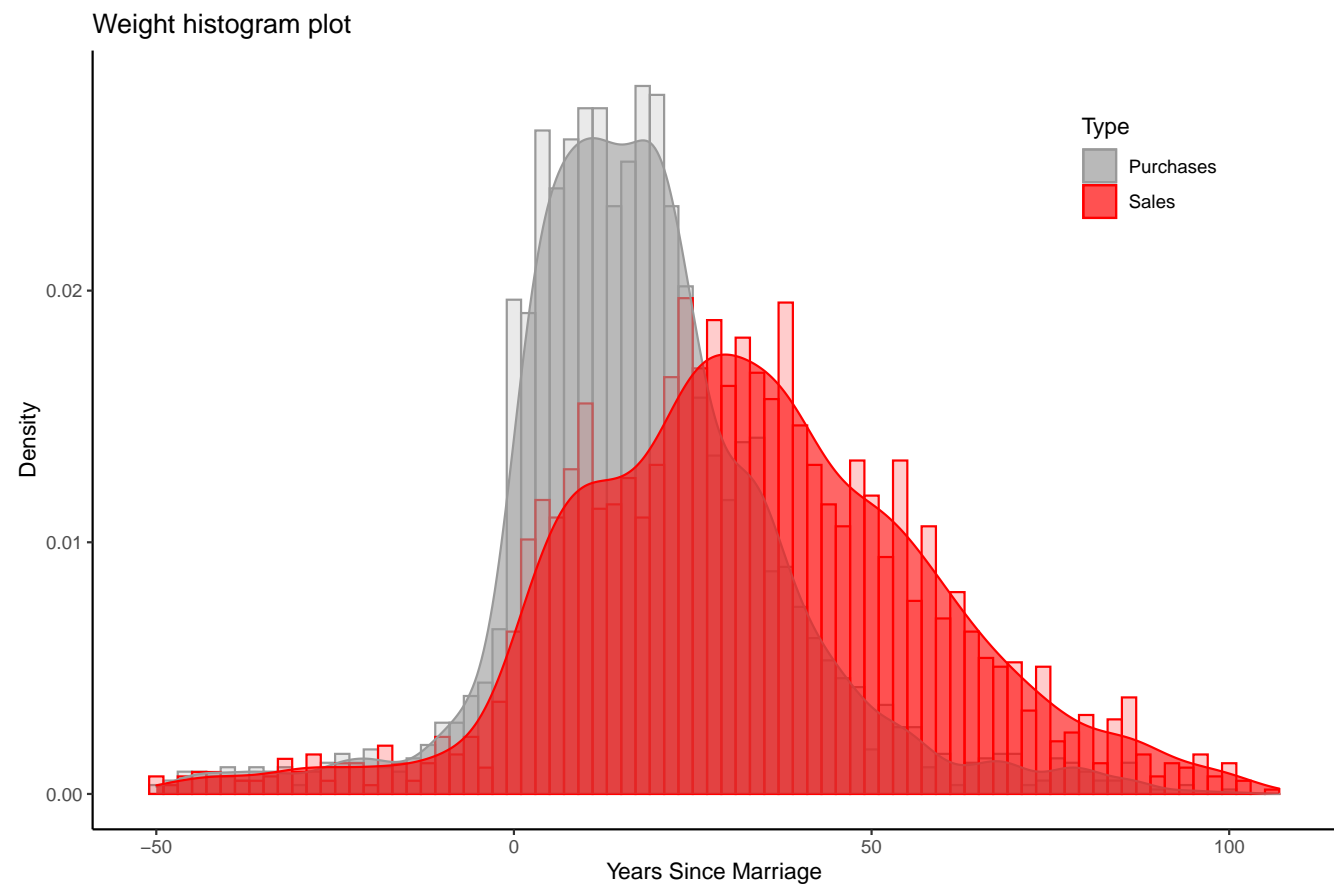

Notes: This figure plots the distribution of buyer and seller ages by the number of years that has passed since marriage. The plot is based on 5694 observations, including 2826 buyers and 2868 sellers. Bins are based per two years, and the density reflects the fraction of total persons (combining buyers and sellers) in that age bin. The tail observations might reflect a small number of mismatches. The plot is truncated at 50 years before marriage, excluding 31 observations. 
purchases starts dropping quickly to almost zero until 60 years after marriage, when nearly every individual has died. This is the prime time for housing sales: about 25 years after marriage the number of sales exceeds the number of purchases, and the sale distribution peaks approximately 30-35 years after marriage, around age 60. Afterward, the number of sales gradually decreases towards zero.

Taking the difference between the number of buyers and sellers per age group as a measure of average net investment demand for housing by age group, it appears that sellers at older ages form a comparatively large fraction of the number of sellers in the market. This contrasts with the relatively limited fraction of older individuals in the population. There are two reasons for this pattern. First, and most importantly, due to high mortality rates about half of the properties in the market were sold by heirs of the owner, rather than the owner itself. If it is profitable to rent out the property, or occupy it themselves, heirs might not sell the property immediately after the death of the original owner and hold on to it for longer periods of time. Second, individuals that had sufficient wealth to own real estate might have lived longer than the rest of the general population.

In short, our evidence suggests that demand for Amsterdam real estate investments rises rapidly between age 25 and 35, stabilizes at middle ages and starts decline rapidly from the late forties, with a peak in sales volume around age 60 to 65 . This matches the evidence on house prices in Figure 6.3, and is also in line with modern life-cycle portfolio theory. Generally, individuals also buy and sell larger houses at older ages, with average house value increasing by $0.35 \%$ per year for each year since marriage (see Appendix Table 6.8).

The transaction activity of individuals at different ages informs about when individuals buy and sell homes, but not about the relative importance of property in their portfolio over time. To track how housing investment varied over the life-cycle, we match names of individuals in the estate tax records of Amsterdam (1688-1780) to marriage records, using the same matching method. The estate tax records provide detailed data on portfolio composition and wealth at death for a third of of the population that died with any wealth. Details on this data and the data collection procedure can be found in Korevaar (2020). In total we have 855 matched portfolios. The original database of portfolio records is much larger, but very few of the individuals could be matched accurately to their marriage records. Conditional on owning any wealth, real estate was the largest item in the typical household portfolio, with a mean portfolio share around 60 percent.

To estimate how total real estate investment varied over the life-cycle, we regress the fraction of total wealth in real estate on the numbers of years since marriage, both linearly and including a quadratic term. Based on the fraction of observations that dies before marrying (wrong matches), the data suggest over $60 \%$ of observations are matched correctly, implying our estimated coefficients will be slightly biased towards zero.

One concern is that the the real estate investments of individuals dying at a certain age might not be representative for the people alive at that age, even in an era where death typically came suddenly. For example, women often became older than men 
and wealthy people might have lived longer. To address these issues, we also estimate a model where we control for gender and total wealth. We additionally include yearof-death fixed effects. Table 6.4 reports the results.

Table 6.4: Real Estate Wealth by Age, Amsterdam, 1688-1780.

\begin{tabular}{|c|c|c|c|c|c|c|}
\hline & \multicolumn{6}{|c|}{ Dependent variable: } \\
\hline & \multicolumn{3}{|c|}{ \% Real Estate Wealth } & \multicolumn{3}{|c|}{$\log ($ Real Estate Wealth +1$)$} \\
\hline & (1) & (2) & (3) & (4) & (5) & (6) \\
\hline Years since Marriage & $\begin{array}{c}-0.239^{* * *} \\
(0.088)\end{array}$ & $\begin{array}{l}0.561^{*} \\
(0.292)\end{array}$ & $\begin{array}{c}0.710^{* *} \\
(0.293)\end{array}$ & $\begin{array}{c}0.017^{* *} \\
(0.007)\end{array}$ & $\begin{array}{c}0.072^{* * *} \\
(0.025)\end{array}$ & $\begin{array}{c}0.070^{* * *} \\
(0.026)\end{array}$ \\
\hline Years since Marriage $^{2}$ & & $\begin{array}{c}-0.012^{* * *} \\
(0.004)\end{array}$ & $\begin{array}{c}-0.013^{* * *} \\
(0.004)\end{array}$ & & $\begin{array}{c}-0.001^{* *} \\
(0.0004)\end{array}$ & $\begin{array}{c}-0.001^{* *} \\
(0.0004)\end{array}$ \\
\hline $\log$ Total Wealth & & & $\begin{array}{c}-7.418^{* * *} \\
(0.910)\end{array}$ & & & \\
\hline Gender & & & $\begin{array}{c}4.946 \\
(3.014)\end{array}$ & & & $\begin{array}{c}0.360 \\
(0.264)\end{array}$ \\
\hline Constant & $\begin{array}{c}66.446^{* * *} \\
(2.982) \\
\end{array}$ & $\begin{array}{c}56.839^{* * *} \\
(4.476) \\
\end{array}$ & $\begin{array}{c}144.230^{* * *} \\
(41.909)\end{array}$ & $\begin{array}{c}5.663^{* * *} \\
(0.252)\end{array}$ & $\begin{array}{c}5.004^{* * *} \\
(0.379)\end{array}$ & $\begin{array}{l}6.462^{*} \\
(3.630)\end{array}$ \\
\hline Year FE & No & No & Yes & No & No & Yes \\
\hline Observations & 855 & 855 & 855 & 855 & 855 & 855 \\
\hline $\mathrm{R}^{2}$ & 0.009 & 0.018 & 0.188 & 0.006 & 0.012 & 0.117 \\
\hline Adjusted $\mathrm{R}^{2}$ & 0.008 & 0.016 & 0.095 & 0.005 & 0.010 & 0.019 \\
\hline Residual Std. Error & 42.968 & 42.787 & 41.022 & 3.630 & 3.621 & 3.605 \\
\hline F Statistic & 7.456 & 7.873 & 2.035 & 5.288 & 5.362 & 1.189 \\
\hline
\end{tabular}

Notes: This table reports the results of a regression of the fraction of wealth in real estate (Columns 1-3) and $\log$ Total Real Estate Wealth (Columns 4-6) on the years since marriage, either linearly (Columns 1 and 4), including a quadratic term (Columns 2 and 5), and adding controls (Columns 3 and 6). ${ }^{*} \mathrm{p}<0.1$; ${ }^{* *} \mathrm{p}<0.05 ;{ }^{* * *} \mathrm{p}<0.01$

Comparing Columns 1 and 4 shows that whereas total real estate wealth increased over the lifetime (by 1.7 percent per year after marriage), the fraction of wealth invested in real estate decreased over the lifetime (by 0.25 percent per year after marriage). Both effects are non-linear: The fraction or total amount of wealth in real estate increases in the first years after marriage, but declines afterward. The estimated tipping point is around 25 years after marriage for the fraction of wealth in real estate, and around 35 years for total real estate wealth. This implies individuals on average started divesting from real estate around age 60 to 65 . These numbers are comparable with the estimates in Figure 6.6. These numbers do not change when controlling for total wealth or gender. Importantly, these patterns are comparable to what is observed in modern markets (e.g. Poterba and Samwick, 2001).

In summary, our evidence on housing transactions and investment suggests that our historical estimates on the impact of demographic changes on house prices likely 
are much more comparable to their modern equivalents than those for rental prices, at least after accounting for child mortality. This suggests that reductions in demand for housing investment at old ages may have a substantial impact on prices when cohorts are large.

\subsubsection{Demographic Demand for Bond Investment}

In most of this paper, we have focused on the relation between changes in the demographic structure and the housing market. However, the large differences in the fraction of real estate in household portfolios across age groups suggest there might be differences for other asset classes too. Most notably, life-cycle models predict the fraction of wealth in safe investments, most notably bonds, to increase in age. To more specifically examine the relationship between bond investments and age in our data, we replicate the analysis in Table 6.4 with data on government bonds, the secondlargest asset class. Table 6.5 reports the results.

In line with life-cycle portfolio theory, the findings for bonds are exactly opposite to those for real estate, with both the share and absolute levels of wealth invested in government bonds increasing over the life-cycle. The increase is particularly large at older ages, and the effect is robust for controlling for total wealth and differences across genders.

Establishing the impact of these changes on government bond yields is more difficult, because the bond yield series is based on comparatively few transactions from different sources, and the expected price impact less clear-cut. For young cohorts, we would only expect negative price impacts if young cohorts sell government bonds to buy real estate, but young individuals generally owned very few bonds. For older cohorts, transactions from heirs selling their inherited bonds might offset the positive impact from older people still alive transitioning to bonds. Because we do not have transactions data on government bonds, we cannot identify to what extent this was the case. $^{16}$

\subsection{Conclusion}

The main conclusion of this paper is that changes in demographic structure have significant and predictive effects on housing costs, but that these effects vary across rent and house prices. We find that current increases in fertility rates lead to mild increases in rental prices 20-30 years later, but have large impacts on house prices and rentprice ratios. We document the opposite effects for fertility on housing costs 60-65 years later, when house prices reduce, and rent-price ratios increase.

The strong impact on house prices suggests that wealthier households purchase property in young adulthood both to satisfy their demand for housing consumption and their demand for saving. They sell their property at older ages when they stop

\footnotetext{
${ }^{16}$ In Appendix 6.A we test for predictability of bond yields. Compared to the effect on rent-price ratios, we find opposite coefficients of lagged fertility on bond yields for young cohorts, but similar effects for older cohorts. Unsurprisingly, none of these effects is significant though.
} 
Table 6.5: Bond Investment by Age, Amsterdam, 1688-1780.

\begin{tabular}{|c|c|c|c|c|c|c|}
\hline & \multicolumn{6}{|c|}{ Dependent variable: } \\
\hline & \multicolumn{3}{|c|}{ \% Bonds } & \multicolumn{3}{|c|}{$\log ($ Bond Wealth +1$)$} \\
\hline & $(1)$ & (2) & (3) & (4) & (5) & (6) \\
\hline Years since Marriage & $\begin{array}{c}0.187^{* *} \\
(0.080)\end{array}$ & $\begin{array}{c}-0.547^{* *} \\
(0.269)\end{array}$ & $\begin{array}{c}-0.630^{* *} \\
(0.275)\end{array}$ & $\begin{array}{c}0.044^{* * *} \\
(0.009)\end{array}$ & $\begin{array}{l}-0.018 \\
(0.030)\end{array}$ & $\begin{array}{l}-0.022 \\
(0.031)\end{array}$ \\
\hline Years since Marriage $^{2}$ & & $\begin{array}{c}0.011^{* * *} \\
(0.004)\end{array}$ & $\begin{array}{c}0.012^{* * *} \\
(0.004)\end{array}$ & & $\begin{array}{l}0.001^{* *} \\
(0.0004)\end{array}$ & $\begin{array}{l}0.001^{* *} \\
(0.0004)\end{array}$ \\
\hline log Total Wealth & & & $\begin{array}{c}3.853^{* * *} \\
(0.857)\end{array}$ & & & \\
\hline Gender & & & $\begin{array}{c}-6.977^{* *} \\
(2.837)\end{array}$ & & & $\begin{array}{c}-0.928^{* * *} \\
(0.317)\end{array}$ \\
\hline Constant & $\begin{array}{c}25.950^{* * *} \\
(2.740) \\
\end{array}$ & $\begin{array}{c}34.766^{* * *} \\
(4.113)\end{array}$ & $\begin{array}{l}-15.630 \\
(39.451)\end{array}$ & $\begin{array}{c}2.887^{* * *} \\
(0.300)\end{array}$ & $\begin{array}{c}3.635^{* * *} \\
(0.452)\end{array}$ & $\begin{array}{c}0.987 \\
(4.368) \\
\end{array}$ \\
\hline Year FE & No & No & Yes & No & No & Yes \\
\hline Observations & 855 & 855 & 855 & 855 & 855 & 855 \\
\hline $\mathrm{R}^{2}$ & 0.006 & 0.016 & 0.146 & 0.028 & 0.034 & 0.122 \\
\hline Adjusted $\mathrm{R}^{2}$ & 0.005 & 0.013 & 0.049 & 0.027 & 0.031 & 0.023 \\
\hline Residual Std. Error & 39.489 & 39.323 & 38.616 & 4.331 & 4.321 & 4.339 \\
\hline F Statistic & 5.387 & 6.817 & 1.502 & 24.671 & 14.839 & 1.236 \\
\hline
\end{tabular}

Notes: This table reports the results of a regression of the fraction of wealth in government bonds (Columns 1-3) and log total government bond wealth (Columns 4-6) on the years since marriage, either linearly (Columns 1 and 4), including a quadratic term (Columns 2 and 5), and adding controls (Columns 3 and 6). The effects are exactly opposite of those in 6.4, with both total bond investment and the fraction of wealth in bonds increasing in age, with the increase particularly rapid at older ages. ${ }^{*} \mathrm{p}<0.1$; ${ }^{* *} \mathrm{p}<0.05$; ${ }^{* * *} \mathrm{p}<0.01$ 
working or approach the final stages of their life. The limited effect on rental prices indicates that increases in housing supply absorb most of the increases in housing demand, or that this effect is comparatively small.

Our study is the first to document that changes in demographic structure have significant impacts on changes in rent-price ratios and corresponding housing risk premia. Existing literature has found limited support for this hypothesis in other markets. We think that the significant impact of demographic structure on house prices originates from the fact that real estate is the leading investment asset for ordinary households, both historically and nowadays, as owner-occupiers typically invest the majority of their wealth in their property. Holdings of stocks and bonds tend to be much more concentrated.

This implies that in countries with rapidly aging populations, reduced investment demand for housing will likely result in lower house price growth, when baby boomers retire or gradually pass away. In cities that are still growing, the influx of migrants or the arrival of new-born life will either immediately or in the future lead to rising housing costs. However, if supply can adjust gradually, the effects on rent prices will be mild. 


\section{A Demographic Demand and Bond Yields}

The differences in the demand for bond investments across age groups documented in the main body of the paper suggest that changes in demographic structure potentially might also influence bond yields. To test this hypothesis, we estimate Eq. (6.1) with changes in log bond yields as the dependent variable. If changes in total asset demand drive the effects we find, instead of the specific demand for housing investments, we should expect changes in bond yields to respond similarly to changes in demographics. In Figure 6.7 we report the effect of five-year lagged fertility on changes in bond yields, and compare these to changes in rent-price ratios, both estimated for the 1625-1913 period. In the rent-price regressions, we do not control for changes in interest rates.

Figure 6.7: The Effect of Lagged Fertility on Bond Yields.

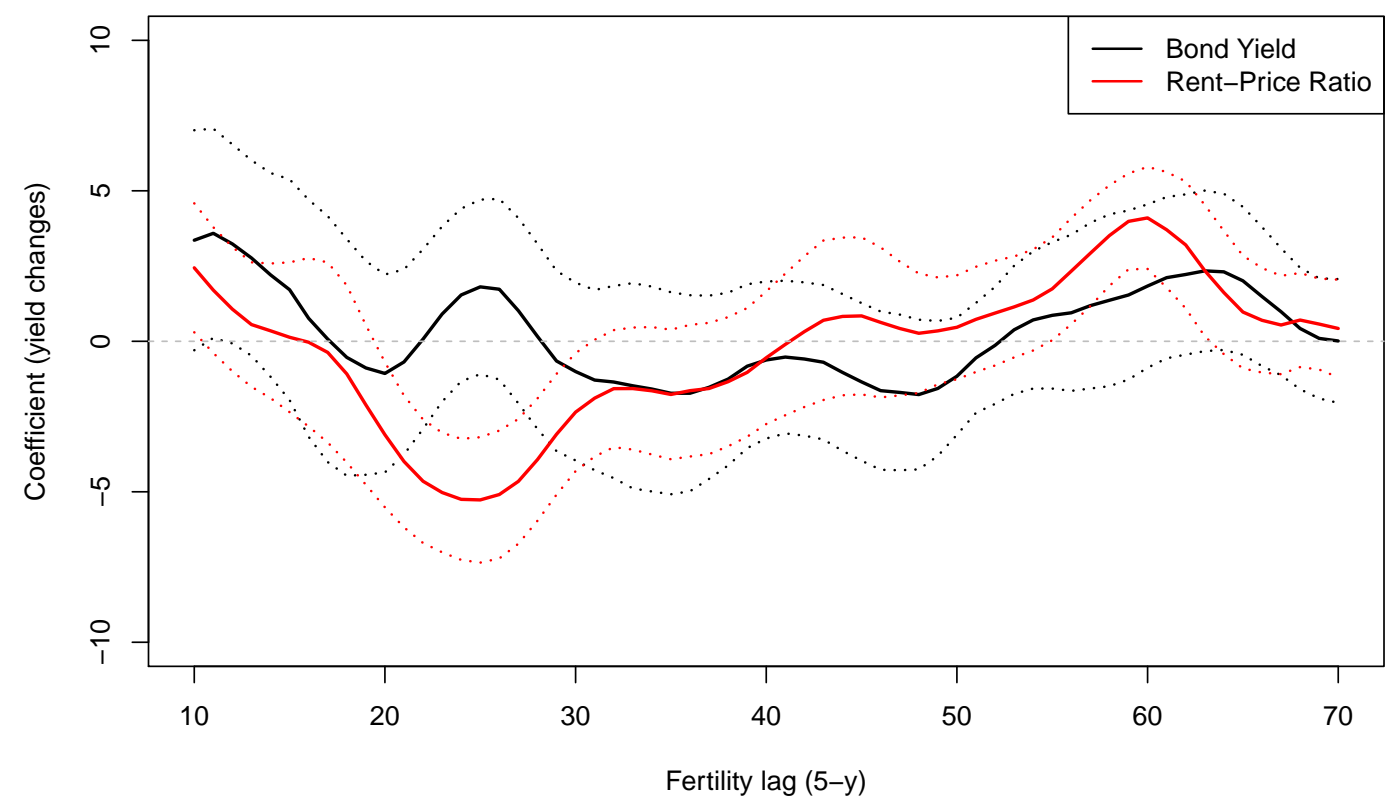

Notes: These figures report the effect of lagged five-year fertility on 5-year changes in (log) bond yield and rent-price ratios. All regressions control for current demographic rates, wages and consumer prices. For further interpretation, see Figure 6.3.

In general, we find no significant effects of lagged fertility on changes in bond yields, although we estimate the coefficients less precisely than we do for changes in rent-price ratios. Most importantly, the large reductions we find in rent-price ratios for fertility lags between 20 and 30, do not appear in bond yields. For older ages, both bond yields and rent-price ratios show similar trends, with higher bond yields for cohorts around age 60, but these effects are insignificant for the bond yield.

Table 6.6 reports modified regression results for Eq. (6.1), with changes in rentprice ratios (Columns 1-2) and bond yields (Columns 3-4) as dependent variables, and 
fertility 60-64 years ago as an additional independent variable. As expected, fertility 23-27 years ago negatively predicts changes in rent-price ratios, while fertility 60-64 years ago positively predicts yields. Most importantly, these effects do not change when we do not control for changes in interest rates (Column 2). Correspondingly, Columns 3 and 4 confirm that lagged fertility does not significantly predict changes in bond yields. The coefficients on lagged fertility are also much smaller in size compared to Columns 1 and 2, suggesting a lack of statistical power does not merely drive their insignificance. In short, these findings suggest that changes in demographic demand primarily influence housing risk premia.

Table 6.6: Results for Lagged Fertility and Bond Yields.

\begin{tabular}{lcccc}
\hline \hline & \multicolumn{4}{c}{ Dependent variable: } \\
\cline { 2 - 5 } & \multicolumn{2}{c}{$\Delta_{5}\left(r_{t}-h p i_{t}\right)$} & \multicolumn{2}{c}{$\Delta_{5} i_{t}$} \\
& $(1)$ & $(2)$ & $(4)$ \\
\hline Fertility: $F_{t-23}$ & $-4.941^{* * *}$ & $-4.720^{* * *}$ & 0.932 & 1.266 \\
& $(0.954)$ & $(1.073)$ & $(1.599)$ & $(1.529)$ \\
Fertility: $F_{t-60}$ & $3.981^{* *}$ & $4.441^{* * *}$ & 1.857 & 1.697 \\
& $(0.694)$ & $(0.880)$ & $(1.368)$ & $(1.161)$ \\
Bond yield: $\Delta_{5} i_{t}$ & $0.242^{* * *}$ & & & \\
& $(0.060)$ & & & \\
Constant & Yes & Yes & Yes & Yes \\
Controls & Yes & Yes & Yes & No \\
\hline Observations & 284 & 284 & 285 & 285 \\
$\mathrm{R}^{2}$ & 0.502 & 0.421 & 0.072 & 0.027 \\
Adjusted $\mathrm{R}^{2}$ & 0.483 & 0.402 & 0.042 & 0.020 \\
Residual Std. Error & 0.103 & 0.110 & 0.170 & 0.172 \\
F Statistic & 27.469 & 22.176 & 2.372 & 3.851 \\
\hline \hline Note: & & $* \mathrm{p}<0.1 ; * * \mathrm{p}<0.05 ;{ }^{* * *} \mathrm{p}<0.01$ \\
\hline
\end{tabular}

Notes: ${ }^{*} \mathrm{p}<0.1 ;{ }^{* *} \mathrm{p}<0.05 ;{ }^{* * *} \mathrm{p}<0.01$. These regressions estimated the impact of lagged fertility on fiveyear changes in rental yields (Column 1-2) and bond yields (Columns 3-4), estimated for the time period from 1627-1913. Fertility observations start and end 60 years earlier. Between parentheses, Newey-West standard errors using a lag-length of five years, are provided.

We see two potential reasons for this finding. First, the lack of any effect for young cohorts could simply result from the fact that young adults increasingly start buying real estate, but are not yet active in other asset markets because they have accumulated few wealth to begin with. As a result, bond yields only could only change by limited amounts. Second, the fact that bond yields do not decrease for birth cohorts corresponding to seniors, could result from the fact that bond sales from old individuals that have recently died outweigh the increased demand from old individuals that 
are still alive, and increase their bond exposure.

It is practically impossible to establish the magnitude of these channels, because there is barely any data available on the number of transactions in the bond market. As a result, it is also not possible to link transactions to the ages of buyers and sellers. The relatively limited data that is available on the bond market also implies we should be careful in interpreting the estimated effects.

Finally, the series of bond yields is based on a comparatively small set of total transactions (Gelderblom and Jonker, 2011) and combined with several other sources, and because the market for bonds operated very differently than the market for real estate, it is possible this yield series is not entirely representative. We thus should be careful in drawing strong conclusions about the impact of demographic changes on bond prices.

\section{B Supplementary Tables and Figures}

Table 6.7: Statistics Rental Value Regressions.

\begin{tabular}{|c|c|c|}
\hline & \multicolumn{2}{|c|}{ Dependent variable: } \\
\hline & \multicolumn{2}{|c|}{ log Rental Value } \\
\hline Constant & No & Yes \\
\hline Age FE & Yes & Yes \\
\hline Profession FE & No & Yes \\
\hline Marital Status FE & No & Yes \\
\hline Observations & 17,339 & 12,738 \\
\hline $\mathrm{R}^{2}$ & 0.674 & 0.487 \\
\hline Adjusted $\mathrm{R}^{2}$ & 0.672 & 0.463 \\
\hline Residual Std. Error & 2.948 & 0.642 \\
\hline F Statistic & 360.163 & 19.824 \\
\hline
\end{tabular}

Notes: This table contains the summary statistics from the rental value regressions. The dependent variable in these regressions is the log rental value of a property in 1832, with as independent variables agedummies corresponding to the inhabitants of each property in 1851. The regression in Column 1 does not use a constant, the regression in Column 2 does use a constant and additionally controls for the profession of the main tenant of each property and his or her marital status 
Table 6.8: Transaction Prices by Age.

\begin{tabular}{|c|c|c|c|c|}
\hline & \multicolumn{4}{|c|}{ Dependent variable: } \\
\hline & \multicolumn{2}{|c|}{ log Purchase Price } & \multicolumn{2}{|c|}{ log Sales Price } \\
\hline & (1) & $(2)$ & (3) & (4) \\
\hline Years since Marriage & $\begin{array}{c}0.003^{* * *} \\
(0.001)\end{array}$ & $\begin{array}{c}0.003^{* * *} \\
(0.001)\end{array}$ & $0.004^{* * *}$ & $0.003^{* * *}$ \\
\hline Constant & $\begin{array}{c}7.950^{* * *} \\
(0.028)\end{array}$ & $\begin{array}{c}7.511^{* * *} \\
(0.172)\end{array}$ & $\begin{array}{c}7.859^{* * *} \\
(0.033)\end{array}$ & $\begin{array}{c}7.125^{* * *} \\
(0.179) \\
\end{array}$ \\
\hline Year FE & No & Yes & No & Yes \\
\hline Observations & 2,799 & 2,799 & 2,848 & 2,848 \\
\hline $\mathrm{R}^{2}$ & 0.003 & 0.073 & 0.007 & 0.061 \\
\hline Adjusted $\mathrm{R}^{2}$ & 0.003 & 0.052 & 0.007 & 0.040 \\
\hline Residual Std. Error & 1.065 & 1.039 & 1.076 & 1.057 \\
\hline F Statistic & 9.324 & 3.529 & 20.064 & 2.960 \\
\hline
\end{tabular}

Notes: This table reports the output of a regression of log transactions prices on the number of years that has passed since marriage, for the subset of unique buyers (Columns 1-2) and sellers (Columns 3-4) used in Figure 6.6. Average housing values increase by about $0.35 \%$ per year since marriage. This effect is robust to including time fixed effects (Column 2 and 4 ). ${ }^{*} \mathrm{p}<0.1 ;{ }^{* *} \mathrm{p}<0.05 ;{ }^{* * *} \mathrm{p}<0.01$ 
Figure 6.8: Log Housing Demand by Age (1851, Amsterdam), with controls

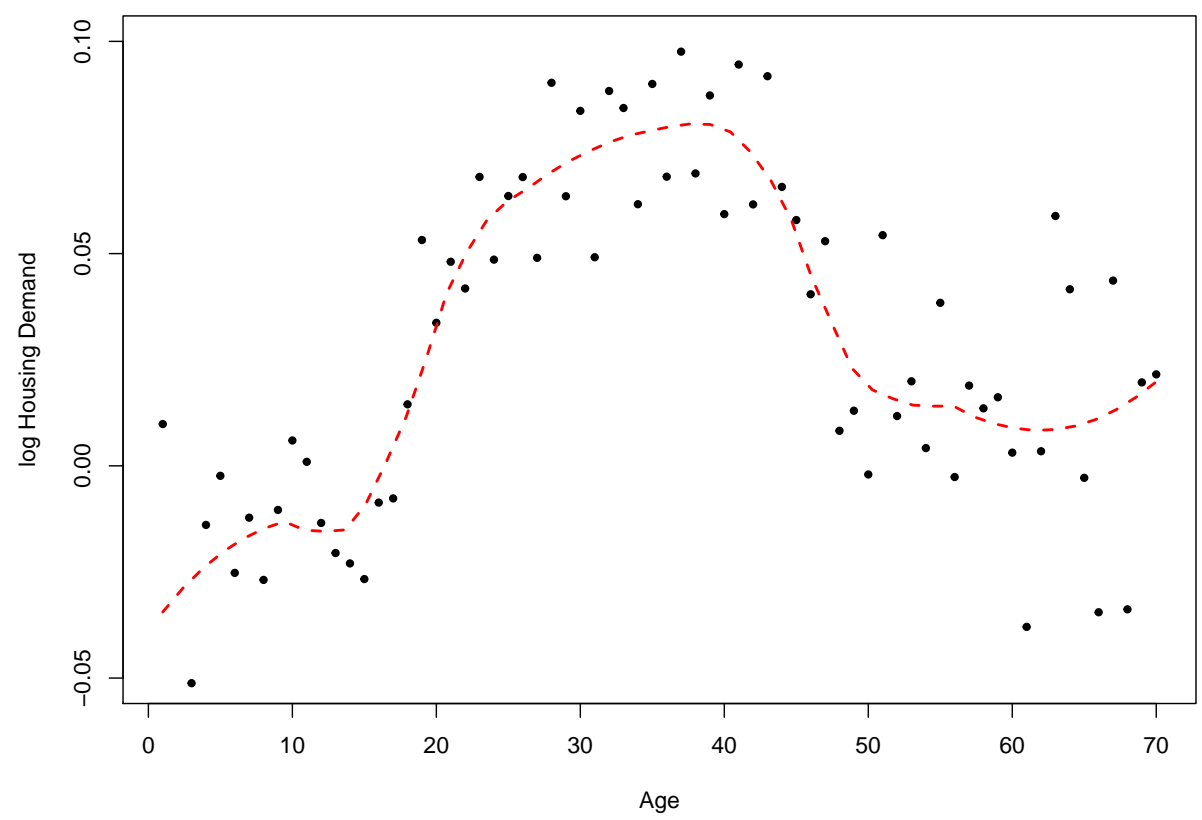

Notes: This figure plots the annual coefficients of a regression of property log rental value on agedummies for each inhabitant, controlling for the profession and marital status of the main tenant. Summary statistics are in Table 6.7. The coefficients are substantially lower than those in 6.5 due to the presence of a constant. The age-demand pattern is similar though. Standard errors are between $1-2 \%$ up to age 50 , and increase to $4 \%$ between age 50 and 70 . We exclude ages after age 70 due to a low number of observations. For reference, we plot a loess curve through the points (quadratic, span $=0.3$ ) 
Figure 6.9: Lagged Fertility and Rent Prices (Non-Overlapping).

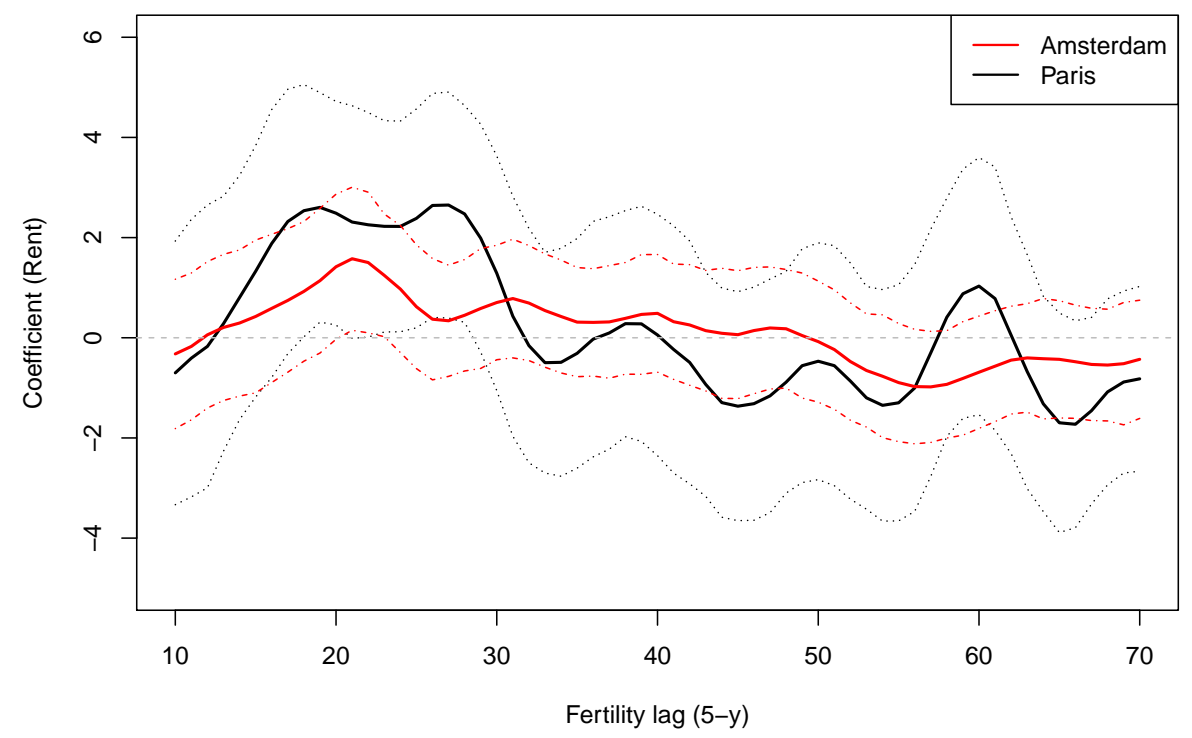

Figure 6.10: Lagged Fertility, Rental Yields and House Prices (Non-Overlapping).

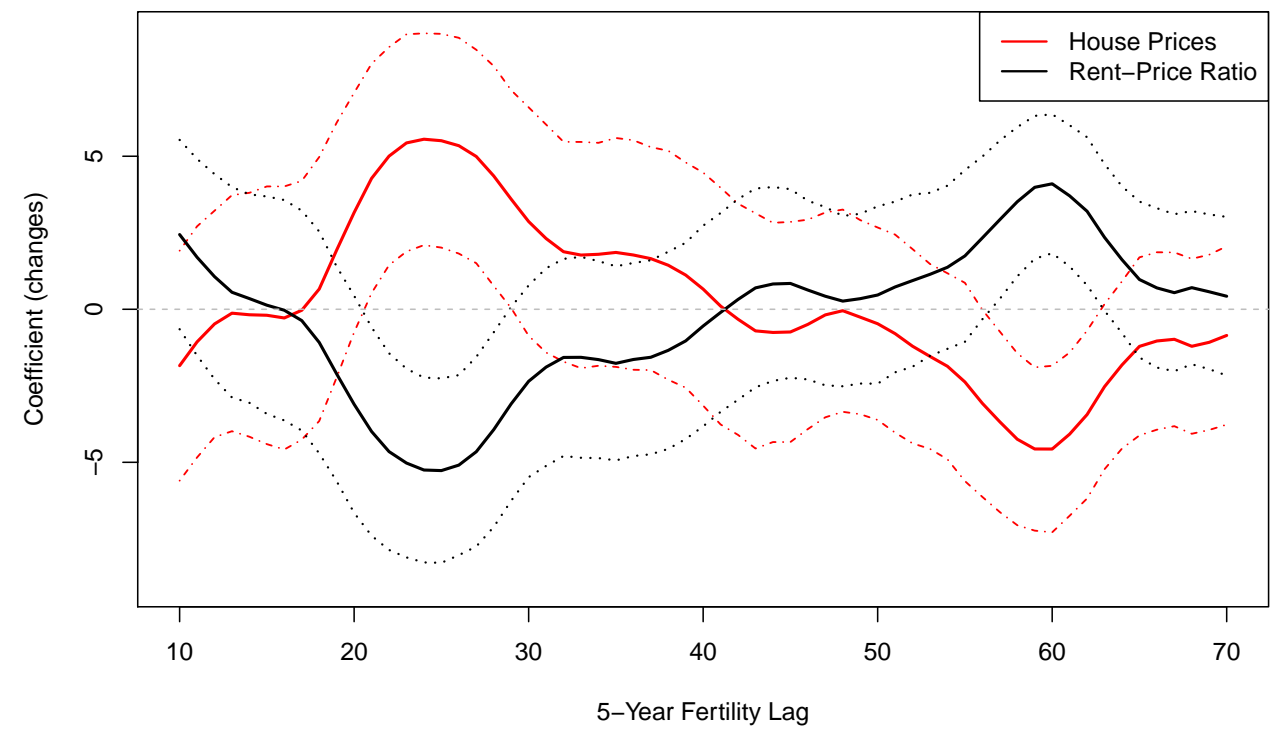

Notes: These figures are constructed similar to Figure 6.2 and 6.3, except that the estimates are obtained using regressions that do not contain overlapping observations. The coefficients and confidence intervals in the figure are based on the average of five non-overlapping regressions, with the starting year shifted by one year for each regression 
Figure 6.11: Lagged Fertility and Rent Prices (3-Year Changes).

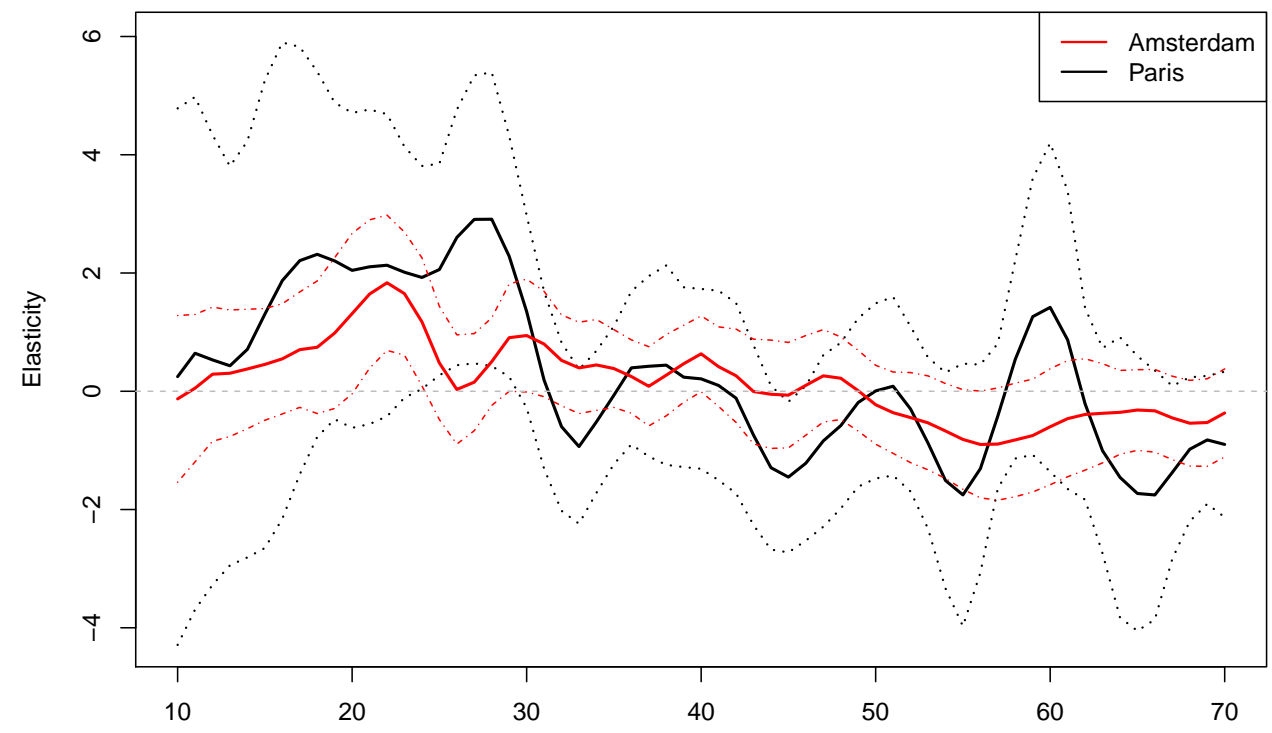

Figure 6.12: Lagged Fertility, Rental Yields and House Prices (3-Year Changes).

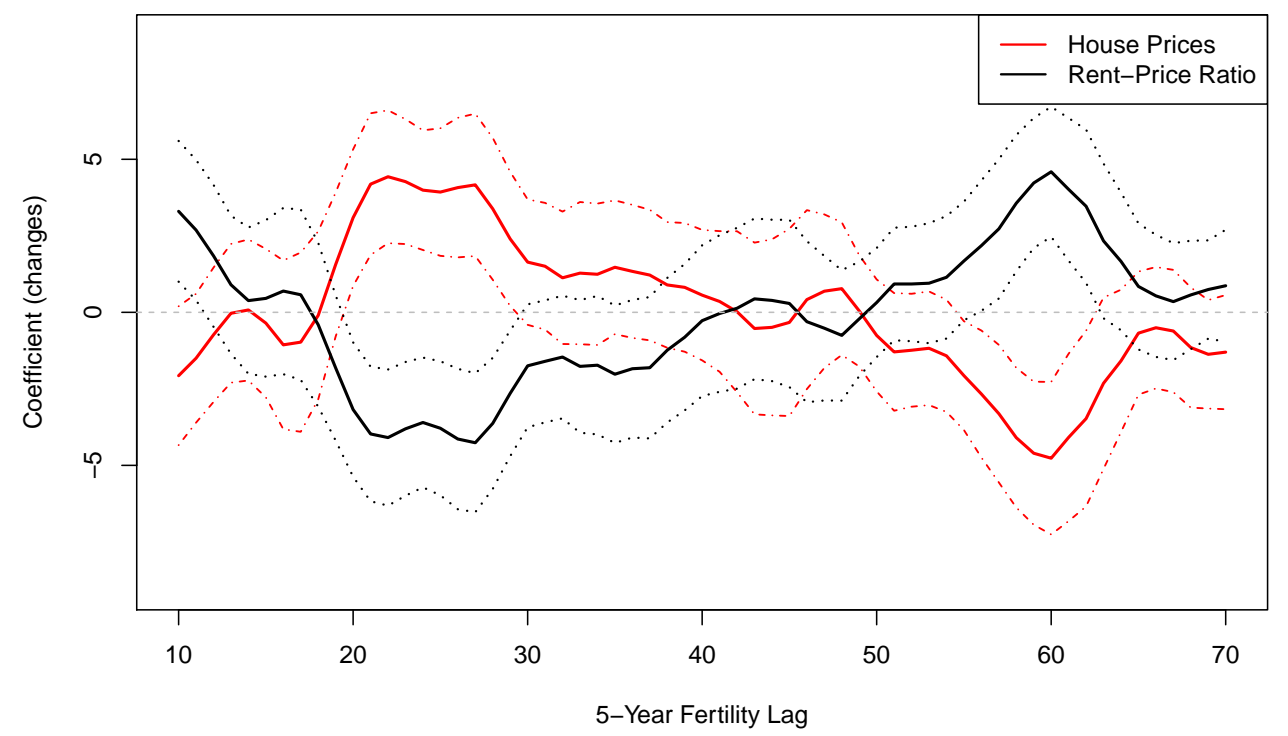

Notes: These figures are constructed similar to Figure 6.2 and 6.3, but use 3-year changes instead of 5-year changes. The lag length in the Newey-West procedure is increased to 10 years 
Figure 6.13: Lagged Fertility and Rent Prices (10-Year Changes).

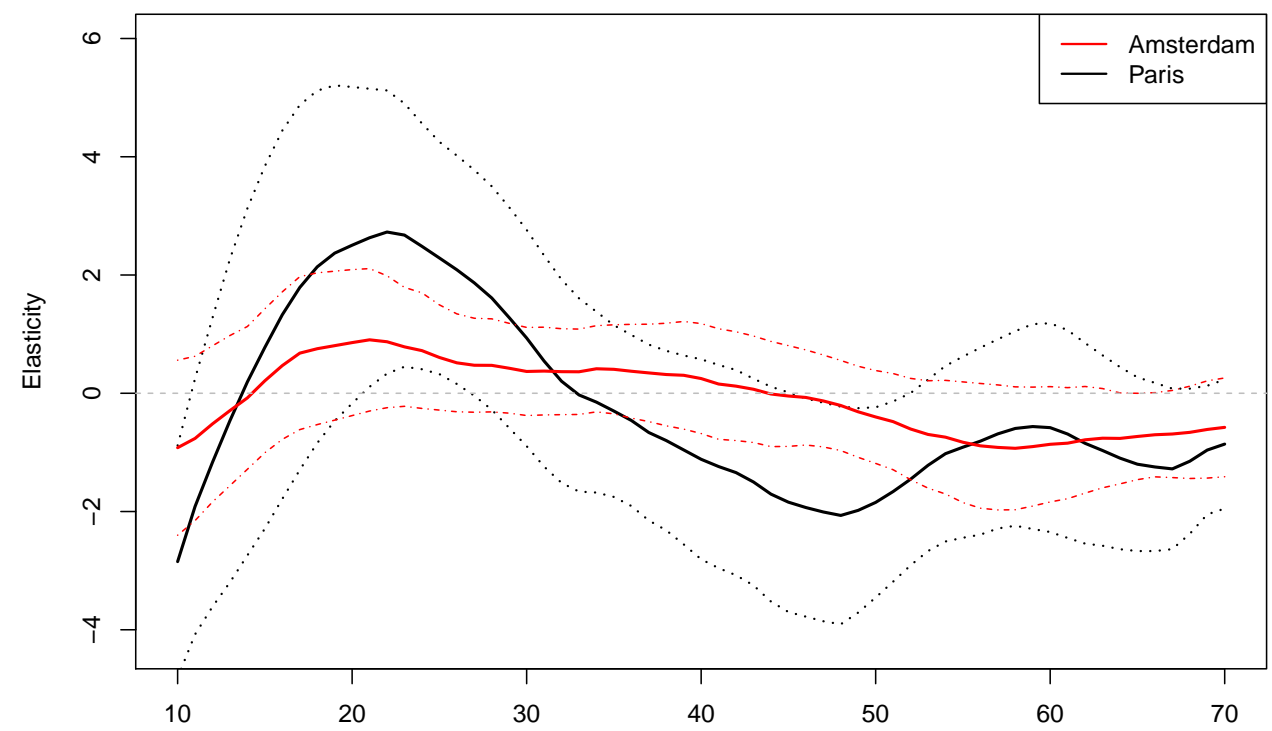

Figure 6.14: Lagged Fertility, Rental Yields and House Prices (10-Year Changes).

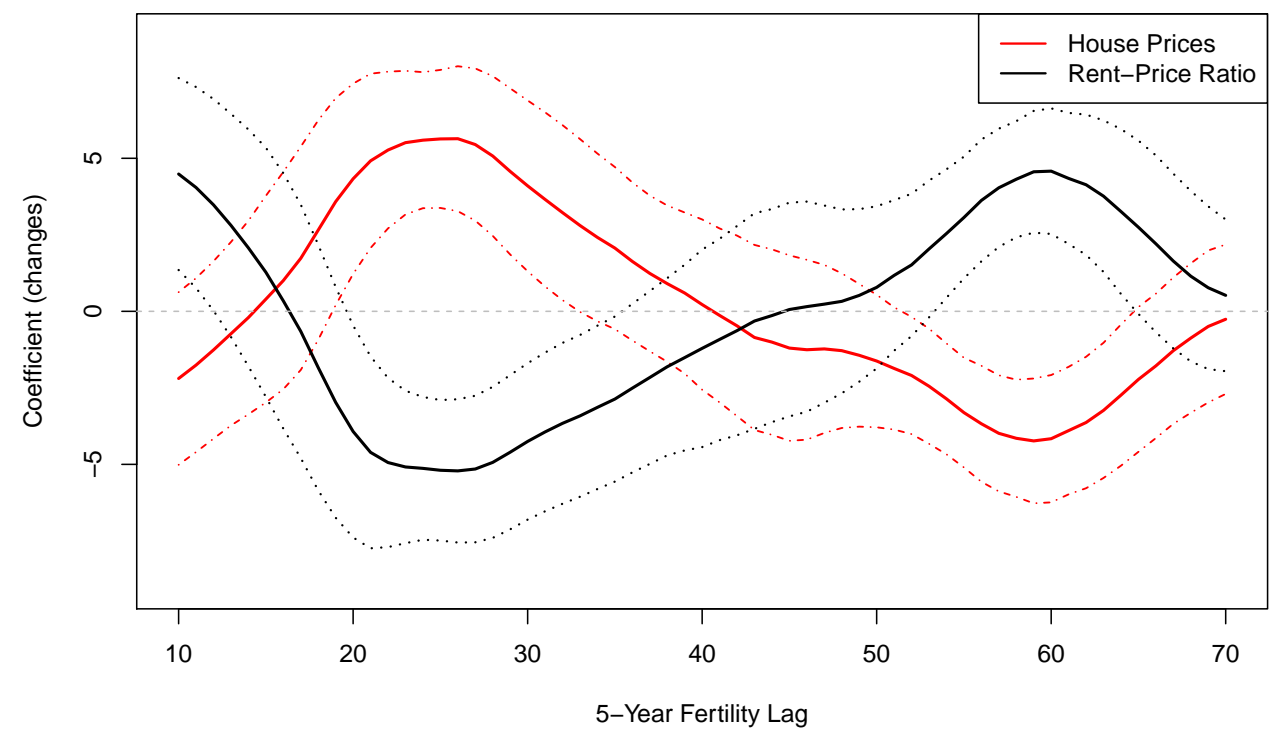

Notes: These figures are constructed similar to Figure 6.2 and 6.3, but use 3-year changes instead of 5-year changes. The lag length in the Newey-West procedure is increased to 10 years 
Figure 6.15: Lagged Fertility and Rent Prices (Growth Only).

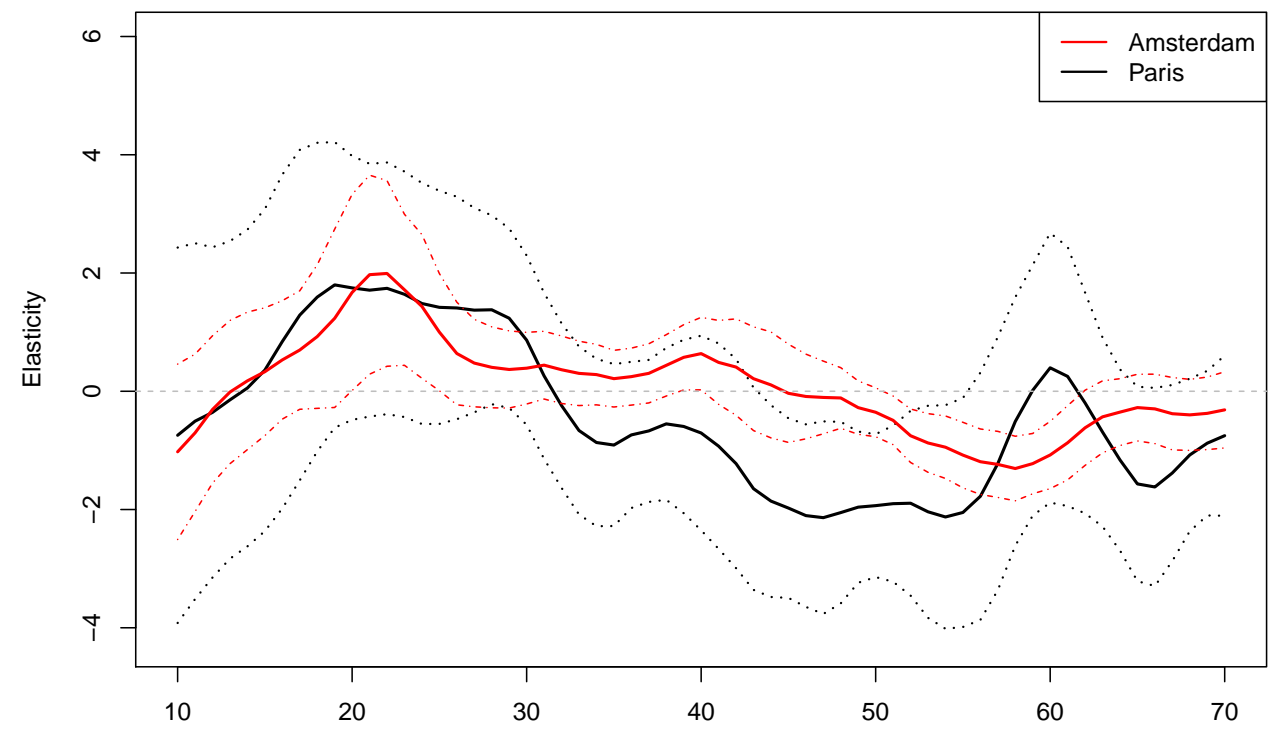

Figure 6.16: Lagged Fertility, Rental Yields and House Prices (Growth Only).

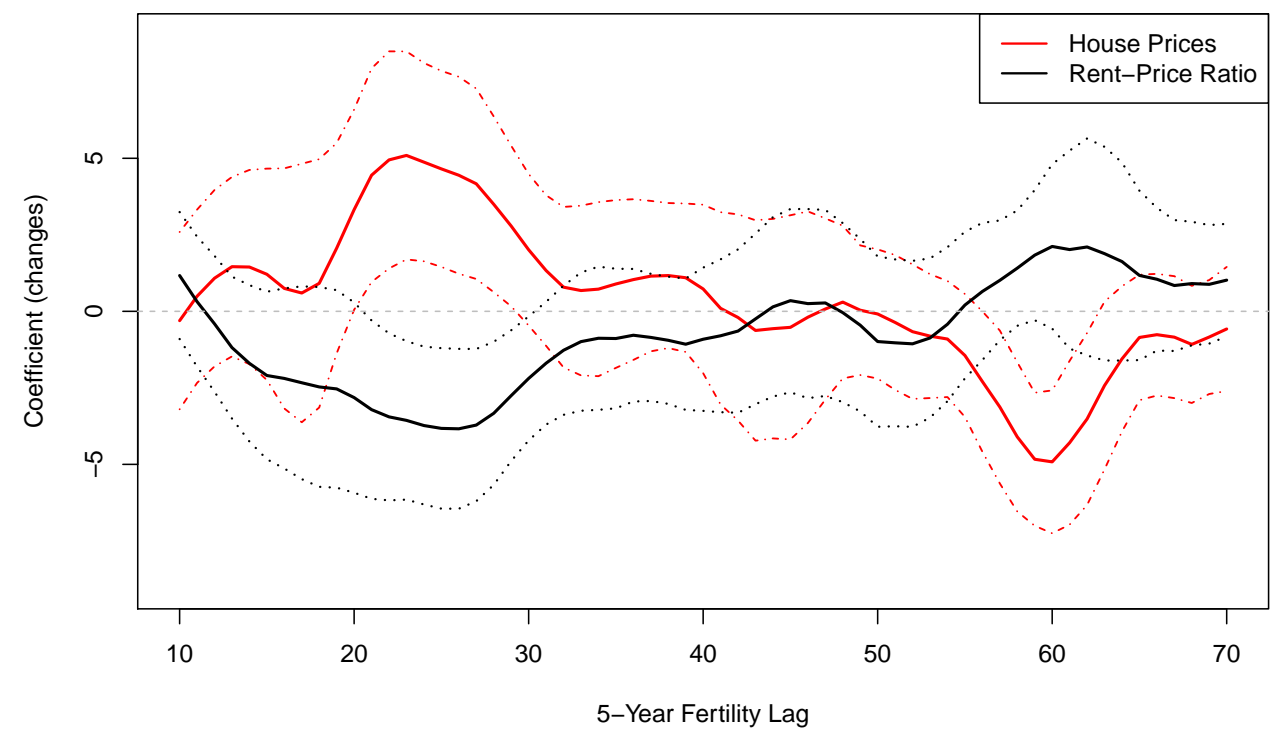

Notes: These figures are constructed similar to Figure 6.2 and 6.3, but instead only use observations that correspond to periods of positive population growth. 


\section{Chapter 7}

\section{Housing Markets in a Pandemic*}

\subsection{Introduction}

The recent outbreak of COVID-19 has brought the globalized world to a standstill, costing the lives of hundred-thousands of people and keeping millions in 'lockdown' in their homes. Although its economic effects are still unfolding, one of the many affected sectors is the housing market. In some heavily-affected cities, early evidence suggests that prices and demand have been falling rapidly, while other areas have not, or not yet, experienced such effects. For example, prices have been falling rapidly in Manhattan, while demand in sub-urban areas around New York has increased. ${ }^{2}$

However, there is still significant uncertainty surrounding the short-term impact of COVID-19 on urban housing markets, and at this point in time it is not yet possible to determine whether the pandemic will have any lasting impacts on future growth trajectories of cities and their housing markets. In general, assessing the impact of epidemics on housing markets, both over the short- and long-term, is challenging. While epidemics typically arrive exogenously, they are also infrequent, such that data availability is limited. Experts have argued that the current pandemic is the worst since the Spanish Flu, which happened over a century ago (Ferguson et al., 2020). Because major epidemics affect the lives of nearly everyone, it is also difficult to separate causal effects from underlying time trends within a single epidemic.

The goal of this paper is to estimate the impact of pandemics on urban housing markets over the short- and long-term. To do so, we exploit outbreaks of cholera in Paris (1832 and 1849) and the plague in Amsterdam (ten outbreaks, 16th-17th centuries). Each of these outbreaks resulted in high mortality and significant economic disruption. Importantly, Amsterdam and Paris already had highly-developed housing markets, and unique micro-level data survived in the archives of both cities, allowing us to track mortality and the developments in the housing market following an epidemic. We focus on cholera and the plague, because the other two major pandemics for which we have data, the smallpox epidemic in the 1870s and the Spanish Flu in

\footnotetext{
${ }^{*}$ This chapter is co-authored with Marc Francke (University of Amsterdam).

2'New Yorkers Are Fleeing to the Suburbs: “The Demand Is Insane”', New York Times, August 31, 2020.
} 
1918, were directly linked to wars that also affected the housing market. We show that these epidemics depressed rent and sales prices in the short-term, with the effects on sales prices being particularly large in the first six months of an epidemic, and in heavily affected areas. However, both Amsterdam and Paris were very resilient to these outbreaks, with population and house price growth quickly reverting to prior trends.

We start the paper by providing a descriptive overview of the outbreaks that affected Amsterdam and Paris, and how they affected society. In both Paris and Amsterdam, the outbreaks arrived in an era of rapid urban growth. Paris grew rapidly in the 19th century, and Amsterdam experienced its Golden Age when the outbreaks hit the city. Similar to today, the epidemics had a large impact on daily life and the economy, and hit poor areas with significant urban crowding more than wealthier areas. Very recent evidence has also suggested this for the current pandemic (Borjas, 2020; Almagro et al., 2020). One important difference is that these pandemics were much deadlier, killing on average a few percent of the population. In Paris, the cholera pandemics did follow shortly after the revolutions of 1830 and 1848, and in the paper we address how we rule out that our effects are driven by revolutionary activity.

To start our empirical analysis, we use existing rent and house price indices to evaluate how aggregate prices were affected by an epidemic. We find that after an outbreak aggregate house prices fell each year by about six percent until one year after the end of an epidemic. We find the same pattern for rent prices, but these declined only by three percent per year. Confirming the exogenous arrival of pandemics, we do not find any significant trends in house and rent price growth in the years prior to an epidemic.

To provide a more detailed picture of the impact of the outbreak on different segments and parts of the housing market, the main specifications in this paper aim to estimate the impact of the outbreaks over the very short-term and across neighborhoods. For Amsterdam, our data cover multiple outbreaks and a sufficient number of transactions to estimate short-term price effects. Controlling for annual price trends, we find that properties sold within six months after the outbreak of an epidemic realized about $13 \%$ lower prices. This effect is robust when adjusting for month fixed effects, types of sale, and changes in the composition of properties changing hands. Importantly, this effect is temporary: it is only present in the first six months of an epidemic.

For Paris, our data only cover two outbreaks, but contrary to Amsterdam we do possess much more information about the geographic dispersion of the epidemic. We use this to study whether heavily affected neighborhoods experienced worse price declines than other neighborhoods. We find that a doubling of cholera mortality reduced neighborhood-level house price growth following the epidemic by about ten percent, but that this decline did not persist over time. After the 1849 outbreak, which affected neighborhood prices most heavily, prices in heavy-affected areas recovered to the levels of less-affected areas in about five years. These effects hold when we control for annual time trends in city-wide prices, and for differences in neighborhood poverty and revolutionary activity.

Are these historical estimates still relevant today? On the one hand, these epi- 
demics might be the closest comparison to the current situation in major cities. The pandemics we study resulted in a large number of deaths and caused major disruptions to economic activity. They happened in growing cities with a substantial flow of migrants and large buy-to-let property markets. On the other hand, today's urban economies are different from historical Amsterdam and Paris, and the current pandemic will almost certainly result in lower mortality rates than the pandemics we study. Because each epidemic and its context are different, it is difficult to extrapolate point estimates from previous outbreaks.

Accordingly, related literature on the impact of epidemics on house prices differs in the estimated coefficients. For example, for the less severe SARS outbreak in Hong Kong in 2003, Wong (2008) estimated a small house price decline of only 1.5 percent. For the current pandemic, Ling et al. (2020) find that a one standard deviation increase in daily local COVID-19 cases depressed REIT (real estate investment trust) returns by 0.24 percent the following day, but these effects can be mitigated if localities take nonpharmaceutical interventions. REITs themselves lost significant value, with a price drop of 49 percent in March 2020. Given that regular housing market data tends to be less directly available, to the best of our knowledge there are not yet any studies that look at the impact on house prices and activity in the residential housing market, as we do in this paper.

Relative to these studies, the main contribution of our paper is that we cover multiple epidemics and also study the recovery of prices over longer periods of time and across neighborhoods, and the potential long-term impacts of epidemics on these cities and their housing markets. We find that despite sizeable effects on property prices in the short-term, housing markets recovered quickly from the epidemics that we study.

In the final part of the paper, we aim to provide potential explanations for the empirical facts that we document in the main body of the paper. We highlight three important potential mechanisms in the response of urban housing markets to a major pandemic, which likely hold more generally. First, the large short-term impact of epidemics on house prices relative to rent prices suggests the demand for housing investment falls more than the demand for housing services (measured by rent prices). One channel through which this can happen is that epidemics temporarily increase risk perception or risk aversion and corresponding risk premia, in line with literature on other disasters. ${ }^{3}$ The fact that this increase is temporary could help to explain why prices fall more than rents in the short-term. Uncertainty regarding future rent prices could play a role as well.

Second, we find that house and rent price growth quickly returned to their initial trends, implying Paris and Amsterdam were highly resilient to shocks caused by epidemics, despite being more affected than their national populations. One important reason is that population losses due to epidemics were quickly compensated by increasing migration. As a result, the demand for housing consumption was not strongly

\footnotetext{
${ }^{3}$ Existing literature has shown that exposure to major natural disasters (Cameron and Shah, 2015; Goetzmann et al., 2016) or violence (Callen et al., 2014) can result in increased risk aversion or pessimism. Epidemics might have similar consequences.
} 
affected by epidemics. This finding contributes to a literature documenting the resilience of large cities to major shocks. Existing work has focused on the physical destruction of cities due to bombing (Davis and Weinstein, 2002; Brakman et al., 2004; Miguel and Roland, 2011), general warfare (Sanso-Navarro et al., 2015), or city fires (Hornbeck and Keniston, 2017). Rather than destroying physical capital, pandemics result in significant losses to human capital: the death of a substantial part of the population.

Finally, the recovery of Parisian house prices, even in heavily-affected neighborhoods that experienced large price drops, highlights the role of urban policy when cities are exposed to major shocks. In Paris, the outbreak of cholera proved to be a catalyst for significant urban redevelopment, as the outbreak made the government realize that the clogged and dense areas of Paris were detrimental to health. The government started significant urban renovations that improved local amenities, particularly in heavily affected areas. We find these coincided with recovering property prices. Hornbeck and Keniston (2017) suggest a similar mechanism. They find that the Great Boston Fire of 1872, which burnt down many old low-quality buildings, paved the way for a higher-quality housing stock, and accordingly increased land values. In related work, Ambrus et al. (2020) exploit the London Broad Street cholera outbreak in 1854 to show the epidemic created a pocket of poverty in the city, persistently lowering rents in the areas affected by the outbreak. This outbreak was confined to a single neighborhood, and it did not result in large changes in infrastructure or housing construction. The different policy response to the London epidemic might explain why the findings of Ambrus et al. (2020) differ from those in our study and in Hornbeck and Keniston (2017).

Note that the focus of our paper is different from that of Ambrus et al. (2020). Ambrus et al. (2020) exploit the cholera outbreak to estimate how local income shocks affect neighborhood sorting and wealth over the longer-term, and achieve identification from the fact that the epidemic was highly local. The contribution of our paper is that we study the housing market impacts of epidemics that effect an entire city and its economy, focusing specifically on the housing market. Inherent to a disastrous pandemic is that everyone is exposed to the health and economic consequences of the outbreak, although in varying amounts. This makes it difficult if not impossible to observe a control group, but also implies that the outbreak will have larger and likely differentiated impacts on the dynamics in housing markets relative to more concentrated outbreaks.

\subsection{Historical Background}

\subsubsection{Plague in Amsterdam}

In the 16th and 17th centuries, outbreaks of plague frequently ravaged large parts of Europe (Alfani, 2013), and also hit Amsterdam. To obtain mortality data for Amsterdam in this period, we use burial registers from parishes and cemeteries provided to us by the Amsterdam city archives (from 1554). Because parish registers are missing 
in some periods, we construct relative estimates of mortality. We compute these by dividing per parish or cemetery in each month and year the number of deaths relative to the preceding and following five years. To aggregate data into a single statistic, we take the average of all parishes and cemeteries, weighted by the number of deaths in each parish or cemetery.

Data on plague outbreaks in Amsterdam comes from Noordegraaf and Valk (1996), which lists each year for which historical sources mention a plague outbreak. They do not provide information on the severity or timing of these. In this paper, we will use two mortality measures. At the annual level, we define a year to be a plague year if annual excess mortality is higher than $25 \%$ and Noordegraaf and Valk mention a plague year. To be more precise about the start of plague outbreaks, we construct a monthly measure. We define the start of a plague epidemic if, for the first time, excess mortality in a given month exceeds $100 \%$, and Noordegraaf and Valk mention a plague outbreak in the same year. We count epidemics that last for more than a year only in the month of the first outbreak.

Figure 7.1 plots the estimated evolution of annual mortality in Amsterdam between 1554 and 1700. Nearly all major spikes in annual mortality coincide with the ten different periods we identified as major plague epidemics. ${ }^{4}$ The duration of a plague outbreak varied between two months and two years, with an average of nine months. Major plague epidemics were deadly; the largest epidemics wiped out over ten percent of the total population. Potentially, this number is even higher due to the under-registration of deaths during severe outbreaks (Noordegraaf and Valk, 1996).

These outbreaks often ravaged other parts of the Dutch Republic and Europe at the same time, but it remains unclear why and how plague reached Amsterdam exactly in these years. Because of the high levels of urbanization, trade activity and frequent warfare, diseases could spread quickly in the Dutch Republic (Rommes, 2015). However, trade activity and war cannot explain the exact timing of these outbreaks, nor the disappearance of plague after 1667, because they were near-permanent features of the Dutch economy. However, while the Dutch Republic was engaged in war for the majority of time in this period, war activity did not happen within or close to Amsterdam except in the 1570s. Most likely, the timing of the outbreaks was thus exogenous to the state of the Amsterdam economy and housing market.

Although it is hard to compare mortality estimates over time and across space, plague likely affected Amsterdam more heavily than other places in the Low Countries (see Curtis, 2016). While people died of the plague across all classes, poor people seem to have been more affected. For example, during plague months relative mortality on the Karthuizerkerkhof, the cemetery in the poor Jordaan area, was about $50 \%$ higher than on other cemeteries, although this effect varied substantially across epidemics. Unfortunately, the data do not allow for a more detailed breakdown of mortality by neighborhood, because the burial records do not report on addresses of the death.

The Amsterdam plague outbreaks resulted in widespread death and despair, and

\footnotetext{
${ }^{4}$ Based on our definition, epidemics started in 1557, 1573, 1601, 1617, 1624, 1635, 1652, 1655, 1663, and 1666. The 1666 epidemic was the smallest of these.
} 
Figure 7.1: Mortality per 1000 Inhabitants.

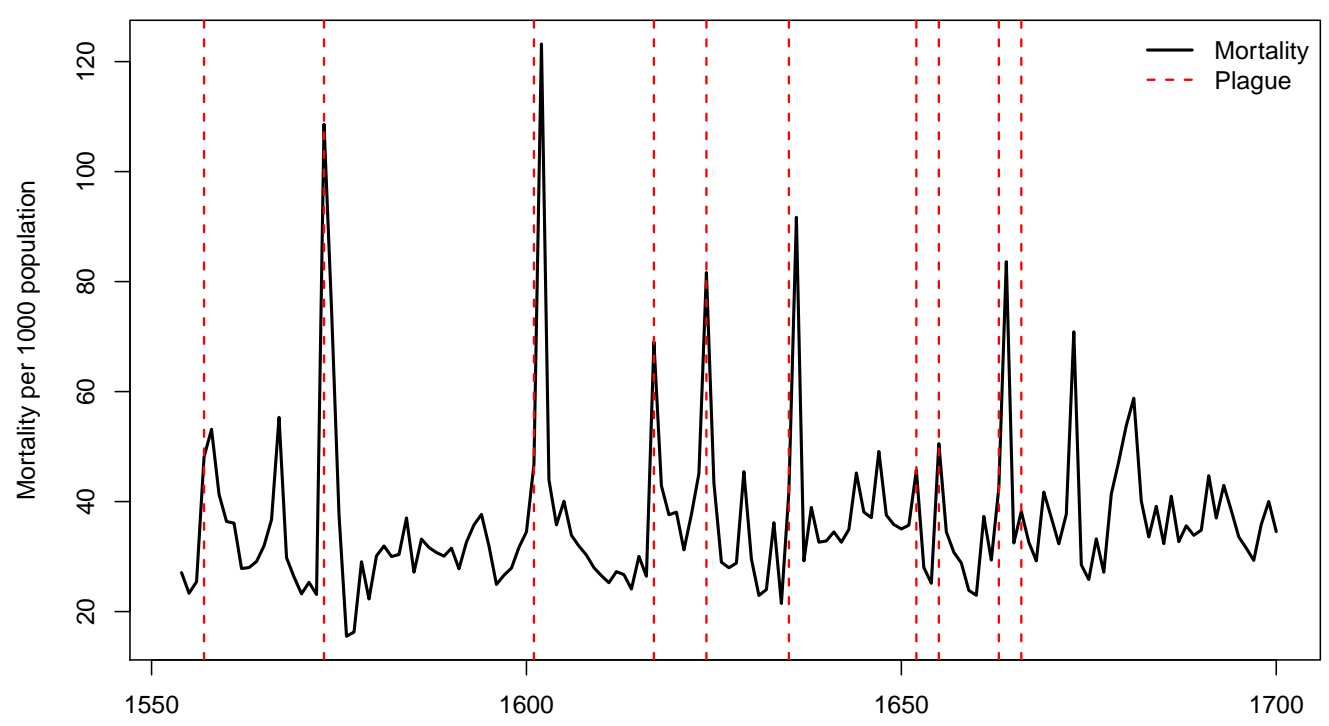

Notes: These figures plot the estimated total mortality per 1000 inhabitants in Amsterdam. The dashed line represents the starting year of an identified plague epidemic. To convert these into approximate death rates, we extrapolated based on mortality rates reported in Van Leeuwen and Oeppen (1993) for the late 17 th century.

also affected the economy. Mooij (2001) writes that during plague outbreaks "the merchant city became a ghost city: trade and business activity came to a halt, market squares were empty, and shops and workshops closed their doors." Sometimes this was the result of direct government interventions. Noordegraaf and Valk (1996) mention that the plague law of 1558 prohibited people from visiting markets, inns, churches, and other places where many people gathered. These had real economic consequences: Noordegraaf and Valk quote owners of inns who complained they lost most of their income because travelers avoided Amsterdam due to the epidemic. How large these impacts were is nonetheless hard to identify. With Amsterdam's economy build on trade, it seems unlikely interventions lasted very long. For example, De Vries (1981) writes that, to his surprise, passenger volumes on barges in Holland were barely affected in the years around epidemics.

\subsubsection{Cholera in Paris}

Cholera arrived in Paris for the first time in March 1832, and the outbreak came unexpectedly. As late as 1831, when cholera started breaking out all across Europe, the famous French doctor Baron de Larrey (1831) wrote that "the topographic situation of France is so advantageous, that there is little reason to worry about the introduction of cholera-morbus in this country." However, within a month of the outbreak in March, the 'cholera-morbus' killed over 11,500 people in the city. The total death count of the epidemic amounted to more than 18,500 people or about 2.5 percent of the to- 
tal population. It took until March 1849 for the second epidemic to arrive. Although the outbreak spread less quickly than the initial epidemic in 1832, by the end of the epidemic in 1849 over 15,000 people had died, 1.5 percent of the total population.

Among the most vivid descriptions of the 1832 epidemic is that of German writer Heinrich Heine (1872). He describes the epidemic left the city in a quiet state of despair, with increased security measures and sanitary committees. But the epidemic also raised tensions across social classes, and stories went around quickly that the government had poisoned wells, fueling a rebellion in 1832 prominently described in Victor Hugo's Les Miserables. Tensions in Paris were already high before the outbreaks, following one to two years after the revolutions of July 1830 and February 1848. Although the outbreaks were exogenous to the state of the local Parisian economy, originating from abroad and affecting the entire French population, they thus did arrive in already turbulent times.

The outbreaks did not affect everyone equally. Building on the figures reported in the official government reports about the epidemics, Administration Générale de l'Assistance Publique (1850) and De Châteauneuf (1834), Figure 7.2 reports the mortality per neighborhood in Paris during both epidemics. Although cholera affected people of all ages and classes, the first outbreak of cholera, visible in Panel 7.2a, primarily affected the most central areas of the city, where up to six percent of the total population died. In these areas, the working class lived in a maze of narrow streets and over-populated, unhealthy homes (Le Mée, 1998). Even in better neighborhoods, the most impoverished alleys and streets were most affected. This is also reflected in housing values: our data show average house prices and rents were substantially lower in heavy affected areas.

Figure 7.2: Cholera Mortality per 1000 Inhabitants.



(a) Paris, 1832

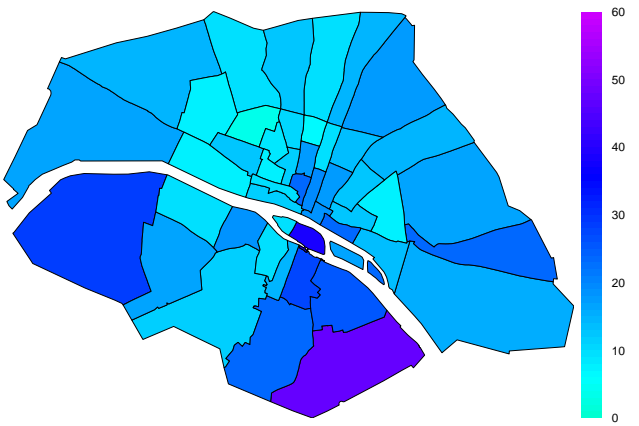

(b) Paris, 1849

Notes: These figures plot the cholera mortality per 1000 inhabitants in Paris. In both epidemics, in each neighbourhood 1 to 6 percent of population died. Boundaries are based on Vasserot quartiers. The correlation in neighbourhood mortality between epidemics is 0.5 .

The government recognized that there existed a close link between poor and dense neighborhoods and cholera mortality, although, unaware of the exact cause of cholera, 
they primarily believed such poor neighborhoods favored the development of miasmas (De Châteauneuf, 1834). This link was confirmed during the 1849 outbreak. Mortality levels were high in the working-class areas in the cities on the left bank but had gone down in the historical city center (Panel 7.2b), where much of the slum housing had been cleared (Le Mée, 1998).

\subsubsection{Urban Growth and the Housing Market}

One important element to understanding the impact of the epidemics on the Parisian and Amsterdam property market is that both cities were growing substantially in the decades around the epidemics.

From the late 16th century to the late 1660s, the period when most plague epidemics ravaged the city, Amsterdam's population grew from about 30,000 people in the 1580 s to over 200,000 people by 1670 , with no periods of population decline over 5 year horizons (Nusteling, 1985). This implied that population levels recovered quickly after outbreaks, although detailed data at the annual level is not available to track exactly how quick this recovery was. Economic historians have named this Dutch Golden Age the 'first round of modern economic growth' (De Vries and Van der Woude, 1997). Similarly, the population of Paris increased from about 600,000 in 1810 to almost about 1.7 million by 1860 Mairie de Paris (1967a). Only between 1846 and 1851, a period of crisis and cholera, population growth was halted temporarily. Crucial to the sustained growth of both cities were high levels of immigration.

The growth of these cities is also visible in the developments in aggregate property prices and rents. In Figure 7.3 we plot the evolution in rent prices and house prices in this period, together with vertical dashed lines that mark the price level just before the start of an outbreak. In both Paris and Amsterdam rent prices rise substantially over the studied period. This is not only the case in nominal terms, which is depicted in Figure 7.3, but also in real terms. In Amsterdam, rent prices and house prices do fall substantially after the 1660s, following the end of the Golden Age and a decline in population. The large increase in house prices relative to rent prices in the period before 1670, and the contraction afterwards is primarily the rate of falling interest rates in the Dutch Golden Age and increasing rates afterwards. In nearly all cases, epidemics coincided in both cities with a subsequent fall in house prices, but this pattern seems less consistent for rent prices.

Both Paris and Amsterdam already had highly-developed and active housing markets at this time. Most properties were buy-to-let properties owned by investors, with only a minority of the population owning its own house. ${ }^{5}$ In both cities, properties could be sold in private sales via search-and-matching, and in public auctions. These auctions were a transparent way for investors to gauge the state of the housing market, and they were used for a large fraction of housing sales. Some of these sales were foreclosures, but most were regular sales. ${ }^{6}$

\footnotetext{
${ }^{5}$ In 1562 in Amsterdam 31\% of properties were owner-occupied, and this reduced to $15 \%$ by 1805 (Korevaar, 2020). In Paris, home-ownership was only a few percent (Kesztenbaum and Rosenthal, 2017).

${ }^{6}$ In Paris, 36\% of properties were sold in auctions, and in Amsterdam this fraction was likely even
} 
Figure 7.3: Housing Prices and Rents Around Epidemics.

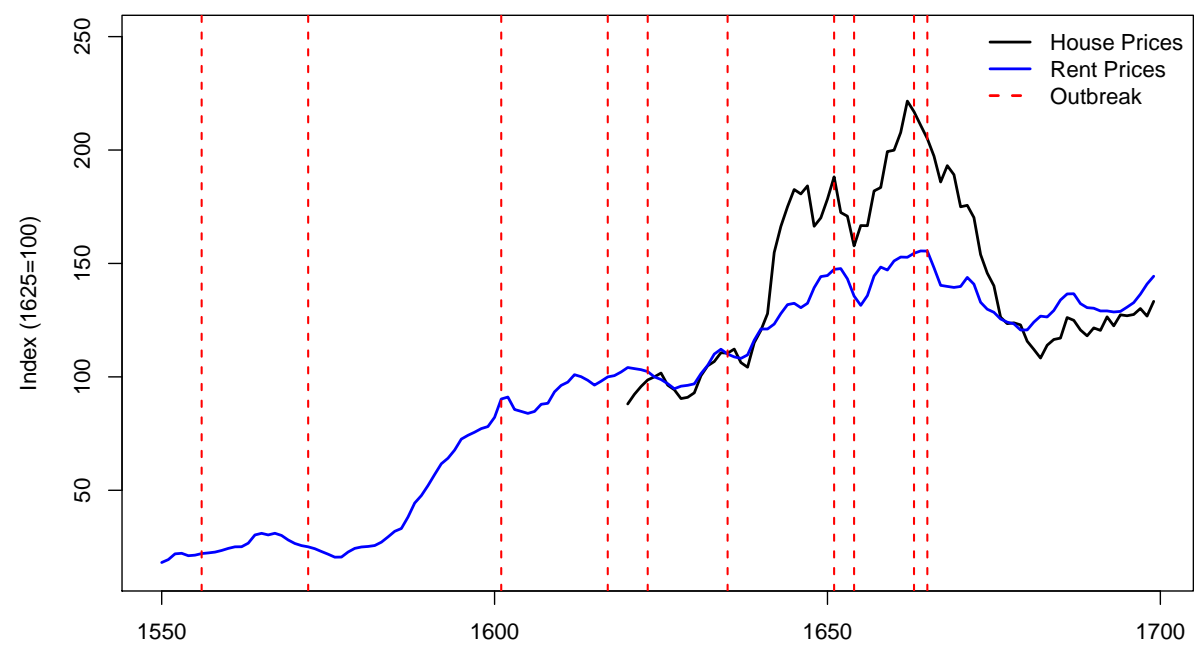

(a) Amsterdam

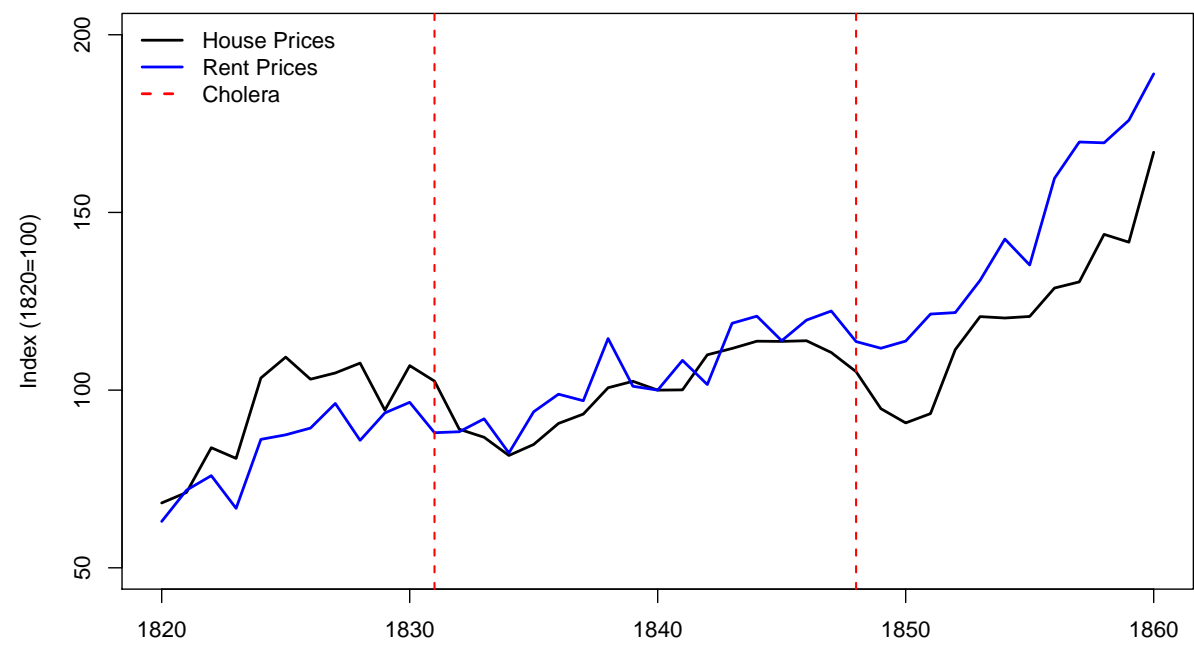

(b) Paris

Notes: These figures plot the evolution of house prices and rents in both Paris and Amsterdam, with the dashed line indicating the price level before an outbreak started. These indices are from Eichholtz et al. (2020b) for Amsterdam and Paris housing rents, and for house prices from (Eichholtz et al., 2020c, Paris) and (Francke and Korevaar, 2020, Amsterdam). The rent price indices cover 12 epidemics lasting together 17 years, and the house price indices cover eight epidemics lasting together ten years. The house price indices cover a smaller period because insufficient data is available to estimate an index before 1620 .

higher. For more detail, see Appendix 7.A. 


\subsection{Analysis}

Cholera and the plague caused significant mortality and economic disruption in Paris and Amsterdam. In this section, we analyze how these factors influenced house prices and rents. We refer the interested reader to 7.A for a broader discussion on the effects of the epidemics on other parts of the housing market.

\subsubsection{Data}

To estimate changes in house values and volume, we gather data on sale and rent prices from administrative records. For Amsterdam, we use mandatory governmental registrations of property purchases, provided by the Amsterdam city archives. This data provides information on 158,757 house transactions, both regular sales and foreclosure sales, between the late 16th century and 1811. Although registers are missing for some years, in particular in the 16th and 17th centuries, the registers that have survived do contain the universe of housing transactions in the period they cover. Transaction prices on regular sales were only recorded from 1637, implying the number of transaction prices is more limited before 1637. For our analysis, we use the repeatsales price pairs and aggregate index Korevaar (2020) identified.

For Paris, we use data from Eichholtz et al. (2020c) originating from the sommier foncier, a government register containing information on the universe of sale prices in Paris between 1809-1943. ${ }^{7}$ In total, we draw on a sample of 39,786 sales prices, covering 17,300 properties. We match the addresses in the data to their respective neighborhoods, in order to link housing transactions and rent prices to neighborhood mortality measures published in the official government reports.

To track developments in aggregate housing prices and rents, we use the indices of rent prices and house prices presented in Figure 7.3 for both cities (from Eichholtz et al., 2020b,c; Korevaar, 2020). These are repeat-sale or repeat-rent indices that mostly build on the same sources that we use, and we refer to their papers for more background on the transactions data. It is important to note that the rent price indices only use data from new rental contracts, coming from institutional investors (Amsterdam) or rentals for entire properties (Paris). They thus do reflect market conditions, at least at the annual level. As potential control variables, we use information on wages and consumer prices (Eichholtz et al., 2020a), and bond interest rates. For Amsterdam, we use Holland annuity bond yields (Gelderblom and Jonker, 2011), and for Paris French 5\% annuity bond yields from Hautcoeur and Riva (2018).

\footnotetext{
${ }^{7}$ This database also contains information on rent prices, but these do not correspond to new leases but actual rents. Given that rental contracts often lasted many years, current rents typically do not correspond to market conditions, so we exclude rents from our analysis.
} 


\subsubsection{Aggregate Impact on House Prices and Rents}

To assess the impact of the epidemics on aggregate house prices and rents, we start by estimating the following model:

$$
\delta_{j, t}=\alpha_{j}+\text { Epidemic }_{j, t} \beta_{1}+\text { Epidemic }_{j, t-1} \beta_{2}+x_{j, t}^{\prime} \gamma+\varepsilon_{j, t},
$$

where $\delta_{j, t}$ denotes the aggregate log house price return $\left(\Delta p_{j, t}\right)$ or log rent index return $\left(\Delta r_{j, t}\right)$ in city $j$ in year $t$. We will also consider a model where we look at the difference between changes in rents and prices: the implied change in gross rental yields. In all specifications we stack the Amsterdam and Paris data, assuming that the coefficients $\beta$ and $\gamma$ do not differ between the cities. Only the constant $\alpha_{j}$ varies over the cities.

Epidemic $_{j, t}$ is an annual dummy variable that takes the value of 1 if there is a severe epidemic of cholera or plague, and Epidemic ${ }_{j, t-1}$ is a dummy if there was an epidemic in the previous year (but not in the current year). $x_{j, t}$ is a vector of control variables, including changes in consumer prices and wages and interest rates. We also consider a model where we control for rent or house price growth in the three years around an epidemic, to detect potentially unobserved time trends. For each city, we only include data between ten years before the first epidemic (if available), and ten years after the final epidemic. Table 7.1 reports the estimation results.

For house prices, we document a reduction in house prices of about 0.055 (in logs) per year during an epidemic (first column). After an epidemic, prices fall by another 0.041 . For rental prices, the effects are substantially smaller, with rent prices falling by 0.030 during an epidemic and another 0.025 when an epidemic ends (second column). Given that the fall in house prices exceeds those in rent prices, we also find increases in rental yields during and just after epidemics, although not consistently significant (third column). These effects are robust to the inclusion of control variables (columns four to six). We also do not find any significant deviations in house or rent price growth from their average level before an outbreak. About one to two years after the end of an epidemic, price growth is not significantly different anymore from its average trend. Note that we also do not find significant evidence for above-average growth after a pandemic, which would suggest an even quicker rebound of prices. In summary this suggests that, at least at annual level, epidemics provide a temporary break in the growth rates of rental prices and sales prices.

If the specific year in which an outbreak arrives to a city is exogenous to its economy, as we have asserted here, the estimates in Table 7.1 identify the actual impact of these epidemics on house prices and rents. However, there are several potential limitations to these conclusions.

First, because the indices are in some years based on a small number of observations, measurement error could be affecting the statistical significance and magnitude of our results. Second, other economic trends coinciding with outbreaks could explain part of the effect since the number of epidemics is still small in absolute terms. For example, the Parisian outbreaks of cholera followed one to two years after the revolutions of 1830 and 1848. Third, these analyses do not allow to distinguish between more and less severe epidemics, even though the epidemics varied significantly 
Table 7.1: House Prices and Rents in Epidemics.

\begin{tabular}{|c|c|c|c|c|c|c|}
\hline & \multicolumn{6}{|c|}{ Dependent variable: } \\
\hline & $\Delta p_{t}$ & $\Delta r_{t}$ & $\Delta r_{t}-\Delta p_{t}$ & $\Delta p_{t}$ & $\Delta r_{t}$ & $\Delta r_{t}-\Delta p_{t}$ \\
\hline Epidemic $_{t+3}$ & & & & $\begin{array}{l}-0.031 \\
(0.028)\end{array}$ & $\begin{array}{c}0.003 \\
(0.011)\end{array}$ & $\begin{array}{c}0.044 \\
(0.033)\end{array}$ \\
\hline Epidemic $_{t+2}$ & & & & $\begin{array}{c}0.027 \\
(0.020)\end{array}$ & $\begin{array}{c}-0.004 \\
(0.012)\end{array}$ & $\begin{array}{l}-0.029 \\
(0.022)\end{array}$ \\
\hline Epidemic $_{t+1}$ & & & & $\begin{array}{r}-0.008 \\
(0.019)\end{array}$ & $\begin{array}{l}-0.013 \\
(0.013)\end{array}$ & $\begin{array}{l}-0.011 \\
(0.018)\end{array}$ \\
\hline Epidemic $_{t}$ & $\begin{array}{l}-0.055 \\
(0.025)\end{array}$ & $\begin{array}{l}-0.030 \\
(0.008)\end{array}$ & $\begin{array}{c}0.028 \\
(0.028)\end{array}$ & $\begin{array}{l}-0.068 \\
(0.029)\end{array}$ & $\begin{array}{l}-0.029 \\
(0.011)\end{array}$ & $\begin{array}{c}0.024 \\
(0.026)\end{array}$ \\
\hline Epidemic $_{t-1}$ & $\begin{array}{l}-0.041 \\
(0.012)\end{array}$ & $\begin{array}{l}-0.025 \\
(0.011)\end{array}$ & $\begin{array}{c}0.031 \\
(0.015)\end{array}$ & $\begin{array}{l}-0.062 \\
(0.015)\end{array}$ & $\begin{array}{l}-0.031 \\
(0.011)\end{array}$ & $\begin{array}{c}0.031 \\
(0.016)\end{array}$ \\
\hline Epidemic $_{t-2}$ & & & & $\begin{array}{l}-0.046 \\
(0.025)\end{array}$ & $\begin{array}{l}-0.037 \\
(0.021)\end{array}$ & $\begin{array}{c}0.011 \\
(0.020)\end{array}$ \\
\hline Epidemic $_{t-3}$ & & & & $\begin{array}{c}0.021 \\
(0.026)\end{array}$ & $\begin{array}{l}-0.012 \\
(0.020) \\
\end{array}$ & $\begin{array}{l}-0.037 \\
(0.031) \\
\end{array}$ \\
\hline Controls & No & No & No & Yes & Yes & Yes \\
\hline City FE & Yes & Yes & Yes & Yes & Yes & Yes \\
\hline Constant & Yes & Yes & Yes & Yes & Yes & Yes \\
\hline Observations & 94 & 164 & 94 & 94 & 118 & 94 \\
\hline $\mathrm{R}^{2}$ & 0.076 & 0.034 & 0.024 & 0.238 & 0.173 & 0.086 \\
\hline Adjusted $\mathrm{R}^{2}$ & 0.056 & 0.022 & 0.002 & 0.146 & 0.096 & -0.024 \\
\hline Residual Std. Error & 0.064 & 0.055 & 0.070 & 0.061 & 0.053 & 0.071 \\
\hline F Statistic & 3.737 & 2.808 & 1.098 & 2.594 & 2.237 & 0.783 \\
\hline
\end{tabular}

Notes: Estimation results from Eq. (7.1). Standard Errors are adjusted for heteroskedasticity and autocorrelation using Andrews standard errors with a quadratic spectral kernel. 
in their mortality. Finally, because many epidemics only lasted a few months, using annual changes might already be too coarse to measure their short-term impacts.

We exploit the relative strengths of our data for Amsterdam and Paris to alleviate these issues. First, we exploit differences in the exact timing of the arrival of the plague in Amsterdam to estimate its short-term impact on prices. Our Amsterdam data covers a much larger number of epidemics, and we correspondingly have more transactions happening around epidemics relative to Paris, for which such an analysis is not possible.

Controlling for annual time trends and month fixed effects, we aim to identify whether the arrival of plagues resulted in significant price distortion in the six months following the start of the outbreak. This enables us to measure short-term price effects. Additionally, this alleviates concerns about potentially unobserved economic time trends, as this methodology only requires the outbreak of plague to be exogenous within a calendar year, rather than across years, as assumed in the previous analysis.

For Paris, mortality data is also available at neighborhood level. We exploit crosssectional differences in the severity of the cholera outbreak to study whether more or less-affected neighborhoods experience different price trajectories after an outbreak, controlling for city-wide trends. This also enables us to control for aggregate economic changes in the city such as the 1830 and 1848 revolutions, that happened shortly before the outbreaks. By tracking price differences in these neighborhoods over time, we also estimate whether price differences among differently affected neighborhoods persist over time, and if these are confounded by existing pre-trends or other neighborhood specific factors.

\subsubsection{Repeat Sales Model}

We estimate price trends and the impact of epidemics by a repeat sales model (Bailey et al., 1963), given by

$$
\ln P_{i, t}-\ln P_{i, s}=\alpha+\mu_{t}-\mu_{s}+\left(x_{i, t}-x_{i, s}\right)^{\prime} \beta+\varepsilon_{i, t}-\varepsilon_{i, s}
$$

The left-hand-side is the difference in log prices of house $i$ at the time of sale $t$ and purchase $s$, where $s<t, t=1, \ldots, T$ and $T$ is the number of periods. The vector $\mu=$ $\left(\mu_{0}, \ldots, \mu_{T}\right)^{\prime}$ represents the log price index, where $\mu_{0}=0$. The term $\mu_{t}-\mu_{s}$ is the change in log price index between the time of purchase and sale. The vector $\left(x_{i, t}-x_{i, s}\right)$ consists of covariates, representing changes in characteristics between the date of purchase and sale. The constant $\alpha$ is a holding period independent return (Goetzmann and Spiegel, 1995). The error terms $\varepsilon_{i, t}$ are independently and normally distributed with zero mean and variance $\sigma_{\varepsilon}^{2}$.

We apply three modifications on the repeat sales model (7.2). First, in order to reduce the impact of noise on the index, due to low number of observations and/or outliers, we use a stochastic log price index specification, replacing the time fixed effects, following Goetzmann (1992), Kuo (1999) and Francke (2010). The log price index is specified as a random walk, given by $\mu_{t} \sim N\left(\mu_{t-1}, \sigma_{\mu}^{2}\right)$. 
Second, we use a time-weighted repeat sales model to control for periodic (annual) price changes as precisely as possible by taking into account the proportion of the period during which the property was "held" (Geltner, 1997). For that reason we replace the integer values $s, t$ by continuous variables, where for example $t=1.25$ indicates that the property has been sold 1 year and 3 months after the start of the index. Define $f_{s}=\lfloor s\rfloor+1-s$, and $f_{t}=t-\lfloor t\rfloor$, denoting respectively the proportion was held in the period of purchase and sale, where $\lfloor t\rfloor$ is the greatest integer less than or equal to $t$. We subsequently replace $\mu_{t}-\mu_{s}$ in Eq. (7.2) by $\left(1-f_{t}\right) \mu_{\lfloor t\rfloor}+f_{t} \mu_{\lfloor t\rfloor+1}-\left(f_{s} \mu_{\lfloor s\rfloor}+\left(1-f_{s}\right) \mu_{\lfloor s\rfloor+1}\right)$.

Third, we add interaction effects from lower frequency (for example four year periods) time varying effects $\lambda^{j}$ and time-invariant covariates $z_{j}$, where $\lambda^{j}$ is a $\left(T^{\prime}+1\right)$ vector with the first element being equal to 0 , so $\lambda_{0}^{j}=0$, and $T^{\prime}$ is the number of periods at the lower frequency. We use lower frequencies because we have an insufficient number of observations to compute annual time fixed effects $\lambda_{j}$ precisely.

The modified repeat sales model can be expressed as

$$
\begin{aligned}
\ln P_{i, t}-\ln P_{i, s} & =\alpha+d_{i, s, t}^{\mu} \mu+\sum_{j=1}^{J} z_{i, j} d_{i, s, t}^{\lambda} \lambda^{j}+\left(x_{i, t}-x_{i, s}\right)^{\prime} \beta+\varepsilon_{i, t}-\varepsilon_{i, s}, \\
\mu_{\tau} & \sim \mathscr{N}\left(\mu_{\tau-1}, \sigma_{\mu}^{2}\right), \mu_{0}=0, \tau=0,1, \ldots, T
\end{aligned}
$$

where $d_{i, s, t}^{\mu}$ is given by

$$
(\underbrace{0 \cdots 0}_{1, \ldots,\lfloor s\rfloor-1} \underbrace{-f_{i, s}}_{\lfloor s\rfloor} \underbrace{-\left(1-f_{i, s}\right)}_{\lfloor s\rfloor+1} \underbrace{0 \cdots 0}_{\lfloor s\rfloor+2, \ldots,\lfloor t\rfloor-1} \underbrace{1-f_{i, t}}_{\lfloor t\rfloor} \underbrace{f_{i, t}}_{\lfloor t\rfloor+1} \underbrace{0 \cdots 0}_{\lfloor t\rfloor+2, \ldots, T}),
$$

and $d_{i, s, t}^{\lambda}$ is defined likewise at the lower frequency. The model has been estimated by Stan, a flexible probabilistic programming language for Bayesian statistical modeling. We use non-informative priors for $\left(\sigma_{\varepsilon}^{2}, \sigma_{\mu}^{2}, \beta, \lambda\right) .^{8}$

\subsubsection{Short-Term Price Responses in Amsterdam}

To estimate the short-term impact of the plague on house prices in Amsterdam we estimate the modified repeat sales model (7.3). The covariates $\left(x_{i, t}-x_{i, s}\right)$ contain monthly dummy variables to deal with seasonal effects and dummy variables to control for potential price discounts due to distressed sales after a foreclosure or after the death of the owner. Most importantly, the covariates include the variables of interest related to the plague. The dummy variable Plague is equal to 1 when within the six months prior to the transaction date, a plague epidemic has started. The 6 and 12 months lagged variables are denoted by Plague.L6M and Plague.L12M.

The repeat sales sample contains seven plague outbreaks in the periods: 1601Sep1602Dec, 1617Aug-1617Dec, 1624Jul-1624Dec, 1635Oct-1636Nov, 1652Aug-1652Nov,

\footnotetext{
${ }^{8}$ Alternatively, conditional on the variances $\left(\sigma_{\varepsilon}^{2}, \sigma_{\mu}^{2}\right)$ the time-weighted repeat sales model (7.2) can be estimated by generalized least squares, providing estimates of $(\mu, \beta, \lambda)$. The variance parameters are subsequently estimated by maximum likelihood (see for more details Francke, 2010). Results are similar.
} 
1655Aug-1655Dec, and 1663Oct-1664Nov. In total 191 repeat sales have a plague outbreak in the six months preceding the sale date.

Table 7.2 presents estimation results from the modified repeat sales model. ${ }^{9} \mathrm{We}$ find a negative short-term effect of the plague on house prices of 0.136 (in logs), see the first column. If we do add lags of the plague variable (columns two and three), the results for the Plague variable are similar. The coefficients for the first lag (Plague.L6M) in the second and third column are small and statistically insignificant. The coefficient for the second lag (Plague.L12M in the third column) is positive, 0.089, and statistically significant ${ }^{10}$, suggesting prices partly recover after 12 to 18 months from the start of the plague.

In columns four and five we test whether the effect is different for the bottom and top third of properties, based on the average log transaction price per street. We estimate the log average transaction price by taking the coefficients on street fixed effects from a regression of the log transaction price on sale type, year fixed effects and street fixed effects. In column four we have two variables (Plague Cheap and Plague Expensive), where the plague variable is interacted with the bottom and top third transaction average price. We do not find a significant difference between cheap, medium and expensive properties.

In column five we have one variable representing the price level (-1 for cheap properties, 1 for expensive properties, and 0 otherwise) with time-varying coefficients $\lambda$, see Eq. (7.3). In column five we report the differences in the time-varying coefficients around the plague epidemics. We use periods of two years as frequency for $\lambda$. We expect the differences in coefficients to be negative, but we do not find consistent supportive evidence for these claims. ${ }^{11}$

The results in columns 4 and 5 do not provide significant evidence for large differences in the price effects of a pandemic on cheap areas, which were likely more affected by the plague outbreaks, relative to expensive areas. However, these results might be driven by the fact that the coefficients are imprecisely estimated. Some streets have only a few observations, resulting in noisy estimates of the price level, and the rapid change of Amsterdam in the 17th century implied that neighborhood status could also change quickly. We only have street names and no exact addresses, so it is not possible to use another level of aggregation, like neighborhoods. The major canals in Amsterdam, for which we have most transactions, are very long and therefore located in multiple neighborhoods. In the next section, we therefore conduct a similar analysis for Paris, for which we have detailed data on epidemic intensity and on the precise location of the properties in our sample of transactions, allowing for more precise identification.

Finally, as a robustness check 7.B reports output based on a hedonic price model

\footnotetext{
${ }^{9}$ Our results on the effect of the plague variables are robust to various specifications: The exclusion of the constant in the repeat sales model, the inclusion of property-specific random walks (Case and Shiller, 1987, 1989), and the exclusion of the prior for the log price index, leading to the standard repeat sales model with time fixed effects.

${ }^{10}$ The $95 \%$ credible interval is $(0.001 ; 0.178)$.

${ }^{11}$ Similar results are found using four years periods (not reported).
} 
(Rosen, 1974), which is due to the limited number of hedonic variables variables less precisely estimated, but has more price observations around plagues. The estimated price drop in the first six months after the start of an epidemic is around 0.09 in logs.

\subsubsection{Neighbourhood Price Responses in Paris}

For Paris we estimate the modified repeat sales model (7.3), comparing developments in house prices across neighborhoods more or less affected by cholera. We interact time fixed effects with the cholera mortality in the neighborhood in which the property is located ( $z$ and $\lambda$ in Eq. (7.3)). For additional precision, the time dummy variables cover periods starting from the 1st of April, because both cholera outbreaks started around the end of March. We estimate these models separately using 1832 neighborhood mortality and 1849 neighborhood mortality (in logs). We do not include variables that indicate the six months after the start of the cholera outbreak (like the Plague variable in Amsterdam), because Paris 'only' had two cholera outbreaks, and therefore a very limited number of total transactions in the first few months after outbreaks. ${ }^{12}$ To maximize the number of repeat-sales, we estimate the model on the entire period before World War I.

Because the epidemics happened shortly after the revolutions of 1830 and 1848, and affected poor neighborhoods more than wealthier neighborhoods, price effects might not be driven by cholera mortality but by differential trajectories in neighborhoods after the revolution, in particular between poor and wealthy neighborhoods. To adjust for neighborhood poverty, we first estimate the average log transaction price per neighborhood over the entire 1809-1848 period, before the major renovations of Haussmann, controlling for aggregate price changes using annual time fixed effects. Absent neighborhood level data on income, we assume that average housing values are a close proxy for neighborhood status, following Ambrus et al. (2020) and Kesztenbaum and Rosenthal (2017). ${ }^{13}$ Similar to neighborhood mortality, we interact time fixed effects with the log average transaction price for each neighborhood.

For the 1849 period, we can additionally test whether our results are driven by revolutionary activity. During the main insurgences in February and June 1848, barricades were put up in the east of the city, where most worker neighborhoods were located, and not in the conservative west of the city. ${ }^{14}$ In 1830, there was no such a spatial division in revolutionary activity, with barricades all across the cities, and the main skirmishes taking place among the main boulevards and along the embankments of the Seine. To adjust for these, we construct a dummy taking the value of 1 if a property is in the west of the city (no barricades), and 0 if it is in the east (with barricades)

Note that cholera mortality correlates significantly with both revolutionary activity

\footnotetext{
${ }^{12}$ We do have estimates of (lagged) Cholera variables (not reported). The corresponding coefficients are negative (apart from the first lag), however statistically insignificant.

${ }^{13}$ The correlation between average prices estimated for the 1809-1831 period (4907 observations) and the 1809-1848 period (9263 observations is 0.97 . Given the higher precision of the 1809-1848 estimates, we use these for both samples.

${ }^{14}$ For a map of barricades, see L'Histoire (2018).
} 
Table 7.2: Estimation Results Price Responses Amsterdam.

\begin{tabular}{|c|c|c|c|c|c|}
\hline \multirow[b]{3}{*}{ Plague } & \multicolumn{5}{|c|}{ Dependent variable: } \\
\hline & \multicolumn{5}{|c|}{$\ln P_{i, t}-\ln P_{i, s}$} \\
\hline & $\begin{array}{l}-0.136 \\
(0.045)\end{array}$ & $\begin{array}{l}-0.137 \\
(0.045)\end{array}$ & $\begin{array}{l}-0.121 \\
(0.046)\end{array}$ & $\begin{array}{l}-0.150 \\
(0.051)\end{array}$ & $\begin{array}{l}-0.137 \\
(0.043)\end{array}$ \\
\hline Plague.L6M & & $\begin{array}{c}0.000 \\
(0.036)\end{array}$ & $\begin{array}{c}0.019 \\
(0.037)\end{array}$ & & \\
\hline Plague.L12M & & & $\begin{array}{c}0.089 \\
(0.045)\end{array}$ & & \\
\hline Plague Cheap & & & & $\begin{array}{c}0.006 \\
(0.110)\end{array}$ & \\
\hline Plague Expensive & & & & $\begin{array}{c}0.099 \\
(0.120)\end{array}$ & \\
\hline Foreclosure Sale & $\begin{array}{l}-0.021 \\
(0.013)\end{array}$ & $\begin{array}{l}-0.021 \\
(0.013)\end{array}$ & $\begin{array}{l}-0.021 \\
(0.013)\end{array}$ & $\begin{array}{l}-0.021 \\
(0.013)\end{array}$ & $\begin{array}{l}-0.009 \\
(0.012)\end{array}$ \\
\hline Widow & $\begin{array}{l}-0.046 \\
(0.009)\end{array}$ & $\begin{array}{l}-0.045 \\
(0.009)\end{array}$ & $\begin{array}{l}-0.046 \\
(0.009)\end{array}$ & $\begin{array}{l}-0.045 \\
(0.009)\end{array}$ & $\begin{array}{l}-0.044 \\
(0.009)\end{array}$ \\
\hline Heirs & $\begin{array}{l}-0.036 \\
(0.007)\end{array}$ & $\begin{array}{l}-0.036 \\
(0.007)\end{array}$ & $\begin{array}{l}-0.036 \\
(0.007)\end{array}$ & $\begin{array}{l}-0.036 \\
(0.007)\end{array}$ & $\begin{array}{l}-0.035 \\
(0.006)\end{array}$ \\
\hline Constant & $\begin{array}{c}0.061 \\
(0.005)\end{array}$ & $\begin{array}{c}0.060 \\
(0.005)\end{array}$ & $\begin{array}{c}0.061 \\
(0.005)\end{array}$ & $\begin{array}{c}0.060 \\
(0.005)\end{array}$ & $\begin{array}{c}0.066 \\
(0.005)\end{array}$ \\
\hline$\overline{\lambda_{1620}-\lambda_{1618}}$ & & & & & $\begin{array}{l}-0.917 \\
(0.427)\end{array}$ \\
\hline$\lambda_{1626}-\lambda_{1624}$ & & & & & $\begin{array}{l}-0.208 \\
(0.372)\end{array}$ \\
\hline$\lambda_{1638}-\lambda_{1636}$ & & & & & $\begin{array}{c}0.022 \\
(0.143)\end{array}$ \\
\hline$\lambda_{1654}-\lambda_{1652}$ & & & & & $\begin{array}{c}0.137 \\
(0.077)\end{array}$ \\
\hline$\lambda_{1656}-\lambda_{1654}$ & & & & & $\begin{array}{l}-0.041 \\
(0.075)\end{array}$ \\
\hline$\lambda_{1666}-\lambda_{1664}$ & & & & & $\begin{array}{l}-0.172 \\
(0.102)\end{array}$ \\
\hline$\overline{\sigma_{\varepsilon}}$ & $\begin{array}{l}0.380 \\
(0.001)\end{array}$ & $\begin{array}{l}0.380 \\
(0.001)\end{array}$ & $\begin{array}{l}0.380 \\
(0.001)\end{array}$ & $\begin{array}{l}0.380 \\
(0.001)\end{array}$ & $\begin{array}{c}0.371 \\
(0.001)\end{array}$ \\
\hline$\sigma_{\mu}$ & $\begin{array}{c}0.071 \\
(0.005)\end{array}$ & $\begin{array}{c}0.071 \\
(0.005)\end{array}$ & $\begin{array}{c}0.071 \\
(0.005)\end{array}$ & $\begin{array}{c}0.071 \\
(0.005)\end{array}$ & $\begin{array}{c}0.070 \\
(0.005)\end{array}$ \\
\hline PSIS-LOO value & $-31,381.5$ & $-31,382.8$ & $-31,382.3$ & $-31,384.2$ & NA \\
\hline Interaction effect & No & No & No & No & Yes \\
\hline $\begin{array}{l}\text { Month FE } \\
\text { Observations }\end{array}$ & & & $\begin{array}{c}\text { Yes } \\
39,281\end{array}$ & & \\
\hline Sample Period & & & $602-1811$ & & \\
\hline
\end{tabular}

Notes: This table reports the output of the modified repeat sales model (7.3). Standard errors are reported between parentheses. In all specifications, we control for potential price differences resulting from foreclosure sales and from transfers of properties by heirs or widows, following the death of the owner. PSIS-LOO stands for Leave-one-out crossvalidation using Pareto-smoothed importance sampling (Vehtari et al., 2017). 
in 1848 ( $r=0.36$, where $r$ denotes correlation) and neighborhood level average prices ( $r=-0.49$ for $1832, r=-0.63$ for 1849 ). We control for these observations, and the effect of cholera mortality per four-year time interval. Given the correlation across these measures, and the limited amount of data, using shorter time intervals results in imprecisely estimated coefficients.

Figure 7.4: Price-Variation in Neighbourhoods by Cholera Mortality.
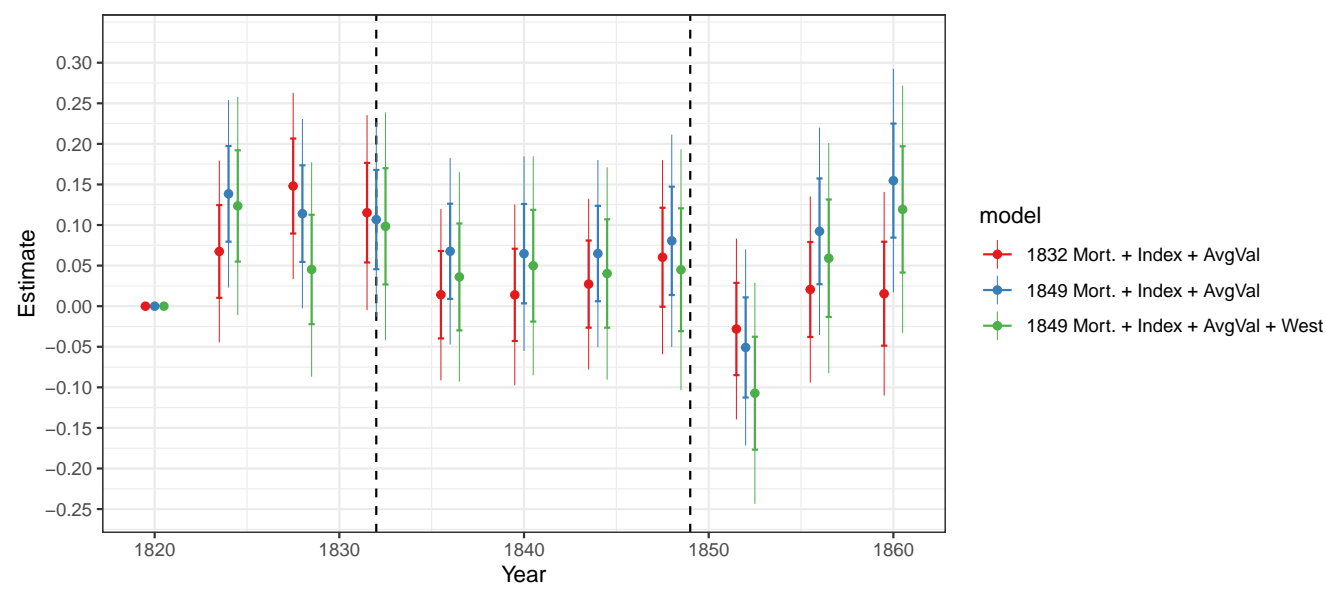

Notes: This figure plots the estimates of the mortality interaction coefficients in the period from 1820 to 1860, the $\lambda \mathrm{s}$ in Eq. (7.3), based on the 1832 (1832 Mort., in red) and the 1849 cholera log mortality (1849 Mort., in blue and green). A coefficient of 0.1 implies that in the year of observation a neighbourhood had ten percent higher prices compared to a neighbourhood with half its cholera mortality, relative to the base year of 1820 . Around the point estimate we plot $+1 /-1$ standard error (thick bar), and a $95 \%$ confidence interval based on these errors (thin bar). We use 4-year periods for the lower frequency process $\lambda$. In the legenda 'AvgVal' and 'West' refer to additional interaction effects ( $z$-variables in Eq. (7.3)), where 'AvgVal' is a proxy for neighborhood status, and 'West' is a dummy variable measuring revolutionary activity. 'Index' is the annual log price index $\mu$ in Eq. (7.3).

Figure 7.4 plots the evolution of the mortality coefficients, where 1820 is the base year, so $\lambda_{1820}^{\text {Mortality }}=0$. We show results for three different model specifications, where the differences concern the interaction effects $z$. The first specification (red in Figure 7.4) has as interaction effects: (i) log mortality in 1832 and (ii) the average neighborhood log transaction price, the second specification (in blue): (i) log mortality in 1849 and (ii) the average neighborhood log transaction price, and the third specification (in green): (i) log mortality in 1849, (ii) the average neighborhood log transaction price, and (iii) a dummy variable indicating revolutionary activity. More details on the estimation results can be found in Table 7.3.

Mortality correlates across the two epidemics, so the $\lambda^{\text {Mortality }}$ coefficients in the models using 1832 and 1849 mortality rates evolve similarly over time. Between 1820 and 1828, neighborhoods with a high cholera-mortality in 1832 experienced higher levels of price growth relative to less-affected neighborhoods.

This is a period of rapid price and population growth in the city in general, which might have led to particularly fast price growth in the central areas, which were also 
most affected by the outbreak in 1832. Prices remain relatively stable in the years leading to the epidemic. Between 1832 and 1836, high-mortality areas fall in prices relative to low-mortality areas, with a relative price drop of 0.101 in logs, see the first column in Table 7.3. The probability that the price change is positive is $0.046 .{ }^{15}$ Relative prices in more- and less affected neighborhoods remain at similar levels until the late 1840s. In summary, there is evidence that the outbreak of 1832 led to large price declines in heavily-affected areas. Prices of more- and less affected neighborhoods experienced different price developments in the years leading to the epidemics.

For 1849 mortality the evidence is more consistent and significant. After the outbreak of 1832, prices in more and less-affected neighborhoods in the 1849 epidemic do not display any visible and significant time trend until the outbreak, both in the model that only controls for aggregate time trends and differences across poor and rich neighborhoods, and the model that additionally controls for east-west differences during the 1848 Revolution. After 1848, we find sharp drops in property prices, with prices in high-mortality areas falling by significantly more than prices in low-mortality areas. The additional drop between 1848 and 1852 is 0.131 in logs (the probability that the price change is positive is 0.019 ), and 0.152 in logs (the probability that the price change is positive is 0.021 ) when controlling for differences in revolutionary activity, see the second and third column in Table 7.3. However, prices also bounce back quickly, with no significant differences anymore after $1860 .^{16}$

\subsection{Mechanisms and Implications}

Our combined findings on Paris and Amsterdam point to three important effects. First, house prices and rents both decline after epidemics, but this effect is more pronounced for house prices. Second, house price declines are particularly significant in the first six months after an outbreak (Amsterdam) and in heavily-affected areas (Paris). Third, these large initial price declines are transitory: heavily affected areas recover in prices, and aggregate house and rent price growth return to their initial growth paths within a few years after an epidemic.

In this section, we discuss potential mechanisms driving these effects and the role of policy responses in shaping the trajectories of house prices and rents after the epidemics.

\subsubsection{Housing Demand \& Urban Growth}

Because cholera and plague killed a significant fraction of the population, total housing demand declined significantly during an outbreak. This reduction in housing demand could be strengthened further if the epidemics also resulted in significant drops in income, for which we only have anecdotal evidence. In line with this channel, we find rent prices to decline. However, this response is small, with aggregate rent prices

\footnotetext{
${ }^{15}$ In this Bayesian setting we do not report $p$-values.

${ }^{16}$ This pattern also persists after 1860 .
} 
Table 7.3: Estimation Results Price Responses Paris.

\begin{tabular}{|c|c|c|c|}
\hline \multirow[b]{3}{*}{ Auction sale } & \multicolumn{3}{|c|}{ Dependent variable: } \\
\hline & \multicolumn{3}{|c|}{$\ln P_{i, t}-\ln P_{i, s}$} \\
\hline & $\begin{array}{c}0.045 \\
(0.008)\end{array}$ & $\begin{array}{c}0.044 \\
(0.008)\end{array}$ & $\begin{array}{c}0.042 \\
(0.008)\end{array}$ \\
\hline Constant & $\begin{array}{c}0.118 \\
(0.008)\end{array}$ & $\begin{array}{c}0.119 \\
(0.009)\end{array}$ & $\begin{array}{c}0.116 \\
(0.008)\end{array}$ \\
\hline$\lambda_{1836}^{\text {Mortality }}-\lambda_{1832}^{\text {Mortality }}$ & $\begin{array}{l}-0.101 \\
(0.061)\end{array}$ & $\begin{array}{l}-0.039 \\
(0.066)\end{array}$ & $\begin{array}{l}-0.062 \\
(0.076)\end{array}$ \\
\hline$\lambda_{1840}^{\text {Mortality }}-\lambda_{1832}^{\text {Mortality }}$ & $\begin{array}{l}-0.101 \\
(0.056)\end{array}$ & $\begin{array}{l}-0.042 \\
(0.058)\end{array}$ & $\begin{array}{l}-0.049 \\
(0.068)\end{array}$ \\
\hline$\lambda_{1852}^{\text {Mortality }}-\lambda_{1848}^{\text {Mortality }}$ & $\begin{array}{l}-0.088 \\
(0.055)\end{array}$ & $\begin{array}{l}-0.131 \\
(0.064)\end{array}$ & $\begin{array}{l}-0.152 \\
(0.074)\end{array}$ \\
\hline$\sigma_{\varepsilon}$ & $\begin{array}{c}0.366 \\
(0.003)\end{array}$ & $\begin{array}{c}0.366 \\
(0.003)\end{array}$ & $\begin{array}{c}0.365 \\
(0.003)\end{array}$ \\
\hline$\sigma_{\mu}$ & $\begin{array}{c}0.090 \\
(0.011)\end{array}$ & $\begin{array}{c}0.069 \\
(0.011)\end{array}$ & $\begin{array}{c}0.077 \\
(0.012)\end{array}$ \\
\hline PSIS-LOO value & -7296.9 & -7305.5 & -7285.9 \\
\hline Interaction effects $(\lambda$ & & & \\
\hline Mortality (in log) & 1832 & 1849 & 1849 \\
\hline AvgVal & Yes & Yes & Yes \\
\hline West & No & No & Yes \\
\hline Observations & & 9,531 & \\
\hline Sample Period & & 1809-1913 & \\
\hline
\end{tabular}

Notes: This table presents estimation results for three different specifications of the modified repeat sales model given by Eq. (7.3), corresponding to the ones plotted in Figure 7.2. The interaction effect 'AvgVal' is a proxy for neighborhood status using average transaction price, and the interaction effect 'West' a dummy variable measuring revolutionary activity based on the position of barricades. The coefficient on auction sales is positive and statistically significant in all specifications. Auctions were widely used to efficiently sell proprieties. PSIS-LOO stands for Leave-one-out cross-validation using Pareto-smoothed importance sampling (Vehtari et al., 2017). 
only declining by about three percent per year until one to two years after the epidemic. Rent price growth returns to its previous level afterward (see Table 7.1 and Figure 7.3).

An explanation for this finding is that the loss of population was quickly made up by increasing migration in both cities. During the period when plagues frequently occurred, Amsterdam experienced its famous Golden Age, with the population increasing from about 30,000 in 1580 to over 200,000 inhabitants in the 1660s (Nusteling, 1985). In Paris, the population grew by almost $15 \%$ between 1831 and 1836, despite a deadly cholera epidemic. Population growth halted around the epidemic in 1849, but already recovered in the early 1850s.

One important implication of this finding is that large pandemics, and their corresponding demographic shocks, do not seem to affect the long-term growth trajectories of large cities. Of course, these effects might be different in less successful cities, or in rural areas, for which do not have data (see Alfani and Percoco, 2019).

\subsubsection{Potential Channels for Short Term Price Drops}

The fact that epidemics altered the demand and supply for housing could explain the trajectories of rent prices. However, a demand-and-supply based explanation cannot explain why sale prices fall more than rents over the very short-term, and in heavier affected areas. One potential channel is that investors became more pessimistic about future housing demand and corresponding (growth of) rents and that this decreased their valuation of properties. Note that if investors had perfect foresight on rents, or extrapolated the experience of previous outbreaks, property prices would fall by less than rent prices during an epidemic, because rent price drops were temporary. Such changes in expectations can only explain the fall in house prices if investors became very pessimistic and expected housing demand to continue falling after the epidemics. Although we cannot test how likely this channel is, such pessimistic expectations were unjustified ex-post and if investors considered previous outbreaks.

A second channel is that epidemics temporarily increased discount rates, by higher interest rates and/or housing risk premia. Interest rate fluctuations can only explain a minor part of this effect since the estimates in Table 7.1 hardly change when controlling for aggregate interest rates. This also does not explain why prices fall more in heavily-affected areas. ${ }^{17}$ It is more likely that an epidemic temporarily increased perceived investment risk and risk aversion, and so risk premia. For example, changes in wealth or expected income triggered by epidemics could increase risk aversion, such as in the canonical model of Campbell and Cochrane (1999). The prospect of uncertainty in future income can generate similar increases in risk aversion (e.g. Guiso and Paiella, 2008). Second, theoretical and empirical work shows that when risks are salient, and when events trigger negative emotions, risk aversion can temporarily increase significantly (e.g. Loewenstein, 2000; Bordalo et al., 2012; Cohn et al., 2015;

\footnotetext{
${ }^{17}$ Bond interest data for Amsterdam is less precise than for Paris, but more granular archival data on mortgage interest rates revealed these changed little during outbreaks (Amsterdam City Archives, Archive 5065).
} 
Guiso et al., 2018), and affect risk perception (Slovic et al., 2007). This mechanism could explain why the fall in house prices is particularly large in the short-term and in heavily-affected areas. Uncertainty resolves when the epidemic ends, while homeowners in heavily-affected areas are more exposed to the outbreak, either directly or through their tenants.

One concern is that properties might sell at lower property prices due to changes in the composition of buyers, sellers, and properties for sale, instead of an increase in aggregate risk premia. For example, properties might sell at discounted prices because distressed sellers sell to the first available buyer, rather than waiting to realize the fundamental market price. This mechanism has been well-documented for foreclosure sales (e.g. Campbell et al., 2011), but might also apply to regular fire sales. Table 7.2 shows that different types of properties did not realize different prices during plague epidemics in Amsterdam, and that foreclosed properties did not realize lower prices either. ${ }^{18}$ In 7.A.3 and 7.A.4, we show there is no difference in total foreclosure volume and realized holding periods during an outbreak, implying evidence for fire sales is limited.

\subsubsection{Housing Supply \& Urban Planning}

In the short-term, epidemics coincided with falling construction activity, with estimated completed construction going down on average by $40 \%$ (see 7.A.1). However, epidemics had more significant consequences on housing supply over the long run. The City of Paris is probably the most prominent example. After the 1832 outbreak, the government quickly realized that the areas worst affected by cholera were those with high population densities, narrow streets, and with poor inhabitants. When Count de Rambuteau came to power in Paris in 1833, he proclaimed that his mission was to provide "air, water and shadow" to all citizens in Paris, and started clearing unhealthy housing in the worst-affected central areas of the city, as well as introducing public urinals to improve sanitation (Park, 2018). The 1849 outbreak confirmed the validity of this approach since the central areas that were most affected by Rambuteau's renovations, had much lower mortality than in 1832. This confirmation paved the way for the renowned Haussmann renovations that started in the 1850s. These destroyed nearly all of the unhealthy medieval Paris and gave the city the image it still has today, with its wide boulevards and large apartment blocks. Although the movement to create a more healthy Paris already started before the outbreak of cholera (Park, 2018), following the huge increases in population density of the central parts of the city, cholera turned out to be the catalyst that was needed to push through large scale renovations.

Plague also affected urban planning and housing supply in Amsterdam. Similar to Paris, Amsterdam experienced enormous inflows of migrants, forcing the city to expand significantly. Just prior to the outbreaks in the years 1617-1618 and 16631664 , the government had started selling plots of land for these expansions. Strikingly, plots continued to be sold in the plague years, and the city even started selling these

\footnotetext{
${ }^{18}$ The likely cause for the absence of a foreclosure discount is that there was a large and liquid auction market for real estate property in Amsterdam, where both regular and foreclosed properties were sold.
} 
plots with mortgages, such that investors did not have to pay the full price upfront (Abrahamse et al., 2015). These mortgages were used widely, in particular around outbreaks. ${ }^{19}$ We do not know if the government took these measures because of the pandemic, but they do display a strong commitment to keeping supply expansion going even during epidemics. Beyond housing, the outbreaks of plague caused the city to focus on improving the urban water infrastructure, which was thought to be related to the spread of plague (Abrahamse, 2010).

Each of these developments might have contributed to the evolution of house prices and rents we observe after epidemics. First, the regeneration of areas heavily affected by cholera likely played an important role in the fact that house prices and rents in these areas did not stay persistently lower relative to less affected areas in Paris, as Ambrus et al. (2020) find for London. The introduction of wider streets, the clearance of slum housing, and access to clean water could improve the valuations of both new and existing properties. ${ }^{20}$ Second, the continued expansion of housing supply in both cities after epidemics limited longer-term price growth and could reinforce migration towards the city.

\subsection{Conclusion}

This paper studies the impact of pandemics, the plague in 17th-century Amsterdam and cholera in 19th-century Paris, on house prices and rents, using micro-data. We find that major epidemics cause economically and statistically significant, but shortlived declines in house prices, and smaller declines in rent prices. Declines in prices are most substantial just after the outbreak of an epidemic and in heavily-affected areas.

Although various mechanisms could explain this finding, the most plausible explanation for the large and temporary decline in property prices is that epidemics temporarily increase housing risk premia, due to increased uncertainty and economic disruption.

About one to two years after the end of an epidemic, price growth is not significantly different anymore from its average trend. We attribute the absence of any longterm effect on house prices and rents to the resilience of cities to major shocks. In both Paris and Amsterdam, the outbreaks did not stop a massive flow of migrants from coming to the city. In Paris, the epidemic even proved to be a catalyst for significant urban change, and rent and house prices recovered even in the worst-affected areas.

\footnotetext{
${ }^{19}$ Amsterdam City Archives, Archive 5065: Register van Rentebrieven.

${ }^{20}$ In London the policy response was restricted to the shutdown of the affected pump.
} 


\section{A Beyond Prices: Housing Markets in Epidemics}

In this Appendix, we provide a descriptive overview of other developments in the Amsterdam and Paris housing market during epidemics. We will discuss changes in housing supply, mortgage supply, transaction volume \& foreclosures, and time-betweensales. For a more detailed description of the structure of the housing market in this period, see Korevaar (2020) for Amsterdam and Eichholtz et al. (2020c) for Paris.

\section{A.1 Housing Supply and Construction}

\section{Amsterdam}

Abrahamse (2010) notes that the 1617-1618 epidemic temporarily halted the building industry, with masons and carpenters complaining they experienced a very bad year. From 1632, there are government statistics on the rental value of newly completed buildings in the city, which were made for the purpose of property taxation. ${ }^{21}$ For all four epidemics that hit the city after 1632, we find that the number of completed properties falls in the year following the start of the outbreak, with an average fall in completed construction of $38 \%$, with the fall ranging from $27 \%$ to $48 \%$ across all four epidemics. Because most outbreaks started in the fall, it is unlikely they still had a large effect on completed construction in the year of the outbreak itself. However, we should note that the levels of construction both before and after an epidemic varied significantly: there was significant construction taking place around the 1635-1636 epidemic and even more so during the 1663-1664 epidemic, while construction was already at very low rates around the epidemics in the 1650 s.

\section{Paris}

In Paris, the outbreaks of cholera coincided with a slump in building activity as well. Based on data from Daumard (1965), the total rental value of new construction fell by about $70 \%$ in 1849 , and the slump in building activity continued until 1852. After 1852, construction quickly resumed due to the start of the Hausmann renovations of Paris. It should be noted that construction was already falling significantly in 1848, due to the economic crisis and revolution that Paris was experiencing at that time.

For 1832, we do not possess exact numbers on the rental value of new construction. The closest equivalent to a construction estimate is the number of bricks that entered Paris in each year, because bricks are essential for housing construction. The number of bricks fell by about 10\% in 1832 (relative to a fall of about 33\% in 1849), but recovered quickly in the following year (Daumard, 1965). This is consistent with the stronger population growth that happened in the early 1830s, at least when comparing to the period around 1850. Again, we should note that the number of bricks that entered the city was already falling sharply in 1831 .

In short, our evidence for both Paris and Amsterdam suggests that housing construction slowed down during an epidemic, consistent with the significant economic

\footnotetext{
${ }^{21}$ Source: Amsterdam City Archives, Archive 5044.
} 
and demographic turmoil brought by these epidemics. We want to stress that our evidence on housing construction should be treated as suggestive evidence: we do not have consistent data on housing construction available for all epidemics, leaving too little power for any formal statistical test, and it is hard to control for pre-trends given that the epidemics also coincided with other shocks in building activity, most notably in Paris in 1849 and in Amsterdam around 1663.

\section{A.2 Mortgage Originations}

\section{Amsterdam}

In the 17th century, a significant fraction of properties was funded using a peer-topeer mortgage, typically supplied by the seller of the property. The closest analogy to a modern mortgage was a losrente contract, which was an interest-only mortgage without a maturity date and an LTV of up to $100 \%$. The borrower could repay the capital sum whenever he wanted. Between the 1630s and the 1660s, around $20 \%$ of real estate transactions were financed using such a loan. The City of Amsterdam also often provided such mortgages when it was selling plots of land. Beyond these longterm loans, properties could also be financed using a schepenkennis, which was either a loan without interest used to specify a payment schedule (typically for just a year), or a short-term interest-bearing loan with a maturity of up to several years (Gelderblom et al., 2017). We do not know exactly how many of these loans were used as mortgages.

We briefly highlight how long-term mortgage volume changed around the epidemics after 1630, using data on the number of losrenten from Korevaar (2020). During the outbreaks in 1635-1636 and 1652, we document significant reductions in the number of mortgages, with the number of contracts dropping monotonically from 321 in 1634 to 134 in 1637, and from 100 contracts in 1651 to just 73 in 1653. There is no fall in mortgage activity during the smaller outbreak in 1655, but it should be noted that mortgage activity was already at very low levels before the outbreak, since there were only 37 mortgages issued in 1654 and around 60 in 1655 and 1656. The outbreak of 1663-1664 is an outlier with respect to the number of mortgages, because mortgage volume doubled in 1664, but fell in subsequent years. Most of the increase in contracts was driven by mortgages on the sales of plots of land by the city. It is possible they hoped to increase land revenue by providing credit, but we do not know whether this decision was related to the outbreak. In 1617-1618, when the city issued a large number of plots of land during a plague epidemic, the government also issued loans to buyers of plots of land for a $50 \%$ LTV.

\section{Paris}

For Paris, we do not have detailed data on mortgage originations around outbreaks of cholera. However, Paris already had a well-developed mortgage market in the 19th century, with a centralized mortgage register (hypotheques), and a large and active market for peer-to-peer loans (Hoffman, 2000). Comparatively, this market was also 
substantially larger than the peer-to-peer loan market in Amsterdam, at least during the Ancien Regime (Hoffman, 2000; Gelderblom et al., 2017).

\section{A.3 Transaction Volume \& Foreclosures}

Both Paris and Amsterdam had institutions in place that permitted creditors to auction properties in case the owner foreclosed on its loans or any other type of required payment. These auctions were organized centrally and were also a common way to sell non-foreclosed properties. In Amsterdam, the records do not allow us to distinguish between regular private sales and auctions sales since only foreclosures were registered separately. However, the available auction lists suggest the number of transacted properties was large relative to total volume. For example, in the year 1743, 548 properties were put up for sale, relative to 613 realized total transactions in the cities. Although not every property put up for sale in an auction would eventually transact, this suggests a large fraction of real estate transactions in Amsterdam happened through auctions.

\section{Amsterdam}

For Amsterdam, we can reconstruct total volume in the housing market for a substantial number of months, building on the turnover data presented in Korevaar (2020). For four epidemics, we have precise monthly data on regular transaction volume, and for five epidemics we have monthly data on foreclosure volume. This implies that, contrary to our more scattered data on construction and mortgage volume, we have enough observations to statistically test the impact of pandemics on volume.

To do so, we regress the monthly level of turnover on a set of annual time dummies that indicate the number of years until or since the closest outbreak of a plague epidemic, with the number of years ranging from -2 years (12-24 months before the outbreak) to 3 years after the outbreak (24-36 months). We also control for seasonality by including month fixed effects. To estimate the regression, we only incorporate data that is between -24 months and 36 months from an epidemic. Because our volume estimates are monthly, but our plague dummies annual, there is significant autocorrelation (and heteroskedasticity) in the residuals of this regression. We adjust standard errors for heteroskedasticity and autocorrelation using Andrews (1991) HAC errors.

Table 7.4 reports the results of these regressions, both for regular sales and foreclosure sales. We use transaction volume in the year before an epidemic as a baseline. Transaction volume is expressed as a percentage of the total housing stock.

The estimates suggest that transaction volume declined significantly during an outbreak, with monthly transaction volume going down by 0.05 percentage points. On average, 0.2 percent of the housing stock traded hands in each month, implying that transaction volume fell by about 25 percent during these epidemics. ${ }^{22}$

\footnotetext{
${ }^{22}$ As a robustness check, we also modeled monthly transaction volume in a local linear trend model, that models log sales as a function of a linear trend, a seasonal component and the six-monthly plague variables that we also used in our analysis on Amsterdam prices. This revealed that volume primarily
} 
Table 7.4: Monthly Transaction Volume around Epidemics.

\begin{tabular}{lcc}
\hline \hline & \multicolumn{2}{c}{ Volume: } \\
\cline { 2 - 3 } & Regular & Foreclosures \\
\hline Epidemic $_{t-2}$ & 0.003 & 0.001 \\
& $(0.023)$ & $(0.006)$ \\
Epidemic $_{t}$ & -0.049 & -0.001 \\
& $(0.023)$ & $(0.006)$ \\
Epidemic $_{t+1}$ & -0.026 & 0.004 \\
& $(0.025)$ & $(0.006)$ \\
Epidemic $_{t+2}$ & 0.019 & 0.012 \\
& $(0.027)$ & $(0.006)$ \\
\hline Month FE & Yes & Yes \\
Constant & Yes & Yes \\
\hline Observations & 258 & 260 \\
$\mathrm{R}^{2}$ & 0.740 & 0.252 \\
Adjusted $\mathrm{R}^{2}$ & 0.724 & 0.206 \\
Residual Std. Error & 0.083 & 0.028 \\
F Statistic & 46.034 & 5.488 \\
\hline \hline
\end{tabular}

Notes: HAC-consistent standard errors are reported between parentheses. 
For foreclosure volume, we find no significant effects in the first two years after an outbreak, but a significant increase in foreclosure volume 24 to 36 months later. This increase $(0.01$ percentage point of the housing stock per month) is about 25 percent relative to average monthly foreclosure volume. It should not be surprising that there is a delay between foreclosure sales and the outbreak of an epidemic: lenders might have waited for the epidemic to be over before starting a formal foreclosure procedure, both to give debtors extra time to pay or to avoid selling in a distressed market.

\section{Paris}

Because our data are only for a sample of streets, we cannot reconstruct transaction volume for Paris. However, the number of transactions in our sample provide, at least over the short-term, an estimate of the changes in transaction activity in the city. Figure 7.5 plots the volume of annual auction sales and private sales for the streets covered by our data, from 1820 to 1860 . In line with our observations on housing construction, transaction volume already dropped substantially in the year before the outbreak, following the economic crisis around the 1830 revolution and the 1848 revolution. In 1849, transaction volume even increases relative to its previous levels, although this is entirely driven by an increase in the number of auctions.

Figure 7.5: Transactions in Paris.

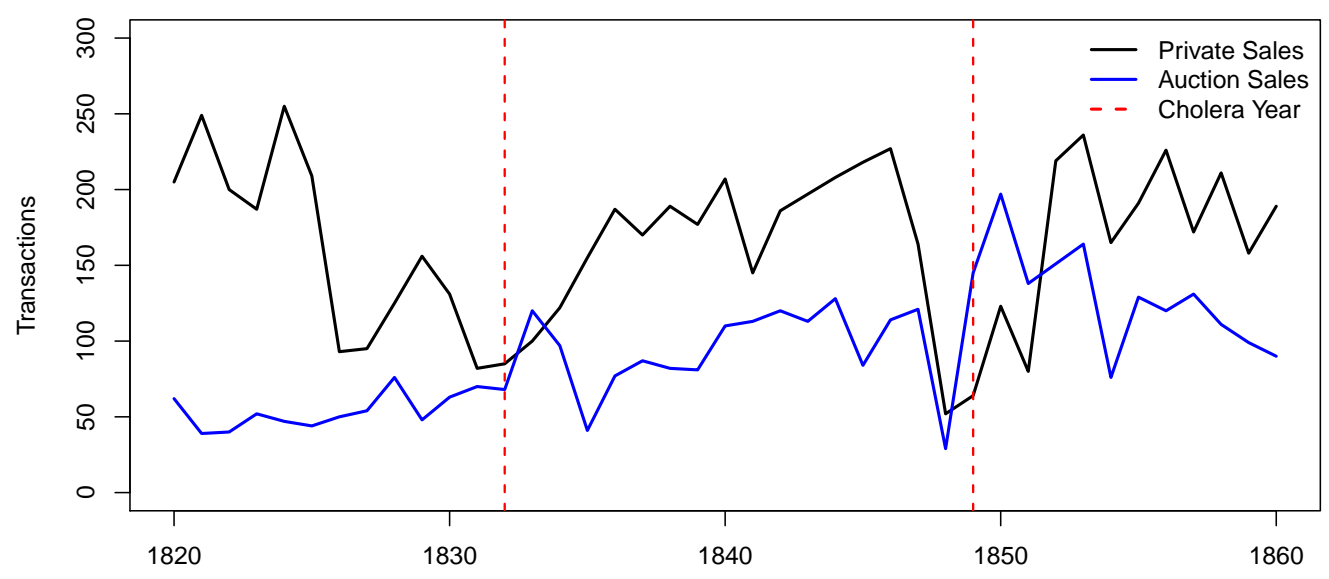

Notes: These figures plot the annual number of transactions in our sample, separating auction sales and private sales.

\section{A.4 Time-Between-Sales}

We want to check whether the time-between-sales changes during or just after an epidemic. When owners are forced to sell properties due to the effects of the outbreak of an epidemic, the average time-between-sales might go down. For all repeat sale pairs 
the time-between-sales is calculated as the difference (in days) between the date of selling and buying a property. We model the average time-between-sales per date of the second sale pair $\left(\mathrm{TBS}_{t}\right)$ as

$$
\operatorname{lnTBS} S_{t}=\mu_{t}+x_{t}^{\prime} \beta+\varepsilon_{t}, \mu_{t+1}=\mu_{t}+\kappa_{t}+\zeta_{t}, \kappa_{t+1}=\kappa_{t}+\xi_{t},
$$

where $\mu_{t}$ is the log time-between-sales trend, specified as a local linear trend model. ${ }^{23}$ The vector $x_{t}$ contains dummy variables for epidemics, specified similarly as in subsection 7.3.4 for the plague. Table 7.5 provides the estimation results for the coefficients of the epidemic dummy variables for Amsterdam and Paris. We do not find statistical significant changes in the average time-between-sales during or just after the outbreak of an epidemic. Note that the average number of second sales per month is small, 6.2 and 9.7 for Amsterdam and Paris, respectively. So results may be sensitive to outliers.

Table 7.5: Estimation Results for Time-between-Sales.

\begin{tabular}{lcc}
\hline \hline \multicolumn{2}{c}{ Dependent variable: $\ln T^{2} S_{t}$} \\
\hline & Amsterdam & Paris \\
\hline Epidemic & 0.037 & -0.072 \\
& $(0.118)$ & $(0.130)$ \\
Epidemic.L6M & -0.157 & 0.038 \\
& $(0.119)$ & $(0.131)$ \\
Epidemic.L12M & 0.108 & 0.109 \\
& $(0.124)$ & $(0.130)$ \\
\hline Observations & 274 & 479 \\
Sample Period & $1645(1)-1669(12)$ & $1820(1)-1859(12)$ \\
\hline \hline
\end{tabular}

Notes: Standard errors are reported between parentheses.

\section{B Results Using a Hedonic Price Model}

In this section of the appendix, we estimate a hedonic price model that aims to control for quality of the sold properties using actually observed quality characteristics. One advantage of this model is that it does not require properties to be sold repeatedly. Because our transaction data for the 17 th century is incomplete, the number of repeatsales around some of the epidemics is small. Using a hedonic price model, we can include over 1000 transaction prices within six months of an epidemic. A disadvantage of this approach is that the data provide very little information on housing quality beyond location, implying estimates contain significant noise.

\footnotetext{
${ }^{23}$ See Durbin and Koopman (2012) for more details on the local linear trend model. The model has been estimated by the STAMP software for State Space Models.
} 
The hedonic price model is given by:

$$
\ln P_{i, t}=\alpha+\mu_{t}+x_{i, t}^{\prime} \beta+\varepsilon_{i, t},
$$

where $\mu_{t}$ is the log price index, $x_{i, t}$ is a vector of control variables, and $\varepsilon_{i, t}$ is the error term with zero mean and variance $\sigma_{\epsilon}^{2}$. Control variables are street fixed effects and very crude descriptions of the property, like the presence of a building, a garden, a shop, etcetera. In total, we have 25 property related dummy variables. We use identical variables for the plague as in the repeat sales model.

Table 7.6: Estimation Results Price Responses Amsterdam, Hedonic Price Model

\begin{tabular}{lccc}
\hline \hline & \multicolumn{3}{c}{ Dependent variable: } \\
\cline { 2 - 4 } & \multicolumn{3}{c}{$\ln P_{i, t}$} \\
\hline Plague & -0.085 & -0.088 & -0.088 \\
Plague.L6M & $(0.044)$ & $(0.046)$ & $(0.051)$ \\
& & -0.009 & -0.0095 \\
Plague.L12M & & $(0.046)$ & $(0.056)$ \\
& & & -0.001 \\
Foreclosure Sale & 0.024 & 0.024 & 0.024 \\
& $(0.014)$ & $(0.014)$ & $(0.014)$ \\
\hline Adj. R ${ }^{2}$ & 0.501 & 0.501 & 0.501 \\
$\sigma_{\varepsilon}$ & 0.827 & 0.827 & 0.827 \\
\hline Constant & \multicolumn{3}{c}{ Yes } \\
Year FE & \multicolumn{3}{c}{ Yes } \\
Month FE & \multicolumn{3}{c}{ Yes } \\
Hedonic Controls & \multicolumn{3}{c}{133,123} \\
Observations & \multicolumn{3}{c}{$1600-1811$} \\
Sample Period &
\end{tabular}

Notes: Standard errors are reported between parentheses.

The results of the hedonic price model are reported in Table 7.6. In general, the plague variables in the hedonic price model are similar, but slightly smaller and less significant compared to the ones in the repeat sales model. The estimated effect is about minus $9 \%$ (significant at the 10 percent level). The weaker significant is unsurprising because the hedonic price model is less precisely estimated than the repeatsales model (i.e. the high $\sigma_{\varepsilon}$ relative to Table 7.2). 


\section{Chapter 8}

\section{Summary of Findings}

Inspired by the challenges faced by modern housing markets, the chapters of this dissertation exploit the long course of history to create a better understanding of the dynamics in modern housing markets. The first set of studies does so by obtaining and analyzing new data on the evolution of housing rents (Chapter 2), affordability (Chapter 3), and housing returns (Chapter 4). The second set of studies uses specific episodes in history to study phenomena that are hard to understand on the basis of modern, shorter-term data (Chapters 5 to 7 ). In this section, I will briefly summarize the results of each of these studies.

Chapters 2 and 3 combine the investor and tenant perspective on housing to study one of the most significant challenges in urban housing markets: the development of housing rents and their affordability in large cities around the world. Chapter 2 focuses on the evolution of housing rents as income to investors. Based on a dataset of 436,000 rent observations covering rents in seven cities; Amsterdam, Antwerp, Bruges, Brussels, Ghent, London, and Paris, we present new indices of housing rents dating back to 1500. Long-term growth in real rental prices has been limited but has differed substantially across cities. While modern global cities like Paris and London experienced substantial real rental price growth of $0.3 \%$ per year, cities such as Ghent and Bruges, which lost their important status, did not experience long-term real rental price growth for half a millennium. Focusing on returns of high-growth cities thus provides biased estimates of future rental returns.

Chapter 3 analyzes these issues from the perspective of a tenant and studies the long-term development of housing affordability, housing quality, and housing inequality. In the period before 1900, we show that markets were unregulated and that rent prices and wages rose in tandem when cities grew, while housing quality and inequality increased. After 1900, housing affordability started improving substantially, and we show that short-term improvements in this period were partially attributable to rent controls. Most of the surge in housing expenditure that did occur over time is due to increasing housing quality rather than rising rent. In the past decades, urban housing has been more affordable than at any other time in history.

Chapter 4 retakes a pure investor perspective and provides the first evidence of the 
actual rate of return and risk to residential real estate, both at the aggregate level and at the property level. It employs hand-collected archival data for Paris (1809-1942) and Amsterdam (1900-1979), combining microdata on rents, transaction prices, and assessed values for the same homes, as well as information about property-level taxes and costs. In all, this amounted to over 170,000 observations of rents, prices, or taxes, covering about 40,000 properties. Over the period of study, the real geometric total return to housing, net of costs and taxes, was 4.0 percent per year for Paris and 4.8 percent for Amsterdam. All real long-term total returns originate from net rental yields. At the property-level, the yield at purchase is an essential determinant of the total gross holding period return, even for longer holding periods. In the short-term, idiosyncratic risk is the dominant component of total risk, but this reduces to about 50 percent for holding periods of up to 20 years.

Rather than focusing on risk and return only, Chapter 5 investigates the impact of investor demand on house prices, specifically focusing on whether investors 'reach for yield' when interest rates are low. This chapter exploits the setting of $17^{\text {th }}-18^{\text {th }}$ century Amsterdam, using newly-collected archival data on 164,067 property transactions and 25,962 investment portfolios. In this period, Holland was often drawn into expensive warfare abroad. Wars were uncorrelated to the Amsterdam economy, but exogenously increased the supply of Holland bonds, which investors bought for a stable income. These shocks caused large booms and busts in house prices, while bond yields only changed by small amounts. Housing cycles were amplified because wealthy investors reached for yield, actively purchasing higher-yielding assets in periods of peace when interest rates declined. For the top $1 \%$ of society, a $1 \%$ reduction in bond yields increased the share of wealth in real estate by $12 \%$. This reach for yield reduced risk premia and resulted in a persistent increase in housing wealth inequality.

Chapter 6 studies how population aging and urbanization affect housing markets. This chapter exploits historical demographic shocks to identify the causal effect of urban demographic change on housing costs, building on half a millennium of data on house prices, rents, and demographics from Paris and Amsterdam. We show that a one percentage point increase in the current five-year birth rate increases house prices about 25 years later by 5\%, but reduces prices 60-65 years later by the same amount. These changes are primarily driven by the age-dependent demand for housing as investment asset: we find large impacts of demographic structure on rental yields, but smaller and less significant impacts on bond yields and rent prices.

Chapter 7 studies how housing markets respond to the outbreak of major epidemics. It answers this question by analyzing unique transaction and mortality data around historical outbreaks of the plague in Amsterdam and cholera in Paris. We document that these outbreaks had a significant negative impact on house prices, but a smaller impact on rent prices. We find particularly large reductions in house prices during the first six months of an epidemic, as well as in heavily-affected areas. However, these price shocks were only transitory, and both cities quickly reverted to their initial price paths. Our findings suggest that urban housing markets are very resilient to major shocks originating from pandemics, even if they result in a substantial number of deaths. 


\section{Chapter 9}

\section{Research Impact}

The title and very first page of this dissertation reads "Financial Lessons from the Long History of Housing Markets." To close the circle, this final chapter aims to conclude with the lessons that can be drawn from the past and their relevance for modern society. Housing is important for many different actors in society. For households, a house is a place to live and an investment for the future. For investors, real estate is the largest investable asset class, whose risks and returns are not yet fully understood. For policymakers, housing is important both because the status of the housing market is closely linked to the state of the macro-economy, and because housing markets are a significant contributor to economic opportunity and inequality. My dissertation contains important lessons for each of these groups.

\subsection{Lessons for Households}

With housing rents and prices rising substantially in cities, many households feel that urban housing affordability is quickly deteriorating. To some extent, the findings of Chapter 2 and Chapter 3 confirm this sentiment. In the $21^{\text {st }}$ century, housing affordability has stagnated or worsened in nearly all of the cities studied in these chapters, as rent prices continued to increase while real wage growth stagnated. However, over the long-term, urban households are still in a very favorable position. On average, real rent prices today are comparable to their levels in 1900, but given the enormous improvements in wages and the reduction in income inequality, households today can afford to buy or rent much larger and better quality housing than at any time in history. This holds even in cities like Paris or London, which are often considered to be extremely expensive. So one important lesson for households is that their housing expenses have primarily increased because of rising housing quality, and not because of rising rent prices.

Yet at the same time, we cannot neglect that improvements in urban affordability and housing quality appear to have halted in recent years, in particular due to the growing popularity of cities. This is not inconsistent with the historical record, as Chapter 2 shows that urban population growth coincided with significant increases in 
rental costs over time. Historically, cities responded to increasing populations and rising housing costs with significant urban expansions. This allowed both to house more inhabitants and to limit increases in housing rents. Limited rental price growth could further support future population growth. As a result, real housing rents have therefore only increased in limited amounts over the long run, even in cities that grew enormously (Chapter 2). Nowadays, the use of strict planning regulations has often hampered housing expansion and driven up housing costs (Glaeser and Gyourko, 2018). If supply adjusts, rent price increases will level off or even reverse. Thus, household support for housing supply expansion is crucial.

There might be other reasons why households could see their cost of housing change over time. Chapter 6 shows that changes in demographic structure have robust and predictive impacts on the cost of housing, with the impact being particularly large on house prices. Throughout the long course of history, cities with comparatively large cohorts of young people have consistently experienced large house price increases, whereas large cohorts of older people resulted in price declines. This suggests that population aging might reduce house price growth in the coming decades.

Finally, Chapter 7 addresses a question that is currently very high on the household agenda: how will the coronavirus impact the housing market? Our findings suggest that epidemics exert little influence on the development of housing rents, but do result in significant but short-lived declines in house price growth.

\subsection{Lessons for Policymakers}

These lessons for households are also relevant for policymakers, who can exert much more control over the supply of housing. To a large extent, the findings of this thesis support the long-familiar adage in housing economics that housing supply matters. The lesson is simple: policymakers should make sure we build enough homes, and the current COVID-19 crisis is not making that any less relevant (Chapter 7). But there are other valuable and more novel lessons to be learned. First of all, Chapter 3 shows that unregulated urban growth results in increased housing inequality. When cities grow, rental prices of cheaper housing appreciate at faster rates than those of more expensive housing. Beyond this inequality in prices, inequality in housing consumption increases as well. Thus, if markets are unregulated, urban growth will likely result in increasing inequality. Existing research has shown such inequalities might have important consequences for social mobility (Chetty and Hendren, 2018a,b).

A second issue that is currently very high on the policy agenda is the regulation of investors in the housing market. Investors are increasingly buying real estate, but the causes and consequences of this behavior have not yet been documented. One channel that is often highlighted in these debates, but not yet identified, is the role of reach for yield motives among investors. Chapter 5 shows that in periods with exogenously low interest rates, wealthy investors increasingly reach for yield in real estate, and likely also in other assets. There are three policy-relevant lessons to be drawn from this finding. First, reach for yield behavior is not restricted to institutions but 
also prevalent among individual investors investing for themselves. Reach for yield behavior becomes increasingly prominent among investors for whom capital is an important source of total income, in particular if this income is strongly exposed to fluctuations in yields. This suggests that reaching for yield results from individual preferences, rather than from misalignment between the incentives in the financial industry and the preferences of the investors whose money they manage. It also implies that limiting competitive pressures in industry may not eradicate search for yield behavior. Second, my findings indicate that reach for yield behavior might amplify boom-bust cycles in house prices. Since housing market volatility might have significant implications for the aggregate economy, as highlighted during the recent crisis, monetary policymakers might need to consider reach for yield motives in setting interest rates. Third, because reaching for yield drives up house prices, and is particularly prominent among wealthy investors, it increases housing wealth inequality. During a reach-for-yield boom, investors increasingly purchase the property from less wealthy investors. These changes in the distribution of housing wealth might have important consequences for future wealth inequality and dynamics within cities.

A final policy-relevant lesson is that housing booms and busts are of all times. For as long as we have written history, crisis and boom periods have occurred, and it would be hard to believe that we can entirely prevent a future crisis from happening. After the recent financial crisis, policymakers have put significant emphasis on restricting the expansion of mortgage credit, which played an important role in the spread of the 2007-2008 financial crisis. Chapter 5 shows that such measures are not a sufficient condition to prevent future crises from happening: $17^{\text {th }}-18^{\text {th }}$ century Amsterdam experienced several major housing crises, despite having a negligible market for private credit. The important lesson here is that a credit boom is not a necessary condition for a housing boom (and bust).

\subsection{Lessons for Investors}

This thesis contains important lessons for investors, particularly for investors that have long-term horizons, such as pension funds and sovereign wealth funds, but also for individuals that try to support their income with housing market investments.

One lesson important for each of these groups is the realization that all real housing returns over the long term accumulate from rental cash flows rather than capital gains (Chapters 2 and 4).Even in nominal terms, capital gains only form a small fraction of total returns. Of course, capital gains move substantially over the short-term due to changes in interest rates and expectations of future rental growth, but over the long-term, these changes are of minor relevance.

The importance of rental cash flows for housing returns also implies that it is of crucial importance that investors make sensible assessments of their growth over the long-term. Most evidence on long-term rental- or house price growth typically comes from cities that have been very successful in the past. However, Chapter 2 shows that looking at such cities only will induce a 'survivorship bias' in return estimates since 
cities do not keep growing forever, and some even reduce in importance over time. This is particularly important for the future as urbanization is expected to slow down. The evidence in Chapter 2 shows that cities without substantial growth have not experienced any long-term real rental growth. This might be a more realistic prediction for the future.

The importance of rents might be even higher for long-term investors that hold concentrated real estate portfolios. The typical investor in the housing market owns only one or just a few properties, implying significant exposure to idiosyncratic risks. Chapter 4 shows that idiosyncratic risk is the main component of total risk for holding periods of up to twenty years, while reducing gradually in importance over time. At the same time, the rental yield at the time of purchase is an essential predictor of the total return over the holding period. Thus, property investors should look carefully at their yields at purchase, and compare them to the yields in the market, in order to avoid losing significant amounts of money.

Finally, Chapter 6 documents there are substantial predictive components in housing markets due to changes in the demographic structure of populations. Investors could benefit from these predictive changes by purchasing rental properties before a large cohort of young adults enters the market. This could earn these investors both higher rents and significant short-term capital gains. 


\section{Bibliography}

Abel, A. B. (2001). Will bequests attenuate the predicted meltdown in stock prices when baby boomers retire? Review of Economics and Statistics, 83(4):589-595.

Abel, A. B. (2003). The effects of a baby boom on stock prices and capital accumulation in the presence of social security. Econometrica, 71(2):551-578.

Abrahamse, J. E. (2010). De grote uitleg van Amsterdam: stadsontwikkeling in de zeventiende eeuw. Thoth.

Abrahamse, J. E., Deneweth, H., Kosian, M., and Schmitz, E. (2015). Gouden kansen? Vastgoedstrategieën van bouwondernemers in de stadsuitleg van Amsterdam in de Gouden Eeuw. Bulletin KNOB, pages 229-257.

Abramitzky, R., Boustan, L. P., Eriksson, K., Feigenbaum, J. J., and Pérez, S. (2019). Automated linking of historical data. NBER Working Paper.

ADIL (2009). La part du loyer dans le budget des menages parisiens. http://www . lefigaro.fr/assets/pdf/bourse-patrimoine/immoadil.pdf.

Administration Générale de l'Assistance Publique (1850). Rapport sur les épidémies cholériques de 1832 et de 1849: dans les établissements dépendant de l'Administration générale de l'assistance publique de la ville de Paris. Paul Dupont.

Aladangady, A., Albouy, D., and Zabek, M. (2017). Housing inequality. NBER Working Paper.

Albertazzi, U., Becker, B., and Boucinha, M. (2018). Portfolio rebalancing and the transmission of large-scale asset programmes: evidence from the euro area. $E C B$ Working Paper.

Alfani, G. (2013). Plague in seventeenth-century Europe and the decline of Italy: an epidemiological hypothesis. European Review of Economic History, 17(4):408-430.

Alfani, G. and Percoco, M. (2019). Plague and long-term development: The lasting effects of the 1629-30 epidemic on the Italian cities. The Economic History Review, 72(4):1175-1201. 
Allen, M. T., Rutherford, J., Rutherford, R., and Yavas, A. (2018). Impact of investors in distressed housing markets. Journal of Real Estate Finance and Economics, 56(4):622-652.

Allen, R. C. (2001). The great divergence in European wages and prices from the Middle Ages to the First World War. Explorations in Economic History, 38(4):411-447.

Almagro, M., Coven, J., Gupta, A., and Orane-Hutchinson, A. (2020). Racial disparities in frontline workers and housing crowding during COVID-19: Evidence from geolocation data.

Ambrose, B. W., Coulson, N. E., and Yoshida, J. (2015). The repeat rent index. Review of Economics and Statistics, 97(5):939-950.

Ambrose, B. W., Eichholtz, P., and Lindenthal, T. (2013). House prices and fundamentals: 355 years of evidence. Journal of Money, Credit and Banking, 45(2-3):477-491.

Ambrus, A., Field, E., and Gonzalez, R. (2020). Loss in the time of cholera: Long-run impact of a disease epidemic on the urban landscape. American Economic Review, 110(2):475-525.

Ammer, J., Claessens, S., Tabova, A., and Wroblewski, C. (2019). Home country interest rates and international investment in us bonds. Journal of International Money and Finance, 95:212-227.

Andonov, A., Bauer, R. M., and Cremers, K. (2017). Pension fund asset allocation and liability discount rates. Review of Financial Studies, 30(8):2555-2595.

Annaert, J., Buelens, F., and Deloof, M. (2015). Long-run stock returns: evidence from Belgium 1838-2010. Cliometrica, 9(1):77-95.

Arbulu, P. (1998). La bourse de Paris au XIXème siecle: l'exemple d'un marche émergent devenu efficient. Revue d'économie financière, pages 213-249.

Arnott, R. (1995). Time for revisionism on rent control? Journal of Economic Perspectives, 9(1):99-120.

Autor, D. H., Palmer, C. J., and Pathak, P. A. (2014). Housing market spillovers: Evidence from the end of rent control in Cambridge, Massachusetts. Journal of Political Economy, 122(3):661-717.

Avondts, G. (1971). De huishuren te Brussel, 1500-1800.

Avondts, G. and Scholliers, P. (1977). Gentse prijzen, huishuren en budgetonderzoeken in de 19 e en 20e eeuw. Brussel, BE: VUB.

Badarinza, C. and Ramadorai, T. (2018). Home away from home? Foreign demand and London house prices. Journal of Financial Economics, 130(3):532-555. 
Baer, W. C. (2014). Using housing quality to track change in the standard of living and poverty for seventeenth-century London. Historical Methods: A Journal of Quantitative and Interdisciplinary History, 47(1):1-18.

Baetens, R. (1976). De Nazomer van Antwerpens welvaart: de diaspora en het handelshuis De Groote tijdens de eerste helft der 17de eeuw: prijs geschiedenis 1972 van het Gemeentekrediet. Boekdeel II. Brussel, BE: Gemeentekrediet van België.

Bailey, M. J., Muth, R. F., and Nourse, H. O. (1963). A regression method for real estate price index construction. Journal of the American Statistical Association, 58(304):933-942.

Banque Nationale de Belgique (1980). Statistiques économiques belges, 1970-1980. Brussel, BE: Departement d'études et de documentation.

Baron de Larrey, D. J. (1831). Mémoire sur le choléra-morbus. Imprimerie de Mme. Huzard (née Vallat la Chapelle).

Baum-Snow, N. and Pavan, R. (2013). Inequality and city size. Review of Economics and Statistics, 95(5):1535-1548.

Bayet, A. (1997). Deux siècles d'évolution des salaires en France. Insee Staff Report.

Becker, B. and Ivashina, V. (2015). Reaching for yield in the bond market. Journal of Finance, 70(5):1863-1902.

Becker, G. S. (1960). An economic analysis of fertility. In Demographic and economic change in developed countries, pages 209-240. Columbia University Press.

Bernanke, B. S., Bertaut, C. C., Demarco, L., and Kamin, S. B. (2011). International capital flows and the return to safe assets in the United States, 2003-2007. FRB International Finance Discussion Paper, no. 1014.

Bernanke, B. S. et al. (2005). The global saving glut and the US current account deficit. NBER Working Paper.

Bettendorf, L. and Buyst, E. (1997). Rent control and virtual prices: A case study for interwar Belgium. Journal of Economic History, 57(3):654-673.

Biraben, J. and Blanchet, D. (1999). Essay on the population of Paris and its vicinity since the sixteenth century. Population (English selection), 11(1):155-188.

Bleakley, H. and Lin, J. (2012). Portage and path dependence. Quarterly Journal of Economics, 127(2):587-644.

Boerner, L., van Bochove, C., and Quint, D. (2016). Anglo-Dutch premium auctions in eighteenth-century Amsterdam. SSRN Working Paper no. 2001074.

Bonneval, L. (2011). Le contrôle des loyers empêche-t-il l'investissement dans l'immobilier? Metropolitics Blog. 
Bordalo, P., Gennaioli, N., and Shleifer, A. (2012). Salience theory of choice under risk. Quarterly Journal of Economics, 127(3):1243-1285.

Borjas, G. J. (2020). Demographic determinants of testing incidence and COVID-19 infections in New York city neighborhoods. NBER Working Paper.

Bourillon, F. (2008). De l'estime au cadastre. Les systèmes cadastraux aux XIXe et XXe siècles, chapter A propos de la représentativité du cadastre, les contributions directes et le cadastre parisien au XIXe siècle. Paris.

Bracke, P. (2015). House prices and rents: microevidence from a matched data set in Central London. Real Estate Economics, 43(2):403-431.

Bracke, P. (2019). How much do investors pay for houses? Real Estate Economics, forthcoming.

Bracke, P., Pinchbeck, E. W., and Wyatt, J. (2018). The Time Value of Housing: Historical Evidence on Discount Rates. Economic Journal, 128(613):1820-1843.

Brakman, S., Garretsen, H., and Schramm, M. (2004). The strategic bombing of german cities during world war ii and its impact on city growth. Journal of Economic Geography, 4(2):201-218.

Brandon, P. (2015). War, Capital, and the Dutch State (1588-1795). Brill.

Brandon, P. (2018). The whole art of war is reduced to money: remittances, short-term credit and financial intermediation in Anglo-Dutch military finance, 1688-1713. Financial History Review, 25(1):19-41.

Broadberry, S., Campbell, B. M., Klein, A., Overton, M., and Van Leeuwen, B. (2015). British economic growth, 1270-1870. Cambridge University Press, Cambridge, UK.

Brounen, D., Eichholtz, P., Straetmans, S., and Theebe, M. A. J. (2014). Inflation protection from homeownership: Long-run evidence, 1814-2008. Real Estate Economics, 42(3):662-689.

Brown, L. N. (1970). Comparative rent control. International \& Comparative Law Quarterly, 19(2):205-216.

Brown, S. J., Goetzmann, W., Ibbotson, R. G., and Ross, S. A. (1992). Survivorship bias in performance studies. Review of Financial Studies, 5(4):553-580.

Buyst, E. (1992). An economic history of residential building in Belgium between 1890 and 1961. Koninklijke Academie voor Letteren, Wetenschappen en Schone Kunsten.

Callen, M., Isaqzadeh, M., Long, J. D., and Sprenger, C. (2014). Violence and risk preference: Experimental evidence from Afghanistan. American Economic Review, 104(1):123-48. 
Cambridge Dictionary (2018). Cambridge Online Dictionary. Cambridge University Press, Cambridge, UK.

Cameron, L. and Shah, M. (2015). Risk-taking behavior in the wake of natural disasters. Journal of Human Resources, 50(2):484-515.

Campbell, J. Y. (2017). Financial decisions and markets: a course in asset pricing. Princeton University Press.

Campbell, J. Y. and Cochrane, J. H. (1999). By force of habit: A consumption-based explanation of aggregate stock market behavior. Journal of Political Economy, 107(2):205-251.

Campbell, J. Y., Giglio, S., and Pathak, P. (2011). Forced sales and house prices. American Economic Review, 101(5):2108-31.

Campbell, J. Y. and Sigalov, R. (2020). Portfolio choice with sustainable spending: A model of reaching for yield. Technical report, National Bureau of Economic Research.

Campbell, S. D., Davis, M. A., Gallin, J., and Martin, R. F. (2009). What moves housing markets: A variance decomposition of the rent-price ratio. Journal of Urban Economics, 66(2):90-102.

Cantoni, D. and Yuchtman, N. (2020). Historical natural experiments: Bridging economics and economic history. NBER Working Paper.

Carter, A. (1953). Dutch foreign investment, 1738-1800. Economica, 20(80):322-340.

Case, K. E. and Shiller, R. J. (1987). Prices of single-family homes since 1970: new indexes for four cities. New England Economic Review, (9):45-56.

Case, K. E. and Shiller, R. J. (1989). The efficiency of the market for single-family homes. American Economic Review, 79(1):125-137.

Cassiers, I. and Solar, P. (1990). Wages and productivity in Belgium, 1910-60. Oxford Bulletin of Economics and Statistics, 52(4):437-449.

Cau, C., van Leeuwen, S., Scheltus, J., Scheltus, P., and Scheltus, I. (1658). Groot placaet-boeck, vervattende de placaten, ordonnantien ende edicten van de doorluchtige, hoogh mog. heeren Staten Generael der Vereenighde Nederlanden ende vande ed. groot-mog. heeren Staten van Hollandt en West-Vrieslandt, mits-gaders vande ed. mog. heeren Staten van Zeelandt, volume 1-9. Johannes Allart.

CGEDD (2018). Indices du prix de l'immobilier résidentiel à paris depuis 1200. http://www.cgedd.developpement-durable.gouv.fr/ prix-immobilier-evolution-a-long-terme-a1048.html. 
Chambers, D., Spaenjers, C., and Steiner, E. (2020). The rate of return on real estate: Long-run micro-level evidence. HEC Paris Research Paper No. FIN-2019-1342.

Charlot, E. and Dupâquier, J. (1967). Mouvement annuel de la population de la ville de Paris de 1670 à 1821. Annales de Démographie Historique, pages 511-519.

Chetty, R. and Hendren, N. (2018a). The impacts of neighborhoods on intergenerational mobility i: Childhood exposure effects. Quarterly Journal of Economics, 133(3):1107-1162.

Chetty, R. and Hendren, N. (2018b). The impacts of neighborhoods on intergenerational mobility ii: County-level estimates. Quarterly Journal of Economics, 133(3):1163-1228.

Chinco, A. and Mayer, C. (2015). Misinformed speculators and mispricing in the housing market. Review of Financial Studies, 29(2):486-522.

Chodorow-Reich, G. (2014). Effects of unconventional monetary policy on financial institutions. Brookings Papers on Economic Activity, 2014(1):155-227.

Choi, J. and Kronlund, M. (2017). Reaching for yield in corporate bond mutual funds. Review of Financial Studies, 31(5):1930-1965.

Claeys, R. (1921). L'Indice du cout de la vie du bureau statistique de la ville d'Amsterdam. Revue d'économie politique, 35(2):165-182.

Clark, G. (2002). Shelter from the storm: Housing and the industrial revolution, 15501909. Journal of Economic History, 62(2):489-511.

Clark, G. and Cummins, N. (2009). Urbanization, mortality, and fertility in Malthusian England. American Economic Review, 99(2):242-247.

Cohn, A., Engelmann, J., Fehr, E., and Maréchal, M. A. (2015). Evidence for countercyclical risk aversion: An experiment with financial professionals. American Economic Review, 105(2):860-85.

Collin-Dufresne, P., Johannes, M., and Lochstoer, L. A. (2017). Asset pricing when 'this time is different'. Review of Financial Studies, 30(2):505-535.

Combes, P.-P., Duranton, G., and Gobillon, L. (2019). The costs of agglomeration: House and land prices in French cities. Review of Economic Studies.

Cosemans, A. (1966). Bijdrage tot de demografische en sociale geschiedenis van de stad Brussel: 1796-1846. Brussels, BE: Crédit communal de Belgique.

Curtis, D. R. (2016). Was plague an exclusively urban phenomenon? Plague mortality in the seventeenth-century Low Countries. Journal of Interdisciplinary History, 47(2):139-170. 
Cvijanovic, D. and Spaenjers, C. (2018). 'We'll always have Paris': Out-of-country buyers in the housing market. Kenan Institute of Private Enterprise Research Paper, (1825).

Dambruyne, J. (2001). Mensen en centen: Het 16de-eeuwse Gent in demografisch en economisch perspectief, volume 26. Gent, BE: Maatschappij voor Geschiedenis en Oudheidkunde.

Daumard, A. (1958). Paris et les archives de l'Enregistrement. Annales ESC, 13(2):289303.

Daumard, A. (1965). Maisons de Paris et propriétaires parisiens au XIXe siècle, 18091880. Cujas, Paris.

Davis, D. R. and Weinstein, D. E. (2002). Bones, bombs, and break points: the geography of economic activity. American Economic Review, 92(5):1269-1289.

De Belder, J. (1977). De behuizing te Antwerpen op het einde van de xviiie eeuw. Belgisch Tijdschrift voor Nieuwe Geschiedenis, 8:367-447.

De Châteauneuf, L.-F. B. (1834). Rapport sur la marche et les effets du choléra-morbus dans Paris et les communes rurales du département de la Seine, année 1832. Imprimerie royale.

De Jong, J. J. (1985). Met goed fatsoen: de elite in een Hollandse stad, Gouda 1700-1780, volume 5. De Bataafsche Leeuw.

De Vries, J. (1981). Barges and capitalism: passenger transportation in the Dutch economy, 1632-1839, volume 4. Utrecht: HES Publishers.

De Vries, J. (2008). The industrious revolution: consumer behavior and the household economy, 1650 to the present. Cambridge University Press, Cambridge, UK.

De Vries, J. and Van der Woude, A. (1997). The first modern economy: Success, failure, and perseverance of the Dutch economy, 1500-1815. Cambridge University Press.

DeFusco, A. A., Nathanson, C. G., and Zwick, E. (2017). Speculative dynamics of prices and volume. NBER Working Paper.

DellaVigna, S. and Pollet, J. M. (2007). Demographics and industry returns. American Economic Review, 97(5):1667-1702.

Deneweth, H. (2010). Een demografische knoop ontward? Brugse bevolkingscijfers voor de vroegmoderne tijd. Handelingen van het Genootschap voor Geschiedenis, $147: 3-48$.

Département de la Seine (1890). Les propriétés bâties de la ville de Paris en 1889 et en 1890. Paris. 
Département de la Seine (1901). Le livre foncier de 1901. Paris.

Département de la Seine (1911). Le livre foncier de 1911. Paris.

Deprez, P. (1957). Het Gentse bevolkingscijfer in de tweede helft van de achttiende eeuw. Handelingen der Maatschappij voor Geschiedenis en Oudheidkunde te Gent, $11(1)$.

Derks, J. F. A. (1933). De waarde van aandeelen en obligaties als object van belegging. Uitgeverij Lumax - Utrecht.

Desmond, M. and Wilmers, N. (2019). Do the poor pay more for housing? Exploitation, profit, and risk in rental markets. American Journal of Sociology, 124(4):1090-1124.

Dettling, L. J. and Kearney, M. S. (2014). House prices and birth rates: The impact of the real estate market on the decision to have a baby. Journal of Public Economics, 110:82-100.

Devaney, S. (2010). Trends in office rents in the city of london: 1867-1959. Explorations in Economic History, 47(2):198-212.

Di Maggio, M. and Kacperczyk, M. (2017). The unintended consequences of the zero lower bound policy. Journal of Financial Economics, 123(1):59-80.

Diamond, R., McQuade, T., and Qian, F. (2019). The effects of rent control expansion on tenants, landlords, and inequality: Evidence from San Francisco. American Economic Review, 109(9):3365-94.

Dimson, E., Marsh, P., and Staunton, M. (2009). Triumph of the optimists: 101 years of global investment returns. Princeton University Press.

Dimson, E., Marsh, P. R., and Staunton, M. (2018). Credit Suisse Global Investment Returns Yearbook 2018. Credit Suisse Research Institute.

Dormans, E. H. M. (1991). Het tekort: staatsschuld in de tijd der Republiek. Neha.

Downs, A. (1988). Residential rent controls. Washington, DC: Urban Land Institute.

Driscoll, J. C. and Kraay, A. C. (1998). Consistent covariance matrix estimation with spatially dependent panel data. Review of Economics and Statistics, 80(4):549-560.

Dröes, M., Houben, A., and Van Lamoen, R. (2017). De prijsstijgingen op de Amsterdamse huizenmarkt onder de loep. Economisch-Statistische Berichten, 102.

Dröes, M. I. and Francke, M. K. (2017). What causes the price-turnover correlation in European housing markets? Journal of Real Estate Finance and Economics, pages 1-29.

Duon, G. (1943). Evolution de la valeur vénale des immeubles parisiens. Journal de la Société Française de Statistique, 84:169-192. 
Duon, G. (1946). Documents sur le problème du logement à Paris. Ministère de l'économie. Service national des statistiques. Direction de la statistique générale, Paris.

Durbin, J. and Koopman, S. J. (2012). Time Series Analysis by State Space Methods. Oxford University Press, second edition.

Eeckhout, J., Pinheiro, R., and Schmidheiny, K. (2014). Spatial sorting. Journal of Political Economy, 122(3):554-620.

Eichholtz, P. (1997). A long run house price index: The Herengracht index, 1628-1973. Real Estate Economics, 25(2):175-192.

Eichholtz, P., Koedijk, K., and Otten, R. (2000). De eeuw van het aandeel. EconomischStatistische Berichten, 85(4238):24-24.

Eichholtz, P. and Lindenthal, T. (2014). Demographics, human capital, and the demand for housing. Journal of Housing Economics, 26:19-32.

Eichholtz, P. M. A., Korevaar, M., and Lindenthal, T. (2020a). 500 years of housing affordability, quality and inequality. Mimeo.

Eichholtz, P. M. A., Korevaar, M., and Lindenthal, T. (2020b). 500 years of housing rents. Mimeo.

Eichholtz, P. M. A., Korevaar, M., and Lindenthal, T. (2020c). The total return and risk to residential real estate. SSRN Working Paper no. 3549278.

Eiling, E., Giambona, E., Lopez Aliouchkin, R., and Tuijp, P. (2019). Homeowners' risk premia: Evidence from zip code housing returns. SSRN Working Paper no. 3312391.

Eisfeldt, A. and Demers, A. (2018). Total returns to single family rentals. NBER Working Paper No. 21804.

Eitrheim, Ø. and Erlandsen, S. K. (2004). House price indices for Norway 1819-2003. Historical Monetary Statistics for Norway 1819-2003, page 349.

Ellickson, R. C. and Le Bris, D. (2019). The damage inflicted by French rent controls between 1914 and 1948. Metropolitics Blog, February, 26.

Engelhardt, G. V. and Poterba, J. M. (1991). House prices and demographic change. Regional Science and Urban Economics, 21(4):539-546.

Faure, A. and Lévy-Vroelant, C. (2007). Une chambre en ville. Hôtels meublés à Paris, 1860-1990. Creaphis, Grane.

Favara, G. and Imbs, J. (2015). Credit supply and the price of housing. American Economic Review, 105(3):958-92. 
Favilukis, J., Ludvigson, S. C., and Van Nieuwerburgh, S. (2017). The macroeconomic effects of housing wealth, housing finance, and limited risk sharing in general equilibrium. Journal of Political Economy, 125(1):140-223.

Feenstra, H. A. (2018). Between shared and conflicting interests: The political economy of the markets for public debt in the Dutch Republic, 1600-1795. PhD Dissertation.

Félibien, M. (1725). Histoire de la ville de Paris, volume 4. Paris, FR: Guillaume Desprez.

Ferguson, N., Laydon, D., Nedjati-Gilani, G., et al. (2020). Impact of nonpharmaceutical interventions (npis) to reduce covid-19 mortality and healthcare demand.

Fischel, W. A. (2004). An economic history of zoning and a cure for its exclusionary effects. Urban Studies, 41(2):317-340.

Fishback, P. and Kollmann, T. (2014). New multicity estimates of the changes in home values, 1920-1940. In Housing and Mortgage Markets in Historical Perspective, pages 203-244. University of Chicago Press.

Fishback, P. V., Flores-Lagunes, A., Horrace, W. C., Kantor, S., and Treber, J. (2010). The influence of the home owners' loan corporation on housing markets during the 1930s. Review of Financial Studies, 24(6):1782-1813.

Flavin, M. and Yamashita, T. (2002). Owner-occupied housing and the composition of the household portfolio. American Economic Review, 92(1):345-362.

Florida, R. (2017). The new urban crisis: gentrification, housing bubbles, growing inequality, and what we can do about it. Oneworld Publications.

FOD-WASO (2018). Indexcijfer van de conventionele lonen. http://www. werk. belgie. be/moduleDefault . aspx?id=7390.

Fogli, A. and Guerrieri, V. (2019). The end of the American dream? Inequality and segregation in US cities. Technical report, National Bureau of Economic Research.

Frame, W. S. and Steiner, E. (2018). Unconventional monetary policy and risk-taking: Evidence from agency mortgage reits. Available at SSRN 3191945.

Francke, M. and Korevaar, M. (2020). Baby booms and asset booms: Demography and the housing market. SSRN Working Paper no. 3368036.

Francke, M. K. (2010). Repeat sales index for thin markets: A structural time series approach. Journal of Real Estate Finance and Economics, 41(1):24-52.

Friedman, M. and Stigler, G. J. (1946). Roofs or ceilings? The current housing problem. Foundation for Economic Education, Irvington-on-Hudson, NY. 
Fritschy, W. (2017). Public Finance of the Dutch Republic in Comparative Perspective: The Viability of an Early Modern Federal State (1570s-1795). Brill.

Fryske Akademy (2018). HISGIS project Amsterdam, Kadaster 1832. http://www . hisgis.nl/hisgis/gewesten/amsterdam/kaart1830/amsterdam1832.

Fu, F. (2009). Idiosyncratic risk and the cross-section of expected stock returns. Journal of Financial Economics, 91(1):24-37.

Gallin, J. (2008). The long-run relationship between house prices and rents. Real Estate Economics, 36(4):635-658.

Garcia, D. (2019). Second home buying and the housing boom and bust. Federal Reserve Working Paper No. 2019-029.

Gatzlaff, D. H. and Ling, D. C. (1994). Measuring changes in local house prices: An empirical investigation of alternative methodologies. Journal of Urban Economics, 35(2):221-244.

Geanakoplos, J., Magill, M., and Quinzii, M. (2004). Demography and the longrun predictability of the stock market. Brookings Papers on Economic Activity, 2004(1):241-325.

Gelderblom, O. and Jonker, J. (2009). With a view to hold: The emergence of institutional investors on the Amsterdam securities market during the seventeenth and eighteenth centuries. The origins and development of financial markets and institutions, page 71 .

Gelderblom, O., Jonker, J., and Hup, M. (2017). Financing in Europe, chapter Public Functions, Private Markets: Credit Registration by Aldermen and Notaries in the Low Countries, 1500-1800. Number 6. Palgrave.

Gelderblom, O. and Jonker, J. P. (2011). Public finance and economic growth. the case of Holland in the seventeenth century. Journal of Economic History, 71(1):1-39.

Geltner, D. (1997). Bias and precision of estimates of housing investment risk based on repeat-sales indices: a simulation analysis. Journal of Real Estate Finance and Economics, 14(1-2):155-171.

Gemeente Amsterdam (1923). Statistiek der bevolking van Amsterdam tot 1921. Müller, Amsterdam.

Gemeente Amsterdam (2018). Statistical yearbooks amsterdam, 1895-2017. https: //www.ois.amsterdam.nl/publicaties/\#.

Gemeente Amsterdam (2019). Amsterdam in cijfers. Bureau Onderzoek en Statistiek, Gemeente Amsterdam. 
Giacoletti, M. (2019). Idiosyncratic risk in housing markets. Working Paper SSRN No. 2995323.

Giglio, S., Maggiori, M., and Stroebel, J. (2015). Very long-run discount rates. Quarterly Journal of Economics, 130(1):1-53.

Giglio, S., Maggiori, M., Stroebel, J., and Weber, A. (2018). Climate change and longrun discount rates: Evidence from real estate. Chicago Booth Research Paper No. 17-22.

Glaeser, E. and Gyourko, J. (2003). The impact of building restrictions on housing affordability. Economic Policy Review, 9(2).

Glaeser, E. and Gyourko, J. (2018). The economic implications of housing supply. Journal of Economic Perspectives, 32(1):3-30.

Glaeser, E. L. (2013). A nation of gamblers: Real estate speculation and American history. American Economic Review, 103(3):1-42.

Glaeser, E. L., Gottlieb, J. D., and Tobio, K. (2012). Housing booms and city centers. American Economic Review, 102(3):127-33.

Glaeser, E. L. and Gyourko, J. (2005). Urban decline and durable housing. Journal of Political Economy, 113(2):345-375.

Glaeser, E. L. and Luttmer, E. F. (2003). The misallocation of housing under rent control. American Economic Review, 93(4):1027-1046.

Glaeser, E. L. and Nathanson, C. G. (2014). Housing bubbles. NBER Working Paper.

Glaeser, E. L. and Nathanson, C. G. (2017). An extrapolative model of house price dynamics. Journal of Financial Economics, 126(1):147-170.

Goetzmann, W. N. (1992). The accuracy of real estate indices: Repeat sale estimators. Journal of Real Estate Finance and Economics, 5(1):5-53.

Goetzmann, W. N., Kim, D., and Shiller, R. J. (2016). Crash beliefs from investor surveys. NBER Working Paper, (w22143).

Goetzmann, W. N. and Spiegel, M. (1995). Non-temporal components of residential real estate appreciation. Review of Economics and Statistics, 77:199-206.

Goldstein, I., Witmer, J., Yang, J., et al. (2018). Following the Money: Evidence for the Portfolio Balance Channel of Quantitative Easing. Bank of Canada.

Golez, B. and Koudijs, P. (2017). Four centuries of return predictability. Journal of Financial Economics.

Gordon, R. J. and VanGoethem, T. (2005). A century of housing shelter prices: Is there a downward bias in the CPI? NBER Working Paper. 
Goyal, A. (2004). Demographics, stock market flows, and stock returns. Journal of Financial and Quantitative Analysis, 39(1):115-142.

Great Britain Board of Trade (1910). Cost of living in Belgian towns. Report of an enquiry by the Board of trade into working class rents, housing and retail prices. London, UK: Darling and Sons, Ltd.

Green, R. and Hendershott, P. H. (1996). Age, housing demand, and real house prices. Regional Science and Urban Economics, 26(5):465-480.

Green, R. K. and Lee, H. (2016). Age, demographics, and the demand for housing, revisited. Regional Science and Urban Economics, 61(May):86-98.

Guerrieri, V., Hartley, D., and Hurst, E. (2013). Endogenous gentrification and housing price dynamics. Journal of Public Economics, 100:45-60.

Guiso, L. and Paiella, M. (2008). Risk aversion, wealth, and background risk. Journal of the European Economic Association, 6(6):1109-1150.

Guiso, L., Sapienza, P., and Zingales, L. (2018). Time varying risk aversion. Journal of Financial Economics, 128(3):403-421.

Gyourko, J. and Linneman, P. (1993). The affordability of the American dream: An examination of the last 30 years. Journal of Housing Research, pages 39-72.

Gyourko, J., Mayer, C., and Sinai, T. (2013). Superstar cities. American Economic Journal: Economic Policy, 5(4):167-99.

Gyourko, J. and Tracy, J. (1999). A look at real housing prices and incomes: Some implications for housing affordability and quality. Federal Reserve Bank of New York Economic Policy Review, 5(3):63.

Hamilton, B. W. (1991). The baby boom, the baby bust, and the housing market: a second look. Regional Science and Urban Economics, 21(4):547-552.

Harding, J. P., Rosenthal, S. S., and Sirmans, C. (2007). Depreciation of housing capital, maintenance, and house price inflation: Estimates from a repeat sales model. Journal of Urban Economics, 61(2):193-217.

Harding, V. (1990). The population of London, 1550-1700: a review of the published evidence. The London Journal, 15(2):111-128.

Hart, S. (1973). Een sociale structuur van de Amsterdamse bevolking in de 18e eeuw. Amstelodamum.

Hart, S. (1976). Geschrift en getal: een keuze uit de demografisch-, economisch-en sociaal-historische studiën op grond van Amsterdamse en Zaanse archivalia, 16001800, volume 9. Historische Vereniging Holland. 
Hau, H. and Lai, S. (2016). Asset allocation and monetary policy: Evidence from the eurozone. Journal of Financial Economics, 120(2):309-329.

Haughwout, A., Lee, D., Tracy, J. S., and Van der Klaauw, W. (2011). Real estate investors, the leverage cycle, and the housing market crisis. FRB of New York Staff Report, (514).

Hautcoeur, P.-C. and Riva, A. (2018). The data for financial history (DFIH) database. http://dfih.fr/.

Heine, H. (1872). Französische zustände, volume 8. Hoffmann und Campe.

Henau, A. (1991). De Belgische huishuren gedurende het interbellum.

Hilber, C. A. and Vermeulen, W. (2016). The impact of supply constraints on house prices in England. Economic Journal, 126(591):358-405.

Hillairet, J. (2004). Dictionnaire historique des rues de Paris. Editions de Minuit, Paris.

Hiller, N. and Lerbs, O. W. (2016). Aging and urban house prices. Regional Science and Urban Economics, 60:276-291.

Himmelberg, C., Mayer, C., and Sinai, T. (2005). Assessing high house prices: Bubbles, fundamentals and misperceptions. Journal of Economic Perspectives, 19(4):67-92.

Hoffman, P. T. (2000). Growth in a Traditional Society: The French Countryside, 14501815. Princeton University Press.

Hoffman, P. T., Jacks, D. S., Levin, P. A., and Lindert, P. H. (2002). Real inequality in Europe since 1500. Journal of Economic History, 62(2):322-355.

Hoffman, P. T., Postel-Vinay, G., and Rosenthal, J.-L. (2001). Priceless Markets: The Political Economy of Credit in Paris, 1660-1870. University of Chicago Press, Chicago.

Holland, A. S. (1991). The baby boom and the housing market: Another look at the evidence. Regional Science and Urban Economics, 21(4):565-571.

Homer, S. and Sylla, R. E. (1996). A history of interest rates. Rutgers University Press.

Horlings, E. and Smits, J. P. (1996). Private consumer expenditure in the Netherlands, 1800-1913. Economic and Social History in the Netherlands, 7:15-40.

Hornbeck, R. and Keniston, D. (2017). Creative destruction: Barriers to urban growth and the great boston fire of 1872. American Economic Review, 107(6):1365-98.

Huurcommissie (2017). Honderd jaar in dienst van huurder en verhuurder. https://www. huurcommissie.nl/fileadmin/afbeeldingen/Downloads/ Over_de_Huurcommissie/HC_Jubileumboek_100_-jarig_bestaan_2017.pdf. 
INSEE (2018). Database official French statistics. https://www.insee.fr/fr/ statistiques.

Jones, D. C. (1928). The cost of living of a sample of middle-class families. Journal of the Royal Statistical Society, 91(4):463-518.

Jordà, O., Knoll, K., Kuvshinov, D., Schularick, M., and Taylor, A. M. (2019a). The rate of return on everything, 1870-2015. Quarterly Journal of Economics, 134(3):1225-1298.

Jordà, O., Schularick, M., and Taylor, A. M. (2019b). The total risk premium puzzle. NBER Working Paper No. 25653.

Kesztenbaum, L. and Rosenthal, J.-L. (2017). Sewers' diffusion and the decline of mortality: The case of Paris, 1880-1914. Journal of Urban Economics, 98:174-186.

Kholodilin, K. A. (2018). Measuring stick-style housing policies: A multi-country longitudinal database of governmental regulations. DIW Berlin Discussion Paper No. 1727.

Knoll, K. (2017). Our Home in Days Gone By: Housing Markets in Advanced Economies in Historical Perspective. PhD thesis, Freie Universität Berlin.

Knoll, K., Schularick, M., and Steger, T. (2017). No price like home: Global house prices, 1870-2012. American Economic Review, 107(2):331-53.

Koijen, R. S., Koulischer, F., Nguyen, B., and Yogo, M. (2018). Inspecting the mechanism of quantitative easing in the euro area. Banque de France Working Paper.

Kooijmans, L. (1985). Onder regenten: de elite in een Hollandse stad, Hoorn 1700-1780. De Bataafsche Leeuw.

Korevaar, M. (2020). Reach for yield and real estate: The impact of investor demand on house prices. Mimeo.

Koudijs, P. (2016). The boats that did not sail: Asset price volatility in a natural experiment. Journal of Finance, 71(3):1185-1226.

Koudijs, P. and Voth, H.-J. (2016). Leverage and beliefs: personal experience and risktaking in margin lending. American Economic Review, 106(11):3367-3400.

Kuijpers, E., Prak, M., Kloek, J., and Tilmans, K. (2002). Burger, ingezetene, vreemdeling. Burgerschap in Amsterdam in de 17e en 18e eeuw. Amsterdam University Press.

Kuo, B. S. (1999). Asymptotics of ML estimator for regression models with a stochastic trend component. Econometric Theory, 15:24-29.

La Spada, G. (2018). Competition, reach for yield, and money market funds. Journal of Financial Economics, 129(1):87-110. 
Laeven, L. and Popov, A. (2017). Waking up from the American dream: on the experience of young americans during the housing boom of the 2000s. Journal of Money, Credit and Banking, 49(5):861-895.

Laloli, H. (2018). Historische databestanden over amsterdam. www. amsterdamhistorie.nl/data.

Landers, J., John, L., et al. (1993). Death and the metropolis: studies in the demographic history of London, 1670-1830, volume 20. Cambridge University Press.

Landvoigt, T., Piazzesi, M., and Schneider, M. (2015). The housing market(s) of San Diego. American Economic Review, 105(4):1371-1407.

Le Bris, D., Goetzmann, W. N., and Pouget, S. (2019). The present value relation over six centuries: The case of the Bazacle company. Journal of Financial Economics, 132(1):248-265.

Le Bris, D. and Hautcoeur, P.-C. (2010). A challenge to triumphant optimists? a blue chips index for the paris stock exchange, 1854-2007. Financial History Review, 17(2):141-183.

Le Mée, R. (1998). Le choléra et la question des logements insalubres à Paris (18321849). Population (french edition), pages 379-397.

Le Roy Ladurie, E. and Couperie, P. (1970). Le mouvement des loyers parisiens de la fin du Moyen Age au XVIII e siècle. In Annales. Histoire, Sciences Sociales, volume 25, pages 1002-1023. Cambridge University Press.

Lemercier de Jauvelle, R. (1906). Répertoire général des contributions directes. Oberthur, Rennes.

Leombroni, M., Piazzesi, M., Schneider, M., and Rogers, C. (2020). Inflation and the price of real assets. NBER Working Paper.

Lesger, C. (1986). Huur en Conjunctuur: de woningmarkt in Amsterdam, 1550-1850, volume 10. Historisch Seminarium van de Universiteit van Amsterdam, Amsterdam, NL.

Levy, H. (1978). Equilibrium in an imperfect market: A constraint on the number of securities in the portfolio. American Economic Review, 68(4):643-658.

L'Histoire (2018). La révolution de février 1848 à paris. https : //www. thinglink . com/scene/1020670863348858883?buttonSource=viewLimits.

Lian, C., Ma, Y., and Wang, C. (2018). Low interest rates and risk taking: Evidence from individual investment decisions. Review of Financial Studies.

Liesker, R. and Fritschy, W. (2004). Gewestelijke financien ten tijde van de Republiek der Verenigde Nederlanden: Holland (1572-1795). Inst. voor Nederlandse Geschiedenis. 
Ling, D. C., Ooi, J. T., and Le, T. T. (2015). Explaining house price dynamics: Isolating the role of nonfundamentals. Journal of Money, Credit and Banking, 47(S1):87-125.

Ling, D. C., Wang, C., and Zhou, T. (2020). A First Look at the Impact of COVID-19 on Commercial Real Estate Prices: Asset-Level Evidence. The Review of Asset Pricing Studies.

Loewenstein, G. (2000). Emotions in economic theory and economic behavior. American Economic Review, 90(2):426-432.

Lourens, P. and Lucassen, J. M. W. G. (1997). Inwonertallen van Nederlandse steden ca. 1300-1800. NEHA.

Lovenheim, M. F. and Mumford, K. J. (2013). Do family wealth shocks affect fertility choices: Evidence from the housing market. Review of Economics and Statistics, 95(2):464-475.

Lyon-Caen, N. (2018). Combien vaut Paris? la monarchie, les loyers et les boues de la capitale à l?époque moderne. Annuaire-Bulletin de la Société de l?histoire de France, 552(2014):179-198.

Mairie de Paris (1967a). Annuaire Statistique de la Ville de Paris, volume 1900, 1950, 1967. Paris, FR: Impremerie Nationale.

Mairie de Paris (1967b). Annuaire statistique de la Ville de Paris. Impremerie Nationale.

Mankiw, N. G. and Weil, D. N. (1989). The baby boom, the baby bust, and the housing market. Regional Science and Urban Economics, 19(2):235-258.

Margo, R. A. (1996). The rental price of housing in New York City, 1830-1860. Journal of Economic History, 56(3):605-625.

Marnata, F. (1961). Les loyers bourgeois de Paris, 1860-1958. Armand Colin, Paris.

Marnef, G. (1996). Antwerpen in de tijd van de Reformatie. Ondergronds protestantisme in een handelsmetropool 1550, volume 1577. Meulenhoff, Amsterdam, NL.

Martinez-Miera, D. and Repullo, R. (2017). Search for yield. Econometrica, 85(2):351378.

Massaloux, J.-P. (1989). La régie de l'enregistrement et des domaines aux XVIIIe et XIXe siècles. Étude historique. Droz.

Mayor of London (2017). Housing in London: 2017. https ://data . london.gov .uk/ dataset/housing-london.

Mayor of London (2018). What is homes for Londoners? https://www . london.gov.uk/what-we-do/housing-and-land/homes-londoners/ what-homes-londoners. Accessed: June 10, 2018. 
McCants, A. E. C. (1997). Civic charity in a golden age: orphan care in early modern Amsterdam. University of Illinois Press, Champaign, IL.

Merton, R. C. (1969). Lifetime portfolio selection under uncertainty: The continuoustime case. Review of Economics and Statistics, pages 247-257.

Merton, R. C. (1987). A simple model of capital market equilibrium with incomplete information. Journal of Finance, 42(3):483.

Mian, A. and Sufi, A. (2009). The consequences of mortgage credit expansion: Evidence from the US mortgage default crisis. Quarterly Journal of Economics, 124(4):1449-1496.

Mian, A. and Sufi, A. (2011). House prices, home equity-based borrowing, and the us household leverage crisis. American Economic Review, 101(5):2132-56.

Mian, A. and Sufi, A. (2015). House of debt: How they (and you) caused the Great Recession, and how we can prevent it from happening again. University of Chicago Press.

Michotte, F. (1937). L'évolution des prix de détail en Belgique de 1830 à 1913. Recherches Économiques de Louvain/Louvain Economic Review, 8(3):345-357.

Miguel, E. and Roland, G. (2011). The long-run impact of bombing vietnam. Journal of Development Economics, 96(1):1-15.

Milanovic, B., Lindert, P. H., and Williamson, J. G. (2010). Pre-industrial inequality. The Economic Journal, 121(551):255-272.

Mills, J., Molloy, R., and Zarutskie, R. (2019). Large-scale buy-to-rent investors in the single-family housing market: The emergence of a new asset class. Real Estate Economics.

Monin, H. and Lazard, L. (1920). Sommier des biens nationaux de la ville de Paris, conservé aux Archives de la Seine, volume 1-2. L. Cerf.

Mooij, A. (2001). Van pest tot aids. Vijf eeuwen besmettelijke ziekten in Amsterdam. Thoth, Bussum.

Moran, P. A. P. (1950). Notes on continuous stochastic phenomena. Biometrika, 37(1/2):17-23.

Neal, L. (1993). The rise of financial capitalism: International capital markets in the age of reason. Cambridge University Press.

Nelisse, P. (2008). Stedelijke erfpacht. Doetinchem: Reed Business.

Nicholas, T. and Scherbina, A. (2013). Real estate prices during the roaring twenties and the Great Depression. Real Estate Economics, 41(2):278-309. 
Nijskens, R., Lohuis, M., Hilbers, P., and Heeringa, W. (2019). Hot Property. Springer.

Noordegraaf, L. and Valk, G. (1996). De Gave Gods. De pest in Holland vanaf de late Middeleeuwen. Bert Bakker.

Nunn, N. and Qian, N. (2011). The potato's contribution to population and urbanization: Evidence from a historical experiment. Quarterly Journal of Economics, 126(2):593-650.

Nusteling, H. P. H. (1985). Welvaart en werkgelegenheid in Amsterdam, 1540-1860: een relaas over demografie, economie en sociale politiek van een wereldstad. Bataafsche Leeuw.

Office for National Statistics (2018). Database official UK statistics. https://www . ons.gov.uk/.

Oldewelt, W. F. (1945). Kohier van de personeele quotisatie te Amsterdam over het jaar 1742. Genootschap Amstelodamun.

Pardailhé-Galabrun, A. (1991). The birth of intimacy: privacy and domestic life in early modern Paris. University of Pennsylvania Press, Philadelphia, PA.

Park, S.-Y. (2018). Ideals of the Body: Architecture, Urbanism, and Hygiene in Postrevolutionary Paris. University of Pittsburgh Press.

Peeters, M. (1939). L'évolution des salaires en Belgique de 1831 à 1913. Recherches Économiques de Louvain/Louvain Economic Review, 10(4):389-420.

Peng, L. (2016). The risk and return of commercial real estate: A property level analysis. Real Estate Economics, 44(3):555-583.

Peng, L. and Thibodeau, T. G. (2017). Idiosyncratic risk of house prices: Evidence from 26 million home sales. Real Estate Economics, 45(2):340-375.

Piazzesi, M. and Schneider, M. (2009). Momentum traders in the housing market: Survey evidence and a search model. American Economic Review, 99(2):406-411.

Piazzesi, M., Schneider, M., and Tuzel, S. (2007). Housing, consumption and asset pricing. Journal of Financial Economics, 83(3):531-569.

Piketty, T. (2001). Les hauts revenus en France au XXe siècle. Grasset, Paris.

Piketty, T. (2014). Capital in the Twenty-First Century. Paris School of Economics, Paris.

Piketty, T., Postel-Vinay, G., and Rosenthal, J.-L. (2006). Wealth concentration in a developing economy: Paris and France, 1807-1994. American Economic Review, 96(1):236-256.

Piketty, T. and Zucman, G. (2014). Capital is back: Wealth-income ratios in rich countries 1700-2010. Quarterly Journal of Economics, 129(3):1255-1310. 
Pitkin, J. R. and Myers, D. (1994). The specification of demographic effects on housing demand: avoiding the age-cohort fallacy. Journal of Housing Economics, 3(3):240250.

Poterba, J. (2004). The impact of population aging on financial markets. NBER Working Paper.

Poterba, J. M. (2001). Demographic structure and asset returns. Review of Economics and Statistics, 83(4):565-584.

Poterba, J. M. and Samwick, A. (2001). Household portfolio allocation over the life cycle. In Aging issues in the United States and Japan, pages 65-104. University of Chicago Press.

Prak, M. R. (1985). Gezeten burgers: De elite in een Hollandse stad, Leiden 1700-1780. De Bataafsche Leeuw.

Quetelet, L. A. J. (1846). Sur les anciens recensements de la population belge. Bulletin de la commission centrale de statistique de Belgique, 3.

Quigley, J. M. and Raphael, S. (2004). Is housing unaffordable? Why isn't it more affordable? Journal of Economic Perspectives, 18(1):191-214.

Quigley, J. M. and Raphael, S. (2005). Regulation and the high cost of housing in California. American Economic Review, 95(2):323-328.

Raff, D., Wachter, S., and Yan, S. (2013). Real estate prices in Beijing, 1644 to 1840. Explorations in Economic History, 50(3):368-386.

Rajan, R. and Ramcharan, R. (2015). The anatomy of a credit crisis: The boom and bust in farm land prices in the United States in the 1920s. American Economic Review, 105(4):1439-77.

Rajan, R. G. (2006). Has finance made the world riskier? European Financial Management, 12(4):499-533.

Ridolfi, L. (2019). Six centuries of real wages in France from Louis IX to Napoleon III: 1250-1860. Journal of Economic History, 79(3):589-627.

Riley, J. (1980). International government finance and the Amsterdam capital market, 1740-1815. Cambridge University Press.

Rommes, R. (2015). Plague in Northwestern Europe. The Dutch experience, 13501670. Popolazione e storia, 16(2):47-71.

Rooseboom, G. (1656). Recueil van verscheyde keuren, en costumen: Midtsgaders maniere van procederen binnen de stadt Amsterdam. Ian Hendricks.

Rosen, S. (1974). Hedonic prices and implicit markets: Product differentiation in pure competition. Journal of Political Economy, 82(1):34-55. 
Ryckbosch, W. (2016). Economic inequality and growth before the industrial revolution: the case of the Low Countries. European Review of Economic History, 20(1):122.

Sá, F. (2016). The effect of foreign investors on local housing markets: Evidence from the UK. CEPR Discussion Paper No. DP11658.

Sagi, J. S. (2020). Asset-level risk and return in real estate investments. Review of Financial Studies.

Samy, L. (2015). Indices of house prices and rent prices of residential property in London, 1895-1939. Oxford Discussion Paper No. 134.

Sanso-Navarro, M., Sanz, F., and Vera-Cabello, M. (2015). The impact of the American Civil War on city growth. Urban Studies, 52(16):3070-3085.

Schmelzing, P. (2020). Eight centuries of global real interest rates, R-G, and the 'suprasecular' decline, 1311-2018. Bank of England Working Paper.

Scholliers, E. (1960). De levensstandaard in de XVe en XVIe eeuw te Antwerpen: Loonarbeid en honger. De Sikkel, Antwerpen, BE.

Scholliers, P. (1978). Koopkracht en indexkoppeling. de Brusselse levensstandaard tijdens en na de Eerste Wereldoorlog, 1914-1925. Revue Belge d'Histoire Contemporaine, (3):4.

Schrage, P., Nijhof, E., and Wielsma, P. (1989). Inkomensontwikkeling van werkenden en werklozen in Nederland, 1913-1939. Tijdschrift voor Sociale Geschiedenis, (14):347-394.

Segers, Y. (1999). De huishuren in België, 1800-1920. voorstelling van een databank. Tijdschrift voor Sociale Geschiedenis, 2:2072-232.

Sentrie, P. (2007). Een demografische schets van West-Vlaanderen. Master's thesis, Universiteit Gent.

Shiller, R. J. (2005). Irrational Exuberance. Princeton University Press.

Siegel, J. J. (2014). Stocks for the long run, volume 5. McGraw-Hill New York.

Sims, D. P. (2007). Out of control: What can we learn from the end of Massachusetts rent control? Journal of Urban Economics, 61(1):129-151.

Sinai, T. and Souleles, N. S. (2005). Owner-occupied housing as a hedge against rent risk. Quarterly Journal of Economics, 120(2):763-789.

Singer-Kérel, J. (1961). Le coût de la vie à Paris de 1840 à 1954. A. Colin., Paris, FR.

Slovic, P., Finucane, M. L., Peters, E., and MacGregor, D. G. (2007). The affect heuristic. European Journal of Operational Research, 177(3):1333-1352. 
Smid, R. (2019). Speculanten en revolutiebouwers: Projectontwikkeling in Amsterdam 1877-1940. Uitgeverij van Tilt, Nijmegen.

Smith, A. (1776). An Inquiry Into the Nature and Causes of the Wealth of Nations. W. Strahan and T. Cadell, London, UK.

Soltow, L. and Van Zanden, J. L. (1998). Income and wealth inequality in the Netherlands, 16th-20th century. Maklu, Antwerpen, BE.

Sommer, K., Sullivan, P., and Verbrugge, R. (2013). The equilibrium effect of fundamentals on house prices and rents. Journal of Monetary Economics, 60(7):854-870.

Statistics Belgium (2018a). Annuaire statistique de la Belgique. http://extranet.arch.be:8180/stat/?lg=nl.

Statistics Belgium (2018b). Be.stat database official Belgian statistics. https:// bestat.statbel.fgov.be/bestat/.

Statistics Netherlands (2018). Nederland in cijfers: Database official Dutch statistics. https://opendata.cbs.nl/statline/\#/CBS/nl/.

Stone, M. E. (2006). What is housing affordability? the case for the residual income approach. Housing policy debate, 17.1(151-184).

Takáts, E. (2012). Aging and house prices. Journal of Housing Economics, 21(2):131141.

Thomas, R. and Dimsdale, N. (2017). A millennium of UK data, BoE OBRA dataset. http://www. bankofengland.co.uk/research/Pages/onebank/ threecenturies. aspx.

United Nations (2017). World population prospects: the 2017 revision: key findings and advance tables.

Van Bochove, C. (2013). Configuring financial markets in preindustrial Europe. Journal of Economic History, 73(1):247-278.

Van Bochove, C., Deneweth, H., and Zuijderduijn, J. (2015). Real estate and mortgage finance in England and the Low Countries, 1300-1800. Continuity and Change, 30(1):9-38.

Van Bunge, W. (2018). The exception of the Dutch enlightenment. In From Bayle to the Batavian Revolution, pages 1-20. BRILL.

Van den Eeckhout, P. and Scholliers, P. (1979). Lonen en prijzen in België in de 19e en 20e eeuw: de Brusselse huishuren: 1800-1940. Vrije Universiteit Brussel, Brussel, BE.

Van der Voort, J. P. (1973). De Westindische plantages van 1720-1795: financiën en handel. PhD thesis, Radboud Universiteit. 
Van der Wee, H. (1963). The growth of the Antwerp market and the European economy: fourteenth-sixteenth centuries. Nijhoff, Den Haag, NL.

Van Dillen, J. G. (1929). Bronnen tot de geschiedenis van het bedrijfsleven en het gildewezen van Amsterdam. Nijhoff, Den Haag, NL.

Van Iterson, W. (1939). Willig Decreet in Holland en Utrecht. Tjeenk Willink, Haarlem.

Van Leeuwen, M. H. and Oeppen, J. E. (1993). Reconstructing the demographic regime of Amsterdam 1681-1920. Economic and Social History in the Netherlands, 5:61-102.

Van Riel, A. (2018). Postponing conformity. Dissertation in progress.

Van Ryssel, D. (1967). De Gentse huishuren tussen 1500 en 1795: bijdrage tot de kennis van de konjunktuur van de stad. Gemeentekrediet van België, Brussel, BE.

Van Wassenaer, J. H. (1737). Amsterdamsche Secretary. Gerrit Bos.

Van Werveke, H. (1948). De Curve van het Gentse bevolkingscijfer in de 17e en de 18e eeuw. Paleis der Academiën, Brussel, BE.

Van Zanden, J. L. (2018). The prices of the most important consumer goods, and indices of wages and the cost of living in the western part of the Netherlands, 14501800. http://www. iisg.nl/hpw/data.php\#netherlands.

van Zanden, J. L., De Moor, T., and Carmichael, S. (2019). Capital Women: The European Marriage Pattern, Female Empowerment and Economic Development in Western Europe 1300-1800. Oxford University Press.

Van Zanden, J. L. and Van Leeuwen, B. (2012). Persistent but not consistent: The growth of national income in Holland 1347-1807. Explorations in Economic History, 49(2):119-130.

Vanhaute, E. and Hannes, J. (2007). Economische verandering en inkomensongelijkheid. de inkomensverdeling in de Oost-Vlaamse steden in de negentiende eeuw. Tijdschrift voor Sociale en Economische Geschiedenis, 4(2):86-109.

Vehtari, A., Gelman, A., and Gabry, J. (2017). Practical Bayesian model evaluation using leave-one-out cross-validation and WAIC. Statistics and Computing, 27(5):14131432.

Verbeemen, J. (1956). De werking van economische factoren op de stedelijke demografie der XVIIe en der XVIIIe eeuw in de Zuidelijke Nederlanden. Revue Belge de Philologie et d'Histoire, 34(3):680-700.

Verlinden, C., editor (1972). Dokumenten voor de geschiedenis van prijzen en lonen in Vlaanderen en Brabant: XVe-XVIIIe eeuw, volume I-IV, Brugge. De Tempel. 
Vermeulen, I. (2002). Bijdrage tot de studie van de mortaliteit in Gent tijdens de 18de eeuw. casus: de Sint-Salvatorparochie. Handelingen der Maatschappij voor Geschiedenis en Oudheidkunde te Gent, 1.

Verwey, G. (1943). Prijsverloop van 426 huizen te Amsterdam, welke voor 1880 reeds van eigenaar wisselden. Economisch Historisch Jaarboek, 22:251-303.

Wetzer, T. (2018). Bossche encyclopedie. https://WwW.bossche-encyclopedie. $\mathrm{nl} /$.

White, E. N., Snowden, K., and Fishback, P. (2014). Housing and mortgage markets in historical perspective. University of Chicago Press.

Willis, J. W. (1950). Short history of rent control laws. Cornell Law Quarterly, 36:54.

Wilson, C. H. (1941). Anglo-Dutch commerce \& finance in the eighteenth century. CUP Archive.

Wilson, W. (2017). A short history of rent control. https://researchbriefings. files.parliament.uk/.../SN06747.pdf.

Winkler, W. E. (1999). The state of record linkage and current research problems. In Statistical Research Division, US Census Bureau. Citeseer.

Wong, G. (2008). Has SARS infected the property market? Evidence from Hong Kong. Journal of Urban Economics, 63(1):74-95.

Woodward, S. E. (1991). Economists' prejudices: Why the Mankiw-Weil story is not credible. Regional Science and Urban Economics, 21(4):531-537.

Xu, C. (2018). Reshaping global trade: The immediate and long-run effects of bank failures. Mimeo.

Zillesen, C. (1800). Wiskunstig Onderzoek. J.C. Leeuwesteyn. 